*ak RMIS View/Frint Document Cover Sheet tow

This document was retrieved from the Documentation and Records Manaqement (DRM) ISEARCH System. It is intended for Information only and may not be the most recent or updated version. Contact a Document Service Center (see Hanford Info for locations) if you need additional retrieval information.

Accession \#: D296004558

Document \#: SD-W379-ES-003

Title/Desc:

CSB TRADE STUDY FINAL REPORT

Pages: 333 


\begin{tabular}{|c|c|}
\hline $\begin{array}{l}\text { JANO4 } 1950 \\
\text { An sta } 14\end{array}$ & 1. EDT NO 611475 \\
\hline
\end{tabular}

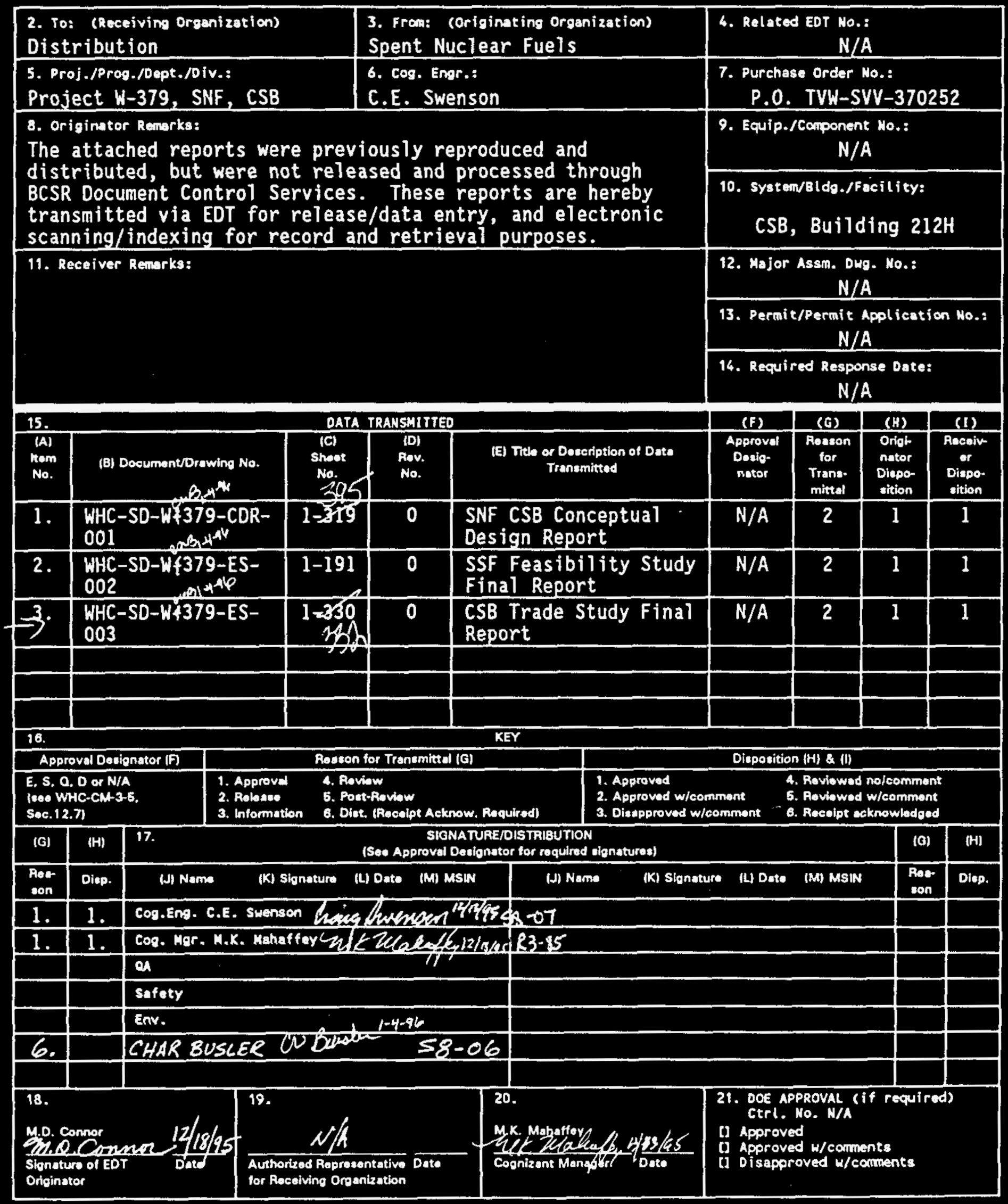




\section{Canister Storage Bullding Trade Study Final Report}

C.E.Swenson

Westinghouse Hanford Company, Richland, WA 99352

U.S. Department of Energy Contract DE-AC06-87RL10930

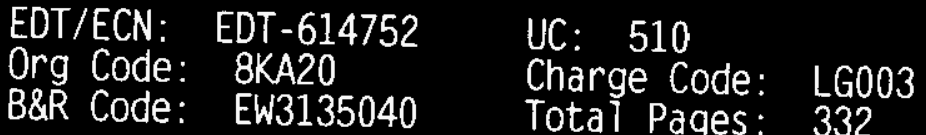

Key Words: Project W379, SNF, CSB, Trade Study, Engineering Study,
Report.

Abstract: This study was performed to evaluate the impact of several technical issues related to the usage of the Canister Storage Building (CSB) to safely stage and store $\mathrm{N}$-Reactor spent fuel currently located at K-Basin 100KW and 100KE. Each technical issue formed the basis for an individual trade study used to develop the ROM cost ans schedule estimates. The study used concept 20 from the Fluor prepared "Staging and Storage Facility (SSF) Feasibility Report" as the basis for development of the individual trade studies.

Fluent is a registered trademark of Fluent. Inc. Hanover. NH

Flotran is a registered trademark of SAS Acquisition Corp, Houston, PA.

TRADEMARK DISCLAIMER. Reference herein to any specific comercial product, process, or service by endorsenent, recommendation, or favoring by the United not necessarily constitute or imply its its contractors or subcontractors.

Printed in the United States of America. To obtain copies of this document, contact: WHC/BCS

Document Control Services, P.0. Box 1970, Mailstop H6-08, Richland HA 99352, Phone (509) 372-2420;
Fax (509) 376-4989.
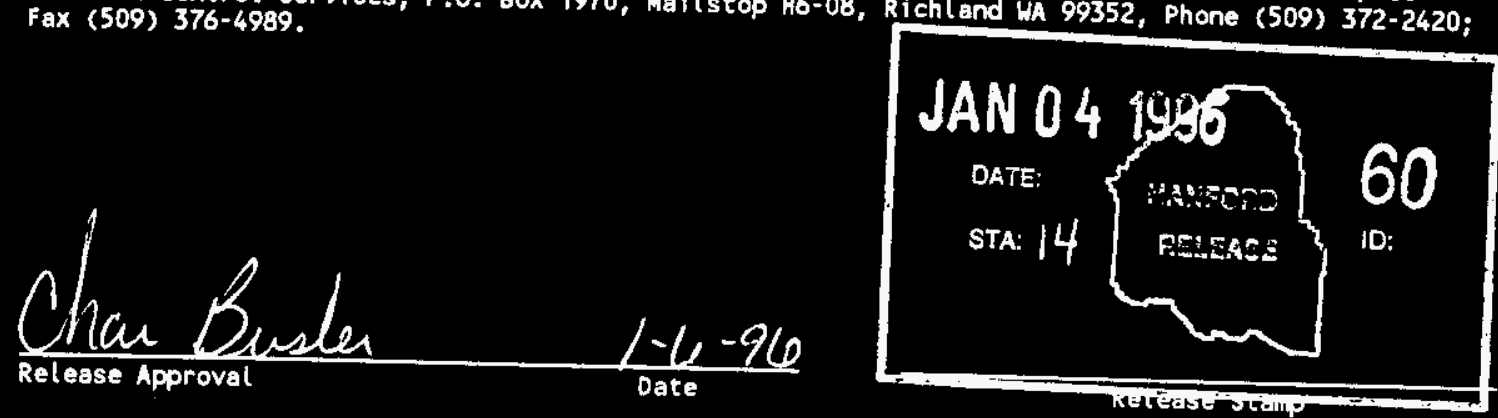

Approved for Public Release 


\title{
CANISTER STORAGE BUILDING TRADE STUDY Final Report
}

\author{
Prepared for \\ Westinghouse Hanford Company
}

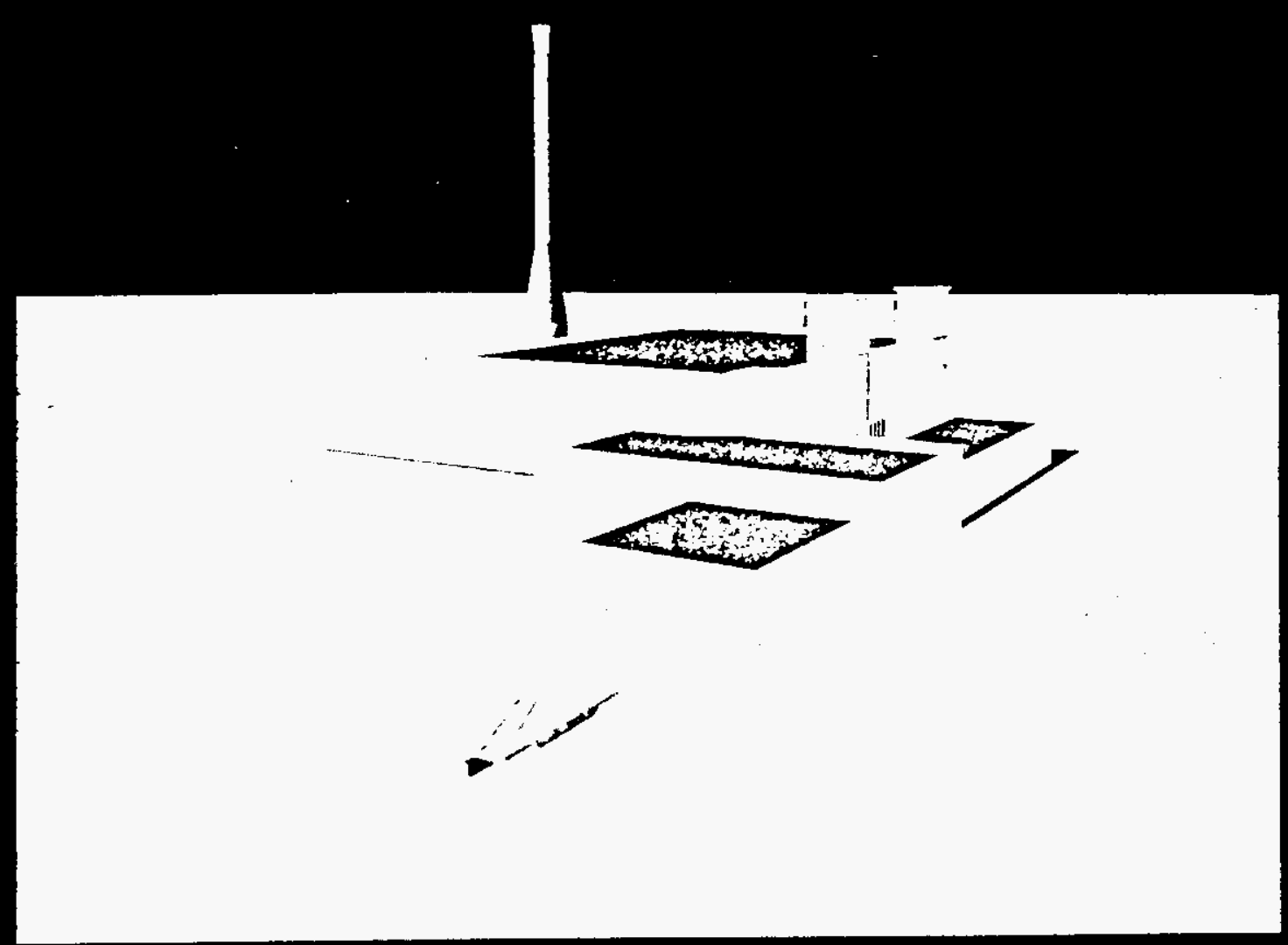

\author{
Prepared By \\ Fluor Daniel, Inc. \\ Government Services Operating Company \\ May 1995
}




\section{NOTICE}

This report was prepared as an account of work sponsored by the United States Government and not for the purpose of reliance by any third party. Neither the United States nor the Department of Energy, nor any or their employees, nor any of their contractors, subcontractors, or their employees, makes any warranty, express or implied, of assumes any legal liability or responsibility for the accuracy, completeness, or usefulness of any information, apparatus, product or process disclosed or represents that its use would not infringe privately-owned rights. Reference herein to any specific commercial product, process, or service by trade name, mark, manufacturer, or otherwise, does not necessarily constitute or imply its endorsement, recommendation, or favoring by the United states Government or any agency thereof nor any contractor, subcontractor or their employees. The views and opinions of authors expressed herein do not necessarily state or reflect those of the United States Government or any agency thereof, nor any contractor, subcontractor or their employees. Use of any part of this report shall be at the user's sole risk and shall constitute a release and an agreement to defend and indemnify the United States, the Department of Energy and/or any of their employees, contractors, subcontractors and/or their employees, against any and all liability in connection therewith, regardless of fault or negligence. 


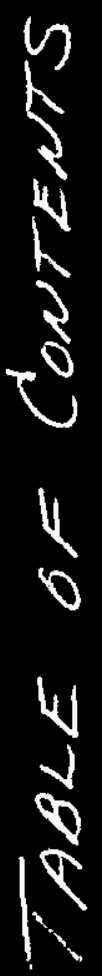

TOC

WHC-SD-W379-ES-003 ReV. 0 
TABLE OF CONTMATS

Page

LIST OF DRAWINGS AND FIGURES . . . . . . . . . . . iv LIST OF TABLES . . . . . . . . . . . . . . . . . . vi vi LIST OF ACRONYMS . . . . . . . . . . . . . . . . viii

EXECUTIVE SUMMARY . . . . . . . . . . . . . . . . . 1

1.0

1.1

1.2

1.3

1.4

2.0

2. 1

2.1.1

2.1.2

2.1.3

2.1 .4

2.1 .5

2.1.6

2.1.7

2. 2

2. 2.1

2. 2.2

2. 2.3

2. 2.4

2. 2.5

2. 2.6

2. 2.7

2. 3

2.3.1

2.3 .1 .1

2.3.1.2

$2.3 \cdot 1 \cdot 3$

2.3 .1 .4

2.3 .1 .5

2.3 .1 .6

2.3 .1 .7

2.3 .2

2.3 .2 .1 2.3.2.2 2.3 .2 .3
INTRODUCTION

BACKGROUND

STUDY OBJECTIVES

SCOPE OF WORK

DESIGN BASIS

CONCEPT 2D TECHNICAL DESCRIPTION

FACILITY DESCRIPTION

Plot Plans

Rail Tunnel/Cask Unloading Area

MCO Servicing

Cask Unloading pool water Treatment

System

MCO Cooling and FVAC

Structural

Material Flow

FEASIBILITY ISSUES

Structural

Thermal / HVAC

Contamination Control

Criticality

Shielding

Conversion

Health Physics

SAFETY ANALYSIS

APPLICABLE REQUIREMENTS

DOE Orders

DOE Standards

NRC Regulations

Other Federal Regulations

Washington state Regulations

WHC Requirements

ANSI/ANS Standards

DESIGN BASIS ACCIDENTS

SAFETY CLASSIFICATIONS

DBA Methodology

Assumptions

Results
$1-1$

1-1

$1-2$

$1-3$

$1-4$

- 2-1

2-1

- 2-1

2-1

- 2-6

2-8

$2-15$

2- 20

2-21

$2-33$

$2-33$

$2-34$

2-39

2-41

2-5I

2- 55

$2-55$

$2-57$

$2-57$

2-58

2-59

2- 60

2- 60

2-6I

$2-61$

$2-61$

$2-61$

$2-62$

$2-66$

$2-69$ 
TABLE OF CONHDATS

Page

2.4

2. 4.1

2.4 .1 .1

2.4 .1 .2

2.4 .1 .3

2.4 .1 .4

2.4 .1 .5

2.4 .1 .6

2.4 .1 .7

2.4 .1 .8

2.4 .2

2.4 .2 .1

2.4 .3

2.4 .3 .1

2.4 .3 .2

$2.4 .3 \cdot 3$

2.4 .3 .4

2.4 .3 .5

2.4 .3 .6

$2 \cdot 5$

2.5.1

2.5 .1 .1

2.5 .2

2.6

2.6.1

2.6 .2

2.7

2.8

3.0

3.1
COST ESTIMATES

ESTIMATE BASIS

Assumptions

Estimate Inclusions

Estimate Exclusions

Work Breakdown structure (WBS)

Quantities

References

Escalation

Contingency

CONCEPT 2D CAPITAL COST

Concept 2D Cost Estimate

SIGNIEICANT OPERATING COST

DIFEERENCES

Operating Labor During staging

Fuel Cooling During staging

Heating, Ventilation, and Lighting

Crane Usage

Pool Water Sterilization

Chemical Consumption

SCHEDULES

SCHEDULE ASSUMPTIONS

General

CONCEPT 2D SCHEDULE

CONCLUSIONS AND RECOMMENDATIONS

FEASIBILITY OF CSB ADAPTATION

OTHER TECHNICAL CONCERNS

REFERENCES

DESIGN BASIS

TRADE STUDY REPORTS

TABLE OF CONTENTS

Task Description

A Facility Confinement Investigation

B MCO Receipt and Staging Function and Area Removal

C Cask Decontamination Function and Area Removal

D One Track Rail Service

E Storage Tube Material Investigation

F MCO Shipment Reduction

G Damp-Dried MCO

H RCRA Functions: Prevention and Detection of MCO Leaks
$2-70$

$2-70$

$2-74$

$2-75$

$2-75$

2-76

$2-78$

$2-78$

$2-78$

$2-79$

$2-79$

2-79

$2-79$

$2-79$

2-80

$2-80$

$2-80$

$2-85$

$2-85$

$2-85$

$2-85$

$2-85$

$2-87$

$2-87$

$2-87$

$2-87$

$2-90$

$2-94$

3-1

3-1

Tab

A

B

C

D

E

F

G

H

\begin{abstract}
$3-1$
3.2

INTRODUCTION

APPENDIX CALCULATIONS
\end{abstract}




\section{IIST OF DRAWINGS AND FIGURSS}

\section{Page}

FIGURE 2-1, MASTER SITE PLAN CONCEPT 20............... 2-2

FIGURE 2-2, PLOT PLAN CONCEPT 20 . . . . . . . . . . . . . 2-3

FIGURE 2-3, FLOOR PLAN CONCEPT 2D.................. . . $2-4$

FIGURE 2-4, MCO SERVICE STATION FOR CONCEPT 2D . . . . . . . . . . 2-9

FIGURE 2-5, PROCESS BLOCK FLOW DIAGRAM, POOL WATER TREATMENT . . . . 2-13

FIGURE 2-6, SSF FEASIBILITY STUDY CONCEPT 2D VAULT -

HVAC SYSTEM . . . . . . . . . . . . . . . . . 2-16

FIGURE 2-7, CONCEPT 20 OPERATING AREA HVAC SYSTEM . . . . . . . . 2-17

FIGURE 2-8, CONCEPT 20 POOL WATER TREATMENT BUILDING HVAC

SYSTEM ...................... 2-18

FIGURE 2-9, CONCEPT 20 OPERATING AREA HVAC EMERGENCY VENT

SYSTEM . . . . . . . . . . . . . . . . . . . 2-19

FIGURE 2-10, CONCEPT 20 STAGING MATERIAL FLOW DIAGRAM,

IN RAIL TUNNEL/CASK UNLOADING AREA . . . . . . . . . 2-23

FIGURE 2-11, CONCEPT 20 STAGING MATERIAL TIME STUDY IN CASK

UNLOADING AND STORAGE AREA ............. 2-24

FIGURE 2-12, CONCEPT 20 STAGING MATERIAL FLOW DIAGRAM, IN STORAGE

TUBES AREA ................... 2-25

FIGURE 2-13, CONCEPT 20 STAGING MATERIAL TIME STUDY IN STORAGE

TUBES AREA ...................... 2-26

FIGURE 2-14, CONCEPT 2D STORAGE MATERIAL FLOW DIAGRAM TO AND

FROM FUTURE STABILIZATION FACILITY . . . . . . . . . 2-27

FIGURE 2-15, CONCEPT 20 STORAGE MATERIAL TIME STUDY OUT \&

INTO STORAGE TUBES . . . . . . . . . . . . . . 2-28

FIGURE 2-16, OVERHEAD CASK/CRANE PICKUP AND DELIVERY . . . . . . . . . 2-32

FIGURE 2-17, PASSIVE COOLING VAULT TEMPERATURE PROFILE

CONCEPT 2D..................... 2-37

FIGURE 2-18, PASSIVE COOLING VELOCITY PROFILE, CONCEPT 20 . . . . 2-38 


\section{LIST OE DRANINGS AND FIGURAS}

Page

FIGURE 2-19, SENSITIVITY TO SPACING, 31 FUEL ELEMENTS

(IN A TRIANGULAR ARRAY) PER LAYER, 12 LAYERS, 7 COLUMNS . 2-47

FIGURE 2-20, FUEL ELEMENTS IN A SINGLE LAYER OF AN MCO MODEL . . . . . 2-48

FIgURE 2-21, CSB VAULT MODEL SHOWING TUBES IN TRIANGULAR ARRAY . . . . 2-49

FIGURE 2-22, CROSS SET OF STORAGE TUBES SHOWING MCO AND

CANISTER WALLS ................. 2-50

FIGURE 2-23, CONCEPT 20 WBS AREAS . . . . . . . . . . . . . 2-77

FIGURE 2-24, STAGING \& STORAGE FACILITY CONCEPT 20 CSB ADAPTATION . . 2-88 


\section{CSB TRADE STUDY}

List of Tables

Page

TABLE 1, COST ESTIMATE SUMMARY . . . . . . . . . . . . . . . . 3

TABLE 2-1, EQUIPMENT LIST STAGING AND STORAGE

FACILITY SSF (CONCEPT 2D) . . . . . . . . . . . . 2-10

TABLE 2-2, EQUIPMENT LIST STAGING AND STORAGE

FACILITY SSF (CONCEPT 2D) ............... 2-14

TABLE 2-3, 10 CANISTER MCO TRANSFER SYSTEMS . . . . . . . . . . . 2-30

TABLE 2-4, 10 CANISTER MCO TRANSFER SYSTEMS . . . . . . . . . . . 2-31

TABLE 2-5, CONCEPT 20 THERMAL ANALYSIS - SUMMARY . . . . . . . . . . 2-36

TABLE 2-6, DENSITIES OF SOME MATERIALS . . . . . . . . . . . . . . 2-44

TABLE 2-7, COMPOSITION OF MATERIALS USED IN

RADIATION SHIELDING CALCULATIONS ........... 2-45

TABLE 2-8, SAFETY ANALYSIS RESULTS SUMMARY . . . . . . . . . . . . 2-71

TABLE 2-9, DOE/WHC SAFETY CLASS STRUCTURES, SYSTEMS, AND COMPONENTS ("STAGING PHASE") . . . . . . . . . 2-72

TABLE 2-10, DOE/WHC SAFETY CLASS STRUCTURES, SYSTEMS, AND COMPONENTS "STORAGE PHASE" ......... . 2-73

TABLE 2-11, CONCEPT 20 PROJECT COST SUMMARY . . . . . . . . . . . . 2-81

TABLE 2-12, CONCEPT $20 \$$ EXPENDITURE . . . . . . . . . . . . . . 2-82

TABLE 2-13, CONCEPT 20 WORK BREAKDOWN STRUCTURE SUMMARY . . . . . . . . . 2-83

TABLE 2-14, CONCEPT 20 ESTIMATE SUMMARY BY WBS . . . . . . . . . . . 2-84

TABLE $3-1$, COST ESTIMATE SUMMARY . . . . . . . . . . . . . . 3-2 


\section{IIST OF ACRONYMS}

\begin{tabular}{|c|c|}
\hline 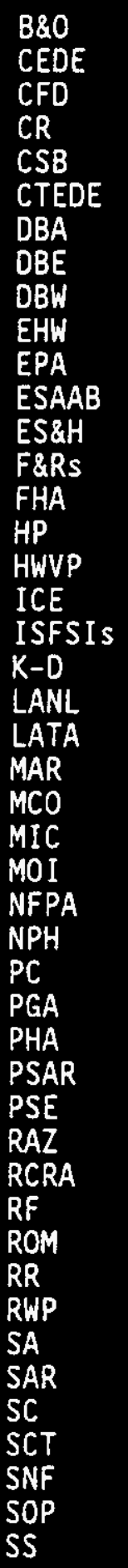 & $\begin{array}{l}\text { Business and Occupation Tax } \\
\text { Committed Effective Dose Equivalent } \\
\text { Computational Fluid Dynamic } \\
\text { Change Request } \\
\text { Canister Storage Building } \\
\text { Cumulative Total Effective Dose Equivalent } \\
\text { Design Basis Accident } \\
\text { Design Basis Earthquake } \\
\text { Design Basis Wind } \\
\text { Extremely Hazardous Waste } \\
\text { Environmental Protection Agency } \\
\text { Energy System Acquisition Advisory Board } \\
\text { Environmental, Safety and Health } \\
\text { Functions and Requirements } \\
\text { Fire Hazards Analysis } \\
\text { Health Physics } \\
\text { Hanford Waste Vitrification Plant } \\
\text { Independent Cost Estimate } \\
\text { Independent Spent Fuel Storage Installations } \\
\text { Key Decision } \\
\text { Los Alamos National Laboratory } \\
\text { Los Alamos Tech Associates } \\
\text { Material At Risk } \\
\text { Multi-Canister Overpack } \\
\text { Microbiologically Influenced Corrosion } \\
\text { Maximum Offsite Individual } \\
\text { National Fire Protection Association } \\
\text { Natural Phenomena Hazards } \\
\text { Performance Category } \\
\text { Peak Ground Acceleration } \\
\text { Preliminary Hazards Analysis } \\
\text { Preliminary Safety Analysis Report } \\
\text { Preliminary Safety Evaluation } \\
\text { Radiation Access Zone } \\
\text { Resource Conservation and Recovery Act } \\
\text { Release Fraction } \\
\text { Rough Order of Magnitude } \\
\text { Respiration Rate } \\
\text { Radiation Work Permit } \\
\text { Specific Activity } \\
\text { Safety Analysis Report } \\
\text { Safety Class } \\
\text { Shielded Canister Transporter } \\
\text { Spent Nuclear Fuel } \\
\text { Step-0ff-Pads } \\
\text { Stainless Steel }\end{array}$ \\
\hline
\end{tabular}


CSB Trade Study

Westinghouse Hanford Company

WHC P.O. TVW-SVV-370252
Fluor Daniel, Inc.

Government Services Contract 04436306

\section{IIST OF ACRONYMS}

SSCS

SSF

SWP

TSD

TSR

TWRS

WAC

WBS

WHC
Structures, Systems and Components

Staging and Storage Facility

Special Work Permit

Treatment, Storage and Disposal

Technical Safety Requirements

Tank Waste Remediation System

Washington Administrative Code

Work Breakdown Structure

Westinghouse Hanford Company 

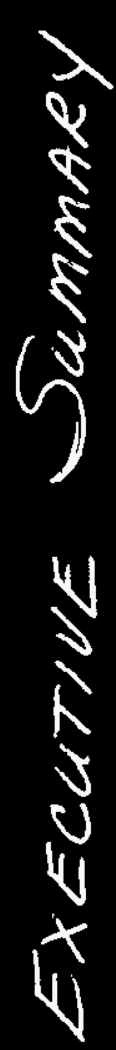

a

WHC-SD-W379-ES-003 Rev. 0 
This study was performed to evaluate the impact of several technical issues related to the usage of the Canister storage Building(CSB) of the Hanford Waste Vitrification Plant(FWVP) Project to safely stage and store $N$-Reactor spent fuel currently located at $\mathrm{K}$-Basin $100 \mathrm{KW}$ and $100 \mathrm{KE}$. Each technical issue formed the basis for an individual Trade study that was used to develop Rough Order Magnitude(ROM) cost and schedule estimates. The study used Concept 2D from the Fluor Daniel prepared "Staging and Storage Facility (SSE) Feasibility Report", dated February 1995, as the basis for development of the individual trade studies.

Concept $2 \mathrm{D}$ was a variation of Concepts $2 \mathrm{~A}$ and $2 \mathrm{C}$ presented in the feasibility study. Concept $2 \mathrm{D}$ had storage tubes installed in only two of the three vaults, resulting in a total of 440 storage tubes. The storage tubes were fabricated of Corten material. The vaults containing tubes were cooled with $35^{\circ} \mathrm{F}$ refrigerated air during the staging phase and convective cooling once all the fuel had been stabilized. The MCO characteristics included 880 MCOs with 8 fuel Canisters stacked four high per MCO and a temperature of $100^{\circ} \mathrm{F}$. Heat generation per MCO was $176 \mathrm{~W}$ (Nominal) and $328 \mathrm{~W}$ (Limit), based on an $80 \%$ Nominal, $5 \%$ Limit and $15 \%$ below Nominal distribution. The fuel centerline temperature after stabilization was limited to $400^{\circ} \mathrm{F}$.

To perform the trade studies WHC requested further modification to Concept 2D, including revising MCO characteristics. Concept 2D was to be adjusted to accommodate 750 MCOs with 10 fuel canisters stacked five high per MCO with a maximum temperature of $100^{\circ} \mathrm{F}$. Heat generation per MCO was increased to $221 \mathrm{~W}$ (Nominal) and 482 W(Limit), based on an $80 \%$ Nominal and $20 \%$ Limit distribution. Fluor Daniel was further instructed not to reconfigure the building for 750 MCOs, but to continue on a with 220 storage tube per vault arrangement. To ensure that worst case loads were used for our heat load calculations it was assumed that all 220 tubes per vault were filled with two MCOs each. The fuel centerline temperature remained at $400^{\circ} \mathrm{F}$ after stabilization.

A re-evaluation of Concept $2 \mathrm{D}$ with the modifications indicated is presented in section 2.0 . The results of the re-evaluation found that it is not feasible to adapt the current design of the CSB and comply with the functions and requirements of the SSF. The high heat load per MCO and $80 / 20$ MCO distribution would require $35^{\circ} \mathrm{F}$ refrigerated air operating in excess of 500,000 CFM to achieve a $105^{\circ} \mathrm{F}$ MCO temperature, not $100^{\circ} \mathrm{F}$ as required.

The re-evaluation also highlighted several other technical challenges that would need to be overcome to meet operating and 
safety concerns. By increasing the allowable MCo temperature requirement to $100^{\circ} \mathrm{F}$, hydrogen gas production due to water in the MCOs will be increased requiring the tubes to be vented and purged more often. The volume of hydrogen gas would be high enough to warrant the purging of nearly 100 tubes per day or roughly $25 \%$ of all tubes would require purging daily during the staging phase prior to stabilization. The $100^{\circ} \mathrm{F}$ MCO temperature would further exacerbate Microbiological Influenced Corrosion (MIC) reducing the fuel storage time and life of the MCO. The radionuclide concentrations are also much higher for the revised MCO requiring significantly thicker shielding, especially for the facility (handling) cask within the CSB, to ensure worker safety. The heavier cask will also increase the crane capacities required to handle the material flow. During conceptual design an investigation into remote handling of the MCOs without a cask might be given consideration. The dose rates and exposure concerns would further complicate use of the empty vault in the future. To protect personnel in the future it may be required to isolate the empty vault with sufficient shielding at the air intake and exhaust plenum, as well as increase the common wall thickness.

The study also included an evaluation of the technical, cost and schedule impacts to Concept $2 \mathrm{D}$ due to eight independent Trade studies. The estimate for concept $2 \mathrm{D}$ was updated to reflect structural and mechanical changes. An allowance was left in the estimate for HVAC equipment with the understanding that a change may occur as a result of the technical feasibility evaluation. In addition, the cost of transport and facility casks and the railroad donkey engine were excluded from the Concept $2 \mathrm{D}$ estimate update to more accurately reflect only facility cost. A summary of the cost estimates for each of the Trade studies in relation to Concept 2D is provided in Table 1 . In terms of the construction schedule, it appears that only Task " $k$ " of the Trade studies, $i . e$. RCRA Functions: Prevention and Detection of MCO leaks, would have an impact on the proposed construction schedule end date indicated in Section 2.5. It is estimated that RCRA compliance would extend the facility completion date by a minimum of two months. Some intermediate activities may be enhanced by certain other Trade studies. 


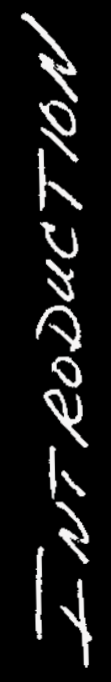

$\stackrel{0}{0}$

$0+1$

WHC-SD-W379-ES-003 ReV. 0 


\subsection{INIRODUCIION}

\subsection{Background}

In January 1995 Westinghouse Hanford Company (WHC) commissioned Fluor Daniel to investigate the feasibility of adapting the design of the HWVP Canister storage Building (CSB) to meet the needs of the WHC Spent Nuclear Fuel Project for a Staging and Storage Facility (SSF) and to develop Rough order of Magnitude (ROM) cost and schedule estimates. The SSF is to store spent N-Reactor fuel in Multi-Canister overpacks (MCOs) filled with water until a stabilization Facility is available to stabilize the fuel. After stabilization of the fuel the MCOs will be returned to the SSF for storage until a geologic repository is available for final disposal. The study investigated two concepts for the SSF which were selected by WHC, 1) the use of water cooling prior to stabilization of the fuel followed by passive dry storage, and 2) the use of refrigerated air cooling prior to stabilization followed by passive dry storage.

The design criteria for the study stipulated that the water temperature in the MCO prior to stabilization is to be limited to $50^{\circ} \mathrm{F}$ maximum and the fuel centerline temperature after stabilization is to be limited to $400^{\circ} \mathrm{F}$ maximum.

The study report was completed in late February 1995 and was issued to WHC. The study found that it is feasible to adapt the design and partially completed construction of the CSB to meet the functions and requirements of the SSF using either of the specified concepts.

Under Concept 1 , the MCOs are stored in racks in a single layer in an open pool of water with a recirculating water treatment system which returns the water to the pool at $44-45^{\circ}$ F. This portion of the SSF utilizes approximately $1 / 3$ of the completed CSB foundation. The balance of the facility, which utilizes the remaining $2 / 3$ of the CSB foundation and the design of the CSB dry storage vaults, is constructed so that it is operational at the same time as the stabilization Facility. After stabilization, the MCOs are returned to the newly constructed dry storage vaults of the SSF, where they remain in passive dry storage until a geologic repository is available for final disposal.

Two alternatives were evaluated under Concept 1 . Alternative IB provides 512 storage tube locations for dry storage in two vaults and does not require any addition to the CSB foundation footprint. Alternative $1 \mathrm{C}$ provides 660 storage tubes and requires the addition of space for another vault to the CSB footprint. 
Under Concept 2, the MCOs are stored in two layers in water filled tubes extending into three, below grade, concrete enclosed, shielding vaults cooled by recirculating $35^{\circ} \mathrm{F}$ refrigerated air. This utilizes the entire foundation and design of the CSB. After stabilization, the storage tubes are drained of water and the MCOs reinstalled. When all the MCOs have been stabilized, the recirculating refrigerated air system is shut down and natural circulation passive air cooling established.

During review of the draft of this report, interest was expressed in other alternatives which were not constrained by the Design Basis. In particular, it was indicated that it was possible that the $50^{\circ} \mathrm{F}$ MCO temperature limit prior to stabilization could be relaxed. If this temperature were relaxed to about $100^{\circ} \mathrm{F}$, it would be possible to store the MCOs in dry Corten storage tubes cooled by refrigerated air. Relaxing the MCO temperature limit prior to stabilization would not have any significant affect on the design or cost of the water cooled alternatives, i.e. Concept 1 .

In order to permit evaluation of these other alternatives against those previously studied, ROM cost estimates were developed for the following additional alternatives:

Alternative 2C. This alternative is the same as Alternative 2A (660 storage tubes) except that the storage tubes are not filled with water, allowing Corten to be used, which results in an MCO temperature of about $100^{\circ} \mathrm{F}$ when cooled with $35^{\circ} \mathrm{F}$ refrigerated air.

Alternative 2D. This Alternative is the same as Alternative $2 \mathrm{C}$ except that storage tubes are installed in only two of the three vaults, resulting in a total of 440 storage tubes. The number of storage tubes in two vaults could be increased to 512 using the same configuration as for Alternative 18, but the cost of this was not evaluated. The MCO temperature would be about the same as for Alternative $2 \mathrm{C}$ (about $100^{\circ} \mathrm{F}$ ).

Alternative 25. This alternative is the same as Alternative $2 \mathrm{~A}$ except that storage tubes are installed in only two of the three vaults, resulting in a total of 440 storage tubes. As above, the number of storage tubes in two vaults could be increased to 512. The MCO temperature would be about the same as for Alternative $2 \mathrm{~A}$ (about $50^{\circ} \mathrm{F}$ ).

\subsection{Study Objectives}

The objectives of this study were to determine any new facility functions and evaluate the impacts to the cost estimate, risk and safety issues and design/construction

$$
\text { 1-2 }
$$


schedule for the Concept 2D, i.e. Alternate 2D for the SSF Feasibility study. This study will be performed concurrently with the Spent Nuclear Fuels (SNF) CSB conceptual design effort and be used as basis for development of a conceptual design.

\subsection{Scope of Work}

Using Fluor Daniel Concept 2D (Ary stage/dry store $/ 100^{\circ} \mathrm{F}$ MCO/3 vaults one without tubes/Corten tubes) from the Fluor Daniel SSF Feasibility Study, dated February 1995, perform trade studies and prepare individual reports documenting the results of each investigation in accordance with statement of Work, Revision 5, dated April 21, 1995, in Attachment 1 of WHC Work Order TVW-SVV-370252, Modification No. 90 . Use the same criteria as the SSF Feasibility study, unless directed otherwise. The trade studies are as follows:

Concept 2D. Adjust for 750 MCOs with 10 canisters stacked 5high per MCO. Use MCO characteristics defined in Section 3.2.2.1.2.2 of WHC-SNE-FRD-014, "Draft Performance Specification for the Spent Nuclear Fuel Canister storage Building", Rev. A, dated May 1995. Do not reconfigure the twVP CSB storage vaults to support only 750 MCOs. Storage tube quantity should remain at 220 tubes per vault for a total tube count of 440 tubes (two vaults). Revise cost and schedule data from the SSF Feasibility study as appropriate.

Task A Further investigate the requirements for safety Class 1 confinement of the operating spaces above the storage tubes. A negative air pressure relative to atmospheric pressure is required. Considerations include, but are not limited to, sealing the building, providing airlocks, and adequate capacity exhaust fans to maintain a negative relative air pressure. Refer to the draft Preliminary Safety Evaluation (PSE).

Task B Remove the new MCO receipt and staging, i.e. cask/MCO unloading and storage, function and area.

Task C Remove the cask decontamination, i.e. wash area, function and area.

Task D Simplify rail service to one track with passing track outside facility.

Task $\mathbf{E}$ Determine the technical feasibility of nonstainless steel water-filled tubes. Recommend material to resist wet corrosion for only 7 years versus 40 years. 
Task $\mathrm{F}$ Reduce from 4 to 2 shipments per day. Handling equipment demands should be reduced.

Task $G$ Evaluate handling and staging MCOs shipped drained, damp dried from $\mathrm{K}$-Basin assuming 10 SNF canisters per MCO. Determine cooling requirements and investigate natural circulation cooling during staging.

Task $\mathrm{H}$ Functions to comply with Resource Conservation and Recovery Act (RCRA) for prevention and detection of MCO and tube leaks.

\subsection{Design Basis}

The criteria for the trade studies is the same as the SSF Feasibility Study unless noted otherwise. MCO characteristics are defined in Section 3.2.2.1.2.2 of WHC-SNF-FRD-014, "Draft Performance Specification for the Spent Nuclear Fuel Canister Storage Building", Rev. A, dated May 1995. Design Basis requirements are defined in Section 2.8 . 


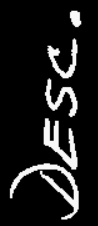

2
2
2
$k$
$v$

N

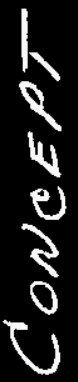

0

N

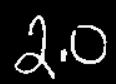

WHC-SD-W379-ES-002 Rev. 0 


\subsection{CONCEPT 2D TECENICAL DESCRIPTION}

\subsection{FACILITY DESCRIPTION}

\section{1 .1 plot plans} Figure 2-1 shows the outline of the Concept $2 D$ SSF and an assumed
adjacent stabilization Facility superimposed on a modified Master Site Plan for what was previously the HWVP site within the 200 East Area. The SSF is shown on the location of the existing CSB foundation. Other existing buildings, roads, rail lines and underground utilities in the area are shown' in their current locations. New facilities which have been proposed for
construction in the area as shown in the Master Site Blan prepared by Fluor Daniel for the Tank Waste Remediation System (TWRS) Site Integration Task Force have been rearranged to be compatible with the Concept 2D layout and location. The Figure shows that location of the SSF on the existing CSB foundation is feasible and provides good access to all required utilities, roads and rail lines. It also shows that location of the SSF in this area is compatible with plans for other facilities which have been proposed for construction in the area.

A more detailed plot plan for Alternative $2 D$ is shown in Figure 22. The Stabilization Facility outline shown in Figure $2-2$ shows one possible location for the stabilization Facility relative to the SSF based on a $100^{\prime} \times 100^{\prime}$ foot print and is not intended to portray an accurate representation of its size or geometry.

\section{1 .2 Rail Tunnel/Cask Jnloading Area}

\subsubsection{General Description}

The Rail Tunnel/Cask Unloading area is a new addition of approximately 10,000 square feet to the original CSB design. It is located in the north west corner of the CSB and interfaces with the MCO Storage Tube Area via a covered water canal as shown in Figure 2-3.

The main functions of this area are to safely receive, handle and prepare the incoming packaged MCO for placement in the storage tubes prior to stabilization. The packaged MCos are delivered inside a transport cask, via rail car or truck, one at a time. Before being returned to the $\mathrm{K}$-Basins, the transport casks are prepared for handling and loaded with an empty MCO.

In addition to the underwater transfer canal to transfer MCOs to a receiving station within the operating area of the storage facility where they can be retrieved by the bottom loading MCo shield cask for transfer to their storage tubes, the Rail Tunnel/Cask UnIoading

$$
2-1
$$




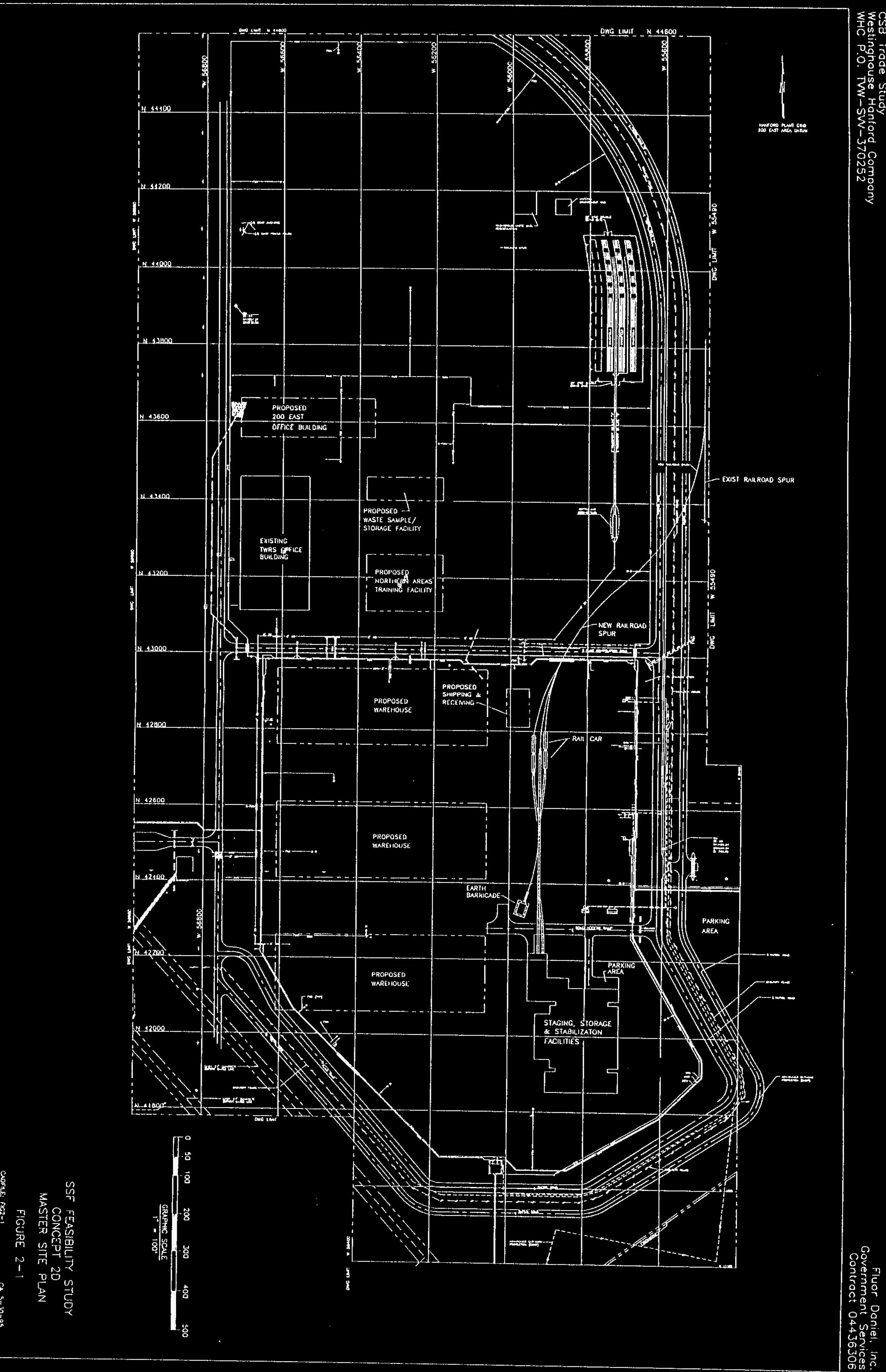




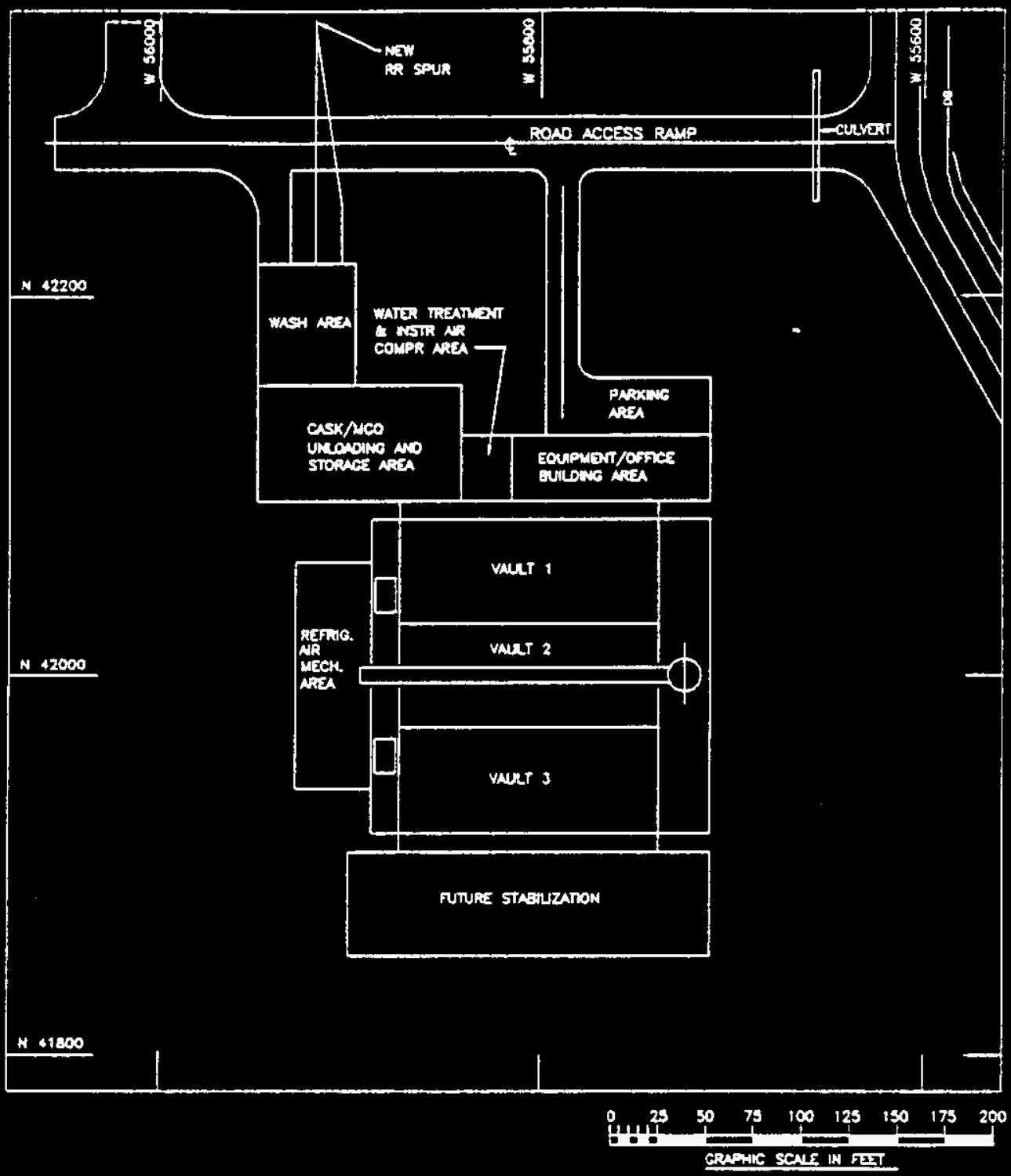

\section{SSF FEASIBILITY STUDY CONCEPT 20 \\ PLOT PLAN}

FIGURE $2-2$

CAOFIL: FG2-2

CA $5-30-95$

$2-3$ 


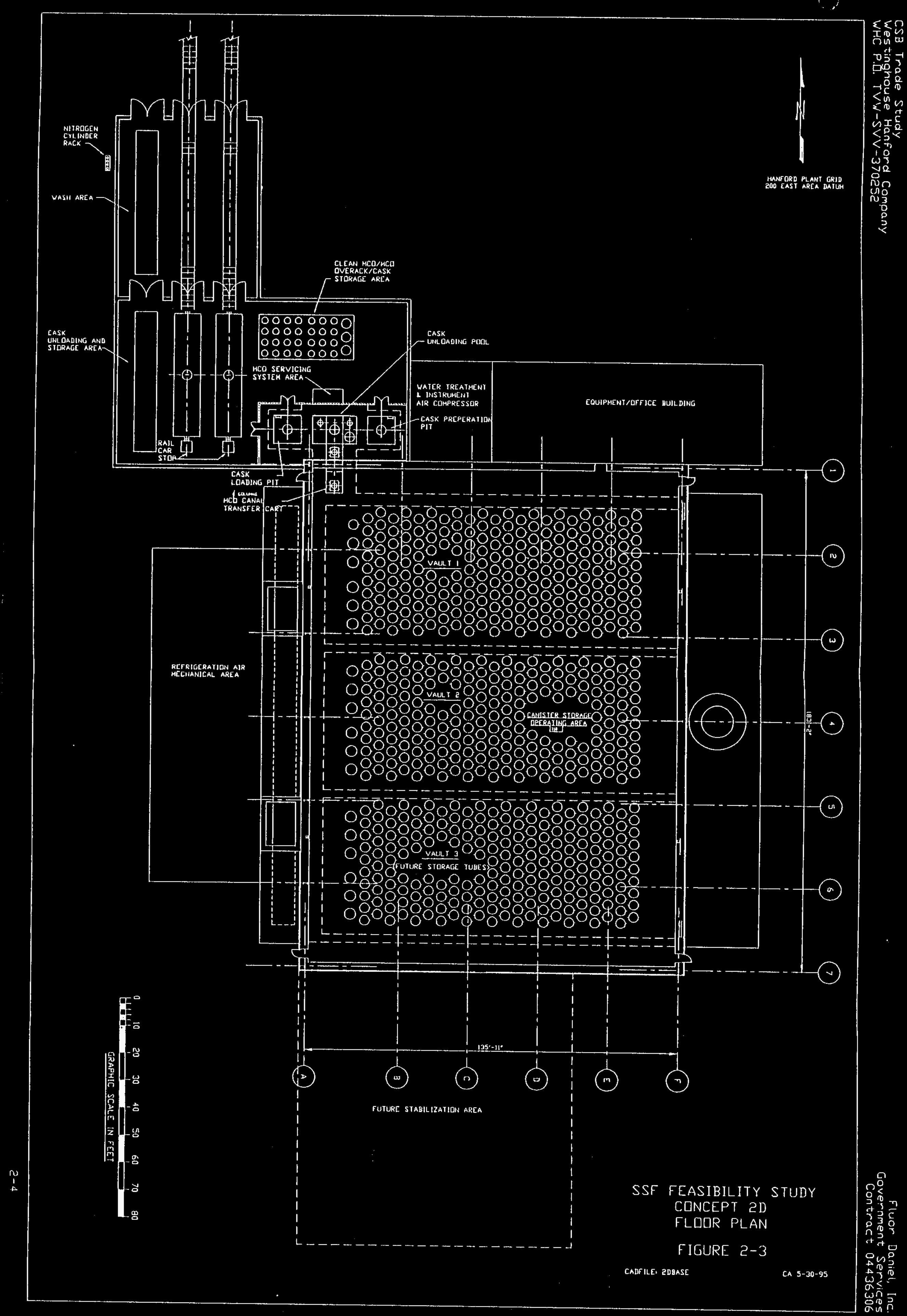


Area contains the following:

(2)

\author{
rail cars outside the facility \\ rail cars in the facility \\ transport casks: (2) clean, ready for use, \\ contaminated, waiting for decontamination and \\ in the decontamination pit \\ empty new MCOs \\ empty new MCO overpack
}

The Rail Tunnel/Cask Unloading Area includes the Wash Area, the Cask Unloading and Storage Area, the Cask Preparation Pit, the Cask Unloading Pool, MCO Transfer Canal, MCO Transfer Canal Cart and the Cask Loading Pit.

A remotely operated hot cell type facility was considered as an alternative to the Cask Preparation Pit/Cask Unloading Pool/MCo Transfer Canal/Cask Loading Pit, but was expected to be more costly and was therefore not considered further.

\subsubsection{Wash Area}

The Wash Area is a air lock confinement area where the incoming railroad cars and delivery truck/trailer are washed prior entering the Cask Unloading and Storage Area. Two railroad cars, and the donkey engine, and a truck trailer parked in parallel can be accommodated inside. A permanent ceiling installed liquid spray arrangement allows wash/decon of the shipping cask upper section. Hand held wash/decon lances are available for the lower areas. Wash water can be pumped out of one or more sumps into a hold tank for monitoring, before being sent through the non-radioactive drain line to the 200 area.

\subsubsection{Cask Unloading and Storage Area}

The Cask Unloading and Storage Area is designed for unloading and loading transport casks and for handling and storage of empty MCOs. Two railroad cars, one truck trailer, twenty eight MCos, one MCo overpack and two clean ready to use shipping casks can be accommodated in this area. A cask unloading overhead crane, with an auxiliary hoist, running in the west/east direction services this area. A fifteen foot tall wall partially isolates this area from the Cask Preparation Pit, the Cask Unloading Pool, MCO Transfer Canal and the Cask Loading Pit, but allows the passage of the overhead crane above it.

\subsubsection{Cask Preparation Pit}

The Cask Preparation Pit is dedicated to the preparation of shipping casks for unloading, which consists primarily of unbolting the cask cover. A sleeve, anchored to the bottom of the pit,

$$
2-5
$$


receives and restrains the cask. Access working platforms are affixed to the upper interior walls of the pit. The overhead crane is used to handle the cask. The' Cask Preparation Pit could also be used for additional cask decontamination or other pre-unloading services if necessary.

\subsubsection{Cask Unloading Pool/MCO Transfer Canal}

The Cask Unloading Pool, adjacent to the Cask Preparation Pit west end, is dedicated to unloading MCOs from their casks, MCO servicing and placing defective MCOs in an overpack. Underwater fixtures are provided to support the cask cover and two MCOs during servicing. Required MCO servicing is performed underwater at this location, using specially designed tools as described in section 2.1.3. An opening,i.e. MCO Transfer Canal, through the common wall separating the Unloading Pool with the MCo Storage Area Transfer Canal Pool allows underwater transfer of $\mathrm{MCO}^{\prime} \mathrm{s}$ from one pool to the other. To minimize cross contamination to the MCO Storage Area Transfer Canal Pool, the pool water return flow is directed toward the Unloading pool. In case contamination is detected in the Unloading Pool a portable gate can be placed in the wall opening to isolate the two pools. When retrieving an empty cask from the pool, the water in the cask is arained above the Unloading Pool using special tools. The overhead crane is used to handle the cask and the portable gate. The auxiliary hoist is used to handle the cask cover, MCO and overpack.

The underwater transfer of the MCO from the Unloading Pool to the Storage Area Transfer Canal Pool is accomplished using the MCO Transfer Canal Cart.

\section{1:2.6 Cask Loading Pit}

The Cask Loading Pit, similar in construction to the Cask Preparation Pit, is located west of the Cask Unloading Pool and is dedicated to cask preparation for return to the $\mathrm{K}$-basins. With the cover removed, the cask is decontaminated, and an empty MCO is loaded inside the cask. The gap between cask cavity and MCO is filled with deionized water. Finally the cask cover is bolted on and decontaminated if necessary. The now ready to use cask is transferred to a storage position or to an empty railroad car located in the Cask Loading and Storage area.

\section{1 .3 MCO Sexvicing}

\subsubsection{Functional Description}

After each MCO is received into the SSF for staging, the MCO will be purged with nitrogen, then deionized water will be added if needed to reach the desired level in the MCo. The servicing will be done with the MCO submerged in the Cask Unloading Pool. A pool

$$
2-6
$$


water treatment system will maintain pool temperature, clarity, and radioactive contamination at acceptable levels.

\subsubsection{Syst:em Design Requirements}

Once all MCOs have been received, only water-filled MCOs will need to be serviced. Based on the water reaction rate with uranium and the evaporation rate at $100^{\circ} \mathrm{F}$, the worst MCO must be serviced at least every 300 days. Since there is no means of determining the water level within an MCO, a conservative schedule must be established to ensure that the top canister in the most active MCo does not become dry. This requires servicing at least 3 MCOs per day, starting within 300 days after placement." For water-filied MCOs, it was assumed that the hydrogen inside each MCO does not constitute a hazard, assuming the MCOs are designed so they will not release gas in the event of a Design Basis Accident (if this assumption is incorrect, then more than 500 MCOs per day must be purged in order to keep hydrogen concentrations below the hazardous level of $6 \%$. The pool water will provide sufficient shielding for operators above the pool to assist in making the necessary piping or hose connections to the MCO using specially designed tools. Water will flow into the servicing area from the MCo storage Area Transfer Canal Bool, then back to the pool treatment system. The containment and confinement requirements for this area are as defined in ANSI/ANS Standard 57-7. Because of the greater chance for contamination of the pool when MCO valves are opened, the water turnover time in the service area is $36 \mathrm{hr}$, half that of the ANSI standard requirement.

\subsubsection{Design Assumptions}

The MCO will be designed so that a grapple can be attached for transporting it underwater without the cask. The MCo will have at least three valved connections that can be remotely connected to piping or hoses, with each valve capable of remote operation (see Figure 2-4). One of the connections will have an interior dip tube which extends a known length below the desired water level (but above any sludge), and another connection will terminate at the top of the MCo, so that a differential pressure sensor in the service area can determine the MCO water level. One of the differential pressure legs will also be used for nitrogen purging, described below. The third valved connection will allow the MCo to be filled while the water level is monitored.

\subsubsection{Mechanical Design and Operation}

The servicing of 4 MCOs per day requires two service stations in the servicing area. Each station is equipped with a gas collection pot, filter, piping, and instruments that must be connected to the MCO for servicing. The station is attached by flexible hoses to fixed piping for nitrogen, water, and vent gas. The basic 
components of a station are shown on Figure 2-4. The system equipment 1 ist (Table 2-1) indicates the major items needed for the two stations as well as auxiliary equipment that supports the function of the stations.

The cask unloading crane brings the shielding cask with MCo into the Cask Unloading Pool. The cask provides operator shielding until the cask is covered by at least $8 \mathrm{ft}$ of water. After the crane removes the cask lid and places the MCO on an underwater stand for servicing, the operator manually positions the servicing piping assembly onto the MCO, remotely couples the piping to the MCO connections and prepares to operate the MCO valves. The vent gas pressure and contamination level are monitored before the gas is released through a HEPA filter to the operating area building stack. Upstream of the HEPA filter is a shielded gas collection pot which will serve as a radiation monitor source, catch any entrained liquid in the vent gas, and provide capability for gas sampling. After the pressure in the MCO is released, sufficient nitrogen is purged through the MCO to reduce the hydrogen concentration to $1 \%$ by volume or less. After purging, the nitrogen flow is reduced in order to measure the level of water in the MCO. Nitrogen is stored in cylinders delivered by truck to a rack outside the building. If needed, deionized water is added by a metering pump through the collection pot in order to flush any contamination back into the MCO. The valves on the MCO are closed after servicing, the service station is disconnected, and the MCO is transported underwater by the MCO Transfer Canal Cart into the MCo Storage Area Transfer Canal Pool.

\subsubsection{Cask Unloading Pool Water Treatment System}

\section{1:4.1 Functional Description}

After each MCO is received and passed through the Cask Preparation Pit, the MCO will be placed in the Cask Unloading Pool. The pool water provides shielding and cooling for the worst case. The pool water treatment system will maintain pool temperature, clarity, and radioactive contamination at acceptable levels. Although no leakage is expected from MCOs or system components, the pool and its water treatment system are designed to minimize radiation exposure in the event of leakage due to a credible accident.

\subsubsection{System Design Requirements}

The nominal value of heat generation per MCO is $221 \mathrm{~W}$ and the maximum value is $482 \mathrm{~W}$. At $100^{\circ} \mathrm{F}$ the maximum MCO produces near 40 $\mathrm{L} /$ day of hydrogen gas contaminated with $4.62 \mathrm{mCi} / \mathrm{I}$ of $\mathrm{Kr}-85$. The nominal values apply to $80 \%$ of the MCOs, the upper Iimits apply to $20 \%$. There are no particulates or condensible vapors generated during non-accident conditions. The total system cooling duty is based on the maximum MCO. 


\section{FIGURE $2-4$ \\ MCO SERVICE STATION \\ CONCEPT 2D}

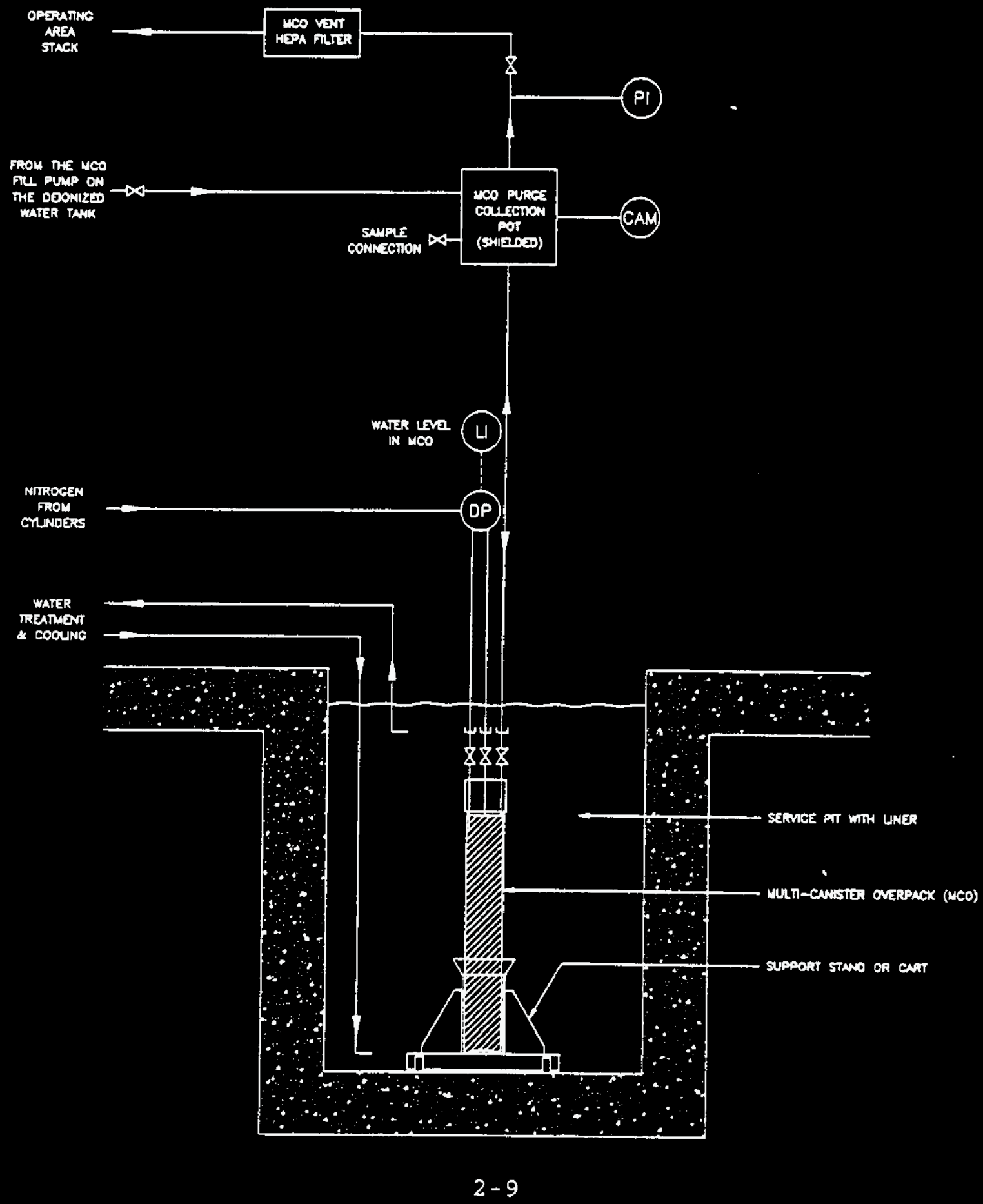

WHC-SD-W379-ES-003 ReV. 0 
CSB Trade Srudy

West inghouse Hanford Company

WHC P.O. TVW-SVV-370252

Page No. 1

$02 / 14 / 95$
TABLE 2-1

E O I P MENT L I S T

STAGING AND STORAGE FACILITY

SSF

(CONCEPT 2D)

EOUIPHENT

DESCRIPIIOH

EQUIPHENT

ID

CAPACITY/FLOU RATE

Protcal size

(DIA $X$ H)

MATERIAL

POUER

HEAT
LOAD

COMHENT

YCO SERYICIUE SYSIE:

WITROGEH CYL JMDER RACK

$\mathbf{R - 1}$

40 SCF/DAY

FOUR G" OO $\times$ 5' H CYLINDERS

STEEL.

DECON SOLUTION TANKS

$V-1 A / B / C / D$

ATmOS. PRESS.

for $3,00 \times 4 \cdot 4$

$0.1 \mathrm{GPH}, 150$ PSIO

$1,00 \times 1144$

P-1A/B

$12^{11} 00 \times 14^{\prime \prime}$

Fluor Daniel, Inc.

Government Services

Contract 04436306

MCO PURGE COLLECTION POIS

BETA/GAMMA PROCESS MOHIIORS

MCO VENT MEPA FILTERS
$0.1 \mathrm{GPM}$

$1100 \times 144$

3. $00 \times 8.4$

$1,00 \times 1 \cdot 4^{\prime \prime}$

$31000 \times 3140$

$10 \mathrm{CFM}, 1 \mathrm{M}$

$v \cdot 2$

$\cdot 2 \alpha / 8$

$1 \mathrm{GPM}, 10$ PSIG
F - 1A/B
$300 \times 3 \times 4$

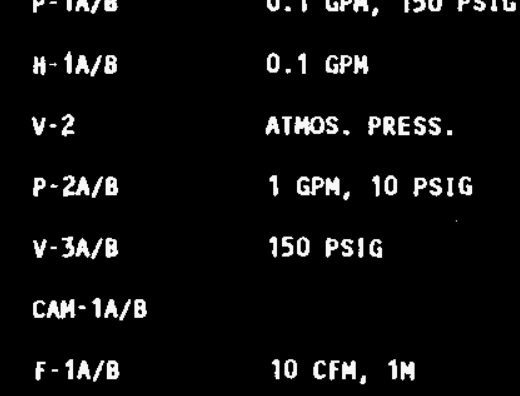

SS

ss

STEEL

SS

SS

ss

SS Boor
MUCLEAR GRADE CARIRIDGE FILTER 
The pool is lined with stainless steel to ensure water purity, to prevent water migration through the concrete pool structure, and to allow decontamination at the end of the facility life. As recommended by DOE Order 6430.1A, Section 1320, the Iiner has a leak detection system with a collection sump in the concrete structure.

The water treatment system returns water which has been purified and cooled to $95^{\circ} \mathrm{F}$. This will maintain the MCO at $100^{\circ} \mathrm{F}$ or less under normal conditions. The system has sufficient redundancy (or else contingency back-up capability within the available response time) so that a single failure of any active component (such as a pump, filter, or control) will not cause loss of system function. The following requirements of ANSI/ANS 57.7 and NRC Reg Guide 3.49 are met: Clarity will be sufficient to clearly see to the bottom of the pool. Contamination will be maintained at an annual average gross activity level of $5 \times 10^{-4} \mathrm{mCi} / \mathrm{L}$ or less during normal operation. The recirculation rate is sufficient to turnover the pool volume in 36 hours and the deionization units will not be regenerated. The piping is designed so that water will not siphon out of the pool in the event of a piping leak. Because of the small size of the units, the resin beds are replaced when they become saturated.

The system will maintain a safe condition after loss of normal power, loss of cooling, and Design Basis Accidents such as earthquake; in these cases, credit will be taken for portable equipment that can be moved in during the period of time before temperatures, hydrogen concentration, or contamination levels exceed safe levels. The clean-up system will have the capacity for the worst-credible release of contamination into the pool.

\subsubsection{Design Assumptions}

The MCO will be designed so that a grapple can be attached for transporting it underwater without the cask. The laboratory required for periodic analysis of pool water samples is not part of this facility. Fresh make-up to the deionizer will come from the site sanitary water, containing 95.1 ppm dissolved solids, 1 ess than 10 ppm suspended solids, $\mathrm{pH} 7.80$, and $\mathrm{CaCO}_{3}$ hardness of 73.46 ppm.

\subsubsection{Mechanical Design and Operation}

Figure 2-3 shows the arrangement of the Cask Unloading Pool and associated areas. MCOs are transported to and from the cask unloading pool by the MCO Transfer Cart. The depth of water above the MCO Transfer Cart allows the MCO being transported to be covered by 8 ft of water at all times.

$$
2-11
$$


Refer to Figure 2-5, the block diagram for pool water treatment and cooling. The pool water treatment system consists of pool skimmers and flow distribution piping, recirculation pumps, high-efficiency filters, filter backwash equipment, deionization units, deionization unit replacement, waste slurry holding, waste water holding, water chillers, and water sterilizers.

Table 2-2 lists the major equipment for the pool water treatment system. The skimmers remove floating debris from the cask unloading pool. Inlet and outlet piping for the pool is designed to provide distribution of flow through the pool with minimum pressure loss. One operating pump and one spare provide a 36 hr turnover of the pool volume during normal operation. If contamination in the pool becomes abnormally high, both pumps can be operated to increase the recirculation rate. The filters are nuclear-grade filters with a particle capture size of one micron. Compressed air at 300 psig will be produced to improve backwashing and to supply the facility instrument air system. Stainless steel material was chosen for the compressed air to avoid getting pipe scale particles on the clean side of the filters during backwash. The deionization unit is a duplex package of two trains, so that one train can remain in operation while the other is out of service. Each train removes both anions and cations (positively and negatively charged ions) from the water in resin beds. If contamination in the pool becomes abnormally high, both trains can be temporarily operated in parallel to increase the recirculation rate. The design of the filters and deionizers for accident conditions is discussed in section 2.2.3.3. Normally, deionization resin replacement is required less than once per year.

Pool water treatment system drainage will go to the waste water hold tank to be neutralized and monitored before being picked up by a truck with a pump. Pool water filtrate slurry will go to the contaminated waste slurry hold tank to be monitored before being pressurized into a shielded container on a truck, using compressed air. Fresh resin can be exchanged into the deionization units from the shielded room containing the units. Separate curbed areas are provided for truck loading and unloading at the tanks for waste water and contaminated waste slurry.

Each chiller is sized for the maximum heat input from the MCo, heat gains from the surroundings, and the dissipated energy from the 10 hp recirculating pump. A $100 \%$ spare chiller and heat exchanger is provided, although interruptions in cooling can be tolerated. In the event of loss of cooling, the pool requires over 165 hours to warm up $10^{\circ} \mathrm{F}$. However, recovery from an overheated condition requires some spare cooling capacity. The pool water sterilizers, along with chemical addition, inhibit biological growth which would cloud the water. The glass in the ultraviolet sterilizers wiIl require regular cleaning. The equipment used to detect excessive

$$
2-12
$$


CSB Trade Study

West inghouse Hanford Company

WHC P.O. TVW-SVV-370252
Fluor Daniel, Inc. Government Services Contract 04436306

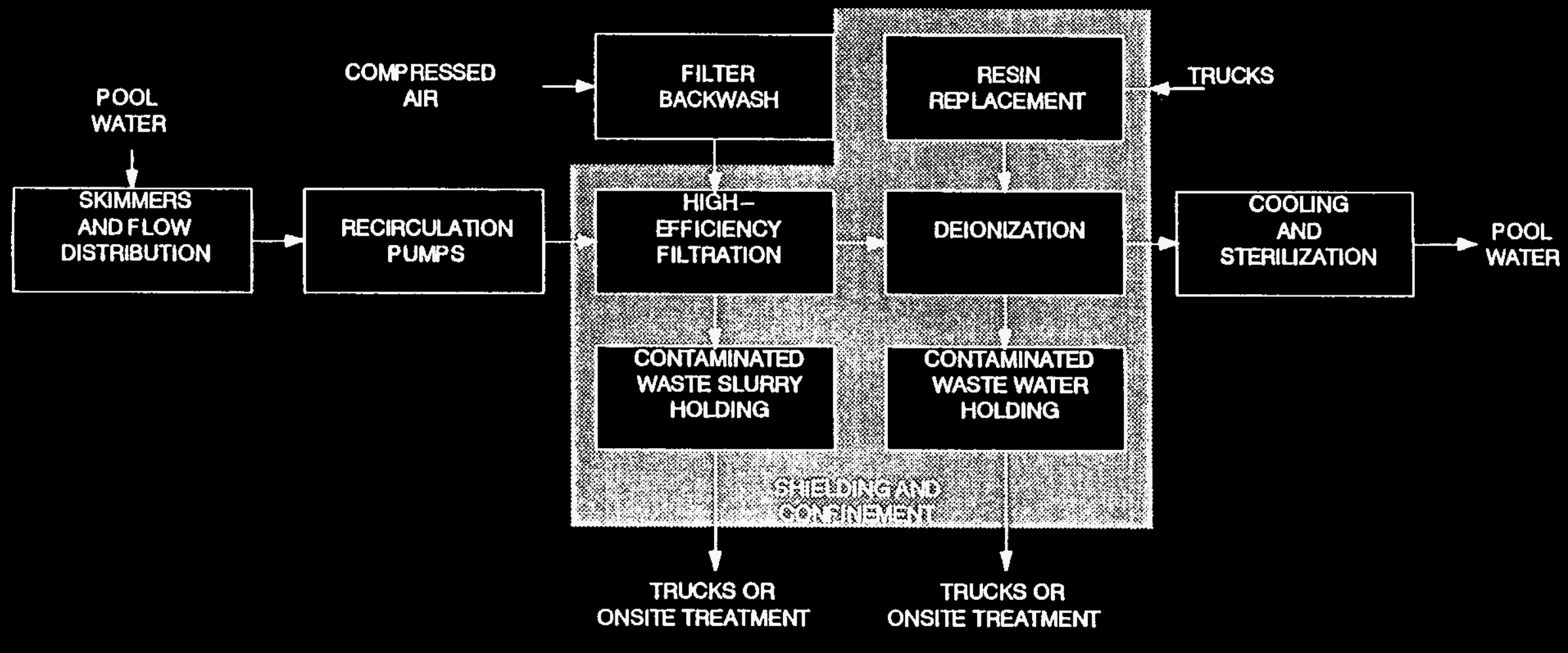

FIGURE 2-5

PROCESS BLOCK FLOW DIAGRAM

CASK UNLOADING POOL

WATER TREATMENT 


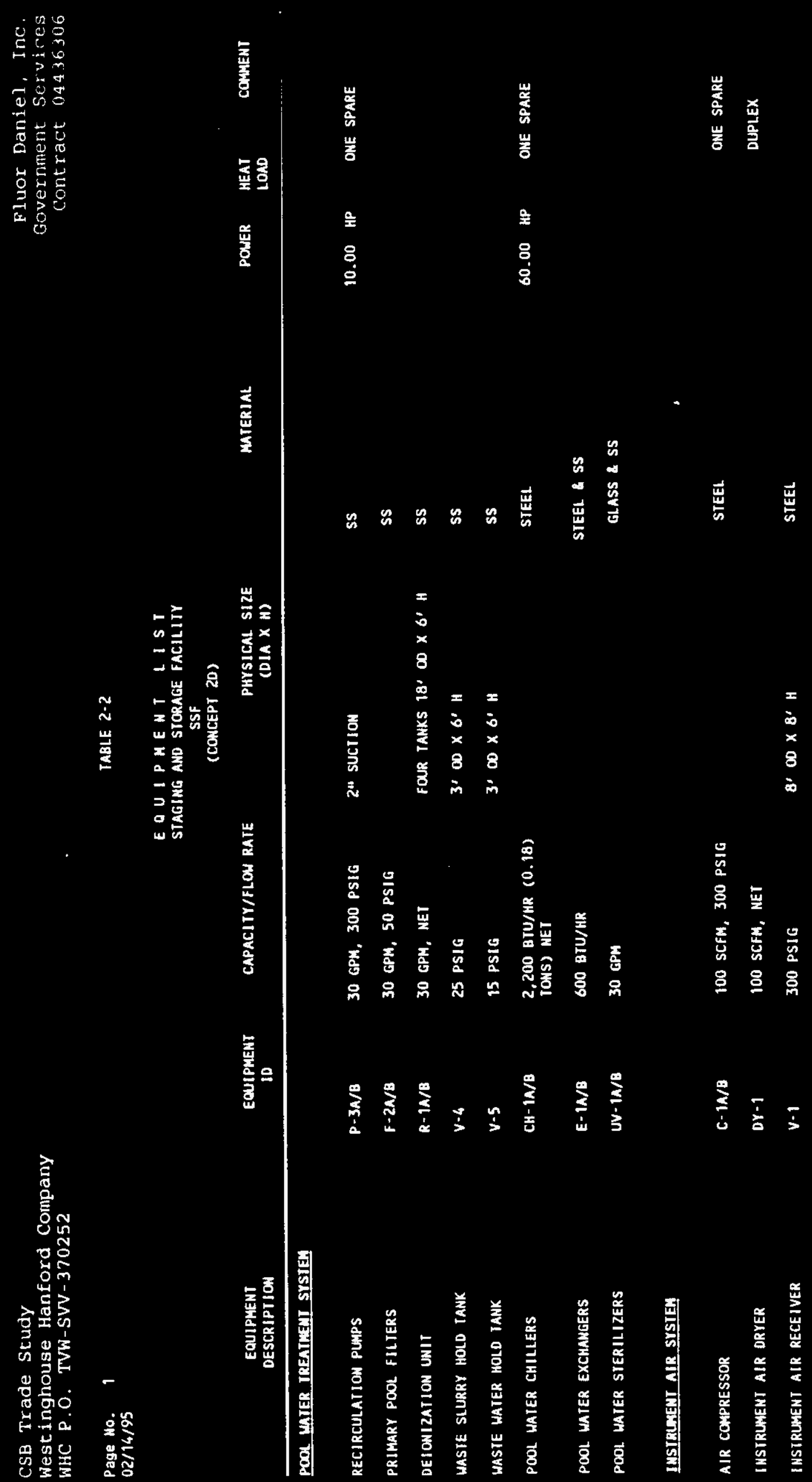


contamination in the pool and locate a leaking MCo is discussed in Seation 2,2.3.3.

\subsubsection{MCO Cooling and EVAC}

2.1.5.1. FVAC Systems for Normal Operation

Vault Refrigerated Air System. The block flow diagram for the FVAC system serving the SSF Vaults during staging is shown on Figure 26. The FVAC system is a recirculating refrigerated air system consisting of five 50,000 CFM Air Handling Units (4-operating and 1-standby) which supply chilled air at $35^{\circ} \mathrm{F}$ to the vault. This supply air temperature to the vault will maintain the MCOs at $111^{\circ} \mathrm{F}$. The $11^{\circ} \mathrm{F}$ does not comply with current MCO temperature $\left(100^{\circ} \mathrm{F}\right)$ requirements, but is used as the basis for the RoM cost estimate. Since the MCO's are stored in dry air filled Corten tubes which serve as a secondary confinement barrier, the air inside the vault will not be contaminated.

Vault Passive Ventilation system. The passive ventilation system for the vault during dry storage will be identical to the CSB design. This concept has two vaults, each with 220 tubes. There are provisions for 11 overpacks and the tube spacing for this concept will be identical to the CSB design. A third vault is provided as in the original CSB design, however, no tubes will be installed.

Operating Area HVAC System. The Operating Area HVAC System for the CSB design will be modified to accommodate the ventilation system for the MCO service area and the MCo/Cask unloading and storage area. The system is capable of diluting the hydrogen and krypton85 'to acceptable levels by introducing sufficient amounts of outside air. The block flow diagram for this system is depicted in Figure 2-7).

Pool Water Treatment Building. This building consists of clean areas and potentially contaminated areas. A single HVAC system will be used to serve these areas.

The block flow diagram for the HVAC system serving these areas is shown on Figure 2-8. Redundant 2,000 CFM Air Handling Units (AFU-1) and AfU-2) with evaporative cooler and heating coil supply air to these areas and the air is exhausted through redundant bisp filter plenums (PF-1 and $P F-2)$ and exhaust fans $(E F-1$ and $E F-2)$.

\subsubsection{HVAC Systems for Abnormal Operation}

Vault Refrigerated Air system. It has been estimated that on failure of the vault refrigerated air system used during staging, the MCO temperature will increase by $30^{\circ} \mathrm{F}$ in approximately 20 hours. Concept $2 \mathrm{D}$ is currently not a safety class system.

$$
2-15
$$


CSB Trade Study

West inghouse Hanford Company

WHC P.O. TVW-SVV- 370252
Government Services Contract 04436306

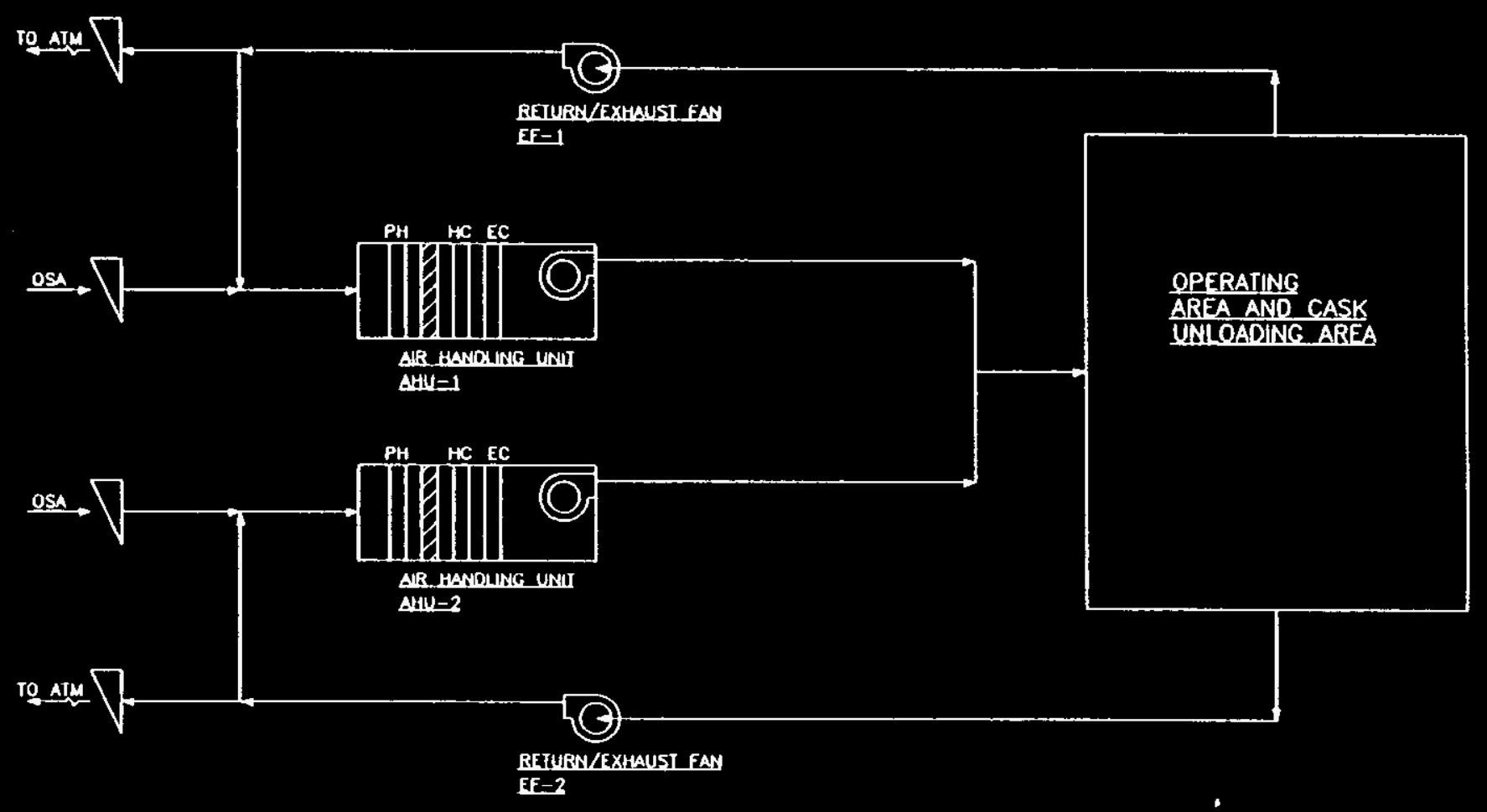

\footnotetext{
FIGURE: $\quad 2-7$

SSF FEASIBILITY STUDY

CONCEPI 20

opERAIING AREA

HVAC SYSTEM
}

Romin: nez-y

$2-17$

WHC-SD-W379-ES-003 Rev. 


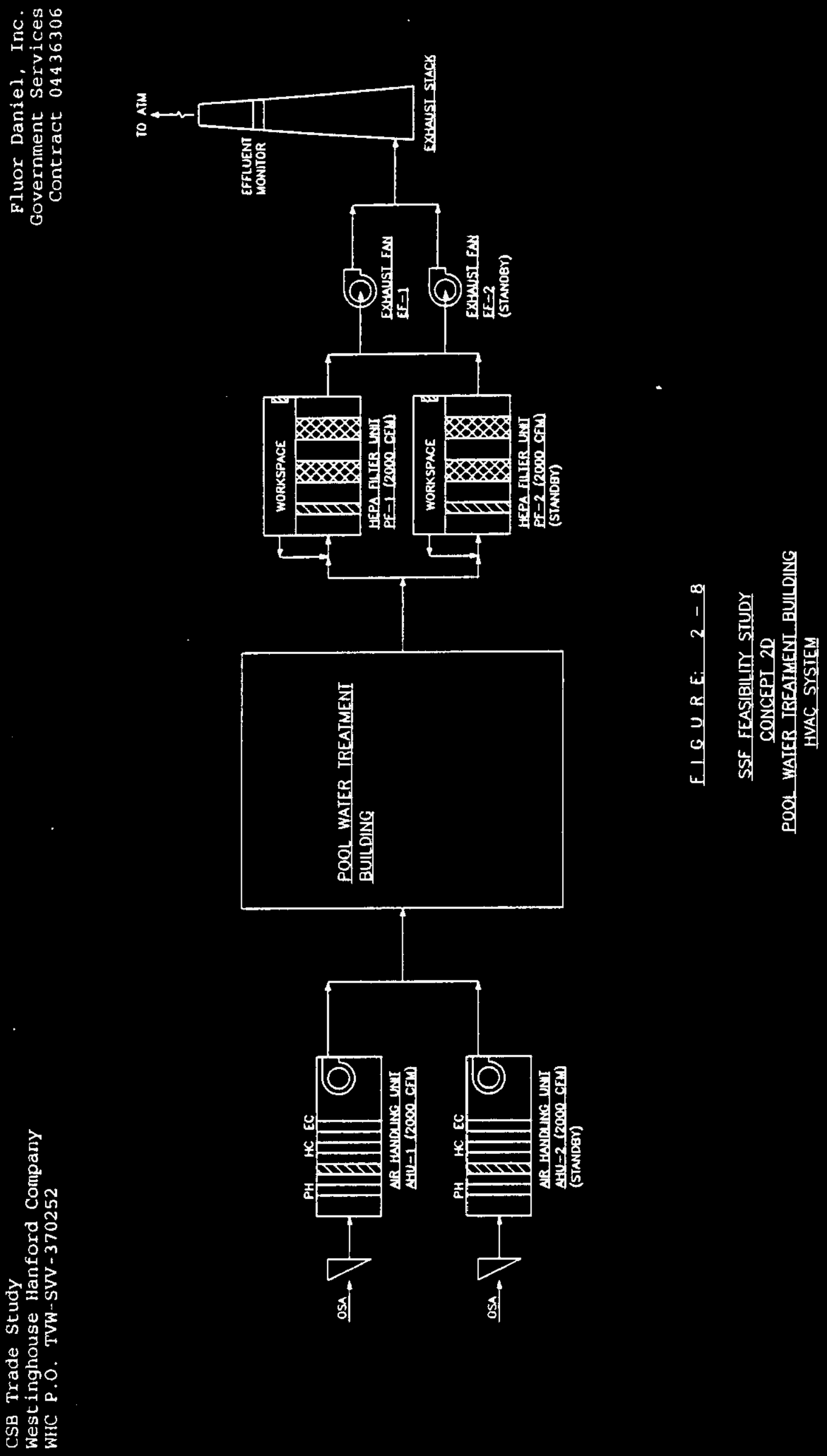




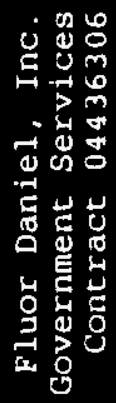

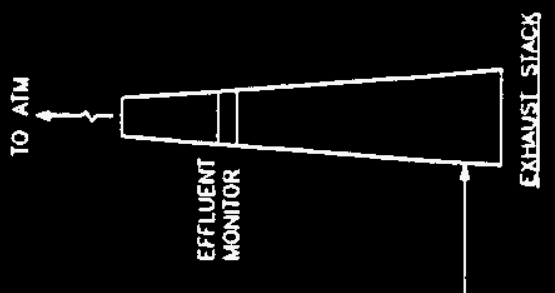

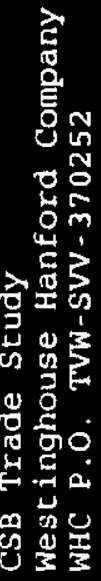

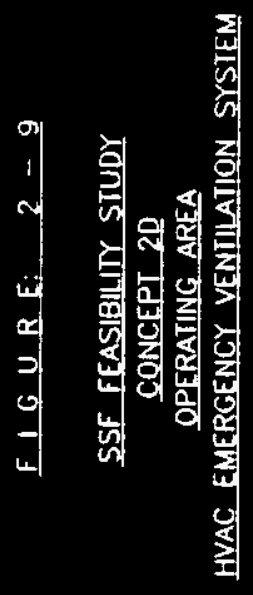


Adequate time would mostly likely not be available in the event of a sustained loss of refrigerated air cooling to bring in mobile emergency cooling capability before MCO temperatures became excessive.

Vault Passive Ventilation system. The vault passive ventilation system used during dry storage is designed to operate following all DBA's. No other FVAC systems are required for operation of the vaults during abnormal operation.

Operating Area. The block flow diagram for the FVAC system for emergency ventilation of the Operating Area is shown on Figure 29). This system is designed to be activated following an accident (potential drop of an MCO and release of contamination to the operating area) and is interlocked to stop the normally operating FVAC system. The EVAC system consists of two trains with HEPA filter plenums (PF-1 and $\mathrm{PF}-2$ ) and exhaust fans (EF-1 and $\mathrm{EF}-2$ ).

\section{1 .6 struetural}

The CSB below grade concrete vaults and the operating floor will essentially remain the same as originally designed. Vaults 1 and 2 will be used for the staging and storage of the MCOs containing SNE, and vault 3 will remain empty for future storage of undefined material. The existing 3 feet east-west wall between vaults $2 \& 3$ must be increased to 42 " to provide adequate shielding protection to persons entering the vault 3 for activation at a later date. Preliminary HVAC calculations indicate that the concrete surface temperature inside the vaults during staging and support phases will not exceed $150^{\circ} \mathrm{F}$. Therefore, the insulating concrete may be deleted from the original design. Also the 1 inch metallic traffic topping over the concrete operating floor will be replaced with a less expensive concrete sealer / hardener since the MCOs are to be handled by crane and not by shielded transporters. The structural consequence of dropping the facility cask containing MCo from a 3 foot height on the operating floor will require further evaluation including a crane with features to prevent a drop. The storage tubes will be of Corten material similar to those designed for the CSB.

The existing design of the steel shelter over the operating floor will be modified to include crane rails and girders for the overhead crane for the cask/Mco handling system. This building height will be increased by approximately 12 feet and the currently designed steel columns and portion of roof trusses members will be replaced with stronger sections. The north wall of the operating building may require relocation north by approximately $8^{\prime}-0^{\prime \prime}$ to accommodate crane operation. The Cask/MCO Unloading and Storage Area Building is approximately 170 feet long, 61 feet wide, and 33 ft high. This building will have an overhead crane for unloading

$$
2-20
$$


an I loading of casks and MCOs. Within this building is below grade cask unlcading and MCO transfer pool. The concrete pit floor and walls will be lined with $1 / 4$ inch and $3 / 16$ inch stainless steel plate respectively, complete with leak detection system. The Wash Area Building is approximately 64 feet long, 50 feet wide and 27 feet high. These buildings will be constructed of structural steel framing enclosed by insulated metal siding and metal roof deck.

The Pool Water Treatment \& Instrument Air Compressor Building is approximately 35 by 30 by 17 feet high steel structure. The Equipment /Office/Generator Area Building will be a steel frame building and similar in construction to the existing CSB equipment/office area building except, the size will be approximately 100 by 33 by 17 feet high. The Refrigerated Air Mechanical Area Building is approximately 120 by 40 by 20 feet high steel framed structure enclosed by insulated metal siding and metal roof deck.

An FVAC duct, approximately $10 \mathrm{ft}$ by 5 ft in size will be added connecting the exhaust stack and the Refrigerated Air Mechanical Area. This duct will be supported by the operating shelter. Refrigerated air will be retumed to the air inlet ducts via ducts from the Refrigerated Air Mechanical Area. Removable blinds in the air inlet ducts and exhaust stack will isolate the refrigerated air system from the environment. The inlet air temperature to the vault will be about $35^{\circ} \mathrm{F}$ during the staging phase.

The preliminary safety classification of the SSCs for the staging and storage phases is defined in Tables 2-9 and 2-10 respectively.

\section{1:7 Material Flow}

\subsubsection{General Description}

The Material Flow includes two distinct phases: the staging Material Flow and the storage Material flow which takes place only after completion of the stabilization Facility.

\subsubsection{Staging Material Flow}

The Staging Material Flow involves tasks and sequences necessary to place packaged MCOs, received from the K-Basins, into forced air cooled storage tubes in the storage Tube Area, prior to stabilization.

The staging Material flow begins with a packaged MCo in a cask, on top of a rail road car or truck parked outside the Rail Tunnel/Cask Unloading Area. It terminates at the removal, from the facility, of a decontaminated cask loaded with an empty, ready to use, MCO.

$$
2-21
$$


Figures 2-10 through 2-13 depict the tasks, sequences, equipment and estimated time required to perform the tasks.

It is assumed that placement of the bottom impact absorbers inside the storage tubes is performed during the completion of construction. The upper impact absorbers are assumed to be installed in a campaign style manner during a down time period.

\subsubsection{Storage Material Flow}

The storage material flow involves tasks and sequences for storing stabilized MCOs inside dry, passively cooled storage tubes. These tubes being the same used for the prior staging phase. This phase will occur only after the stabilization Facility has been made operative.

The Storage Material Flow begins with the removal of an MCo from a storage tube and its transfer to the stabilization Facility. It terminates with closure of a dry storage tube after loading a stabilized MCO in it. If required, MCOs can be retrieved and sent to the stabilization Facility for overpacking by reversing the sequences order. Figures 2-14 and 2-15 depict the tasks,

sequences, equipment and estimated time required to perform the tasks.

It is assumed that removal and replacement of the upper impact absorbers inside the storage tubes is performed outside the MCO handIing time frame. The bottom impact absorbers remain in place and do not require handling. The upper impact absorbers are assumed to be removed and reinstalled in a campaign style manner, during a down time period.

\subsubsection{Overhead Crane Design and Operation}

For loading MCOs into the storage tubes in the SSF dry staging/storage vaults an overhead crane with associated casks and fixtures will be used. The overhead crane system is similar to methods used in Europe and at the Fort st. Vrain Fuel storage Facility. Other methods for loading the storage tubes are possible, i.e. a Shielded Canister Transporter(SCT) as was designed for FWVP/CSB, but were deemed less attractive for this application.

The size and weight of the MCO will have an affect on the handing equipment and overall capital and operating cost of the system adopted. Two different size MCOs were considered in this evaluation:

1) A 10 canister MCO, 181 inches long, weighing 11,600 1bs.

2) A 10 canister MCO, 181 inches long, weighing 13,100 Ibs.

$$
2-22
$$



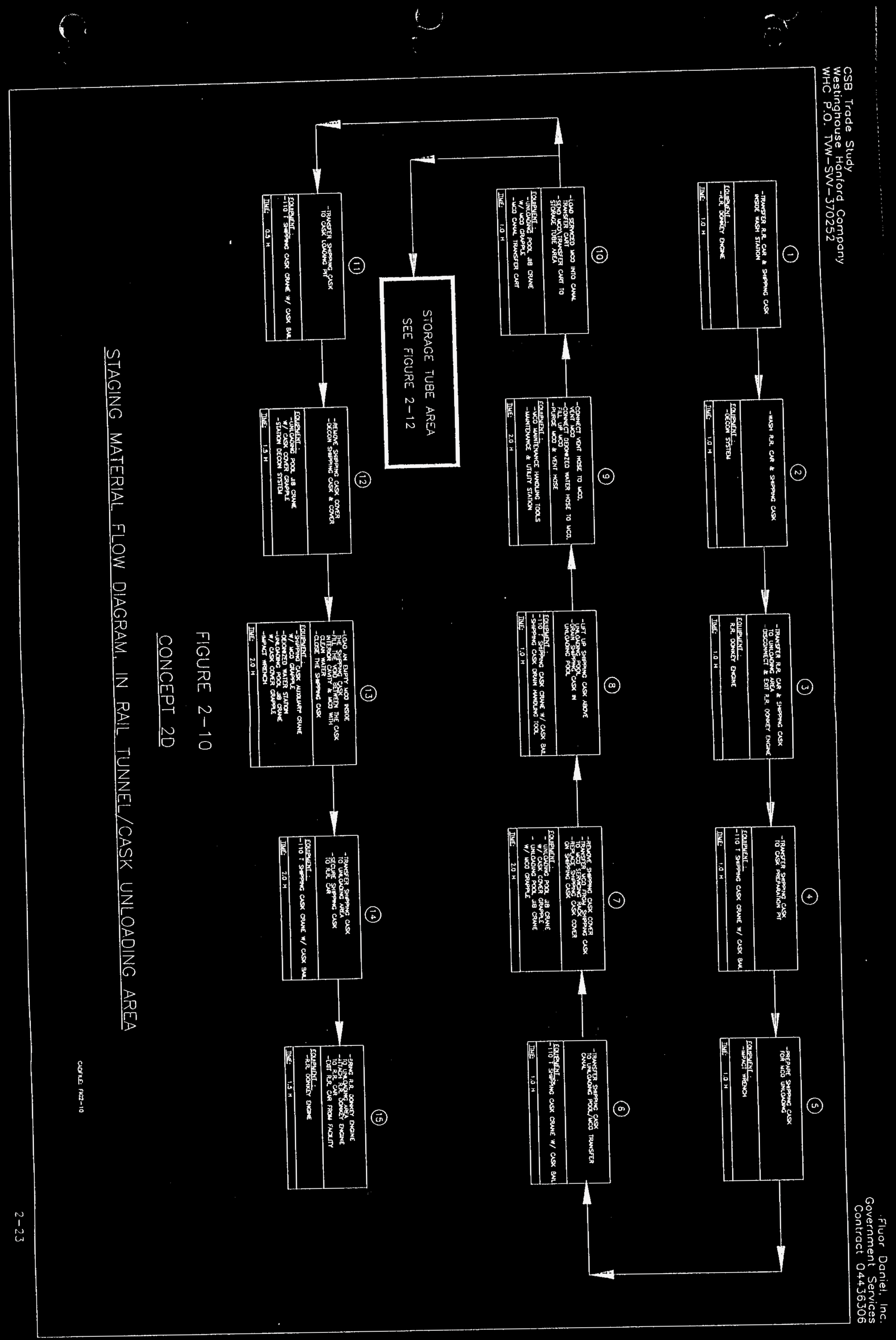


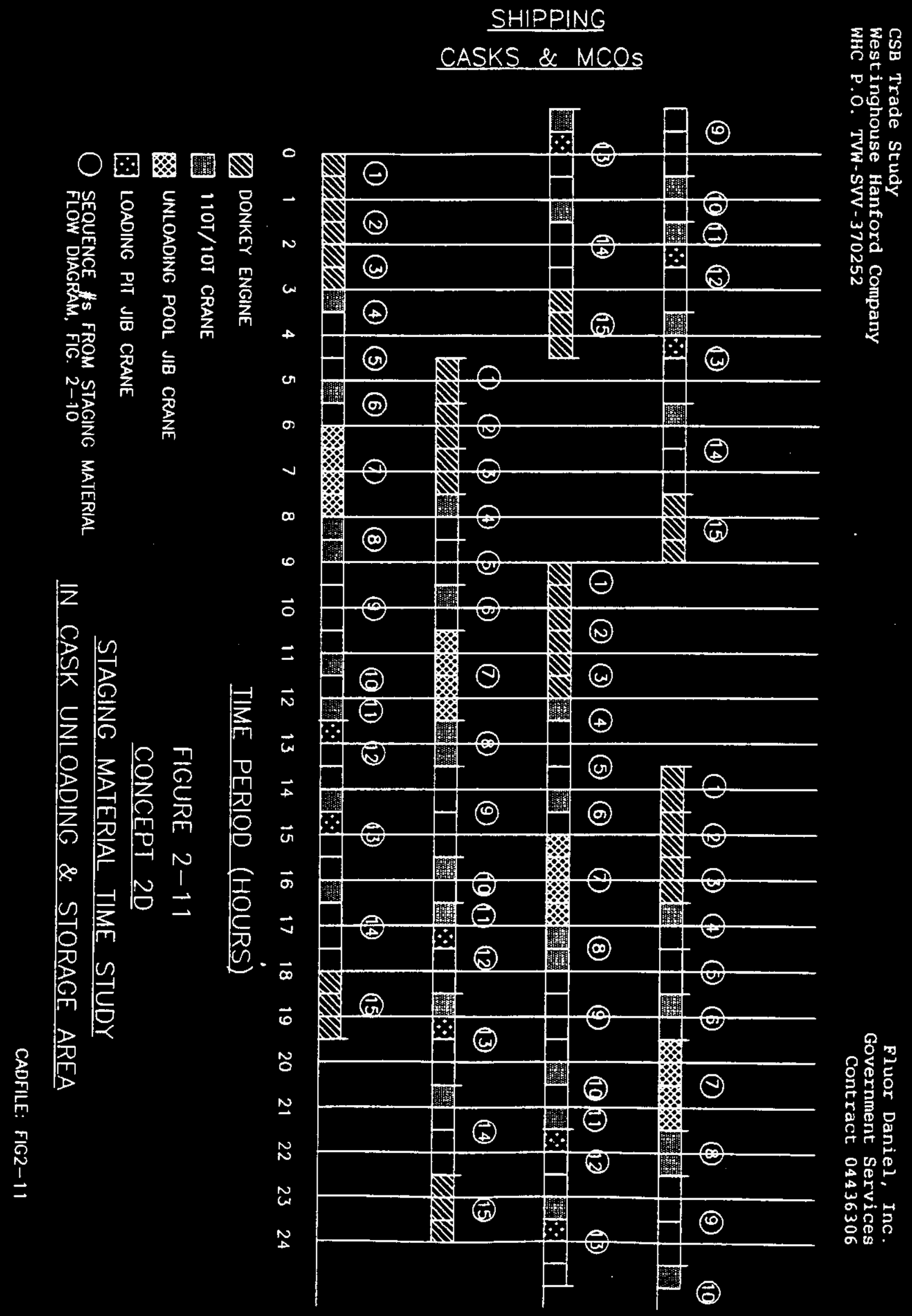




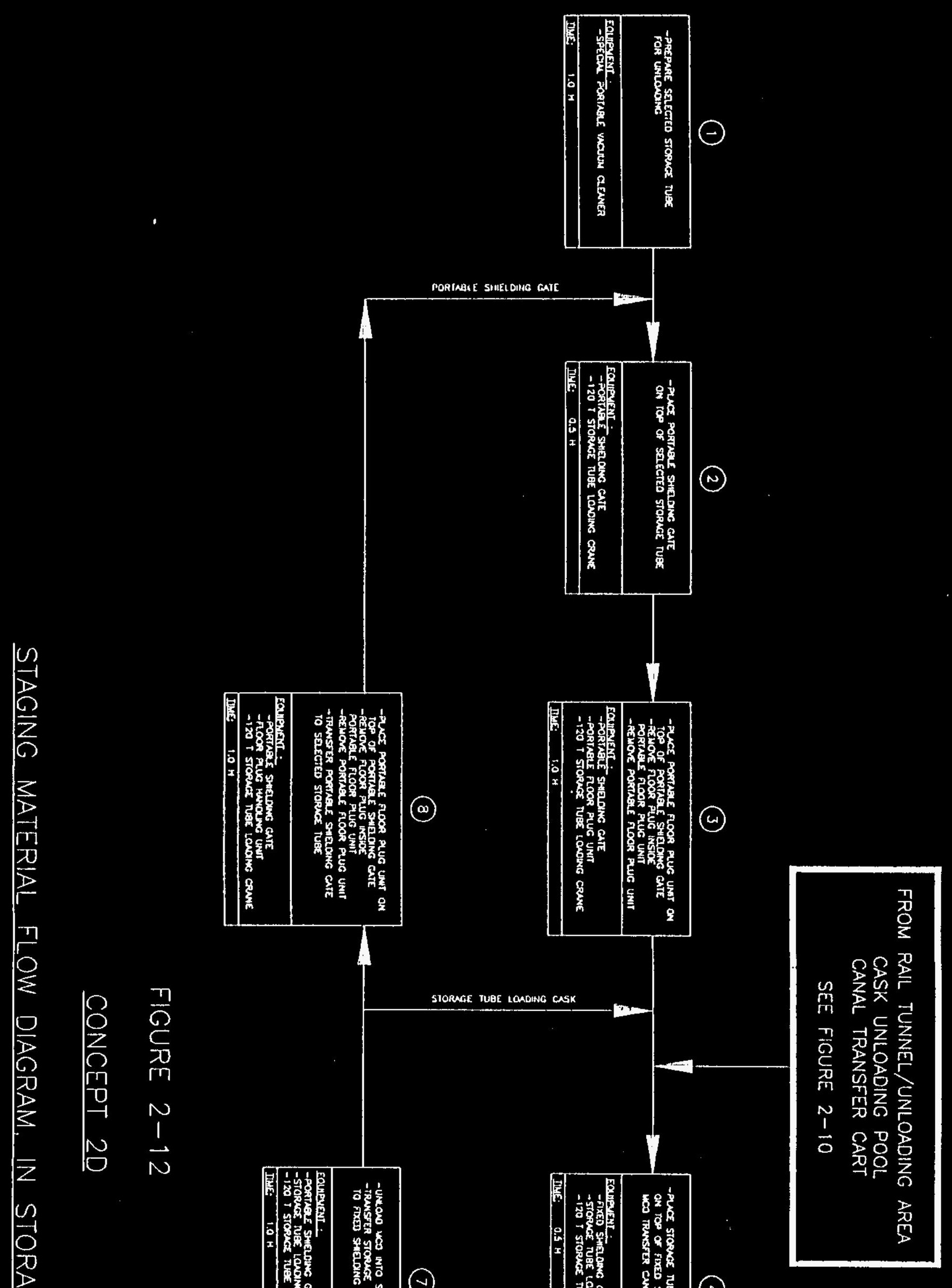




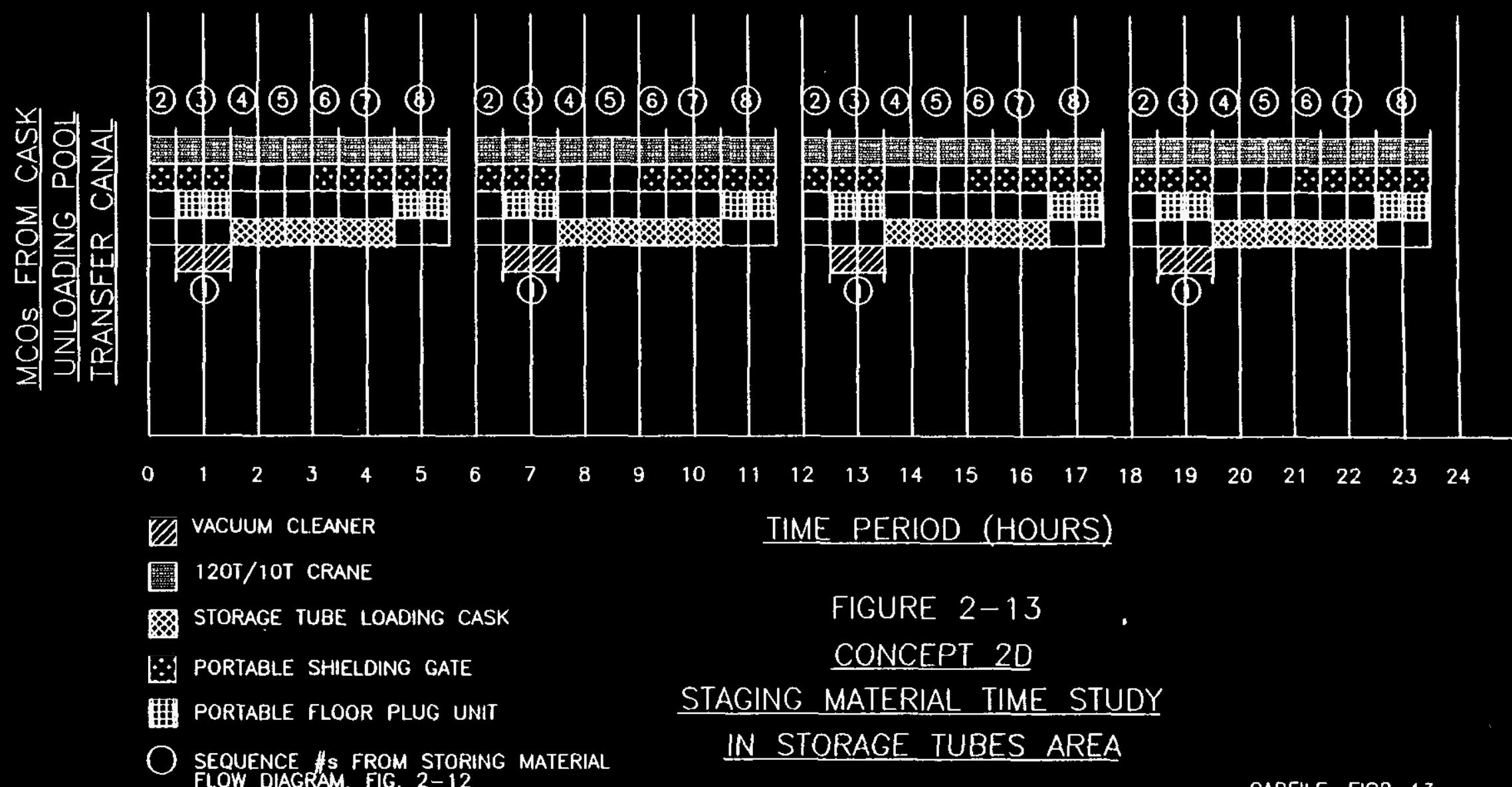

CADFILE: FIG2-13 
$\begin{array}{lll}0 & 0\end{array}$

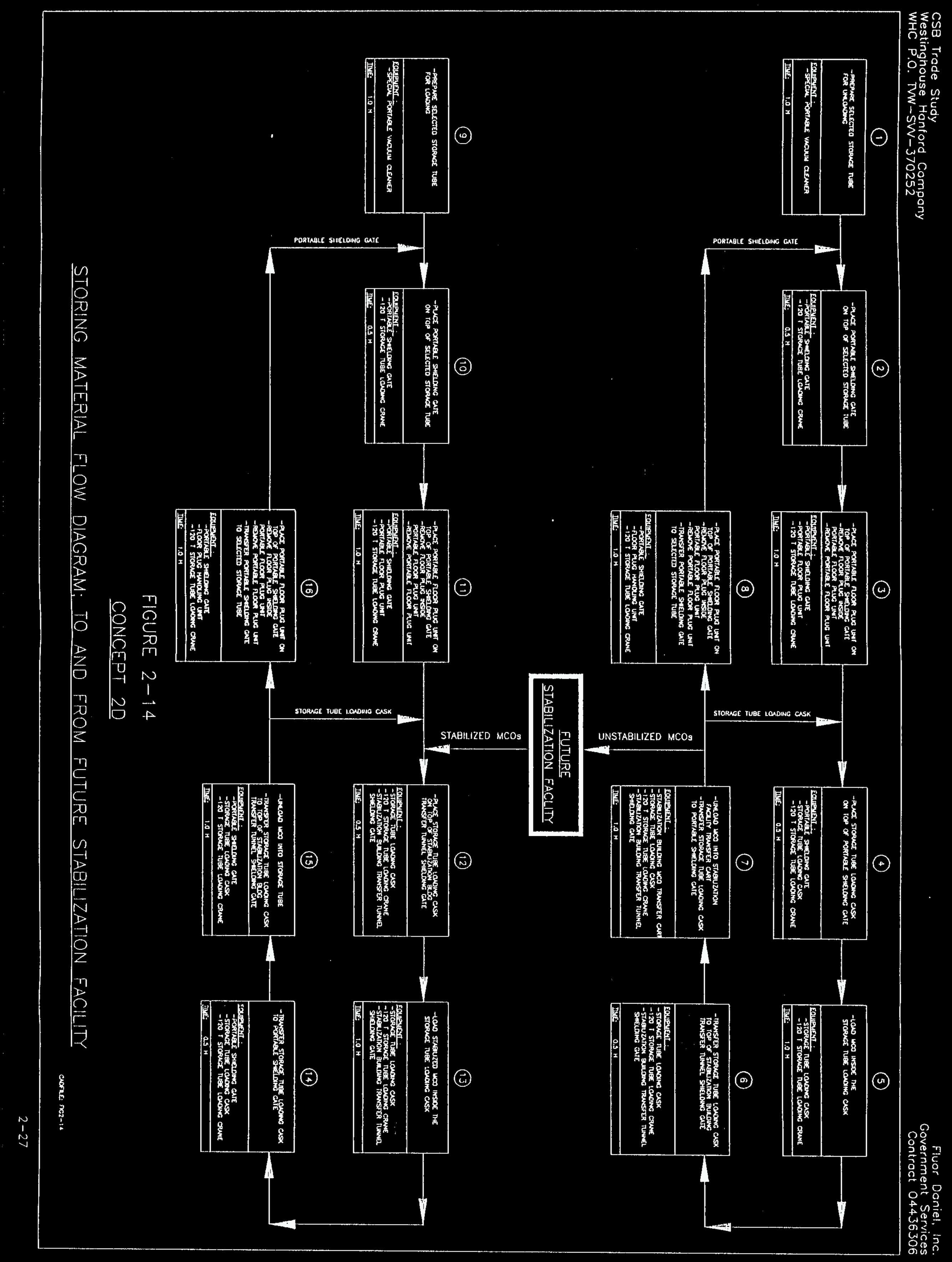




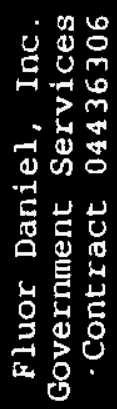
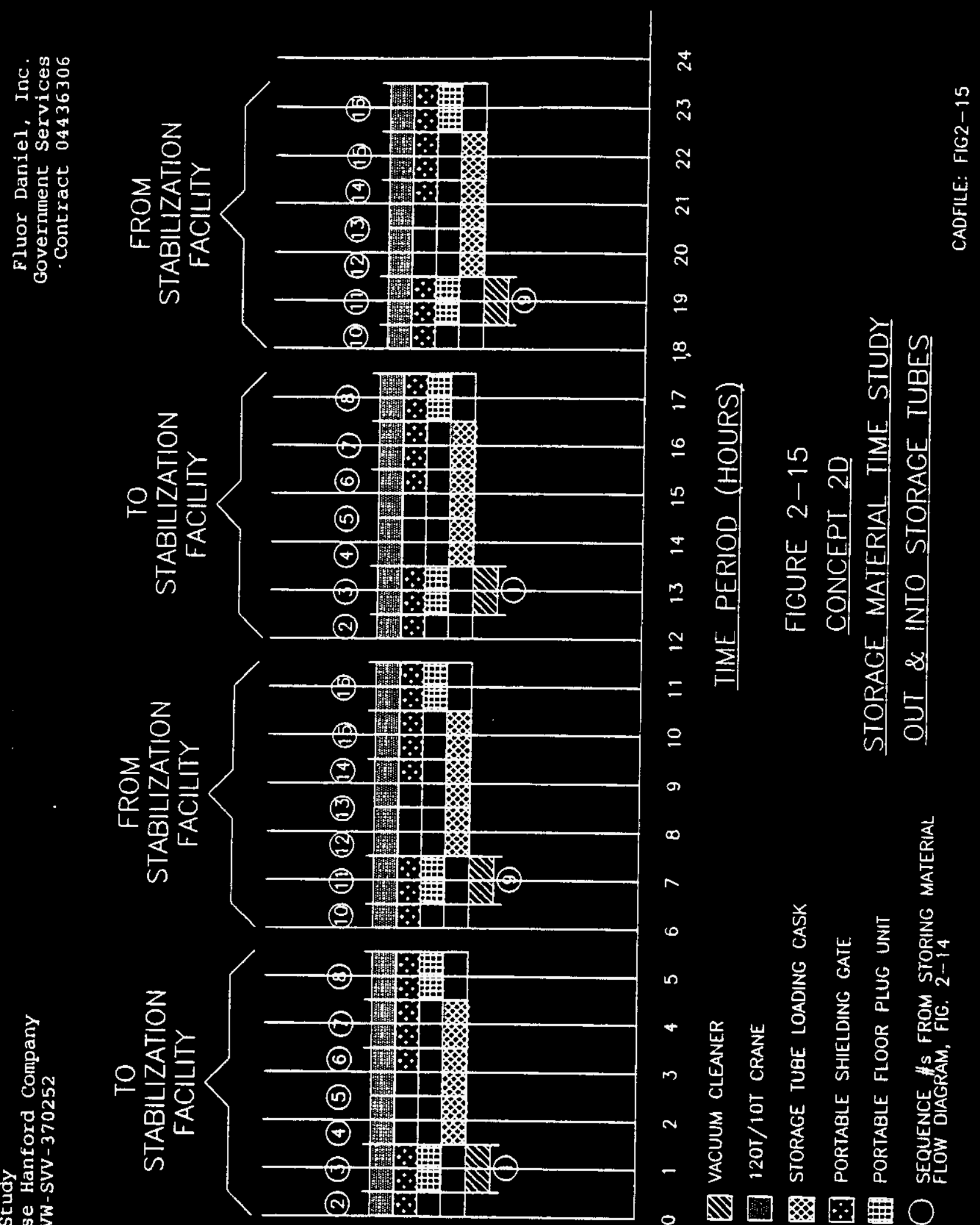

$\stackrel{\infty}{-}$

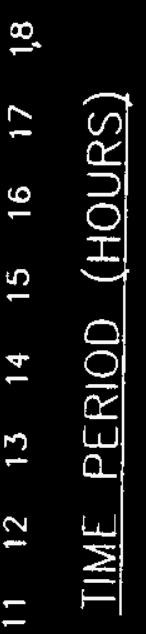

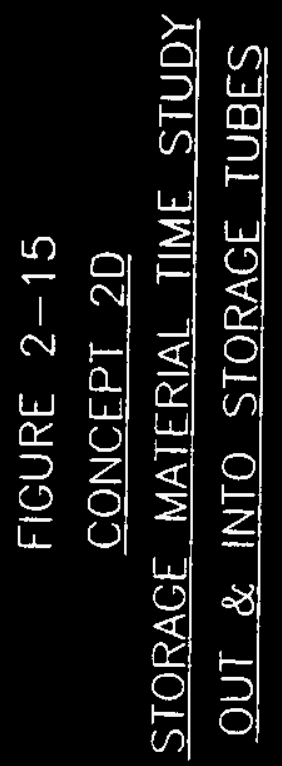

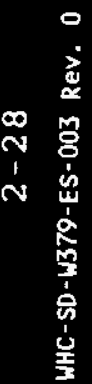

崩岂实

네가

g。

$\rightarrow$ a

品岁焉

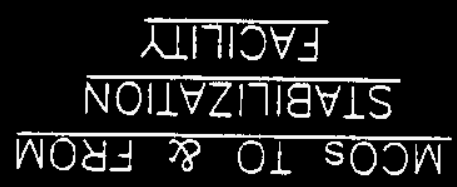


The equipment required for the transfer systems associated with each of the above MCOs is described in Tables 2-3 and 2-4. Figure 2-16 describes the possible operation of this equipment. Cask weights were based on the requirements defined in section 2.8 , Design Basis, Section 3.2.2.1.2.2 of WHC-SNF-FWD-014, "Draft Performance Specification for the spent Nuclear Fuel Canister Storage Building", Rev. A, dated May 1995. Crane capacities were estimated based on the heaviest loads to be lifted including the weight of the cask based on shielding requirements defined in Section 2.2.5.7, and the safety margins required for critical lifts at Hanford. The SSF crane capacity was based on a safety margin of $125 \%$ of the heaviest lift anticipated.

The MCO shield cask is a bottom loading cask that incorporates an MCO grapple and hoist assembly. It would be positioned above a shield gate located above a selected SSF storage tube. The storage tube shield plug is handled (removed and installed) using a handling flask. This system is similar to that employed at the Fort St. Vrain fuel storage facility and at several locations in Europe. The MCO Transfer Canal will be the point of entry for the MCo for the overhead crane/cask method. This station would require a floor plug shield gate.

The overhead cask/crane method will require a means to transport the MCO to the Stabilization Plant. If the stabilization Plant is close coupled to the dry storage facility an unshielded transfer cart operating in a below grade tunnel can be used to make the transfer similar to in Figure 2-16. If the stabilization plant is at a distant location, a top-loading shipping cask can be used.

The overhead cask/crane will require four basic components to load the canisters into the SSF storage tubes.

1) The bottom loading MCO shield cask

2) The floor plug shield gate

3) The portable shielded floor plug handling flask

4) The 120T overhead bridge crane with 10T auxiliary hoist

The bottom loading MCo shield cask will contain an integral hoist and grapple system to handle the MCO. It will incorporate a shield gate at the bottom and a ventilation system to control the atmosphere within the storage tube during MCO transfer.

The floor plug shield gate is used to seal and shield the storage tube when the tube's shield plug is removed. The gate is located over the desired storage tube using the overhead bridge crane. The portable shielded floor plug handling flask is then mated with the top of the shield gate. A grapple within the flask is used to lift the plug thru the open shield gate. The gate is then closed and the flask containing the plug removed. The storage tube is now ready for installation of the $\mathrm{MCO}$. 


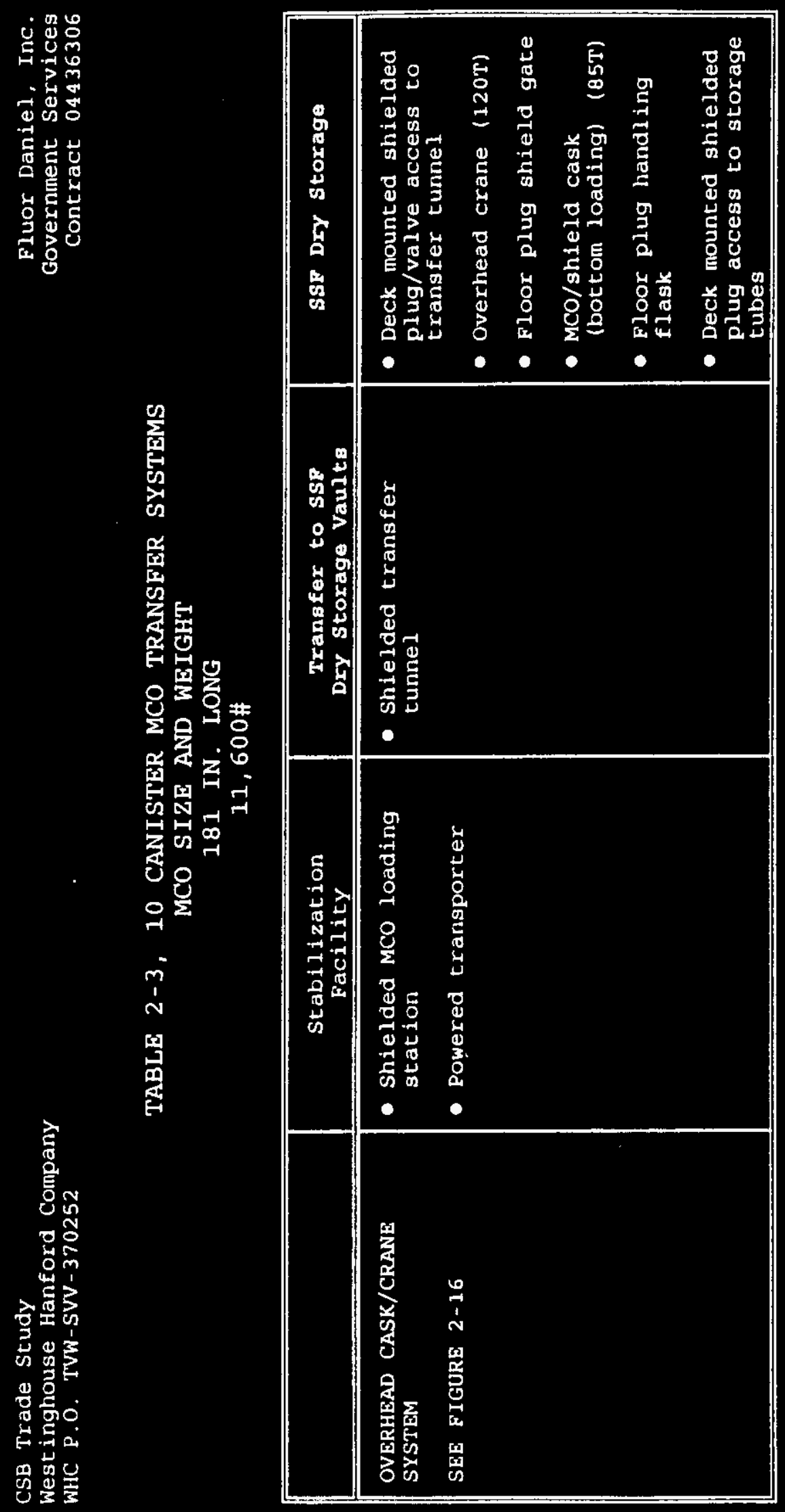




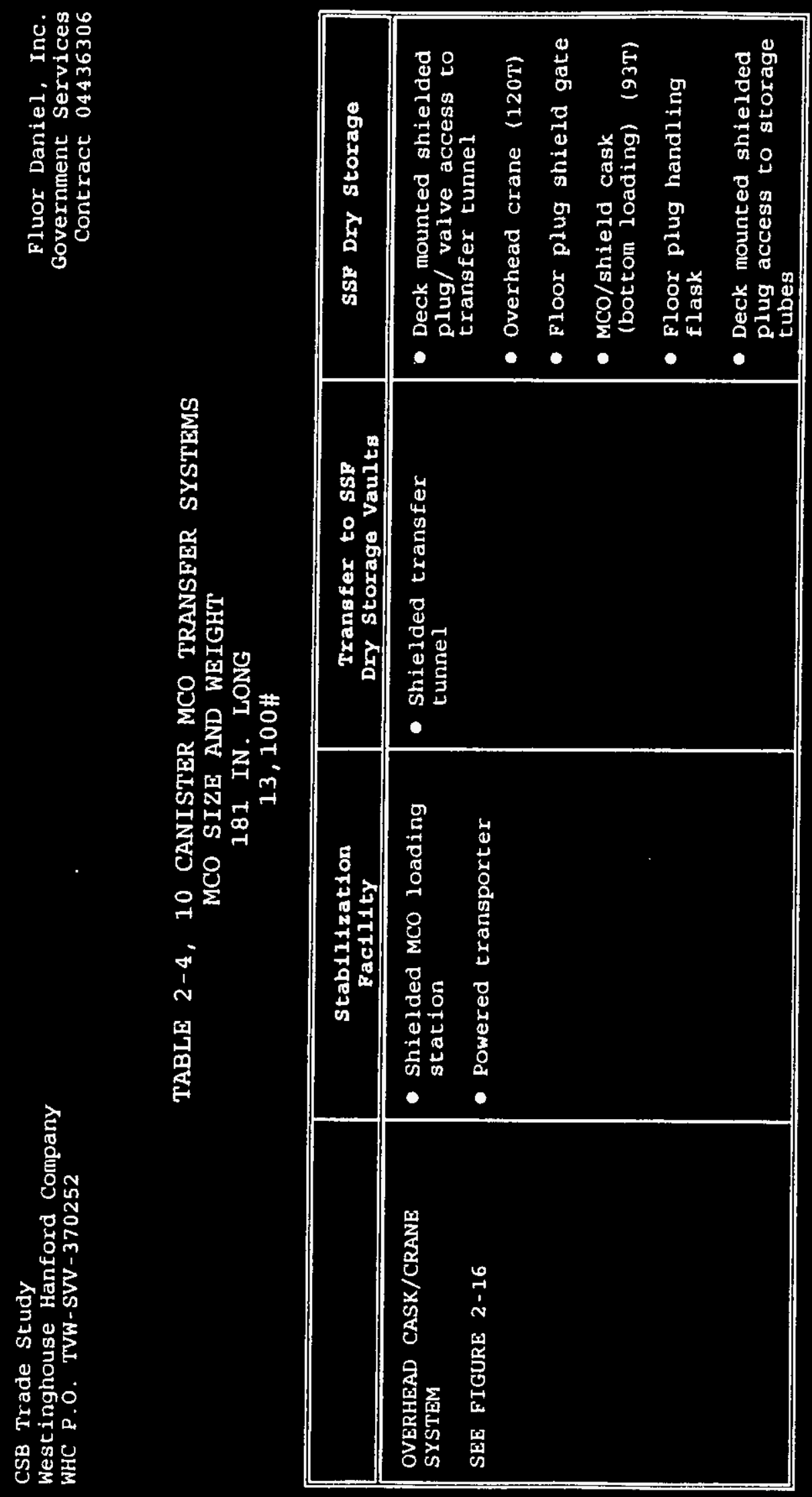


CSB Mrade Stucy

Nest:.ngtouse Fanford Company

WHC P.O. TVN-SVV-370252 5.uor Jante.., Inc. Government Services

Contract 04436306

FIGURE $2-16$

OVERHEAD CASK/CRANE PICKUP AND DELIVERY

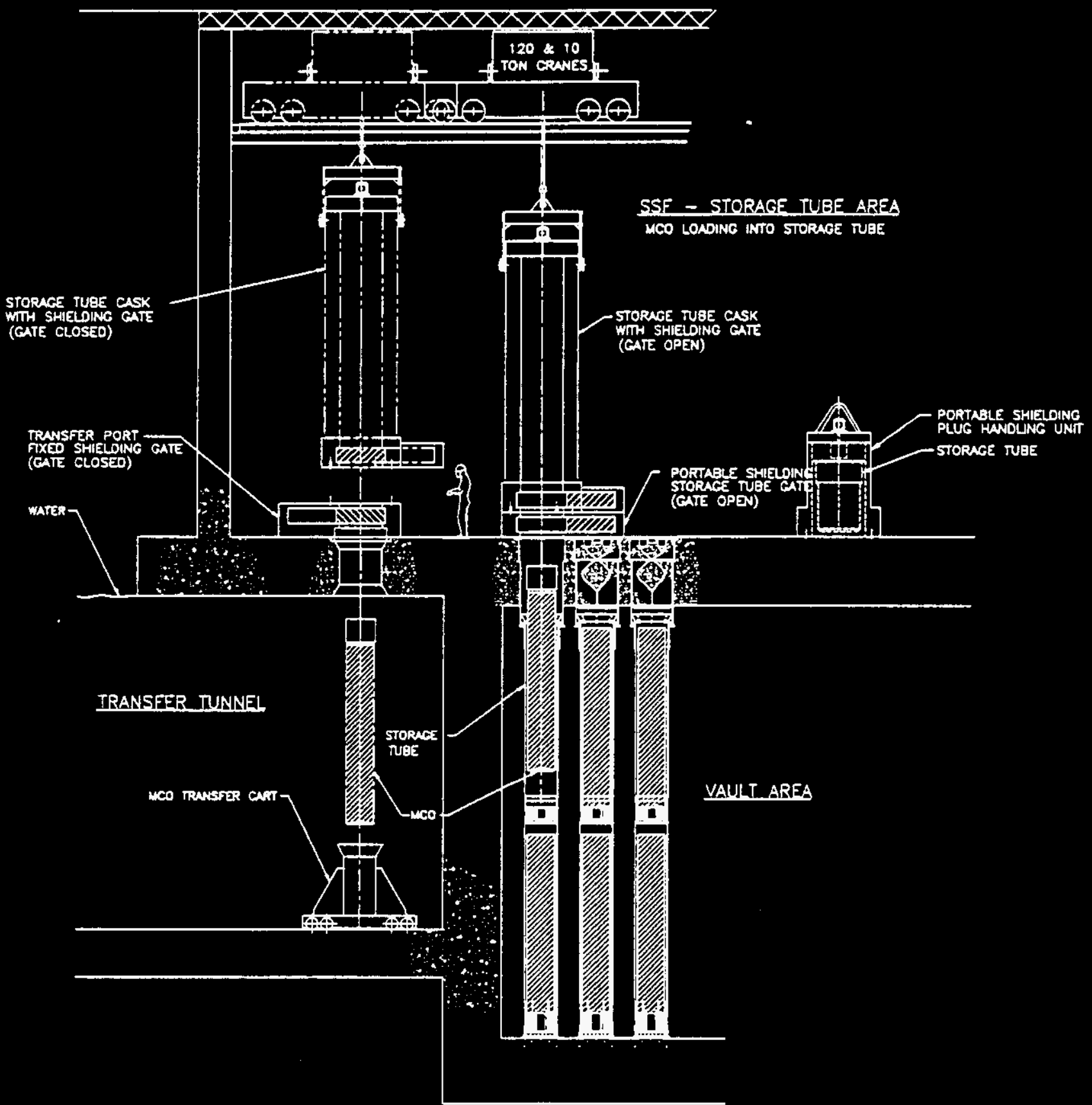

CADFIL: FG2-16 
The MCO contained within the MCO storage tube loading cask is next positioned on top of the shield gate using the overhead bridge crane. The floor gate and the MCO cask bottom gate are next opened and the MCO lowered into the storage tube. Upon reaching bottom, the MCO cask grapple is disengaged and raised back into the MCO cask. The gates are closed and the MCO cask removed from the storage tube. Finally, the storage tube floor plug is reinstalled, and the floor gate removed and installed over the next storage tube to be loaded.

\subsection{FEASIEILITY ISSUES}

\subsection{1 stractural}

The SSE Feasibility study final report dated February 1995 (Reference FDI transmittal No. FRT-2604) had enumerated on two structural issues: (a) seismic criteria change; (b) existing CSB configuration/design adaption. With respect to the seismic criteria WHC has confirmed that the basis for design will be Hanford Plant Standard SDC 4.1, Revision 12 as specified in the Draft Performance Specification document WHC-SNF-FRD-014. The design and evaluation of the SSCs will be based on UCRL 15910 as Hanford site has not implemented the replacement document DOE-STD- 1020-94. The CSB had been designed to $0.35 \mathrm{~g}$ PGA and there should be little impact to the concrete vault design for adaption to SNF SSE. The operating floor shelter will have to be redesigned for the 12 feet increase in height and addition of bridge crane lead.

Further, the document "Implementation strategies for U.S. DOE Order 5480.28 Natural Phenomena Hazards Mitigation" by Tom Conrads of WHC, has correlated WHC safety class 1 (high hazard) as equal to performance category (PC) 3 of DOE Order 5480.28. For PC-3 the earthquake return period is 2000 years in DOE-STD-1020, whereas in UCRL 15910 the return period is 5000 years for high hazard (WHC SC-1) usage. From Figure $5-1 b$ of Geomatrix Consultants report "Probabilistic Seismic Hazard Analysis" (Project No. 2169, May 1993), the PGA for 2000 year return is $0.19 \mathrm{~g}$ and for 5000 year return is $0.28 \mathrm{~g}$. These values when multiplied by 1.25 scale factor, as given in DOE-STD-1020, will give design PGA of 0.249 for PC-3 and $0.35 \mathrm{~g}$ for UCRL high hazard usage facility. Therefore, DOE-STD1020 PC-3 level earthquake forces are much less than UCRL 15910 high hazard class provided the correlation of PC-3 with WHC SC-1as stated my Mr. Conrads is correct.

The MCo/Cask drop over the operating floor during crane handing will require further evaluation including a crane with features to prevent a drop. Also as-built drawings of the partially constructed CSB need to be developed prior to start of detailed design. Field inspection of the existing construction by an experienced structural engineer is recommended to evaluate any sign

$2-33$ 
of rebar corrosion that may have initiated since the stop of work in 1.992. An optional Gantry crane handling of the MCO/Cask over the vault area should be investigated during conceptual design.

The performance specification WHC-SNE-FRD-014 requires the SC-1 structures design life as 200 years. This new requirement will require further investigation of the concrete degradation due to various factors such as temperature, wet-dry exposure, reactive chemicals in aggregates, sulfates in soil, etc.

\subsubsection{Thermal/HVAC}

This section documents the results of a series of thermal analyses that were performed to assess the feasibility of meeting the MultiCanister Overpack (MCO) temperature requirements during wet and dry storage with the Concept $2 \mathrm{D}$ staging and storage Facility (SSF). These analyses were performed for forced refrigerated air and passive ventilation systems.

The thermal feasibility analyses is based on storage of MCo's in dry air filled tubes in vaults 1 and 2 with a forced refrigeration air cooling of the tubes during staging. $\mathrm{MCO}^{\prime} \mathrm{s}$ are removed and returned to the tubes after stabilization. After all fuel is stabilized, the passive air ventilation system is made operational. Vault 3 will contain no storage tubes.

\subsubsection{Design Basis Assumptions}

The following design basis assumptions were used for the thermal analyses:

The heat generation rate was based on a total $880 \mathrm{MCO}^{\prime} \mathrm{s}$. Twenty (20) percent are assumed to be at the upper limit (maximum) $(482 \mathrm{~W})$ and the remaining $80 \%$ are assumed to be at the nominal (average) value $(22 I \mathrm{~W})$. Due to the preliminary nature of the heat transfer calculations a ten percent safety factor was used for the heat generation rate. Additional heat loads were added for building heat gains and fan heat.

- The heat generation for the Iimiting case (482 W) per MCO was used for the calculating the $\mathrm{MCO}^{\prime} \mathrm{s}$ temperature assuming that it is located at the end of the vault.

- The design basis required storage conditions are as follows:

Staging: The MCO temperature at $100^{\circ} \mathrm{F}$.

Storage: Maximum fuel centerline temperature at $400^{\circ} \mathrm{F}$.

- During the staging operation the MCO provides primary confinement and the dry air filled storage tubes provide the

$$
2-34
$$


secondary confinement. It is assumed that the interior of the st:orage tubes are isolated from the vault, which would prevent the vault from getting contaminated.

- The total flow is assumed to be evenly and uniformly distributed around each of the containment tubes. This is a critical assumption that must be assured by design and verified by additional analyses using Computational Fluid Dynamic (CFD) techniques.

- The heat transfer coefficients for air were calculated at the point of maximum vault air temperature.

- One dimensional (radial) heat transfer only. Two-dimensional (radial and axial) heat transfer was not modeled.

- Heat transfer by radiation between the tubes was not considered.

\subsubsection{Summary of Results:}

The results of the thermal analyses during staging are shown in Table 2-5 and involve various combinations of MCO's surrounded by air in tubes for different ventilation flow rates. The analyses were performed for $35^{\circ} \mathrm{F}$ and $50^{\circ} \mathrm{F}$ supply air.

The results indicate that it is not feasible to maintain the Mco temperature at $100^{\circ} \mathrm{F}$ with a refrigerated forced air ventilation system. This system would require 200,000 to 500,000 CFM at a supply air temperature of $35^{\circ} \mathrm{F}$ based on the above heat generation rate to maintain the MCO temperature between $105^{\circ} \mathrm{F}$ and $111^{\circ} \mathrm{F}$. The temperature of $35^{\circ} \mathrm{F}$ was selected to prevent freezing of $\mathrm{MCO}$ 's having very low heat generation. The MCO temperature is calculated on the basis that the MCO is located at the end of the vault with the limiting heat load.

The results of the themal analyses during storage operation with the existing CSB design concept, assuming the same intake structure, vault size and exhaust stack (height and diameter) indicate that an MCO fuel centerline temperature of $270^{\circ} \mathrm{F}$ can be maintained by a passive ventilation system. This is based on an inlet air temperature of $115^{\circ} \mathrm{F}$ (same design basis as CSB) and a ventilation flow rate of $53,000 \mathrm{CFM}$. The vault air temperature distribution and velocity profile for a fully loaded vault during passive ventilation are shown in Figures 2-17 and 2-18.

The above results demonstrate that it is not feasible to use the refrigerated air system to maintain the MCO temperature below $100^{\circ} \mathrm{F}$ during the staging operation. However, the passive 
TABLE - 2-5

CONCEPT 2D

THERMAL ANALYSIS - SUMMARY

\begin{tabular}{|c|c|c|}
\hline \multicolumn{2}{|c|}{ MCO TEMPERATURE FOR } & \multirow{2}{*}{$\begin{array}{c}\text { SUPPLY AR } \\
\text { QUANTITY } \\
\text { (CFM) }\end{array}$} \\
\hline Supply $\underset{(\mathrm{F})}{\operatorname{air}}=35 \mathrm{~F}$ & $\begin{array}{c}\text { Supply } \underset{ }{\text { air }} \\
(\mathrm{F})\end{array}$ & \\
\hline 213 & 232 & 10,000 \\
\hline 159 & 176 & 20,000 \\
\hline 142 & 158 & 30,000 \\
\hline 133 & 149 & 40,000 \\
\hline 128 & 144 & 50,000 \\
\hline 125 & 140 & 60,000 \\
\hline 122 & 138 & 70,000 \\
\hline 120 & 136 & 80,000 \\
\hline 119 & 134 & 90,000 \\
\hline 117 & 133 & 100,000 \\
\hline 116 & 132 & 110,000 \\
\hline 115 & 130 & 130,000 \\
\hline 114 & 129 & 140,000 \\
\hline 113 & 128 & 160,000 \\
\hline 112 & 127 & 180,000 \\
\hline 111 & 126 & 200,000 \\
\hline 110 & 125 & 230,000 \\
\hline 109 & 124 & 260,000 \\
\hline 108 & 123 & 300,000 \\
\hline 107 & 122 & 350,000 \\
\hline 106 & 121 & 400,000 \\
\hline 105 & 120 & 500,000 \\
\hline
\end{tabular}

$2-36$

UHC-SD-W379-ES-0.03 ReV. O 
CSB Trade Sะudy

West:-nghouse Fanford Company

WEC E.O. TVW-SVV-370252
Fiuor Daniel, Inc.

Government Services

Contract 04436306

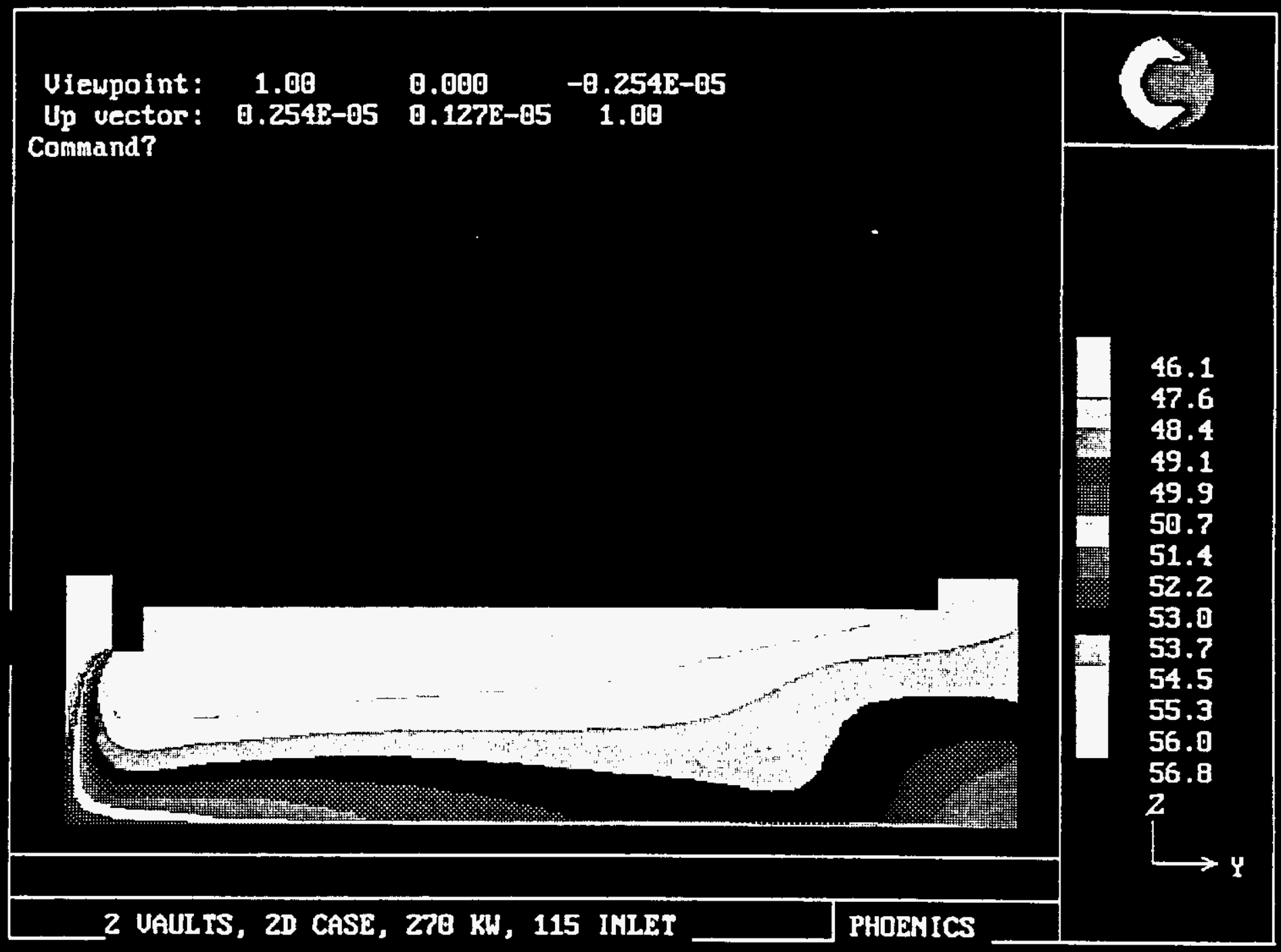

FIGURE 2-17

PASSIVE COOLING VAULT TEMPERATURE

PROFILE CONCEPT 2D

$$
2-37
$$


CSB Iracie Stucly

Westinghouse Yanford Company

WHC F.O. TVW-SWV-370252
Fluor Daniel, Inc.

Government Services

Contract 04436306

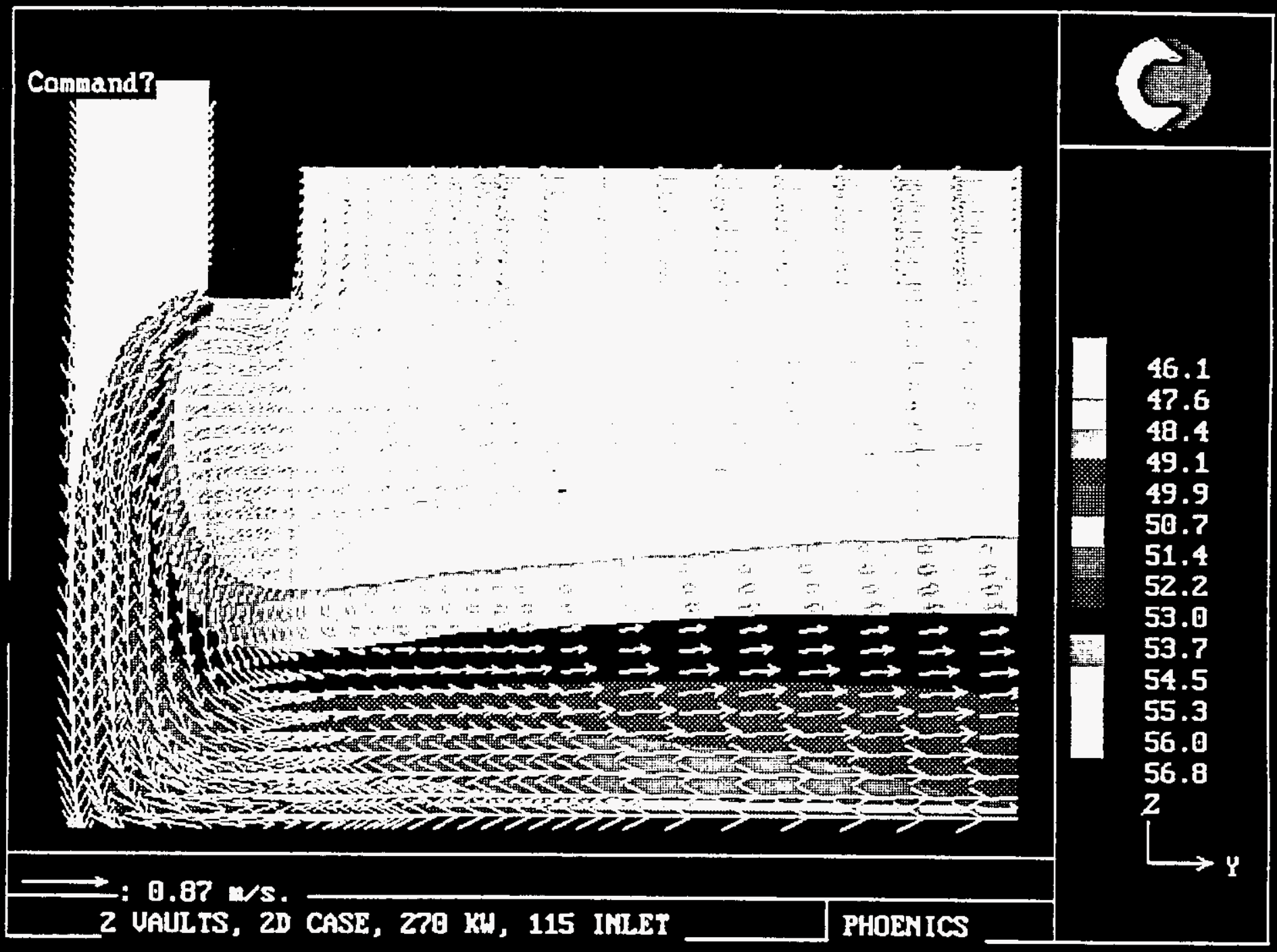

FIGURE 2-18

PASSIVE COOLING VELOCITY PROFILE, CONCEPT 2D 
ventilation systems can maintain the MCO temperature below the 400 ${ }^{\circ} \mathrm{F}$ limit during the storage operation.

It must be emphasized that these are rough conservative feasibility analyses using limited design information and do not cover ali limiting or upset conditions. More detailed analyses are required using CFD techniques to cover all limiting and upset conditions and to verify some basic assumptions. Also no analysis was performed for $\mathrm{MCO}^{\prime} \mathrm{s}$ stored in an overpack.

\subsubsection{Contamination Control}

\section{$2.2 .3 .1 \quad$ Introduction}

The potential hazards are from gas normally generated by the MCos before stabilization and from the unlikely failure of an Mco to contain the spent fuel. The feasibility concern is whether the MCOs can be cooled and vented while maintaining acceptable confinement/containment.

The unstabilized MCOs normally generate decay heat and hydrogen gas. The gas is contaminated and the rate of gas generation roughly doubles for every $10^{\circ} \mathrm{C}\left(18^{\circ} \mathrm{F}\right)$. The gas must be released from the MCOs without creating a fire or explosion hazard and without exceeding acceptable levels of contamination in occupied areas. The MCOs must be cooled to reduce the rate of gas generation and to prevent the MCOs from drying out. If the water contained in the unstabilized MCOs evaporates and uranium metal or uranium hydride from the fuel is exposed to air, there is a hazard of pyrophoric reaction. This intense reaction could melt the MCO shell, causing the release of fine particles of oxidized fuel containing radionuclides.

The remainder of this section discusses confinement and containment issues during normal MCO venting or accident conditions during staging and storage.

\subsubsection{Normal Operation}

MCo Servicing. The MCOs require servicing after receipt from the K-Basins prior to staging: After each MCO is received into the SSF, the MCO is purged with nitrogen and deionized water is added if needed to reach the desired level in the MCo. The services can be done with the MCo submerged in the Cask Unloading Pool. The pool temperature, clarity, and radioactive contamination must be maintained at acceptable levels; also, the level of contamination above the pool must be acceptable for controlled occupancy. The issues concerning gas and liquid releases from the MCO while submerged are discussed in section 2.2.3.1. The design includes the normal building ventilation system for dilution of hydrogen and

$$
2-39
$$


krypton-85, and an MCO servicing system that vents MCO gas to a stack and prevents overfilling of MCOs.

Closed Trbe staging. During abnormal operation, i.e. when the floor plug is removed, gas vented from the MCOs rises through the storage tube to reach the operating area, which is normally ventilated with enough fresh air (over $10,000 \mathrm{cfm}$ ) to dilute the hydrogen and krypton-85 to acceptable levels. However, since the storage tube is normally an enclosed space in which hydrogen could accumulate, provisions must be made to ensure that explosive concentrations do not develop. The following paragraph describes one concept for achieving this objective.

Each storage tube has a sealed floor plug with an embedded vent line and two test lines. The test lines have normally-closed valves and the vent line contains a HEPA filter. The tubes as originally designed can contain a pressure of almost 5 psig before the plug lifts from its sealed seat; the tube wall and bellows were designed for higher pressures. It would be simple to add a relief device to each vent line so that the vent would only be used if the pressure in the tube were to rise to about $4 \mathrm{psig.} \mathrm{With} \mathrm{a} \mathrm{local}$ pressure indicator added to each tube plug, pressures could be monitored and a portable cart used to sample and purge each tube with nitrogen. The cart would consist of a nitrogen cylinder on wheels, a regulator, a vent HEPA filter (similar to the one in the tube plug), and half-inch hoses to connect to the test lines on the plug. As long as each tube is vented and purged with nitrogen before the pressure rises above 0.8 psig, the hydrogen concentration will not exceed $6 \%$ by volume. A $6 \%$ mixture of hydrogen in nitrogen is non-flammable when mixed with any proportion of air. At the nominal design hydrogen generation rate, a tube with one MCO takes 4.8 days to reach 0.8 psig after venting and purging. With 750 MCOs staged in 375 tubes, an average of 78 tubes per day would have to be vented and purged to maintain nonhazardous mixtures of hydrogen in the tubes.

Passive Air-Cooled Storage. After stabilization, the MCos do not normally vent gas. There are no contamination issues during normal operation.

\subsubsection{Abnormal Operation}

uco servicing. The Cask Unloading pool could become contaminated in the event of the failure of an MCo during unloading or servicing. Until the accident is quantified, it is assumed that the unmitigated consequences are severe enough to require safety class 1 or 2 systems, as defined in WHC document MRP 5.46 and DOE order 6430.1A. To prevent this potential contamination from reaching the soil, the pit must be lined with stainless steel and monitored for leakage. Any place where pit water is contained, there must be a way to inspect or test for leaks; this includes any piping that penetrates through walls or the ground. The glycol 
coolant: in the chillers must have monitors or test connections to detect any J.eaks across the glycol/pit water heat exchangers.

The operating area above the pit could become contaminated in the event of a crane accident during cask or MCO handling. Should any abnormal contamination be detected above the pool, alarms warn the operators to leave the area and the Emergency Ventilation system is activated. This system ensures that there is no unfiltered release from the building and that the hydrogen concentration remains orders of magnitude below the flammable limit.

The dropping of an MCO in the pool is not the worst MCO accident (compared, for example, to an accident during MCO handling above the storage tube operating floor), but this accident is a basis for designing the pool water treatment system. The pool water filters and deionizers are sized to contain the upper limit corrosion products from an MCO. The soluble corrosion products (cesium hydroxide) do not pose a criticality threat in the deionizer. The critically-safe geometry for the filters has not been determined in this study, due to time limitations.

Closed Tube staging. If there is a failure of an MCO during staging, the HEPA filter in the sealed tube plug will prevent airborne contamination from spreading out of the tube. The tube plugs have test fittings which allow for periodic water sampling to detect MCO failure. The contamination is localized, but there is no built-in design feature for clean-up.

Passive Air-Cooled storage. If there is a failure of a stabilized MCO during storage in a tube, only one tube becomes contaminated. The floor plugs have HEPA filters and test fittings which allow for periodic gas sampling to detect MCO failure. The contamination is localized, but there is no built-in design feature for clean-up.

\subsubsection{Criticality \\ 2.2.4.1 Introduction}

One of the issues identified at the start of the SsF Feasibility Study was the minimum allowable spacing between MCO's, from a criticality standpoint, and the identification of a feasible storage configuration based on criticality considerations. Some of the conclusions reached as part of other concepts within the SSF Feasibility study are applicable to Concept $2 \mathrm{D}$ and are addressed herein. Since criticality safety was identified as a potential design driver, an analysis effort was undertaken to identify and quantify restrictions on $N$-Reactor fuel storage configurations based on criticality. Although the Design Basis contained in Section 2.8 indicates that there are no restrictions on MCo spacing 
and stiacking based on criticality, it was decided to continue the analysi.s to verify the Design Basis.

\subsubsection{Summary of Results}

Prelimunary criticality calculations were performed with simplified geometries, taking no credit for structural material, such as canister and MCO walls, and all simplifying assumptions made were conservative. These calculations confirmed that the MCO's could be stacked, even when loaded with five layers of canisters, and can be placed side-by-side without additional space between MCO's. The worst-case $k_{\text {ort }}$ calculated was less than 0.90 , well within the 0.95 Iimit imposed by the Nuclear Criticality Safety Manual, Section 2.0, Paragraph 5.1.3, Allowed Maximum Calculated K-effective.

\subsubsection{Criteria and Assumptions}

The criteria and standards on which these criticality calculations are based, as well as the assumption used in formulating the computations, are given the following paragraphs.

Applicable Orders and standards. The criticality calculations performed in support of this feasibility study conform with the following criteria and standards:

$$
\begin{aligned}
& \text { DOE Order 5480.24, "Nuclear Criticality Safety" } \\
& \text { DOE-STD-3007-93, "Guidelines for Preparing Criticality Safety } \\
& \text { Evaluations at Department of Energy Non-reactor Nuclear } \\
& \text { Facilities" } \\
& \text { WAC-CM-4-29, "Nuclear Criticality Safety Manual," issued } \\
& \text { September 15, 1988. }
\end{aligned}
$$

Choice of Computer Models. The principal tool selected for criticality calculations is the PC version of MCNP, Version 4A, developed and supported by the Los Alamos National Laboratory (LANL), Reference 2. This code was selected because of its great flexibility, high fidelity modeling (e.g., ENDF/B-V continuous cross sections), and the ability to perform both shielding and criticality calculations.

Another code available for criticality calculations is KENO, Version V.A (contained in the SCALE-PC, Version 4.1; Reference 3). This code was not used to perform criticality calculations directly for this study, but was used to compare results during the validation and verification process.

Code Verification $s$ Validation. All codes used in shielding and criticality calculations at Fluor Daniel have been verified by running the test problems supplied with the code packages. The 
test problem results are shown to be in agreement either with the published documentation supplied as part of the code package, or with the sample problem output, if supplied. This information is documented, dated, and retained on file at Fluor Daniel. Any changes, such as upgrades, corrections, modifications, etc., are incorporated into the documentation following rerunning of the verification problems.

MCNP, Version 4A is the latest version, Reference 2, of a widely used and well accepted radiation transport code employed for a wide variety of radiation analyses including neutron, photon and electron transport, and criticality. IANL has performed extensive calculations with MCNP, duplicating a wide range of experimental results, to validate the models contained in this code. The results of these benchmark cases are documented in References 4 and 5. The version of MCNP4A used at Fluor Daniel was tested by exercising the twenty-five sample problems supplied by LANL, and the results were found to be in agreement within reasonable statistical limits. These sample problems are designed to exercise a broad range of the code's computational capabilities, including criticality calculations, which is addressed by five of the twentyfive sample problems.

Material Properties. The densities and composition of materials used in the criticality calculations are given in Tables 2-6 and 2-7.

Preliminary Calculations. Preliminary criticality calculations were performed to define the worst case spacing of fuel elements inside a canister, and/or each layer of a CSB storage tube. To this end, a computational model of seven storage tubes was formulated; with 12 vertical layers, each layer consisting of 31 fuel elements in a triangular pitch array. The material composition of this array consisted of fuel elements only: concentric cylinders of $1.25 \%$ enriched uranium, with zirconium cladding. All voids and spaces within the fuel elements and storage tubes were filled with water, and water was medium surrounding these storage tubes on all sides. The koze of the configuration was calculated, varying the pitch of the triangular array. The results are shown in figure 2-19. The important result of these calculations is that the worst case spacing between fuel elements is 3.2 inches.

The spacing between storage tubes, was 55 inches. These tubes were again arranged in a hexagonal pattern, in cross section, which approximated the storage tube configuration within the CSB vaults. Because of this spacing between tubes, and because the tubes were immersed in water, there was no appreciable interaction between the tubes, and the results show no sensitivity to variations in this spacing (except when the tubes were placed very close together, as discussed below). 
TABLE 2-6

DENSITIES OF SOME MATERIALS

Material

Air

Aluminum

Iron (Steel)
Density $(g / c c)$

0.00122

2.70

7.83
Material

Uranium

Water

Zirconium

\section{Densitv $(a / c c)$}
18.7
1.0
6.4

The fractional densities for compound materials used in this study are listed in Table 2-7. 


\begin{tabular}{|c|c|c|c|c|}
\hline \multicolumn{5}{|c|}{$\begin{array}{c}\text { TABLE } 2-7 \\
\text { COMPOSITION OF MATERIALS USED IN RADIATION SHIELDING } \\
\text { CALCULATIONS } \\
\text { (Given as Eractional Densities in } \mathrm{g} / \mathrm{cm}^{3} \text { ) }\end{array}$} \\
\hline $\begin{array}{l}\text { Atomic } \\
\text { Number }\end{array}$ & Element & Aix & 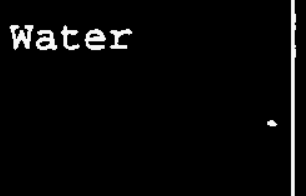 & $\begin{array}{l}\text { Stainless } \\
\text { Steel } \\
304 L \\
\text { ASTM A240 }\end{array}$ \\
\hline 1 & $\mathrm{E}$ & & 0.11111 & \\
\hline 5 & $\mathrm{~B}^{10}$ & & & \\
\hline 5 & $\mathrm{~B}^{11}$ & & & \\
\hline 6 & C & 0.00000017 & & 0.0023 \\
\hline 7 & $\mathbf{N}$ & 0.00092132 & & \\
\hline 8 & 0 & 0.00028276 & 0.88889 & \\
\hline 11 & $\mathrm{Na}$ & & & \\
\hline 12 & $\mathrm{Mg}$ & & & \\
\hline 13 & Al & & & \\
\hline 14 & $\mathrm{Si}$ & & & 0.0587 \\
\hline 15 & $\mathrm{P}$ & & & 0.0035 \\
\hline 16 & $\mathrm{~S}$ & & & 0.0023 \\
\hline 18 & Ar & 0.00001575 & & \\
\hline 19 & $\mathrm{~K}$ & & & \\
\hline 20 & $\mathrm{Ca}$ & & & \\
\hline 22 & $\mathrm{Ti}$ & & & \\
\hline 24 & $\mathrm{Cr}$ & & & 1.5660 \\
\hline 25 & $\mathrm{Mn}$ & & & 0.1566 \\
\hline 26 & $\mathrm{Ee}$ & & & 5.1009 \\
\hline 28 & $\mathrm{Ni}$ & & & 0.9396 \\
\hline Total & & 0.00122 & 1.00 & 7.8299 \\
\hline
\end{tabular}

$$
2-45
$$




\subsubsection{Results of Calculations}

A computational model was formulated which could address key factors with respect to criticality safety for concept 2D. AII uncertainties were compensated for with conservative assumptions. In the event these assumptions led to an unacceptable risk of a criticality event, it was planned to perform sensitivity studies to identify safe limits.

In this computational model, fuel elements were arranged in columns, each containing 280 fuel elements. Each column contained fuel arranged in patterns representative of two MCO's, stacked one on top of the other. Each MCO was modeled with five vertical layers of canisters, two canisters of 28 fuel elements, per layer. The 28 fuel elements in each layer were arranged in a pattern similar to that found in the canisters, Figure 2-20, but the center-to-center separation between fuel elements was taken to be 3.2 inches, the worst-case spacing from Figure 2-19.

In a nominal CSB vault, 220 such columns would have been arranged in a hexagonal pattern. This pattern was modeled as a triangular pitch array, with a 55 inch center-to-center separation between columns, Figure 2-21. (Since interaction between columns is negligible, this will be shown in what follows, changing the size of this array was not required.) The closest spacing between columns, which could be achieved in a flooded pool, was assumed to be 26 inches, center-to-center. This assumes a bare MCo, no tube, and a minimal amount of structural material for keeping the 24 inch OD MCO in place. For this calculation, no credit was taken for either the MCO or the canister walls. In fact, the only materials included in this model are the fuel, cladding, and the surrounding water. The results for this configuration gave a $k_{\text {ofe }}$ of 0.81289 with a standard deviation of 0.00091 (calculation ID: NF032). Replacing the water outside the MCO boundaries with air, gave a k off of $0.87063,+/-0.00073$ (NF033). This increase is probably due to the increased interaction between columns for this close a spacing.

To evaluate the impact of some of the structural material, assumed to be stainless steel (SS 304 ), the case with air outside the MCO was repeated, but this time the canister walls were included in the model. This calculation gave a $k_{\text {opp }}$ of 0.77375 , with a standard deviation of 0.00065 (NF034). Including the MCO wall material, further reduced the $k_{\text {ofe }}$ to $0.74524+1-0.00069$ (NF035). (To accommodate the 3.2 inch spacing between fuel elements, the canister outside diameter was taken to be 9.2 inches and its thickness 0.25 inches, Figure 2-22. This should be compared to a standard schedule 20,8 inch pipe which has an outside diameter of 8.625 inches and the same thickness.)

Increasing the spacing between columns to 55 inches and including the tube material, reduced the $k_{\text {eff }}$ to $0.7234+/-0.00061$ (NF036).

$$
2-46
$$




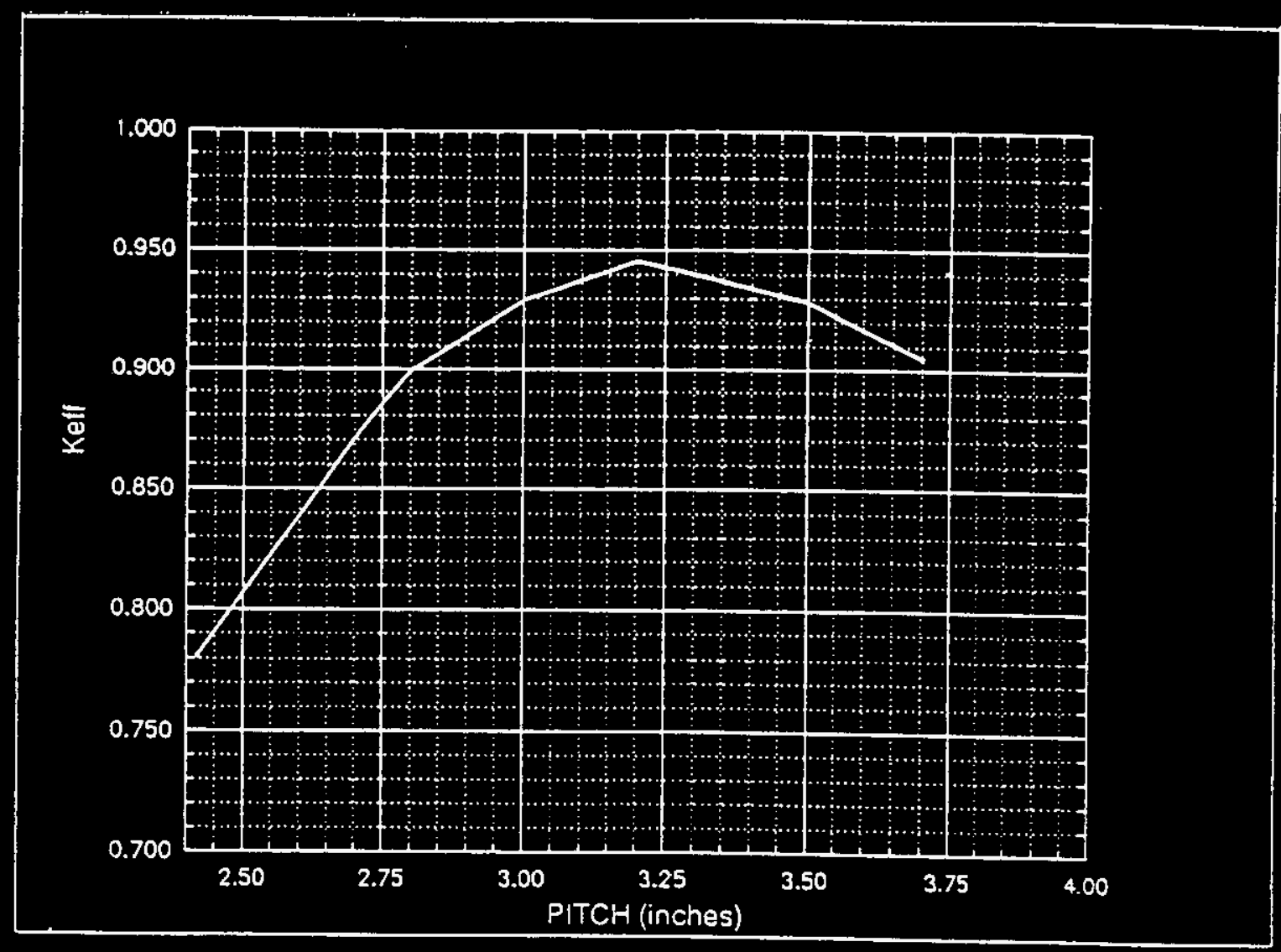

FIGURE 2-19

SENSITIVITY TO SPACING, 31 EUEL ELEMENTS (IN A TRIANGULAR ARRAY) PER LAYER, 12 LAYERS, 7 COLUMNS 


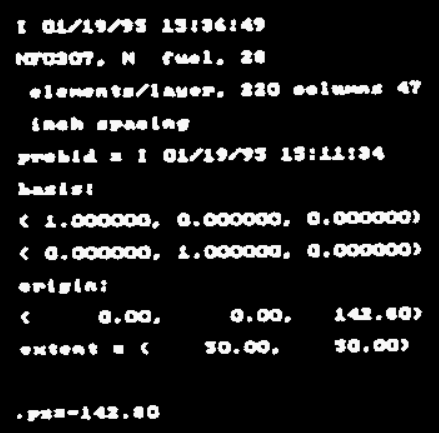

FIGURE 2-20

FUEL ELEMENTS IN A SINGLE IAAYER OF AN MCO MODEL

$$
2-48
$$



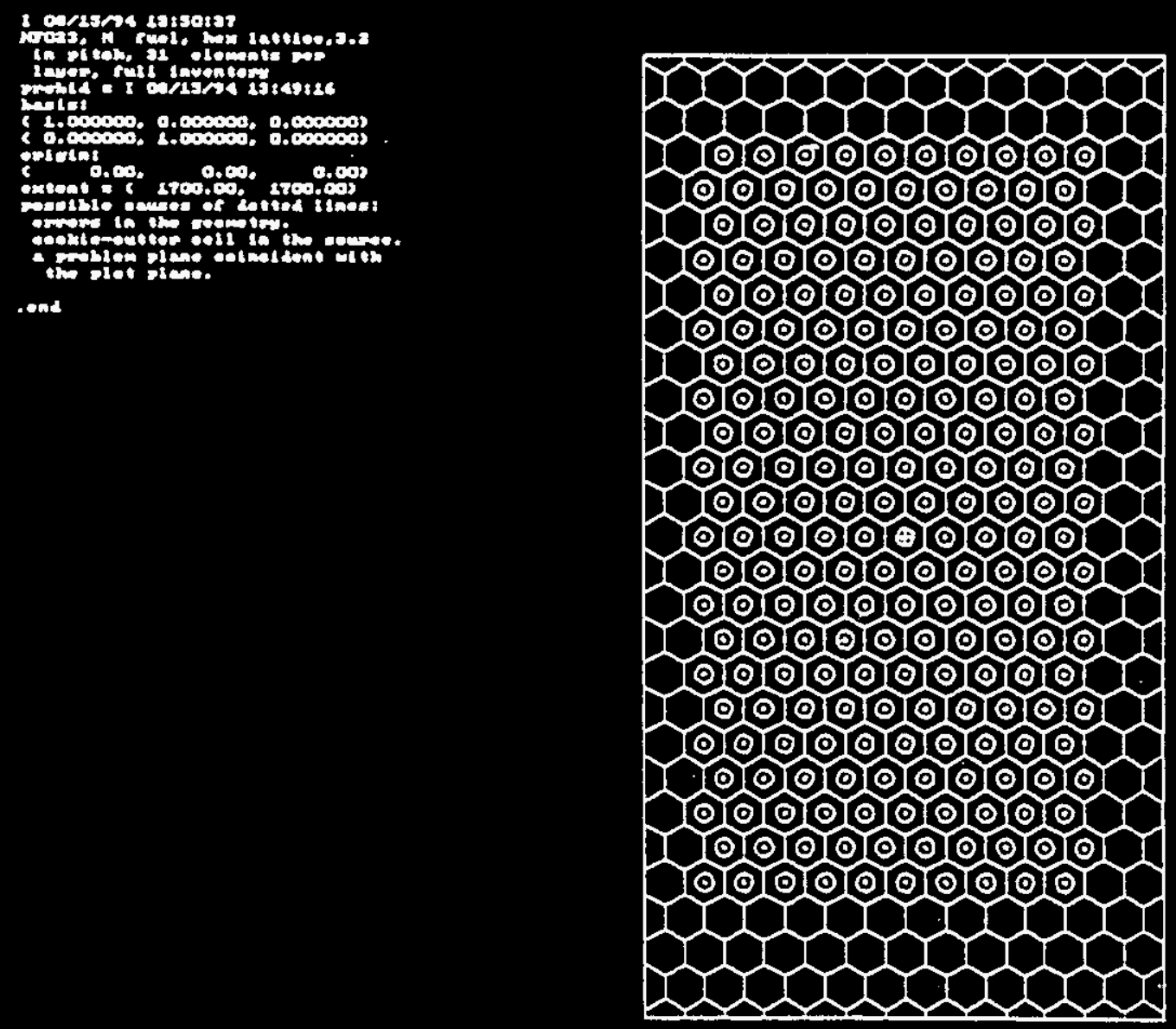

FIGURE 2-21

CSB VAULT MODEL SHOWING STORAGE TUBES IN A TRIANGULAR ARRAY 

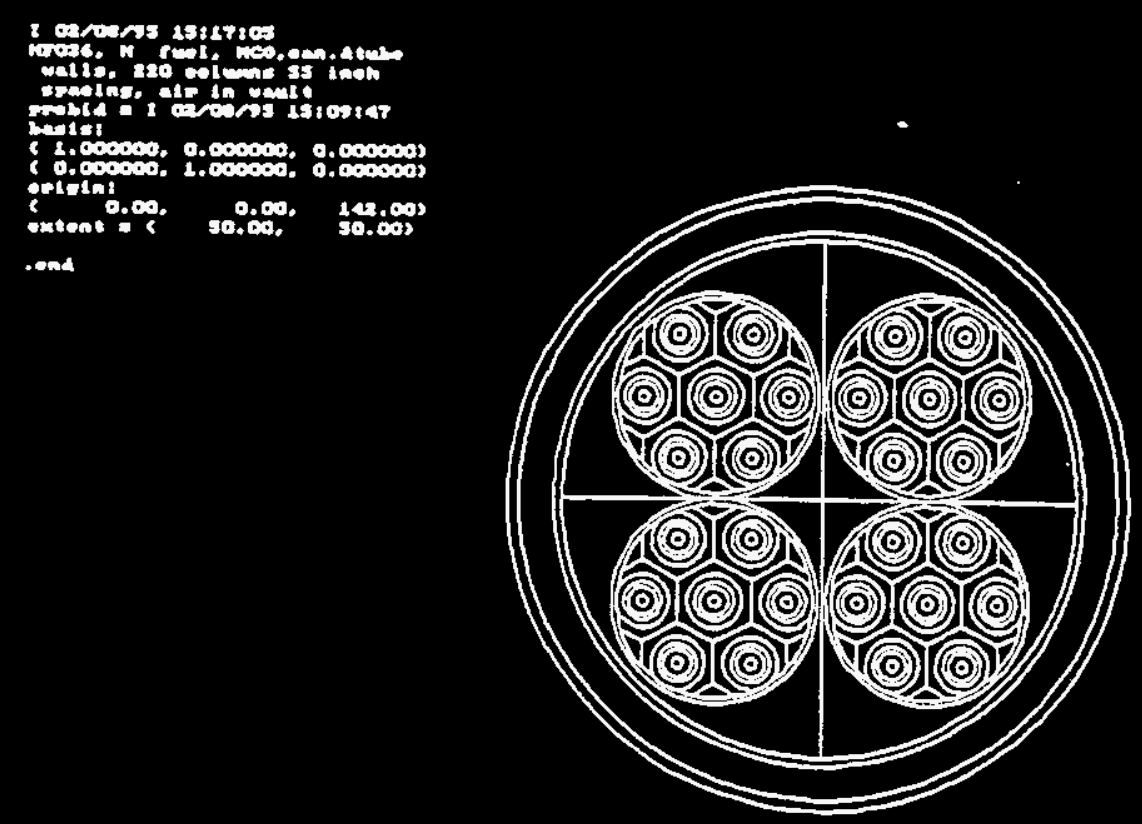

FIGURE 2-22

CROSS SECTION OF STORAGE TUBE SHOWING MCO AND CANISTER WALLS

$2-50$ 
The relatively small decrease between this case and case NF035, indicates tinat the interaction between columns has already been significant:y reduced by the addition of the MCo wall material.

Case NF036 i.s representative of Concept 2D storage of $\mathrm{MCO}^{\prime} \mathrm{s}$ in air filled tubes with forced refrigerated air cooling of the tubes. Eliminating water from the calculation will result in an undermoderated situation with an effective decrease in $k_{\text {ott }}$. Filling the vault with water would have only a minor effect on the vault $k_{\text {ore, }}$ since there is only negligible interaction between tubes at this spacing and when taking credit for tube and MCO wall thicknesses. (The case of a water filled vault is a credible accident scenario and would have to be considered in a criticality safety evaluation. Partial filling of the vault with water may actually be a worst case situation, as was illustrated by comparing results for cases NF032 and NF033.)

\subsubsection{Shielding}

Shielding calculations during the feasibility study evaluations were performed with Microshield 4 which is adequate for the bulk shielding studies performed. The adequacy of this method was calculated using the MCNP, Version 4A, code. Penetrations, ducts, and cracks were not evaluated but are noted where additional work will be needed in the future. Some allowances were taken with the bulk shielding thicknesses in anticipation of the more complicated geometries.

Shielding issues associated with Concept $2 D$ which were not addressed in either the Feasibility study or the Trade study, but which may contribute to design changes, include the following:

\section{- Tube Closure Design, Tube Spacing}

Tube spacing in the vault may depend, in part, on the design of the tube closure at the operating floor level. Exposure levels above tube closures will depend on operating floor thickness and radiation streaming through gaps around the closures. Any penetrations through these closures, for gas/Iiquid sampling, may also contribute to these exposure levels. The MCO's internal structure may favor propagation in the axial directions, enhancing the radiation environment at the top and bottom of the tubes. (This will be particularly significant after stabilization.)

\section{- Unfinished Vault Capable of Future Outfitting}

An unfinished vault presents several closure and shielding problems. Openings to both the intake and exhaust plenums will have to be closed off both to reduce radiation in this vault and to restrict refrigerated air flow through the unused vault.

$$
2-51
$$


Provisions must be made to remove these barriers, under a high radiation environment, when this vault is eventually activated.

- Temporary Refrigerated Air System

The means of delivering refrigerated air to the vaults may require additional ducting and wall penetrations. These ducts, and wall penetrations will have to be designed to preserve the required low radiation exposure levels outside the building. Any closures to existing air intakes and exhausts will have to be removed, under enhanced radiation conditions, when the switch is made to passive cooling for stabilized fuel.

\subsubsection{Introduction}

The shielding issues for Concept 2D involve health protection of the occupants of the SSF throughout its life. During the SSF Feasibility study selection of an appropriate source term was examined by looking at the defined "limit" (maximum) source and another "shield" (average) source, as well as a combination of the two sources. There are several water conditions that must be met at all times to provide a maximum dose rate of $0.2 \mathrm{mrem} / \mathrm{hr}$. These include the minimum pool water depth over the filled MCo racks and the minimum water level over an individual MCO. The interior and exterior wall thicknesses are important to provide health protection during possible construction activities. The operating floor thickness must protect workers during maintenance activities. The thickness of the transporter or shielded cask must provide adequate shielding during transport, insertion and removal of the shield plugs and $\mathrm{MCO}^{\prime} \mathrm{s}$.

\section{2:5.2 Source Selection}

Three possible sources were examined to determine the most appropriate for the shielding studies. The "maximum" source is that found in Section 2.8, Basis For Design, "Draft MCO Table" by R. G. Cowan, March 17, 1995. The "shield" source is that found in Table 3.6 - Safety Basis Radionuclides - referenced as the shield source in paragraph 3.6 - Shielding Design Basis of the "Draft Design Basis Feed Development", A. L. Pajunen, December 22, 1994. Direction from Westinghouse indicated that the "maximum" source identified with 10 canisters should be used. Previous experience and the increased number of radionuclides in the "shield" source prompted examination of the two sources. The "shield" source is based on the most radioactive fuel elements currently in the $\mathrm{K}$ Basins. Apparently, there is only 0.6 metric tons of this material, which is considerably less than one filled MCo. However, three cases were examined: 1) filled MCO with the "maximum" source; 2) filled MCO with the "average" source; and 3) combined MCO with 0.6 metric tons of the "average" source and the balance of the fuel elements of the "maximum" source. A simple geometry of an 
MCO immersed in water with a 2 foot concrete wall was used to evaluate the three sources. All other things being equal, except for the radionuclide composition, the resulting dose rates were: "maximum" - $0.0112 \mathrm{mrem} / \mathrm{hr}$; "average" - $0.0122 \mathrm{mrem} / \mathrm{hr}$; and "combined" - 0.0114 mrem/hr. The limit source was selected since all sources were very close to being equal.

The impact on shielding requirements, of changing the Mco configuration to include five layers of canisters, instead of four, and changing the isotope mix to that specified as the "Maximum" MCO (Appendix 1), was evaluated. This was done by generating a more representative model of the MCO geometry for use in MCNP Monte Carlo simulations. Sample calculations were ferformed with this model, using a gamma source based on the "Maximum" MCO isotope mix. The results of these calculations confirmed that the conservative approach used to define shielding requirements based on the MCO source model discussed above were adequate to accommodate the increased source of the new MCO model. The changes in shielding requirements, recommended as part of this Trade study, are based on the lowered exposure level requirement for occupied areas (i.e., lowered from $0.5 \mathrm{mrem} / \mathrm{h}$ to $0.2 \mathrm{mrem} / \mathrm{h}$ ).

\subsubsection{Minimum Water Depth Over a Single MCO}

The MCO is brought into the SSF in a shielded cask. The cask is immersed in water before withdrawing the MCO. Radiation shielding of the MCO is provided by the water surrounding the cask and the MCO. Whenever the MCO is not in the cask, it must be surrounded and covered by water. Personnel do not generally have access to the sides or bottom of the pool so only the top of the MCo must be shielded. This shielding is provided by establishing a minimum water depth above the MCO which must be maintained. This minimum water depth is 8 feet.

\subsubsection{Minimum Concrete Thickness of Interior and Exterior Walls}

There are several construction sequence possibilities for the SSF. The thickness of the interior walls is not important from a health protection standpoint if all construction is performed initially. However, if one vault is constructed first and filled and the other storage vaults are built at a later time, the construction workers will need to be shielded against radiation penetrating the interior wall between the filled vault and the adjacent vault. An additional need for personnel access to a vault could be for cleanup before conversion to natural convection cooling. If this cleanup is required, all $\mathrm{MCO}^{\prime} \mathrm{s}$ in the vault to be cleaned will need to be removed. Radiation levels from adjacent filled vaults will need to be less than $0.2 \mathrm{mrem} / \mathrm{hr}$ to avoid partial emptying of the adjacent vaults. The minimum wall thickness required is 42 inches of full density standard concrete. Since the interior walls are currently 36 inches of full density concrete, the wall thickness is

$$
2-53
$$


less than adequate for maintenance activities near the wall. At one time, there was an additional layer of thermal concrete (Iow density) applied to the interior surfaces of the vaults. If this additional thermal layer is included in the SSF design, the shielding may be adequate. Also, since entry into the vault will only occur if cleanup is required, localized shielding might be a better solution than increasing the wall thickness.

An unfinished vault presents several shielding problems, in addition to the inside wall thickness requirements. Openings to both the intake and exhaust plenums will have to be closed off with shielding materials to reduce radiation exposure levels in this vault during any future reconfiguration. Provisions must be made this vault is eventuals, under a high radiation environment, when

The second construction sequence involves the construction of the Stabilization Facility adjacent to the exhaust plenum. Excavation could remove all of the soil surrounding the exterior wall. Again, the minimum wall thickness is 42 inches, so that the 54 inch
exterior wall is more than adequate.

\subsubsection{Minimum Thickness of Operating Floor}

Radiation protection of personnel from stabilized MCO's in dry storage is provided by the concrete operating floor. This floor, along with the individual shield plugs which provide access into each storage tube, must provide shielding sufficient to maintain a target dose rate of $0.2 \mathrm{mrem} / \mathrm{hr}$. The minimum floor thickness must be 48 inches. This floor thickness allows for a solid floor. When the floor is cast with plug holes and the holes are fitted with plugs which do not completely fill the space, radiation streaming is possible. Plugs and holes with steps solve this problem. It is inches which wimated the current design thickness of the floor is 60 the holes and will provide adequate shielding. The geometry with date.
dales and plugs will need to be examined thoroughly at a later

\subsubsection{Minimum Transporter/Cask Thickness of Steel and Tungsten}

There are two options for transporting the Mco's filled with stabilized fuel tubes. The first would involve a stand alone The second would would be driven around on the operating floor. would be moved with an a special remote controlled cask which health protection and heread crane. In either case, personnel contact dose rate is $0.2 \mathrm{mrem} / \mathrm{hr}$ weight are important. The target this dose rate is 14 inches. this dose rate is 4.7 inches. Thickness of tungsten to achieve expensive, but considerably lighter. The tungsten shield is more transporter or overhead crane. These thicknesses the cost of the 
shielding only. These shielding requirements will need to be reviewed for neutron shielding adequacy (Section 2.2.5.8)

\subsubsection{Special Shielding Issues (Neutrons, Betas)}

A neutron source was not provided and neutrons have been ignored during this study. However, in future design efforts, neutron dose rates will need to be evaluated. The areas of particular concern are the incoming and outgoing casks and the transporter/cask. These shielding structures are designed to provide adequate gamma shielding. Additional neutron shielding may be needed. The neutron source will result from some $\alpha, n$ reactions and spontaneous fission of the transuranics.

The beta source does not appear to be a significant shielding source in the MCO. The shielding concern is not to provide beta shielding which is provided by the shell of the MCO, but to provide adequate shielding of the Bremsstrahlung radiation resulting from the beta absorption in the gamma shield.

The secondary photon source, resulting from the "Maximum" MCO (Section 2.8) mix of beta emitting isotopes, was evaluated using MCNP. This source of photons was found to contribute less than $3 \%$ of the exposure rate contributed by the gammas.

\subsubsection{Conversion}

Conversion of Concept $2 D$ from refrigerated air cooling of unstabilized fuel to passive dry storage will be accomplished after stabilization of all the MCOs is complete. As MCOs are removed for stabilization, MCOs containing dry stabilized fuel will be installed in dry storage tubes upon return from the stabilization Facility. When all of the fuel has been stabilized and higher fuel and vault temperatures can be tolerated, blinds in the air intake plenums and stack would be removed, air refrigeration equipment would be shut down and isolated if necessary, allowing natural circulation cooling to be established.

There do not appear to be any additional feasibility issues associated with the conversion from refrigerated air cooling to passive dry storage for this concept other than shielding and radiation safety, already addressed.

\subsubsection{Eealth Physics}

2.2 .7 .1 Objective

Perform a Health Physics (HP) analytical review of the use of the Canister storage Building (CSB) as a staging and storage facility (SSF) for the $\mathrm{N}$-reactor fuel.

$$
2-55
$$




\subsubsection{Sumary}

Whereas the facility as designed for the Fanford Waste Vitrification plant (HWVP) project is ideally suited for the storage of spent fuel, there are some features of concept $2 \mathrm{D}$ that will need to be altered in order to meet the latest DOE requirements such as DOE/EH-0256T, Radiological Control Manual, Rev. 1, April 1994. For example, the facility will require change rooms, step-off-pads (SOP), and a personnel decontamination facility. In addition, the concept of allowing the third vault to remain empty will not work from an HP or an FVAC stand point without major changes to the building. The building modifications will more than likely off-set any potential savings attributable to deferring the third vault work at this time. Although data concerning the potential neutron source associated with the max $A$ multi-canister overpack (MCO) shielding source is not available at this time, it is inevitable that there will be more neutrons associated with this source than there were with the FwVP source because this source contains far more fissile material. Further, since a neutron shield was required on the HWVP transporter, be advised that it will be required as an integral part of the shipping cask and as part of the floor plug shield valve. Finally, it is beyond the scope of this study and left to later design stages to verify that workers will be able to remain on the operating floor during insertion of the MCo into the storage tubes.

\subsubsection{Facility Description And Evaluation}

It should be noted that although the CSB was designed when the yearly exposure for radiation workers was 1,000 mrem cumulative total effective dose equivalent (CTEDE), the Westinghouse Hanford Corporation (WHC) and the Fluor Daniel Inc. (FDI), Health Physics departments mutually agreed that this dose should be divided into $400 \mathrm{mrem} / \mathrm{yr}$, whole body dose, and $600 \mathrm{mrem} / \mathrm{yr}$ for internal dose exposure. The DOE regulation cited above, Iimits the yearly CTEDE to radiation workers to $500 \mathrm{mrem}$. This means that the CSB is designed in compliance with the latest contemporary DoE regulations. The design of the operating floor meets the latest WEC requirements for a radiation access zone (RAZ) 1 which permits 40 hours per week occupation.

The Radiological Control Manual (Rad Con) manual requires the HP facilities noted above in the summary. In addition, the sops must be contiguous with the radiological areas that reguire radiation work permit (RWP)/special work permit (SWP) such as the cask handling, storage, preparation and operating areas.

If the third vault remains empty, without any flow restrictions, then the preponderance of natural convection air, after stabilization, will flow through the empty vault and not through the MCO filled vaults. Flow restrictors will be difficult, if not impossible, to remove if WHC finds a use for the vault at a later 
date because it is currently inconceivable that anyone can enter the area after the first and second vaults are filled with MCOs. Please be advised that even if the wall thickness between the second and third vault is increased, the scattering around the exhaust and inlet plenums will most likely produce a RAZ 5, which does not allow access.

The shipping cask and the floor plug shield valve will have to provide shielding against gammas, beta originated bremsstrahlung radiation ( $\mathrm{X}$-rays) and neutrons. The preliminary estimates without bremsstrahlung or neutrons, indicate that the maximum MCO will produce a dose rate of approximately $200 \mathrm{R} / \mathrm{h}$ at three feet from the midsection of the overpack. It should be noted that the shielding requirement to allow this source to become contact maintained in a RAZ 1 would be approximately 14 inches of steel. This shield may exceed the weight restrictions for the CSB floor and crane. This is one of the reasons why it may not be possible to allow workers to remain on the operating floor during insertion of the MCO into the storage tubes.

\section{3 .0 SAFETY ANALYSIS}

\subsubsection{APRLICABLE REQUIREMGATS}

The environmental, safety and health (ES\&H) requirements applicable to the SSF are very similar to the requirements applied to the KWVP CSB, especially for the storage phase. Other than updated requirements for protection against natural phenomena (recently issued DOB-STD-1020), all such requirements applicable to the CSB will apply to the SSF.

The CSB design (the starting point for the SSF design) was completed using these ES\&H requirements as part of the design basis. This CSB design has been reviewed and approved by the DOE, WHC and the state of Washington as meeting all these requirements. This successful track record should ease the regulatory process for the SSE.

On the other hand, the fact that spent nuclear fuel (SNF) is being stored instead of glass, and the necessity for wet storage of unstabilized fuel in the staging phase, will make several new additional requirements applicable to the SSF. For example, in addition to meeting the requirements applicable to the CSB, WHC has indicated that the SSF will be required to meet the intent of Nuclear Regulatory Commission requirements for SNF storage facilities. 


\subsubsection{DOE Orders}

The following safety related DOE Orders are applicable to the SSF. The technical descriptions provided in this report are intended to meet these regulations. They are the core of the safety design basis for the facility:

\subsection{DOE Order 6430.1A, General Design Criteria}

This is the primary design requirements document which the SSF must meet. Key safety related sections influencing the SSF design include :

1. Section 0200-1.3Radiological Siting Guidelines

Section 1300-1.4Guidelines on Limiting Exposure of the Public

Establish offsite exposure limits for normal operations, and the basic 25 rem offsite dose Iimit for Design Basis Accidents (DBAs).

2. Section 1300 Special Facilities (in general)

Section 1300-3Safety Class Criteria (in particular)

Identify the requirements for DOE Safety Class (SC) structures, systems and components (SSCs), including the single Failure Criterion.

\section{Section 1320Irradiated Fissile Material storage Facilities}

Identifies special design requirements applicable to dry-type spent nuclear fuel (SNF) storage facilities such as the SSF. It also requires the designer to consider the applicability of NRC SNF storage requirements, such as 10CFR72 and Regulatory Guide 3.60 to the design of DOE SNF facilities. It requires primary and secondary confinement systems.

\subsection{DOE Order 5480.5, Safety of Nuclear Facilities}

Identifies general safety requirements applicable to the SSF, including effluent release limits for normal operation.

\subsection{DOE Order 5480.22, Technical Safety Requirements}

This Order defines the requirements for the Technical Safety Requirements (TSR) document. The TSRs are an agreement between a facility's operating management and the DOE regarding the safe operation of the facility. They define the safe operating limits, surveillance requirements, and management controls under which the facility must operate to maintain its safety design basis. The TSRs are based on the facility Safety Analysis Report (SAR). They are closely related to the assumptions made in the Design Basis Accident (DBA) analyses regarding the initial condition of 
the facility (e.g., operability of Safety Class systems) when each accident is initiated.

\subsection{DOE Order 5480.23, Nuclear Safety Analysis Reports}

This order defines the requirements for the preparation, review, and approval of DOE Safety Analysis Reports (SARs). It also describes acceptable SAR format, content, and level of detail. WHC has applied for an exemption from this order and has indicated that the SSF SAR will meet the intent of the format and content requirements in NRC Regulatory Guide 3.48 .

2.3.1.1.5 DOE Order 5480.28, Natural Phenomena Hazards (NPH) Mitigation

This Order identifies the seismic and other NPH protection requirements applicable to the SSF. To a large degree, this order and its implementing standards define the design of SsF structures.

\subsubsection{DOE Standards}

The following safety related DOE standards are applicable to the SSF. These standards generally provide guidance to the designer for meeting the intent of the above DOE Orders:

2.3.1.2.1 DOE Standard 1020, Natural Phenomena Hazards Design and Evaluation Criteria for DOE Facilities

This standard defines the detailed NPH design criteria applicable to each DOE site for structures to meet the intent of DOE Order 5480.28 .

2.3.1.2.2 DOE Standard 1021, Natural Phenomena Hazards Performance Categorization Guidelines for Structures, Systems and Components

This standard defines DOE structural Performance Categories applicable the safety related structures in a facility as a function of the facility's Hazard Category. It also defines the structural requirements for each Performance Category to meet the intent of DOE Order 5480.28.

2.3.1.2.3 DOE Standard 1027, Hazard Categorization and Accident Analysis Techniques for Compliance with DOE Order 5480.23

This Standard provides standard techniques for determining the hazard level of a facility, and for performing a Preliminary Hazards Analysis. 


\section{3 .1 .3 NRC Regulations}

2.3.1.3.1 10CFR72, Licensing Requirements for the Independent Storage of Spent Nuclear Fuel and High-Level Radioactive Waste

Part 72 prescribes high level design and other licensing requirements for the independent storage of SNF. Its requirements in the design and safety analysis area are specified in more detail in Regulatory Guide 3.54 .

\subsection{Regulatory Guides}

WHC has indicated that the SSF must meet the intent of the following NRC Regulatory Guides:

1. Regulatory Guide 1.25, Assumptions Used for Evaluating the Potential Radiological Consequences of a Fuel Handling Accident in the Fuel Handling and storage Facility for Boiling Water and Pressurized Water Reactors

This Regulatory Guide identifies the assumptions required to be used in performing accident analysis for SNF storage facilities.

2. Regulatory Guide 3.48, standard Format and Content for the Safety Analysis Report for an Independent Spent Fuel storage Installation or Monitored Retrievable storage Installation (Dry storage)

WHC has indicated that the SSF SAR will meet the intent of the format and content requirements of these Regulatory Guides, rather than the requirements of DOE 5480.23 , from which it has requested exemption.

3. Regulatory Guide 3.60, Design of an Independent Spent Fuel Storage Installation (Dry Type).

Generally, this Regulatory Guide merely finds acceptable the use of ANSI/ANS 57.9-1992 in the design of dry type Independent Spent Fuel storage Installations (ISFSIs).

\subsubsection{Other Federal Regulations}

2.3.1.4.1 National Environmental Policy Act

NEPA will require the preparation, review and approval of an Environmental Impact statement for the SSE design. 


\subsection{Resource Conservation and Recovery Act (RCRA)}

Enforcement of RCRA requirements generally is delegated to the individual states. For the state of washington, RCRA requirements are implemented primarily through WAC 173-303.

\subsubsection{Washington State Regulations}

Washington Administrative Code (WAC) 173-303

This (and several other statutes) implement the requirements of the Federal Resource Conservation and Recovery Act (RCRA) for the State of Washington. The primary objective of the 173-303 is to prevent the release of dangerous wastes into the ground water.

If the facility would contain dangerous wastes, it must apply to the Washington state Department of Ecology for a Dangerous Waste Permit. Key requirements of the RCRA that affect the design include a requirement for double containment of dangerous Iiquids and detection within 24 hours and collection of any leakage.

\subsubsection{WaC Requirements}

WHC-CM-4-46, Nonreactor Facility Safety Analysis

Provides requirements for the preparation, review and approval of safety analyses for facilities at the Hanford site. In particular, Section 9.0 (Draft Revision OB) of this manual defines a graded system for safety classification of systems, components, and structures (SSCs). It specifies design requirements applicable to the four WHC safety categories: Safety Class 1 (DOE Safety Class-offsite hazard), Safety Class 2 (onsite hazard only), Safety Class 3 (facility hazard only), and Non-Safety.

Section 9.0 (in Table 2 of Attachment 1) of WHC-CM-4-46 also specifies frequency-dependent Radiological Dose Limits for DBAs. These limits are discussed below in section 6.2 .

\subsubsection{ANSI/ANS Standards}

Standard 57.9, Design Criteria for an Independent Spent Fuel Storage Installation (Dry Type)

Provides detailed design criteria for dry type ISFSIs such as the SSE. This standard requires a minimum of two barriers between the SNF and the outside environment.

\subsubsection{DESIGN BASIS ACCIDENT/SAFTHY CLASSIFICATIONS}

This section documents the results of a first-cut Design Basis Accident (DBA) analysis for the SSF. It describes the

$$
2-61
$$


pre-conceptual safety design basis of SSF Feasibility Design Concept 2D, including the basis for determination of required Safety Class (SC) SSCs.

A spectrum of candidate accident scenarios is postulated. Included are scenarios required to be addressed by programmatic requirements and additional scenarios identified by the WHC Draft Preliminary Hazards Analysis (PHA). All postulated scenarios are addressed.

The radiological consequences for each DBA are calculated for SSF Feasibility Design Concept 2D. The SSF is located on the site of the HWVP CSB (20,000 meter site boundary distance).

These consequences are compared with the onsite and offsite radiological dose limits of WHC-CM-4-46, Section 9.0 (Revision OB). Where unmitigated consequences exceed the dose limits, mitigating SSCs are designated as SC-2 or SC-1 as appropriate. Credit is taken for the operability of these SSCs to mitigate the consequences of the DBA to within the dose limit.

These frequency-dependent dose limits include the following:

A. Offsite:

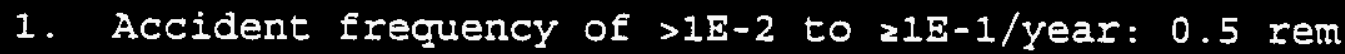

2. Accident frequency of $>1 E-4$ to $\leq 1 E-2 /$ year: 5 rem

3. Accident frequency of $>1 E-6$ to $\leqslant 1$ E-4/year:25 rem

B. Onsite:

1. Accident frequency of $>1 E-2$ to $21 \mathrm{E}-1 /$ year: 5 rem

2. Accident frequency of $>1 E-4$ to $\leq 1 E-2 /$ year: 25 rem

3. Accident frequency of $>1 E-6$ to $\leq 1 E-4 /$ year: 100 rem

\subsubsection{DBA Methodology}

\subsection{Event Consequences}

The methodology described in DOE-STD-1027-92 is used for this analysis. The following equation, from page $A-6$ of DOE-STD-1027-92, describes the basic method used to calculate the offsite dose for each DBA:

MOI DOSE $=(M A R)$ (RF) (X/Q) (RR) (SA) (CEDE) (1)

or: (Source Activity) (CEDE) (RE) (X/Q) (RR) (Ia) 
where :

MOI Dose - Maximum offsite Individual Dose[rem]

MAR - Material at Risk [grams]; RF - Release Fraction [Unitless]

$R R$ - Respiration Rate [m3/sec]; SA - Specific Activity [ci/g]

$\mathrm{X} / \mathrm{Q}$ - Atmospheric dispersion factor for the [sec/m3] site boundary distance

CEDE - Committed Effective Dose Equivalent [rem/ci] per curie inhaled

Source Activity = (MAR) (SA) [Ci]

\subsection{Initiating Event Frequencies}

Formal quantitative calculation of event frequencies is not included in this assessment. The estimated frequencies listed in Results Table $A$ are based on the frequency categories shown in the WHC Draft PHA.

As stated in the assumptions below, the frequencies of several scenarios are assumed to be below the threshold of credibility, based on the assumed outcomes of future, more detailed safety analyses. These assumptions should be verified or changed in later phases of the design of the SSF, based on the results of these analyses.

\subsection{Scenario Development/Screening}

The first step in the DBA analysis process is a screening process to justify eliminating from consideration all scenarios that are not DBAs. Remaining as DBAs are those scenarios that meet both of the following criteria:

A. The scenario is "credible:" The frequency of occurrence of the initiating event is equal to or greater than 1E-6/year. Accidents with frequencies less than this threshold are considered to be "beyond the design basis," or "not credible." This credibility threshold is defined in Section 1300-1.4.2 (and the Glossary) of DOE Order 6430.1A. The basic credibility threshold of $1 \mathrm{E}-6 / \mathrm{year}$ is modified by DOE-STD-1021 for natural phenomena hazards (NPH) to 1E-5/year. Accidents beyond the design basis, or "residual risk," will be analyzed in later phases of the design as required by DOE order 5480.23 .

B. The scenario is the limiting, or highest consequence, accident in its type: For example, the (credible) spill with the most severe consequence is the "design basis spill." If the plant is

$$
2-63
$$


designed to mitigate the risk of the design basis spill to within the dose limits, then it also can mitigate adequately all spills of lesser consequence.

\subsection{Material At Risk Estimates}

All spent fuel received at the SSF will be contained in Safety Class Multi-Canister Overpacks (MCOs). For the purposes of this assessment, Material At Risk (MAR) is assumed to be the "maximum" inventory of radionuclides in each MCO, taken from the "MCO Description" contained in Section 2.8, times the number of MCOs at risk in each accident scenario. The one exception to this is the "uncontrolled gas discharge" DBA, where the MAR is assumed to be the $\mathrm{Kr}-85$ inventory of one MCO.

Failure of a MCO containing the "maximum" radionuclide inventory would cause a release and a resultant dose that can be calculated. The theoretical inhalation dose that would result from uptake of the entire contents of a MCO (immersion dose for $\mathrm{Kr}-85$ ) is calculated. This doses is the "peak inhalation Committed Effective Dose Equivalent (CEDE) at the source." The method of calculation of this dose source term is described below.

\section{3 .2 .1 .5 Source Terms}

Equation (1a) shown in the Methodology section above can be restated as follows:

MOI Dose

$$
=[\text { (Source Activity [in curies]) }
$$
(RR)]

$(\mathrm{CEDE})] \quad[(\mathrm{RF}) \quad(\mathrm{X} / \mathrm{Q})$

or.

$$
\text { = [Inalation CEDE at the source] }
$$

where:

$$
\begin{gathered}
\text { [Inhalation CEDE } \\
\text { at the Source] }
\end{gathered}
$$

and $K=(R F) \quad(X / Q) \quad(R R)$

The " $K$ " part the dose calculation is independent of the nuclear characteristics of the source MAR. Inhalation CEDE At the Source, on the other hand, is completely characteristic of the each nuclide making up the source term.

In fact, the RF (1E-3 for all isotopes except $K r-85$ ) and $R R(3.5 E-4$ $\mathrm{m} 3 / \mathrm{sec}$ ) and meteorology all are assumed to be fixed for the SSF by DOE-STD-1027-92. The CSB site boundary distance (20,000 meters) fixes $X / Q$ for the $S S F$ as well, as described below.

$$
2-64
$$


Equation 1 is intended to be used to calculate the dose caused by one source radionuclide at a time. The inventory of a Mco comprises several isotopes as listed given in the Appendix 1 "MCO Description".

The dose that would result from a failed MCO containing this mixture of isotopes actually would comprise the sum of the individual doses contributed by each isotope present in the mixture at the time of release:

(Inhalation CEDE $=\sum_{i} \quad$ (Source Activity) $_{i} \quad(C E D E)_{i}$
of the mixture)

The (Source Activity) + values used in this analysis are taken from the Section 2.8 "MCO Proposed Description". The CEDE 1 values are taken from DOE/EH--0070 and DOE/EH--0071.

\subsection{Release Modeling}

As stated above, the release model used for this analysis is taken Erom DOE-STD-1027-92. The Release Fraction (RF) used for each scenario is 1E-3 (except for noble gases such as $\mathrm{Kr}-85$, which have an $R F$ of 1 ). Respiration rate (RR) of the receptor used for each scenario is $3.5 \mathrm{E}-4 \mathrm{~m}^{3} / \mathrm{sec}$. Both are bounding values taken from DOE-STD-1027-92, page A-7.

The offsite receptor distance for the fWVP CSB is 20,000 meters. The onsite receptor distance is 300 meters per DOE-STD-1027-92, page $A-7$.

Atmospheric dispersion factors ( $\mathrm{X} / \mathrm{Q}$ values) are derived for the offisite and onsite receptor distances using the meteorological assumptions recommended for Preliminary Hazard Analyses in Appendix A (p.A-7) of DOE-STD-1027-92:

D-stability weather classification

\section{5 meters/second wind speed}

These parameters are used with the appropriate distances as inputs to the GENII algorithm, documented in PNL-6584, to calculate the following $\mathrm{X} / \mathrm{Qs}$ :

A. Maximum offsite Individual

(MOI) $(20,000$ meter Offsite Boundary):3.206E-7

B. Onsite receptor (300 meters) $: 2.200 \mathrm{E}-4$

These values are significantly less conservative than the $X / Q s$ used for the HWVP CSB accident analyses. At the high end of the range for $X / Q$ is the conservative $X / Q$ used for the HWVP CSB PSAR

$$
2-65
$$


Addendum, the "0-8 hour release" site boundary $\mathrm{X} / \mathrm{Q}, 8.67 \mathrm{E}-6$. This is greater than the DOE-STD-1027 offsite $X / Q$ by a factor of approximately twenty seven. This wide range of $X / Q$ s that are potentially applicable to the SSE is used to calculate the "range" of doses reported in Results Table 2-8 below.

\section{3 .2 .2 Assumptions}

\subsection{Initiating Event Frequency/Credibility}

A. Except for the "MCO failure" DBA, fire anywhere within the ssF is not a credible initiating event. Similarly, fire as a dependent event (e.g., caused by a DBE) is not a credible event. The basis for these assumptions is qualitative at this early phase of the design. The Fire Hazards Analysis (FHA) has not been performed. For several reasons, however, there is a level of confidence that the FHA will result in a detailed facility configuration that positively will prevent the introduction of significant combustibles into the facility and support this assumption.

Historically, SNF storage facilities such as the SSF have posed a substantially lower fire risk than other types of facilities such as reactors and radiochemical processing plants. Normal combustible loadings are at insignificant levels throughout most of the SSF. Review of chemical usage in the facility generally shows minimal use of combustible chemicals.

Process engineering has reviewed the rates and amounts of hydrogen releases from MCOs during normal operation. At the rate of once-through ventilation planned for the operating deck, hydrogen concentrations will stay several orders of magnitude below flammable limits. Even after an extended loss of ventilation (not considered credible) it would take several days for concentrations to reach flammable levels. This could be prevented merely by opening exterior doors to the wind.

For Concept 2D, periodic purging of the tube annulus during normal operation will prevent the buildup of hydrogen to dangerous levels. Even if hydrogen levels did reach flammable levels in the annulus, there is no ignition source in the tube.

There are, however, a few issues identified to date that could bear on the validity of this assumption and should be addressed in detail by the FHA:

i. The capability should be provided for an adequate, timely response to a possible fire resulting from the failure of a MCO, resulting from a handling drop or other leakage of water from a MCO and ignition of the uncovered fuel rods.

$$
2-66
$$


ii. If diesel generators and/or batteries are used for backup electrical power, then the fire risk associated with this equipment should be addressed.

iii. Although it is a relatively smaller risk, the fire risk associated with the use of ion exchange resins, filter media and regenerant chemicals should be addressed.

iv. The FHA should consider the fire risks associated with any use of Iiquid nitrogen inside the SSF, such as the condensation and reevaporation of oxygen from the surrounding atmosphere.

This assumption is key to this assessment. If $t$ t were invalid (if a substantial release due to a fire (not related to a MCo failure) were credible inside the SSF, then SC mitigation may be required to meet the dose limits. Substantial additional SC SSCs could be required. This change could affect the estimated capital cost of the facility significantly.

B. Explosion anywhere within the vicinity of the SSF structure (including the stacks) is not a credible initiating event. Similarly, explosion as a dependent event (e.g., caused by a DBE) is not a credible event. The basis for these assumptions also is qualitative at this early phase of the design, because the Fire Hazards Analysis (FHA) has not been performed. For reasons similar to those listed above for fire, however, there is a level of confidence that the FHA will result in a detailed plant configuration that positively will prevent the creation of a credible explosive hazard in the vicinity of the SSF and support this assumption.

There are, however, a few issues identified to date that could bear on the validity of this assumption and should be addressed in detail by the FHA:

i. If hydrogen gas or other explosive gases or liquids would be used in the facility, the source containers preferably should be located outside the SSF, far enough away so that leakage and explosion involving all the stored gas would not be a credible threat to the SSF structures.

ii. If any such gases are brought into the facility via permanently installed tubing, then the tubing from the storage bottle should be provided with Safety Class isolation valves. These valves must close automatically on high seismic acceleration.

iii. If a bottles of such gases are transported into (the vicinity of) SSF structures, then the frequency and conseguences of the resultant hazard should be limited: 
a) The capacity of the bottles should be minimized, and

b) The amount of time the bottle is in the facility should be minimized.

The FHA should show that an explosion capable of failing safety Class SSF structures is not a credible event.

This assumption also is key to this assessment. If it were invalid (if an explosion capable of threatening failure of SSF structures were credible), then SC mitigation and/or structural upgrades could be required to meet the dose limits. Substantial additional or upgraded SC SSCs could be required. This change could also affect the estimated capital cost significantly.

C. Analysis of aircraft crash, both credibility (frequency) and consequences, is not included in this assessment (i.e., for purposes of this assessment, aircraft crash is assumed not credible). The extensive analysis already done for the HWVP PSAR proves that this is the case.

D. This analysis assumes that a MCO will fail (release its radioactive contents) if dropped from a significant height, both in and out of water, whether or not it is inside a MCo handing cask. In contrast, it is assumed that the transport cask (and the MCO inside $i t)$ will not fail if dropped from any height attainable in the facility, unless the lid is unbolted. If the Iid is unbolted when the cask is dropped, then it is assumed that the impact ejects the MCO from the transport cask and causes the MCO to fail.

Similarly, it is assumed that an uncontrolled discharge of gas from an MCO (due to a relief valve sticking open or a hydrogen burn inside the $\mathrm{MCO}$ ) results in the release of the entire maximum inventory of $\mathrm{Kr}-85$ from the MCO. This is considered to be a very conservative assumption that is a candidate for relaxation if necessary, by more detailed analysis in later phases of the design.

\subsection{Event Consequences}

A. Loss of ventilation due to equipment failure or power failure is not considered to be a DBA initiating event because it causes no release by itself, and requires no mitigation by permanently installed SSCs. In later stages of the design, the effects of these and other equipment failures will be considered in the design of SC SSCs, when taken as single failures in addition to DBA initiating events, as required to meet the single failure criterion of DOE Order 6430.1A, WHC-CM-4-46 (MRP 5.46) and IEEE 379 .

B. It is assumed that SSF SC SSCs will be designed to withstand the effects of the site-specific Design Basis Earthquake (DBE), Design Basis Wind (DBW), and Design Basis Ashfall and other natural

$$
2-68
$$


phenomena hazards without causing an offsite dose exceeding the limit, as required by DOE-STD-1021-92, Reference $L$. This assumption is reflected in the capital cost estimates herein.

C. It is assumed that only one MCO or cask will be moved at a time during any loading, unloading, servicing or inspection activity.

D. FVAC calculations show that approximately 20 hours after forced air cooling is lost, the temperature in the tubes has risen only $30{ }^{\circ} \mathrm{F}$. Concept $2 \mathrm{D}$ is currently not a safety class system. Adequate time would most likely not be available after a loss of cooling or loss of power event to bring in mobile emergency cooling capability well before temperatures reach unaćceptable levels. Based on this assumption, no permanently installed emergency cooling or makeup system is included in the SSF Feasibility Design, in accordance with Section 1320-4 of DOE Order 6430.1A.

\section{$2 \cdot 3 \cdot 2 \cdot 3$ Results}

\subsection{Scenario Screening Results}

Table 2-8 shows the results of the scenario screening process used to determine which scenarios are considered DBAs applicable to each phase of SSF Concept 2D.

\subsection{Material At Risk/Source Terms}

Table 2-8 also shows the MAR quantities/source terms for each DBA.

\subsection{Unmitigated Doses/Facility Hazard Category}

Table 2-8 also shows the unmitigated offsite and onsite dose consequences for each DBA. Dose consequences are compared with the onsite and offsite dose Iimits of Section 2.3.2 above.

As Table 2-8 clearly shows, the total quantity of MAR present in the SSF makes the facility a candidate for DOE Hazard Category 1 (High Hazard), the same category as the $\mathrm{K}$-Basins (and the kWvP CSB).

\section{$2 \cdot 3 \cdot 2 \cdot 3 \cdot 4$ Safety Classifications}

Where unmitigated offsite consequences exceed the applicable dose limit, credit must be taken for the operability of Dog safety class (WHC SC-1) SSCs to prevent or mitigate the consequences of the DBA to within the Iimit. When credit is taken for the SC-1 SCCs shown in Table 2-8, offsite consequences are less than the dose limits for all eight DBAs analyzed, given the Assumptions on which the analysis is based.

Similarly, onsite consequences are less than the onsite limits for

$$
2-69
$$


most DBAs analyzed, again given the assumptions on which the analysis is based. The exceptions are DBA Nos. 2, 3 and 4, MCO failure scenarios. For these accidents, the particulate releases can be filtered by the emergency ventilation exhaust system to a small fraction of the threshold. Along with the particulate, however, the maximum MCO inventory of $\mathrm{Kr}-85$, an unfilterable noble gas, is released.

Calculations show that release of the $\mathrm{Kr}-85$ inventory only from a single MCO may exceed the onsite limits, depending on the $X / Q$ used. If the $X / Q s$ used for the HWVP PSAR are used (resulting in up to 720 rem), the Iimit would be exceeded. This issue probably can be resolved by more detailed analysis in later phases of the design.

Tables 2-8, 2-9 and 2-10 show the SC-2 and SC-1 SSCs required for the SSF design to meet the onsite and offsite dose Iimits.

Structures/Performance Categories. Because the SSF is a candidate for DOE Hazard Category 1 , and because some of the structures Iisted in Table 2-9 and 2-10 provide DOE Safety Class (WHC SC-I) protection against natural phenomena hazards, these structures are candidates for designation as Performance Category 3 as defined in DOE Order 5480.28, and DOE-STD-1021.

Other structures listed in Tables 2-9 and 2-10 provide WHC SC-2 protection against natural phenomena hazards. These structures are Performance Category 2 as defined in DOE Order 5480.28, and DOE-STD-1021.

Systems. As Tables 2-9 and 2-10 show, there are no non-structure-related DOE Safety Class (WHC SC-1) systems required for the SSF (except the MCO pressure boundary itself, which is not part of the SSE scope). These tables also show the WHC SC-2 systems required for each SSF phase.

\subsection{COST ESTIMATES}

\subsubsection{ESTIMATE BASIS}

The capital cost estimates of the Concept 2D SSF configuration was prepared as a Rough Order of Magnitude (ROM) estimate, utilizing a combination of estimating methodologies. The excavation estimate for the vault/plenum area is shown at zero cost. The excavation was performed by the C200-01 construction package contractor, FWVP Project. The estimate for the existing slab constructed by David Mowat Company, (C350-01 construction package contractor), is shown at zero cost. Unit rates for the construction of the below grade portion of the SSF Facility, including the fabrication and installation of the storage tubes, were obtained from the FWVP CSB c350-01 package fair cost estimate. Unit rates for the above grade 

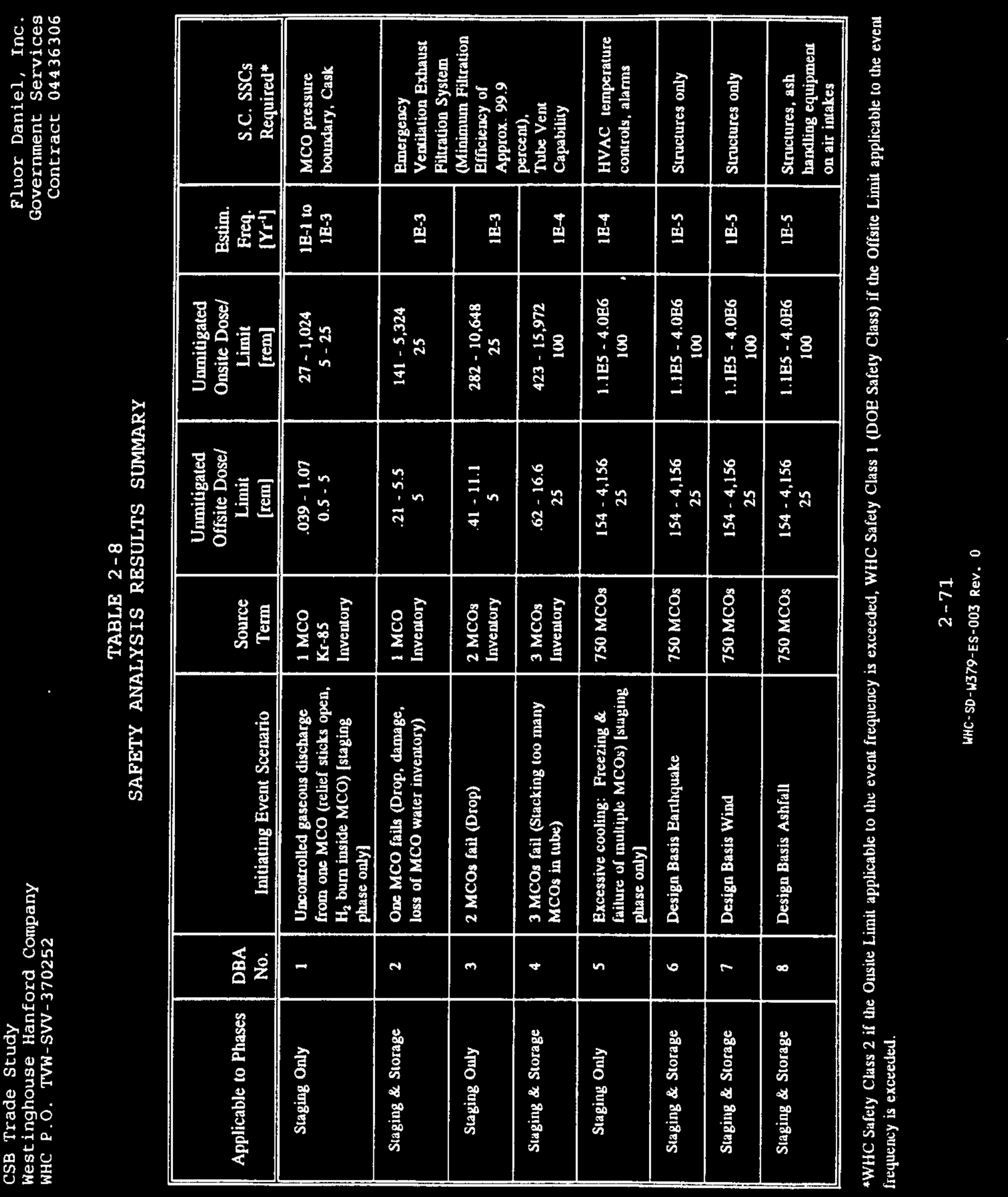


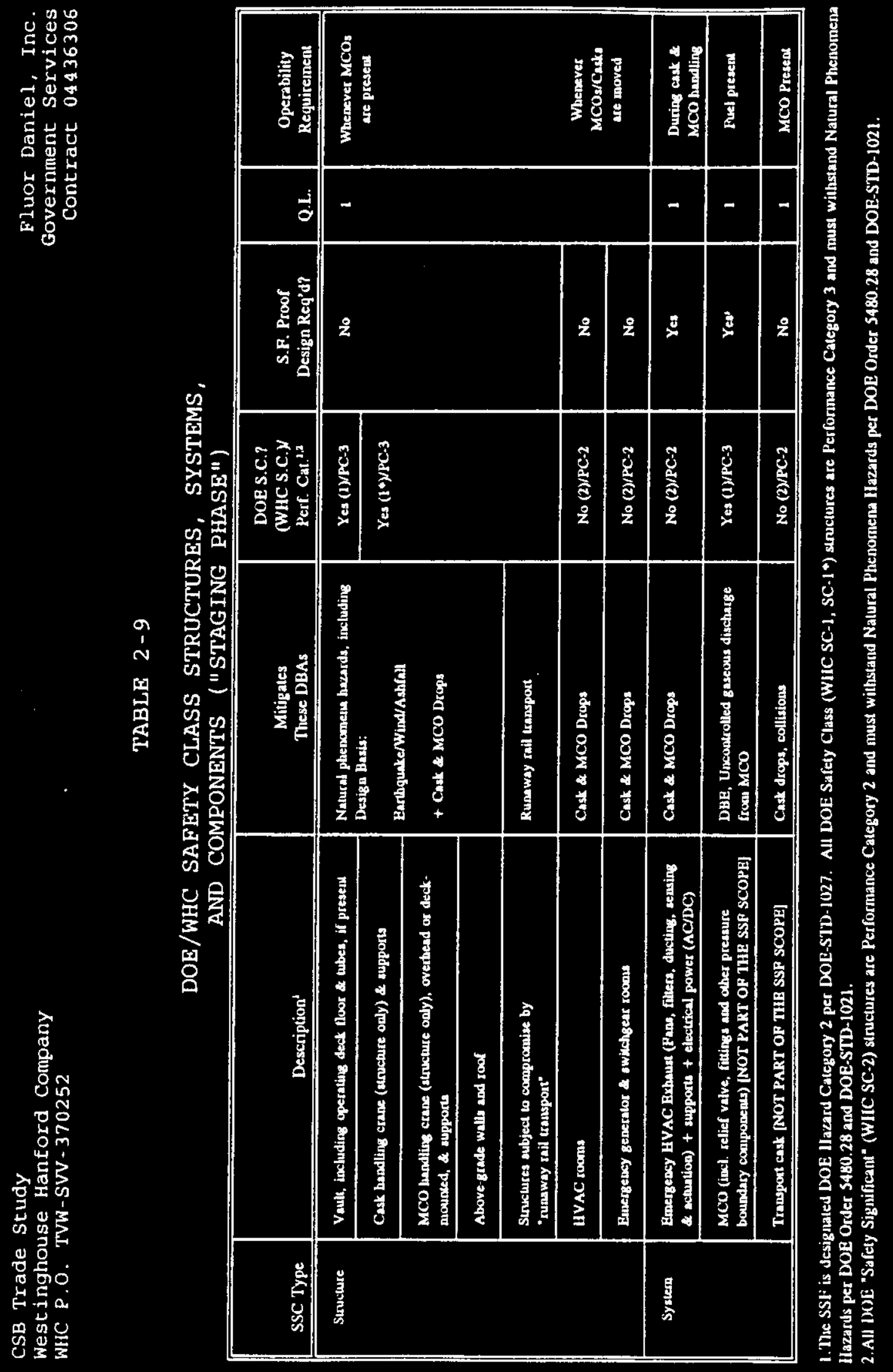




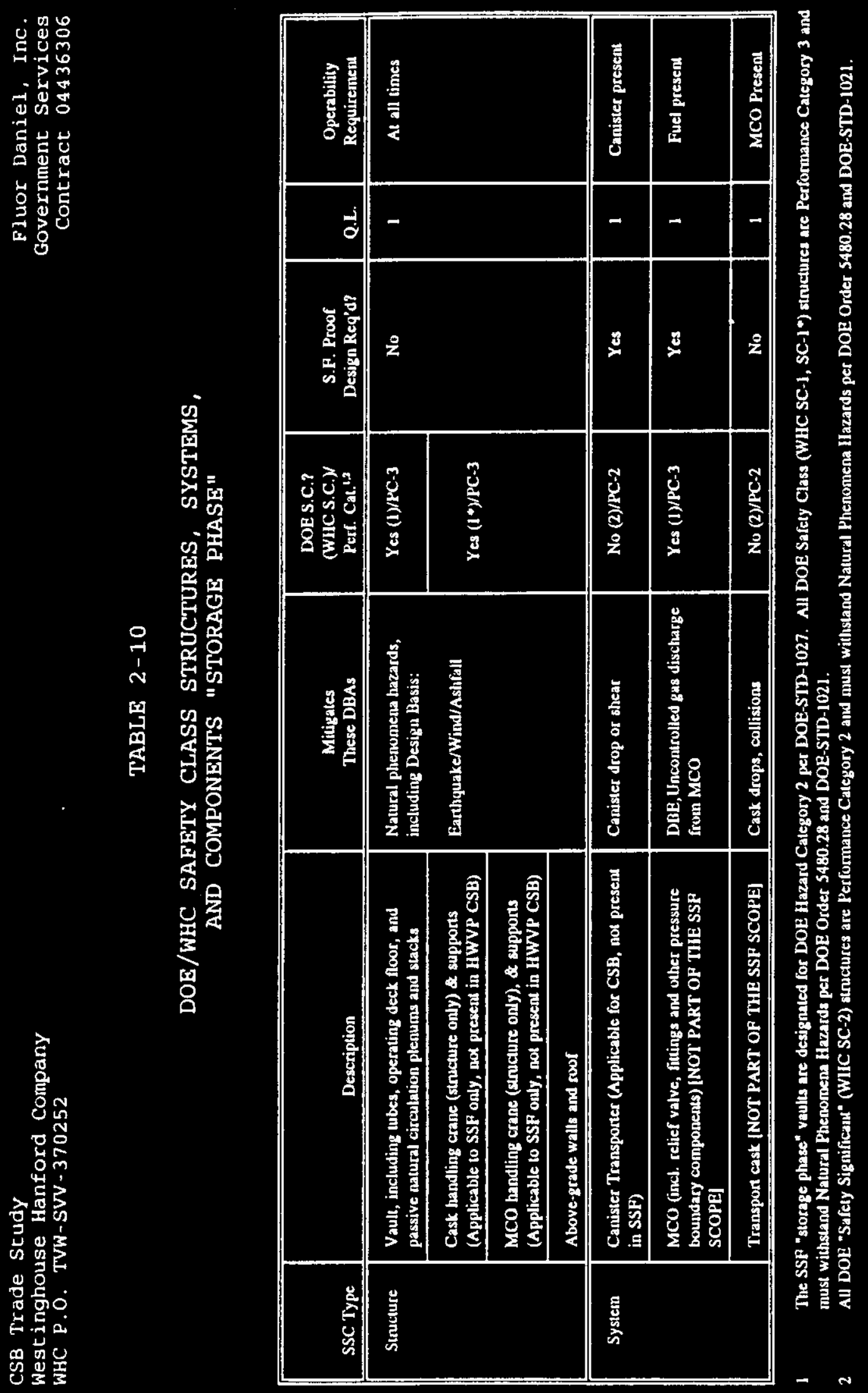


portion of the facility were obtained from the Independent Cost Estimate (ICE) prepared by the architect engineer in October, 1992, as part of the FWVP review of Key Decision (K-D) 3B. Quantities of structural steel were developed by Engineering. The Mechanical and Process equipment requirements were obtained from the Equipment List. Equipment installation and associated bulk material costs were factored from the equipment, which was priced in-house.

Miscellaneous site support costs were derived from quantity takeoff estimates. Estimates for engineering construction, and project management, are expressed as percentages of direct construction and GFE procurement costs.

\subsubsection{Assumptions}

All direct costs are expressed in present day (1995) dollars.

The estimate was based on a standard 40 hour work week.

Sufficient skilled labor is available on site during the period of construction.

- No project mission changes or major rework will occur during the engineering and construction of the facility.

- No radioactive or otherwise contaminated soil, or underground obstructions, will be encountered during excavation for the facility.

- An estimated average craft wage rate of $\$ 31.50 /$ hour was applied to the estimated direct construction manhours. The average rate is based on the current Hanford site stabilization agreement, and current Hanford Site prevailing wages. The estimated rate covers the craft's base wage, plus benefits and state legislated burdens.

Engineering Costs:

$25 \%$ of the direct construction cost estimates of the MCO Loading/Storage, Pool Water Treatment and Infrastructure Areas, including the Refrigeration FVAC Bldg. was added to $12.5 \%$ of the Direct Construction Cost Estimate of the vaults and office areas to provide an estimate of the Conceptual / Advanced Conceptual and Detail Design costs. Conceptual / Advanced Conceptual Design was assumed to be $20 \%$ of the engineering cost estimate, and detail design was assumed to be $80 \%$.

The Title III engineering estimate was calculated at $4.0 \%$ of the direct construction cost estimate.

$$
2-74
$$


- The Titre III inspection estimate was calculated at $4.0 \%$ of the Dixect Construction Cost Estimate.

- Construction management costs were calculated at $8.0 \%$ of direct construction costs.

- Project management costs were calculated at $8.0 \%$ of direct construction costs.

- Field construction is fixed price. An allowance of $53 \%$ was applied to direct field labor dollars to provide for associated indirect field labor, temporary facilities, personnel protection, weather protection," area maintenance, small tools and consumables, field and home office staff. QA/AC staff, construction equipment usage, bond and insurance, and the Washington state business and occupation (B\&O) tax.

- 5\% was applied to direct field materials and equipment to provide for overhead and profit.

- 10\% was applied to direct subcontract costs to provide for overhead and profit.

- Construction acceptance testing was calculated at $3 \%$ of direct field manhours.

- Mobilization and demobilization costs were calculated at $5 \%$ of direct field manhours.

\subsubsection{Estimate Inclusions}

The capital cost estimate includes all conceptual, detailed, field engineering and inspection costs, direct and indirect field construction labor, material, equipment, and subcontract costs, construction management, and project management costs, expended in the execution of the SSF project. The estimate was prepared in present day (1995) dollars and is escalated to the appropriate activity centroid dates dictated by the schedule (Section 2.5).

\subsubsection{Estimate Exclusions}

The following costs were excluded from the scope of the capital cost estimate:

- All capital, start-up and operating spare parts.

- Canister tube impact Iimiters.

- Cask transportation equipment (includes casks (transport \& facility) \& donkey engine).

- Expense funded costs 
- operating costs

- Special work procedure (SWP) construction

- Transfer tunnels and carts to and from the stabilization Facility

\subsubsection{Nork Breakdown Structure (WBS)}

The estimate was accrued to the following WBS:

\begin{tabular}{|c|c|c|c|}
\hline WBS & $\begin{array}{l}\text { ESTIMATE } \\
\text { CODE }^{(1)}\end{array}$ & DESCRIPTION & REMARKS \\
\hline 100 & $210 / 310$ & $\begin{array}{l}\text { Rail Tunnel/Cask } \\
\text { Unloading/Area }\end{array}$ & All Alts \\
\hline 200 & $220 / 320$ & Staging Pool & $N / A$ \\
\hline 300 & $230 / 330$ & $\begin{array}{l}\text { Vaults \& Inlet } \\
\text { Exhaust Plenums }\end{array}$ & All Alts \\
\hline 400 & $240 / 340$ & $\begin{array}{l}\text { Pool Water } \\
\text { Treatment/Inst Air } \\
\text { Compressor }\end{array}$ & All Alts \\
\hline 500 & $250 / 350$ & $\begin{array}{l}\text { HVAC/Office/ } \\
\text { Generator Equipment }\end{array}$ & AlI Alts \\
\hline 600 & $260 / 360$ & $\begin{array}{l}\text { Refrigerated Air } \\
\text { Mechanical Area }\end{array}$ & Alt 2D Only \\
\hline \multirow[t]{4}{*}{700} & 370 & Site support & AlI Alts \\
\hline & 100 & Engineering & AlI Alts \\
\hline & 400 & $\begin{array}{l}\text { Construction } \\
\text { Management }\end{array}$ & AlI Alts \\
\hline & 500 & Project Management & Al1 Alts \\
\hline
\end{tabular}

(1) Note the prefix code 2 indicates Procurement Costs, the prefix code 3, Construction Costs. WBS areas are reflected in Figure 2-23 In addition, the estimate was encoded by DOE code as described in, and required by DOE Order RL5700.3.

The estimate was further accrued by CSI Code of Accounts. 


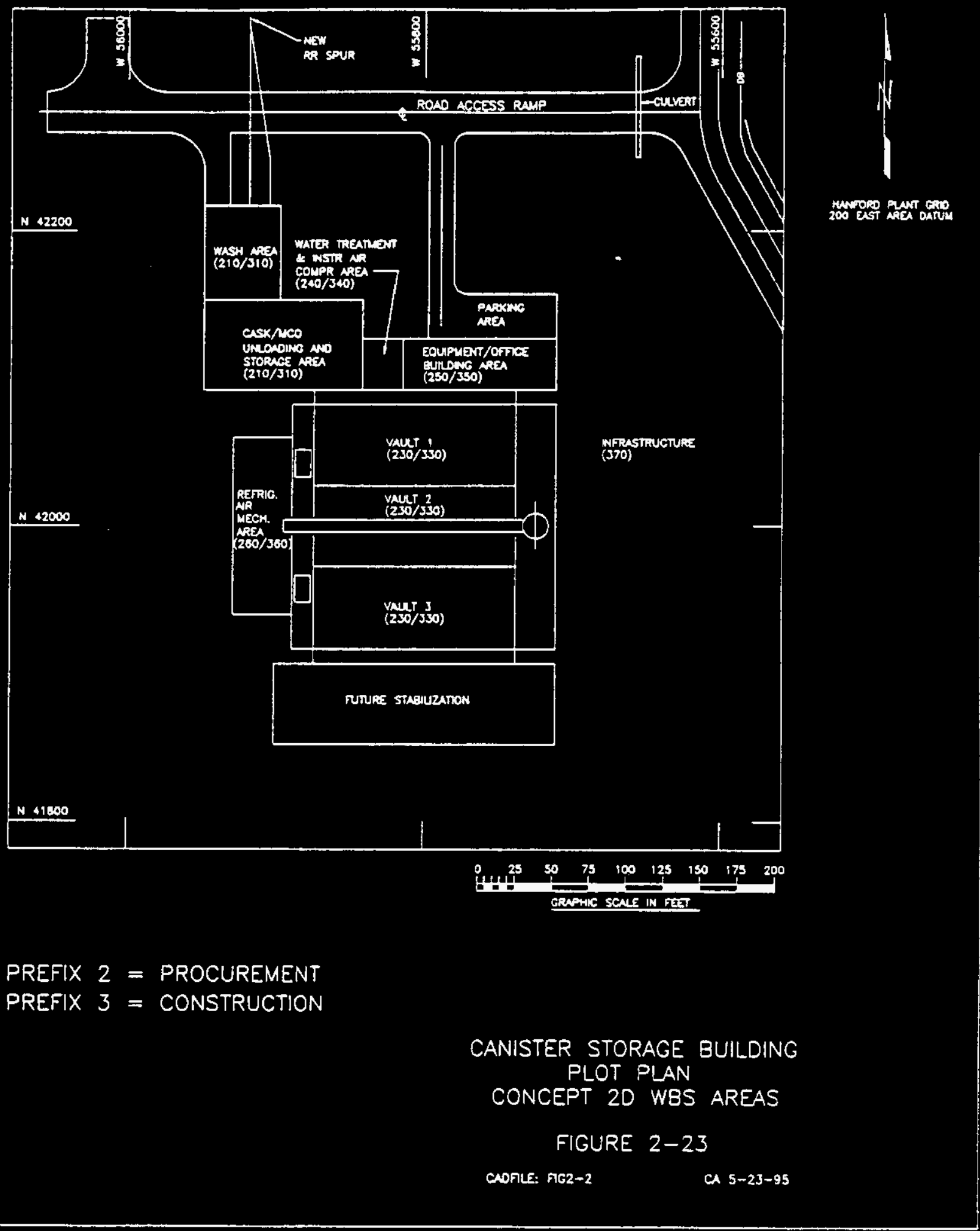




\subsubsection{Quantities}

The following quantity abbreviations were used throughout the estimate for all capital cost estimate line items:

\section{Description}

Excavation and Backfill

Concrete

Structural steel

Liner Plate, Finishes/Coatings

Machinery \& Equipment

Misc. Individual Items

Allowances and Composites

Manhours

\section{Unit Abbreviations}

$\mathrm{Yd}^{3}=$ Cubic yards

Tons

Sq Ft = Square Feet

$\mathrm{EA}=\mathrm{Each}$

EA

Lot

$\mathrm{MF}$

\subsubsection{References}

The following documents were used as reference documents in the preparation of the capital cost estimate.

- Hanford Waste Vitrification Plant (HWVP) Baselined Preliminary Design Estimate, Rev. "F", dated July 1991.

- K-D 3B ICE estimate of Package 350 [(HWVP) Canister Storage Building (CSB)] dated October, 1992.

- Fair cost estimate of Package 350-01 (below grade portion of the HWVP CSB) dated February, 1993.

- Drawings and Equipments Lists prepared in support of the SSF Report.

\subsubsection{Escalation}

The direct costs are expressed in current (1995 dollars). The estimate was evaluated in terms of the study schedule. The following direct costs were escalated to the centroid dates of their respective activities:

- Conceptual and Detailed Engineering - Design through initial construction

- Title III - Engineering and Inspection

- Procurement

- Construction

- Construction Management 


\section{- Project Management}

The escalation table used in the estimate preparation was provided by WHC through ICF Kaiser Hanford, Richland, WA.

\subsubsection{Contingency}

The estimated contingency was developed from an evaluation of the completeness of design information available to estimating, and the reliability of unit cost data obtained from prior estimates. The following contingencies were applied to the direct procurement, construction, and indirect cost centers of the estimate:

\begin{tabular}{lll} 
- Load In/Load Out \& Pool Water Treatment - & $30 \%$ \\
- Infrastructure - & $15 \%$ \\
- Vaults - & $15 \%$ \\
- Engineering - & $15 \%$ \\
- & $15 \%$ \\
\hline & Project Management - & $15 \%$
\end{tabular}

The resulting composite contingency is $17 \%$.

\section{4 .2 CONCEPT 2D CAPITAL COST}

The following capital cost altemative is included in support of Concept 2D, 3 vaults, one empty, processed material stored in 440 (2 vaults) dry Corten tubes.

\subsubsection{Concept 2D Cost Estimate}

Tables 2-11 and 2-12 contain the estimated capital cost and cash flow requirements for Alternative 2D, respectively. Supporting detail is contained in Tables $2-13$ and 2-14.

\subsubsection{SIGNIFICANT OPERATINE COST DIFEERTACES}

Review of the operating costs indicated that Concept $2 \mathrm{D}$ may have higher operating costs than other concepts i.e. a staging pool. The following operating cost factors were considered in reaching this conclusion:

\subsubsection{Operating Labor During staging}

The loading of MCOs into tubes is more labor-intensive than other loading methods such as a pool rack. The distances that a pool crane would have to travel are shorter than for tube storage. placing MCOs in tubes requires many more operating steps, because the floor plug, floor plug handling flask, bottom-loading cask, and impact absorbers have to be handled in addition to the MCo. A task analysis of tube loading shows that 4 operators would be required during the loading, while 2 operators would be required for loading

$$
2-79
$$


pool racks. At the design rate of 4 MCOs per day, the loading will require 300 days. Unloading at the end of staging will require another 300 days. At the current estimated wage plus burdens and overheads rate of $\$ 34.50$ per hour, plus $15 \%$ average shift differential, the Concept 2D labor cost is estimated at $\$ 1,140,000$ more (in present dollars) for loading and unloading.

In Concept 2D during staging, the tubes must be vented and purged at the rate of at least 78 per day to prevent hydrogen from building up in the tubes. If 375 tubes were filled and if 440 tubes were used, 92 tubes per day would require purging (see Section 2.2.3.2); if one were to use Los Alamos Tech Associates (LATA) data, 130 per day would require purging for 375 tubes and 150 per day for 440 tubes; pool concepts would not require this activity. From an estimate of 2 operators working regular days, the Concept 2D labor cost is $\$ 144,000$ more per year of staging. Based on 7 years of staging, the Concept 2D labor cost is $\$ 1,000,000$ more (in present dollars) for venting and purging, with the cost increasing for each year of staging.

Combining the above labor costs without escalation, the Concept 2D labor cost differential (above a pool concept) will be $\$ 2,150,000$ plus $\$ 144,000$ per year for each year that staging extends beyond the assumed staging period of 7 years.

\subsubsection{Fuel Cooling During Staging}

Regardless of the concept used, heat load from the MCOs is the same. However, a pool cooling concept would be more efficient than air cooling, and the heat gain from surroundings would be less for the pool. As a result, the horsepower ratings for the chillers and pool recirculation pumps in a pool concept would be about $500 \mathrm{~kW}$ less than for the chillers and air handling fans in Concept 2D. At the Bonneville Power wholesale rate of 30 mills per $\mathrm{kW}$-hr, Concept 2D costs about $\$ 13,000$ per year more for power.

\subsubsection{Beating, Ventilation, and Iighting}

Because the buildings have about the same size and requirements regardless of concept, there is no significant difference.

\subsubsection{Crane Usage}

In a pool concept the crane would be smaller than the storage crane in Concept 2D. In addition, the storage crane has to travel farther with each MCO and perform more operations. The difference in power consumption averages about $50 \mathrm{~kW}$, and is balanced by the difference below due to water sterilization. This difference is not significant.

$$
2-80
$$



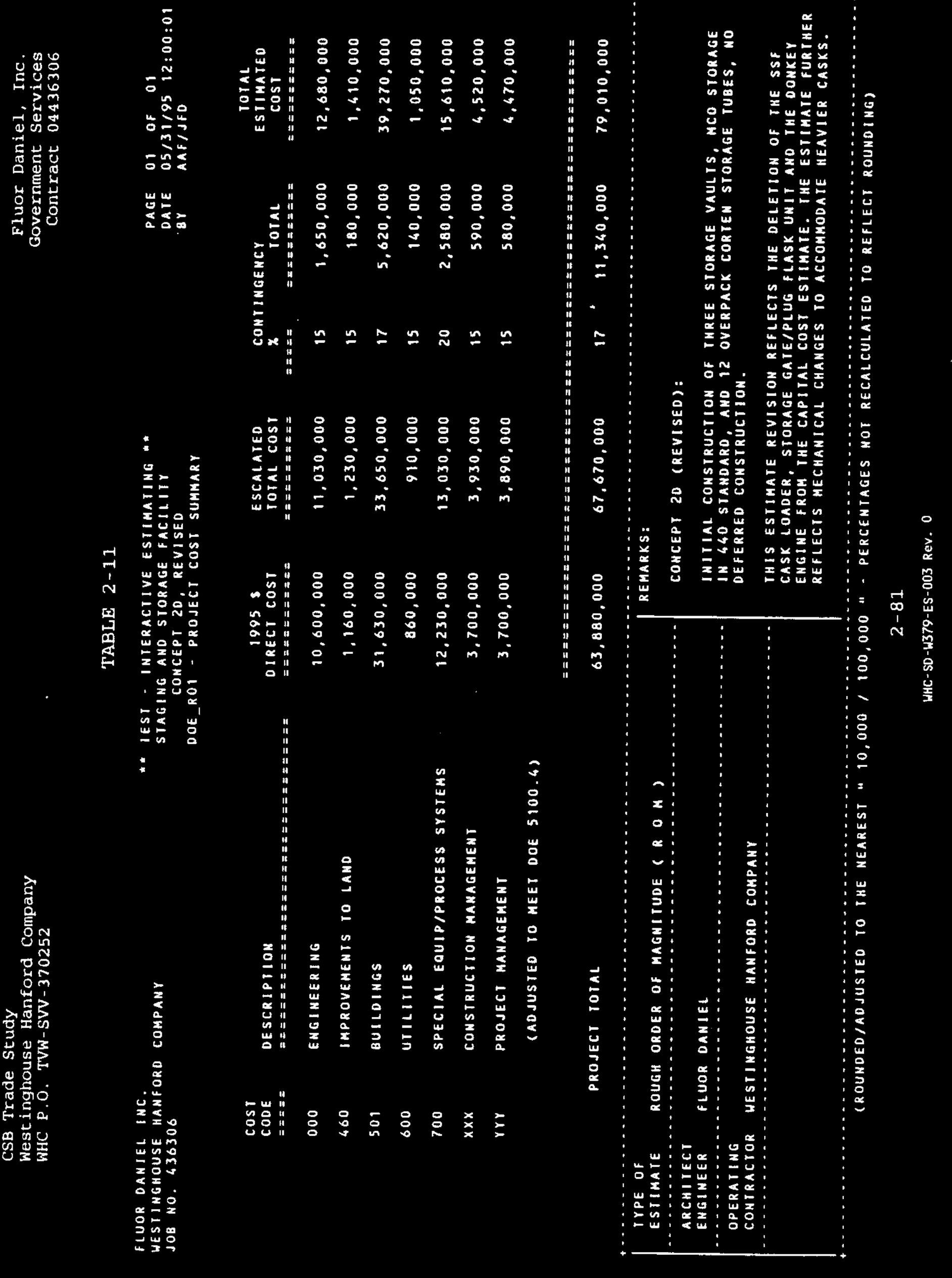
CSB Trade Study

Westinghouse Hanford Company

WHC P.O. TVW-SVV- 370252
Fluor Daniel, Inc.

Government Services

Contract 04436306

\begin{tabular}{|c|c|c|c|c|c|c|c|c|c|c|}
\hline \multirow[b]{2}{*}{ DESCRIPTION } & \multicolumn{9}{|c|}{$\begin{array}{c}\text { Table } 2 \text {-12 } \\
\text { STAGING \& STORAGE FACILITY } \\
\text { CONCEPT } 2 \text { D } \\
\text { \$ EXPENDITURE - FY ESCALATED }(\$ \times 1000)\end{array}$} & \multirow{2}{*}{$\begin{array}{r}\text { 31-May-95 } \\
\text { FY } \\
2003\end{array}$} \\
\hline & TOTAL & $\begin{array}{c}F Y \\
1995\end{array}$ & $\begin{array}{l}\text { FY } \\
1996\end{array}$ & $\begin{array}{l}\text { FY } \\
1997\end{array}$ & $\begin{array}{c}\text { FY } \\
1998\end{array}$ & $\begin{array}{c}\text { FY } \\
1999\end{array}$ & $\underset{2000}{F Y}$ & $\underset{2001}{F Y}$ & $\begin{array}{c}F Y \\
2002\end{array}$ & \\
\hline ENGINEERINGHESIGN & 10,485 & 1,925 & 7,045 & 1,515 & & & & & & \\
\hline TITLE 3 INSP SERVICES & 2,199 & & 764 & 1,435 & & & & & & \\
\hline $\begin{array}{l}\text { PROCUREMENT } \\
\text { PROCUREMENT }\end{array}$ & 24,688 & & 1,865 & 22,823 & & & & & & \\
\hline $\begin{array}{l}\text { CONSTRUCTION } \\
\text { CONSTRUCTION }\end{array}$ & 32,654 & & 6,245 & 26,409 & & & & & & \\
\hline $\begin{array}{l}\text { CONSTRUCTION MGMT } \\
\text { CM }\end{array}$ & 4,521 & & 1,798 & 2,360 & 362 & & & & & \\
\hline $\begin{array}{l}\text { PROJECT MGMT } \\
\text { PM }\end{array}$ & 4,469 & 672 & 1,703 & 1,703 & 391 & & & & & \\
\hline TOTAL & 78,018 & 2,597 & 19,421 & 56,245 & 753 & & & & & \\
\hline
\end{tabular}


CSB TRADE STUDY

NESTINGHOUSE HANFORO COMPANY

HHC P.O. IVH-SVV- 370252
TABLE $2 \cdot 13$

* IESt - Interactive estinating * STAGING AND STORAGE FACILITY CONCEPT 20, REVISED

DOE_RO2 - NORK BREAKDOWN SIRUCIURE SUMMARY
FLUOR DANIEL, INC. GOVERHMENT SERVICES CONTRACT 04436306 DATE OS/31/95 12:00:01 BY AAF/JFD

\section{HBS DESCRIPTION}

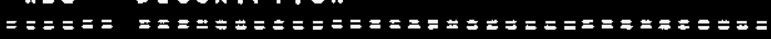

110 CONCEPTUAL / AOVANCED CONCEPTUAL DESH

120 DEIAILED DESIGN

132 TITLE III EKGINEERING

132 TITLE IIJ INSPECTION

SUBTOTAL 1 ENGINEERING

210 RAIL TUNHEL/CASK UHLOAD/HCO SERVICE

230 VAULIS ANO IRLET/EXHAUST PLENUMS

240 POOL UIR COOLING INST AIR COMP

250 HVAC/OFF/ICE/GEMERATOR//EQUIP BLDE

260 HVAC MECHAKICAL ROOK

SUBTOTAL 2 PROCUREMENT

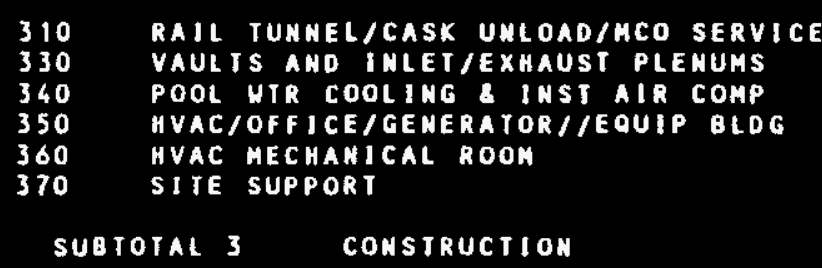

411 CONSTRUCTION MANAGEMEKT

SUBIOTAL 4 CONSTRUCTION MAMAGEMENT

511 PROJECT MAKAGEMENT

SUBTOTAL 5 PROJECT MANAGEMENT

PROJECT TOTAL

\begin{tabular}{|c|c|c|c|c|c|c|c|c|}
\hline $\begin{array}{l}\text { ESTIMATE } \\
\text { SUB TOTAL }\end{array}$ & $\begin{array}{l}\text { ONSITE } \\
\text { INDIRECTS }\end{array}$ & $\begin{array}{l}\text { SUB } \\
\text { TOTAL }\end{array}$ & ESCA & LATION & $\begin{array}{l}\text { SUB } \\
\text { TOTAL }\end{array}$ & $\operatorname{con}{ }_{x}$ & $\begin{array}{l}\text { NGENCY } \\
\text { TOTAL }\end{array}$ & $\begin{array}{l}\text { TOTAL } \\
\text { DOLLRS }\end{array}$ \\
\hline 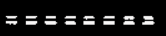 & $==x==x= \pm=$ & 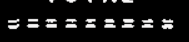 & $==z= \pm=$ & $= \pm== \pm==x$ & $=z= \pm=z= \pm=$ & $=\approx= \pm=$ & $===\equiv=\equiv=\equiv$ & \&= = = = = = \\
\hline $\begin{array}{l}1700000 \\
5200000 \\
1900000 \\
1800000\end{array}$ & $\begin{array}{l}0 \\
0 \\
0 \\
0\end{array}$ & $\begin{array}{l}1700000 \\
5200000 \\
1900000 \\
1800000\end{array}$ & $\begin{array}{l}1.59 \\
3.29 \\
6.25 \\
6.25\end{array}$ & $\begin{array}{l}27030 \\
171080 \\
118750 \\
112500\end{array}$ & $\begin{array}{l}1727030 \\
5371080 \\
2018750 \\
1912500\end{array}$ & $\begin{array}{l}15 \\
15 \\
15 \\
15\end{array}$ & $\begin{array}{l}259055 \\
805662 \\
302813 \\
286875\end{array}$ & $\begin{array}{l}1986085 \\
6176742 \\
2321563 \\
2199375\end{array}$ \\
\hline 10600000 & 0 & 10600000 & 4.05 & 429360 & 11029360 & 15 & 1654405 & 12683765 \\
\hline $\begin{array}{r}2810508 \\
13071181 \\
91911 \\
3600574 \\
152807\end{array}$ & $\begin{array}{l}0 \\
0 \\
0 \\
0 \\
0\end{array}$ & $\begin{array}{r}2810508 \\
13071181 \\
91911 \\
3600574 \\
152807\end{array}$ & $\begin{array}{l}6.67 \\
6.67 \\
6.67 \\
6.67 \\
6.67\end{array}$ & $\begin{array}{r}187461 \\
871847 \\
6131 \\
240159 \\
10192\end{array}$ & $\begin{array}{r}2997969 \\
13943028 \\
98042 \\
3840733 \\
162999\end{array}$ & $\begin{array}{l}30 \\
15 \\
30 \\
15 \\
30\end{array}$ & $\begin{array}{r}899391 \\
2091454 \\
29413 \\
576110 \\
48900\end{array}$ & $\begin{array}{r}3897359 \\
16034483 \\
127454 \\
4416842 \\
211899\end{array}$ \\
\hline 19726981 & 0 & 19726981 & 6.67 & 1315790 & 21042771 & 17 & 3645268 & 24688037 \\
\hline $\begin{array}{r}2429238 \\
18893671 \\
684567 \\
1421807 \\
1302607 \\
1416945\end{array}$ & $\begin{array}{l}\mathbf{0} \\
0 \\
0 \\
0 \\
0 \\
0\end{array}$ & $\begin{array}{r}2429238 \\
18893671 \\
684567 \\
1421807 \\
1302607 \\
1416945\end{array}$ & $\begin{array}{l}6.25 \\
6.25 \\
6.25 \\
6.25 \\
6.25 \\
6.25\end{array}$ & $\begin{array}{r}151828 \\
1180853 \\
42785 \\
88864 \\
81413 \\
88560\end{array}$ & $\begin{array}{r}2581066 \\
20074524 \\
727352 \\
1510671 \\
1384020 \\
1505505\end{array}$ & $\begin{array}{l}30 \\
15 \\
30 \\
15 \\
30 \\
15\end{array}$ & $\begin{array}{r}774320 \\
3011179 \\
218205 \\
226600 \\
415207 \\
225825\end{array}$ & $\begin{array}{r}3355383 \\
23085704 \\
945557 \\
1737271 \\
1799228 \\
1731329\end{array}$ \\
\hline 26148835 & 0 & 26148835 & 6.25 & 1634303 & 27783138 & 18 & 4871336 & 32654472 \\
\hline 3700000 & $\mathbf{0}$ & 3700000 & 6.25 & 231250 & 3931250 & 15 & 589688 & 4520938 \\
\hline 3700000 & 0 & 3700000 & 6.25 & 231250 & 3931250 & 15 & 589688 & 4520938 \\
\hline 3700000 & $\mathbf{0}$ & 3700000 & 5.02 & 185740 & 3885740 & 15 & 582861 & 4468601 \\
\hline 3700000 & $\mathbf{0}$ & 3700000 & 5.02 & 185740 & 3885740 & 15 & 582861 & 4468601 \\
\hline
\end{tabular}

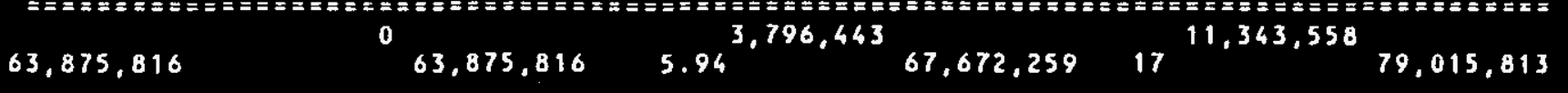




\subsubsection{Pool Water Sterilization}

In a pool concept, the ultraviolet lamps for the sterilizers will consume less than $50 \mathrm{kw}$ of power, which is not significant, and is balanced by the difference above due to cranes.

\subsubsection{Chemical Consumption}

The nitrogen consumption for MCO servicing and the decontamination chemical consumption are the same regardiess of concept. Because pool water deionizers would not require regeneration as water treatment chemical usage is not significant.

\subsection{SCEMULES}

\subsubsection{SCERDULE ASSUMPTIONS}

\subsubsection{General}

These schedules are based on the use of the Canister storage Building (CSB) design and partially completed construction from the Hanford Waste Vitrification Plant (HWVP) Project. Utility tie-ins are available from the completed construction of the fwV project.

WhC provided the date for start of the engineering studies, the Key Decision 0 date of 10 March 1995, and the date of May 9, 1995 for approval by DOE of the Functions and Requirements (F\&Rs) for the project. April 24, 1995 is assumed to be the start of Conceptual Design and Capital funds are assumed to be available in October 1995. The stabilization Facility is assumed to be operational in December 2002 .

This schedule assumes that there will be no annual funding constraints for the duration of the project.

The cost estimates prepared for each alternative provide a basis for each schedule.

An important objective of these schedules was to have the SSF operational and ready to receive $\mathrm{MCO}^{\prime} \mathrm{s}$ from the $\mathrm{K}$-Basins as rapidly as possible. Aggressive, but achievable schedules were therefore developed.

\subsection{Engineering and Design}

Maximum use of the existing engineering and design of the CSB and the results of this feasibility study allows the approximately three month duration for conceptual design. New requirements and additional facilities will have minimal impact to the existing facility design and drawings.

$$
2-85
$$


Client. review changes will have no impact at the end of conceptual engineering and definitive design. Continuous reviews and alignments are required to minimize change.

2.5.1.1.2 Procurement and Construction:

The october 1992 statused Mowat schedule for the CSB was used as a basis for deriving activity durations for completion of the walls, the operating floor and storage tube installation.

The construction of the facility will be performed with specialty subcontractors.

There is no shortage of local craft labor or specialty contractors in the area.

Construction is based on a standard forty hour work week. Scheduled overtime is excluded from this schedule.

The concrete slab and walls that are currently in place will be used with minimal changes required to complete the concrete vault walls and operating floor.

The walls for all vaults will be formed and poured simultaneously.

Rebar for the walls and for the operating floors will be preassembled and set in place with cranes.

Structural steel buildings will be prefabricated in shops, and assembled in the field.

There is no shortage of material locally, including concrete batch plant requirements.

Long lead equipment items will be identified very early so as to not delay construction.

There are no shortages of construction equipment in the area.

Reviews by WHC will be concurrent with the design during all phases with a twenty day review continuing after the end of conceptual design.

DOE reviews will be for twenty days after the wHC review period.

Independent cost verifications will be for twenty days after the WHC review and concurrent with the DOE reviews.

ESAAB reviews will take place for twenty-five days subsequent to the DOE reviews and prior to Key decisions one through four.

$$
2-86
$$


Safety analysis reports will be generated on a one step SAR basis. Final review and approval extends for a nine month period and approval is required prior to start-up. Construction will be allowed to commence based on approval of a preliminary safety evaluation.

\section{5 .1 .4 Concept 2D}

Construction of the operating decks will be concurrent in all three vaults.

Storage tube installation will be concurrent in two vaults.

\section{5 .2 CONCEPT 20 SCABDULE}

Figure 2-24 contains the schedule for concept 2D. It shows that, subject to the above assumptions, it is possible to achieve operation of the SSF in December 1997. The entire facility is constructed initially under this concept so there is no second phase of procurement and construction.

\subsection{CONCIOSIONS AND RECOMMINDATIONS}

\subsubsection{FBASTBILITY OF CSB ADAPTATION}

The results of this study demonstrate that it is currently not feasible to adapt the design of the CSB to meet the F\&Rs of the SSF due to the $100^{\circ} \mathrm{F}$ MCo temperature requirement. If a relaxation of the temperature requirement was to occur then construction of the SSF on the CSB site will enable the already completed CSB site clearing and grubbing, site preparation, excavation, base mat and walls to be utilized for the SSF, saving both time and money. Use of the CSB site for the SSE is also consistent with master plans currently being developed for the fanford site and the objective of moving the N-Reactor fuel away from the Columbia River.

\section{6 .2 OYHER TECanICAT CONCDRHS}

Relaxation of the $100^{\circ} \mathrm{F}$ maximum MCO temperature requirement prior to stabilization would allow further cost reduction alternatives to be considered.

In addition to a relaxation of the MCO Temperature requirement several other technical issues would require further investigation to ensure cost, schedule and safety requirements are achieved including:

- Shielding requirements regarding the empty vault and its future use. 


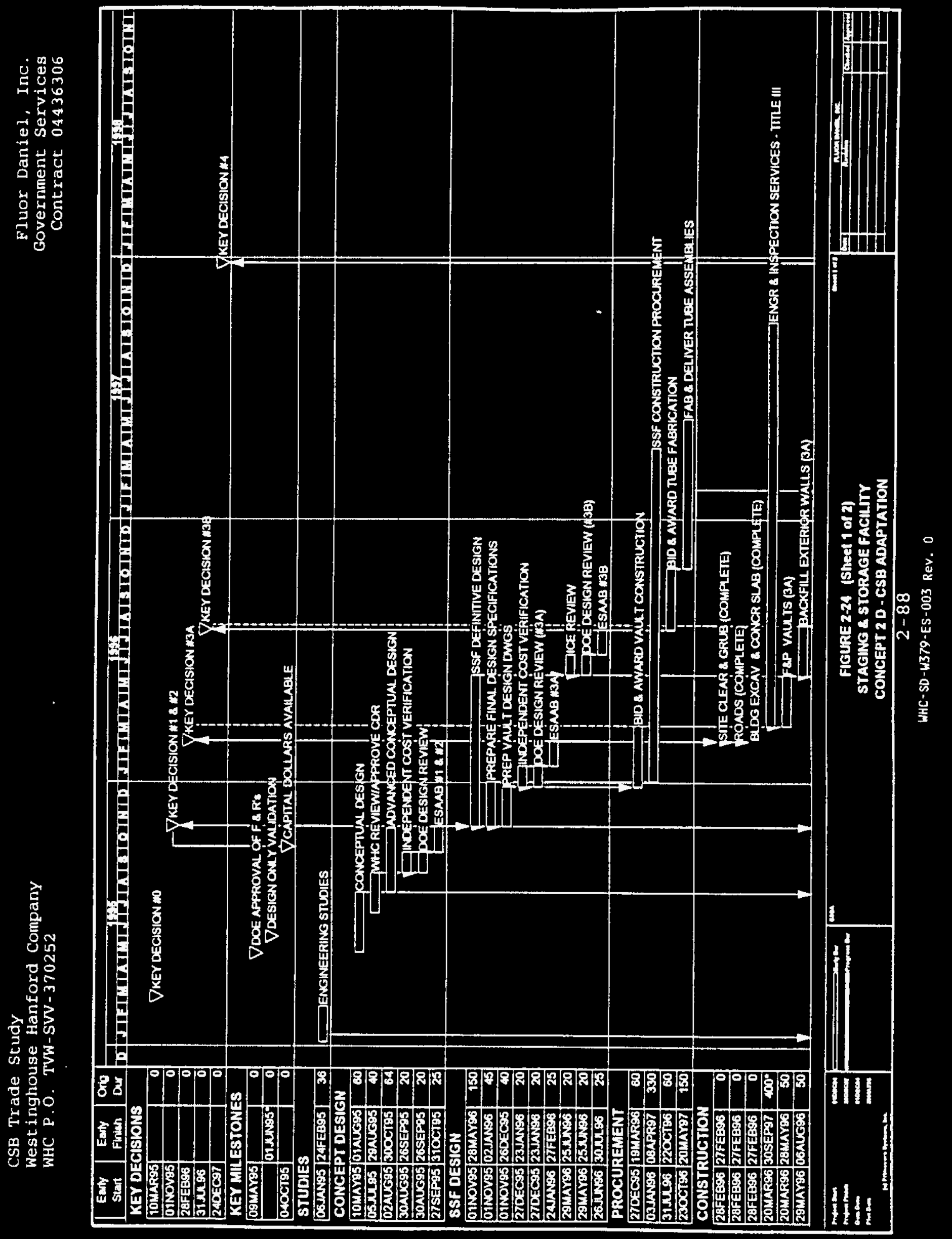




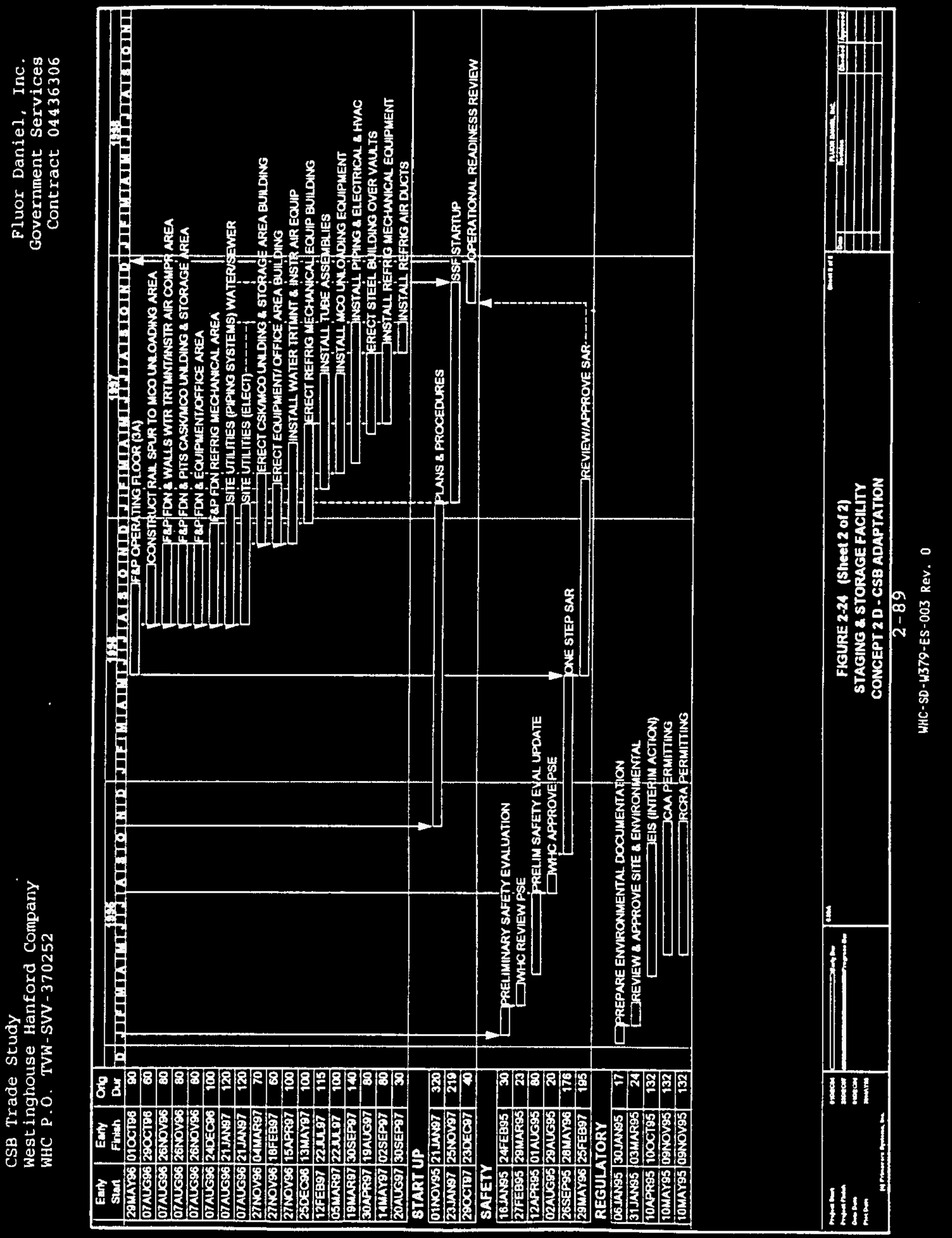


- Contact maintenance and servicing of the transport and facility casks due to the high source dose rates.

- RCRA requirements to detect liquid in the annular space between the MCO and staging tubes.

- Microbiological Influenced Corrosion (MIC) affects on the Stainless steel (SS) MCO due to high MCO temperatures.

- Venting and purging of staging tubes due to hydrogen build-up in the MCOs due to high MCO temperature.

- MCO/Cask drop evaluation over the operating floor.

Emergency response capability in the event of a sustained loss of cooling, e.g. due to DBE or loss of power, to prevent unacceptable high MCO temperatures.

\subsection{REFERMACES}

American National Standards Institute/American Nuclear Society, March 1989, Design Criteria for an Independent Spent Fuel Storage Installation (Water-Pool Type), ANSI/ANS Standard 57.7-1998

American National Standards Institute/American Nuclear Society, May 1992, Design Criteria for an Independent Spent Fuel Storage Installation (Dry Type) ANSI/ANS Standard 57.9-1992

American Nuclear Society, 1988, "Design Criteria for an Independent Spent Fuel Storage Installation (Water Rool Iype), "ANSI/ANS - 57 .7-1988

Anderson, H.L. Ed., 1981, "AIP 50TH Anniversity Physics Vade Mecum," American Institute of Physics, NY

ASHRAE Handbook of Fundamentals

Borenstein, S. W. and Licina, G. C., 1990, "Avoid MIC-Related Problems in Nuclear Cooling Systems", Power, June 1990

Briesmeister, J. F., Editor, November 1993, "MCNP - A General Monte Carlo N-Particle Transport Code, Version 4A," LA$12625-M$

DOE Order 6430.1A (1989), General Design Criteria

DOE Order 6430.1A, April 1989, "General Design Criteria"

Fair cost estimate of Package 350-01 (below grade portion of the HWVP CSB), February, 1993

$$
2-90
$$


Fulton, Johr C., 1994, "Hanford Spent Nuclear Fuel Project Recommended Path Forward", WHC-EP-0830 Rev 0, October 1994

Hanford Waste Vitrification Plant (EWVP) Baselined Rreliminary Design Estimate, JuIy 1991, Rev. "F"

The Health Physics and Radiological Health Handbook

Institute of Electrical and Electronic Engineers, IEEE 379

K-D 3B Ice Estimate of Package 350 [(HWVP) Canister storage Building (CSB)], October, 1992

Nuclear News, June 1994, p. 33, "Energy First in U.S. to Use Fuel 'sipping'"

Oak Ridge National Laboratory, RSIC CCC-619, July 1993, "SCALEPC, Modular Code System for Performing Criticality Safety Analyses for Licensing Evaluation, Version 4.I"

Pacific Northwest Laboratories, December 1988, "The Hanford Environmental Radiation Dosimetry Software System," PNL-6584, Volume 1

Perry, Robert F. (ed.), 1984, "Perry's Chemical Engineers' Handbook," $6 \mathrm{th}$ ed.

"Radiological Control Manual," June 1992, DOE/EH-02561, Rev. 1

Solutions Engineering \& Eacilitating, Inc., 1995, "Value Engineering/Study Analysis Session, Spent Nuclear Fuel Project, staging \& Storage Facility, Project W-379, January 1995

State of Washington Department of Ecology, March 1991, Dangerous Waste Regulations, Washington Administrative Code 173-303,

US Department of Energy, April 1989, General Design Criteria, DOE Order $6430.1 \mathrm{~A}$

US Department of Energy, October 1984, Safety of Nuclear Facilities, DOE Order 5480.5

US Department of Energy, August 1992, Technical Safety Requirements, DOE Order 5480.22

US Department of Energy, April 1992, Nuclear Safety Analysis Reports, DOE Order 5480.23

US Department of Energy, January 1993, Natural Phenomena Hazards Mitigation, DOE Order 5480.28

$$
2-91
$$


US Department of Energy, April 1994, Natural Phenomena Hazards Design and Evaluation Criteria for Department of Energy Facilities, DOE standard 1020-94

US Department of Energy, July 1993, Natural Phenomena Hazards Performance Categorization Criteria for structures, Systems, and Components, DOE Standard 1021-93

US Department of Energy, December 1992, "Hazard Categorization and Accident Analysis Techniques for Compliance with DOE Order 5480.23," DOE Standard 1027-92

US Department of Energy, July 1988, "External Dose-Rate Conversion Factors for Calculation of Dose to the Public," DOE/EH- 0070

US Department of Energy, July 1988, "Internal Dose Conversion Factors for Calculation of Dose to the Public," DOE/EH--0071

US Environmental Protection Agency, National Environmental Policy Act

US Environmental Protection Agency, Resource Conservation and Recovery Act

US Nuclear Regulatory Comission, Licensing Requirements for the Independent Storage of Spent Nuclear Fuel and High-Level Radioactive Waste, 10CFR72

US Nuclear Regulatory Commission, Assumptions Used for Evaluating the Potential Radiological Consequences of a Fuel Handing Accident in the Fuel fandling and storage Facility for Boiling Water and Pressurized Water Reactors, Regulatory Guide 1.25

US Nuclear Regulatory Commission, Standard Format and Content for the Safety Analysis Report for an Independent Spent Fuel Storage Installation (Water Basin Type), Regulatory Guide 3.44

US Nuclear Regulatory Comission, Standard Format and Content for the Safety Analysis Report for an Independent Spent Fuel Storage Installation or Monitored Retrievable Storage Installation (Dry Storage), Regulatory Guide 3.48

US Nuclear Regulatory Commission, December 1981, Design of an Independent Spent Fuel storage Installation (Water Basin Type), Regulatory Guide 3.49 
US Nuc:-ear Regulatory Commission, March 1987, Design of an Independent Spent Fuel Storage Installation (Dry Type), Fegulat:ory Guide 3.60

Westinghouse Hanford Company, 1988, "Nonreactor Facility Safety Arlalysis," WHC-CM-4-46

Westinghouse Hanford Company, August 1991, "Safety Classification of: Systems, Components, and Structures," WHC-CM-1-3, MRP 5.46

Westinghouse Hanford Company, October 1992, "HWVP Canister storage Building Preliminary Safety Analysis Report Addendum," WHC-SD-EWV-PSE-001, Revision OA

Whalen, D.J., D.E. Hollowell, J.S. Hendricks, September 1991, "MCNP: Photon Benchmark Problems," Los Alamos National Laboratory, Report No. LA-12196,

Whalen, D.J., D.A. Cardon, J.L. Uhle, J.S. Hendricks, November 1991, "MCNP: Neutron Benchmark Probiems," Los Alamos National Laboratory, Report No. LA-12212,

WHC-CM-1-3, Section MRP 5.46, Rev. 4, "Safety Classification of Systems, Components, and structures"

WHC-SNF-FRD-014, May 1995, Section 3.2.2.1.2.2, Rev. A, "Draft Performance Specification for the Spent Nuclear Fuel Canister storage Building"

WHC, Implementation Strategies for US Department of Energy Order 5480-28 Natural Phenomena Hazzards Mitigation, T. Conrads, undated 


\subsection{DESIGN BASIS}

The following functions and requirements data was furnished by WHC for use as a design basis for this study:

\section{TRANSPORTATTON INIMEREACES}

$$
\text { RAIT CAR AND CAST }
$$

- SIZE AND WEIGHT OF RAIL CAR: Standard flat-bed rail car

- CASK DIMENSIONS, NEIGHTS, LIFTING POINTS (CASK AND LID): MCO facility cask: 86.5 tons, lifting trunions on side above center of gravity

- EXPECTED SURFACE CONT. LEVEL: Outside: DOT limits worst case; Inside: K-East Basin water; assume decon from top with cask upright. No tip/flip capability required.

- TIE DOWN POINIS: TBD

- MATERIALS/FINISHES (CASK): 304 SS

- CASK C-G's: Geometric center

- rail car transportation safe guard: Standard doE requirements for SNE

- RaIl car posttioning techniQue IN SSE: Designet's choice

- RAIl CAR ATTAChMENT poINTS: TBD for loads; standard couplings front and back.

- storage Facility/CASK handLING

$\begin{array}{ll}\text { - STANDARD RIGGING: } & \text { Pick cask with rigging fixture } \\ \text { - SPECIAL TOOLS } & \text { attached to the crane hook and } \\ \text { - PICK HEIGFT } & \text { lifting trunions Maximum pick } \\ & \text { height at } 2.5 x \text { height of cask from } \\ & \text { floor to bottom of cask. }\end{array}$

- MONITORING REQUIREMENTS: Time from MCO closure and cask seaI at $\mathrm{K}$-Basins. Visual gauge monitoring of MCO - to - cask seal pressure and internal cask temperature. 


\section{- SERVICE REQUIREMENTS}

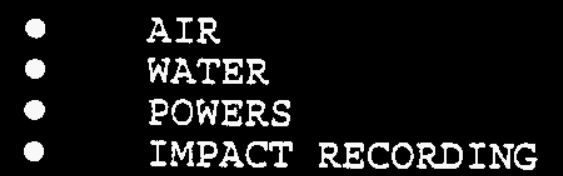

NUMBER OF RAIL CARS:
TBD, no special requirements identified

2 cars in the facility at once for cask unload/load cycle and MCO load/unload cycle

- IAg storage REQUIREMENTS

- rail cars :

- CASKS :

2 cars on rail siding outside

4 casks; 2 clean, ready for use; 1 contaminated, waiting for decontamination; 1 in the

- $\mathrm{MCO}^{\prime} \mathrm{s}$ : decontamination station. 1 week supply at facility: 4/day consumed.

- RaIl car weight - FULL CASK LOAD: standard flatbed rail car plus 86.5 tons cask

- IDENTIFICATION OF ANY OTHER TRANSPORTER CONCEPTS: TBD, assume rail

- SECURITY NEEDS (LIMITS, ETC.): DOE standards for SNF

- transporter conveyance

- LOCOMOTIVES
- TRACKMASTER:
TUGGERS
Designer choice inside facility. Locomotive delivery to facility and pick-up from facility.

- RaIL car materials and surface fiNISh: assume easily decontamination design to facilitate standard wash-down technologies.

- car identification and tracking: Visual

- BRAKE STATUS: Visual indication

MCO INWFRFACES

- SIZE: See attached table

- SHAPE: See attached table

- WEIGHT/CG'S: EMPTY/LOADED: See attached table 
- MATERIAL AND FINISH CONDITION: 304 SS

- IIFTING POINTS/GEOMETRY: TOp of MCO; specifics TBD. Lifting fixtures compatible with normal crane hook.

- ATTACFMENTS FOR MONITORING: MCO lid

- ATTACHMENTS FOR SERVICES: MCO lid

- DEFINITIONS OF SERVICE REQUIREMENTS:
- Vent and inert-gas purge MCO upon receipt;
- Cycle for water addition at $2 \mathrm{MCOs} /$ week after completion of MCO delivery to the SSF

- MONITORING REQUIREMENTS: limit MCO temperatures as listed
below)

- REQUIRED STORAGE

Staging: MCO at $100^{\circ} \mathrm{F}$.

CONDITIONS :

Storage: Fuel centerline temperature at $400 \mathrm{C}$.

- IDENTIFICATION

REQUIREMENTS :

Visual identification of MCO, or per

DOE standard material accountability requirements for SNF

TRACKING REQUIREMENTS :

DOE standard material accountability requirements for SNF

- MINIMUM, MAXIMUM, AVERAGE RADIATION LEVELS: TBD, being calculated

- EXPECTED SURFACE CONDITIONS :

Nominal conditions: clean Upset conditions: $\mathrm{K}$-Basin water contamination

CRITICALLY CONIROL SPACING :

MCO stacking acceptable, MCO placement side-by-side with no gap acceptable.

- INSPECTION REQUIREMENTS: Receipt inspection: MCO - to cask seal verification - visual gauge observation. MCo seal verification - visual gauge observation. Surface contamination of MCO and cask. MCO weight. MCO $\mathrm{H}_{2}$ levels during venting.

$$
2-96
$$


- ORIENTATION REQUIREMENTS: VERTICAL +- 10 degrees

- SEALING SURFACES LOCATION/CONFIGURATION/MATERIALS/ etc.: Top of MCO Iid

- ACCELERATION LIMITS:

Normal crane operating limits; or $2-g$ vertical lift, $1-g$ vertical lowering, $1-g$ horizontal, impact limiters for long vertical placements.

- SOURCE TERMS

$\begin{array}{ll}- & \text { RADIOLOGICAL } \\ - & \text { CHEMICAL } \\ \text { HAZARDOUS } \\ \text { - LIQUID } \\ \text { GAS } \\ \text { THERMAL }\end{array}$

See attached Cowàn list. List must be updated to describe minimum MCO source term, \& of MCOs at minimum levels, sludge source term and \# of sludge MCOs. Assume sludge MCOs contain RCRA waste. Assume $100 \mathrm{~m}^{3}$ of sludge. SSF must meet RCRA waste storage requirements for sludge MCOs.

- standard rigging HARDWARE :

Deployed from crane hook. Designer's choice.

- SPECIAL TOOLS: Deployed Erom crane hook. Designer's choice.

- MAXIMUM ALLOWABLE OPERATION PRESSURE: 125 psig prior to venting. Gas volume 50 liters. Gas venting through breather filter (air cooling) or water trap (water pool cooling).

- RESPONSIBILITY FOR MCO OVERPACK DESIGN: SSE designer

- ALLOWABLE PICK ELEVATIONS: $2.5 \times$ MCO height from floor to bottom of MCO. 
MCO Proposed Description

\section{Draft Rev. A R.G. Cowan May 17, 1995} MCO Radio nuclide Inventory

\begin{tabular}{|c|c|c|c|}
\hline Radio nuclide & Unit & Average & Maximum \\
\hline $\mathbf{U}$ & $\mathbf{k g}$ & 2,800 & 3,287 \\
\hline zr & $\mathbf{k g}$ & 197 & 230 \\
\hline $\mathrm{Pu}$ & $\mathrm{kg}$ & 5 & 100 \\
\hline $\mathbf{S n}$ & k: & 3 & 3 \\
\hline $\mathbf{A}$ & $\mathbf{k g}$ & 2 & 3 \\
\hline c & $\mathrm{kg}$ & 2 & 2 \\
\hline All Other & $\mathbf{k}_{\mathbf{s}}$ & 4 & 5 \\
\hline rotal Mass For One MCO & 53 & 3,013 & 3,630 \\
\hline $\cos -60$ & $\overline{C l}$ & 197 & 786 \\
\hline KredS & $\mathrm{Cl}^{-}$ & 937 & 2,440 \\
\hline SR-90 & $\mathrm{Cl}$ & 14,000 & 27,941 \\
\hline Y-90 & $\mathrm{CH}$ & 14,000 & 27,941 \\
\hline $\operatorname{css}-137$ & $\mathrm{Cl}^{-}$ & 18,000 & 37,926 \\
\hline$B 2-137 m$ & $\mathrm{Ct}^{\prime}$ & 17,067 & 35,906 \\
\hline $\mathrm{Pm}-147$ & $\mathrm{Cl}$ & 1,440 & 8,180 \\
\hline Sm-151 & $\mathrm{Cl}$ & 229 & 344 \\
\hline Eu-154 & $\mathrm{Ct}$ & 171 & 804 \\
\hline$P 25=238$ & $\mathrm{Cl}$ & 167 & 496 \\
\hline $\mathrm{Pu}-239$ & $\mathbf{C H}$ & 300 & 499 \\
\hline $\mathrm{Pu}-240$ & $\mathrm{Cl}$ & 173 & 378 \\
\hline Pu-241 & $\mathrm{Ci}$ & 7,840 & 35,021 \\
\hline Am-241 & $\mathrm{Cl}$ & 420 & 742 \\
\hline All Other & $\mathrm{Ci}$ & 379 & 3,283 \\
\hline Total Activity For One MCO & $\mathbf{C i}$ & 77,320 & 182,692 \\
\hline
\end{tabular}

MCO General Attributes

\begin{tabular}{|c|c|c|c|}
\hline Parmeter & Unit & Average & Maximum \\
\hline Eest ${ }^{(i)}$ & Watt & 221 & 482 \\
\hline Water Weight & $\mathrm{kg}$ & 963 & 984 \\
\hline Staintess/Al & $\mathrm{kg}$ & 1,274 & 1,314 \\
\hline Total MCO Weight & $\mathrm{kg}$ & 5,251 & 5,927 \\
\hline Euel Volume & L & 202 & 243 \\
\hline MCO Volume & $L$ & 1,203 & 1,265 \\
\hline MCO Fuel Fraction & $\%$ & 17 & 19 \\
\hline MCO Length & $\mathbf{c m}$ & 460 & $460^{\circ}$ \\
\hline MCO Diameter & $\mathrm{cm}$ & 61.00 & 62.50 \\
\hline MCOWall thicknesa & cin & 1.00 & 1.00 \\
\hline MCO Top Shieid & $\mathrm{cm}$ & 20 & 20 \\
\hline Canders & & 10 & 10 \\
\hline Cask (20 cm iron) Weight & kg & 20,375 & 20,763 \\
\hline Losded Cask \& MCO & $\mathrm{kg}$ & 25,626 & 26,690 \\
\hline Cask \& MCO & tons & 28.25 & 29.42 \\
\hline Fuel Surtace & sq. $\mathrm{m}$ & 37.77 & 44.34 \\
\hline MCO \& Canisters & sq. $\mathrm{m}$ & 29.17 & 29.40 \\
\hline Total Inside Surface & sq. $m$ & 66.94 & 73.74 \\
\hline
\end{tabular}


MCO Heat Capacity

\begin{tabular}{|c|c|c|c|}
\hline Parameter & Unit & Average & Maximum \\
\hline Uraniuta & $\mathrm{sw}-\mathrm{hr} / \mathrm{C}$ & 0.10 & 0.11 \\
\hline Zirconium & ksw-bel C & 0.02 & 0.03 \\
\hline Stantiless steel & $\mathrm{k} w-\mathrm{hr} / \mathrm{C}$ & 0.11 & 0.18 \\
\hline Water & $\mathbf{k}^{w}-\mathrm{hr} /{ }^{\circ} \mathrm{C}$ & 1.11 & 1.14 \\
\hline Cadk & $\mathrm{kw}-\mathrm{hr} / \mathrm{C}$ & 2.53 & 2.58 \\
\hline Toth & $\mathrm{sw}-\mathrm{b} / \mathrm{C}$ & 3.95 & 4.03 \\
\hline \multicolumn{4}{|l|}{$610^{\prime} \mathrm{c}$} \\
\hline Unaniva Corrosion & $\mathrm{g}^{/ d}$ & 1.74 & 20.44 \\
\hline Gas Generation & Ud & 0.33 & 3.85 \\
\hline Reaction Eleat & Wad & 0.03 & 0.55 \\
\hline Seat hoss & Wat & 36.86 & 36.86 \\
\hline Temperature Rise & C/hr & 0.05 & 0.11 \\
\hline \multicolumn{4}{|l|}{$25^{\circ} \mathrm{C}$} \\
\hline Uranium Corrosion & $8 / d$ & 6.12 & 71.80 \\
\hline Ges generntion & $\sigma \mathrm{d}$ & 1,15 & 13.52 \\
\hline Reaction Heat & Wat & 0.17 & 1.95 \\
\hline Eeat Loss & Wat & 136.31 & 136.31 \\
\hline Temperature Rise & C/hre & $0 . \overline{2}$ & 0.09 \\
\hline \multicolumn{4}{|l|}{ Q $50^{\prime \prime} \mathrm{C}$} \\
\hline Uranium Corrosion & $g / d$ & 49.63 & 582.60 \\
\hline Gus generntion & $\overline{D d}$ & 9.34 & 109.67 \\
\hline Reacrion Eeal & Watt & 1.33 & 15.80 \\
\hline teat Loss & Wati & 302.06 & 302.06 \\
\hline Temperaure Rise & $\mathrm{C} / \mathrm{hr}$ & 0.02 & 0.05 \\
\hline \multicolumn{4}{|l|}{ (1) $75^{\circ} \mathrm{C}$} \\
\hline Uranium Cacsosion & $g / d$ & 402.68 & $4,727,41$ \\
\hline Gas generation & Dd & 79.8 & 889.87 \\
\hline Reiction Heat & Watt & 10.92 & 128.20 \\
\hline Eeat Loss & Wat & 467.81 & 467.81 \\
\hline Temperaure Rase & C/hr & -0.06 & 0.04 \\
\hline \multicolumn{4}{|l|}{$83 \mathrm{C}$} \\
\hline Uranium Corrosion & $g / d$ & 930.37 & $10,922.54$ \\
\hline Gas generation & Ld & 175.13 & $2,056.01$ \\
\hline Reation Beat & Wat & 25.23 & 296.20 \\
\hline EET LOS & Wat & 334.11 & 334.11 \\
\hline Temperature Rise & Clar & 0.07 & 0.06 \\
\hline \multicolumn{4}{|l|}{ (1) $95^{\circ} \mathrm{C}$} \\
\hline Unanium Convosion & g/d & $2,149.39$ & $25,236.18$ \\
\hline Grs generation & $2 d$ & 404.65 & $4,750.34$ \\
\hline Rerction Heat & Wat & 58.29 & 684.35 \\
\hline Heat Lous & Wat & 600.41 & 600.41 \\
\hline Temperature Rite & C/hr & -0.08 & 0.14 \\
\hline
\end{tabular}

(1) Heat generation design feed basis is calculated at $80 \%$ of the attribuces shown under

"Average" and $20 \%$ of those shown under "Maximum"

(2) Cask woight not consistent with requirements to meet shielding.

\section{$2-99$}



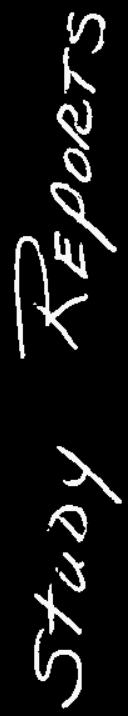

$\underbrace{4}_{0}$

0

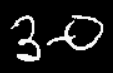

WHC-SO-H379-ES-003 ReV. 0 


\subsection{TRADE STUDY REPORTS}

\subsection{TABLE OF CONTEATS}

\begin{tabular}{clc} 
Task & \multicolumn{1}{c}{ Description } & Tab \\
A & Facility Confinement Investigation & A \\
B & MCO Receipt and Staging Function and Area & B \\
C Removal & C \\
& Cask Decontamination Function and Area & \\
D & One Track Rail Service & D \\
E & Storage Tube Material Investigation & F \\
F & MCO Shipment Reduction & G \\
G & Damp-Dried MCO & H \\
H & RCRA Functions : Prevention and Detection \\
& Of MCO Leaks &
\end{tabular}

\subsection{INTRODUCTION}

In accordance with the Statement of Work, Revision 5, dated April 21, 1995 in Work Order TVW-SVV-37052, Modification No. 90, individual Trade Study Reports have been prepared and are included in this section. Each report is independent of the others; however, each study is based on requirements defined in the Base Case Concept 2D description, Section 2.0. A cost summary is presented in Table 3-1. The cost and schedule basis for the Trade Studies is identical to that defined in Sections 2-4 and 2-5, of the Base Case Concept 2D.

In terms of the Construction schedule, it appears only Task "H", RCRA Functions: Prevention and Detection of MCO leaks, would have an impact on the proposed construction schedule and date. It is estimated that RCRA compliance would extend the facility completion date by a minimum of two months.

No cost data has been provided for Task "G", Damp-Dried MCO, as the analysis demonstrated that it was not feasible to adapt the CSB to comply with the functions and requirements for the SNF CSB. 


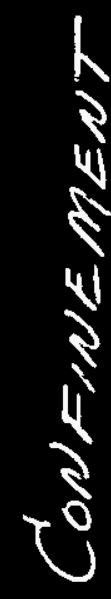

$\frac{1}{v}$

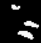

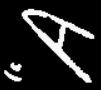

v

N 
CANISTER STORAGE BUILDING

TRADE STUDY REPORT

TASK "A"

FACILITY CONFINEMENT INVESTIGATION

\section{PREPARED FOR WESTINGHOUSE HANFORD COMPANY RICHLAND, WASHINGTON}

PREPARED BY FLUOR DANIEL, INC.

MAY 31, 1995

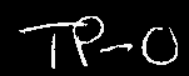

WHC-SO-W379-ES-003 Rev. 0 


\section{LIST OF EIGURES}

1.0 OBJECTIVE

2.0 SUMMARY

3.0 FACILITY DESCRIPTION AND EVALUATION

4.0 SCHEDULE

5.0 COST ESTIMATES

6.0 REFERENCES
PAGE

ii

A-1

$A-1$

$A-I$

$A-3$

A-3

A -3 


\section{LIST OF EIGURBS}

\section{PAGE}

Figure 3-1

CSB Trade Study, Task "A"

A -5

Figure 3-2

\section{Operating Area, HVAC System}

A -6

CSB Trade Study, Task "A" Floor Plan 
The objective of Trade study Task "A" is to investigate the requirements for a safety class 1 (SC-1) confinement of the operating area above the storage vault.

\subsection{SUMMARY}

A SC-I HVAC system is provided for the Operating Area which is capable of maintaining negative pressure during normal and Design Basis Accident (DBA) conditions. The Operating Area structure will be upgraded for SC-1. Emergency power is provided to the HVAC system and the associated equipment by a Class 1E emergency generator system. A minimum of two trains are required to meet the single point failure criterion associated with safety class systems. It is estimated that $\$ 1.7$ miliion in direct cost and $\$ 840,000$ in Engr/PM/CM cost will be added to the construction cost to provide SC-I operating requirements. Should the safety analyses determine the site helicopter crash and design basis fire are credibly, then the cost of the SC-1 structures would increase.

\subsection{FACILITY DESCRIPTION AND EVALUATION}

\section{1 structural}

The facility structural system and materials of construction for Task A requirements will be essentially the same as that of Concept 2D. The SC-1 confinement of the operating floor area above the storage vaults requires the structure to be classified as SC-1 also. The existing shelter is classified as SC-3 structure but designed for SC-1 Design Basis Earthquake (DBE) anchored at $0.35 \mathrm{~g}$ Peak Ground Acceleration (PGA) to prevent collapse over the concrete vault. In addition to DBE, the building will have to be evaluated for other DBAs such as design basis wind, ashfall, fire, and wind generated missile. The operating shelter building structural steel, siding and roof deck cost would increase by approximately 10 percent. Current safety analysis has assumed fire as being not credible within the operating area. Should future fire hazard analysis be shown as credible, the building steel framing system will have to be fireproofed to provide 2 hour resistance rating.

The existing wall system, consisting of corrugated 22 gage steel exterior panel and 22 gage flat liner interior panel with insulation between them, would be specified to provide an adequately sealed enclosure for maintaining negative air pressure within the building. If for SC-1 the site security helicopter crash is considered credible, as it was for the

$$
A-1
$$


HWVP project, the steel building will not meet this requirement. A concrete structure of 24 to 36 inch thick walls and roof would be required for helicopter crash. If the helicopter crash becomes a requirement it would add a significantly to the facility cost, and add 2 to 3 months to the design/construction schedule.

Section 1320-5.4 of DOE 6430.1A states that irradiated fissile material storage facilities need not be protected from missiles, but shall be designed from massive collapse of the building structure or the dropping of heavy objects on to the stored SNE as a result of building structural failures. This requirement could be met by designing to SC-1 DBAs.

The mechanical room containing the SC-1 FVAC equipment and the emergency generator room will be designed to withstand the NRH forces appropriate for SC-1 requirements.

\subsubsection{Structural Issues}

The structural issues described for concept 2D, Section 2.2.1, are also applicable to this task. In addition the two DBA's, fire and helicopter crash, if determined credible would impact significantly the building cost since a concrete structure would be necessary for conforming to these DBAs. The requirements for other DBAs can be met with some modification to the existing operating steel shelter.

\subsection{EVAC System}

The block flow diagram for the HVAC System for the operating Area is shown on Figure 3-1. This RVAC system is designed to provide confinement in the operating areas during normal and DBA conditions. The EVAC supply system consists of two 18,000 CFM air handing units (AFU-1 and 2 ) and the exhaust system consists of exhaust fans (EF-1 and 2) and two stage HEPA filter plenums ( $P F-1,2,3$ and 4 ). The capacity of each filter plenum is 9,000 CFM. The system is capable of diluting the hydrogen and $\mathrm{Kr}-85$ to acceptable levels by introducing sufficient amounts of outside air. The air from the operating Area is exhausted to the atmosphere through a SC-1 exhaust stack. Following a DBA only one train of the exhaust system which is $\mathrm{SC}-1$ is required to operate. The building layout shown on Figure $3-2$ has been modified to accommodate the additional space required to handle the SC-1 FVAC system.

\subsection{Electrical System}

Based on the requirements of the SC-1 FVAC system and the associated equipment required to maintain confinement following a DBA, the size of the emergency SC-1 generators is

$$
A-2
$$


estimated at $80 \mathrm{KW}$. This is based on the assumption that no heating is required after a DBA event. The additional space required to accommodate the generators and associated electrical and control equipment is indicated on Figure 3-2.

\subsection{Plot Plans}

A plot plan for the Concept $2 \mathrm{D}$ is shown on Figure $3-2$. This overall plan includes the additional requirements for a SC-1 HVAC confinement system, emergency generators and the associated equipment.

\subsection{SCHEDULE}

Provided a site helicopter crash is determined not to be a credible accident, no impact is anticipated to the facility completion date indicated in the Concept $2 \mathrm{D}$ base case.

5.0 COST ESTIMATE

The structural steel costs for the operating shelter will increase by approximately 10 percent, for the operating HVAC Mechanical Area by 20 percent, and for the Emergency Generator Area by 20 percent due to sC-1 design requirements. No allowance for fireproofing and helicopter crash is included at this time.

The assumptions, exclusions, and basis for the estimate remain the same as for the Concept 2D Feasibility study. The difference in the direct cost from the baseline Concept 2D estimate is:

$\begin{array}{llrr}\text { Structures, } & \text { add } & \$ & 131,000 \\ \text { HVAC, } & \text { add } & \$ & 517,000 \\ \text { Elect, } & \text { add } & \$ & 101,000 \\ \text { IaC, } & \text { add } & \$ & 962,000 \\ & \text { Subtotal } & \$ 1,711,000 \\ \text { Engr/PM/CM, } & \text { add } & \$ & 838,000 \\ \text { Total direct cost addition } & \$ 2,549,000\end{array}$

\subsection{REFERENCES}

"Staging and Storage Facility Feasibility Study Final Report", Fluor Daniel, Inc., February 1995.

Statement of Work, "Trade Studies for the Evaluation of FWVP Canister Storage Building for Spent Nuclear Fuels", Rev. 5, April 21, 1995. 
WHC-SNF-FRD-014, May 1995, Section 3.2.2.1.2.2, Rev. A, "Draft Performance Specification for the Spent Nuclear Fuel Canister Storage Building" (Contains tabular data from $R$. G. Cowan of WHC on proposed MCO description). 

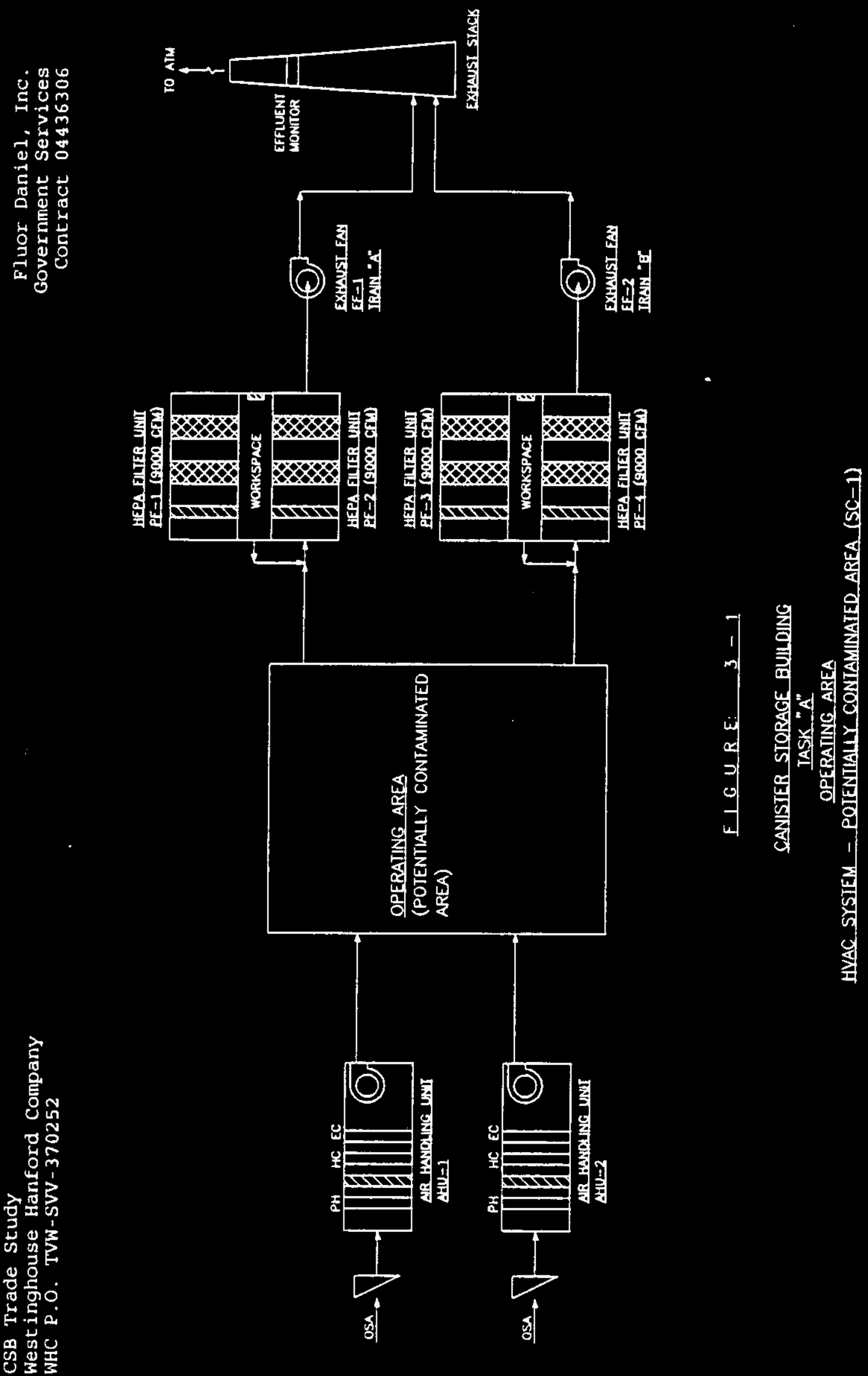

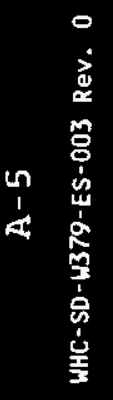

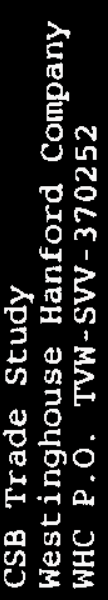


CSB Trade Study

Westinghouse Hanford Company
WHC P. TVW-SVV-37025?

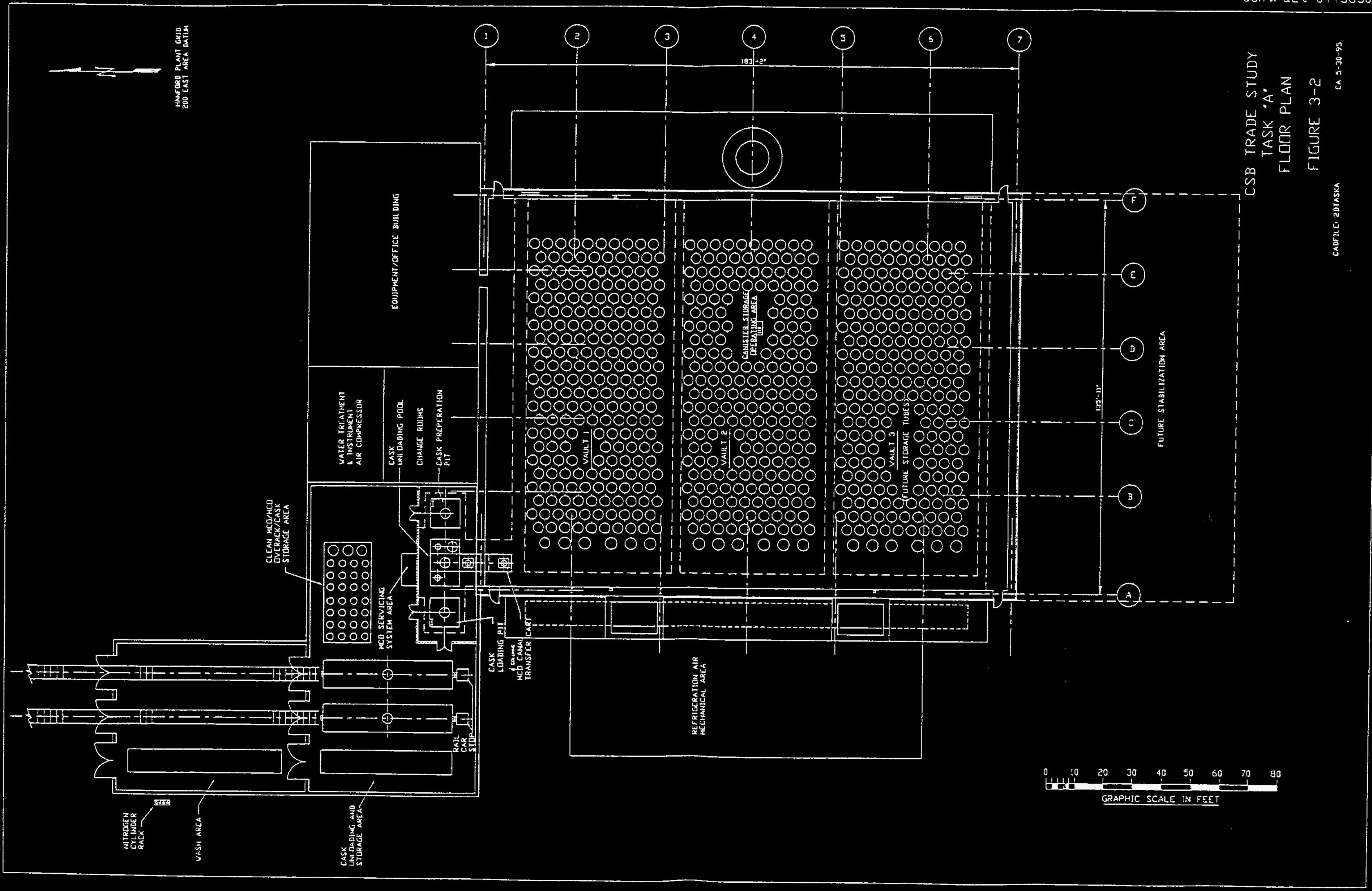


$\int_{5}^{2}$

4

0

$\sum_{0}^{2}$

0

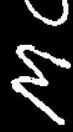

:

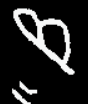

v

1

WHC-50-W379-ES-003 ReV. 0 
CANISTER STORAGE BUILDING

TRADE STUDY REPORT

TASK "B"

MCO RECEIPT AND STAGING FUNCTION AND AREA REMOVAL

\section{PREPARED FOR WESTINGHOUSE HANFORD COMPANY RICHLAND, WASHINGTON \\ PREPARED BY FLUOR DANIEL, INC.}

MAY 31, 1995

01

WHC-SD-W379-ES-003 Rev. O 


\section{TABLE OF COLWFATS}

LIST OF EIGURES

1.0 OBJECTIVE

2.0 SUMMARY

3.0 FACILITY DESCRIPTION AND EVALUATION

4.0 SCHEDULE

5.0 COST ESTIMATES

6.0 REFERENCES
DAGE

ii

B-I

B-1

B-1

B-3

B-3

B-3

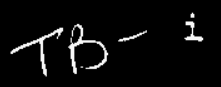




\section{IIST OF FIGURES}

\section{PAGE}

Figure 3-I

CSB Trade Study, Task "B", Floor Plan

$B-4$ 


\subsection{OBJECTIVE}

The objective of Trade study Task " $B$ " is to determine the effects of changing the Base Case Concept 2D by removing the MCO Receipt and Staging Function and Area.

2.0 SUMMARY

The results of this study show that the receipt and staging function and area can be removed from the SSF provided the MCO is shipped in a bottom loading cask and that the MCO is serviced (purged and water level checked) before shipping. The size of the receipt and staging area would be smaller. It is estimated that approximately $\$ 3.2 \mathrm{million}$ may be saved by not constructing this area; however, no reduction in the completion schedule is anticipated.

\subsection{FACILITY DESCRIPTION AND EVALUATION}

\subsection{Plot Plans}

Figure 3-1 shows the floor plan of Concept 2D SSF with Trade study Task B. This is the same as the original feasibility study base case Concept 2D except for the Rail Tunnel/Cask Unloading Area.

\subsection{Rail Tunnel/Cask Unloading Area}

\subsubsection{General Description}

The Rail Tunnel/Cask Unloading Area is a facility of about 4,000 square feet attached to the CSB at the northwest corner. This facility interfaces with the MCO Storage Tube Area via a transfer cart. The main functions of this area are to safely receive and handle incoming MCOs for placement in the storage tubes prior to stabilization. The packaged MCOs are delivered inside a bottom loading transport/facility cask via rail car or truck one at a time.

The bottom loading transport/facility cask will be similar to the bottom loading MCO shield cask as described in the base case except that it must also be designed as a shipping cask.

The Rail Tunnel/Cask Unloading Area will be used as a wash area cask unloading/loading for rail cars and loading on to the transfer cart.

Two railroad cars and a truck trailer parked in parallel can be accommodated inside. A permanent ceiling installed liquid spray arrangement allows wash/decon of the shipping cask upper

$$
\mathrm{B}-1
$$


section. Hand held wash/decon lances are available for the lower areas.

The casks will be unloaded from the railroad cars or truck and loaded on to a transfer cart. A 120 ton overhead crane, with a 10 ton auxiliary hoist running in the east/west direction services this area. The transfer cart runs on rails at floor level and transfers the bottom loading transport/facility cask between the rail tunnel/cask unloading area and the canister storage operating area.

\subsection{Findings}

3.3.1 Impacts

The size of the Rail Tunnel/Cask Unloading Area is reduced from the base case Concept 2D of approximately 10,000 to 4,000 square feet for Task B.

The bridge crane in the Rail Tunnel/Cask Unloading Area must have a larger capacity to handle the heavier cask. For Task $B$ the crane would have a capacity of 120 tons vs 110 for the base case.

For the base case only one bottom loading handling cask is required but for Task B approximately 6 are required.

\subsubsection{Advantages/Disadvantages}

The advantages of removing the MCO receipt and staging function and area are:

- Smaller and less costly building.

- No water pools and associated water treatment system.

- No below grade pits in the Rail Tunnel/Cask Unloading Area.

No MCO servicing area.

The disadvantages of removing the MCO receipt and staging function and area are:

Capacity of the bridge crane increases.

c The design of the bottom loading transport cask will be more complicated than a bottom loading facility cask.

Increase the number of casks.

\section{$B-2$}




\subsubsection{Concerns/Uncertainties}

The concern of removing the MCO receipt and staging area is:

- With no MCO servicing stations the MCO cannot be purged or water level checked and adjusted at the SSF.

There are no uncertainties with removing the MCO receipt and staging area at this time.

\subsection{SCHEDULE}

With the size and complexity reduction of the Rail Tunnel/Cask Unloading and with the removal of the MCO Receipt and Staging Area no impact is anticipated to the facility completion date as indicated in the Concept 2D base case.

\subsection{COST ESTIMATE}

Assumptions, exclusions, and basis for the estimate remain the same as for the Concept 2D Feasibility study. The difference in the direct cost from the baseline Concept 2D estimate is:

$\begin{array}{lr}\text { Structures, deduct } & <\$ 570,000\rangle \\ \text { Mechanical, deduct } & <\$ 1,568,000\rangle \\ \text { Engr/PM/CM, deduct } & \$ \$ 1,049,000\rangle \\ \text { Total direct cost reduction } & <\$ 3,187,000\rangle\end{array}$

\subsection{REFERENCES}

"Staging and Storage Facility Feasibility Study Final Report", Fluor Daniel, Inc., February 1995.

Statement of Work, "Trade Studies for the Evaluation of HWVP Canister Storage Building for Spent Nuclear Fuels", Rev. 5, April 21, 1995.

WHC-SNF-FRD-014, May 1995, Section 3.2.2.1.2.2, Rev. A, "Draft Performance Specification for the Spent Nuclear Fuel Canister Storage Building" (Contains tabular data from $R$. G. Cowan of WHC on proposed MCO description) . 


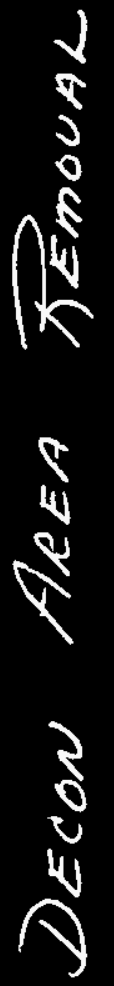

$\Sigma$

U

$v$

n

N

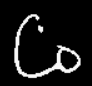

WHC-SD-W379-ES-003 Rev. 0 


\section{CANISTER STORAGE BUILDING}

TRADE STUDY REPORT

TASK "C"

CASK DECONTAMINATION FUNCTION AND AREA REMOVAL

PREPARED FOR WESTINGHOUSE HANFORD COMPANY

RICHLAND, WASHINGTON

PREPARED BY FLUUOR DANIEL, INC.

MAY 31, 1995

COO

WHC-SD-W379-ES-003 ReV. 0 
TARIF OF CONMPNTS

LIST OF FIGURES

1.0 OBJECTIVE

2.0 SUMMMARY

3.0 FACILITY DESCRIPTION AND EVALUATION

4.0 SCHEDULE

5.0 COST ESTIMATES

6.0 REFERENCES
PAGE

ii

$C-1$

C-1

C-1

C-2

C-2

$c-2$

\section{$c^{i}$}




\section{IIST OF FIGURES}

\section{PAGE}

Figure 3-1 CSB Trade Study, Task "C" Floor Plan C-3

Cii 


\subsection{OBJECTIVE}

The objective of Trade study Task "C" is to determine the effects of changing the original feasibility study Base Case Concept 2D by removing the cask decontamination function and area (wash area).

\subsection{SUMMARY}

The results of removing the cask decontamination function and area will reduce the size of the receipt area and amount of equipment. It is estimated that approximately $\$ 1.2$ million may be saved by not constructing this area; however, no reduction in the completion schedule is anticipated.

3.0 EACILITY DESCRIPTION AND EVALUATION

\subsection{Plot Plans}

Figure 3-1 shows the floor plan of the concept 2D SSF with Trade study Task "C". This is the same as base case Concept 2D except for the removal of the wash area from the Rail Tunnel/Cask Unloading Area.

\subsection{Rail Tunnel/Cask Unloading Area}

3.2.1 General Description

The Rail Tunnel/Cask Unloading Area is a facility of about 6,600 square feet attached to the CSB at the northwest corner. This facility interfaces with the MCO storage Tube Area via a covered water canal as shown in Figure 3-1. This task is the same as the base case except for the following changes:

- Removal of the wash area and its associated pumps, tanks, and holding tanks.

\subsection{Findings}

\subsubsection{Impacts}

The size of the Rail Tunnel/Cask Unloading Area is reduced from the base case of approximately 10,000 to 6,600 square feet.

The cycle time for the MCo/Transport Cask within the Rail Tunnel/Cask Unloading Area would be reduced by about 2 hours by removing the wash area. 


\subsubsection{Advantages/Disadvantages}

The advantages of removing the wash area are:

- Smaller building.

- Less equipment required to service incoming shipments.

No disadvantages have been determined at this time.

\section{3 .3 Concerns/Uncertainties}

There are no concerns or uncertainties at this time.

\subsection{SCHEDULE}

With the size and complexity reduction of the Rail Tunnel/Cask Unloading Area and with the removal of the decontamination area no impact is anticipated to the facility completion date as indicated in the concept $2 \mathrm{D}$ base case.

\subsection{COST ESTIMATE}

Assumptions, exclusions, and basis for the estimate remain the same as for the Concept 2D Feasibility study. The difference in the direct cost from the baseline Concept $2 D$ estimate is:

Structures, deduct Mechanical, deduct Engr/BM/CM, deduct Total direct cost reduction

\begin{tabular}{rr}
$<\$$ & $635,000>$ \\
$<\$$ & $143,000>$ \\
$<\$$ & $381,000>$ \\
\hline$<$ & $1,159,000>$
\end{tabular}

\section{6 .0 REFERENCES}

"Staging and Storage Facility Feasibility study Final Report", Fluor Daniel, Inc., February 1995.

Statement of Work, "Trade studies for the Evaluation of HWVP Canister Storage Building for Spent Nuclear Fuels", Rev. 5, April 21, 1995.

WHC-SNF-FRD-014, May 1995, Section 3.2.2.1.2.2, Rev. A, "Draft Performance Specification for the Spent Nuclear Fuel Canister Storage Building" (Contains tabular data from R. G. Cowan of WHC on proposed MCO description).

$$
\mathrm{C}-2
$$




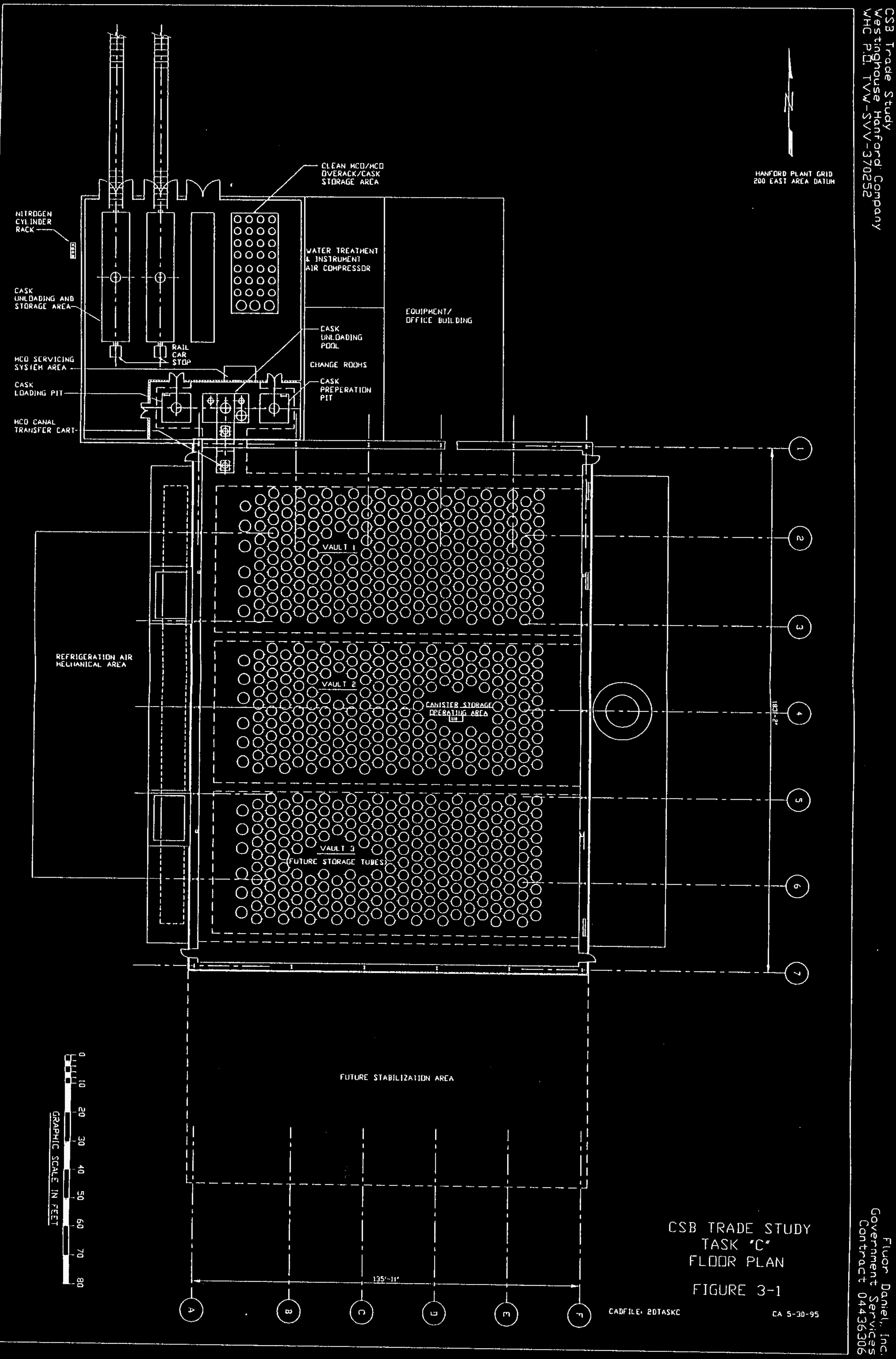


CANISTER STORAGE BUILDING

TRADE STUDY REPORT

TASK "D"

ONE TRACK RAIL SERVICE •

\section{PREPARED FOR WESTINGHOUSE HANFORD COMPANY RICHLAND, WASHINGTON \\ PREPARED BY FLUOR DANIEL, INC.}

MAY 31, 1995

Do

WHC-SD-WS/9-ES-UOS ReV. U 


\section{TABTE OF CONHFATS}

\section{LIST OF FIGURES}

1.0 OBJECTIVE

2.0 SUMMARY

3.0 FACILITY DESCRIPTION AND EVALUATION

4.0 SCHEDULE

5.0 COST ESTIMATES

6.0 REFERENCES
BAGE

ii

$D-1$

D-1

D-I

D-2

D-2

D-2 
CSB Trade Study

Westinghouse Hanford Company

WHC P.O. TVW-SVV-370252
Fluor Daniel, Inc. Government Services Contract 04436306

\section{IIST OF EIEURBS}

PAGE

Figure 3-1

Figure 3-2

Figure 3-3

Figure 3-4
CSB Trade Study, Task "D" Master Site Plan

CSB Trade Study, Task "D" Floor Plan,

Task "D" Staging Material Flow Diagram, D-5 In Rail Tunnel/Cask Unloading Area

Task "D" Staging and Material Time Study In Cask Unloading and Storage Area
$D-4$

D-3

$D-6$ 


\subsection{OBJECTIVE}

The purpose of Trade Study Task " $D$ " was to determine changes to facility functions, technical requirements, identify risk and safety issues, and evaluate the impacts to the cost estimate, and design/construction schedule due to simplification of the rail service to one track with a passing track outside the facility, versus two tracks used in the original feasibility base case concept 20 .

The work was performed under Task "D" of the statement of Work, Revision 5, dated April 21, 1995 in Attachment 1 to WHC Work Order TVW-SVV-370252, Modification 090.

\section{0 SUMMARY}

Except for the smaller size of the railcar Wash Area and the Cask/MCO Unloading and Storage Area due to the elimination of one track within the facility, there are no significant changes to facility functions and technical requirements. The risks, technical and safety issues as enumerated in the Concept 2D Feasibility study Report remain unchanged. There is no impact to the design and construction schedule as given for the base case.

The Cask/MCO transportation on one track into the facility will be able to handle 3.4 shipments per day as opposed to 4 in Concept 2D. The reduction in the estimated direct cost of the facility from the Concept 2D case will be approximately $\$ 98,000.00$ and the cost of Engr/PM/CM is approximately $\$ 49,000$.

\subsection{FACILITY DESCRIPTION AND EVALUATION}

\subsection{Plot Plan}

Figure 3-1 shows the master site plan for Task "D" for the one rail spur entering the CSB. The overall plot showing various buildings floor plans is shown in Figure 3-2 with the reduced footprint of the Wash Area and the Cask/MCo Unloading Area Buildings. A Change Room area has been added.

\subsection{System Descriptions}

The facility system descriptions are similar to those given in the Concept 2D Feasibility study Report. The elimination of one rail track will reduce the track length by about 250 feet i reduce the Cask Wash Area by approximately 1040 square feet; and reduce the Cask/MCO Unloading and storage Area by about 640 square feet. A 1550 square feet area has been added for

$$
D-1
$$


the Change Rooms between the Cask/Mco Unloading and the Equipment/Office Buildings.

There will be some change in the material flow in the Cask Wash and Unloading Areas when using one rail track. It is possible to receive and handle 1 Cask/MCo every 7 hours $(3.4$ per 24 hour workday). Figures $3-4$ and 3-5 depict the tasks, sequences, equipment, and estimated time required to perform the tasks.

\subsection{Facility Issues}

The facility issues and concerns described-for the concept $2 \mathrm{D}$ Feasibility study are also applicable to this Task "D" study. A single rail system in the facility is able to handle 3.4 Casks/MCOs per 24 hour workday.

\subsection{SCHEDULE}

The design/ construction schedule for the Concept 2D Feasibility study is also applicable to this Task study and no new impacts are identified.

5.0 COST ESTIMATES

Assumptions, exclusions, and basis for the estimate remain the same as for the Concept 2D Feasibility study. The difference in the direct cost from the baseline Concept $2 \mathrm{D}$ estimate is:

Structures, add

Railroad, deduct Engr/EM/CM, deduct

Total direct cost reduction

$$
\begin{array}{cc}
\$ & 4,000 \\
<\$ & 102,000\rangle \\
\langle \$ & 49,000\rangle \\
\hline<\$ & 147,000\rangle
\end{array}
$$

\section{6 . 0 REFERENCES}

"Staging and Storage Facility Feasibility Study Final Report", Fluor Daniel, Inc., February 1995. 



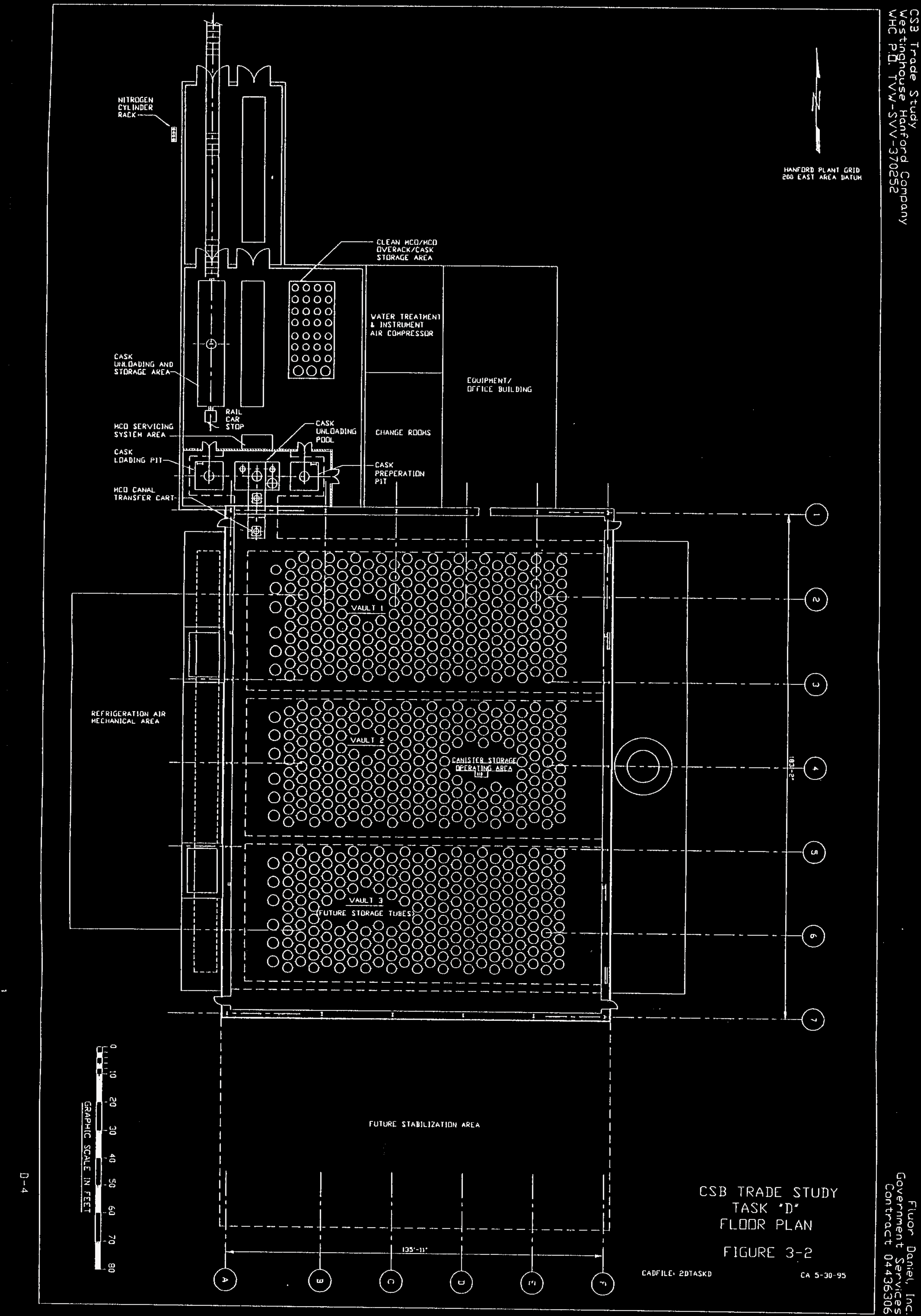




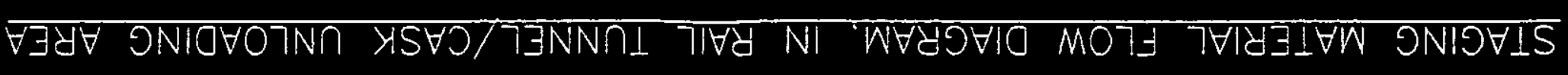

$$
\text { "O, Y्रSVI }
$$

$\varepsilon-\varepsilon$ उyก)

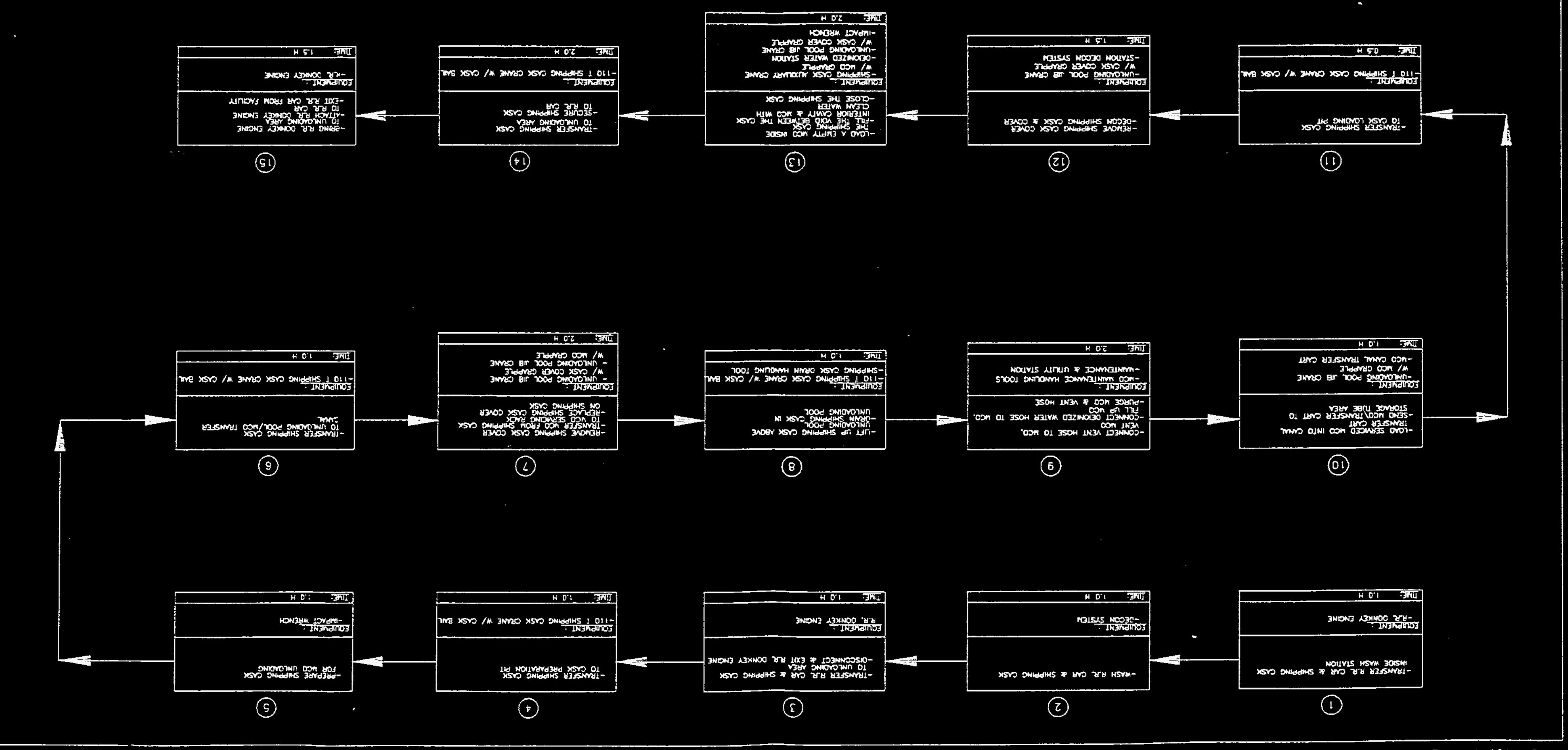



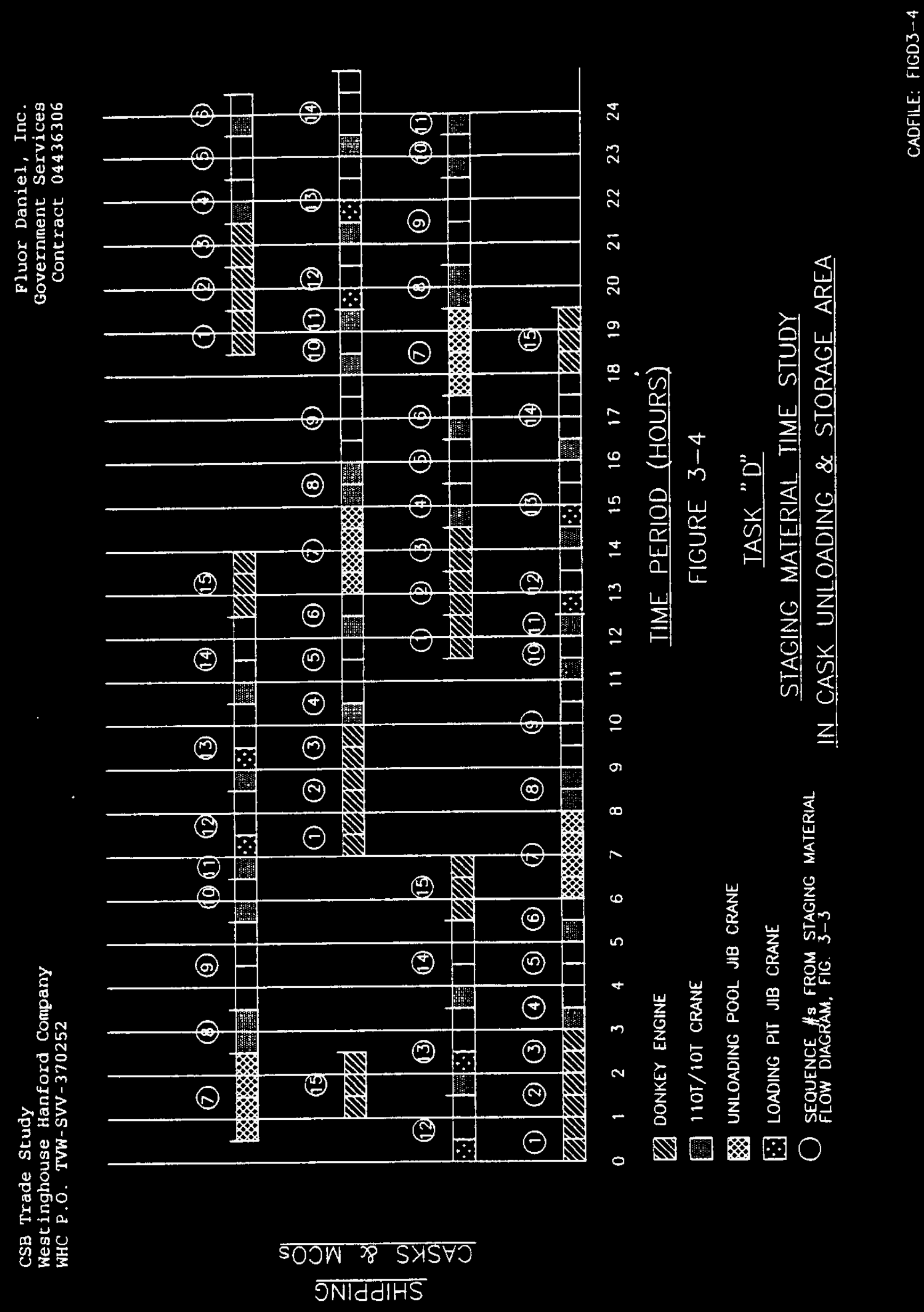


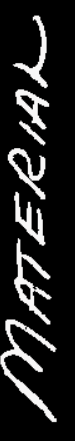

1

$\frac{1}{2}$

$:$

iv

V

17

10

$E$

WHC-SD-W379-ES-003 ReV. 0 


\section{CANISTER STORAGE BUILDING}

TRADE STUDY REPORT

TASK "E"

STORAGE TUBE MATERIAL INVESTIGATION

\section{PREPARED FOR WESTINGHOUSE HANFORD COMPANY RICHLAND, WASHINGTON \\ PREPARED BY FLUOR DANIEL, INC.}

MAY 31, 1995

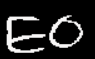

WHC-SD-W379-ES-003 ReV. O 


\section{PABITI OF CONHFHES}

\section{LIST OF FIGURES}

PAGE

1.0 OBJECTIVE

$\mathrm{E}-1$

2.0 SUMMARY

$E-1$

3.0 FACILITY DESCRIPTION AND EVALUATION

$E-3$

4.0 SCHEDULE

E-6

5.0 COST ESTIMATES

E-6

6.0 REFERENCES

$E-6$

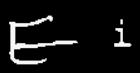




\subsection{OBJECTIVE}

\subsection{Background}

The Canister Storage Building as originally designed in 1992 for the Hanford Waste Vitrification Project contained storage tubes made of ASTM A242 weathering steel (e.g., Corten brand by U.S. Steel). During the staging and storage Facility Feasibility study, stainless steel tube material was proposed for the options involving water-filled tubes. Stainless steel was chosen based on $50^{\circ} \mathrm{F}$ deionized water in the tubes and a 40-year design life. The Feasibility study final Report noted the unresolved technical issue of corrosion of the stainless steel in stagnant (oxygen-depleted) water.

The objective of the trade studies is to resolve technical issues related to the usage of the Canister storage Building to safely stage and store $\mathrm{N}$-Reactor spent fuel now located at $\mathrm{K}$-Basin $100 \mathrm{KW}$ and $100 \mathrm{KE}$. The Trade study Task "E" Statement of Work is to determine the technical feasibility of nonstainless steel water-filled storage tubes and recommend material to resist wet corrosion for only 7 years versus 40 years.

\subsection{Purpose and Need}

Although the building will be used for 40 years (or more), the staging phase when the tubes could be filled with water will not exceed 7 years. Each of the three vaults in the original design contains 220 tubes. The present Eabricated cost of each stainless steel tube was estimated to be $\$ 43,300$, compared to $\$ 17,100$ for weathering steel. Carbon steel would cost 30\% less than weathering steel. The installed cost of stainless tubes would be a major portion of the total building cost. As noted in the Feasibility study Final Report, corrosion of stainless steel is possible in stagnant water.

\subsection{SUMMARY}

A review of Iiterature on corrosion due to stagnant water revealed a threat to not only the storage tubes, but also the inside and outside of the MCOs. Pitting corrosion of stainless steel in oxygen-depleted water is well-known, as is the fact that this form of corrosion is accelerated by bacterial action. The iron-oxidizing bacteria which accelerate the corrosion are found in spent fuel storage pools. The rate of local corrosion is unpredictable, ranging from slight pitting to complete penetration within a few years.

\section{$E-1$}


Although the options for tube design are discussed below, none of these options solves the more important problem of corrosion of the MCO from the inside by stagnant water.

Any option with water-filled tubes requires the addition of a system for detecting that a tube leak has occurred and finding the leaky tube. Even a single undetected tube failure might have severe consequences if this could also cause MCo failure due to high temperature, which might result in contamination of the concrete vault around the tubes. The tube-leak detection system is yet to be defined, subject to many safety and feasibility issues. The building must contain features necessary for recovery and clean-up in the event of leakage.

If the water in each of the tubes is treated and regularly monitored to maintain the $\mathrm{pH}$ above $10.5 \mathrm{with}$ an acceptable concentration of biocide, then it is likely that there will be no unacceptable corrosion due to stagnant water when the tubes are constructed of bare carbon steel or weathering steel. Weathering steel (such as Corten) probably would be suitable for staging and storage. Weathering steel was determined to be preferable to carbon steel for Hirvp storage. The impact absorbers in the tubes would have to be redesigned so that when water treatment chemicals are added, the chemicals will $\mathrm{mix}$ evenly between the top and bottom of the tube. Because of the uncertainty intrinsic to corrosion prediction in these circumstances, and the severe consequences associated with tube failures, further investigation is recommended. Corrosion literature should be searched for reports of corrosion of stainless steel and weathering steel (or carbon steel) in stagnant treated water. Testing is recommended to verify the material choice and to determine the required interval for monitoring and replenishing the treated water.

If further investigation shows that it is not practical to treat and monitor the water in the individual tubes, then the only design using well-developed technology (known to fluor Daniel) which assures the integrity of all tubes and MCOs over a period of 7 years requires an interconnecting water circulation system and stainless steel tubes. Other possible designs are more expensive, require development/testing and/or involve a significant chance of at least one tube failure caused by undetected damage during MCO insertion. Epoxy coating is an option which appears acceptable, subject to verification that there is no problem with dry MCO damage during MCO placement.

Although it may be feasible to connect the tubes and circulate treated water through them, this design is more expensive than the base case, and therefore is a step in the wrong direction. A system of connected tubes is functionally similar to an

$$
\mathrm{E}-2
$$


expensive version of the open pool Alternative 1 of the Feasibility study. Rather than estimate the cost of an undesirable option, it should suffice to say that the cost would exceed that of Alternative $2 \mathrm{~A}$ in the Feasibility study.

\subsection{FACILITY DESCRIPTION AND EVALUATION}

\subsection{System Description}

The N-Reactor fuel consisted of uranium metal with zirconium cladding. The spent fuel has been stored underwater in the east and west $\mathrm{K}$-Basin pools in order to cool the fuel and prevent contact with air. Uranium metal can react with air in an uncontrolled, highly-exothermic (pyrophoric) manner. This pyrophoric reaction could destroy the fuel containers and release the spent fuel in the form of smoke. During the staging phase of operation, metallic fuel contained in stainless steel Multi-Canister Overpacks (MCOs) will be maintained at $100^{\circ} \mathrm{F}$ or less in the tubes using refrigerated forced-air cooling on the outside of the tubes. Although it is not essential to have water in the tubes, water is by far the cheapest and most effective heat transfer fluid. The use of other fluids in the tubes (such as air, nitrogen, helium, or fluorocarbons) will result in greater cooling flow requirements or higher MCO temperatures. Later, the fuel will be removed and stabilized in an adjacent facility. In the stabilization process, fuel surfaces are oxidized to prevent further reaction and to allow higher-temperature storage. Then, in the storage phase, the returned stabilized fuel in MCOs will be stored in dry tubes and maintained at $400^{\circ} \mathrm{F}$ or less by natural convection of outside air.

An MCO is inserted into a tube by an overhead crane equipped with a grapple which grips the top of the MCO. The MCO dimensions are $24^{\prime \prime} O D$ and $15^{\prime}-1 "$ long. The maximum MCO weight is $13,1001 \mathrm{~b}$. The maximum heat generation rate is $482 \mathrm{~W}$ per $\mathrm{MCO}$.

Figure 3-1 shows a typical tube with two MCOs. The top of the tube is covered with a concrete shielding plug. The plug is moved aside when an MCO is inserted. The plug seals the tube, but contains two valved tubing connections. One connection could allow the gas space above the MCOs to be monitored and purged during operation. The other connection has a HEPA filter and would be attached to a relief valve to vent the tube before gas pressure could lift the plug. Below the plug is an embedded funnel which aligns the MCO into the tube during insertion.

Two MCOs will fit in each storage tube, which is 34'-3" from the base to the funnel. The bottom $23^{\prime}-4^{\prime \prime}$ of the tube is $27^{\prime \prime}$

$$
E-3
$$




\section{FIGURE 3-1 \\ TASK "E"}

STORAGE TUBE CONTAINING MCOS

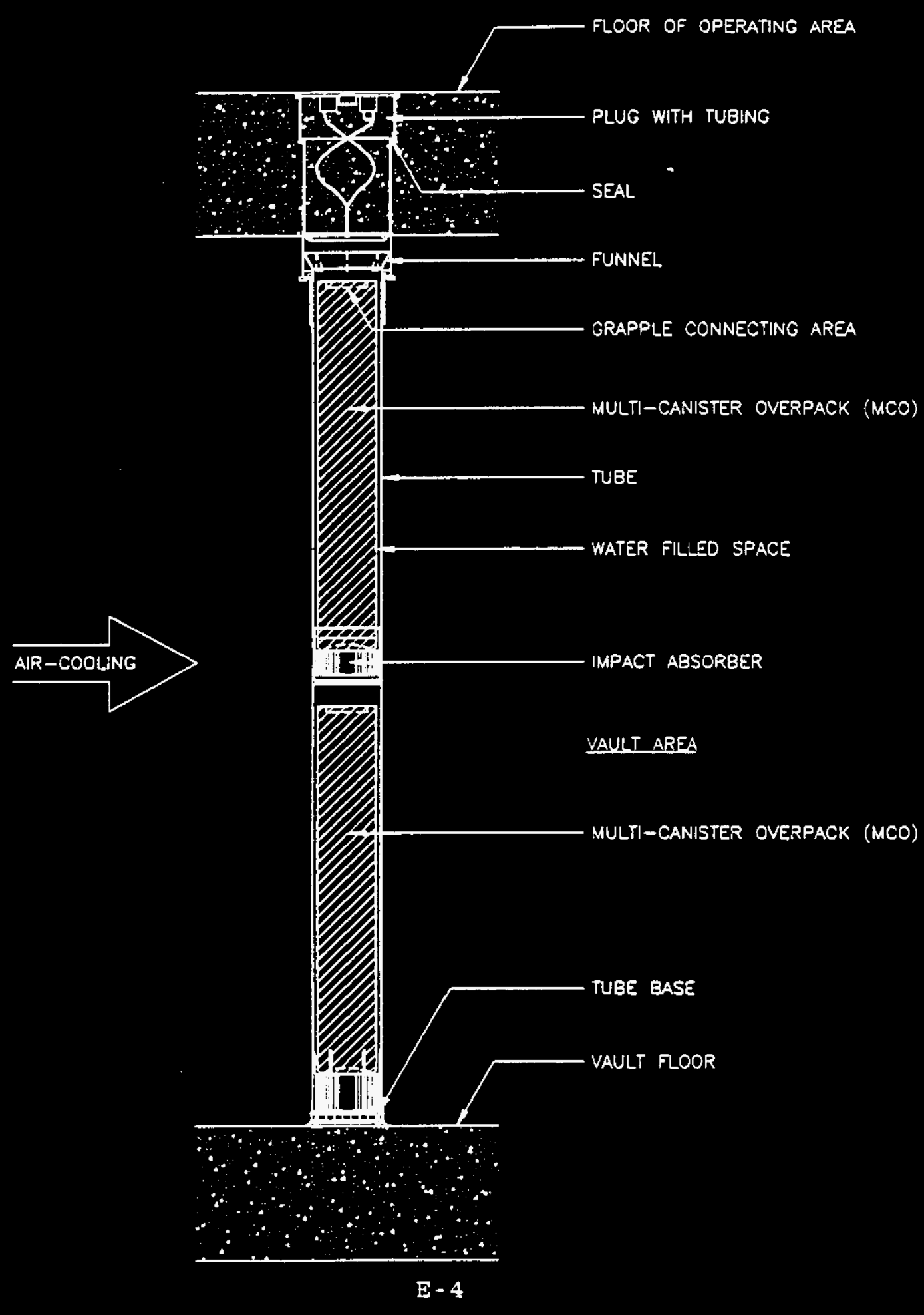

conds noses-1 
ID and 28" OD. The top of the tube is 29" ID and 30" OD. Stainless steel impact absorbers about 18 " high are installed under each MCO in case an MCO is dropped. Stagnant, deionized water at approximately $100^{\circ} \mathrm{F}$ would cover the MCOs. With two MCOs in place, the water volume is 24.8 cubic feet or 185 gallons.

\subsection{Evaluation}

Concern for the design of water-filled tubes is not the general corrosion of the carbon steel tubes but the Mirobiolgicaliy Influenced Corrosion (MIC) of the carbon steel or weathering steel tubes and the stainless steel MCOs due to stagnant water.

MIC is a well-known corrosion phenomenon and is recognized as a serious problem affecting industrial facilities, including nuclear sites. MIC was a major concern of Westinghouse Hanford Company on the FWVP project, based on experience reported by the Tennessee Valley Authority with stainless steel piping (Guthrie and Kuzniak): With the wet design, the carbon steel tubes and the stainless steel canisters (inside and outside) are at risk of MIC. The corrosion could range from minor pitting to complete through-wall penetrations.

Methods of preventing MIC are having constant flow above 5 $\mathrm{ft} / \mathrm{sec}$ to prevent microbes and nutrients from accumulating on the materials surface, treating the water with a biocide to control microbial population, raising the pH to 10.5 or greater, or applying cathodic protection. An effective monitoring program is essential in controlling microbial population.

Provided MIC is prevented, one option for the material of construction for stagnant water-filled storage tubes is carbon steel. Weathering steel, ASTM grade A242, is also acceptable but more expensive. General corrosion of carbon steel tubes is not a major concern due to the fact that the extent of corrosion is dependent on the amount of water and surface area exposed to the water. Carbon steel will only corrode until the dissolved oxygen is consumed. The extent of penetration of corrosion is 0.0006 inch per sq. in. of surface per gallon of water. With the large amount of surface area and the rather small amount of water (approximately 185 gallons) the carbon steel would perform satisfactorily in this application. If MIC is prevented and the corrosion products derived from general corrosion are not a problem, then carbon steel is an acceptable material for the tubes.

Alternative material to eliminate or reduce the corrosion products and possibly avoid MIC of the tubes could be epoxy- 
coated carbon steel or bare carbon steel with cathodic protection. If epoxy-coated carbon steel is considered the design must incorporate the standard preparation techniques such as rounded corners, contoured welds and clean base metal surface. Any pinhole flaw in the coating would result in rapid corrosion of the steel behind the flaw. Coating flaws during fabrication can be detected by holiday testing (electric discharge testing). Damaging of the coating during canister placement seems likely with the current placement mechanism shown in the feasibility study. However, a soft protective bumper around the bottom edge of the MCo could be added to protect the coating during placement. The feasibility of cathodic protection for this application requires further consideration of maintainability. Most importantly, protection of the tubes does not solve the more serious problem of corrosion of the MCO.

From a corrosion viewpoint, it would be best to eliminate water as a cooling media for the MCO. If a change is not possible because of heat transfer limitations, methods of preventing MIC should be implemented. Prevention of MIC would require a method of circulating biocide-treated water between tubes or monitoring the water quality in each tube. Treating or monitoring the water inside the MCO would be required, which might be a difficult or costly task. If MIC cannot be prevented, materials with an assured resistance to MIC must be investigated and tested. The referenced report by Guthrie and Kuzniak suggests that titanium may be a suitable material.

\subsection{SCHEDULE}

The choice of storage tube material does not affect the design or construction schedule of the revised Canister storage Building.

\subsection{COST ESTIMATES}

If unacceptable corrosion of the $M C O$ and tube cannot be prevented by treatment and monitoring the water in each tube, the cost of circulating treated water through the tubes to avoid stagnant conditions will exceed that of Alternative $2 \mathrm{~A}$ in the Feasibility study. Although this water-circulation option will prevent unacceptable corrosion of the storage tubes, it does not address internal corrosion of the MCO by stagnant water.

If the water in the tubes can be treated and monitored to prevent unacceptable corrosion by stagnant water, then weathering steel (such as Corten) is suitable for the tubes. This design has been estimated as Concept 2D.

$$
E-6
$$


The assumptions, exclusions, and basis for the estimate remain the same as for the concept 2D Feasibility study. The difference in the direct cost from the baseline Concept $2 D$ estimate is:

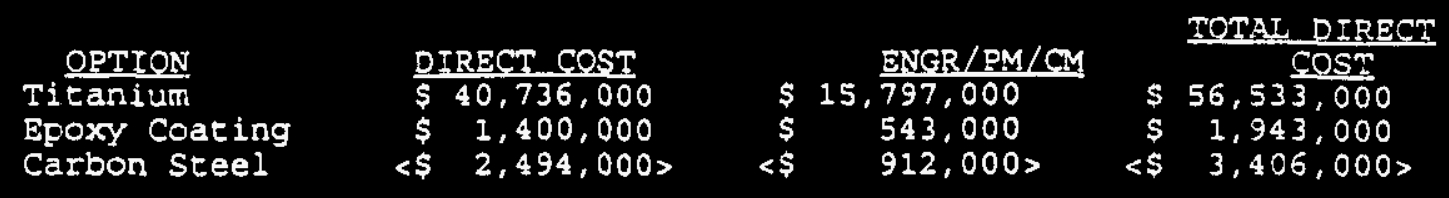

\subsection{REFERENCES}

P.V. Guthrie and W.C. Kuzniak, "Are Our Pipes Safe From Microbiologically Influenced Corrosion?"

Hanford Waste Vitrification Project, memo from Kishor Shah to N.H. Williams, "Project Wide Concern, MIC Impact," 7/8/92.

Hanford Waste Vitrification Project, mechanical drawings for the Canister Storage Building: $\mathrm{F}-2-120142,-120394,-120395$, and -120397 , Rev. 0 (Approved for Construction), 8/28/92.

"Staging and Storage Facility Feasibility Study Final Report", Fluor Daniel, Inc., Feb. 1995.

Statement of Work, "Trade Studies for the Evaluation of the HWVP Canister Storage Building for Spent Nuclear Fuels, "Rev. $5,4 / 21 / 95$.

WHC-SNF-FRD-014, May 1995, Section 3.2.2.1.2.2, Rev. A, "Draft Performance Specification for the Spent Nuclear Fuel Canister Storage Building" (Contains tabular data from $R$. G. Cowan of WHC on proposed MCO description). 


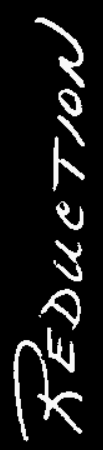

1
5
5
5

0

e

$\S$

1

v

10

F

WHC-SD-W379-ES-003 Rev. O 
CANISTER STORAGE BUILDING

TRADE STUDY REPORT

TASK " $F$ "

MCO SHIPMENT REDUCTION-

\section{PREPARED FOR WESTINGHOUSE HANFORD COMPANY RICHLAND, WASHINGTON \\ PREPARED BY FLUOR DANIEL, INC.}

MAY 31, 1995

Fo

WHC-SD-W379-ES-003 Rev. 0 
CSB Trade Study

Westinghouse Hanford Company

WHC P.O. TVW-SVV-370252
Fluor Daniel, Inc.

Government Services Contract 04436306

TABHD OF CONMFATS

\section{LIST OF FIGURES}

1.0 OBJECTIVE

2.0 SUMMARY

3.0 FACILITY DESCRIPTION AND EVALUATION

4.0 SCHEDULE

5.0 COST ESTIMATES

6.0 REFERENCES

\section{PAGE}

ii

F-1

F-1

F-1

F-2

F-2

F-2

$F-i$ 
CSB Trade Study

Westinghouse Hanford Company

WHC E.O. TVW-SVV-370252

\section{IIST OF FIGURES}

PAGE

Figure 3-1 CSB Trade Study, Task "F" Floor Plan

$F-4$

$$
\text { Fi }
$$

WHC-SD-W379-ES-003 Rev. 0 


\subsection{OBJECTIVE}

The objective of Trade study Task "F" is to determine the effects of changing the original Feasibility study Base Case Concept 2D by reducing MCO shipments from 4 to 2 per day.

2.0 SUMMARY

The results of reducing the MCO shipments from 4 to 2 reduces the size of the receipt area by removing one of the two railroad tracks coming into the building and reduces the quantity handling equipment. It is estimated that approximately $\$ 274,000$ may be saved by not constructing this area; however, no reduction in the completion schedule is anticipated.

\subsection{FACILITY DESCRIPTION AND EVALUATION}

\subsection{Plot Plans}

Figure 3-1 shows the outline of Concept 2D SSF with Trade Study Task " $F$ ". This is similar to the base case Concept 2D except for the Rail Car Wash Area and Rail Tunnel/Cask Unloading Area.

\subsection{Rail Tunnel/Cask Unloading Area}

\subsubsection{General Description}

The Rail Tunnel/Cask Unloading Area is a facility of about 8, 000 square feet attached to the CSB at the northwest corner. This facility interfaces with the MCO storage Tube Area via a covered water canal as shown in Figure 3-1.

This task is the same as the base case except for the following changes:

- Only one MCO servicing station is required.

- The size of the clean MCO/MCO Overpack/Cask Storage Rack can be reduced to $1 / 2$ of the base case rack.

- The Unloading Pool Jib Crane and the Cask Loading Pit Jib Crane are not required. The operations performed by the jib cranes can be done by the 10 ton hoist on the bridge crane because of the reduced use of this crane.

- Only one rail track is required to service the 2 shipments per day.

$$
\text { E-1 }
$$


The operations for Task "F" within the Rail Tunnel/Cask Unloadj.ng Area will be the same as the base case.

\section{3 Findings}

\subsubsection{Impacts}

The size of the Rail Tunnel/Cask Unloading Area including the wash area, is reduced from the base case Concept 2D of approximately 10,000 to 8,100 square feet.

only one rail track is required.

3.3.2 Advantages/Disadvantages

The advantages of two MCO shipments per day are:

- Smaller building.

- Less handing and servicing equipment for the MCOs.

The disadvantage of two MCO shipments per day is:

- It will take longer to remove the spent nuclear fuel from K-Basins.

\subsubsection{Concerns/Uncertainties}

There are no additional concerns or uncertainties from the base case.

\subsection{SCHEDULE}

With the reduction in the size and complexity of the Rail Tunnel/Cask Unloading Area no impact on the schedule is anticipated from Concept 2D.

\subsection{COST ESTIMATE}

Assumptions, exclusions, and basis for the estimate remain the same as for the Concept 2D Feasibility study. The difference in the direct cost from the baseline Concept 20 estimate is:

$\begin{array}{ll}\text { Structures, deduct } & <\$ 98,000\rangle \\ \text { Mechanical, deduct } & <\$ 86,000\rangle \\ \text { Engr/PM/CM, deduct } & \leq \$ 90,000\rangle \\ \text { Total direct cost reduction } & <\$ 274,000\rangle\end{array}$

$$
\text { F-2 }
$$




\section{6 . REFERENCES}

"Staging and Storage Facility Feasibility Study Final Report", Fluor Daniel, Inc., February 1995.

Statement of Work, "Trade studies for the Evaluation of HWVP Canister storage Building for Spent Nuclear Fuels", Rev. 5, April 21, 1995.

WHC-SNE-FRD-014, May 1995, Section 3.2.2.1.2.2, Rev. A, "Draft Performance Specification for the Spent Nuclear Fuel Canister Storage Building" (Contains tabular data from R. G. Cowan of WHC on proposed MCO description). 


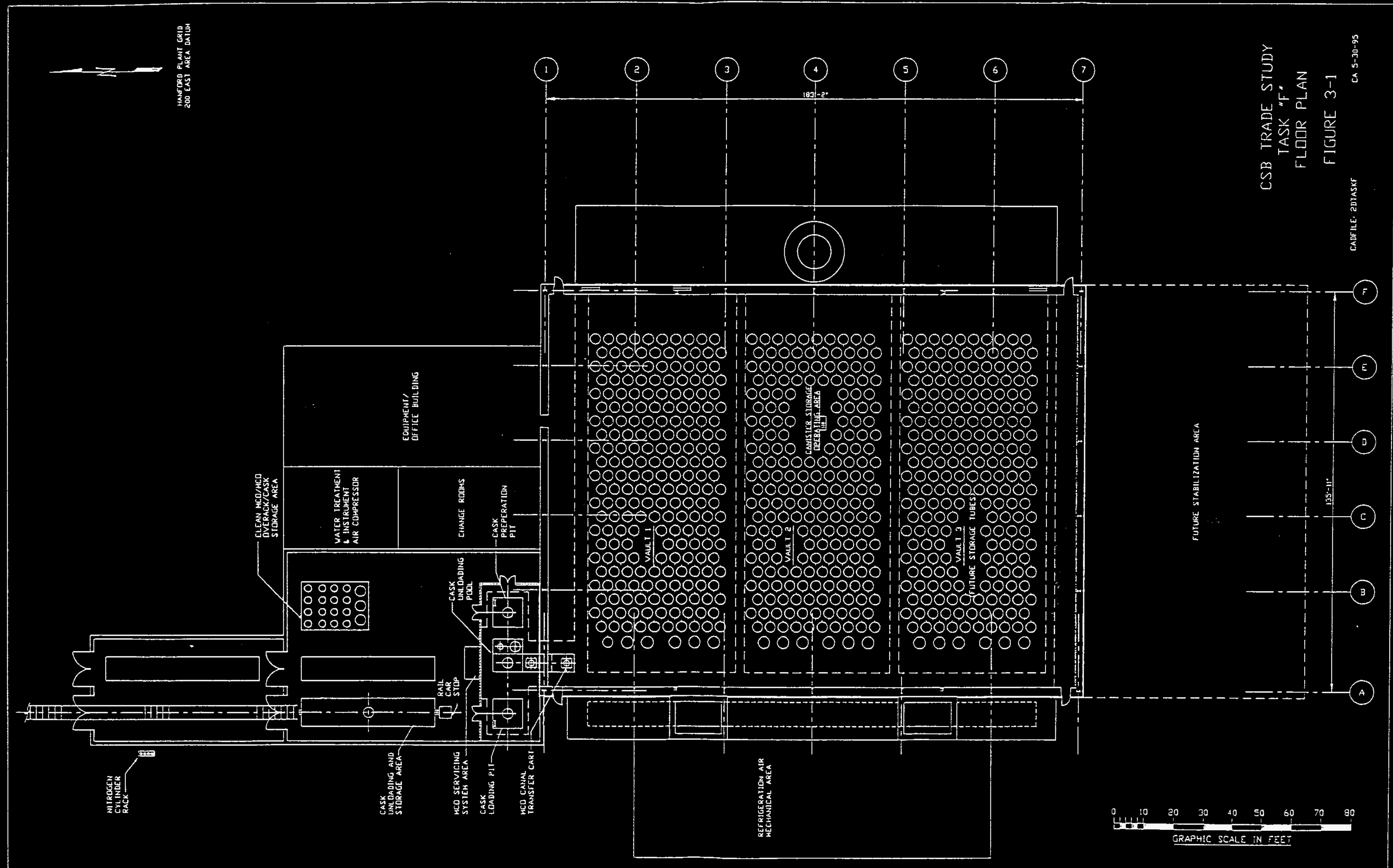




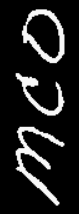

4

ऐ

A

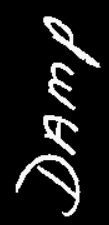

$=$

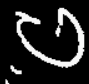

$\Downarrow$

b

赵

G

WHC-SO-W379-ES-003 ReV. O 
CANISTER STORAGE BUILDING

TRADE STUDY REPORT

TASK " $\mathrm{G}$ "

DAMP-DRIED MCO

PREPARED FOR WESTINGHOUSE HANFORD COMPANY

RICHLAND, WASHINGTON

PREPARED BY FLUOR DANIEL, INC.

MAY 31, 1995

Go

WHC-SD-W379-ES-003 Rev. 0 
SE Frace Stucty

Westinctouse tanford Company

WHE P. CI. TVW-SVV-370252
F..ucr Janie.., Inc

Government Services

Contract 04436306

\section{TABIE OF CONHENTS}

\section{LIST OF TABLES}

1.0 OBJECTIVE

2.0 SUMMARY

3.0 FACILITY DESCRIPTION AND EVALUATION

4.0 SCHEDULE

5.0 COST ESTIMATES

6.0 REFERENCES

APQENDIX 1
PAGE

ii

G-1

G-1

G-1

G-3

G-3

G-4

A. - 1

$$
\text { Gi }-i
$$


CSB Trade Study
Westinghouse Fanford Company

WHC P.O. TVW-SVV-370252

F..jor Janiej, rnc

Contract 04436306

\section{IIST OF TABIES}

로GE

Table 3-1

Thermal Analysis - Summary

G-4

$G-i i$

WHC-SD-W379-ES-003 Rev. 0 


\subsection{OBJECTIVE}

The objective of Trade Study Task "G" is to evaluate handing and staging requirements for MCOs shipped drained, damp-dried from $\mathrm{K}$-Basin. Determine cooling requirements for a refrigerated air system during staging operations and investigate natural circulation cooling system during storage operations.

\subsection{SUMMARY}

The results of the thermal analyses for MCOs shipped drained, damp-dried from $\mathrm{K}$-Basin for staging in 2-vaults indicates that it is not feasible to maintain MCO temperatures at $100^{\circ} \mathrm{F}$ with a refrigerated forced air system. However, during the storage operation the MCO temperature can be maintained at $270^{\circ} \mathrm{F}$ by a passive ventilation system, this is below the limiting criteria of $400^{\circ} \mathrm{F}$ for storage operations.

\subsection{EVALUATION OF MCO HANDLING/STAGING AND COOLING REQUIREMENTS}

\subsection{Evaluation of MCO Handing and Staging}

There will be no significant impact in the conceptualized parameters for handling and staging of $\mathrm{MCO}^{\prime} \mathrm{s}$ in the Concept $2 D$.

The immediate affect on handing a dry MCO will be an approximate 1 ton reduction in weight of a loaded transportation cask due to the weight of water. This reduction is not considered large enough to re-size the cask handling cranes for this trade study.

\subsection{Evaluation of MCO Cooling Requirements}

This section documents the results of a series of thermal analyses that were performed to assess the feasibility of meeting the Multi-Canister overpack (MCO) temperature requirements during dry staging with the Concept $2 \mathrm{D}$ staging and Storage Facility (SSF). These analyses were performed for forced refrigerated air and passive ventilation systems.

The thermal feasibility analysis is based on staging of drained, damp-dried MCOs in air filled tubes in vaults 1 and 2 (third vault contains no tubes) with a forced refrigeration air cooling of the tubes during staging. MCOs are removed and returned to the tubes after stabilization. After all fuel is stabilized, the passive air ventilation system is made operational. 
3.2.1 Design Basis Assumptions

The following design basis assumptions were used for the thermal analyses:

The heat generation rate was based on a total 880 MCOs. Twenty percent are assumed to be at the upper limit ("maximum") (482 W) and the remaining eighty percent are assumed to be at the nominal value ("average") (22I W). Due to the preliminary nature of the heat transfer calculations a ten percent safety factor was used for the heat generation rate. Additional heat loads were added for building heat gains.

- The heat generation for the "maximum" case (482 W) per MCO was used for calculating the MCO temperature assuming that it is located at the end of the vault. Each MCO consists of five canisters, each storage tube contains two MCOs, and each vault contains 220 tubes.

The design basis required staging/storage conditions are as follows :

Staging: Maximum MCO temperature at $100^{\circ} \mathrm{F}$. Storage: Maximum fuel centerline temperature at $400^{\circ} \mathrm{F}$.

During the staging operation the MCO provides primary confinement and the air filled storage tubes provide the secondary confinement. It is assumed that the interior of the storage tubes are isolated from the vault, which would prevent the vault from getting contaminated.

- The total flow is assumed to be evenly and uniformly distributed around each of the containment tubes. This is a critical assumption that must be assured by design and verified by additional analyses using Computational Fluid Dynamic (CFD) techniques.

The heat transfer coefficients for air were calculated at the point of maximum vault air temperature.

- One dimensional (radial) heat transfer only. Twodimensional (radial and axial) heat transfer was not modeled.

Heat transfer by radiation between the tubes was not considered. 


\section{$3.2 .2 \quad$ Summary of Results}

The results of the thermal analyses during staging are shown in Table 3-1 and involve various combinations of drained, damp-dried MCOs surrounded by air in tubes for different ventilation flow rates.

The results indicate that it is not feasible to maintain the MCO temperature at $100^{\circ} \mathrm{F}$ with a refrigerated forced air ventilation system with a supply air temperature of $35^{\circ} \mathrm{F}$. With 200,000 CFM system and a supply air temperature of $35^{\circ} \mathrm{F}$ (Concept 2A of the SSF Feasibility study) the MCO temperature can only be maintained at $173^{\circ} \mathrm{F}$ based on the above heat generation rate. The temperature of $35^{\circ} \mathrm{F}$ was selected to maintain the same basis as the previous feasibility study alternatives. The MCO temperature is calculated on the basis that the MCO is located at the end of the vault with the limiting heat load. (The MCo temperature could be maintained at $100^{\circ} \mathrm{F}$ with $200,000 \mathrm{CFM}$ supply ais at minus $37^{\circ} \mathrm{F}$, this is not feasible).

The results of the thermal analyses during storage operation with the existing CSB design concept, assuming the same intake structure, vault size (2-vaults) and exhaust stack (height and diameter) indicates that an MCO temperature of $270^{\circ} \mathrm{F}$ can be maintained by a passive ventilation system. This is based on an inlet air temperature of $115^{\circ} \mathrm{F}$ (same design basis as CSB) and a ventilation flow rate of 53,000 CFM.

The above results indicate that it is not feasible to use the refrigerated air system to maintain the MCO temperature below $100^{\circ} \mathrm{F}$ during the staging operation. However; the passive ventilation system can maintain the MCO temperature below the $400^{\circ} \mathrm{F}$ limit during the storage operation.

It must be emphasized that these are rough conservative feasibility analyses using limited design information and do not cover all limiting or upset conditions. More detailed analyses are required using CFD techniques to cover all limiting and upset conditions and to verify some basic assumptions. Also no analysis was performed for MCOs stored in an overpack.

\subsection{SCHEDULE}

As the Trade Study requirements were determined not feasible the current construction schedule is not impacted. 
TABLE - 3-1

THERMAL ANALYSIS - SUMMARY

(Drained, Damp-Dried MCOs)

\begin{tabular}{|c|c|c|}
\hline $\begin{array}{c}\text { MCO } \\
\text { TEMPERATURE } \\
\left({ }^{\circ} \mathrm{F}\right)\end{array}$ & $\begin{array}{c}\text { SUPPLY AIR } \\
\text { QUANTITY } \\
\text { (CEM) }\end{array}$ & $\begin{array}{c}\text { SUPPLY AIR } \\
\text { TEMPERATURE } \\
\left.\text { TO VAULT }{ }^{\circ} \mathrm{F}\right)\end{array}$ \\
\hline 180 & 100,000 & 35 \\
\hline 176 & 150,000 & 35 \\
\hline 173 & 200,000 & 35 \\
\hline 170 & 300,000 & 35 \\
\hline 168 & 400,000 & 35 \\
\hline 167 & 500,000 & 35 \\
\hline
\end{tabular}

5.0 COST ESTIMATE

As the Trade Study requirements were determined not feasible the current estimate for Concept 2D is not impacted.

\subsection{REFERENCES}

"Staging and Storage Facility Feasibility Study Final Report", Fluor Daniel, Inc., February 1995.

Statement of Work, "Trade Studies for the Evaluation of FWVP Canister Storage Building for Spent Nuclear Fuels", Rev. 5, April 21, 1995.

WHC-SNF-FRD-014, May 1995, Section 3.2.2.1.2.2, Rev. A, "Draft Performance Specification for the Spent Nuclear Fuel Canister storage Building" (Contains tabular data from R. G. Cowan of WHC on proposed MCO description). 
Appendix 1

Calculations specific to TASK "G"

G-5

WHC-SD-W379-ES-003 ReV. 0 


\section{Determine tolerable amount of water in mass} - Closed

If the MCO.S

are staged at $100^{\circ} \mathrm{F}$ rate of $U$ metal corrosion and resultant $\mathrm{H}_{2}$ will increase, as shown in the Independent Technical. Assessment Team on Dry storage of N-Reactor Evel report. According to that report, the corrosion rates at $50^{\circ} \mathrm{F}$

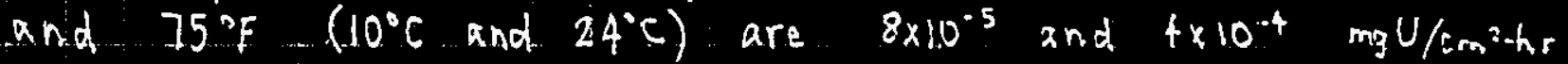
respectively, For a ratio of 5.0. Extrapolating to $100^{\circ} \mathrm{F}$, the corcosion rate would be 10 times greater than at $50^{\circ} \mathrm{F}$, per cannister.

$$
\mathrm{U}+2 \mathrm{H}_{2} \mathrm{O} \rightarrow \mathrm{UO}_{2}+2 \mathrm{H}_{2}
$$

For an 8-ranister. MeO, WHC had us Jesign for $14 \mathrm{~L} / \mathrm{day}$ $\mathrm{H}_{2}$ generation (17\%/year. U oxitation by water) wher the

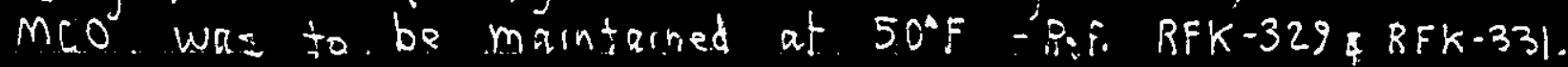

This yolue was cheared in the proeses cal: dated 1-17-9s

In the previous studis with 8-canister Mcos at $50^{\circ} \mathrm{F}$, the servicing required more than twice the erane work than bringing in and placing new mcos. Increasing this work by a factor of 10 makes the design infiasible, because we carnot put in 10 times as many bridge cranes One option is to limit. the moisture in the mico so that the hydrogen concentiration remains safe.

A calculation $(1 / 19 / 95)$ showet that $6 \% \mathrm{H}_{2}-94 \% \mathrm{~N}_{2}$ by volume is non-combustiole when mixed with any proporticn of air.

MCo and cancter dimersions are shown in the following pajes. The gas volume equals. 15.3. . $t^{3}$. Limiting $\mathrm{H}_{2}$ to $6 \%$ meang no more than $0.92 \mathrm{ft}^{3}$ of $\mathrm{H}_{2}$. . If the mco was filled with $15.3 \mathrm{Ft}^{3}$ of $\mathrm{N}_{2}$ at $100^{\circ}$... and $0.92 \mathrm{ft}^{3}$ of $\mathrm{H}_{2}$ are added the pressure increases to $\left.(14.7 \mathrm{ps} 1 \mathrm{a}) \div 16.22 \mathrm{Ft}^{3}\right) /(15.3 \mathrm{Ft}$ $=15.6$ psia $=0.9$. psig. 
FL OR DANIEL $\left(\frac{\pi}{2}\right)$ OATE 4/10/95

CALCULATIONS and SH:ETCHES

CONT. NO. 04436306

SSE TRADE STUDY "G"

BY B. Derhotels CHK
SHEET NO. 2 af 3

tolerable amount of water in MOs

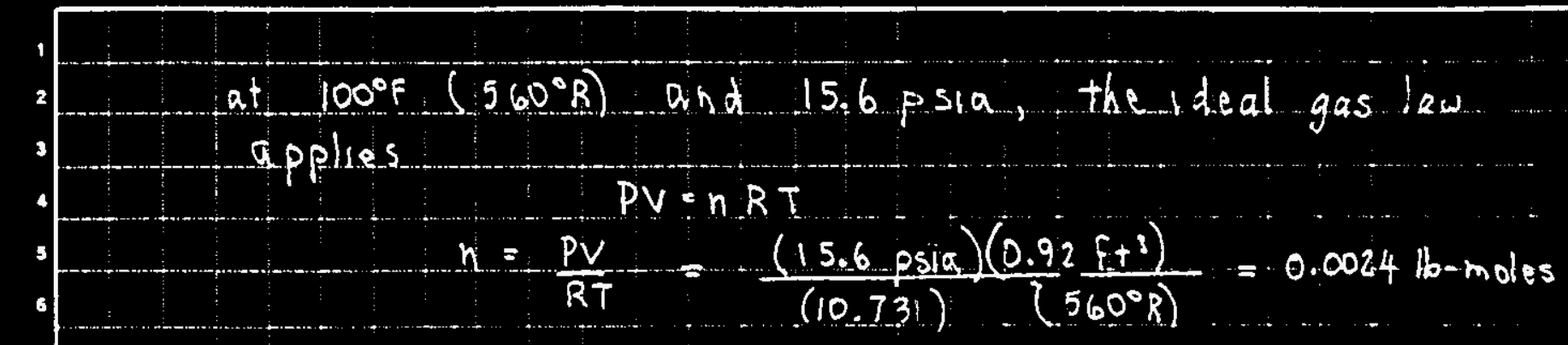

from the corrosion reaction, each mole of $\mathrm{H}_{2} \mathrm{O}$ produces one mole of $\mathrm{H}_{3}$. MW of $\mathrm{H}_{2} \mathrm{O}=18.016$

tolerable water $=(18.016)(0.0024)=0.043$ it of water say 0.04 . 16

at $100^{\circ} \mathrm{F}$, the specific volume of water is $0.01 \mathrm{bl} \mathrm{Ft}^{3} / \mathrm{b}$ which is equivalent. to $27.8 \mathrm{in}^{3} / 16$.

$0.04: 16$ of water is $1.1 \mathrm{in}^{3}$ of water

CONCLUSION: In order to ensure a safe mixture of hydrogen after uranium instal corrosion in an invented 10-Canister MLO, the amount of wafer has to be limited to less than l cubic inch after ar dining.

TIMiNG: At $50^{\circ} \mathrm{F}$ for: 8 canisters in an MCO, the nominal $H_{2}$ rate was $1.2 \mathrm{~L} /$ day... For 10 canisters. of $100^{\circ} \mathrm{F}$, the nominal rate. would be $(10 / 8)(10)(1.2 \mathrm{~L} / \mathrm{day}) /(28.3 . \mathrm{L} / \mathrm{f}+3)=$ $0.53 \mathrm{Ft} / \mathrm{deg}$... Time required for $\mathrm{H}_{2}$ concentration to reach $6 \%=\left(0.92 \mathrm{ft}^{3}\right) /(0.53 \mathrm{ft} / \mathrm{day})=1.7 \mathrm{days}$

For a building containing 750 Meas, 440 McOs per day would have to be secured $(750) /(6.7)=440$. If there are 880 mos, servicing rate is 520 per day. [If $6 \% \mathrm{H}_{2}$ in an moO constitutes a hazard that must be corrected by servicing (monitoring 4 purging)]. $G=7$

WHC-SD-W379-ES-003 Rev, 0

20 
Mark I canister length $=27.05^{\prime \prime}$ not counting vent tubing OD $=985^{\prime \prime}$

canister volume is a little over $2 \pi(d / 2)^{2} h$

$$
\begin{aligned}
=K_{2 \pi} d^{2} h=1 / 2 \pi(9.5 \mathrm{~m})^{2}(27.05 \mathrm{~m}) & =3.835 \mathrm{~m}^{3} \\
& =2.22 . \mathrm{ft}^{3}
\end{aligned}
$$

volume occupied by 10 canisters $=22.2 \mathrm{ft}^{3}$

McQ inside dimensions $=156.75^{\prime \prime}$ length, $23.25^{\prime \prime} \mathrm{zD}$. internal gratings occupy $4^{\prime \prime}$ of length, leaving $152.75^{\prime \prime}$. $\begin{aligned} V=\pi(d / 2)^{2} h=1 / 4 \pi(23.25)^{2}(152.75) & =64.851 \mathrm{in}^{3} \\ & =37.5 \mathrm{ft}^{3}\end{aligned}$

gas volume inside 10 -canister. $M C O=37.5-22.2=15.3 \mathrm{ft}^{2}$ 


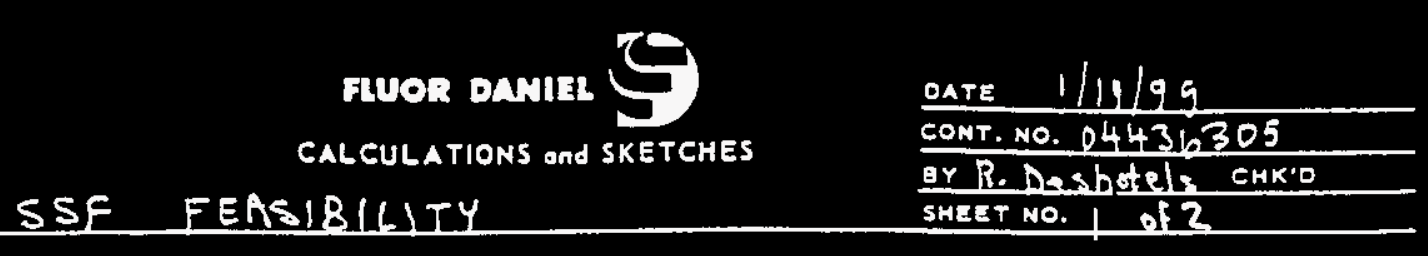

TASK 2 VENTING OF SEALED TUBES,

WITH WERT GAS BLANKET

To prevent an explosive mixture from forming, an inert gas must be used to blanket the tube $\mathrm{CO}_{2}$. bs a possible choice because it inhibits combustion better than nitrogen or argon, and because it can be stored as a liquid at low pressures, which requires. less space. The disadvantage is that $\mathrm{CO}_{2}$ liquid is cold enough (about $-40^{\circ}$ ) to create a hazard to people and structures. $A$ safer choice 1.5 . nitrogen, stored as a high -pressure gas.

From the flammability din gram, we can see that a mixture with $6 \%$ or less hydrogen by volume with $94 \% \mathrm{~N}_{2}$ is nonflammable in any combination with ait.

Storting with a tube. with, two MCO's, and the tube contains $1 \% \mathrm{H}_{2}-99 \% \mathrm{~N}_{2}$ at 14.7 psia pressure, and adding $\mathrm{H}_{2}$ until the $\mathrm{H}_{2}$ concentration reaches $6 \%$ :

$$
\begin{aligned}
& (0.06)(v+54.48)=(0.01)(54.48)+v \quad \text { [Free vol. in tube }=54.48 \mathrm{ft}^{3} \\
& (0.94) v=(0.05)(54.48) \quad \text { see process call. of } 1 / 18,95] \\
& v=2.90 \mathrm{Ft}^{3} \\
& P=(14.7)(54.48+2.90) /(54.48)=15.5 \text { psia }=0.8 p 5: \mathrm{g}
\end{aligned}
$$

So, starting with $99 \% \mathrm{~N}_{2}$, the tube must be purged when the pressure reaches 0.8 pig: to maintain an absolutely safe mixture. This is feasible, since

a 40 tube-periday venting schedule. will vent the tubes at. 0.4 sig. [Ref. process call dated. 1/18/95].

After venting the tube, the tube has to be purged to reduce the $H_{2}$. concentration back to $1 \%$.

The vent gas volume will equal $(1200)(0.494 \mathrm{Ft} / \mathrm{D})=593 \mathrm{ft}^{3} / \mathrm{D}$

WHC-SO-W379-ES- 003 Rev. 0 
The worst case for purge volume is a tube with one mco. When $\mathrm{N}_{2}$ is introduced to the tube, the gas flow will somewhere between bottom:up? plug flow and. continuousin well-mixed.. If the flow were plug-type, the purge volume would be less than $101.34 \mathrm{ft}^{3}$. For well-mixed. Flow, the purge is greater:

$$
\begin{aligned}
& C_{F}=(1.00)-C_{0} e^{-Y N_{0}} \\
& C_{F}=0.99 \quad C_{0}=0.94 \quad V_{0}=101.34 \\
& (0.99)=(1.00)-(0.94) e^{-x} \\
& (0.94) e^{-x}=(0.01) \\
& e^{-x}=0.0106 \\
& x=4.543 \\
& V_{F}=(4.543)(101.34)=460^{\circ} \mathrm{ft}^{3} \text { per purge } \\
& \text { at } 40 \text { purges per dey, purge }=(40)(460)=18,400 \mathrm{ft}^{3} / \mathrm{D}
\end{aligned}
$$

If the $\mathrm{N}_{2}$ is prouided by cylinders, each industrial size cydinder $\left(9^{\prime \prime} 00 \times 5 \mathrm{ft}\right)$ contains $200-230 \mathrm{ft}^{3}$.

Elch purge would use about two cylinders of compressed nitroger for a tube with ene mco. A tube with two Mco's would only require about one cylinder. * Rer Imperial Weiding supply. 
Hydrogen Safety Handbook ,

by Paul M. Ordin

for NASA

Fumbility

LINITS บITH

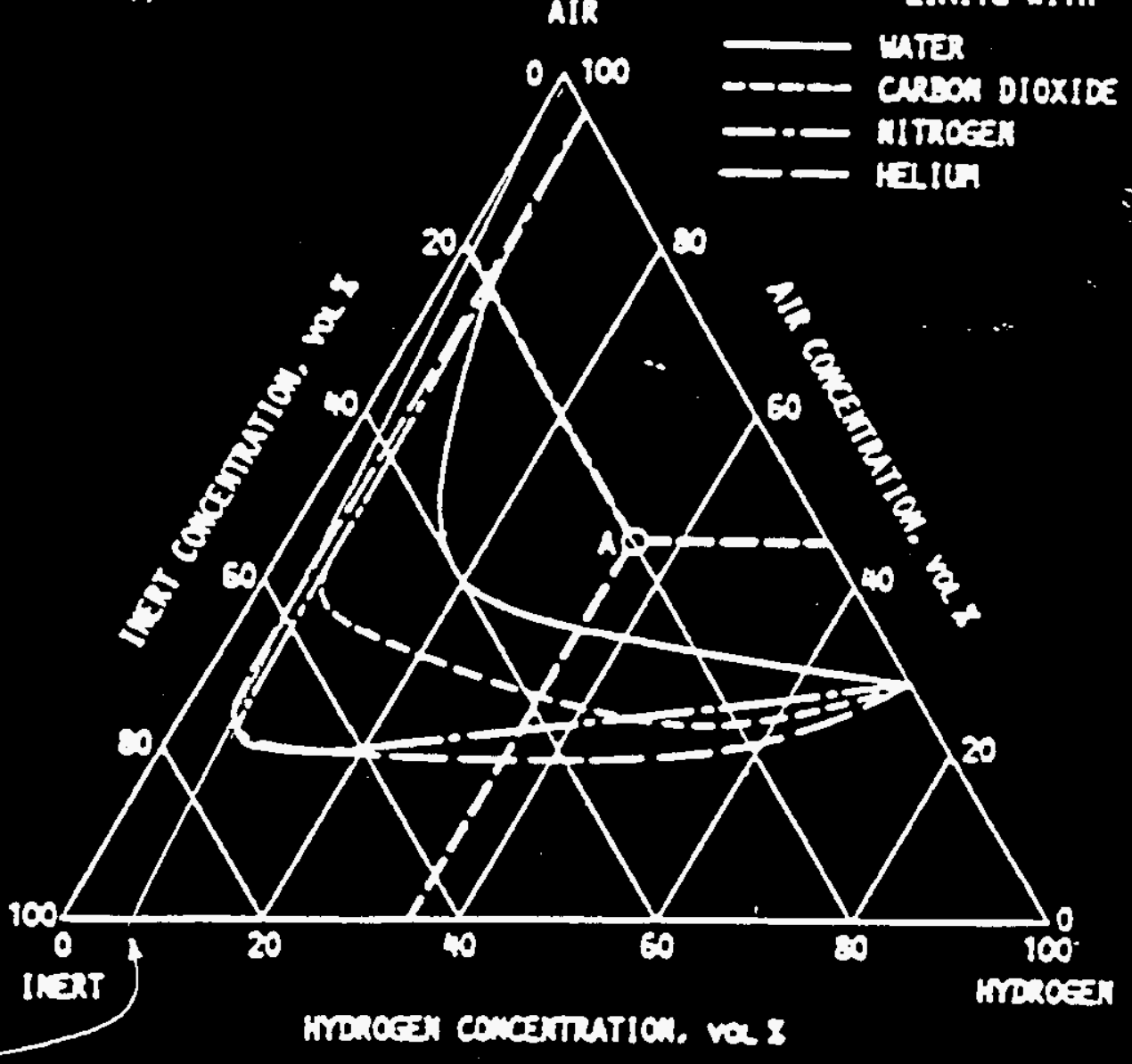

A $6 \% \mathrm{H}_{2}-94 \% \mathrm{~N}_{2}$ mixture is nonflammable when combinet with any proportion of air.
Figure A5. - Effect of nitrogen, helium, carbon dioxide, and water vapor on flammability of hydrogen in air. Example: at point $A$, in flammable range, concentrations are hydrogen, 35 vol \%; air, 45 vol \%; and inert, 20 vol \%.

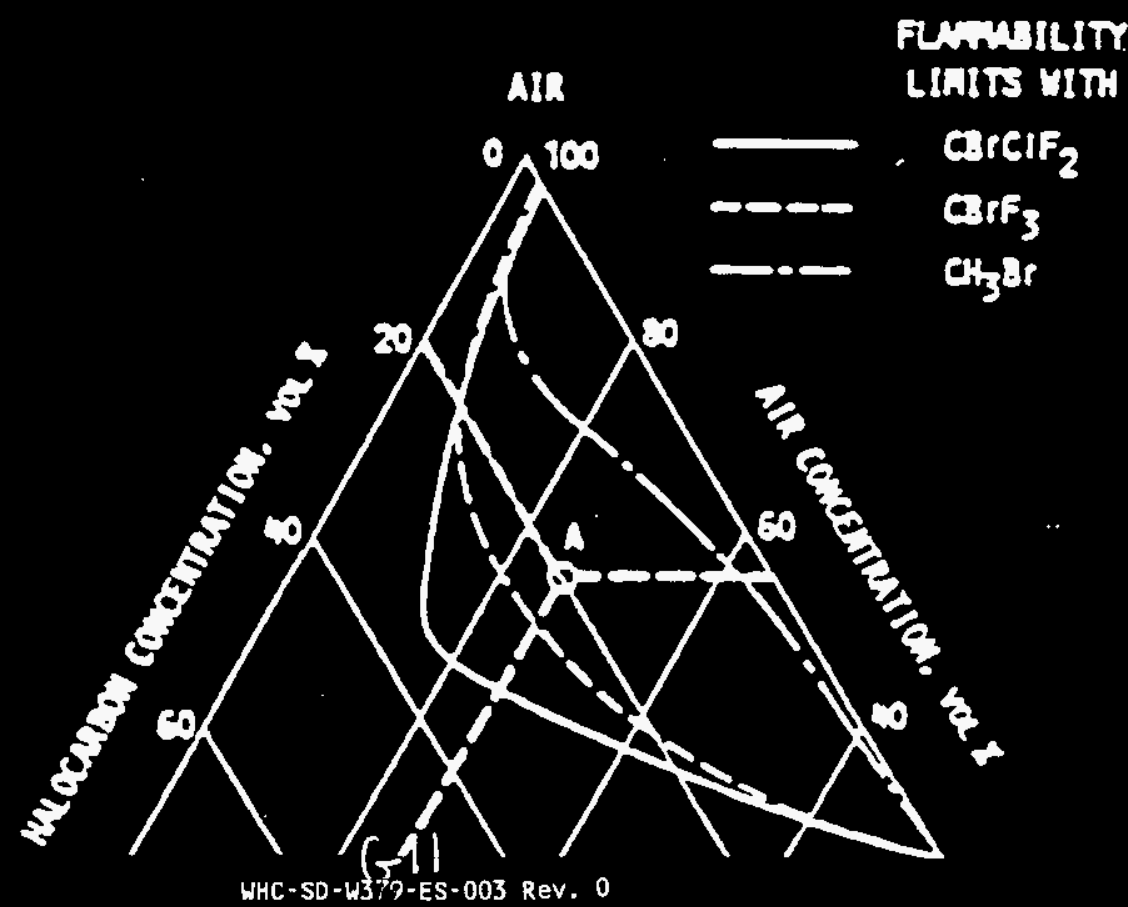


FLUOR DANIEL $1 / 23 / 95$

CALCULATIONS and SKETCHES

CONT. NO. 04431.305

SSE FEASIBILITY

ar R, Deshothls CHK'D

SHEET NO. I of

MOO VENT GAS CONTAMINATION

Design basis shows ${ }^{85} \mathrm{kr}$... present, but no 1 or tritium. Cesium when wet will remain wi the fuel as Cs OH, Which is not volatile. The gas released from an 8-canister MCO is $2.56 \mathrm{~m} \mathrm{Ci} / \mathrm{L}$. nodal, or $4.62 \mathrm{mCi} / \mathrm{h}$ upper. limit. Gas released is 1.2 L day nominal, or. 4 today upper limit. (Ref. FAX from M. Henderson

$$
\begin{aligned}
& 1 / 20 / 95) \text {. } \\
& \text { average release }=\left(2.56 \mathrm{~m} c_{i} / \mathrm{L}\right)(1.2 \mathrm{H} / \mathrm{daj})=3.07 \mathrm{~m} c_{i} / \mathrm{da} \\
& 3,070 \mu C_{i} / d a y=128 \mu C_{i} / h r=2.13 \mu C_{i}: \text { min. per moo }
\end{aligned}
$$

The acceptable contamination in a controlled-aicess area is $1 \times 10^{-5} \mu \mathrm{ij}$ ce (Em D. Padua, a $x=\mathrm{c}$ on 10 CFR 20, including the $10^{-1}$ fat tor specified for $K_{r}{ }^{85}$ $\therefore$ In the DOE Radiological Control Manual, DOE/EH-02561, Rev. 1, Apr. 19\%.

$$
\begin{aligned}
& 1 \mathrm{ft}^{3}=2.8317 \times 10^{4} \mathrm{cc} \\
& 1 \times 10^{-5} \mu C i ! c c=0.283 \mu=i \mathrm{ft}^{3}
\end{aligned}
$$

to maintain an aiseptabie ${ }^{85}$ r level in the occupied area above the MCO's, the air purge/make-up rate must exes:

$$
\begin{aligned}
V & =\left(2.13 \mu \mathrm{Ci}_{\mathrm{imin}}\right) /\left(0.28317 \mu \mathrm{Ci}_{\mathrm{j}} \mathrm{ft}^{3}\right) \\
& =7.5 \mathrm{Ft} / \mathrm{min} \text { per mC }
\end{aligned}
$$

during normal operation $\left(50^{\circ} \mathrm{F}\right)$

$(1200)(7.5)=9,000 \mathrm{ft}^{3} / \mathrm{min}$ minimum purge air for CSE.

This is much more than the purge air regis, to dilute $H_{2}$

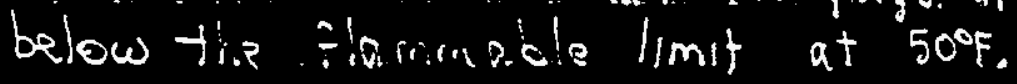

The purge/makes air requirement for $k_{r}$ is indeperderit of temperature.

$$
G-12
$$

WHC-SD-W379-ES-003 ReV. 0 


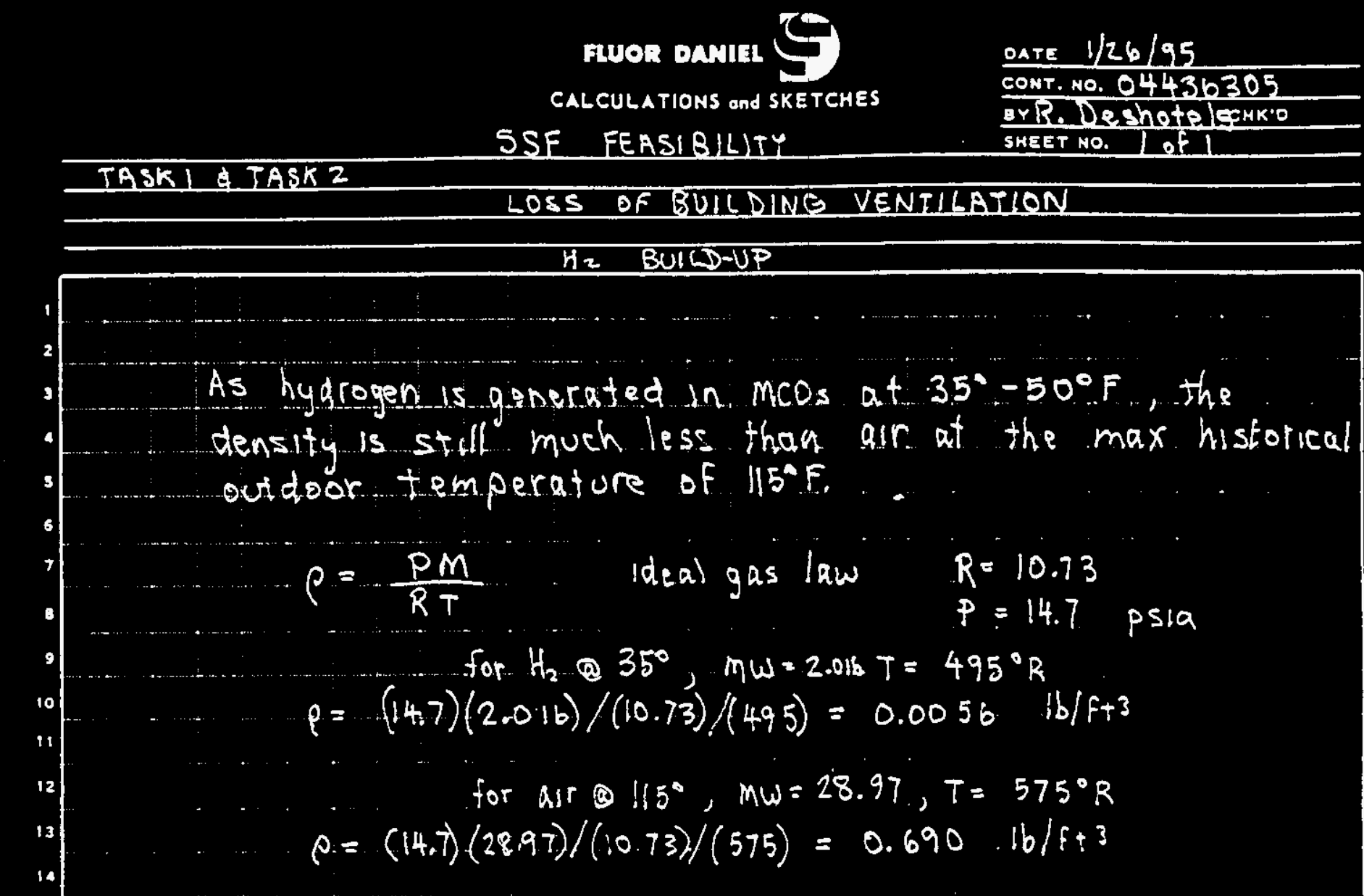

The hydrogen will tend to rise until it mixes with air. By the time any hydrogen molecules rise the 35: A distance from the pool surface or tube plugs to the ceiling, we can assume the hydrogen will be well-mixed with air. (Ref, H-2-119293 Reva) Building is $136 \mathrm{ft} \times 183 \mathrm{ft}$ across (Ref. H-Z-11.9290 Rev. 1). The building volume $=(35)(136)(183)=871,000 \mathrm{ft}^{3}$ At $50^{\circ} \mathrm{F}$ only. $3.5 \mathrm{ft}^{3} / \mathrm{min}$ will reduce $\mathrm{H}_{2}$ concentration to 170 . (Ref. process call. 1/23/95). At the normal flow,

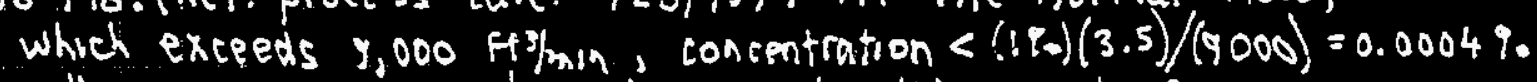
The $H_{2}$ concentration has to reach. $4 \%$ vol before it is flammable in air. $\quad(0.04)(871,000)=34,800 \mathrm{ft}$ ) of $H_{2}$ are required if the arr and $H_{2}$ ore well -mixed.

The building $\mathrm{H}_{2}$ jontration rate is 50.9 ftitiay (process cali 1/23/95) so around 685 days are required before hydrogen poses a fire hazard, with the assumption of well-mixed gas. This assumpion overestimates the time, but is probably close to. the fruition

$G-13$

WHC-SD-W379-ES-003 ReV. 0 


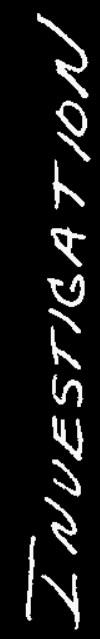

$\frac{1}{4}$

$\mathcal{U}^{\mathrm{Y}}$

2

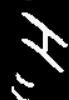

$\checkmark$

$n$

10

$H$

WHC-SD-W379-ES-003 Rev. 0 


\section{CANISTER STORAGE BUILDING}

TRADE STUDY REPORT

TASK " $\mathrm{H}$ "

RCRA FUNCTIONS:

PREVENTION AND DETECTION OF MCO LEAKS

\section{PREPARED FOR WESTINGHOUSE HANFORD COMPANY RICHLAND, WASHINGTON}

PREPARED BY FLUOR DANIEL, INC.

MAY 31, 1995

Ho

WHC-SD-W379-ES-003 Rev. 0 


\section{PABIE OF CONHENAS}

PAGE

1. 0 OBJECTIVE

$\mathrm{H}-1$

2.0 SUMMARY

$F-1$

3.0 FACILITY DESCRIPTION AND EVALUATION

H-1

4.0 SCHEDULE

$\mathrm{H}-11$

5.0 COST ESTIMATES

$\mathrm{H}-12$

6.0 REFERENCES

$\mathrm{H}-13$

$$
\text { H }
$$




\subsection{OBJECTIVE}

Part of the mission of the SNF CSB is to provide environmentally sound staging and storage of $K$ Basin SNF. This mission may require compliance with the Federal Resource Conservation and Recovery Act (RCRA). The purpose of Trade Study "H" is to identify the impacts on the SNF CSB Project assuming compliance with RCRA, and specifically to identify the design functions required to prevent and detect MCO leaks.

\subsection{SUMMARY}

Several SNF CSB functions would be required to comply with RCRA. Some already are a requirement in the base case (e.g., MCO retrievability) and would not cause a cost/schedule impact for the purpose of this trade study. Others are not in Base Case 2D and would be required only to comply with RCRA (e.g., thirty inch minimum separation between rows of MCOs, a requirement which probably would be waived because direct visual inspection of the MCOs would not be feasible).

Only one RCRA-required function would cause significant cost/schedule impact, detection of MCO leakage within twentyfour hours. To achieve this function would appear difficult and expensive, regardless of the approach considered, and would pose significant feasibly issues. Continuously operating MCO leak detection would add approximately $\$ 4.5$ million to the facility cost and extend the scheduled facility completion date by a minimum of two months. Given the Base Case 2D design, featuring an MCO filled with water (the primary heat sink) in a dry tube, potential safety and licensing risk could be incurred by not including this function, even if RCRA compliance is not a project requirement .

\subsection{FACILITY DESCRIPTION AND EVALUATION}

\subsection{Applicability}

The Federal Resource Conservation and Recovery Act (RCRA) gave guidance to the Environmental Protection Agency (IPA) for the "cradle to grave" regulation of hazardous wastes. In general, RCRA regulates the generation, transportation, treatment, storage and disposal of hazardous wastes, and these regulations are found in $40 \mathrm{CER} 260$ to 270 .

The State of Washington has obtained authorization from the EPA to administer the basic RCRA program. The washington Hazardous Waste Management Act (the Washington Act) parallels the federal RCRA requirements, and gives authorization to the Department of Ecology (Ecology) to regulate permitting for the

$$
\mathrm{H}-1
$$


generation, transportation, treatment, storage and disposal of hazardous wastes. The Washington regulations are contained in WAC (Washington Administration Code) 173-303, Dangerous Waste Regulations.

The applicability of WAC 173-303 to the SNF CSB is contained in 173-303-020, Applicability, which reads in part, "This chapter 173-303 WAC shall apply to all persons who handle dangerous wastes including, but not limited to owners and operators of dangerous waste recycling, transfer, storage, treatment, and disposal facilities."

Since spent fuel elements potentially meet the requirements as a Washington State extremely hazardous waste (EHW), see sections 173-303-070 to 173-303-103, the SNF-CSB could require a RCRA type permit from the Department of Ecology, see sections 173-303-800 to 173-303-840. This permit would be for a TSD (Treatment, storage and Disposal) facility for the storage of dangerous wastes.

\subsection{The Regulation of MCOs (as either containers or tanks)}

The regulatory requirements in WAC 173-303 are different for storage of dangerous wastes in containers versus storage in tanks. Section 173-303-040 defines a container as, "Container means any portable device in which a material is stored, transported, treated, disposed of, or otherwise handled, "and a tank as, "Tank means a stationary device designed to contain an accumulation of dangerous waste, and which is constructed primarily of nonearthen materials to provide structurai support."

The main difference of the two definitions appears to be between a portable device and a stationary device. Since an MCO is a portable device, it appears to meet the definition of a container. However, the storage of an MCO in a tube is essentially stationary, and as a result, the regulators (Ecology) may classify the MCOs as a tank.

Since the classification of the MCOs may be that of either a container or a tank, the regulatory requirements for both classifications are presented in this analysis.

\subsection{Containers}

WAC 173-303-630 regulates the use and management of containers used to store dangerous wastes.
$3 \cdot 3 \cdot 1$
$173-303-630(2)$
Condition of Containers
$3 \cdot 3 \cdot 1 \cdot 1$
Regulatory Requirements

$\mathrm{H}-2$ 
If a container holding dangerous waste is not in good condition (e.g., severe rusting, apparent structural defects) or if it begins to leak, the owner or operator must transfer the dangerous waste from the container to a container that is in good condition or manage the waste in some other way that complies with the requirements of 173-303, including that for leaks and spills.

\subsubsection{Regulatory Impact}

The above requirement can be met with retrievable MCos, some type of inspection system (as discussed in 3.3 .3 below), and an overpack capability for leaking MCOs. Retrievability and overpack capability are provided in the base case design.

\subsubsection{I73-303-630(5) Management of Containers}

\subsubsection{Regulatory Requirement}

Subsection (c) requires a minimum thirty-inch separation between isles of containers holding dangerous waste(s), and a row of drums must be no more than two drums wide.

\subsubsection{Regulatory Impact}

These requirements appear to be for containers such as 55-gallon drums and it is not clear how a regulator would apply the requirements to MCOs. A strict application might require a minimum thirty-inch separation between the storage tubes. This is a factor that would need interpretation by the regulators.

Since lethal radiation dose rates preclude direct visual inspection of MCOs, however, these requirements would have no purpose for the SNF CSB. Waiver of this requirement (no change from the base case design) would meet the intent of the regulation.

\section{$3.3 .3 \quad 173-303-630(6) \quad$ Inspections}

\subsubsection{Regulatory Requirement}

At least weekly, the owner or operator must inspect areas where containers are stored, looking for leaking containers and for deterioration of containers and the containment system caused by corrosion, deterioration, or other factors.

\subsubsection{Regulatory Impact}

This is another requirement that is directed at conventional containers, such as 55-gallon drums. For MCOs in a storage tube, the regulators may agree to some type of acceptabie 
weekly leak inspection system. This is another factor that needs interpretation by the regulators.

Compliance with the letter of this requirement clearly is not feasible because of the extremely high MCO dose rate. Weekly direct observation of each $\mathrm{MCO}$, even by remote means such as a fiber optics, clearly is not feasible. CCTV would not fit into a tube. A continuously operating leak detector in each tube should, however, meet the intent of this requirement.

\section{3 .4 \\ $173-303-630(7)$ \\ (7) \\ Containment}

\subsubsection{Regulatory Requirements}

Container storage areas must have a containment system that is capable of collecting, holding and removing spilis and leaks. Spilled or leaked waste must be removed from the containment system in an timely manner as is necessary to prevent overflow.

\subsubsection{Regulatory Impact}

The storage tubes will meet the containment system requirement to collect and hold spills and leaks, if the tubes are designed to be watertight. (Note: The EWVP CSB design does not require the tube to be watertight [leaktight]. Grouted anchor bolts penetrate the bottom plate of each tube.)

Tube/facility design also would have to provide for some manner of removing Iiquid that has leaked from an MCO. Because of the radiation field, removal of liquid would have to be accomplished remotely, after both MCOs have been removed and the leaking MCO has been placed in a MCO overpack.

3.3.5 173-303-630(8) Special Requirements for Ignitable Waste

\subsubsection{Regulatory Requirement}

The owner or operator shall design, operate and maintain ignitable waste container storage in a manner equivalent with the Uniform Fire Code.

\subsubsection{Regulatory Impact}

Section 173-303-630(8) is applicable if the generation of hydrogen in the MCOs is considered possible. However, as long as a sufficient amount of HVAC air exists to dilute hydrogen to levels below the lower explosive limit, which is expected, the requirements of 173-303-630(8) might be waived. If not, the spacial requirements required by the Uniform Fire Code may

$$
\mathrm{H}-4
$$


be necessary (this is another area where the regulators would need to be consulted).

\subsubsection{Sumary of Regulatory Impacts}

A summary of the regulatory impacts for Base Case Concept 2D and the classification of the MCOs as containers follows:

- The MCOs would have to be retrievable (already an intrinsic characteristic of the MCO conceptual design)

- Some type of continuously operating leak detection system would have to be provided in lieu of inspection, which probably is not feasible

- An MCO overpack capability would have to be provided (already provided in the Base Case)

- Depending upon interpretation, a minimum thirty-inch separation (or other spacing arrangement) between storage tubes may be required, but would have no known purpose

- The design would have to include watertight storage tubes and provide for prompt (and probably remote) removal of material that has leaked from an MCO

- Since the entire SNF CSB facility has the potential to be radiologically contaminated, all drainage sumps also should be provided with continuously operating leak detection systems and provisions for removal of accumulated liquids

3.4 Tank Systems

WAC 173-303-640, Tank Systems, applies to owners and operators of facilities that use tank systems to treat or store dangerous wastes. Under the WAC regulations, the MCOs in Concept $2 D$ would be considered the primary containment vessel (or tank) and the storage tubes would be considered the secondary containment vessel.

3.4.1 173-303-640(4) Containment and Detection of Releases:

\subsubsection{Regulatory Requirements}

In order to prevent the release of dangerous waste or dangerous constituents to the environment, secondary containment must be provided that meets the following requirements: secondary confinement systems must be designed (and installed and operated) to prevent any migration of wastes or accumulated liquid out of the system to the soil, 
ground water or surface water at any time during the use of the tank system, and the secondary confinement system must be capable of detecting and collecting releases and accumulated liquids until the collected material is removed.

To meet these requirements, the secondary confinement systems must be provided with a leak detection system that is designed (and operated) so that it will detect the failure of the primary or secondary containment structure or the presence of any release of dangerous waste or accumulated liquid in the secondary containment system within twenty-four hours. Spilled or leaked waste and accumulated precipitation must be removed from the secondary containment system within twentyfour hours.

Secondary containment for tanks must include one or more of the following devices: a liner, a vault, a double-lined tank, or an equivalent device. External Iiner systems serving as secondary confinement must be designed (or operated) to contain one hundred percent of the capacity of the largest tank within its boundary, and must be designed (and installed) to surround the primary tank completely.

The secondary containment requirement applies to ancillary equipment (e.g., tubing and other penetrations of the containment pressure boundary) as well. (Some exemptions exist).

\subsubsection{Regulatory Impact}

In Base Case Concept 2D, the MCOs would be considered the primary containment vessel and the storage tubes containing the MCOs would serve as secondary containment. Thus, the design would have to provide for detection of leaks of the MCOs within twenty-four hours and removal of any material that has leaked into a storage tube within twenty-four hours of detection. Considering the geometry of the storage tubes, the requirement on the secondary containment system for containing one hundred percent of the capacity of the primary vessels is readily met, if the tubes are designed to be watertight.

3.4.2 173-303-640(7) Response to Leaks or Spilis and Disposition of Leaking or Unfit-for-use Tank Systems

\subsubsection{Regulatory Requirements}

A tank system or secondary containment system from which there has been a leak or spill, or which is unfit for use, must be removed from service immediately, and the owner or operator must satisfy the following requirements:

$$
H-6
$$


- Cessation of use; prevent flow or addition of wastes. The owner must immediately stop the flow of dangerous waste into the tank system of secondary confinement system and inspect the system to determine the cause of the release.

- If the release was from the tank system, the owner/operator must, within twenty-four hours after detection of the leak or, if the owner/operator demonstrates that it is not possible, at the earliest practicable time, remove as much of the waste as is necessary to prevent further release of dangerous waste to the enviconment and allow inspection and repair of the tank system to be performed.

If the leak was to the secondary confinement system, all released materials must be removed within twenty-four hours or in a timely a manner as is possible to prevent harm to human health and the environment.

- The owner/operator must immediately conduct a visual inspection of the release and prevent any further migration of the leak or spill.

\section{4 .2 .2 Regulatory Impact}

These requirements are satisfied by having retrievable MCOs, watertight tubes, and the ability to detect and remove (probably remotely) any MCO leakage from inside the storage tubes. A leaking MCO probably could be retrieved and placed in an MCO overpack within twenty four hours. It probably could be shown, however, that (remote) removal of MCo leakage from a storage tube within twenty four hours of detection is not practicable.

3.4.3 173-303-640(9) Special Requirements for Ignitable (or Reactive) Wastes

\subsubsection{Regulatory Requirement}

Ignitable wastes must not be placed in tank systems unless:

- the waste is treated, rendered or mixed before or immediately after placement in the tank system so that the resulting waste, mixture, or dissolution of material no longer meets the definition of ignitable waste and (a) the storage does not generate extreme heat or pressure, fire or explosion or violent reaction (b) produce uncontrolled toxic gases in sufficient quantities to threaten human health, (c) produce uncontrolled flammable fumes or gases in sufficient quantities to pose a risk of 
fire or explosions, (d) damage the structural integrity of the facility or device containing the waste, and (e) through other means, threaten human health or the environment, or

the waste is stored or treated in such a way that it is protected from any material or conditions which may cause the waste to ignite or react.

The owner or operator of a facility which treats or stores ignitable waste in covered tanks must locate the tanks in a manner equivalent to the National Fire Protection Association's (NFPA) buffer zone requirements for tanks.

Along with 173-303-640(9), WAC 173-303-395(1) regulates precautions to be taken with ignitable wastes.

\subsubsection{Regulatory Impact}

As noted earlier, section 173-303-640(9) would be applicable if the generation of hydrogen in the MCOs is considered possible. However, as long as a sufficient amount of HVAC air exists to dilute hydrogen to levels below the lower explosive Iimit, which is expected, the requirements of $173-303-640$ (9) would be satisfied using the provision in part (2) above, i.e. Section 3.3-1.

If section 173-303-640(9) is applicable, a NFPA buffer zone requirement might exist.

\subsubsection{Summary of Regulatory Impacts}

A summary of the regulatory impacts for the designs associated with Base Case Concept $2 \mathrm{D}$ and with the classification of the MCOs as tanks follows:

Some type of system for detecting leaks in the MCOs within twenty-four would have to be provided

The design would have to provide for the removal of any leaked material (from the MCOs) into the storage tubes within twenty-four hours after detection

The MCOs would have to be retrievable (already a characteristic of the Base Case MCO)

Some type of system would have to be provided for inspecting storage tubes (after a leak from an MCO) 
- The spent fuel would have to be stored in such a way that it is protected from any material or conditions which may cause the (hydrogen produced by the) waste to ignite

\subsection{Other Requirements}

There are other regulations in WAC 173-303 that apply to the design of the SNF CSB facility, but these are very generic in nature (e.g., siting criteria) and have not been included here.

\subsection{Summary of Functions To Comply with RCRA Requirements}

Several SNF CSB functions would be required to comply with RCRA, if the stored SNF were classified as "dangerous waste." These functions can be categorized as:

- Already a requirement in the original Feasibility study Base Case Concept 2D,

- Currently not a requirement in the Base Case, but should be a requirement, whether or not RCRA compliance would be required, and

- Currently not a requirement in the Base Case, but would be required only for compliance with RCRA

Only the last category of functions, Iisted in section 3.8 below, would have cost/schedule impacts for the purpose of this trade study.

3.6.1 Functions already a requirement in the Base Case:

MCOs would have to be retrievabie.

MCO overpack capability would have to be provided.

SNF would have to be stored in such a way that it is protected from any material or conditions which may cause it (or the hydrogen produced by it) to ignite. Protective functions would include:

- Adequate MCO cooling

- Storage tube ventilating/purging/inerting capability

- "Explosion-proof" components (e.g., hoist/motor, limit switches) inside the handing cask/floor shield gates, and storage tube, and

- An operating deck HVAC system capable of removing vented hydrogen before it reaches explosive concentrations. 

Case, but should be a requirement, whether or not RCRA compliance would be required:

- The design would have to include watertight storage tubes [HWVP CSB design does not require the tube to be watertight].

- The design would have to provide for prompt (and probably remote) removal of material that has leaked from an MCO.

- Because the entire operating area of the facility has the potential to be radiologicaliy contaminated, all drainage sumps should be provided with continuously operating leak detectors and provisions for removal of accumulated liquids.

3.6.3 Functions currently not a requirement in the Base Case, that would be required only for compliance with RCRA:

Continuously operating MCO leak detection (capable of detecting leakage within twenty four hours) would have to be provided in lieu of inspection, which probably is not Eeasible.

- Capability to inspect storage tubes, probably remotely, after a MCO leak.

- Depending upon interpretation by the regulator, a minimum thirty-inch separation (or other spacing arrangement) between storage tubes may be required. This would have no known purpose, however, given that inspection by direct observation is not feasible. A waiver of this requirement would be anticipated.

\subsection{Detailed Schedule Impacts}

MCO leak detection:

If installation of detectors requires modification of each tube (e.g., watertight penetrations), then the duration of both tube procurement and tube installation could be extended. If installation of detectors requires modification of the operating deck floor (e.g., embedded cable conduits), then the construction duration for the operating deck floor could be extended.

Because of the lead time required, procurement of the MCo leak detection system and other RCRA leak detection

$$
\mathrm{H}-10
$$


systems should be initiated as soon as possible after a decision is made to provide these functions.

- Post-leakage inspection of storage tubes:

No anticipated effects on schedule.

- Minimum thirty inch separation between tubes

No anticipated effects on schedule, if waived.

3.8 Equipment Required to Implement RCRA Functions

The design functions to comply with RCRA would require the following equipment:

- MCo leak detection (per tube, plus one central display panel) :

- In-tube sensor

- Signal path from sensor to display, via water-tight penetration through tube or conduit to and through operating deck, plus cabling to display panel location

The direct cost is estimated to be $\$ 3.0$ million and the cost of Engr/PM/CM approximately $\$ 1.6$ million

- Post-leakage inspection of storage tubes:

No additional equipment would be anticipated above the inspection capability that would have to be built in to provide the leakage removal capability referred to in Section 3.7 above.

- Minimum thirty inch separation between tubes

No additional equipment would be anticipated, if waived.

\subsection{SCHEDULE}

The procurement and installation of an MCO leak detection system extend the facility completion dace a minimum of two months. 
5. 0 COST ESTIMATES

The assumptions, exclusions, and basis for the estimate remain the same as for the concept 2D Feasibility study. The difference in the direct cost from the baseline concept 2D estimate is:

$\begin{array}{lll}\text { Direct cost, } & \text { add } & \$ 3,000,000 \\ \text { Mech/I\&C/Elec } & & \$ 1,470,000 \\ \text { Engr/PM/CM, } & \text { add } & \$ \$ 1,470,000\end{array}$

\subsection{REFERENCES}

"Staging and Storage Facility Feasibility Study Final Report", Fluor Daniel, Inc., February 1995.

WHC-SNF-FRD-014, May 1995, Section 3.2.2.1.2.2, Rev. A, "Draft Performance Specification for the Spent Nuclear Fuel Canister Storage Building" (Contains tabular data from R. G. Cowan of WHC on proposed MCO description). 

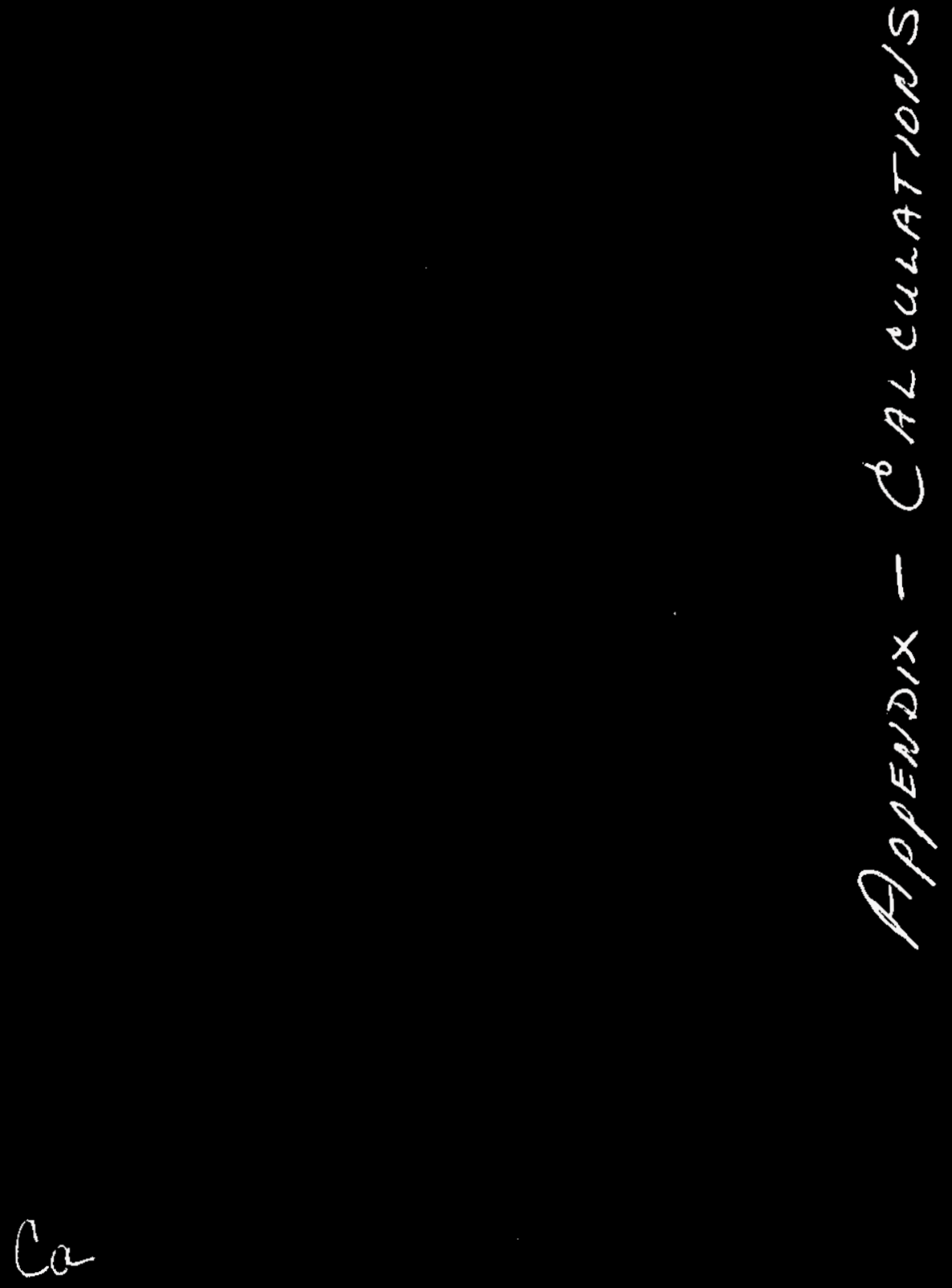

WHC-SD-W379-ES-003 Rev. 0 


\section{PROCESS CALCULATIONS}

\section{CONCEPT 2D}

$$
C_{a-i}
$$

WHC-SD-W379-ES-003 ReV. 0 


\section{Hydrogen generstion at $100^{\circ} \mathrm{F}$
Concentration of $\mathrm{H}_{2}$ in Tubes \\ howed on LATA tests}

For an 8-canister MCo at $50^{\circ} \mathrm{F}$, the nominal. $H_{2}$ genetation rate was 1.2 Lldoy and the max rate was 14 Liday.

At $100^{\circ} \mathrm{F}$, the $\mathrm{H}_{2}$ generation per canister will be $10 \times$ greater, based on LATA info (RFK-339). The $H_{2}$ generation per mco will be greater by $(10 / 8)(10)=12.5$.

The nominal $H_{2}$ generation rate at $100^{\circ} \mathrm{F}$ is

$$
(12.5)(1.2 \mathrm{~L} / \mathrm{D}) /(28.3 \mathrm{~L} / \mathrm{ft} 3)=0.53 \mathrm{ft} / \mathrm{D} \text { per MCO }
$$

The tube volume is $148.2 . \mathrm{ft}^{3}$ ard each. M.co is $45.4 \mathrm{ft}^{3}$

(Ref. Cals. of $1 / 18 / 95$ ) Free volume $=57.4 \mathrm{ft}^{3}$

The $\mathrm{H}_{2}$... volume at $6 \%$ concentration is $3.06 \mathrm{ft}^{3}$

(at this pornt, the tube pressure is 0.8 psig.)

The time for the nominal meOs to form $6 \% \mathrm{H}_{2}$ in tubes: $(3.06) /(0.53) / .2=2.9$ dags

On average the number of tubes to be purged per dily is $(750 \mathrm{mo}) /(2.9 \mathrm{~d}) /(2 \mathrm{mo})=130$ per day

I all 440 tubes are filled, $440 / 2.9=152$ per day,

Total $\mathrm{H}_{2}$ generation $=(7.50)\left(0.53 \mathrm{ft}^{3} / \mathrm{d}\right)=400 \mathrm{ft} / \mathrm{d}=0.3 \mathrm{ft} / \mathrm{men}$ to maintain $\mathrm{H}_{2}$ at $2 \%(1 / 2, L E L)$, required air siow is $14 \mathrm{Ft}^{3} / \mathrm{min}$

However, $k_{r}$ concentration will require much mare flow 
BASE CASE

DATE $5 / 15 / 95$

CONT. NO. O4436306

$\frac{\text { BY RED }}{\text { SHEET NO. }} \frac{\text { CHK'D }}{1 \ln 3}$

$\mathrm{H}_{2}$ Generation at $100^{\circ} \mathrm{F}$.

Time to reach 690 in tubes, based on 5/8/95 FAX

At $100^{\circ} \mathrm{F}$ the nominal Case $\mathrm{A}$. $\mathrm{H}_{2}$ generation rate is about $3.5 \mathrm{~L} / \mathrm{d}$ (see page 2) and the max Case A $\mathrm{H}_{2}$ rate is about 40 Ld (see page 3 ). With $80 \%$ of the canisters nominal (on average) and $20 \% \mathrm{max}$, the average $H_{2}$ rate is $(0.80)(3.5)+(0.20)(40)=10.84 d$

As shown in the calculation of $5 / 8 / 95$, the free volume in a tube with. Two mos is $57.4 \mathrm{ft}^{3}$.

$(57.4 f+3)(28.3 \mathrm{~L} / \mathrm{ft}+3)=1620 \mathrm{~L}$

The $H_{2}$ concentration will reach $6 \%$ when the volume of $\mathrm{H}_{2}$ generated. reaches $(6 \% / 94 \%)(1620 \mathrm{~L})=103 \mathrm{~L}$

The arengetime required for two Mic's to bring the $\mathrm{Hz}$ up to $6 \%$ by vol:

$$
\begin{aligned}
(103 L) /(10.84 m(0-d) /(2 m c 0)= & 4.77 d \\
& \text { say }+.8 \text { days }
\end{aligned}
$$

If there are 750 mos in 375 tubes, the purge has to be fer formed $(375) /(4.8)=78$ per day if all 440 tubes are filled $(440) /(4.8)=92$ per day

Total. $H_{2}$ generation $=(750)(10.8 \mathrm{Ld})=8100 \mathrm{Hd}=5.6 \mathrm{~L} / \mathrm{min}=0.2 \mathrm{H} / \mathrm{m}$ at $880 \mathrm{mcos}_{3} 0.23 \mathrm{ft} / \mathrm{min}$.

to maintain $2 \%$ or less $\mathrm{H}_{2}$, flow reid is $12 \mathrm{ft} / \mathrm{min}$. However, $k_{r}$ concentration will require much moro flow. 


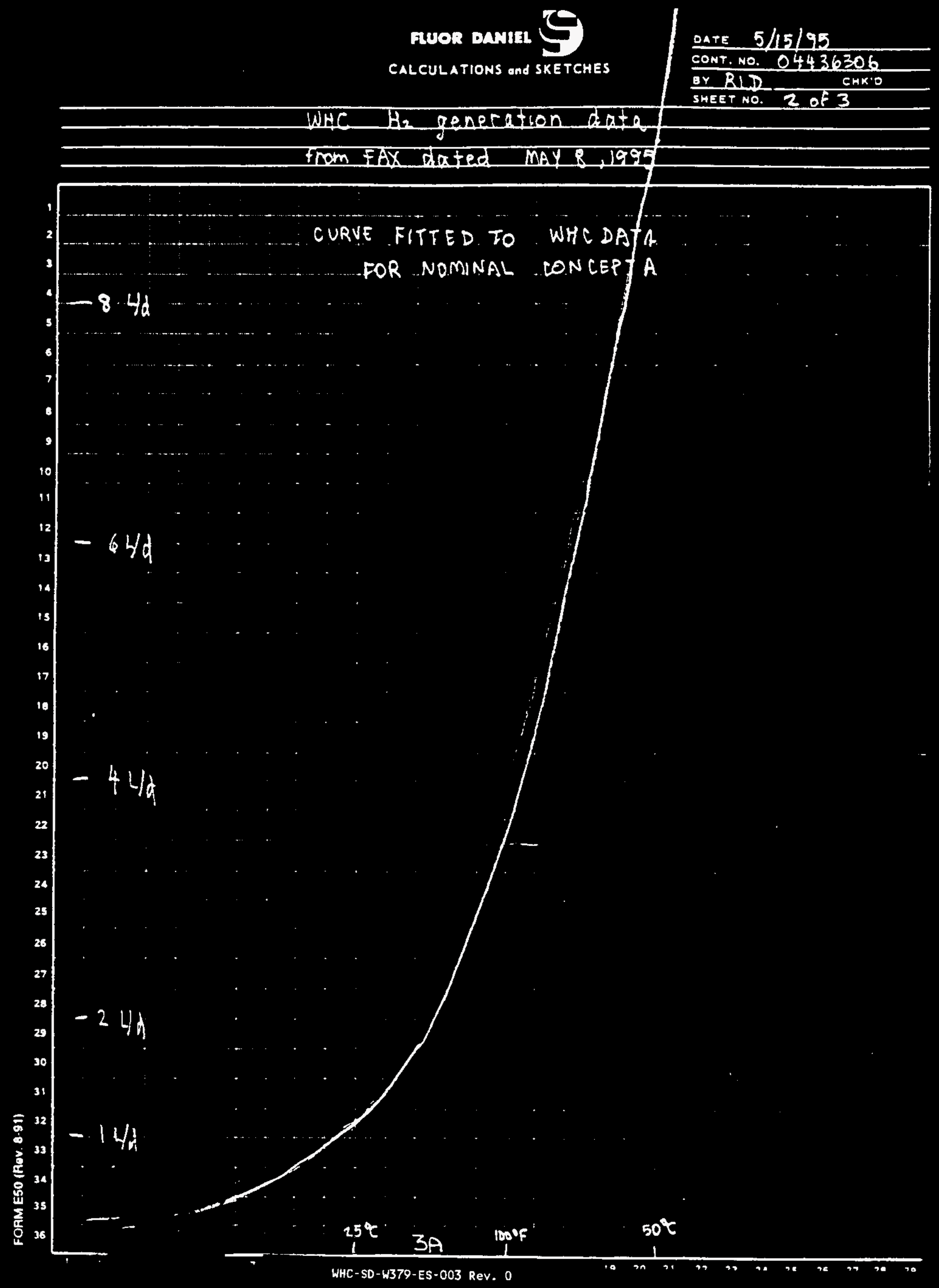




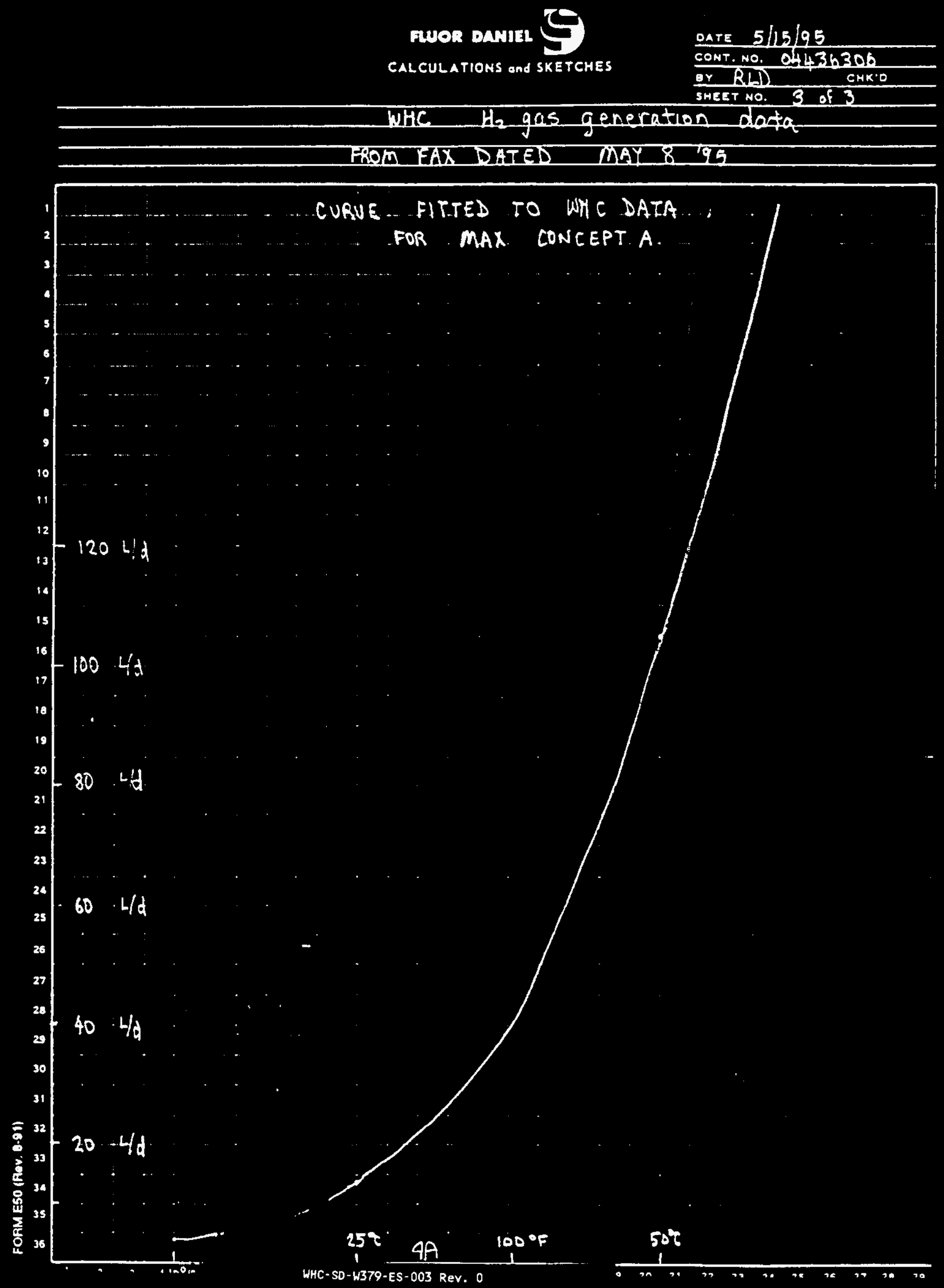


SST FEASIBILITY

TAsk 2 Moo gas release calculation
04436305

RID $1 / 18 / 95$

pol of 2

Option where storage tubes are sealed,

except for a vent line which. is

opened regularly

Worst case leak rate per 8 canister imco is 1440 (if. Fax from craig swanson dated $1 / 16 / 94$ )

$(1440)\left(28.324 / \mathrm{ft}^{3}\right)=0.494 \mathrm{ft}^{3} / \mathrm{D}$

MCO outer dimensions are $14^{\prime}-5.5^{\prime \prime} \times 2^{\prime}-0^{\prime \prime}$ OD. (Design Basis)

nco volume $=\pi(1.0)^{2}(14.46)=45.4 \mathrm{Ft}$ displacement.

existing stor age tube length is $709^{\prime}-0^{\prime \prime}-667^{\prime}-3 / 4^{\prime \prime}-5^{\prime}-10^{\prime \prime}$ for standard tube (Ref H-2-120397 R:y.l) not counting Imprest scioricers. The bottom $23^{\prime}-4^{\prime \prime}$ of tube is $28^{\prime \prime}$ OD, the top $12^{\prime}-1^{\prime \prime}$ is $30^{\prime \prime} 00$. Overall height $=35^{\prime}-5^{\prime \prime}$ (Ref H-2-120395 fie I). The top tube is $2 g^{\prime \prime}$ iD ( $1 / 2^{\prime \prime}$ wail). Impact ris:orber: only have about 4 $1 / 2$ "thickness of sol .1\% meta! with an OD of "SP.5" or 26.5 "

$$
\begin{gathered}
35^{\prime}-5^{\prime \prime} \\
-28^{\prime}-11^{\prime \prime} \\
-\quad 0^{\prime}-9^{\prime \prime} \\
\hline 5^{\prime}-9^{\prime \prime}
\end{gathered}
$$

Just below 5 pig, the plug will lift up.

we must say below say 4 sig

$$
\begin{aligned}
\text { Tube internal volume } & =\frac{1}{4} \pi(27 / 12)^{2}(23.33)+1 / 4 \pi(29 / 12)^{2}(12.0833) \\
& =92.77 \mathrm{Ft}^{3}+55.43 \mathrm{ft}^{3} \\
& =148.2 \mathrm{Ft}^{3} \\
\text { Impact ocsorber }=1 / 4 . & \pi(26.5 / 12)^{2}(4.5 / 12)=14 \mathrm{ft}^{3}
\end{aligned}
$$

Free volume in tube orth single moo \& absorber $=101.3 \mathrm{ft}$ ? by $0,5 f e r$ ce

pressure rise in ie tube will be limited on ting bellows joint $x$ : " top. The vendor calculated 8 pig. maximum preacid. fore the bellows can no longer

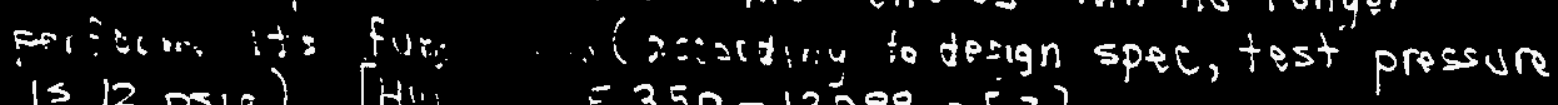
$[3.50-13088$ p. 5,7$]$

$\therefore 5 A$ :

WHC-SD-W379-ES-003 Rev. 0 
TASk 2 Mco gas release

When there is one 8-canister MCO present, the nomber of atmospheric $\mathrm{Ft}^{3}$ can increase to $(101.34)(18.7) /(14.7)=128.92$ :

In - the tube before the pressure approaches 4 psig (18.7 psia). The time required to reach 4 psig is $(128.92-101.34 \mathrm{Ft}) /(0.494 \mathrm{Ft} / \mathrm{D})=56$ days with one 8-canisterm

If there are two 10 canister mco's in a fube, the pressure insreases much faster: gas relexse $=2(10 / 8)(0.494 \mathrm{Ft} / \mathrm{h})=1.235 \mathrm{FH} / \mathrm{D}$ into tube Free volume in tube $=\left(148.20 \mathrm{ft}^{3}\right)-2(45.42 F+3)-2(1.445+3)$

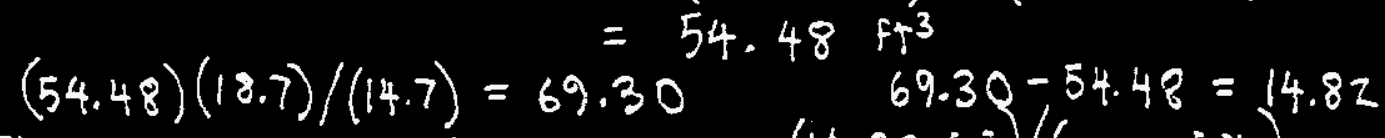

MULTIPLE MLO Maximum:

The time to reach 4 psig $=\left(14.82 \mathrm{H}^{3}\right) /(1.235 \mathrm{Ft} 3 / \mathrm{D})=12$ days for a tube with two 10 -canister MCO's at max gas raf: at the average gas rate, the time would be $(12)(14 \mathrm{~L} / 1.2 \mathrm{~L})=140$ days If we has all 10-canister mco's the number would be about 960 mco's. If the meOs were placed two per tube, there would be 480 tubes to be vented. 44 days is a conservaisue value for the time between venting because it is based on the worst-case gas release; the nominal gas release is less then $10 \%$ of that. Therefore, a conservative estimate of the numbe: of tubes that have to be rented is (4ne 12$)=$ to tubes per dey. For the nominal tube his venting schedule means that we usuall, int the tube before the pressure reaches. psig.

NCLUSION:

The off-gas from

a feasibility problem: schedule, but explos.

NOTE The next calc (1/19/95) shows 6 A

cols does rot couse

"i as pressure or ventiro

$\therefore$ ard has to be addressed. 
FLOR DANIEL 20 DATE $5 / 30 / 95$

CALCULATIONS ORd SKETCHES

CONT. NO. 04436306

BASE CASE

BY R. DeshotelsCHK'D

SHEET NO. L af

MOD SERVICING

BASED ON DATA TESTS

The nominal rate of $\mathrm{H}_{2}$ generation is $0.53 \mathrm{scf} / \mathrm{tay}$. at $100^{\circ} \mathrm{F}$. (See calculation of 5/8/95)

379.45 SCH $=1.16$-mote. $\quad 0.53$ SCR $=0.001416$-male

$$
\mathrm{U}+2 \mathrm{H}_{2} \mathrm{O} \rightarrow \mathrm{UO}_{2}+2 \mathrm{H}_{2}
$$

0.0014 boole of water reacts per day at the nominal rate.

$$
(0.0014 \mathrm{~kb} \text {-mole })(18 \mathrm{Bb} / 16 \text { moe })=0.025 \mathrm{lb}
$$

at $100^{\circ} \mathrm{F}$ the density of water is $62 \mathrm{lo} / \mathrm{ft}^{3}$

$0.025 \mathrm{lb}=0.00040 \mathrm{Ft}^{3}$ of water reacted per day per me o

Assuming the Mco.venits at 100 p sig and $100^{\circ} \mathrm{F}$,

the moisture content of the vent gas is 8,700 ppm bo ty

$\left(0.53\right.$ SeLF $\left.\mathrm{H}_{2}\right) \cdot(0.0087)=0.0046$ SCF water va par

$$
\begin{aligned}
(0.0046 \mathrm{scF})(379.45 \mathrm{scF} / \mathrm{mde}) & =0.000012 \mathrm{lb} \text {-mole moisture } \\
& =0.00024 \mathrm{lb}
\end{aligned}
$$

evaporated moisture is negligible compared to reacted water.

According to Feasibility Study Mas sixth, there is only. 6." freeboard above the top anister. Before 6" of water evaporates, the Moo, s to be serviced. Water. volume $=\pi(1 \mathrm{ft})^{2}(1 / 2 \mathrm{ft}) 1.6 \mathrm{Ft}$

$\left(1.6 \mathrm{Ft}^{3}\right) /(0.00040 \mathrm{ft} / \mathrm{D})=4,000 \mathrm{~d}$ between service $880 \mathrm{mc0} .1$ (ain. 11 years) nominal

880 MOs $/ 4.000=0.22$ IC: $; y$ for nominal.

max $H_{2}$ rate was $12 x$ greater of $7 A$ per day $4.00 / 12=300$ do 


\section{THERMAL ANALYSIS \\ CONCEPT 2D AND TASK "G"}

$$
\text { TA- ii }
$$

WHC-SD-W379-ES-003 ReV. 0 


\section{TABLE OF CONTENTS}

THERMAL ANALYSIS 1

TRANSIENT ANALYSIS $\quad 8$

CFD MODELING 12

$$
\text { TA- iii }
$$

WHC-SD-W379-ES-003 Rev. 0 
C:IEDOWREORT.4

\section{THERMAL ANALYSIS FOR STORING K-BASIN FUEL IN THE HWVP CANISTER STORAGE BUILDING}

Following is the rough calculation of heat transfer in the storage vaults. The assumptions as well as calculation results can be used anly as a first guess. Detailed calculation using the Computational Fluid Dynamics (CFD) technique is proposed on the next stage of this project.

K-Basin fuel elements are stored in 2 vaults of the canister storage.

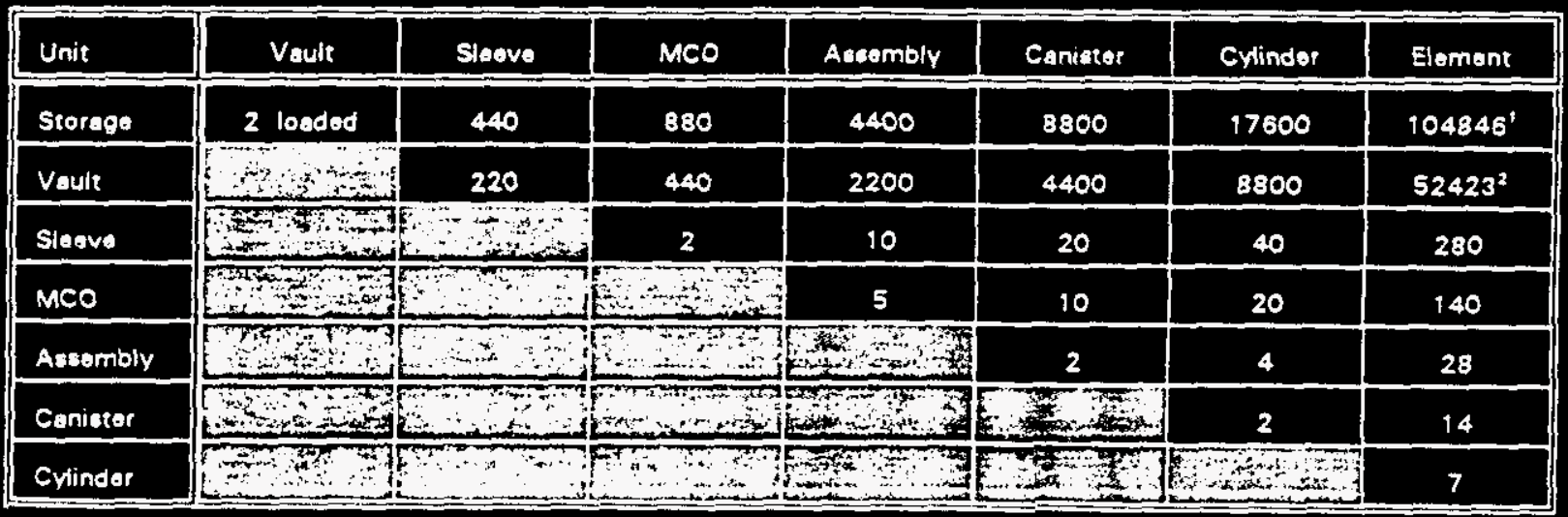

Table 1. Number of Units in the Storage

There is a mixed heat transfer media: air or water inside the MCOs, air between MCOs and sleeves, and air as a cooling media in the vault.

There is $20 \%$ of the maximum heat decay fuel elements and $80 \%$ of the nominal heat decay fuel elements. A single maximum heat decay element is releasing $3.44 \mathrm{~W}$ of heat. A single nominal heat decay element is releasing $1.56 \mathrm{~W}$ of heat.

It is assumed for conservative reason that 280 elements of maximum heat decay $(3.44 \mathrm{~W})$ can be loaded into a sleeve and located in the last row of the vault. This elements will be expressed to the highest vault air temperature. For comparison a number of calculations are made for the high loaded sleeve located at the beginning of the vault in the first row and expressed to the inlet airflow.

At the first stage, coolic 3 air is supplied by the forced ventilation system with $100 \%$ of

\footnotetext{
'Baced on 750 MCO:

${ }^{2}$ Bace on 375 Mcose
} 


$$
\text { TA- } 2
$$

return air. Proposed air inlet temperature is $35^{\circ} \mathrm{F}$. For comparison, inlet temperature of $50^{\circ} \mathrm{F}$ is analysed as well. Maximum allowable temperature of the surface of a fuel element is $100^{\circ} \mathrm{F}$. Calculation is made for the maximum vault load of $320 \mathrm{~kW}$ at for forced ventilation system and maximum vault load of $270 \mathrm{~kW}$ for natural convection. The difference of these loads is due to additional heat load from structures at low supply air temperature.

The purpose of this calculation is to find the maximum temperature of the surface of a fuel element.

The highest temperature is expected at the fuel elements closed to the center of the MCo. Each fuel element is assumed as a solid uranium cylinders surrounded by water or air (Figure 2).

The diameter of the hollow outer element ring is assumed the same as the diameter of the outer zirconium cladding (identified as $\$ 17$ ).

$$
D_{17}=6.1 \mathrm{~cm}=2.4 \mathrm{in}
$$

The diameter of the inner cylinder of the outer element (identified as \#14) is

$$
D_{14}=4.4 \mathrm{~cm}=1.7 \mathrm{in}
$$

Relative diameters for the inner hollow cylinder (Identified as $\# 13$ and $\# 10$ ) are:

$$
\begin{aligned}
& D_{13}=3.2 \mathrm{~cm}=1.25 \mathrm{in} \\
& D_{10}=1.15 \mathrm{~cm}=0.45 \mathrm{in}
\end{aligned}
$$

Relatively the thicknesses of uranium are

$$
\begin{aligned}
& \Delta_{\text {oute }}=2.4-1.7=0.7 \mathrm{in} \\
& \Delta_{\text {inser }}=1.25 \cdot 0.45=0.8 \mathrm{in}
\end{aligned}
$$

The uranium cross-section is

$$
\begin{aligned}
S=\pi & 14\left(\left(D_{17}{ }^{2}-D_{14}{ }^{2}\right)+\left(D_{13}{ }^{2}-D_{10}{ }^{2}\right)\right)=\pi / 4\left(\left(2.4_{17}{ }^{2}-1.7_{14}{ }^{2}\right)+\right. \\
& \left.+\left(1.25_{13}{ }^{2}-0.45_{10}{ }^{2}\right)\right)=3.32 \mathrm{sq} . \mathrm{in}
\end{aligned}
$$

The diameter of the equivalent by is ross-section solid uranium cylinder is

$$
D=(45)^{0.5}=(4 * 3.32 / \pi)^{0.5}=2.06 \text { in }
$$

The volume of a single element is:

$$
V=\pi / 4 \because=\pi / 4(2.06 / 12) \cdot 2=0.0463 \mathrm{ft}^{3}
$$

Since the maximum heat dec:= $\quad 44 \mathrm{~W}$ which is $11.74 \mathrm{Btu} / \mathrm{h}$, the rate of heat flow is 


$$
a_{x}=Q / V=11.74 / 0.0463=253.6 \mathrm{btu} / \mathrm{h}-\mathrm{ft}^{3}
$$

The heat networking model is assumed with a number of zones of heat transfer. Considering a symmetrical heat transfer network the one-dimensional scheme is utilized in the following Figure 1.

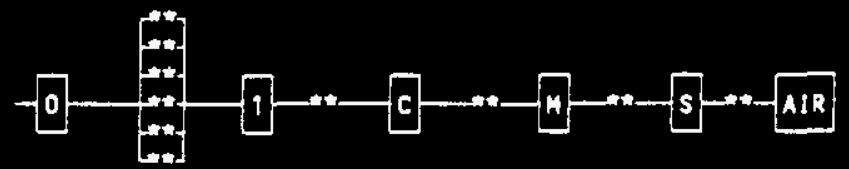

Figure 1. Heat Transfer Network.

$\begin{array}{ll}\text { Gap X: } & \text { between the inner and the outer rings of a fuel element } \\ \text { Gap X-1: } & \text { between the center element and six peripheral fuel elements } \\ \text { Gap 1-C: } & \text { between the peripheral fuel elements and the canister, } \\ \text { Gap C-M: between the canister and the MCO, } \\ \text { Gap M-S: between the MCO and the sleeve, } \\ \text { Gap S-AIR: resistance between the sleeve and surrounding air. }\end{array}$

Networking resistance factors:

Zone $x$; 1 element : $\quad f_{x}=1$

Zone $x-1: 6$ elements: $\quad f_{1}=1+1 / 6=1.17$

Other zones in series: $\quad f=1$

Heat transfer between two adjacent zones $i$ and $i+1$. Zones are assumed as flat

$$
q_{i}=q_{i+1}+k\left(1 / f_{i}\right) A_{i}\left(T_{i}-T_{i+1}\right) n_{i}
$$

where,

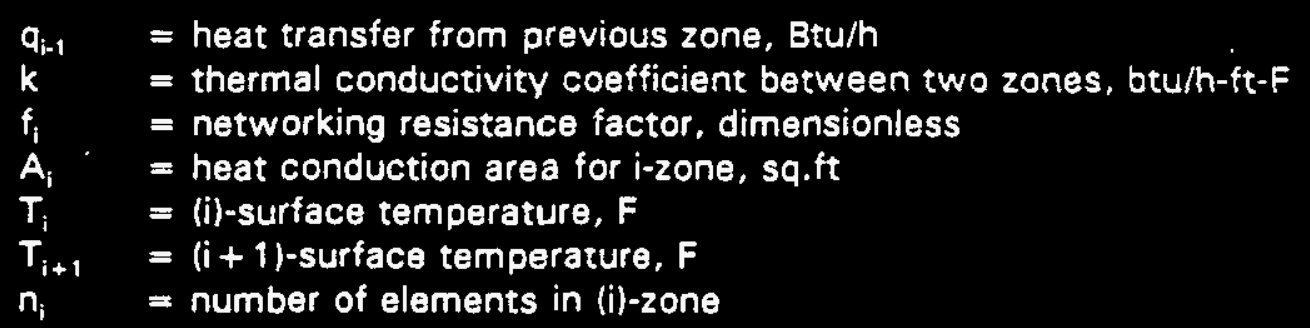

It is assumed for simplification reasons that the thermal conductivity coefficients are not changing with temperatures.

Following calculations, made for heat transfer , reas, considering $80 \%$ of actual height of fuel element.

For zone $x$ the heat transfer area is calcula: - For a single fuel element:

$$
A_{x}=\pi\left(D_{17}\right) L 80 \%=\pi(2.4)=19 \quad .8=169 \text { sq.in }=1.17 \text { sq.ft }
$$




\section{TA 4}

For zone $x-1$ the heat transfer area is calculated for 7 elements:

$$
A_{01}=\pi\left(D_{17} 7\right) \text { (L) } 80 \%=\pi(2.4 \text { 7) }(28) \cdot 0.8=1182 \mathrm{sq} . \mathrm{in}=7.04 \mathrm{sq} . \mathrm{ft}
$$

For zone 1-C the heat transfer area is assumed as an average between 7 elements and cylinder tube surfaces:

$$
\begin{gathered}
A_{1 c}=\left(A_{x 1}+A_{c}\right) / 2 \times 80 \%=\pi L\left(6^{*} D_{x 1}+D_{c}\right) / 2 * 80 \%=\pi(28)\left(6^{*}(2.4)\right. \\
+(9) / 2=0.8=823 \mathrm{sq} . \mathrm{in}=5.72 \mathrm{sq} . \mathrm{ft}
\end{gathered}
$$

For zone $C-M$ the heat transfer area is assumed as an average between 2 assemblies ( 2 canisters, 28 elements) and MCO surfaces:

$$
\begin{aligned}
\left.A_{C M}=\left(4 A_{C}+A_{M}\right) / 2=\pi L(4)_{C}+D_{M}\right) / 2 & =\pi(28)(4 * 9+24) / 2 \\
& =2638 \mathrm{sq} \cdot \mathrm{in}=18.33 \mathrm{sq} . \mathrm{ft}
\end{aligned}
$$

For zone M-S the heat transfer area is assumed as an average between the MCO and the sleeve surfaces (total height is 98 " "3):

$$
\begin{gathered}
A_{M S}=\left(A_{M}+A_{S}\right) / 2=\pi L_{\text {Tor }}\left(D_{M}+D_{S}\right) / 2=\pi(98 * 3)(24+29) / 2=24476 \text { sq.in } \\
=170 \text { sq.ft }
\end{gathered}
$$

Heat transfer surface from a sleeve to the cooling airflow is:

$$
A_{1}=\pi L D_{S}=\pi(164 * 2 / 12)(29 / 12)=208 \text { sq.ft }
$$

Maximum center line temperature at the center zone 0 element (Kreith and Bohn, Principles of Heat Transfer, 5 ed., p.96, Eq.2.51. Ref. 1b)

$$
T_{e l}=T_{x}+a_{x}(D / 2)^{2} /\left(4 i_{\text {uranium }}\right)
$$

where:

$$
\begin{aligned}
q_{x} & =\text { rate of heat flow, Btu/h- } \mathrm{ft}^{3} \\
\lambda_{\text {uranim }}= & \text { thermal conductivity coefficient for uranium, } 17.3 \text { Btu/h-ft- }{ }^{\circ} \mathrm{F} \text { (Kreith } \\
& \text { and Bohn, Principles of heat Transfer, Ed.5, p.A13, Ref. Id). }
\end{aligned}
$$

Heat transfer coefficient, $k$, depends on the media.

The total normal emittance for zirconium is assumed as $\mathrm{f},{ }^{\circ}$ dark paints as 0.85 (ASHRAE 1989 , p.3.8. Table 3. Ref. 2b). For horizontal direction $\mathrm{c}$. heat flow and $90^{\circ} \mathrm{F}$ mean temperature the approximate thermal resistance of plant. ispace for each air gap is $0.77^{\circ} \mathrm{F}-\mathrm{ft}^{2} \cdot \mathrm{h} / \mathrm{Btu}$ (ASHRAE 1989, p.22.3, Table 2. Ref. sit:

Thermal conductivity coefficient for uranium is approxiri: $=$ Iy $17.3 \mathrm{Btu} / \mathrm{h}-\mathrm{ft}-{ }^{\circ} \mathrm{F}$ (Kreith and Bohn, Principles of heat Transfer, Ed.5, p.A 13. Ref. id;

Total heat transfer coefficient for an element with twe $\therefore$ aps and uranium slab 
(zirconium claddings are ignored due to their low thickness) is

$$
\begin{aligned}
& k=1 /\left(R_{\text {opp } 1}+\Delta_{1} / \lambda_{\text {urenivm }}+\Delta_{2} / \lambda_{\text {uronium }}+R_{\text {opp } 2}\right) C \\
& =1 /(0.77+(0.7 / 12) / 17.3+(0.8 / 12) / 17.3+0.77) \cdot 1.1=0.715 \text { Btu/h-ft }{ }^{2}{ }^{\circ} \mathrm{F}
\end{aligned}
$$

where

$$
\begin{aligned}
& \mathbf{R}_{\mathrm{gap}} \quad=\text { Air gap resistance, } \mathrm{F}-\mathrm{ft}^{2}-\mathrm{h} / \mathrm{Btu} \\
& \Delta_{\text {urnnium }} \quad=\text { Thickness of uranium, in } \\
& \text { c } \quad=\text { adjustment coefficient for conductance between elements } \\
& \text { by touching (assumed 1.1) }
\end{aligned}
$$

Following data are taken from HWVP project (FDI calculation No. E350-HV-1802, Book II):

Heat transfer coefficient between overpack and sleeve $h_{0 s}=0.329 \mathrm{Btu} / \mathrm{h}-{ }^{\circ} \mathrm{F}-\mathrm{ft}^{2}$

Heat transfer coefficient between sleeve and airflow is calculated using ASHRAE 1989 Fundamentals, Chapter 3, p.3.15, Ref.2e) as a function of air velocity (vertical plane surfaces, $V<16 \mathrm{fps}$ )

$$
h=0.99+0.21 \mathrm{~V}
$$

If water is used as a media between surfaces the free convection film coefficient is recalculated as:

where,

$$
h=N u *(k / L)=C(G r \operatorname{Pr})^{n}(k / L)
$$

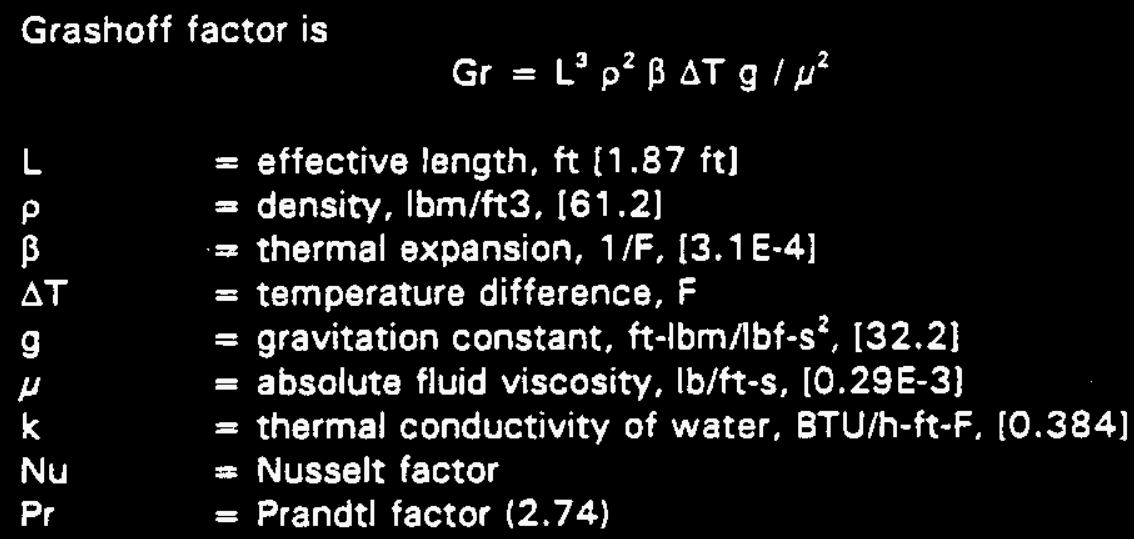

For forced air cooling system airflow is given. If passive cooling is ta ied, airflow is calculated as a function of stack height, air densities, and system res. System conductance (K 1 ) is based on system hydraulic characteristic: Project (FDI calculation No. E350-HV-1802, Book II) for airflow at O. $\Delta P=0.19$ in. WG which is $K 1=0.19 / 90000^{2}=2.34 \cdot 10^{-11}$ in. $\mathrm{K}:$ ance. calculated in HWVP $0000 \mathrm{cfm}$ and $\mathrm{m}^{2}$ for three vaults. For two vaults this coefficient is different due to higher rer. ce in the vaults. 
TA- 6

Following system of simultaneous algebraic equations describes the heat transfer process

1) Maximum temperature in the center line of the centered fuel element, $T_{\text {of }}$, as a function of surface temperature, $T_{x}$

$$
T_{e t}=T_{x}+q(D / 2)^{2} /\left(4 k_{\text {uronium }}\right)
$$

2) Heat transfer between surface of a centered fuel element and six surrounding elements (zone 0.1)

$$
6 q=k\left(1 / f_{1}\right) A_{x 1}\left(T_{x}-T_{1}\right)
$$

3) Heat transfer between surface of six elements and a single canister cylinder (zone 1.C)

$$
7 q=k(1 / f) A_{1 c}\left(T_{1}-T_{c}\right)
$$

4) Heat transfer between surface of assembly and MCO (zone C-M):

$$
28 q=k(1 / f) A_{C M}\left(T_{C}-T_{M}\right)
$$

5) Heat transfer between surface of MCO and sleeve (zone M-S):

$$
280 q=k \quad A_{M S}\left(T_{M} \cdot T_{s}\right)
$$

6) Heat transfer between surface of sleeve and airflow (zone S-Air):

$$
280 q=h A_{s}\left(T_{s}-T_{\text {out }}\right)
$$

7) Heat absorption by airflow

$$
Q=c_{\text {air }} 60\left(p_{\text {in }}+p_{\text {our }}\right) / 2(C F M)\left(T_{\text {our }}-T_{\text {in }}\right)
$$

Following two equations are used for passive ventilation only in order to find airflow. For a forced cooling system airflow is given.

8) Hydraulic resistance of the natural convection system (T-DUCT calculation)

$$
\Delta P=k \uparrow(C F M)^{2}
$$

9) Stack effect

$$
P_{\text {renok }}=0.192\left(\rho_{\text {out }}-\rho_{\text {in }}\right) H
$$

Let us rearrange those equations and present them in a calculation order:

0)

$$
\text { CFM = initial guess }
$$

$$
T=T+Q /(c 60(p+p) / 2 \text { (CFM)) }
$$


2)

$$
\Delta P \quad=k 1(\text { CFM })^{2}
$$

3)

$$
\begin{aligned}
& \rho_{\text {our }}=1.75 E-7 \mathrm{~T}^{2} \text { aur }-0.000166 \mathrm{~T}_{\text {oun }}+0.086 \\
& \rho_{\text {in }}=1.75 E-7 \mathrm{~T}^{2} \text { in }-0.000166 \mathrm{~T}_{\text {in }}+0.086
\end{aligned}
$$

4)

$$
P_{\text {reak }}=0.192\left(p_{\text {our }}-P_{\text {in }}\right) H
$$

If $\Delta P=P_{\text {suek }}$, follow to the next calculation. Other vice change the initial guess and repeat iterations

5

$$
T_{s}=T_{\text {our }}+n_{4} q /\left(h_{s A} A_{s}\right)
$$

6) $T_{0}=T_{s}+n_{3} q /\left(h_{c s} A_{O S}\right)$

7) $T_{c}=T_{0}+n_{2} q /\left(k(1 / f) A_{c o}\right)$

8) $T_{1}=T_{c}+n_{1} q /\left(k(1 / f) A_{1 c}\right)$

9) $\quad T_{x}=T_{1}+n_{x} q /\left(k\left(1 / f_{1}\right) A_{1}\right)$

10) $T_{c l}=T_{x}+q_{x}(D / 2)^{2} /\left(4 k_{\text {uranium }}\right)$ 
$T A-8$

\section{Transient Analysis}

\section{Description}

The following study determines the heat transfer conditions after the loss of cooling air. The time duration will characterize the level of safety associated with the use of cooling air system.

The calculation is based on identification of changes in enthalpy between time periods. The difference between the sum of enthalpies for each material divided by the heat load will identify the time for reaching the particular temperature conditions.

Initial temperatures are assumed at airflow of $200,000 \mathrm{cfm}$ flowing through 2 vaults fully loaded with radioactive material. The total heat load is $320 \mathrm{~kW}$.

\section{Assumptions}

1) The heat from nuclear decay during the loss of cooling airflow is considered to be absorbed by fuel elements, cylinders, and assemblies filled with water, sleeves, and internal air.

2) It is assumed that the total mass of each heat absorption material has the same average temperature.

3) It is assumed for conservative reasons that the sleeves loaded with $3.44 \mathrm{~kW}$ elements located at the end of the vault where the air temperatures are the highest.

4) It is assumed that the difference between temperatures of heat absorbing materials is proportional regardless the fact of the loosing cooling air.

\section{Calculation}

Following heat transfer calculations are obtained for the steady state conditions. Initial data are presented at the time of accident occurrence.

Initial:
Average air temperature in the vault
Sleeve temperature
$=37.35^{\circ} \mathrm{F}$
MCO temperature
$=51.4^{\circ} \mathrm{F}$
Canister temperature
$=110^{\circ} \mathrm{F}$
Water temperature
$=110.8^{\circ} \mathrm{F}$
$=111.85^{\circ} \mathrm{F}$

Following data are the results of calculations made for the different canister temperatures with an approximate interval of $10^{\circ} \mathrm{F}$ in order to identify the change in temperature for each heat absorption material. 
Period 1:

Average air temperature in the vault

Sleeve temperature

MCO temperature

Canister temperature

Water temperature

$=41.75^{\circ} \mathrm{F}$

$=62.6^{\circ} \mathrm{F}$

$=121.2^{\circ} \mathrm{F}$

$=122.0^{\circ} \mathrm{F}$

$=123^{\circ} \mathrm{F}$

Period 2:

Average air temperature in the vault Sleeve temperature

MCO temperature

Canister temperature

Water temperature

Period 3:

Average air temperature in the vault

Sleeve temperature

MCO temperature

Canister temperature

Water temperature

Period 4:

Average air temperature in the vault Sleeve temperature

MCO temperature

Canister temperature

water temperature

Period 5:

Average air temperature in the vault

Sleeve temperature

MCO temperature

Canister temperature

Water temperature

Period 6:

Average air temperature in the vault

Sleeve temperature

MCO temperature

Canister temperature

water temperature $=46.35^{\circ} \mathrm{F}$

$=72.6^{\circ} \mathrm{F}$

$=131.2^{\circ} \mathrm{F}$

$=132.0^{\circ} \mathrm{F}$

$=133^{\circ} \mathrm{F}$

$=51.2^{\circ} \mathrm{F}$

$=82.6^{\circ} \mathrm{F}$

$=141.2^{\circ} \mathrm{F}$

$=142.0^{\circ} \mathrm{F}$

$=143^{\circ} \mathrm{F}$

$=56.1^{\circ} \mathrm{F}$

$=92.6^{\circ} \mathrm{F}$

$=151.2^{\circ} \mathrm{F}$

$=152.0^{\circ} \mathrm{F}$

$=153^{\circ} \mathrm{F}$

$$
\begin{aligned}
& =61.6^{\circ} \mathrm{F} \\
& =102.7^{\circ} \mathrm{F} \\
& =161.3^{\circ} \mathrm{F} \\
& =162.1^{\circ} \mathrm{F} \\
& =163^{\circ} \mathrm{F}
\end{aligned}
$$

$$
\begin{aligned}
& =66.1^{\circ} \mathrm{F} \\
& =112.6^{\circ} \mathrm{F} \\
& =171.2^{\circ} \mathrm{F} \\
& =172.0^{\circ} \mathrm{F} \\
& =173^{\circ} \mathrm{F}
\end{aligned}
$$

Heat load due to nuclear decay from the entire fuel elements is calculated as:

$$
Q=320 \times 3413=1,092,160 \mathrm{Btu} / \mathrm{h}
$$

The difference between enthaipies is calculated as: 


$$
\text { TA } 10
$$

Elements: $\quad \Delta E_{0}=m_{0} c_{0} n_{0}\left(T_{02} \cdot T_{01}\right)$

Cylinders: $\quad \Delta E_{c}=m_{c} c_{c} n_{c}\left(T_{c 2}-T_{c 1}\right)$

Assemblies: $\quad \Delta E_{m}=m_{m} c_{m} n_{m}\left(T_{m 2}-T_{m 1}\right)$

Sleeves: $\quad \Delta E_{0}=m_{0} c_{0} n_{0}\left(T_{02}-T_{01}\right)$

Water in MCO: $\quad \Delta E_{w}=m_{w} c_{w} n_{w}\left(T_{w 2}-T_{w 1}\right)$

Air in the vaults: $\quad \Delta E_{0}=m_{0} c_{0} n_{0}\left(T_{02}-T_{01}\right)$

where:

$$
\begin{array}{ll}
\mathrm{m} & =\text { material mass, } \mathrm{Ib} \\
\mathrm{C} & =\text { specific heat, Btu/lb- }{ }^{\circ} \mathrm{F} \\
\mathrm{n} & =\text { number of elements } \\
\mathrm{T}_{1}, \mathrm{~T}_{2} & =\text { temperatures at different periods, }{ }^{\circ} \mathrm{F}
\end{array}
$$

Following masses are calculated for a single sleeve:

$$
\begin{aligned}
& \text { Elements: } \quad \mathrm{m}_{0} \quad=51.18 \times 280=14330 \mathrm{lb} \\
& \text { Cylinders: } \quad m_{c}=\left(\pi D_{c} L_{c}+2 \pi D_{c}{ }^{2} / 4\right) \sigma_{c} p_{c} n_{c} \\
& =\pi\left(0.68 \times 2.2+2 \times 0.68^{2} / 4\right) 0.021 \times 490 \times 40=2233 \mathrm{lb} \\
& \text { Assemblies: } \quad m_{m}=\left(\pi D_{m} L_{m}+4 \pi D_{m}^{2} / 4\right) \sigma_{m} \rho_{m} n_{m} \\
& =\pi\left(2 \times 2.33+2 \times 2^{2} / 4\right) 0.031 \times 490 \times 10=3178 \mathrm{lb} \\
& \text { Sleeves: } \quad m_{1}=\pi D_{0} L_{i} \sigma, p_{1}=\pi 2.42 \times 36 \times 0.041 \times 490=5498 \mathrm{lb} \\
& \text { Water: } \quad m_{w}=\pi D_{m}^{2} L_{m} \sigma_{w} \rho_{w}-\Sigma(\mathrm{m} / \mathrm{p}) \\
& =\left(\left(\pi 2.38^{2} / 4 \times 36\right) \cdot 14330 / 1190 \cdot 2233 / 490\right. \text {. } \\
& 5498 / 490) 62.4=7843 \mathrm{lb}
\end{aligned}
$$

Following mass is calculated for the entire storage:

Air:

$$
m_{1}=((603 / 12 \times 2 / 3) \times 447 / 12 \times 133) \rho_{c}=11618 \mathrm{lb}
$$

Specific heat is calculated as:

Uranium elements:

$$
c_{0}=0.027 \mathrm{Btu} / \mathrm{lb}-{ }^{\circ} \mathrm{F}
$$

Stainless steal, Cor-ten:

$$
c_{0}=c_{c}=c_{m}=c_{c}=0.11 B \text { Btu/lb- }{ }^{\circ} \mathrm{F}
$$


Water:

Air:

Total enthaipy:

$$
\Sigma \Delta E=\Delta E_{0}+\Delta E_{c}+\Delta E_{m}+\Delta E_{q}+\Delta E_{w}+\Delta E_{0}
$$

Approximate time difference for temperatures at time index 1 to reach temperatures at time index 2 is calculated as:

$$
t=\Sigma \Delta E / Q
$$




\section{TA 12 \\ CFD MODELING}

The PHOENICS (Parabolic, Hyperbolic or Elliptic Numerical Integration Code Series) is a computer program that simulates fluid flow, heat transfer, and other related phenomena. This simulation is based on mathematical derivation from established physical principles. The basic capabilities provided by PHOENICS include:

-- menu driven interface

-- one-, two-, or three-dimensional in Cartesian, cylindrical-polar or coordinats

- steady-state or transient analysis

-- single phase or two-phase media analysis

-- compressible or incompressible flow

-- subsonic, supersonic or transonic flow

The PHOENICS solves the equations for flows, turbulence, mass and heat transfer by a control volume method based on finite element approach. In the present problem, the flow is mostly turbulent and aiso under buoyancy effect of natural convection. This problem is governed by the Navier-Stokes equations representing the conservation of mass, momentum and energy.

PHOENICS has many limitations and restrictions. First, the realism of its simulations cannot exceed that of the assumptions on which its use is based. Secondly, a simulation produced by PHOENICS has an accuracy that depends upon the amount of computer time that its user has been willing or able to spend. Finally, fluid dynamic phenomena being what they are, it cannot be guaranteed that PHOENICS will provide a converged solution to every problem without user's making special settings of solution-control switches.

CHAM company, the author of PHOENICS, stated that the code "is very well validated and developed from over 10 years of commercial use (Easyfiow, release 2.01, page 1)."

There are a number of different simulations performed for this project using PHOENICS, including vault airflow and temperature distribution (CFD/Model), analyses of airflow around the building (Site Model), and study of entry device effect (T-Entry Iniet Model).

The details of PHOENICS simulation technique will be described using the CFD/Model.

\section{Assumptions and Limitations}

Finite volume method requires that the space be divided into discrete elements. The high-irequency and spatially very small fluctuations of turbulent flow variables cannot be quantified directly. Assumptions must be made for these unknown turbulence correlations. The : st compromise between acceptable computer time and accuracy of the simulation of turi' .nt flow phenomena is the k-e turbulent model, that consists of two additional diffi: itial equations for the turbulent kinetic energy $(k)$ and the dissipation rate. 
For all analyzed models flow in the vault under designed conditions are turbulent (Re $>$ 3000).

\section{Main Equations and Numerical Solution}

Steady state turbulent flow in the vault can be described by conservation equations. The governing equations can be written in terms of cartesian tensors.

Continuity equation:

$$
\frac{\partial}{\partial x_{j}}\left(u_{i}\right)=0
$$

where,

$$
\begin{aligned}
& u=\text { component of mean velocity, } \mathrm{m} / \mathrm{s} \\
& x=\text { coordinates, } \mathrm{m} \\
& i, j=\text { directions }
\end{aligned}
$$

Momentum equation:

$$
\frac{\partial}{\partial x_{j}}\left(u_{i} u_{j}\right)=-\frac{1}{p} \frac{\partial P}{\partial x_{j}}+\frac{\partial}{\partial x_{j}}\left(v_{0: 1}\left(\frac{\partial u_{i}}{\partial x_{j}}+\frac{\partial u_{i}}{\partial x_{i}}\right)\right)+g_{i}
$$

where,

$$
\begin{aligned}
& \rho=\text { density, } \mathrm{kg} / \mathrm{m}^{3} \\
& P=\text { pressure, } \mathrm{Pa} \\
& \mathrm{g}=\text { gravity acceleration, } \mathrm{m} / \mathrm{s}^{2} \\
& v_{\text {off }}=v_{t}+v_{1} \\
& v_{a f}, v_{t}, v_{1}=\text { effective, turbulent, and laminar kinematic } \\
& \text { viscosity, } \mathrm{m}^{2} / \mathrm{s}
\end{aligned}
$$

The turbulent kinematic viscosity is

where,

$$
v_{t}=C_{\mu} k^{1 / 2} * I_{u}
$$

$$
I_{n}=\text { mixing length, meters }
$$

$$
1_{n}=C_{\mu} k^{3 / 2} / \mathrm{e}
$$

Turbulent kinetic energy equation is:

$$
\frac{\partial}{\partial x_{j}}\left(k u_{j}\right)=\frac{\partial}{\partial x_{j}}\left(\frac{y_{n k}}{\sigma_{k}}\right) \frac{\partial k}{\partial x_{j}}+G-\varepsilon
$$

where,

$$
\begin{aligned}
y^{-} & =\text {kinetic energy of turbulence, } \mathrm{m}^{2} / \mathrm{s}^{2} \\
& =\text { generation rate of turbulence energy, } \mathrm{m}^{2} / \mathrm{s}^{2} \\
& =\text { dissipation rate of turbulent kinetic energy, } \mathrm{m}^{3} / \mathrm{s}^{3} \\
& =\text { effective prandt numbers in turbulent model }
\end{aligned}
$$




$$
\sigma=v_{\varepsilon}\left(\frac{\partial u_{i}}{\partial x_{j}}+\frac{\partial u_{i}}{\partial x_{i}}\right) \frac{\partial u_{i}}{\partial x_{j}},
$$

Turbulent dissipation rate equation is:

$$
\frac{\partial}{\partial x_{j}}\left(e u_{j}\right)=\frac{\partial}{\partial x_{j}}\left(\frac{v_{e}}{\sigma_{t}}\right) \frac{\partial e}{\partial x_{j}}+\left(C_{1} G-C_{2} e\right) \frac{e}{k}
$$

where,

$$
\begin{aligned}
C_{\mu \prime} C_{1}, C_{2} & =\text { empirical constants, } \\
& =\text { effective Prandt numbers in turbulent model }
\end{aligned}
$$

For the inlet boundary conditions, the air velocity distribution couponent is in z-direction.

The finite-domain technique, used by PHOSNICS, combines the features of the method of Patankar S.V. and Spalding D.B. (1972, "A Calculation Procedure for Heat, Mass and Momentum Transfer in Parabolic glows," Int.J. Heat and Mass Transfer, 21, London, England, 1565-1579). The calculated space area is discretized into finite intervals and the variables are computed only at a finite number of locations called "grid-points." The variables are connected with each other by algebraic equations.

Internally, PHOSNICS solves sets of algebraic equations that represent the consequences of :

\% integrating the differential equations over the finite volume of a computational cell over a finite time

\% approximating the resulting volume, area and time averages by way of interpolation assumptions

It is assumed that, in convection terms, all fluid properties are uniform over cell faces; the timely new values are supposed to prevail throughout the time interval.

For each dependent variable there are as many algebraic equations as there are cells in the integration domain. Thus, there are a set of (NX $x$ NY $x$ NZ) algebraic equations for each dependent variable. pHOENICS solves them in an iterative manner, the object of which is to reduce the imbalance between the left and right sides of every equation to a magnitude that is small enough to be neglected. Iterations are needed because the equations, though inear in appearance, are non-Iinear in general. In each iteration cycle, the coefficients and sources are assumed as constants. On the next iteration, the coefficients and sources are updated from the latest values of the auxiliary and dependent variables, and the linear equations reassembled and solved. Buoyancy sources are included in the appropriate momentum equation.

\section{Model Sotup}

Simulating a real problem requires to setup the model. This is one of the most important steps for 'sbtaining a right solution. Necessary dimension of the problem has to be selpcted. It must be considered, that 3 -dimensional mode 1 with many regions osten makes the solution of a problem very difficult because of increased runn'ng time and convergency problems. Therefore, if reguirement to the accura $y$ is moderate, 2 -dimensional model should be selected. Symetzy in a sdel can be efficiently utilized by reducing model size on symuetrical line" However, in many cases of fluid flow, nonsymmetrical airflow - sern must be selected even in a field that has geometrical symetry. 


$$
\text { TA- } 15
$$

symetry is nonsymetric.

PHOENICS aIlows to choose between 3 different coordinate options: cartesian, cylindrical-polar, and body-fitted.

\section{Woah Caneration}

PHOBNICS allows to generate a mesh automatically by specifying the grid for each coordinate. Input of extents (Bizes) and number of cells allows to visualize the geometry and make necessary correction prior to a run. Also, distance between more accurate results are desired, need more cells. often used to get "closer look" to bet as exponential function. This is necessary.

\section{Analyais Type, Properties, and Boundary Conditione}

PHOBNICS requires to specify the analysis type including hydraulic regime, heat transfer, flow regime (parabolic or elliptic), number of flow phases (one or two), steady-state or transient analysis.

PHOSNICS has a number of physical properties that must be selected including density, laminar and turbulent viscosity, mixing-length, specific

Boundary conditions are the most important and complicated part of input data. They include inlets, outlets, walls, internal plates, obstructions, gravity, and heat sources. There is an opportunity to identify extemal relative pressure at outlet. Heat flux or temperature can be defined for walls as well as for obstructions. Walls allow to calculate airflow resistance as well, One useful option is obstruction porosity between 0 (solid) and I (fully open). Gravity force can be defined for buoyancy calculations, where the strength of buoyancy exists by using Bussinesq approximation associated with reference temperature and expansion coefficient. as a part of obstructions entry, or as an several ways: Erom separate screen, indication received from CHAM of September 3, 1991), that volumetric heat source (PHOSNICS's author, letter of by specific heat.

Solution Yoaftoring and Printout Control

PHOENICS has very extensive interactive capability for solution control. This control includes the initial value of dependent variables, termination of the calculations, relaxation of individual dependent variables, solution The program provion for each depent variable and the terms included in the equations. automatic and false time-s different ways of under-relaxation: linear, texminating the iterations for each dependent opportunity to limit residuals by reached.

During the calculation, converging process is monitored interactively Fig.A.51). Calculation can be inting process is monitored interactively (see the value can be changed. A graph and a table of and parameter type and/or both the hot area valued. A graph and a table of current values are shown for converging process is the one thich total residual for each variable. Good oscillations and is the one which shows that the upper plot stabilizes oscillations and the lower plot shows continuous decrease of residuals. pHOTON. graphic results can be dif.'layed by a post-processor using module sections, variables, vectors in for of iguge that allows to display any crosssections, variables, vectors in for: of color fields and color vectors.

\section{Program Vorifleation and Validation}

Verification and Validation procert: Design Control Procedures Manual "Computer Code Validation and Ver:

has been performed in accordance with tion 4 "Calculations", and section 9 ation"). Following steps are conducted: 


$$
\text { TA } 16
$$

- Available CFD commercial programs were studied and the nost efficient, that is pHOsNICS, has been selected. The cover page of the program has been bigned by the Project Engineer and preapproved by WHC

- The PHOENICS introductory course, given by CHAM of North America, was completed by the originator

- Computer Code susuary has been filled. project Classi-fication is assigned to Class IIIB "Off-the Shelf Design Aid-third party supported." Program validation includes: history of acceptance/ use and analysis of data in literature. As follow from the list of publications (see A.7.5.1) PHOSNICS has been intensively checked and verified by many independent reviewers

- Many bample test problems were run by the originator prior of using the program

- A complete description of model is included into this report

- The checked and the independent reviewer have verified that the model is a reasonable representation of the process or physical phenomenon of interest and outputs are reasonable.

Numerical evaluation including manual calculation has already been used and explained for the AF/Model (Bee FDI calculation B350-HV-1802). Similar evaluation for the CFD/Model is impossible due to a huge number of calculation and program complication. Logical way of verification includes data analyzing and referencing to respectable publications. Comparing to a similar program and/or to the test data are other ways for verification. However, we do not believe that aimilar data exist due to the unique configuration and conditions of canister storage building. There are a number of similar programs, such as FLUENI, FIDAP, FLOTRAN. However, if the results of programs are different, there is no answer which program is correct, since there is no test data. Therefore, the most valuable sources to evaluate auch a large system as PHOSNICS are respectable publications for similar problems and engineering judgment from a highly qualified and experienced engineer.

As gtated by CHAM of North Anerica, PHOsNICS is the industrie's first fullcapability computational fluid dymamics software package for PC. There are over 350 installation of PHOENICS throughout the world. PHOENICS references includes a list of publications that shows large number of applications where PHOENICS has been successfully used for solving many fluid mechanics and heat transfer problems.

\section{Geometry}

Figure Al6a presents the 2-dimensional simulation model. A cross-section through the vertical ayumetry axis in the center of vault is modeled. 


\section{TA- 17}

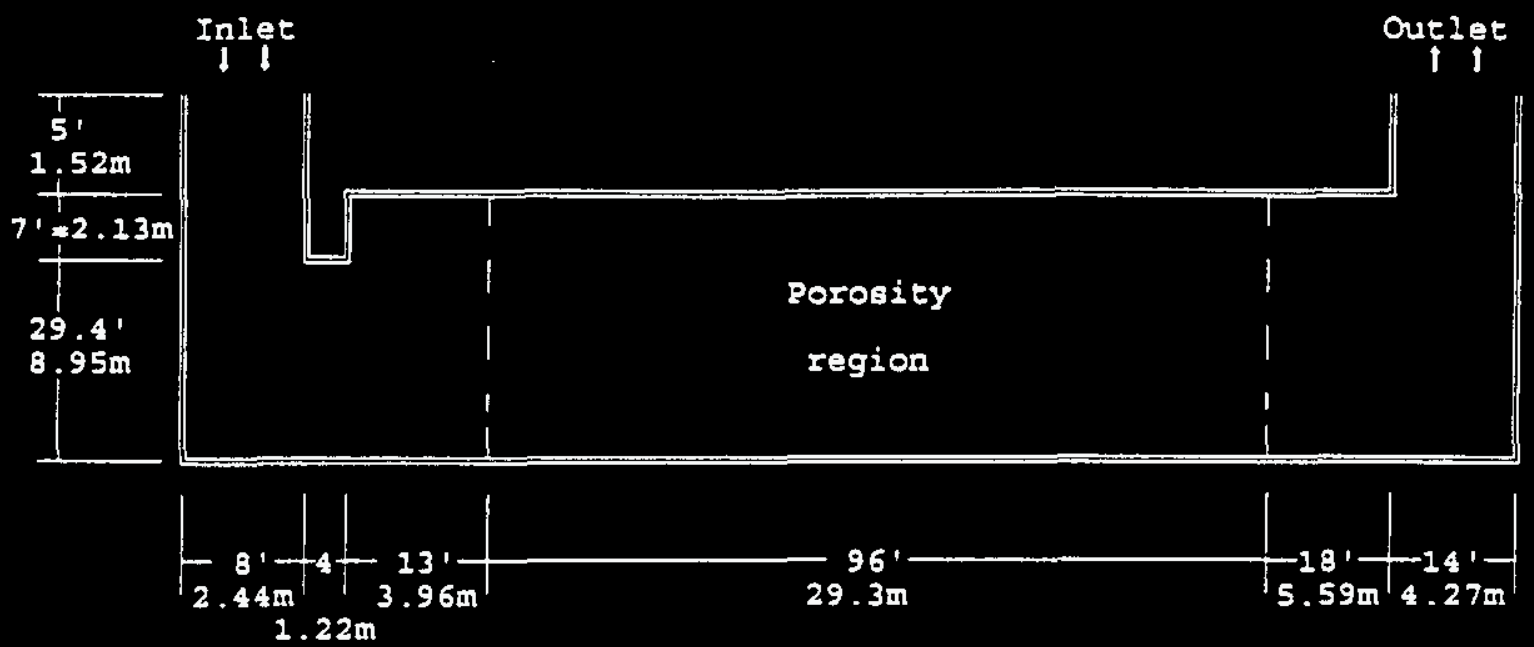

Figure Al6a

Inlet air opening is Iocated at the upper-left part of the model. Outlet opening is located at the upper-right part of the model. The middle part of the vault is occupied by sleeves. Airflow pressure loss in this part of the vault is simulated by using porosity factor. PHOsNICS is not capable of simulating anisotropic porosity that would have some advantages for the specific air flow pattern of space occupied by sleeves. Airflow regime is turbulent since, for maximum loads, Reynolds number is above 3000 . Wall surfaces are assumed adiabatic (conservative approach), however hydraulic resistances of walls are taken into consideration. Because of assumptions such as 2 -dimensional simulation and porosity, temperatures in this simulation will be used as relative values only. The results of simulation will allow to calculate flow pattern in the vault and discover hot areas where temperatures are higher due to the buoyancy effect. The reference air temperatures are at inlet and/or outlet. All dimensions used in gHosnICS are in SI units.

For the model under consideration cartesian grid is selected. This grid consists of cells formed by intersection of planes of constant $z$ and planes of constant $y$. A rectangular grid was constructed using interactive preprocessor Easyflow. Y-direction is divided into 6 regions with physical dimensions shown on Figure 7. Bach region has been divided into different number of cells. Z-direction is divided into 3 regions with equal spacing between cel1s.

\section{Properties}

Air density and laminar viscosity are assumed to be $1.01 \mathrm{~kg} / \mathrm{m}^{3}$ and $2.1 \mathrm{~s}-5$ $\mathrm{m}^{3} / \mathrm{s}$ respectively. Turbulent viscosity is calculated by the program itself as well as the mixing length. Air specific heat is $1004 \mathrm{j} / \mathrm{kg} \cdot{ }^{\circ} \mathrm{C}$ and air thermal conductivity is $0.0263 \mathrm{w} / \mathrm{m}-{ }^{\circ} \mathrm{C}$. There is no need of using variable properties since the buoyancy effect is calculated by Bussinesq approximation with air expansion coefficient.

\section{Boundary Condtiond}

Boundary conditions include: one inlet, one outlet, iills, obstructions, gravity, and heat sources.

Inlet is located in the HIGH face $z$-region \#3, Y.5. I \#1. Uging airflow of $53,000 \mathrm{cfm}$, inlet velocity is calculated for 2 vat: $: 38$ 


$$
\begin{gathered}
\text { TA }-18 \\
v=\frac{53000}{(6 \times(8 \times 21.5))(2 / 3)}=77.0 \mathrm{fpm}=0.393 \mathrm{~m} / \mathrm{s}
\end{gathered}
$$

where:

$6 \times(8 \times 21.5)$ is the total air entry area for 3 vaults, $\mathrm{ft}^{2}$

The direction of air at inlet opening is -z (see Fig.7). Turbulent intensity is recoumended by PHOENICS (see EasyFlow manual, p.6-84) as 2t or 0.02 . Inlet ais temperature assumed is $115^{\circ} \mathrm{F}=46.06^{\circ} \mathrm{C}$. Outlet and wall boundaries and obstructions are as shown in Fig.7. Since we are using constant density and considering buoyancy effect, Bussinesg approximation has been input. For reference temperature of $25^{\circ} \mathrm{C}$ the air volume expansion coefficient is $\beta=0.00336^{\circ} \mathrm{C}^{-1}$. This coefficient is the reciprocal of the absolute teaperature for an ideal gas or $1 /(273+25)=0.00336^{\circ} \mathrm{C}^{-1}$ (see gHosNICS EasyFlow Manual, 0.6 96). Gravity acceleration is taken for negative $\mathrm{z}$-direction as $-9.81 \mathrm{~m} / \mathrm{s}^{2}$.

Effective vault volume is calculated as

$$
\text { Vol, }=96 \times 36 \times(3 \times 50)=518,400 \mathrm{ft}^{3}=14,679 \mathrm{~m}^{3} \text {. }
$$

Vault volume oceupied by sleeves (3 vaults) is

Vol, $=22$ rows $\times 10$ columns $\times 3$ vaults $\times \pi / 4 \times 3^{2} \times 36=167,949 \mathrm{ft}^{3}=4755 \mathrm{~m}^{3}$

Volumetric heat flux is calculated as energy divided by volume and by specific heat considering only 2 vaults:

$$
W_{v}=\frac{W}{(V 01)^{\prime} c_{p}}=\frac{270 \times 1000}{14679 \times 2 / 3 \times 1004}=0.275 \mathrm{~W} / \mathrm{m}^{2}
$$

where :

270 is total decay energy dissipated from canisters in $\mathrm{Kw}$, and 1004 is air specific heat in $j / \mathrm{kg}^{\circ} \mathrm{C}$.

Airflow resistance of the vault is simulated as porosity. Porosity coefficient is calculated as following expression (the same for 2 vaults with 440 sleeves as for 3 vaults with 660 sleeves)

$$
\text { 1. } \mathrm{VOl}, \mathrm{VOl}=1 \cdot 167,949 / 518,400=0.67
$$

\section{Interprotation of Results}

The results of prosnICS modeling are presented is Figures 8 through 13.

Mostly convergency residuals are decreasing. Temperature in Hot trea value plot is increasing by 0.0074 only.

On the right side of the screen the scale of temperatures is displayed. It is easy to find teamperature in a region starting from the white cell isee 53 degree). Temperature fields show that higher air temperacures are in a wide area below the ceiling. Velocity vectors and thermal regions are shown on Fig.14.

There are four major flow regions:

Region 1. The beginning of the stream where entered air is mo. .29 down creating first entry vertex 


$$
\text { TA- } 19
$$

Region 2. Lower stream moving in the direction from inlet to outlet. This atream containg relatively low air temperatures. It cools external walls and floor

Region 3. Higher stream that consists two aubstreams. These substreams Btart about $1 / 4$ to the end of the vault but one of them moves to inlet and the second one moves to the outlet. Air in this region is the hottest in the vault.

Region 4. Second vertex located below the vault outlet opening.

Air buoyancy and slower ais movement in the third flow region create higher temperatures at the top of the vault called "Hot Pillow" or "Hot Area." To know actual air temperature in "fot Area" is important for calculating aurface temperature of the ceiling. The 2-dimensional simulation shows intemal air temperatures at each cell including temperatures of inlet and outlet air. There is a difference between the outlet and the "fot Area" air temperatures due to the buoyancy. The calculation of the hottest air tenperature in the vault is evaluated by adding this temperature difference to the outlet temperature, calculated by the AF/Model. The new air temperature is called "Hot Area air temperature in the vault."

Calculations show maximum "Hot Area" temperature differences between outlet area of $9^{\circ} \mathrm{F}\left(5^{\circ} \mathrm{C}\right)$. The maximum air temperature is $57^{\circ} \mathrm{F}\left(135^{\circ} \mathrm{C}\right)$.

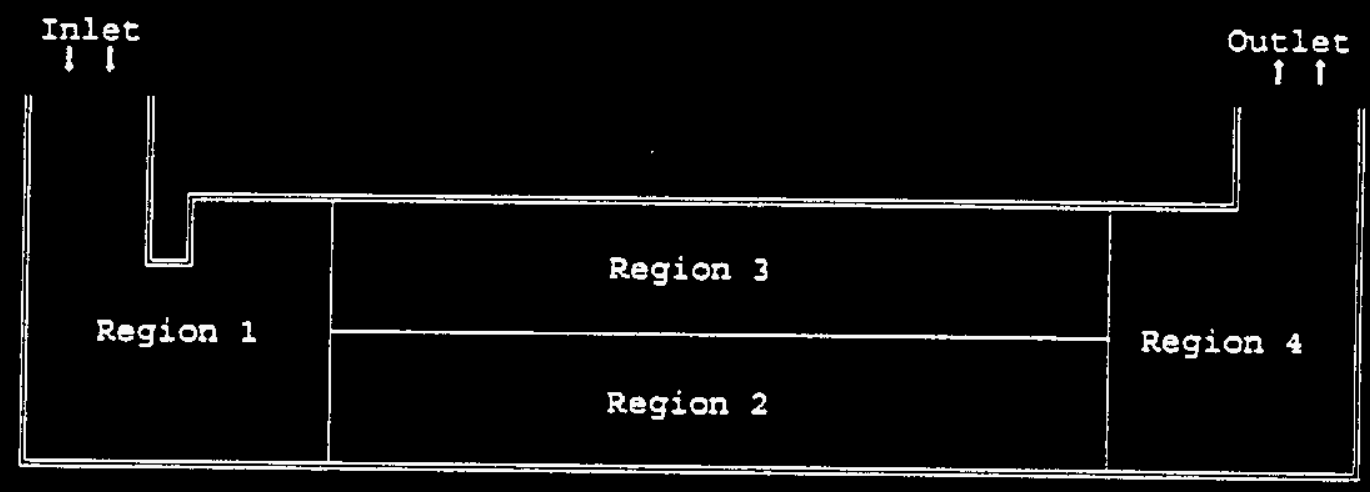

Figure 14. 


$$
\text { Tf } 20
$$

\section{Calculation Tables and Figures}

1. Forced ventilation, water in MCOs, air between MCOs and sleeve, sleeve is located at the end of the vault, inlet temperature is $35^{\circ} \mathrm{F}$, total load is $320 \mathrm{~kW}$. Calculation is conducted for different cooling airflows in the range between 10,000 and 500,000 cfm. The calculations are presented in Tables 2 through 28 . The results are presented in Figure 2 and Table 1.

The results show that after $200,000 \mathrm{cfm}$ the increase of airflow moderately effecting the canister temperature.

2. Similar calculation for inlet air temperature of $50^{\circ} \mathrm{F}$ presented in Tables 29 through $\mathbf{5 5}$ and in Figure 4.

3. Forced ventilation, air in MCOs, air between MCOs and sleeve, Sleeve is located at the end of the vault, inlet temperature is $35^{\circ} \mathrm{F}$, total load is $320 \mathrm{~kW}$. Calculation is conducted for different cooling airflows in the range between 50,000 and 500,000 cfm. The calculations are presented in Tables 56 through 65 . The results are presented in Figure 5.

The results show that after $200,000 \mathrm{cfm}$ the increase of airflow moderately effecting the canister temperature. The substitution of water between MCOs and sleeve by air increasing the canister temperature approximately by $60^{\circ} \mathrm{F}$.

4. Table 66 shows the inlet (supply) air temperature that makes the temperature of nuclear material equal $100^{\circ} \mathrm{F}$. As show it is $-37.3^{\circ} \mathrm{F}$. This temperature is absolutely impractical.

5. Natural convection, air in MCOs, air between MCOs and sleeve, sleeve is located at the end of the vault, inlet temperature is $115^{\circ} \mathrm{F}$, total load is $270 \mathrm{~kW}$ (decreased due to no heat load from constructions). Calculation is conducted to identify the temperature of nuclear material. The results in Table 67 show the temperature between 254 and $269^{\circ} \mathrm{F}$.

6. The calculation of transient heat transfer is shown in Tables 68. The calculations in Tables 69 through 75 are made in order to identify the differences between temperatures when Tcanister has $10^{\circ} \mathrm{F}$ of increment.

The results of calculation are shown in Figure 6.

7. The results of CFD modeling are presented in Figures 8 through 14. 


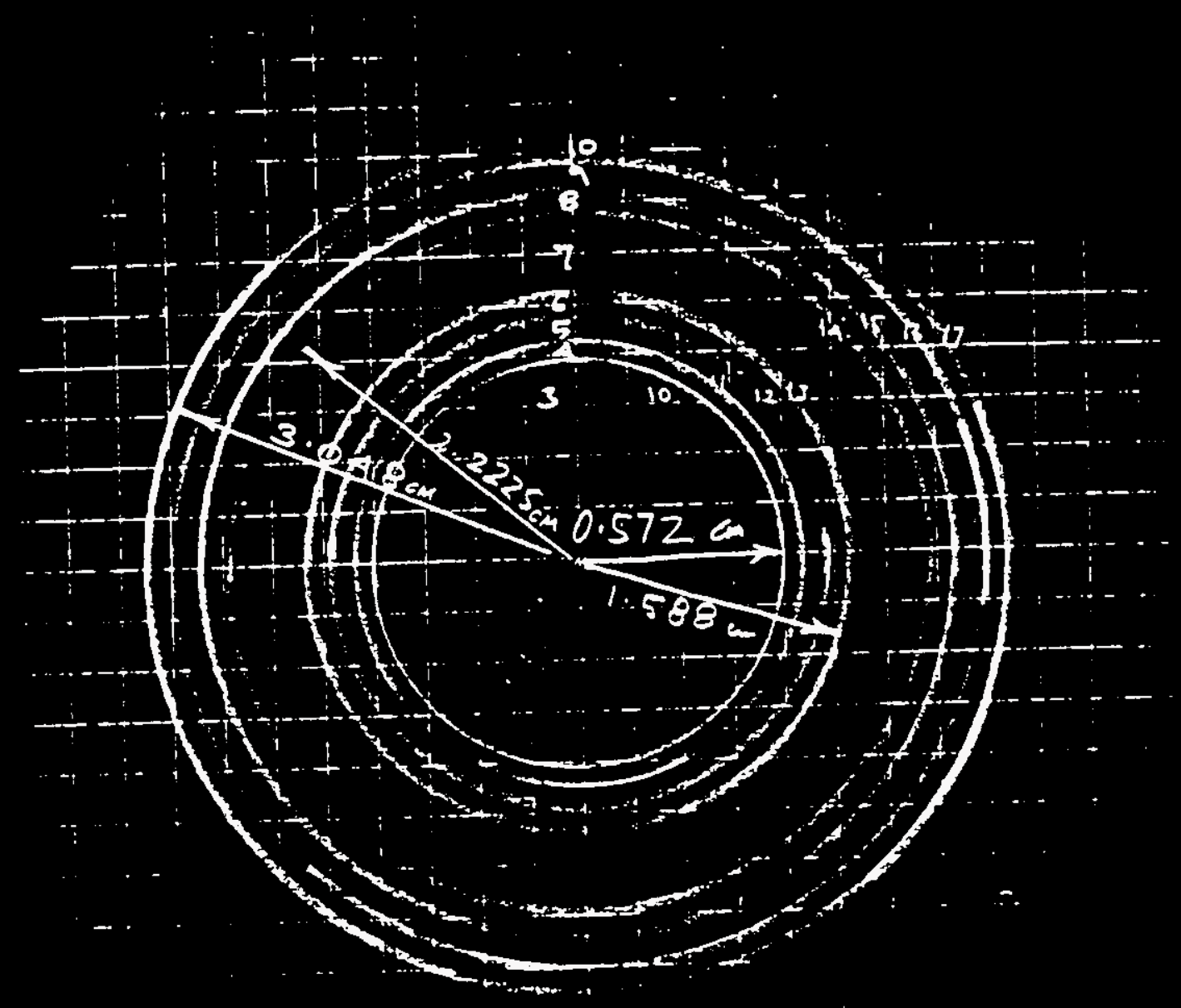

FIGURE 2. FUEL GLEMNT 
CSB Trode Study

Westinghous Hanford Company

WHC P.O. TW-SW-370252
Fluor Danid inc., Government Services Contrect 04ass306

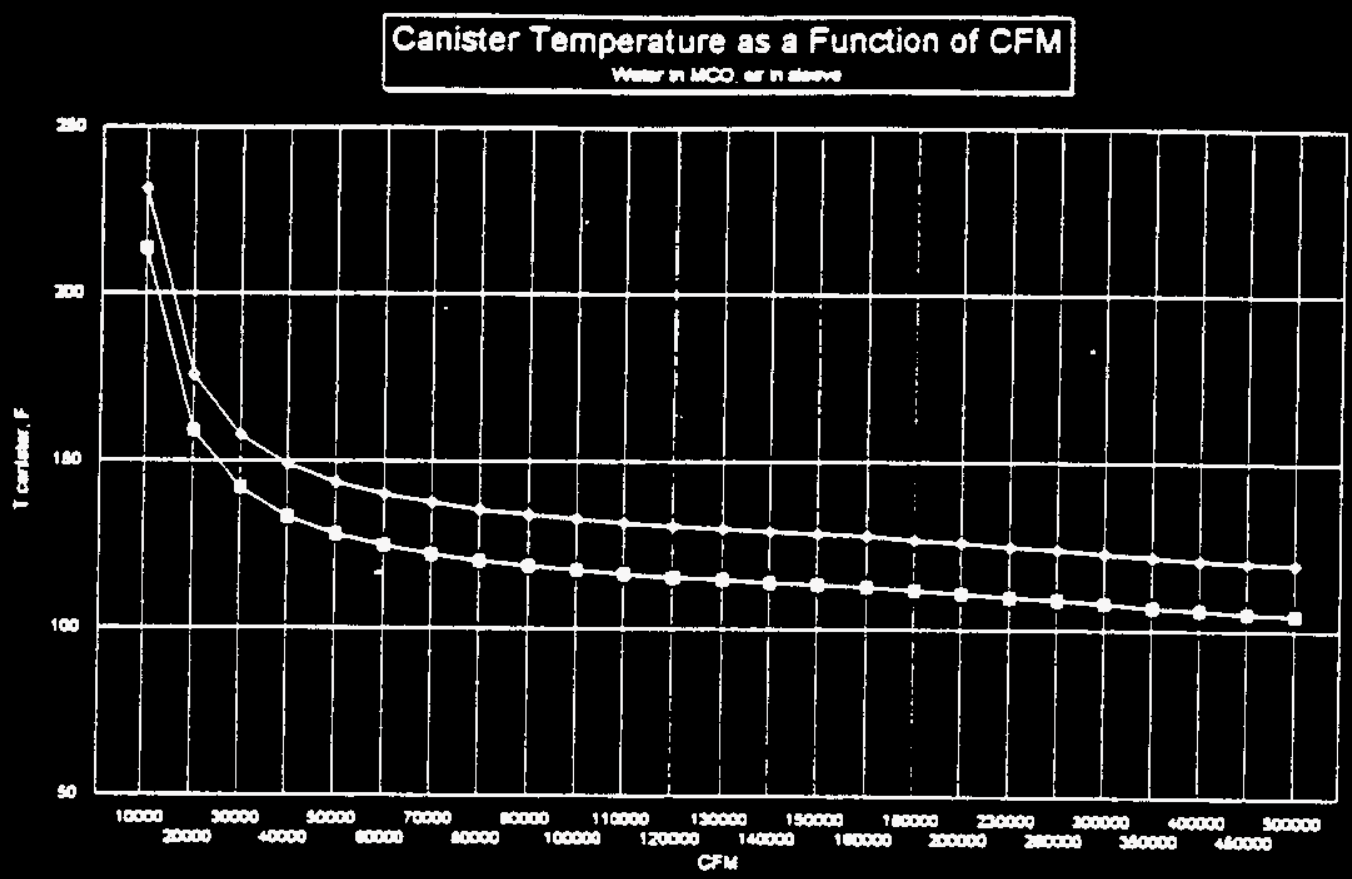

- $\pi n=35 F$

Figure 3 
CSB Trade Srudy

Wertinghouse Hanford Company

WHC P.O. TVW-SW-370252

$$
T A-23
$$

Fluor Daniet loc., Government Services Contract 04436306

\section{alternative 20}

THERMAL ANALYSIS - SUMMARY

\begin{tabular}{|c|c|c|c|}
\hline $\begin{array}{c}\text { MCO WATER TEMPE } \\
\text { SUppy cir }=35 \mathrm{~F} \\
(F)\end{array}$ & $\begin{array}{l}\text { BRATURE FOR } \\
\text { SUpply air }=50 F\end{array}$ & $\begin{array}{l}\text { SUPPLY AIR } \\
\text { QUANTIT } \\
\text { (CFM) }\end{array}$ & REMARKS \\
\hline 213 & 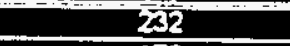 & 10,000 & \\
\hline 159 & 176 & 20,000 & \\
\hline 142 & 158 & 30,000 & \\
\hline 133 & 149 & $40, \infty 00$ & \\
\hline 128 & 144 & 50.000 & \\
\hline 125 & 140 & 60.000 & \\
\hline 122 & 139 & 70.000 & \\
\hline 120 & 136 & 00,000 & \\
\hline 119 & 134 & 90,000 & \\
\hline 117 & 133 & 100,000 & \\
\hline 116 & 132 & 110,000 & \\
\hline 115 & 131 & 120,000 & \\
\hline $4+5=$ & $=-79$ & 439602 & \\
\hline 114 & 129 & 140,000 & \\
\hline 113 & 123 & 150,000 & \\
\hline $313 \ldots$ & 429 & 160,000 & \\
\hline 112 & 127 & 180,000 & \\
\hline 911 & 126 & 200.000 & \\
\hline 110 & 125 & 230,000 & \\
\hline 109 & 124 & 200,000 & \\
\hline 108 & 123 & 300,000 & \\
\hline 107 & 122 & 350,000 & \\
\hline 105 & 121 & 400,000 & \\
\hline$-163-1-1$ & -420 & $2+4900$ & \\
\hline 105 & 120 & 500,000 & \\
\hline
\end{tabular}

TABLE 1 . 
Foreed ventilation - MCOWater - SLEEVEJAr - 880 MCO's - Canister at the End of the Vault - 5 high/2 vaults

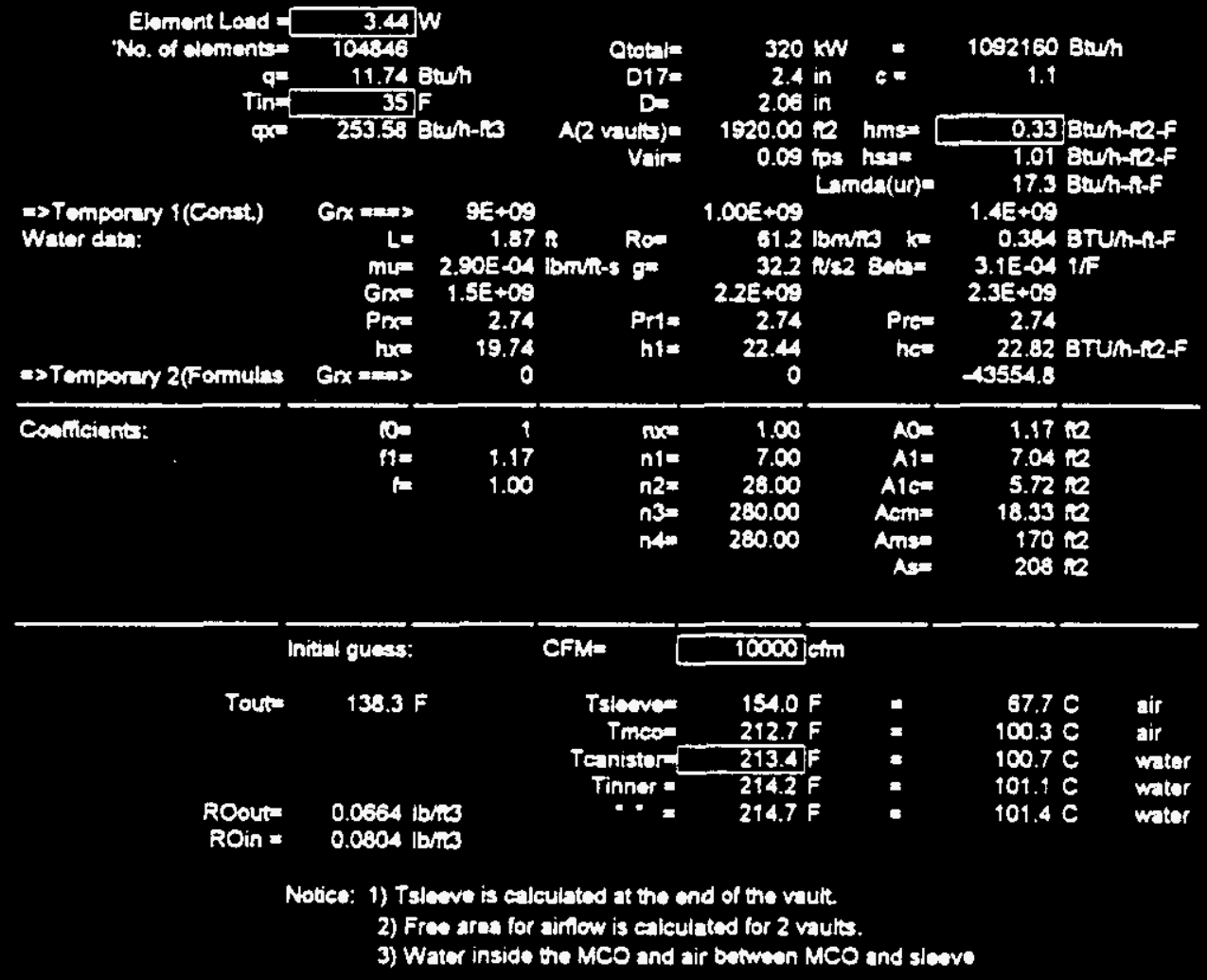

TaBLE 2 
e:Siddu20_4

Forced vendlation - MCOWater - SLEEVE/Ar - 880 MCO's - Canister at the End of the Vault - 5 high/2 vaults

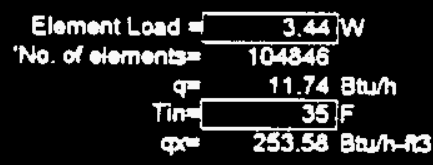
Wator detr:

\begin{tabular}{|c|c|c|}
\hline A Tomporary 2fFormulas & $\begin{array}{l}\text { mox } \\
\text { Gre } \\
\text { Prex } \\
h x= \\
\text { Grx }=\end{array}$ & $\begin{array}{r}2.905 .04 \\
1.55+09 \\
2.74 \\
19.74 \\
0\end{array}$ \\
\hline Cooticients: & $\begin{array}{r}n= \\
f=\end{array}$ & $\begin{array}{r}1 \\
1.17 \\
1.00\end{array}$ \\
\hline
\end{tabular}

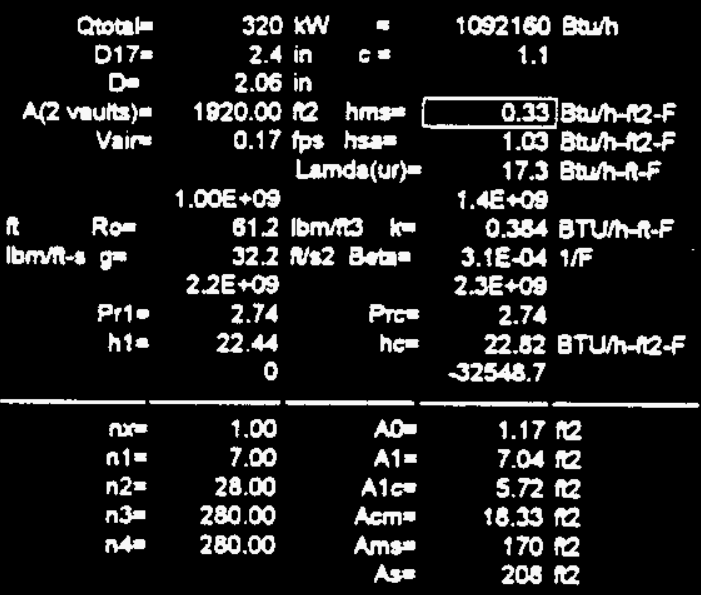

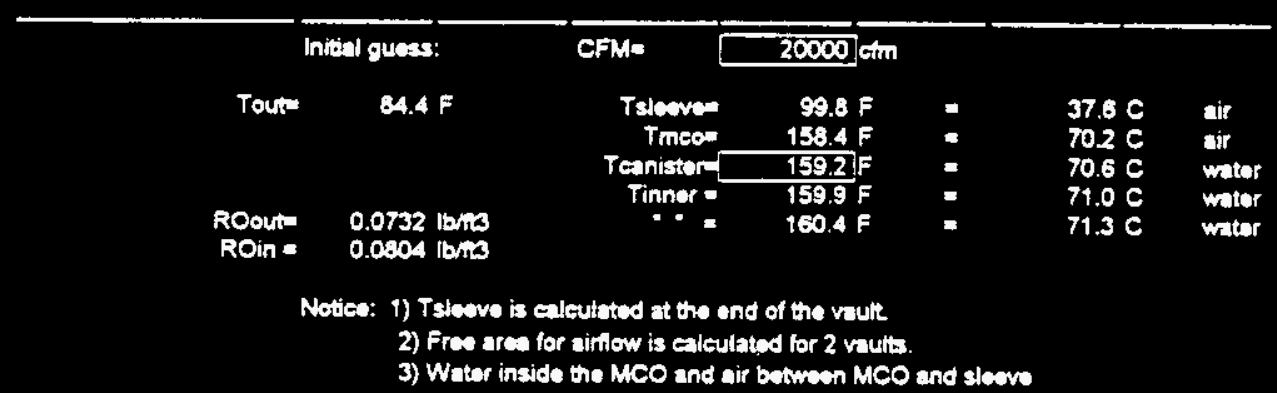

TABLE 3 
TA- 20

e:Sidalzo_4 SSF FUEL STUDY

Forced ventlation - MCOWater - SLEEVEAAr - 880 MCO's - Canister at the End of the Vault - 5 high/2 vaults

\begin{tabular}{|c|c|c|c|c|c|c|c|}
\hline \multirow[b]{2}{*}{$\begin{array}{l}\text { CSTomporary 1(Const) } \\
\text { Water data: }\end{array}$} & \multicolumn{2}{|c|}{$\begin{array}{c}\frac{3.44}{104} \mathrm{~W} \\
11.74 \text { Bum } \\
35 \mathrm{~F} \\
253.58 \text { Bawh-13 }\end{array}$} & 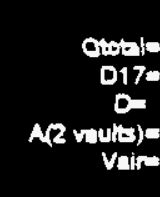 & \multicolumn{2}{|c|}{$\begin{array}{r}320 \mathrm{kw}= \\
2.4 \mathrm{in} \mathrm{c} \\
2.06 \mathrm{in} \\
1920.00 \mathrm{~m} \text { hmse } \\
0.26 \mathrm{tph} \text { hase } \\
\text { Lamda(ur) }=\end{array}$} & \multicolumn{2}{|c|}{$\begin{array}{c}1052180 \mathrm{gam} \\
1.1\end{array}$} \\
\hline & 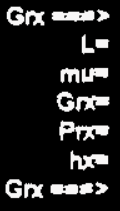 & $\begin{array}{r}95+09 \\
1.87 \\
2.90 E-04 \\
1.55+09 \\
2.74 \\
19.74 \\
0\end{array}$ & $\begin{array}{l}\text { Rrte } \\
\text { his }\end{array}$ & $\begin{array}{r}1.00 E+09 \\
81.2 \\
32.2 \\
2.16 E+09 \\
2.74 \\
22.44 \\
0\end{array}$ & $\begin{array}{l}2 \text { Exten } \\
\text { Prew } \\
\text { hese }\end{array}$ & $\begin{array}{r}1.4 E+09 \\
0.394 \\
3.1 E-04 \\
2.3 E+0.09 \\
2.74 \\
22.62 \\
-20054.8\end{array}$ & $\begin{array}{l}\text { BTuminf } \\
1 / F \\
\text { Brum-iefF }\end{array}$ \\
\hline Conticients: & fin & $\begin{array}{r}1 \\
1.17 \\
1.00\end{array}$ & $\begin{array}{l}n \times= \\
n 1= \\
n 2= \\
n 3= \\
n 40\end{array}$ & $\begin{array}{r}1.00 \\
7.00 \\
28.00 \\
280.00 \\
280.00\end{array}$ & 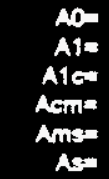 & $\begin{array}{r}1.17 \\
7.04 \\
5.72 \\
18.33 \\
170 \\
208\end{array}$ & \\
\hline & tial guos: & & CFM= & 30000 & & & \\
\hline $\begin{array}{l}\text { ROout: } \\
\text { ROin = }\end{array}$ & $\begin{array}{l}0.0756 \\
0.0804\end{array}$ & & 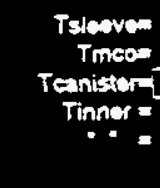 & $\begin{array}{r}82.6 \\
141.2 \\
142.0 \\
142.7 \\
143.2\end{array}$ & $\begin{array}{l}= \\
= \\
= \\
=\end{array}$ & $\begin{array}{l}28.1 \\
60.6 \\
61.0 \\
61.4 \\
61.7\end{array}$ & $\begin{array}{l}\text { air } \\
\text { air } \\
\text { wator } \\
\text { watas } \\
\text { wator }\end{array}$ \\
\hline & $\begin{array}{l}\text { (: 1) } 1 \\
\text { 2) } \\
\text { 3) }\end{array}$ & $\begin{array}{l}\text { Wo is cal } \\
\text { area for } \\
\text { cor inside }\end{array}$ & $\begin{array}{l}\text { aiflow is cale } \\
\text { the MCO and }\end{array}$ & sior 2 ? & and $s$ & & \\
\hline
\end{tabular}

TABLE 4 


\section{$T A-2.7$}

e:Sidaro_4 SSF FUEL STUDY

Foreed ventlation - MCOWater - 8 EEVEJAl - 880 MCO's - Canlster at the End of tho Vault - 5 hlgh/2 vaults

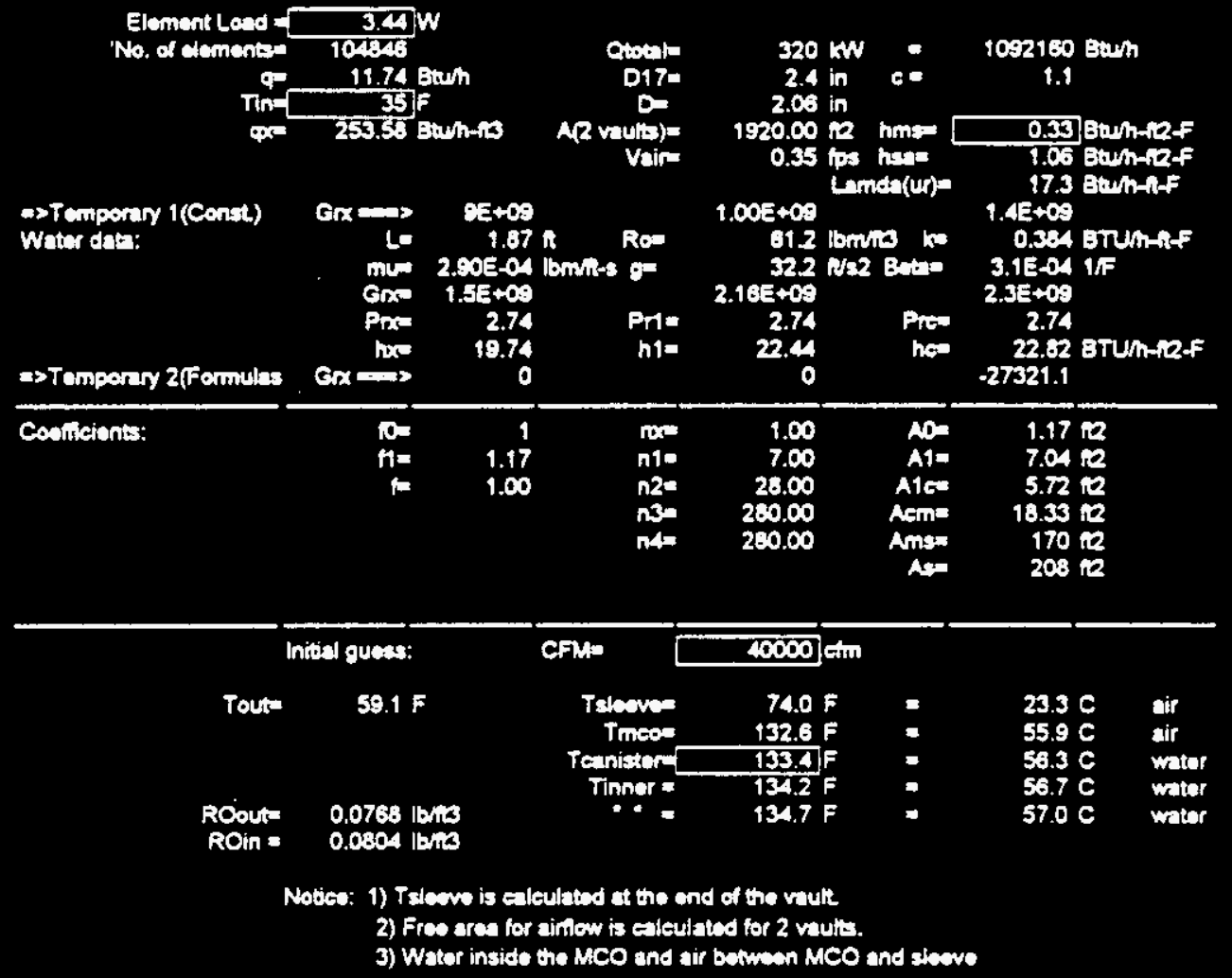

Table 5 
$T A-2 B$

c:Sidd120_4

\section{SSF FUEL STUDY}

Foreed ventiation - MCOWhater - SLEEVEINT - 890 MCO's - Canistar at the End of the Vault - 5 high/2 vaults

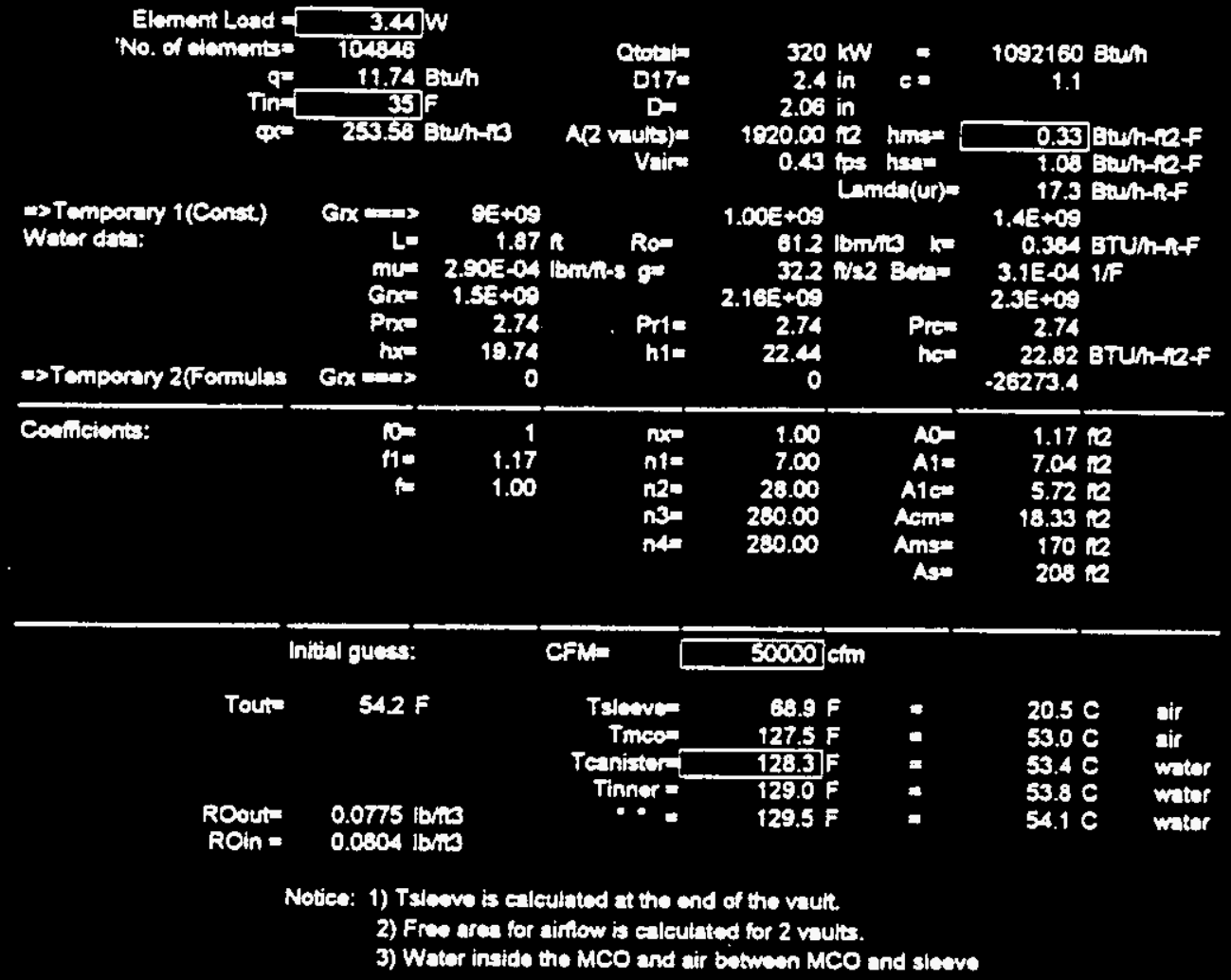

TABLE 6 
e:Sidd20_4 SSF FUEL STUDY

Foread ventation - MCOWater - SLEEVEJAI - 880 MCO's - Canlster at the End or the Vault - $\mathbf{s}$ high/2 vaults

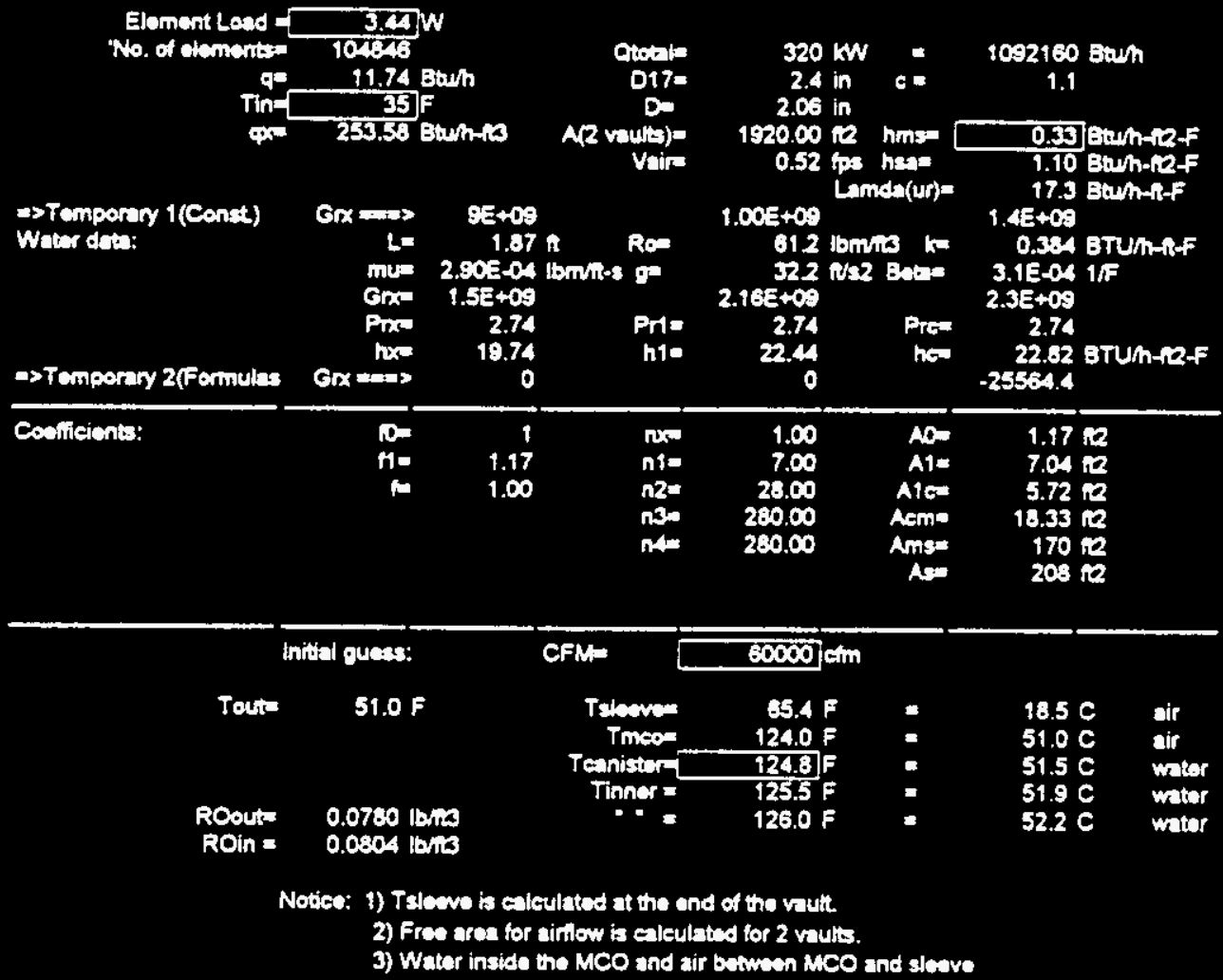

TABLE 7 
TA-SU

e:Sider2o_4 SSF FUEL STUDY

Foreed ventlation - MCOWatar - SLEEVEJAI - 890 MCO's - Canister at the End of the Vault - 5 high/2 vaults

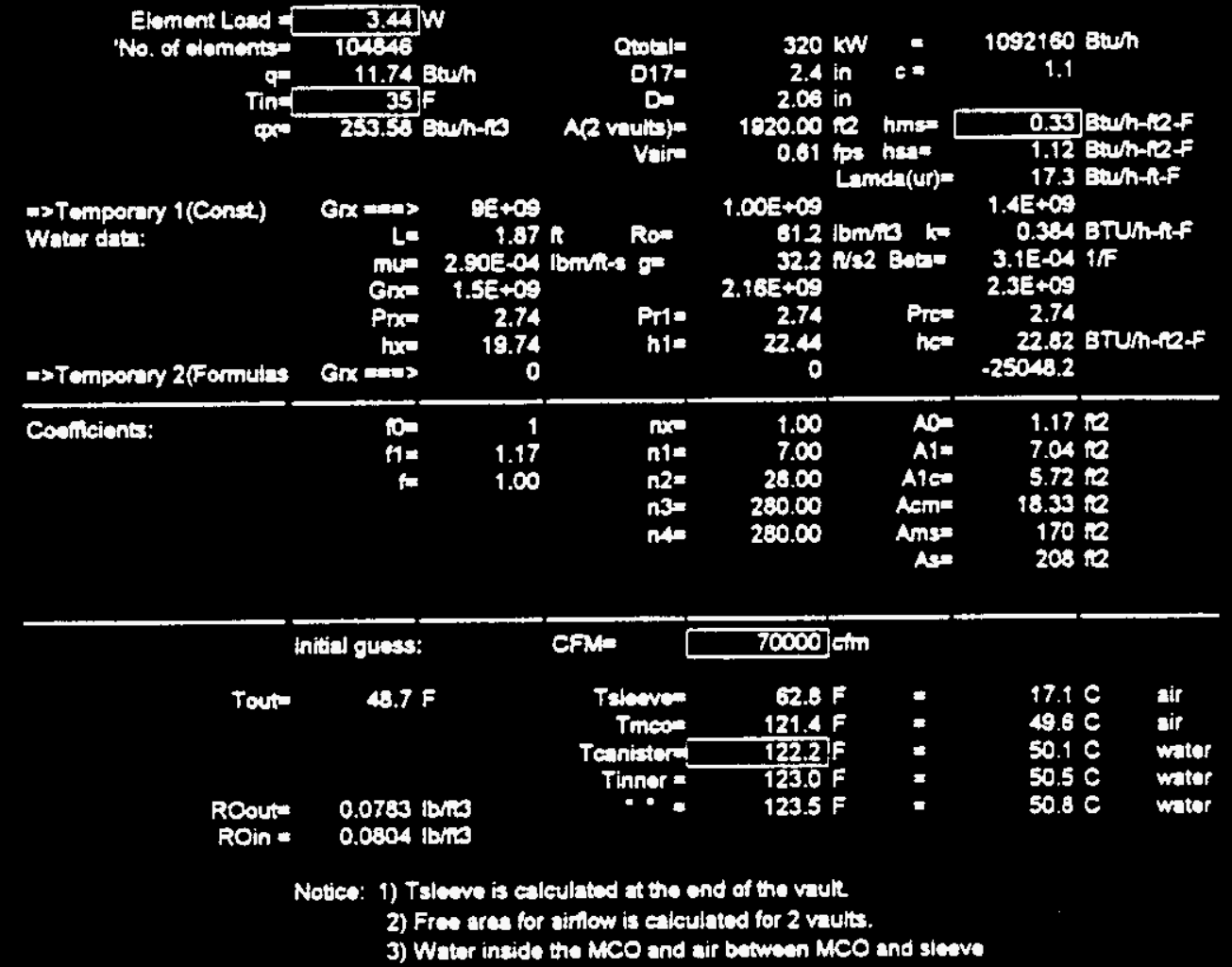

TABLE 8 
e:Siddi2D_4 SSF FUEL STUDY

Foreed ventilation - MCOWator - SLEgVEJAl - 880 MCO's - Canlster at the End of the Vault - 5 high/2 vaults

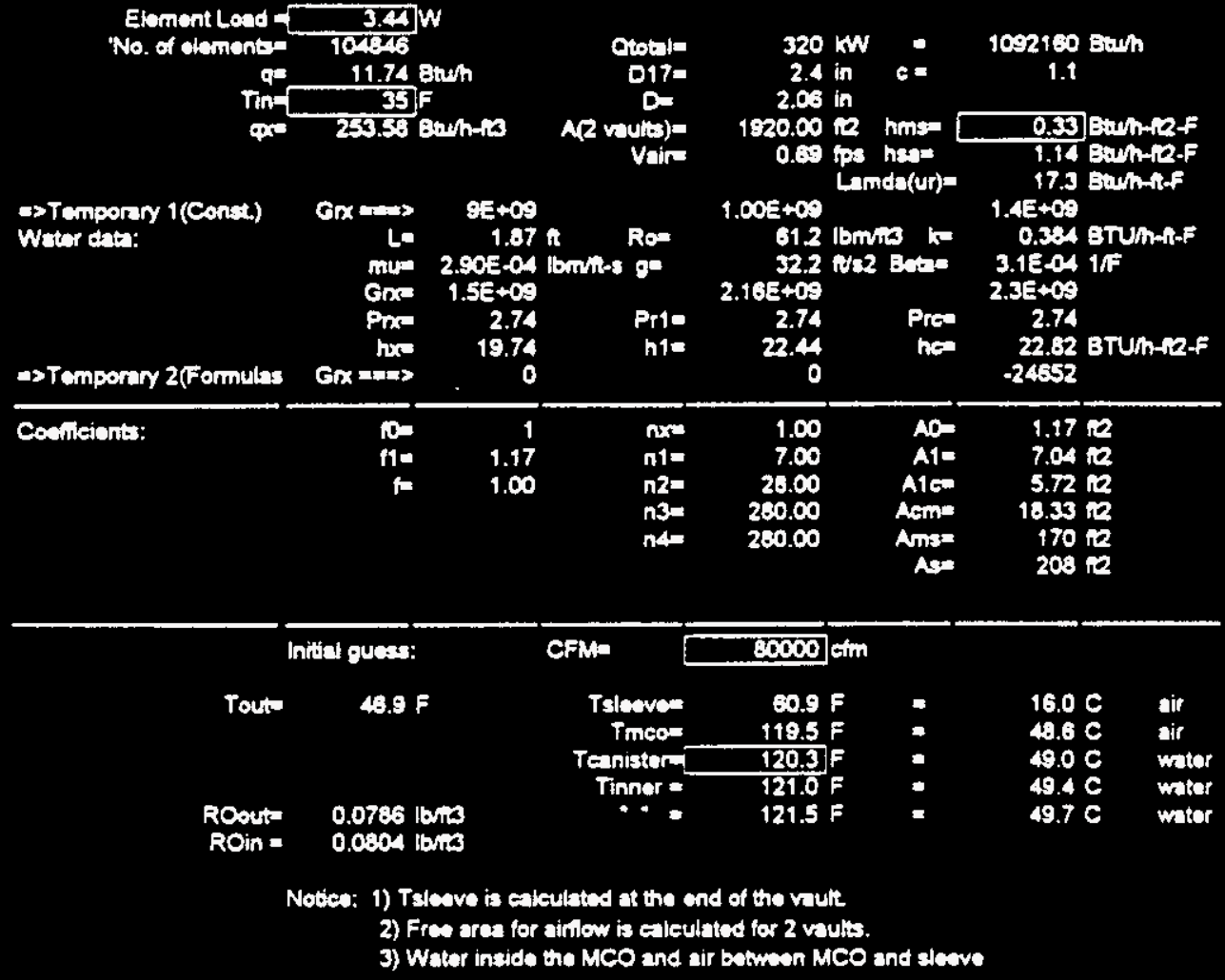

$$
\text { TABLE } 9
$$


6:Siddi2 4 SSF FUEL STUDY

Foreed ventlation - MCOWater - SLEEVY/AL - 880 MCO's - Canister at the End of the Vault - 5 hidh/2 vaults

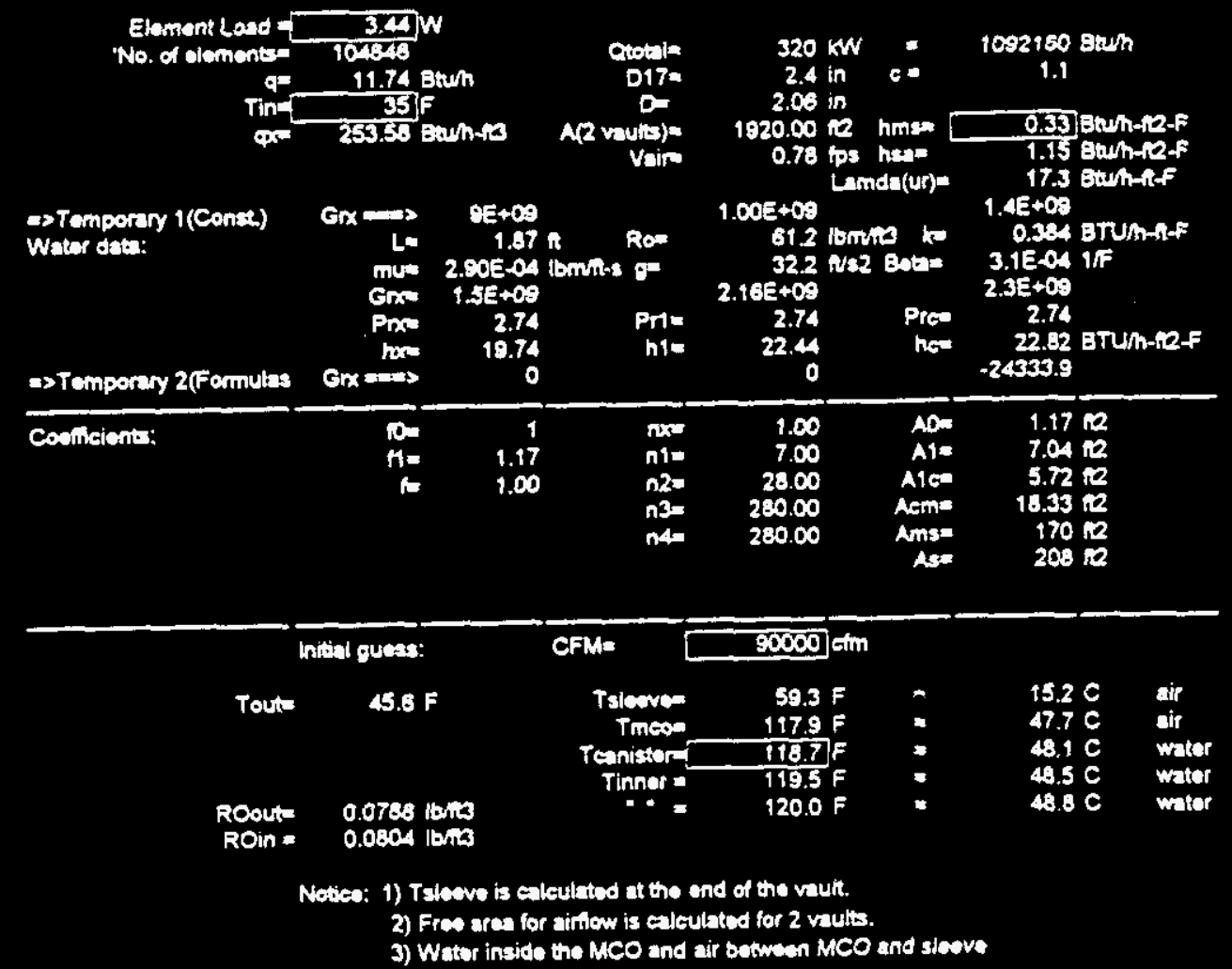

TANE 10 
c:Siddizo-4 SSF FUEL STUDY

Foread venthation - MCOWater - SLEEVEJAIr - 880 MCO's - Canister at the End of the Vautt - 5 high/2 vaults

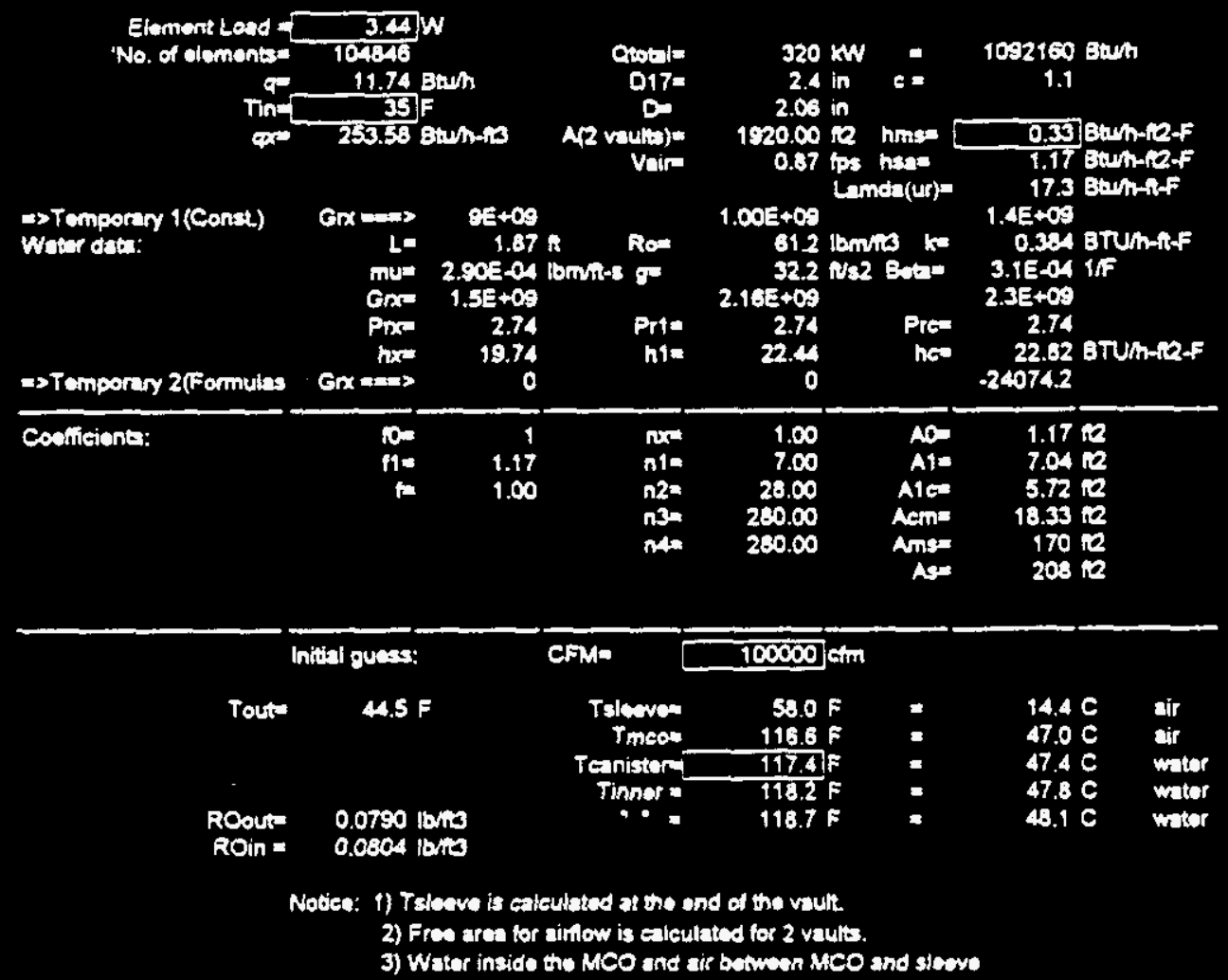

Table $\|$. 
c:Sidal20_4 SSF FUEL STUDY

Foread ventlation - MCOWater - SLEGVEJAIr - 880 mCO's - Canlstar at the End of the Vault - 5 htoh/2 vaults

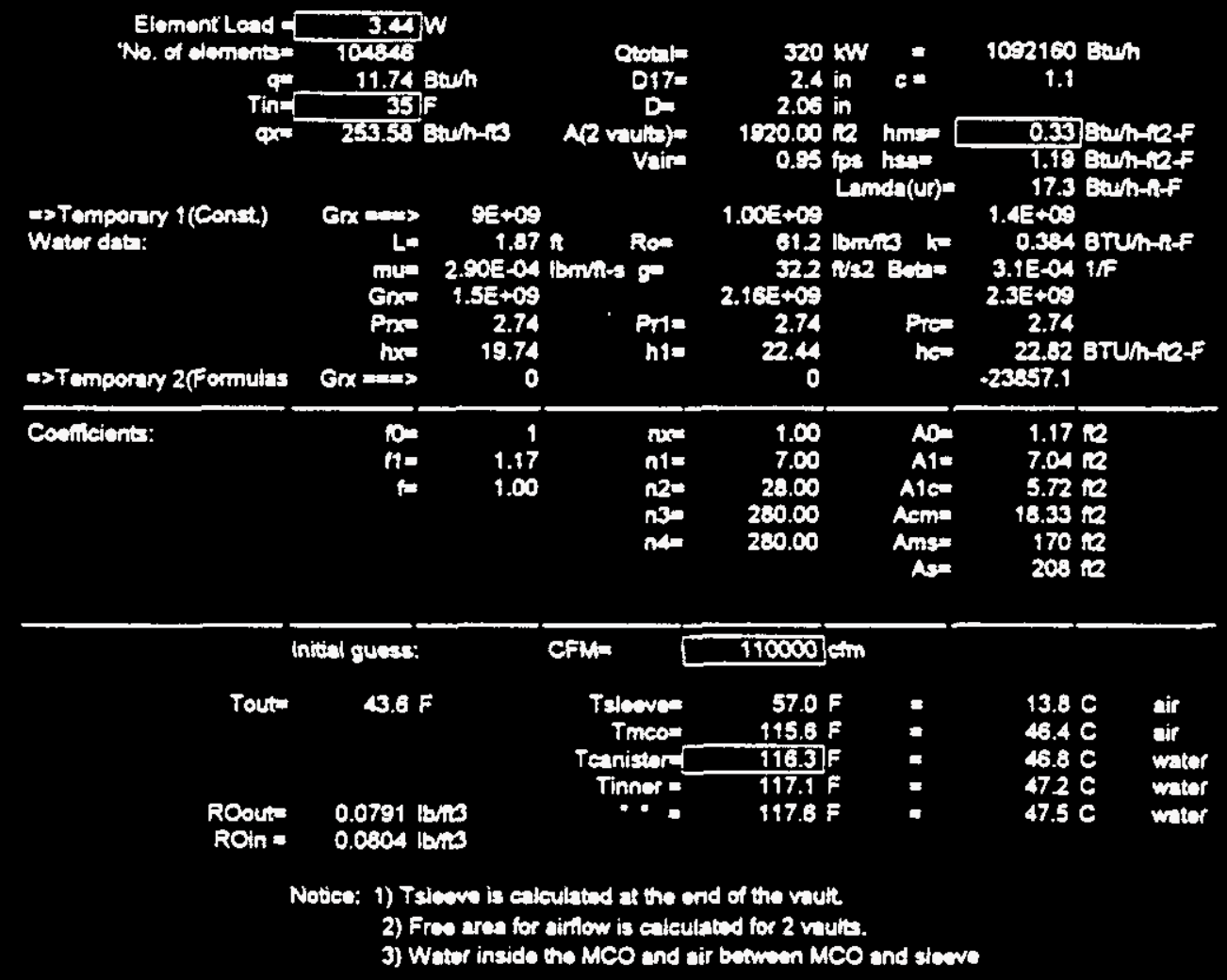

TABLE 12 
e:Sidd2D_4 SSF FUEL STUDY

Foreed ventilation - MCONater - SLEEVEJAIr - 880 MCO's - Canister at the End of the Vault - 5 high/2 vaults

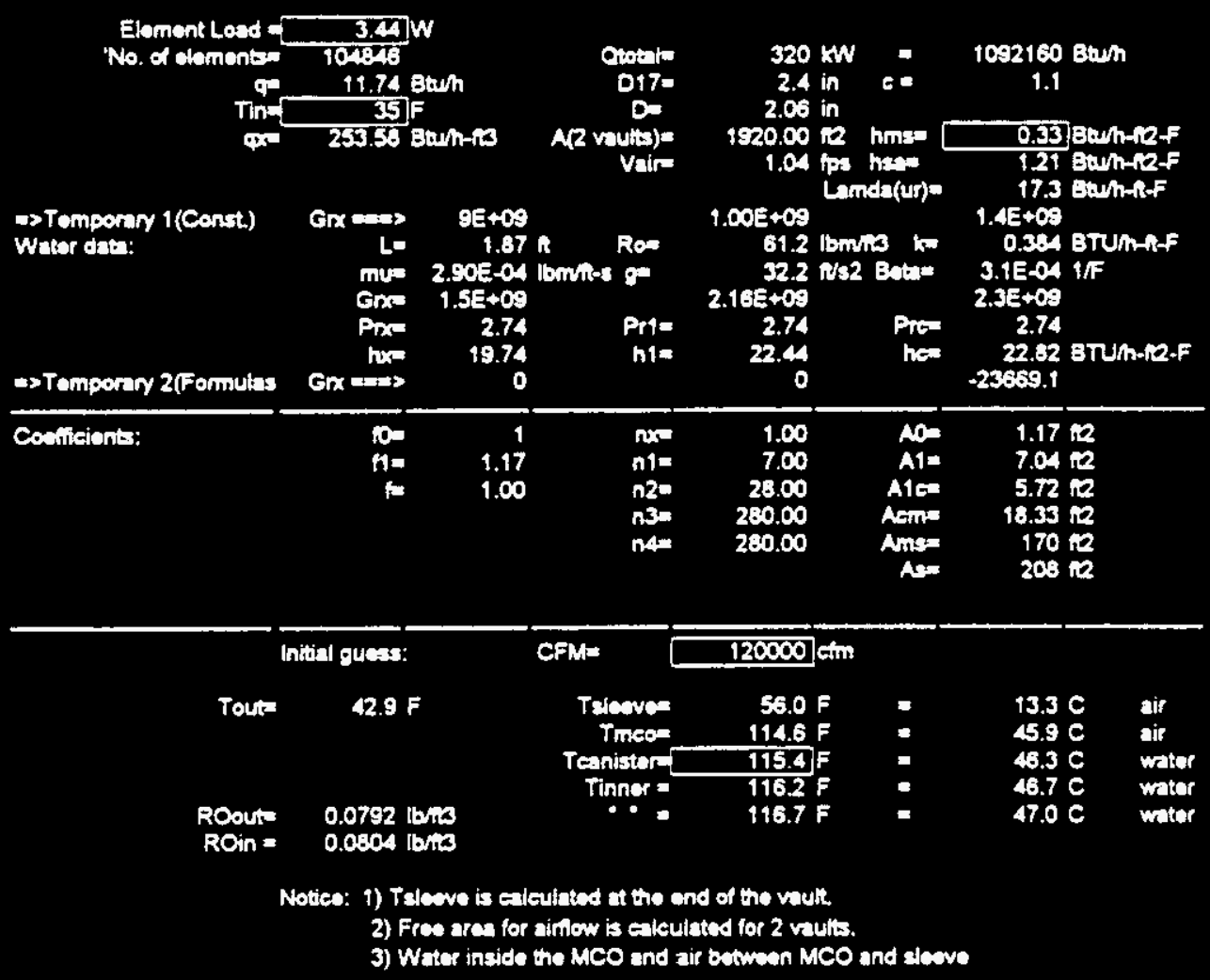

TABLE 13 
Foreed ventlation - MCOWater - SLEEVE/Air - 880 MCO's - Canister at the End of the Vault - 5 high/2 vaults

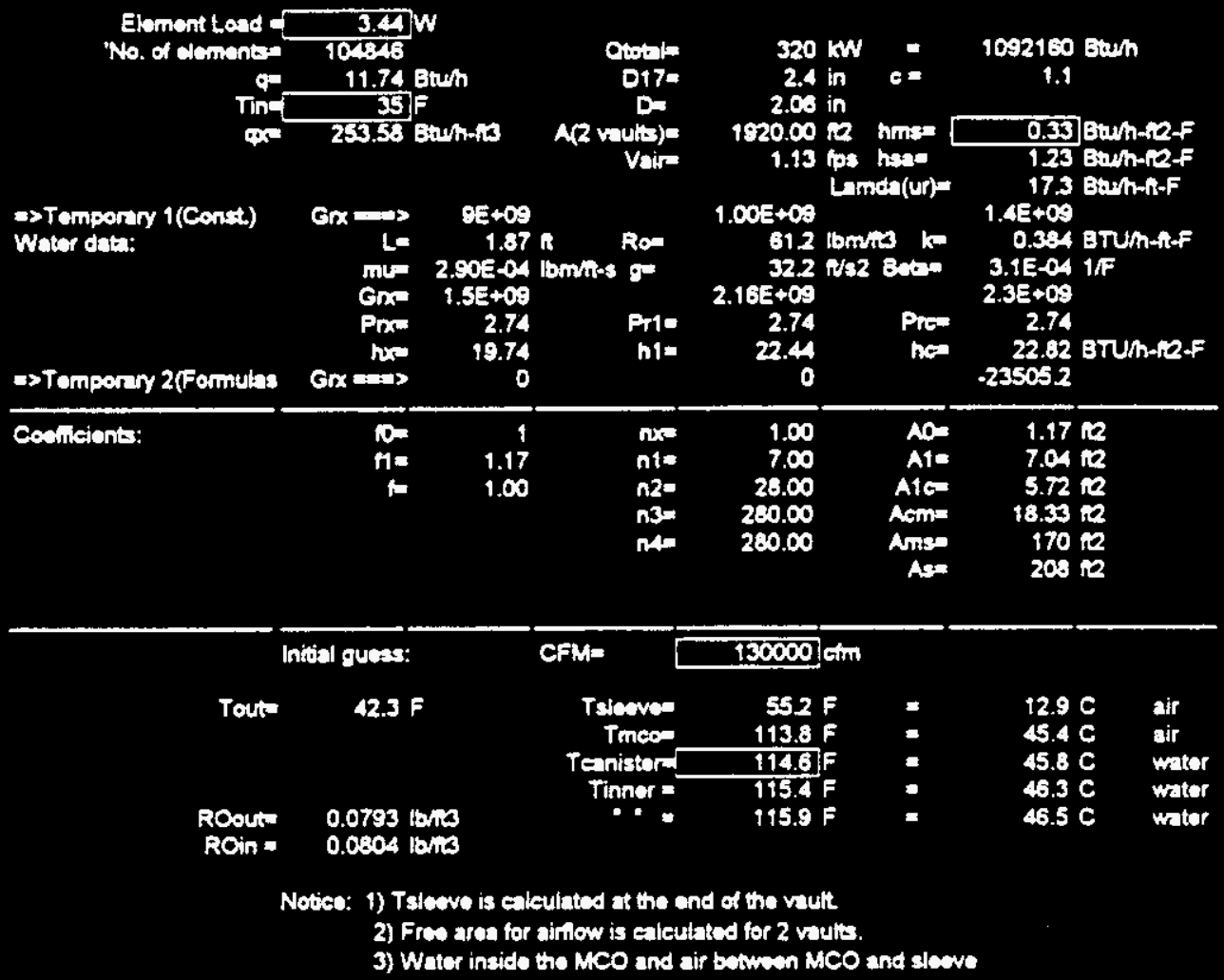

$$
\text { TADE } 14
$$


e:Sidd2D_4 SSF FUEL STUDY

Forced ventiation - MCOWatar - SLEEVEJAIr - 830 mCO's - Canlster at the End of the Vault - 5 hlgh/2 vaults

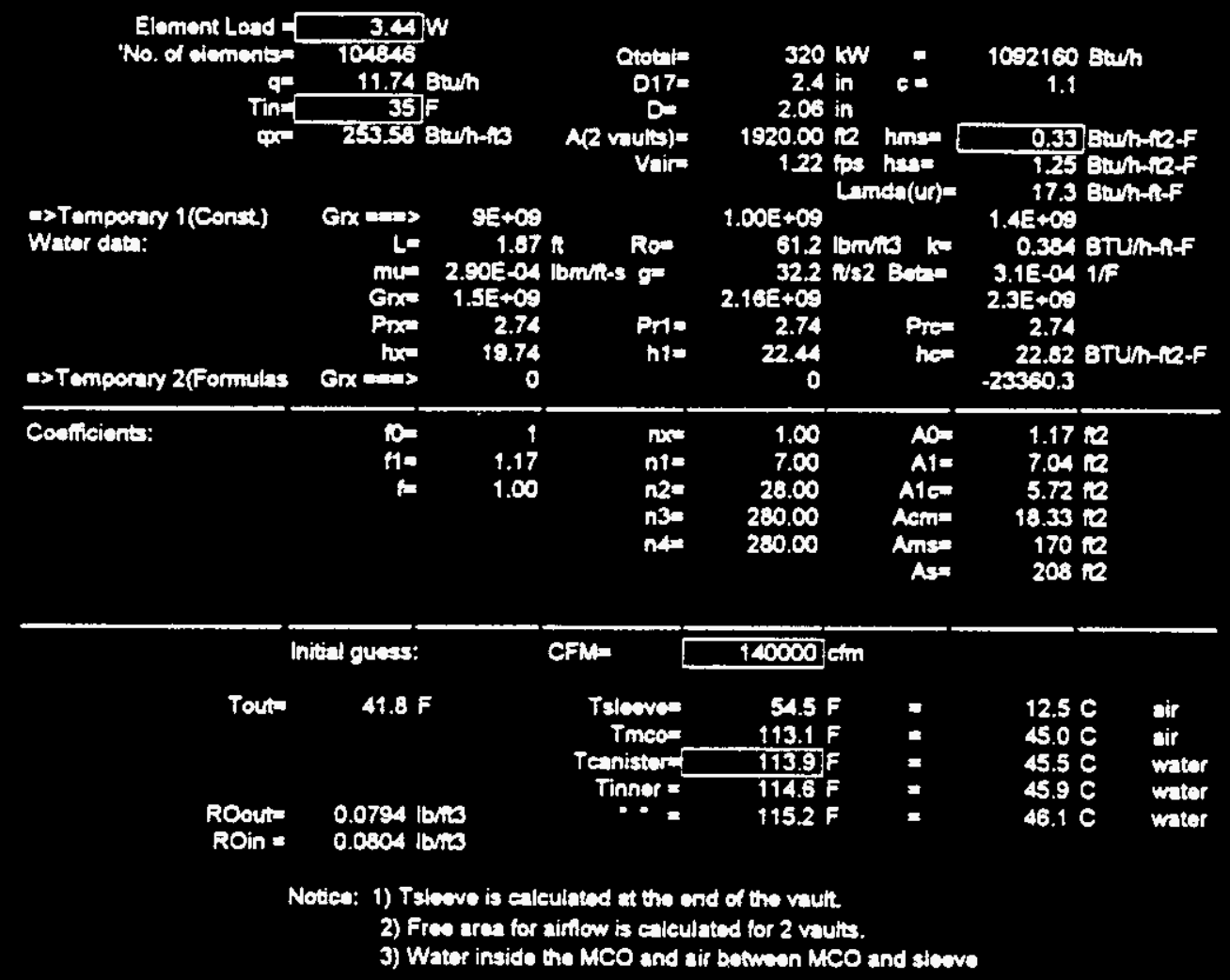

TADLE 15 
::Sidd20_4 SSF FUEL STUDY

Forced ventlation - MCOWatar - SLEEVEJAr - 880 MCO's - Canistar at the End of the Vault - 5 high/2 vaults

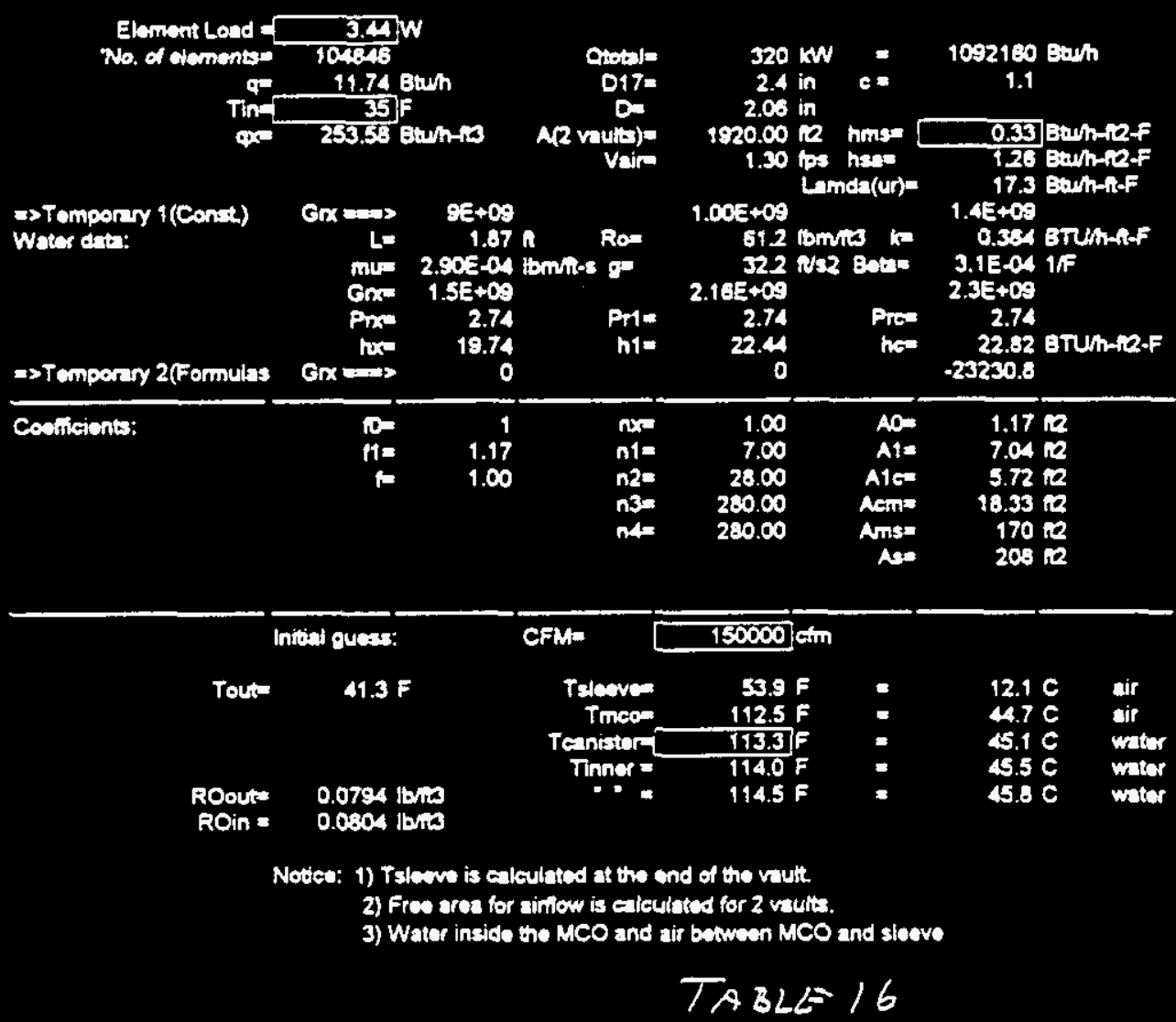


c:Sidd20_4 SSF FUEL STUDY

Foreed ventlation - MCOWater - SLEEVEJAr - 800 MCO's - Canister at the End of the Vault - 5 high/2 vaults

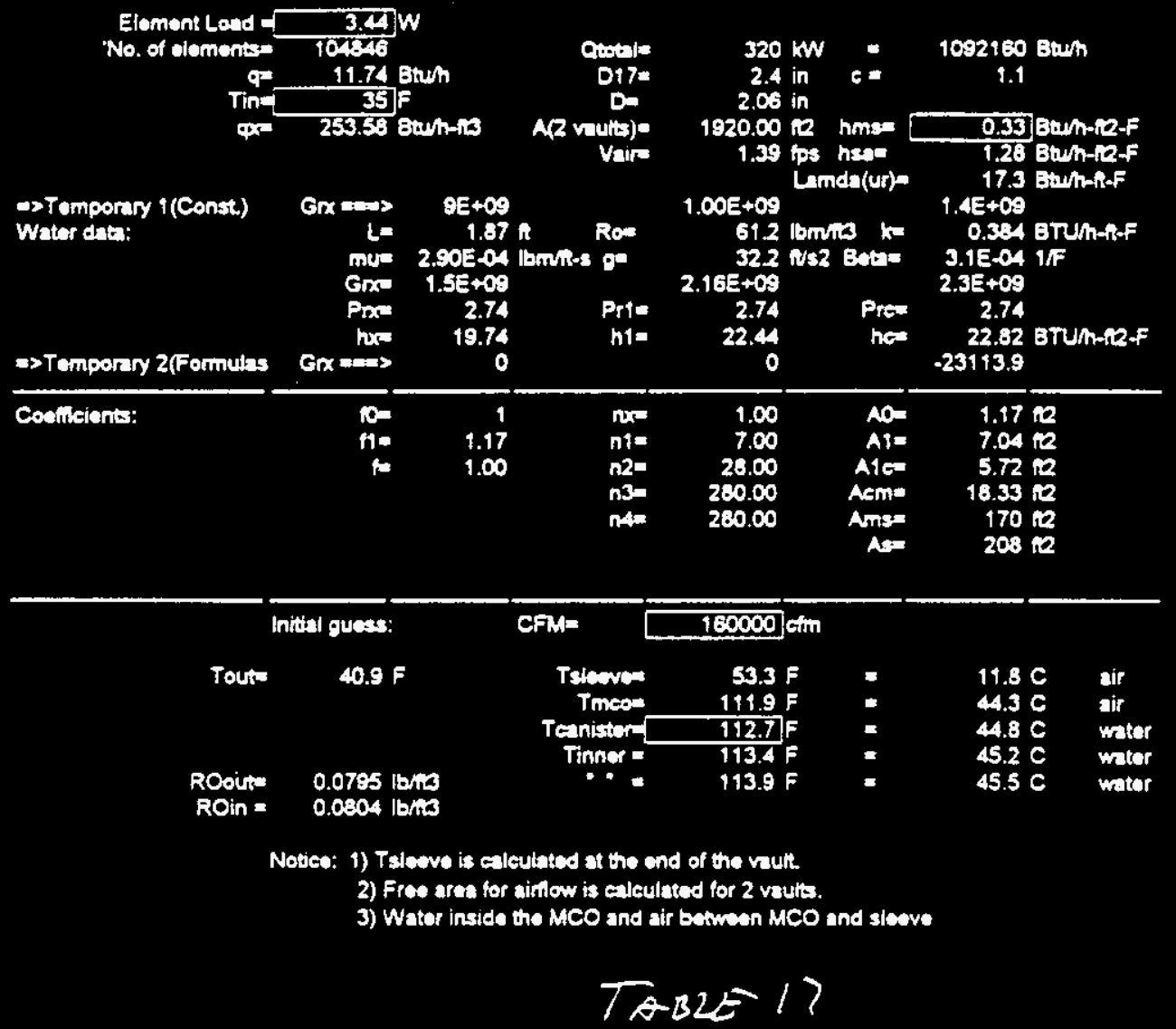




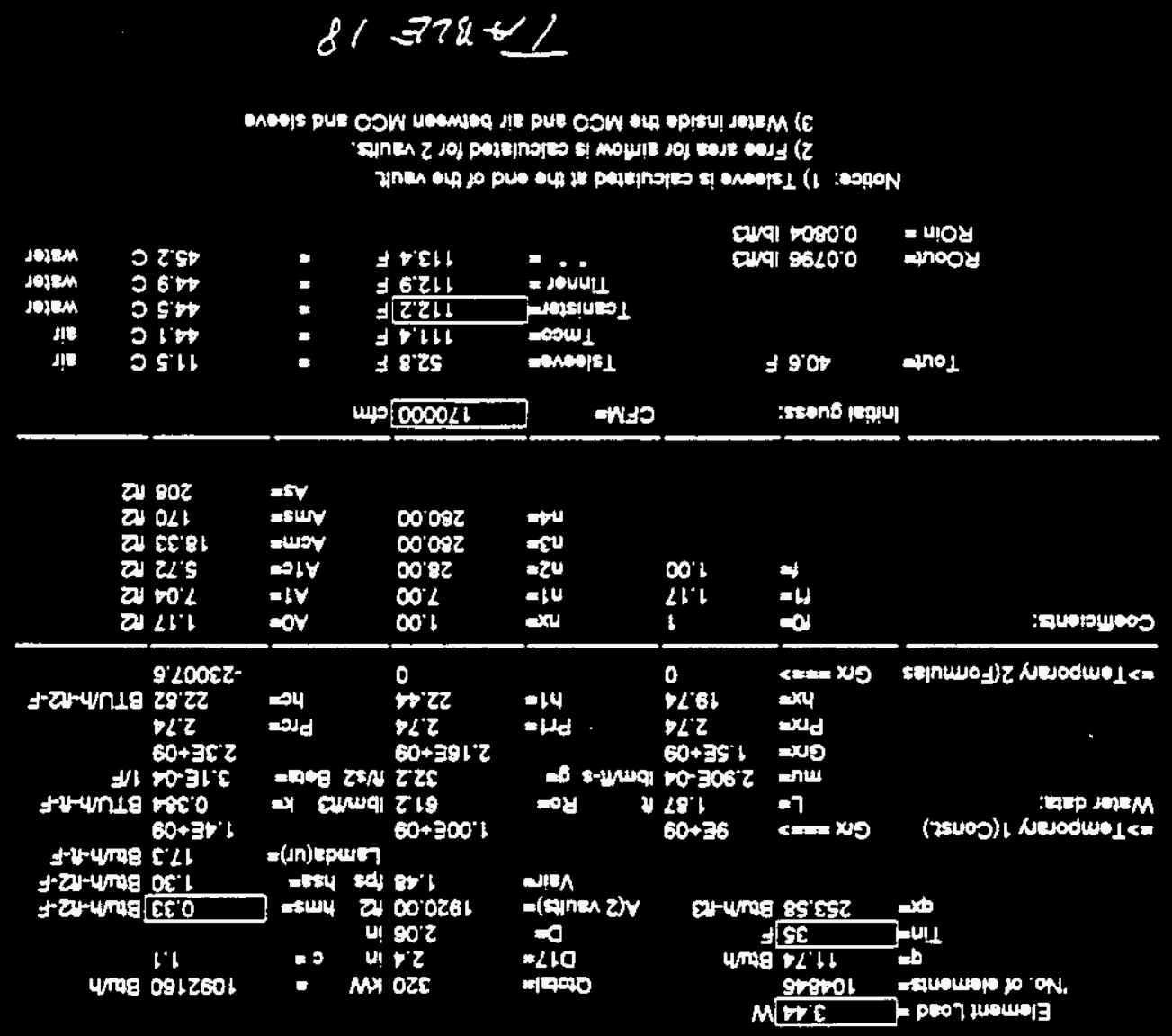

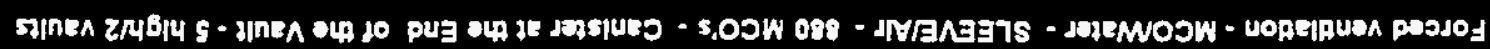
$\lambda \cap \cap \perp s$
$7 \exists \cap \unlhd \quad \exists S$
-azppisi: 
c:Sidd20_4

Foreed ventlatton - MCOWater - SLEEVEANr - 880 MCO's - Canister at the End of the Vault - 5 high/2 vaults

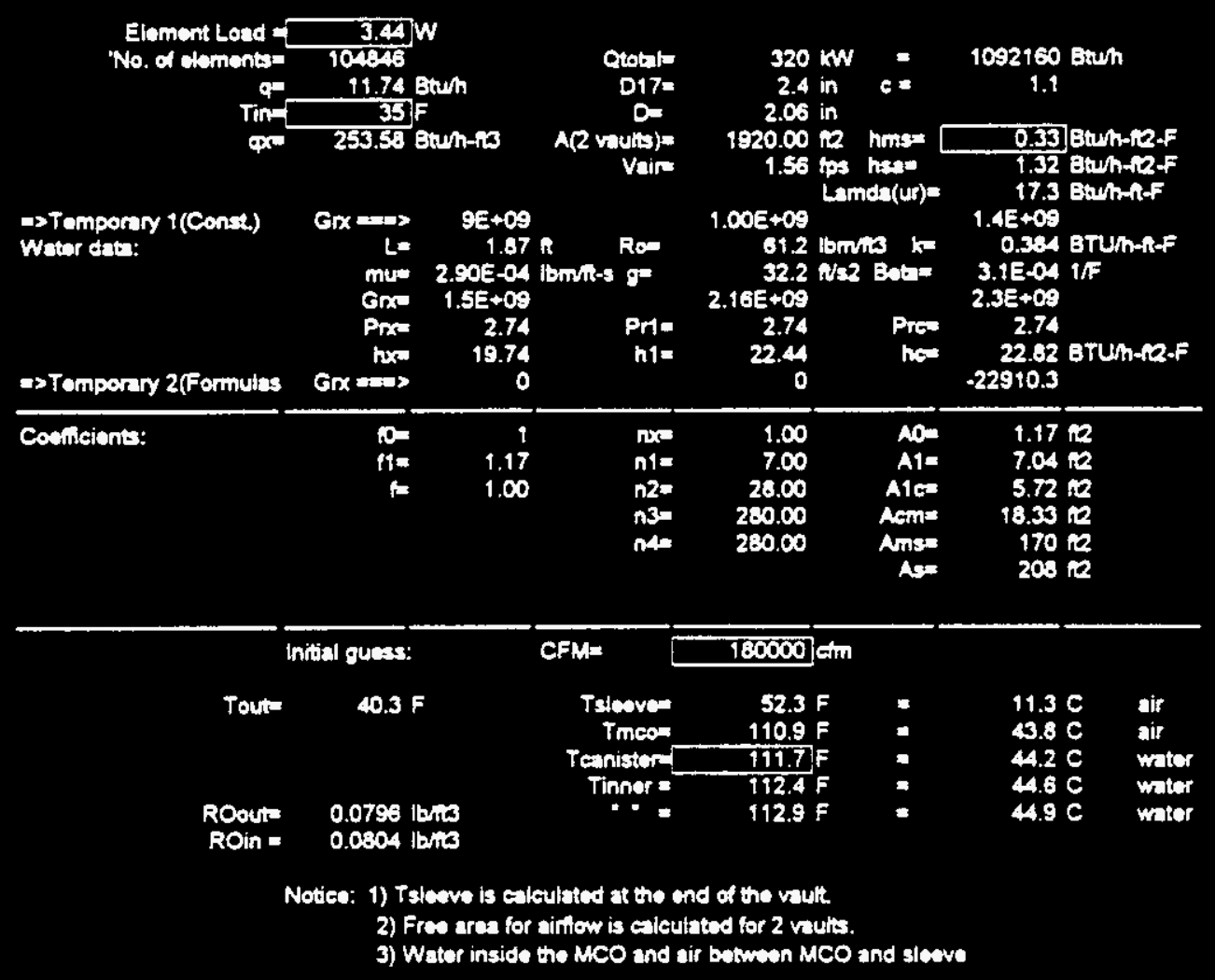

TABLE 19 
c:Siddi20_4 SSF FUEL. STUDY

Foreed ventlatton - MCOWater - SLEEVE/Ar - 880 MCO's - Canlster at the End of the Vault - 5 high/2 vaults

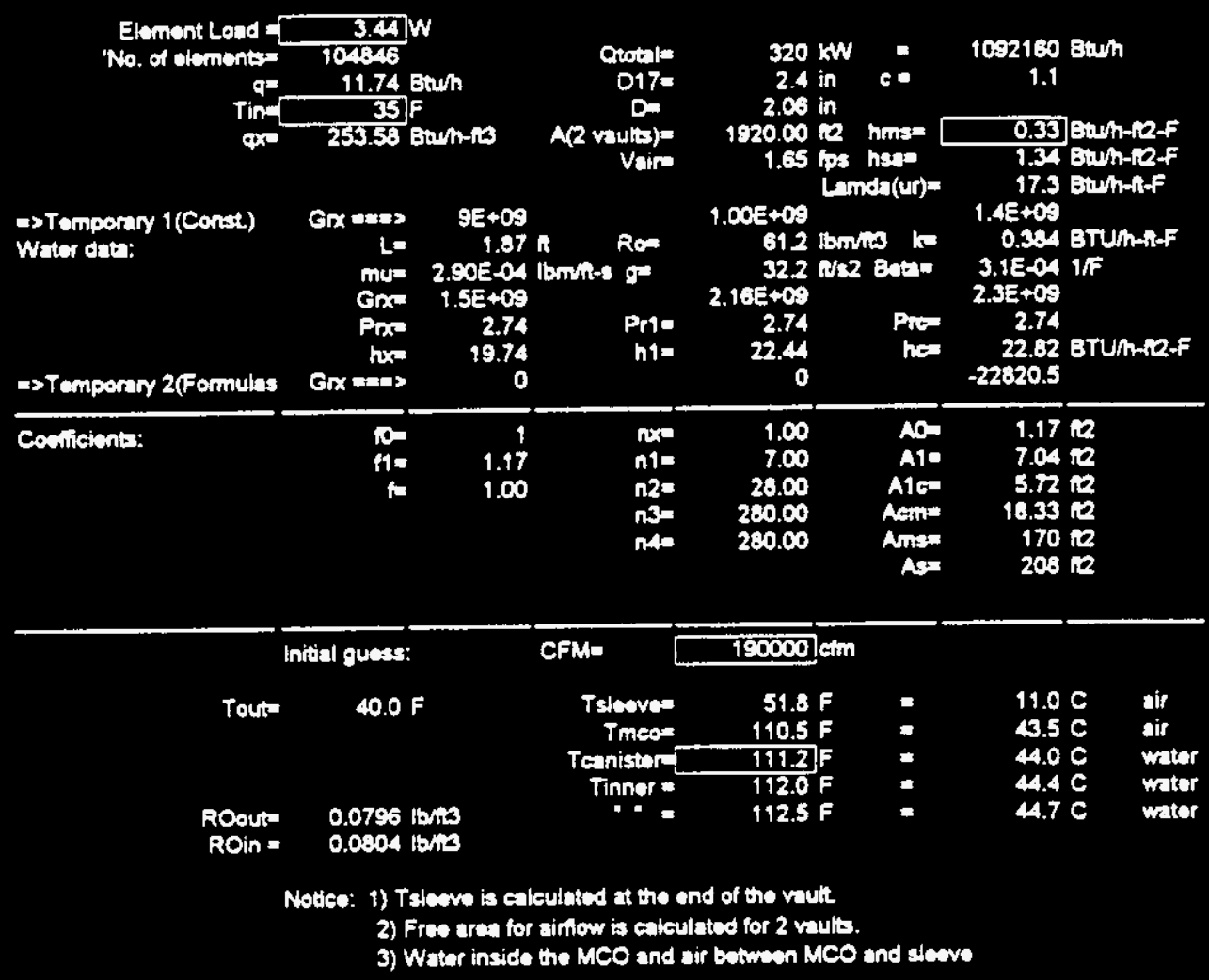

$$
\text { TABLE } 20
$$


c:Sidd120_4

SSF FUEL

STUDY

Foreed ventlation - MCOWater - SLEEVEJAIr - 880 MCO's - Canister at the End of the Vautt - 5 high/2 vaults

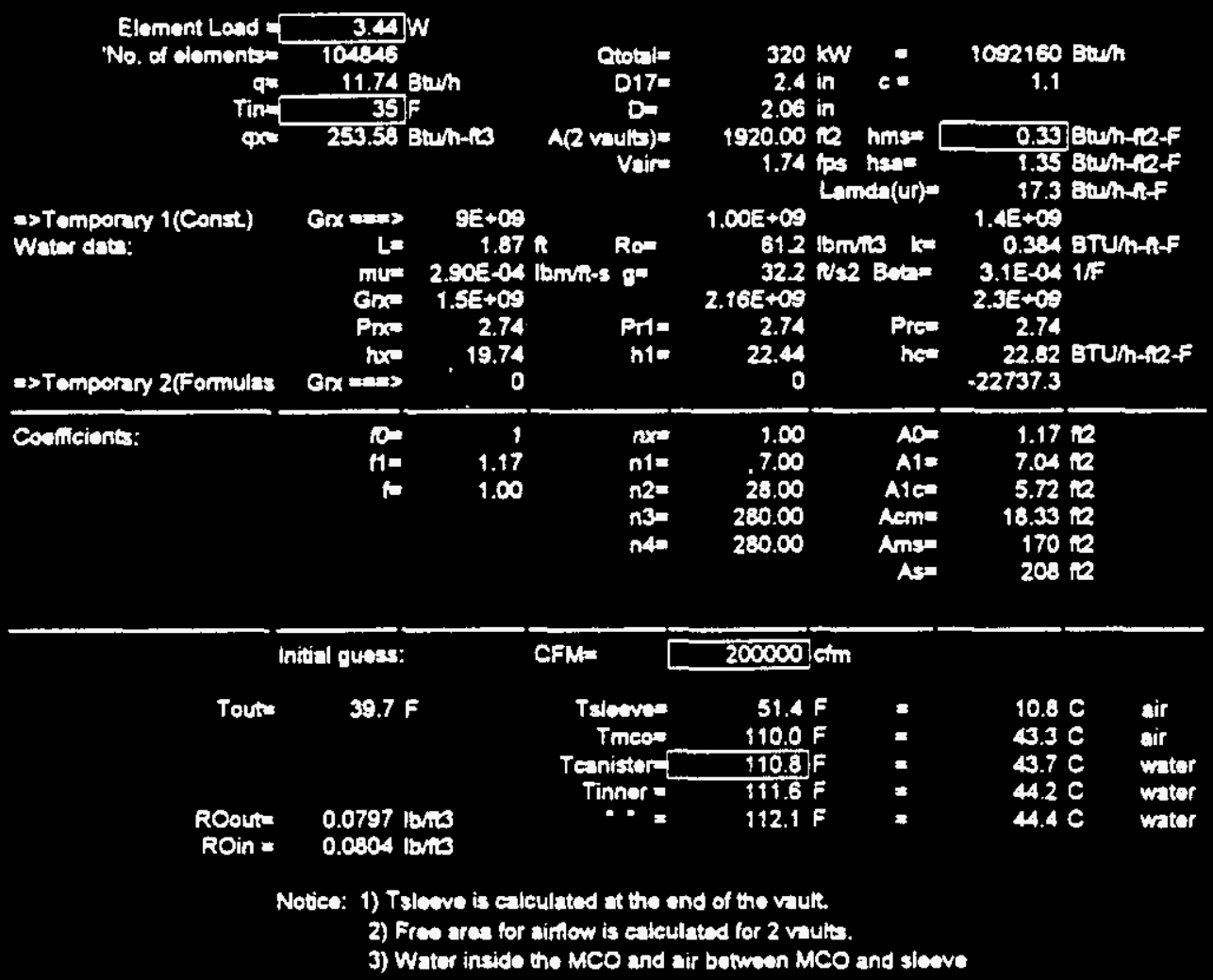

TADLE 21 
eisiddi20_4 SSF FUEL STUDY

Foreed ventlation - MCOWater - StevedAl - 880 MCO's - Canlster at the End of the Vault - 5 hlgh/2 vaults

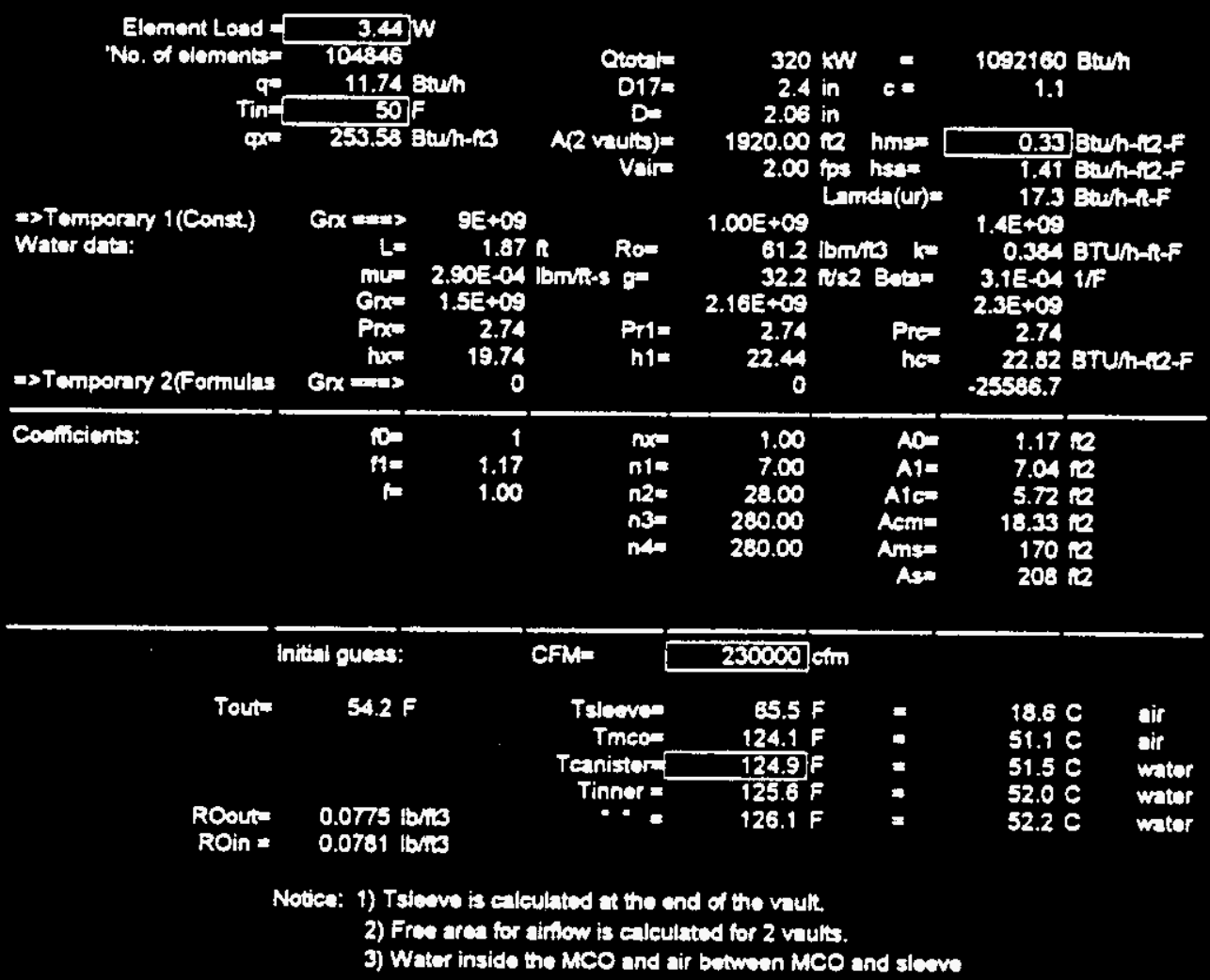

Table 22 
$T A-45$

e:LSiddU20_4

Foreed ventlation - MCOWater - SleevolAir - 880 mCO's - Canlster at the End of the Vault - 5 high/2 vaults

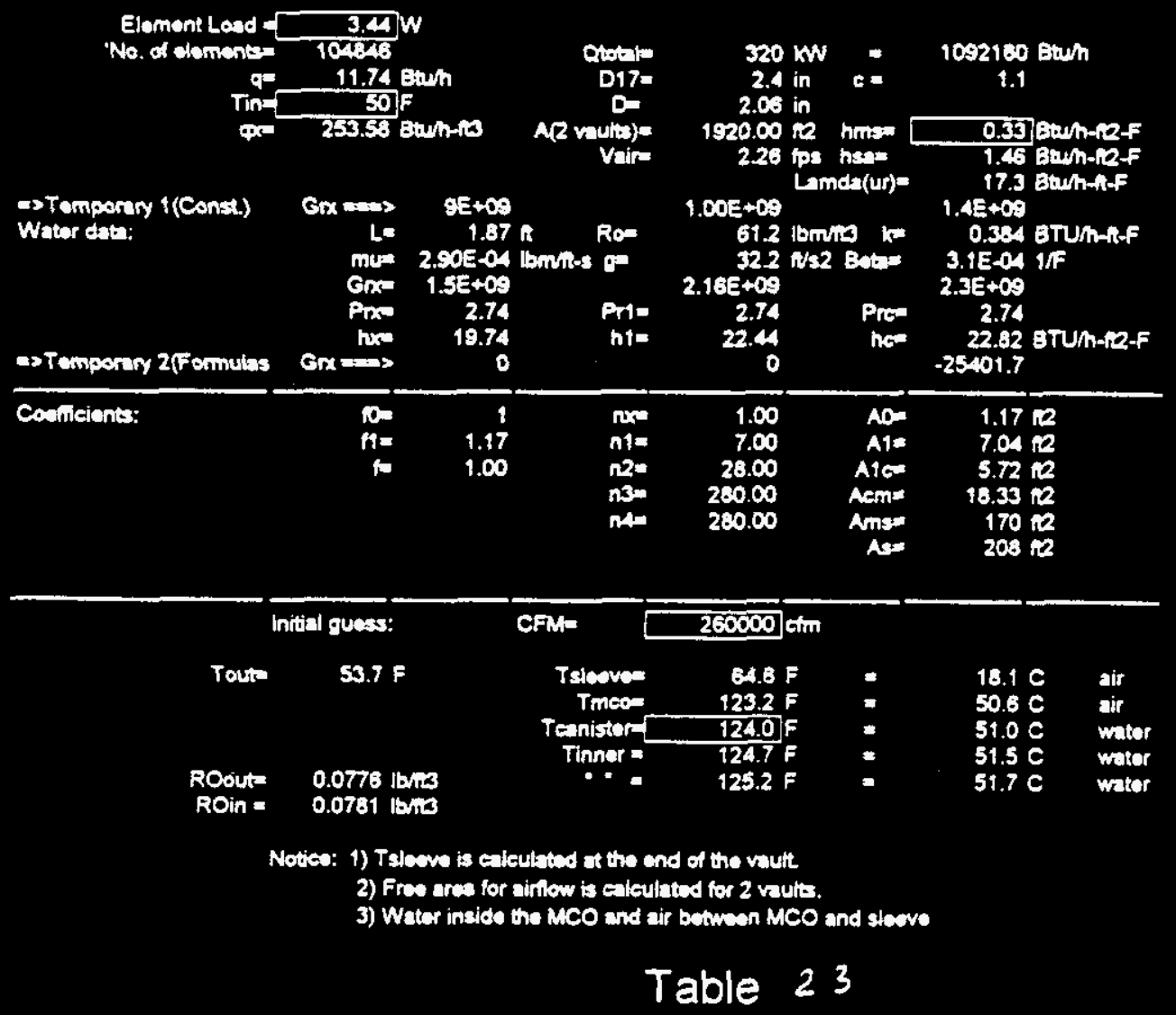


e:sidd120_4 SSF FUEL STUDY

Foreed ventiatton - MCOWater - Siceve/Ar - 880 MCo's - Canlster at the End of the Vault - 5 hlgh/2 vaults

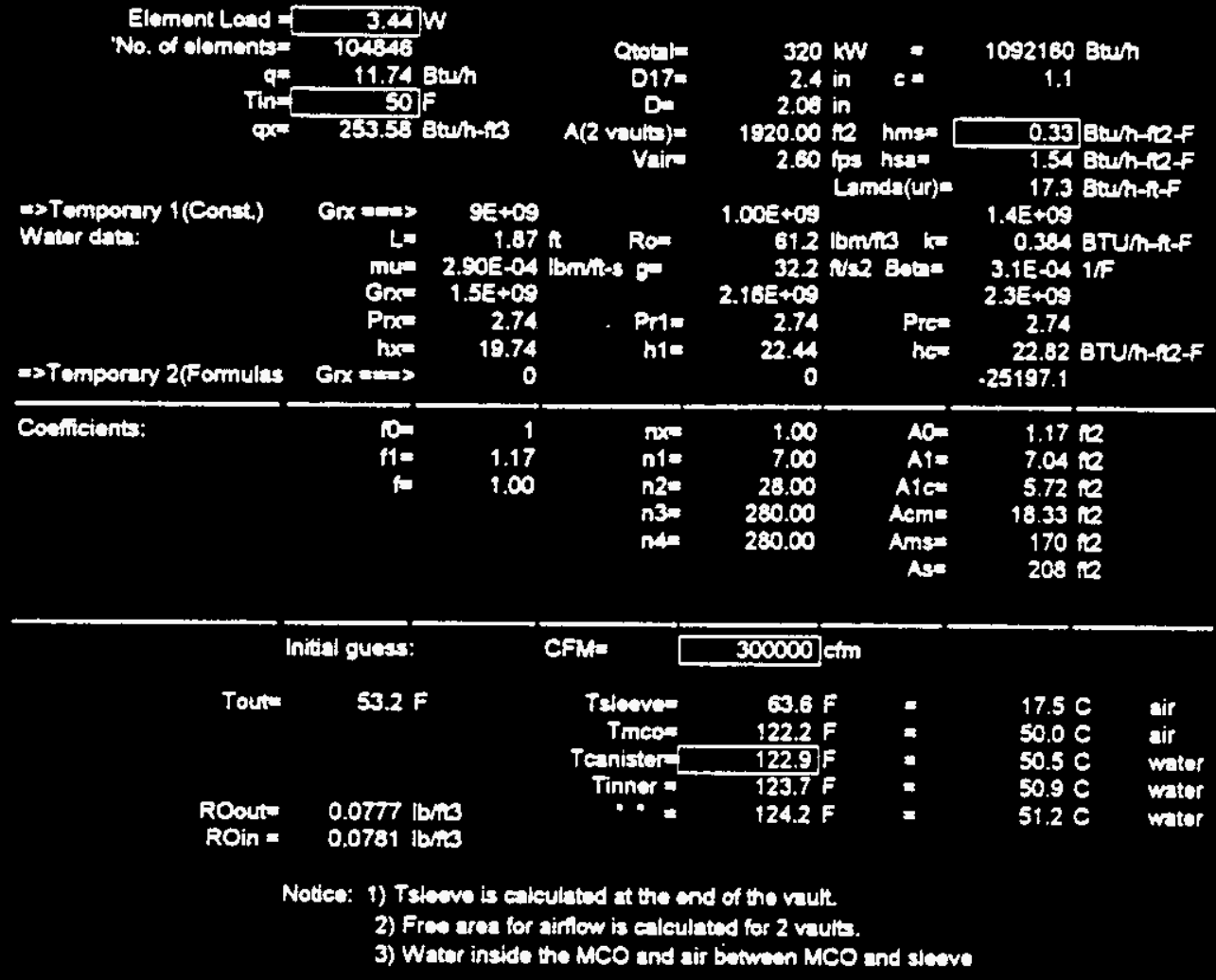

Table 24 


c:Sidd20_4 SSF FUEL STUDY

Foreed ventlation - MCOWater - SlesvelAir - 880 MCO's - Canlster at the End of the Vault - 5 hlgh/2 vaults

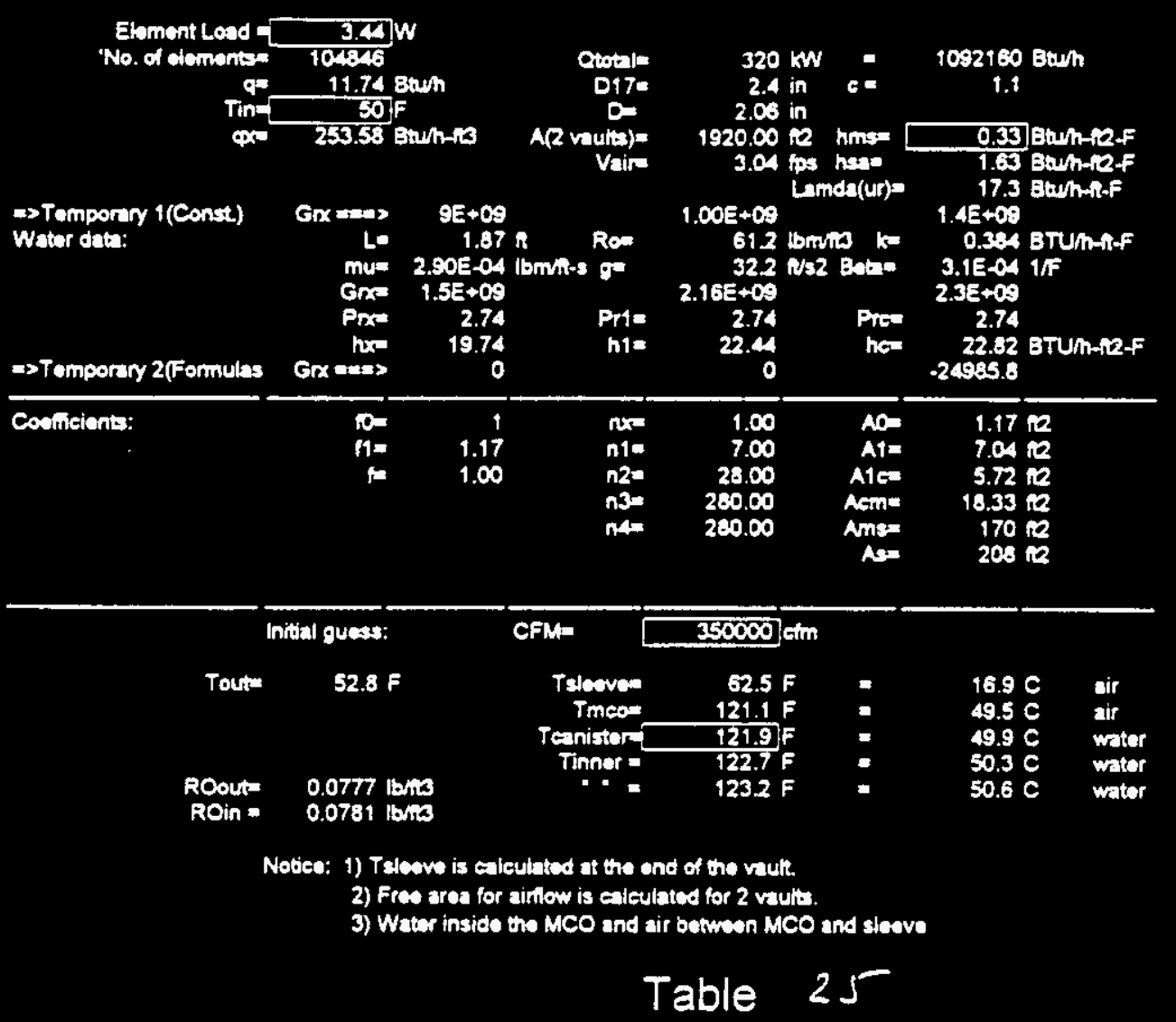




\section{$T A-4 B$}

c:Sidd120_4

\section{SSF FUEL STUDY}

Foreed ventilation - MCOWater - Slecve/AIr - 880 MCO's - Canister at the End of the Vault - 5 high/2 vaults
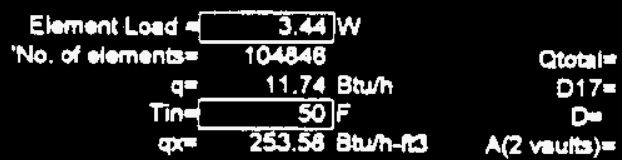

$320 \mathrm{kw}$
$2.4 \mathrm{in} t$
$2.05 \mathrm{in}$

1092160 Bum

QRe 253.58 Bum-in

$A(2$ valita $)=$

1920.00 ie hms:

3.47 tpe has:

estemporary 1(Const)

Wator data:

$1.005+00$ Linda(ur)=

mire $2.00 E-04$ lbminos of

Prxe $\quad 2.74$

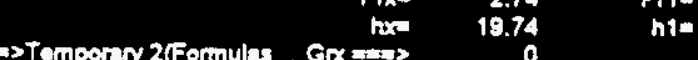

$2.165+0$.

22.74 Pre

$2.3 E+09$

he $\quad 22.82$ BrUm-12.F .24808 .8

\begin{tabular}{|c|c|c|c|c|c|c|}
\hline Conflicionts: & $\begin{array}{l}\text { for } \\
f 1= \\
f=\end{array}$ & $\begin{array}{r}1 \\
1.17 \\
1.00\end{array}$ & $\begin{array}{l}n \times= \\
n 1= \\
n 2= \\
n 3= \\
n 4=\end{array}$ & $\begin{array}{r}1.00 \\
7.00 \\
28.00 \\
280.00 \\
280.00\end{array}$ & 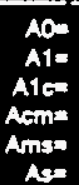 & $\begin{array}{r}1.17 \mathrm{re} \\
7.04 \mathrm{re} \\
5.72 \mathrm{re} \\
18.33 \mathrm{ra} \\
170 \mathrm{re} \\
208 \mathrm{re}\end{array}$ \\
\hline
\end{tabular}

\begin{tabular}{|c|c|c|c|c|c|c|}
\hline \multicolumn{2}{|c|}{ Initial quoss: } & CFM= & 4000000 of & & & \\
\hline $\begin{array}{l}\text { ROout= } \\
\text { ROin = }\end{array}$ & $\begin{array}{l}0.0778 \mathrm{lb} / \mathrm{ha} \\
0.0781 \mathrm{lb} / \mathrm{h}\end{array}$ & $\begin{array}{c}\text { Teloevere } \\
\text { Tmeoe } \\
\text { Teanisterm } \\
\text { Tinner } \\
.-\end{array}$ & $\begin{array}{r}61.6 \mathrm{~F} \\
120.3 \mathrm{~F} \\
121.0 \mathrm{~F} \\
121.8 \mathrm{~F} \\
122.3 \mathrm{~F}\end{array}$ & $\begin{array}{l}: \\
: \\
:\end{array}$ & $\begin{array}{l}16.5 \mathrm{C} \\
49.0 \mathrm{C} \\
49.4 \mathrm{C} \\
49.8 \mathrm{C} \\
50.1 \mathrm{C}\end{array}$ & $\begin{array}{l}\text { air } \\
\text { air } \\
\text { wator } \\
\text { water } \\
\text { woter }\end{array}$ \\
\hline & $\begin{array}{l}\text { co: 1) Trleow } \\
\text { 2) Free } \\
\text { 3) Water }\end{array}$ & $\begin{array}{l}\text { ubted at the } \\
\text { ifflow is calet } \\
\text { the MCO and }\end{array}$ & $\begin{array}{l}f \text { the vault. } \\
\text { f for } 2 \text { vault } \\
\text { twom Men }\end{array}$ & & & \\
\hline
\end{tabular}

Table 26 
e:Sidal20_4

Foreed ventlation - MCOWater - Sleeve/Ajr - 890 MCO's - Canister at the End of the Vault - 5 high/2 vaults

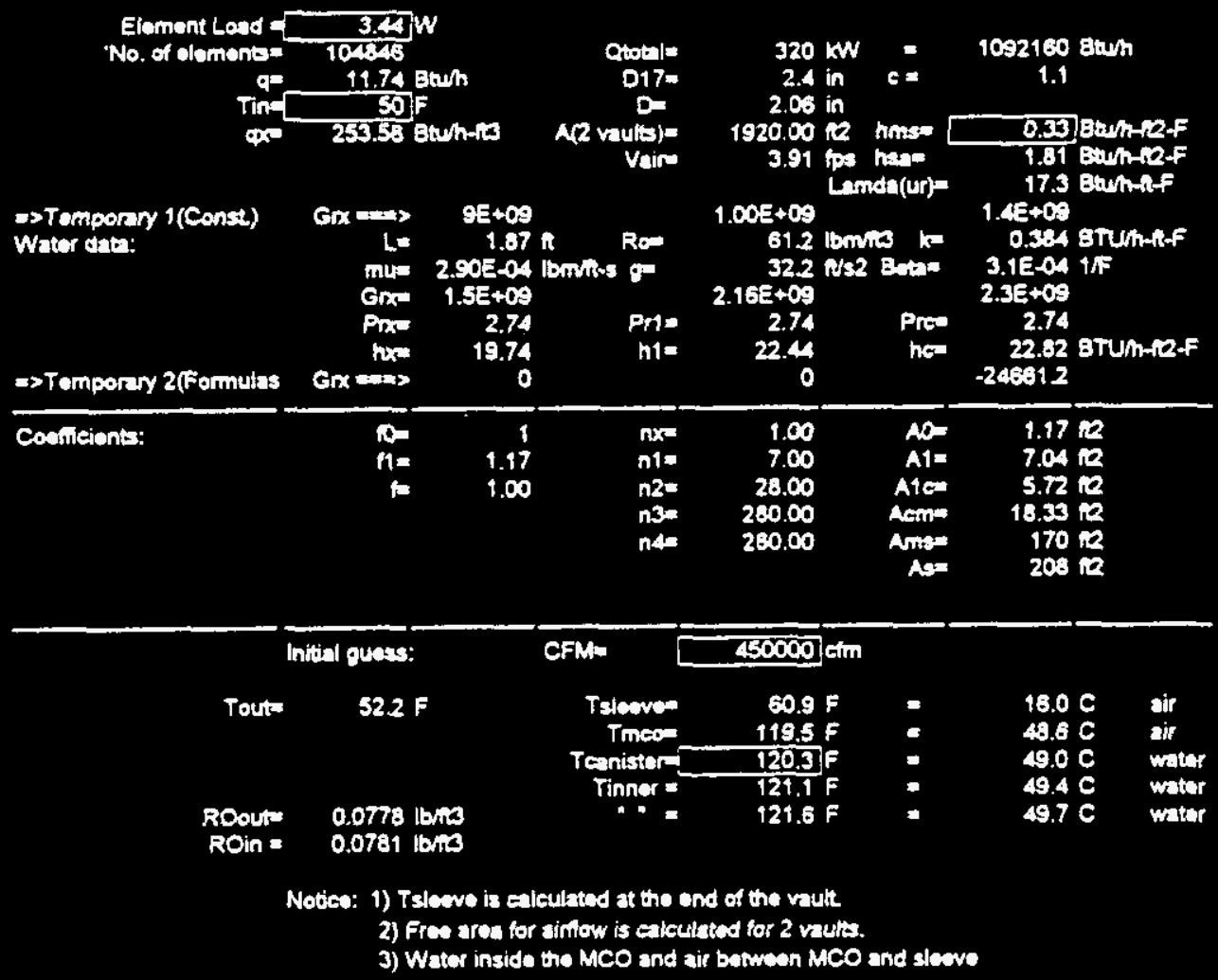

Table 27 
e:Sidd2D_4

\section{SSF FUEL STUDY}

Forced ventlation - MCOWhater - SlesvelAr - 880 MCO's - Canister at the End of the Vault - 5 hlgh/2 vaults

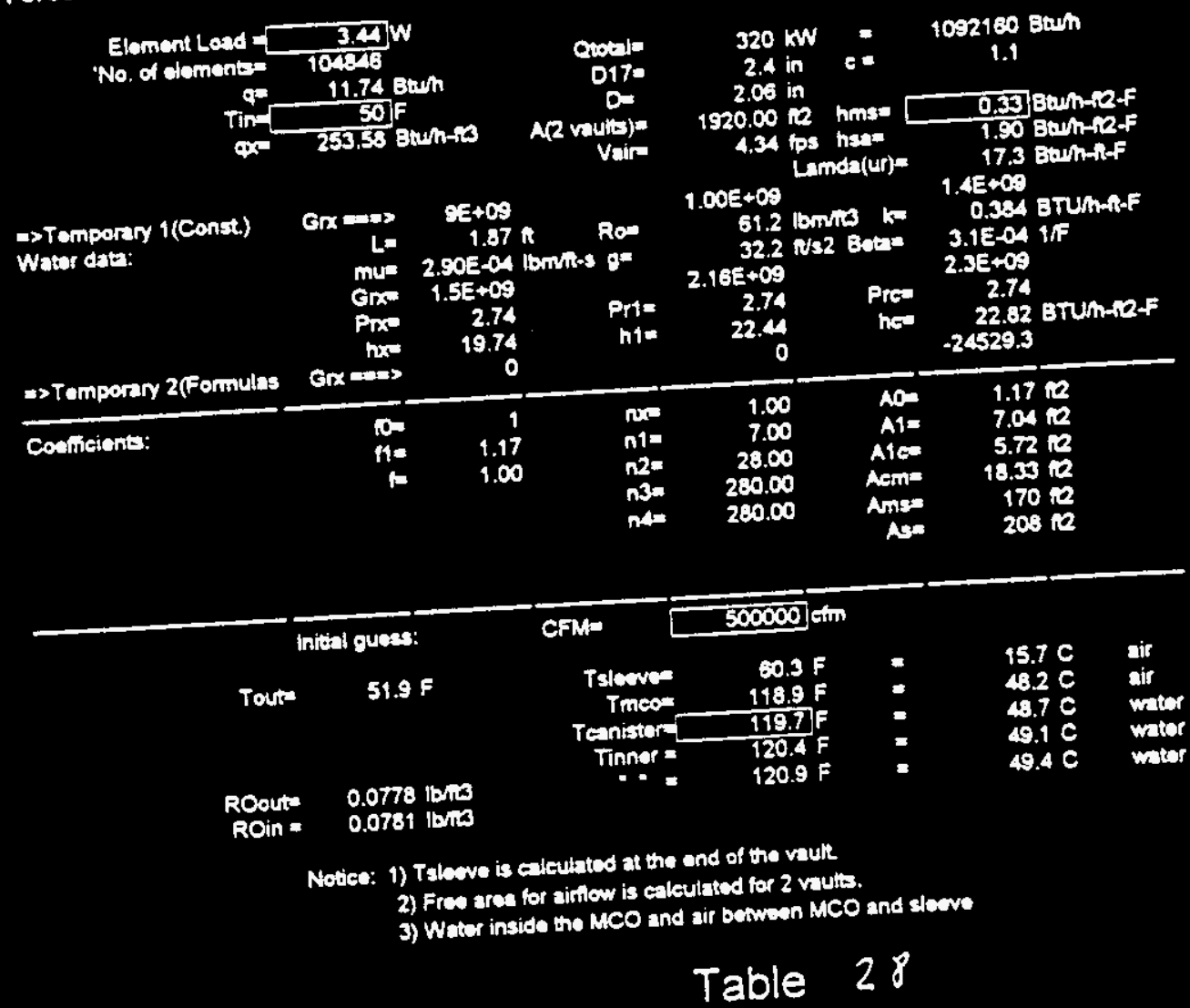


c:1Sidd20 4

Foreed ventlation - MCOWater - SleevelAv - 880 MCO's - Canlster at the End of the Vault - 5 high/2 vaults

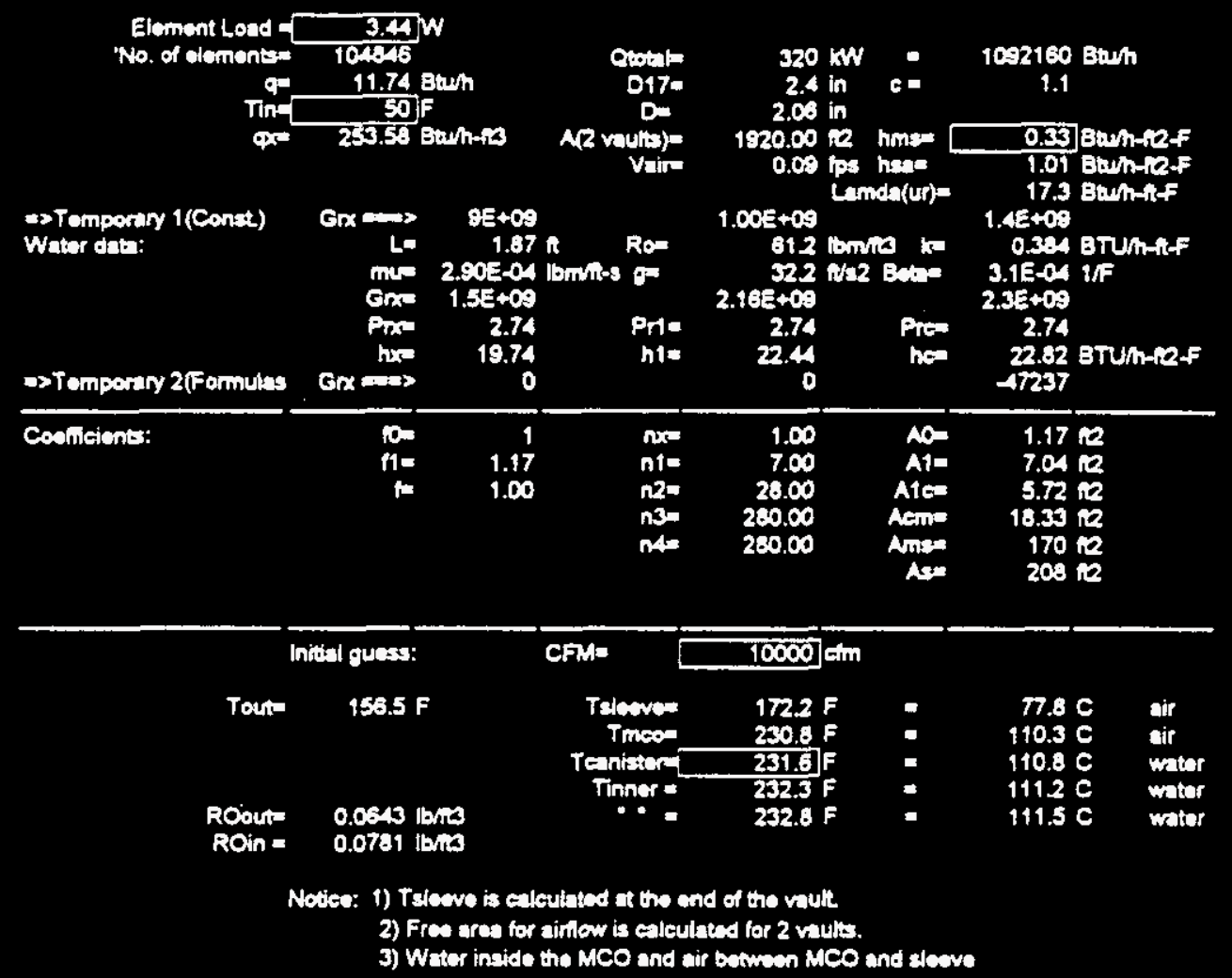

\section{Table 29}

\section{T canister as a function of CFM} Water in MCO. Air in simo

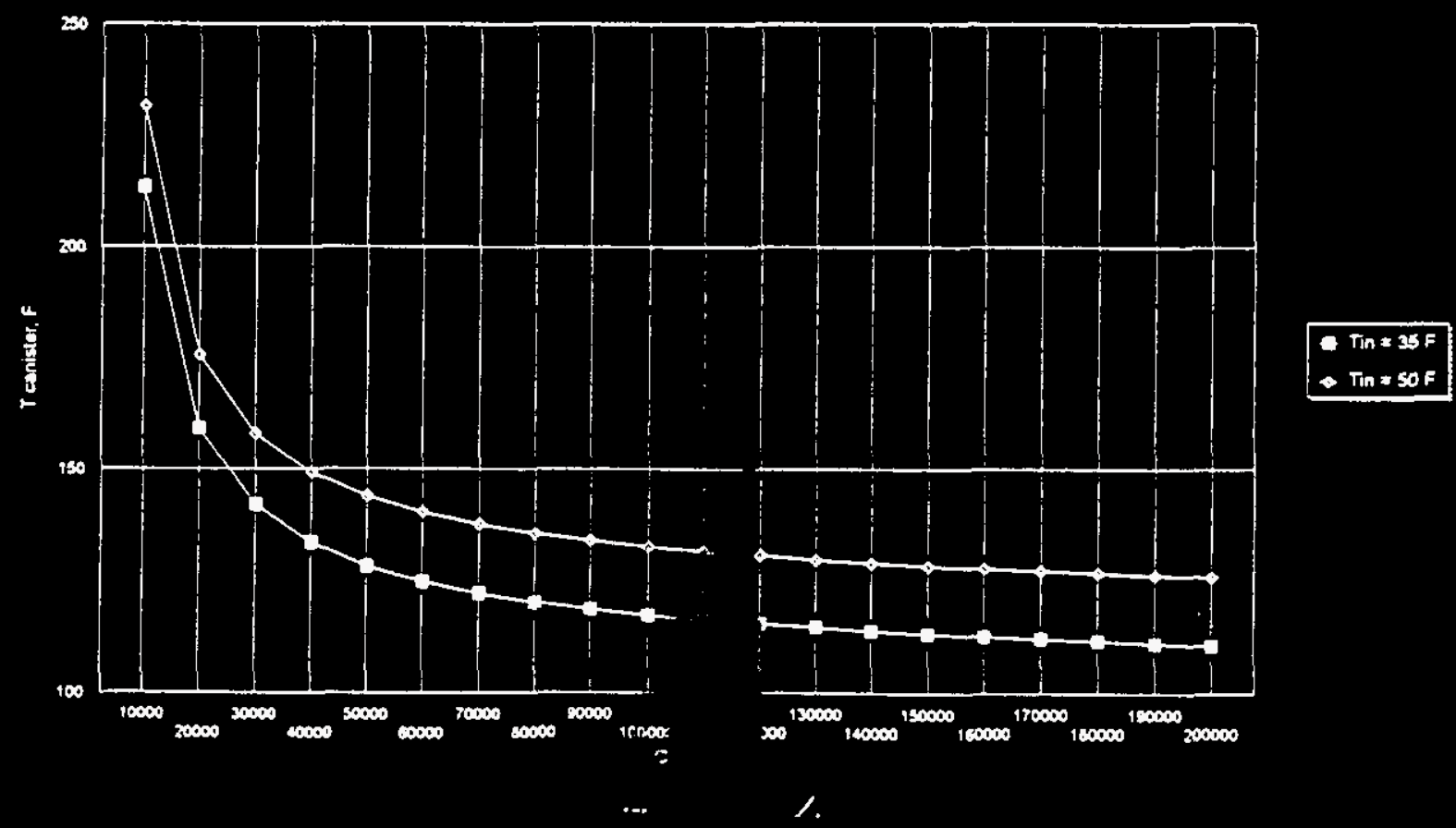

WHC-SD-W379-ES-003 ReV. 0 
c:1Sidd20_4

Foreed ventlation - MCOWater - Slesve/Ar - 880 MCO's - Canistar at the End of the Vault - 5 high/2 vaults

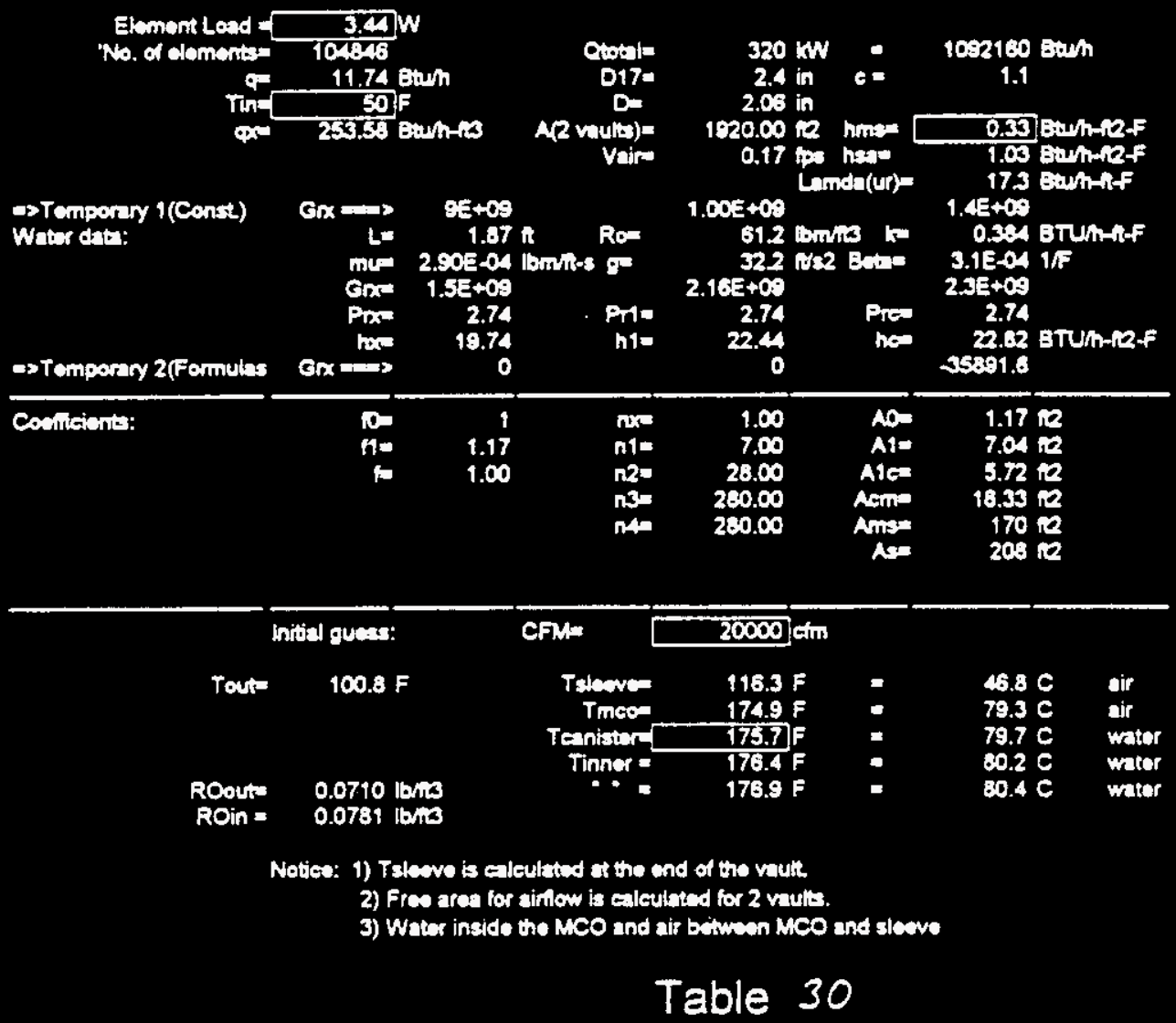


Foreed ventlation - MCOWater - SlesvedNr - 880 MCO's - Canister at the End of the Vault - 5 high/2 vaults

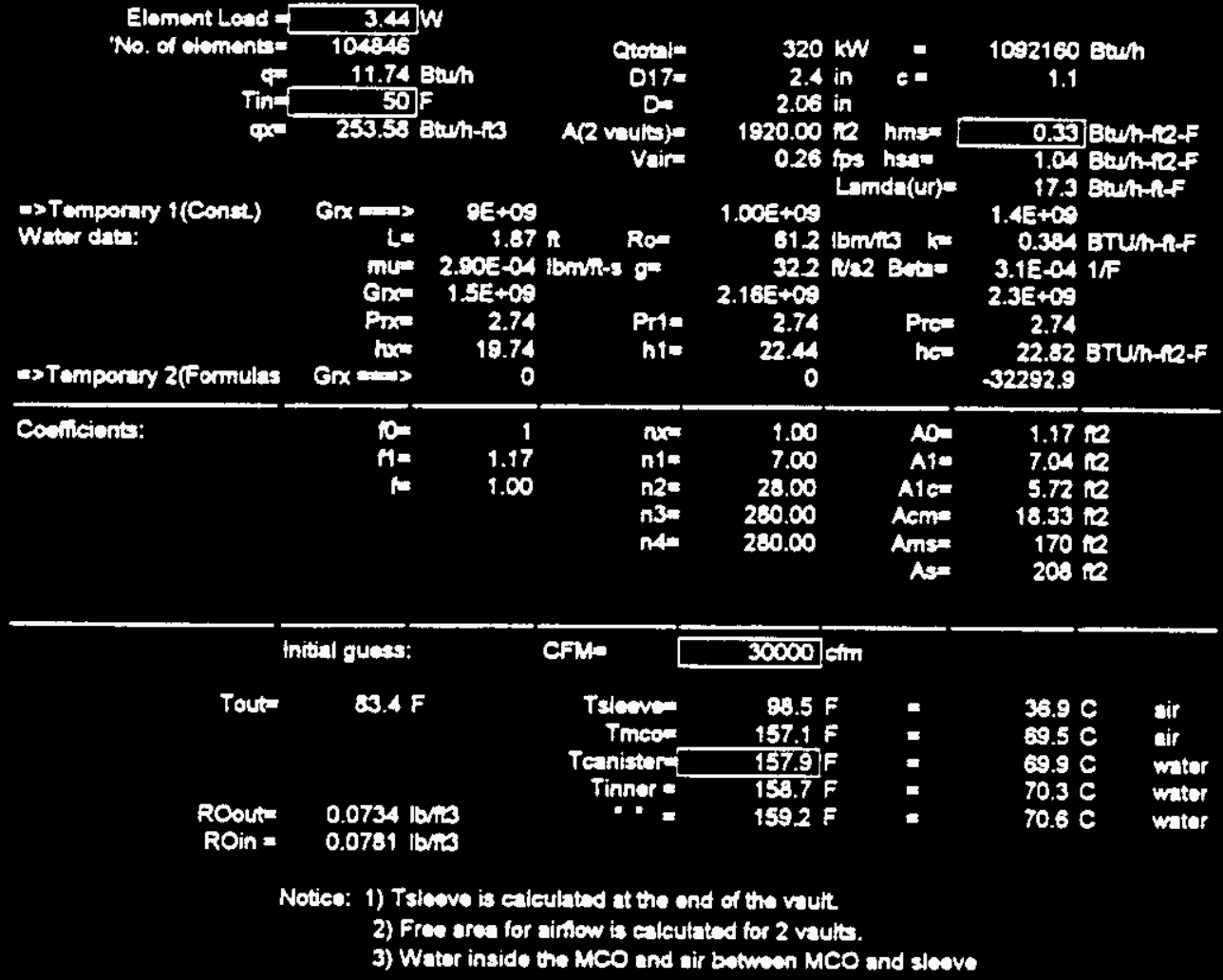

Table 31 
e:Sida120.4 SSF FUEL STUDY

Forced ventiation - MCOWater - SlevvelAir - 880 mCO's - Canister at the End of the Vault - 5 hloh/2 vaults

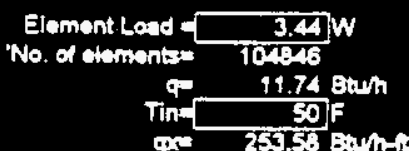

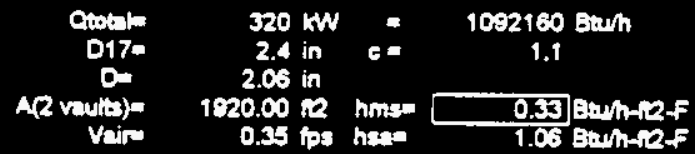

$1.005+0$.

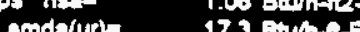

$\rightarrow$ Temporary 1 (Const)

Water dats:

Crx 8000

1.87 R Reo

mue 2.905-04 lomples of

Gra $1.5 E+00$

Prove 2.7

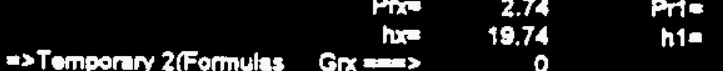

2 lontus ko 0.384 BTUhme

322 Ne2 Eate 3.1E04 $1 / \mathrm{P}$

$2.3 E+09$

$\begin{array}{lrr}2.74 & \text { Prod } & 2.74\end{array}$

he 22.02 BTUh-12

Cowriteiont: 30500.4

0

\begin{tabular}{|c|c|c|}
\hline $\begin{array}{r}1.00 \\
7.00 \\
28.00 \\
280.00 \\
280.00\end{array}$ & $\begin{array}{l}\text { AO= } \\
\text { A1= } \\
\text { AtE= } \\
\text { Acm: } \\
\text { Ams: } \\
\text { Ase }\end{array}$ & $\begin{array}{r}1.17 \mathrm{ra} \\
7.04 \mathrm{re} \\
5.72 \mathrm{re} \\
18.33 \mathrm{ra} \\
170 \mathrm{re} \\
208 \mathrm{ra}\end{array}$ \\
\hline
\end{tabular}

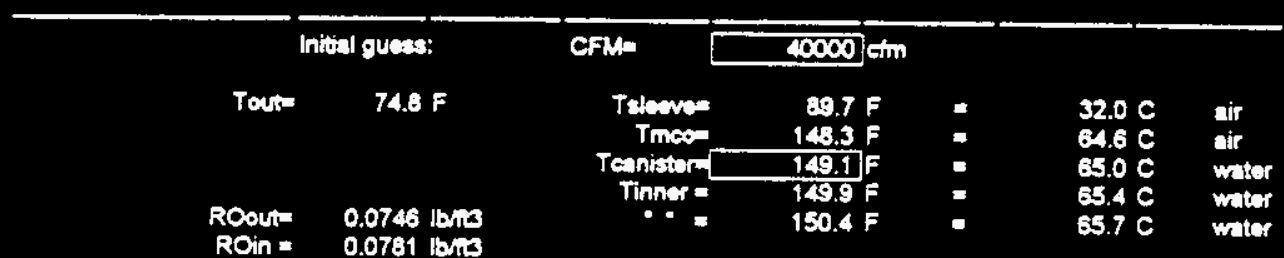

Notice: 1) Tslawe is enkulated at the end of the valt.

2) Fres area for sirtiow is elloulated for 2 vauks.

3) Water inside the MCO and air bitween MCO and slewvo

Table 32 
e:Sidd120_4 SSF FUEL STUDY

Foreed venthation - MCOWater - SlesvelAr - 880 MCO's - Canlster at the End of the Vault - 5 high/2 vaults

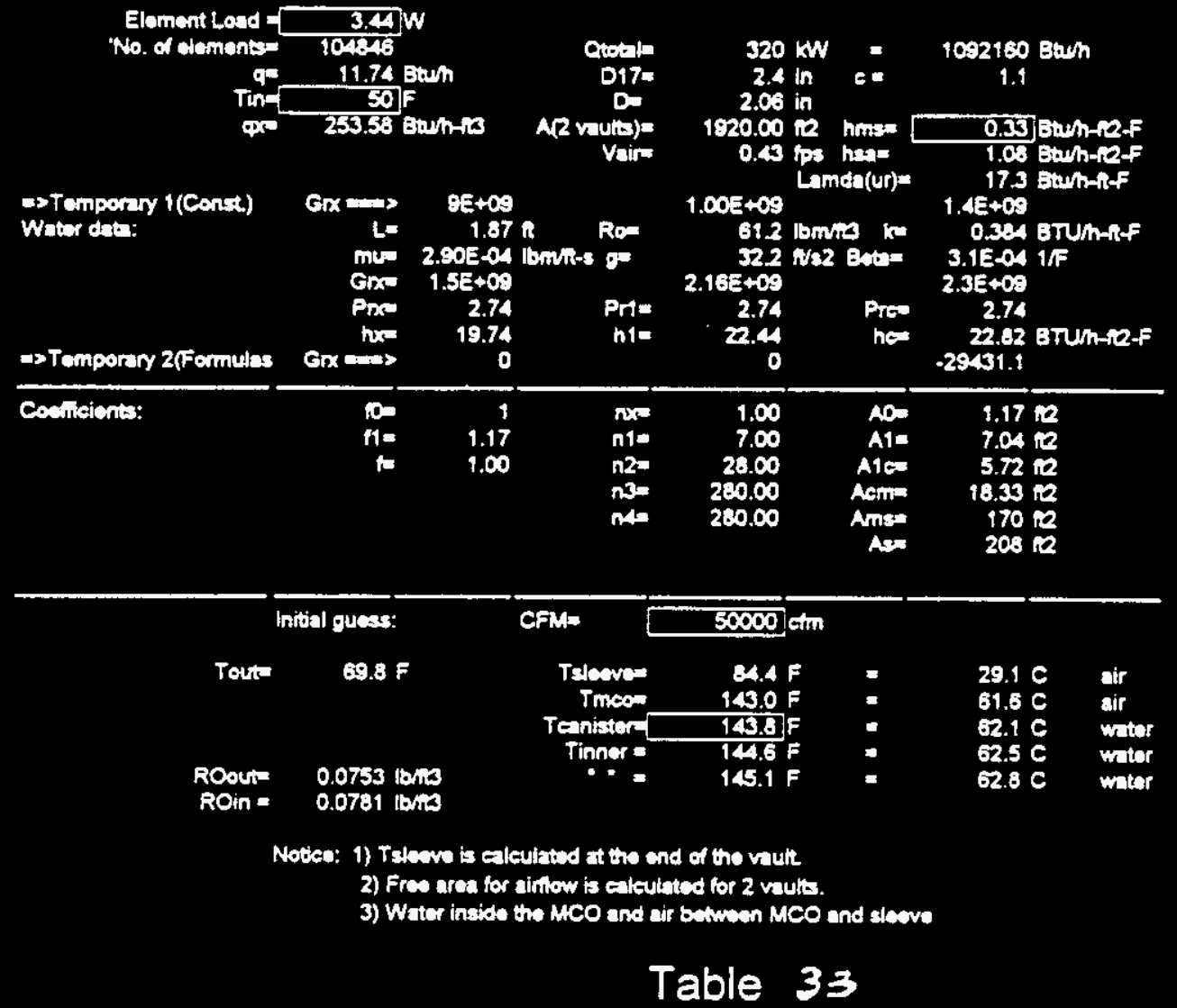


e:Sidd20_4 SSF FUEL STUDY

Foreed ventiation - MCOWater - StesvelAir - 880 MCO's - Canleter at the End of the Vault - 5 high/2 vaults

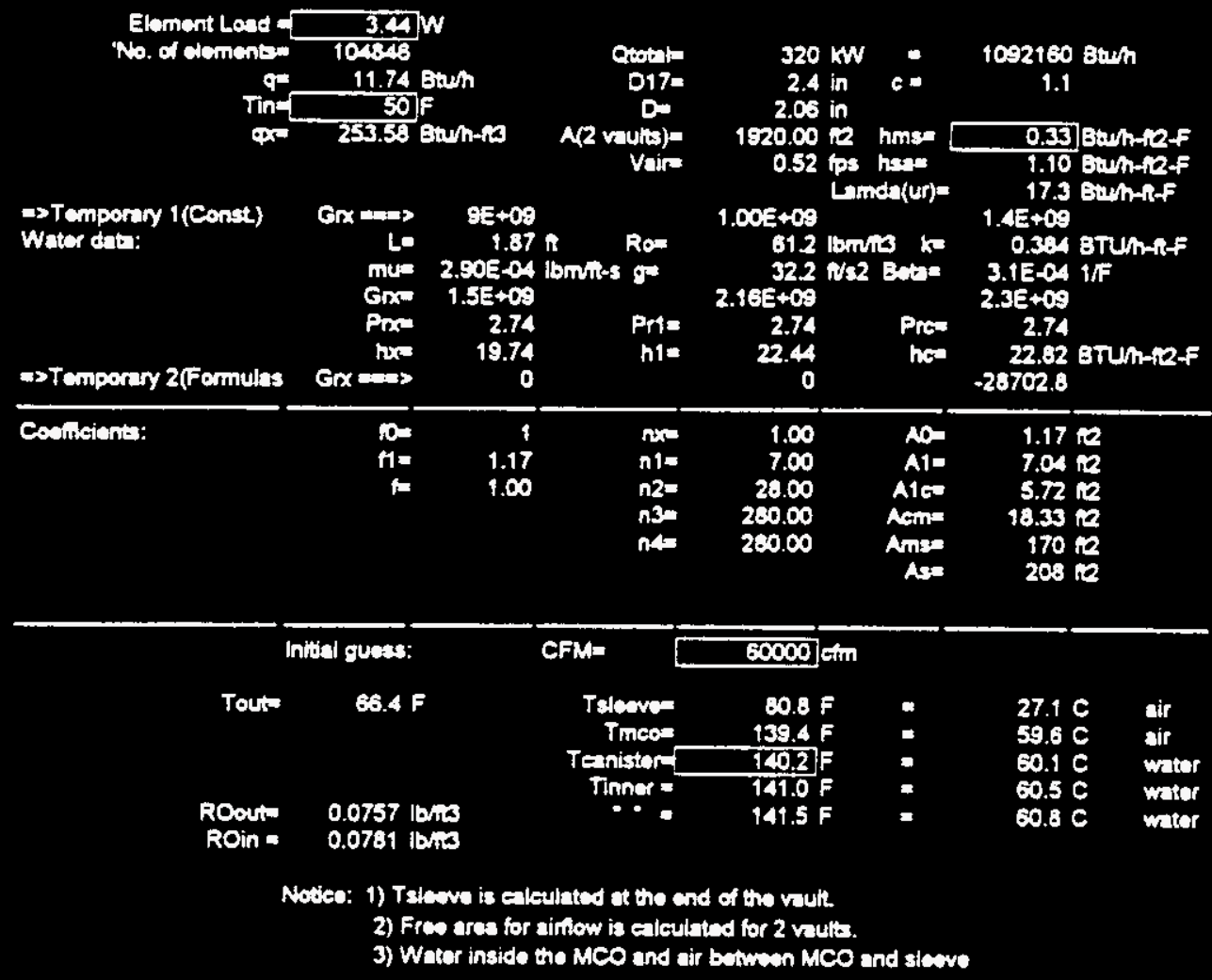

Table 34

WHC-SD-W379-ES-003 ReV. 0 
e:Siddi20_4 SSF FUEL STUDY

Foreed ventilation - MCOWater - SlesvdAr - 880 MCO's - Canistor at the End of the Vault - 5 high/2 vaults

\begin{tabular}{|c|c|c|c|c|c|c|c|c|}
\hline 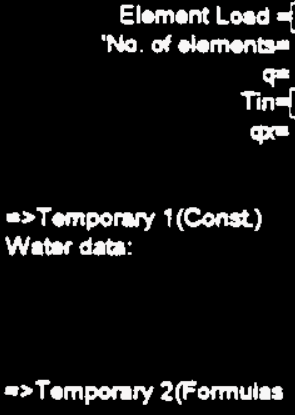 & 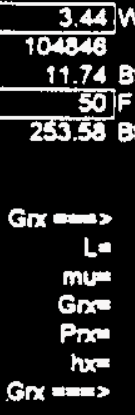 & $\begin{array}{r}9 E+\infty 9 \\
1.87 \\
2.90 E-04 \\
1.5 E+\infty \\
2.74 \\
19.74 \\
0\end{array}$ & 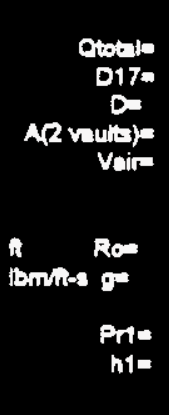 & $\begin{array}{r}320 \\
2.4 \\
2.06 \\
1920.00 \\
0.61 \\
1.00 E+00 \\
61.2 \\
32.2 \\
2.16 E+00 \\
2.74 \\
22.44 \\
0\end{array}$ & 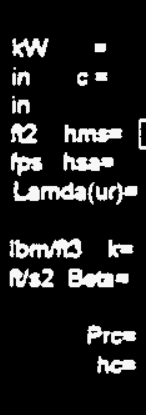 & \multicolumn{3}{|c|}{ 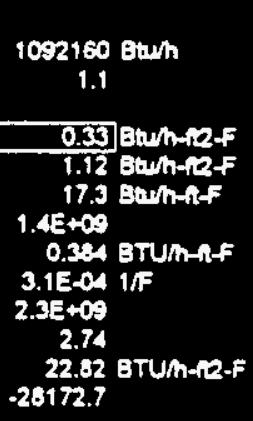 } \\
\hline \multirow[t]{4}{*}{ Conflicionts: } & $\begin{array}{l}100 \\
t= \\
t=\end{array}$ & $\begin{array}{r}1 \\
1.17 \\
1.00\end{array}$ & $\begin{array}{l}n=0 \\
n 10 \\
n 2= \\
n 30 \\
n 40\end{array}$ & $\begin{array}{r}1.00 \\
7.00 \\
28.00 \\
280.00 \\
280.00\end{array}$ & $\begin{array}{l}\text { Ao= } \\
\text { Ale } \\
\text { Ales } \\
\text { Aeme } \\
\text { Anse } \\
\text { Ane }\end{array}$ & $\begin{array}{r}1.17 \\
7.04 \\
5.72 \\
18.33 \\
170 \\
208\end{array}$ & & \\
\hline & tiat gucas: & & CFM= & 70000 & ctim & & & \\
\hline & $\begin{array}{l}0.0781 \text { lb } \\
0.0781 \text { lat }\end{array}$ & & 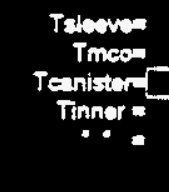 & $\begin{array}{r}76.2 \mathrm{~F} \\
138.8 \mathrm{~F} \\
137.6 \mathrm{~F} \\
138.4 \mathrm{~F} \\
138.9 \mathrm{~F}\end{array}$ & $\begin{array}{l}: \\
: \\
:\end{array}$ & $\begin{array}{l}25.7 \\
58.2 \\
58.6 \\
59.0 \\
59.3\end{array}$ & & $\begin{array}{l}\text { air } \\
\text { air } \\
\text { water } \\
\text { water } \\
\text { water }\end{array}$ \\
\hline & 3) & $\begin{array}{l}0 \text { is } \mathrm{C} \\
\text { rom fo } \\
\text { inside }\end{array}$ & low is tho & $\begin{array}{l}\text { the vault } \\
\text { for } 2 \text { veut }\end{array}$ & $\begin{array}{l}\text { lit } \\
\text { ultas. } \\
\text { ico and }\end{array}$ & & & \\
\hline
\end{tabular}

Table 35 
Foreed ventlation - MCOWater - SlesvelAir - 880 MCO's - Canister at the End of the Vault - 5 hlgh/2 vaults

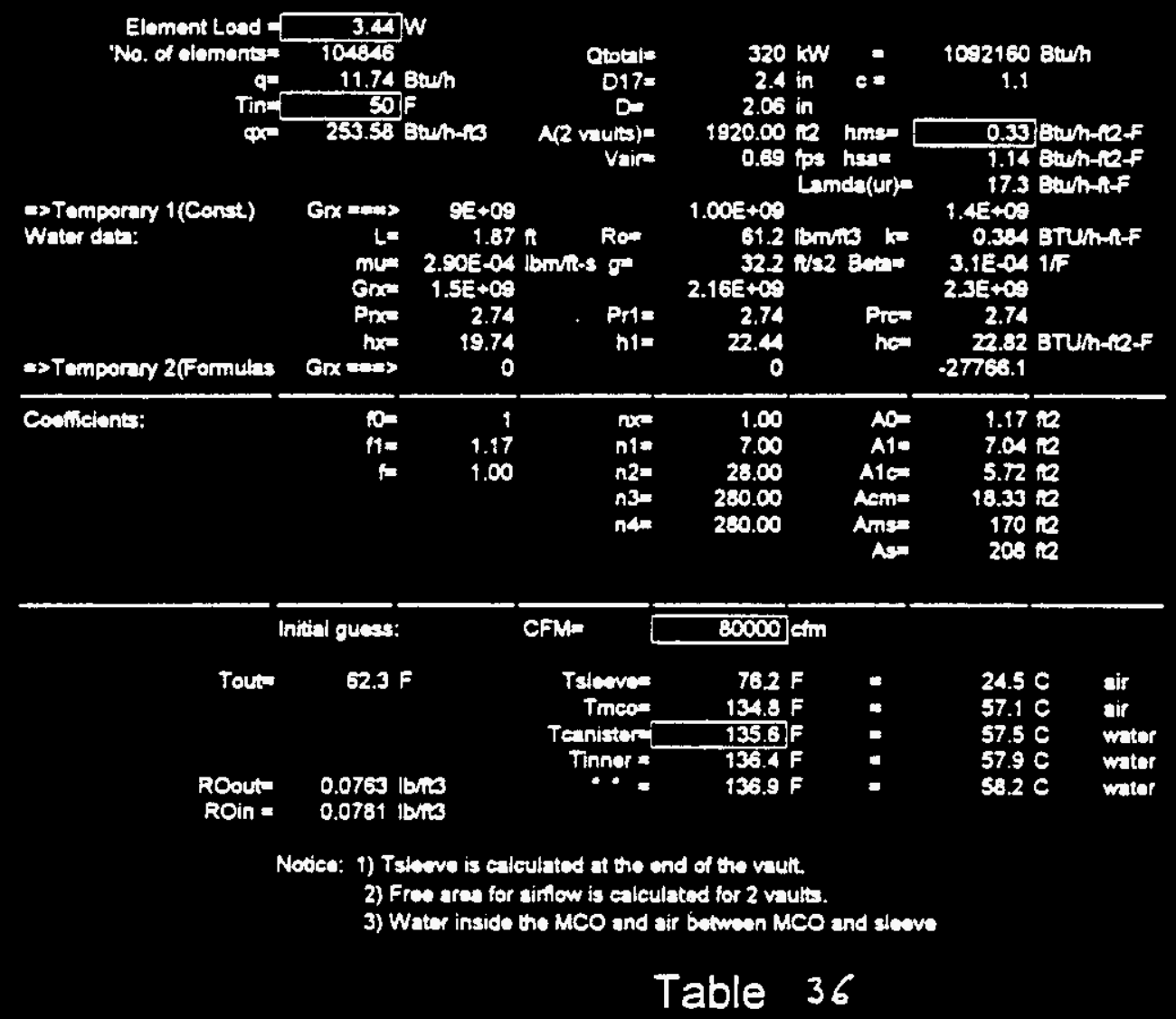


e.:Sidd120_4

\section{SSF FUEL STUDY}

Foreed ventiation - MCOWater - Slesve/AIr - 880 MCO's - Canlster at the End of the Vault - 5 hloh/2 vaults

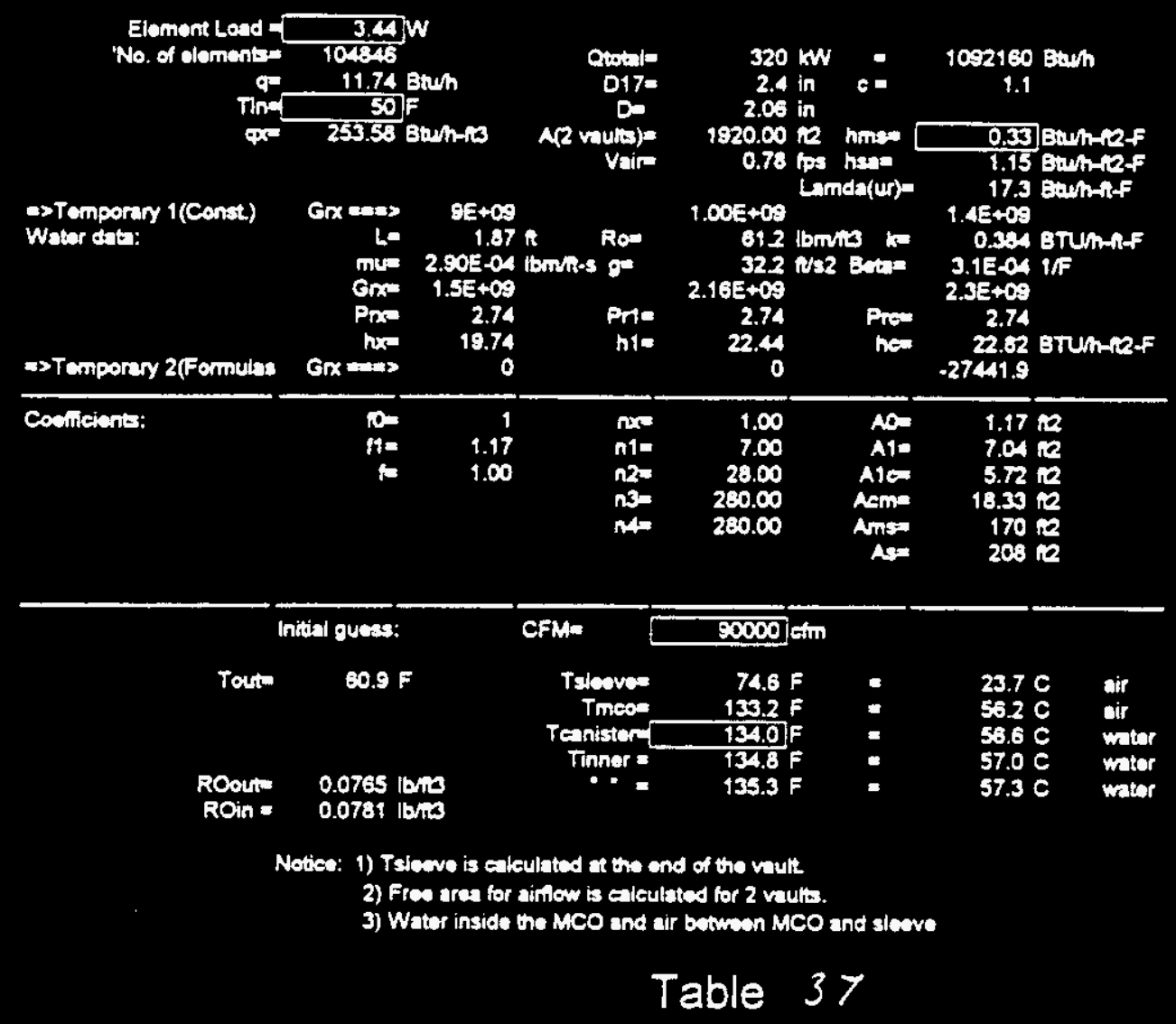


c:Siddro_4 SSF FUEL STUDY

Forced ventiation - MCOWater - Steave/AIr - 880 MCO's - Canister at the End of the Vault - 5 hlgh/2 vaults

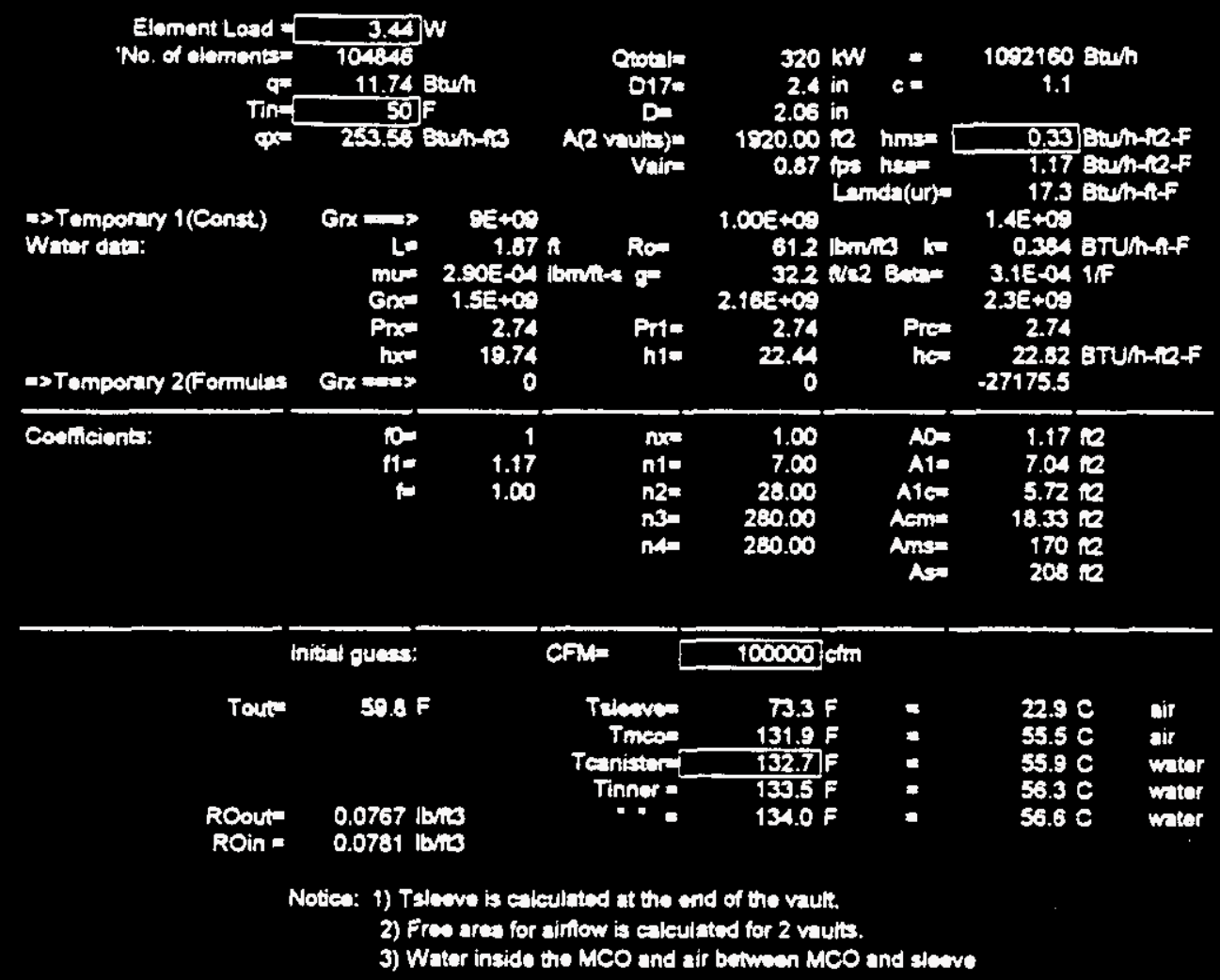

Table 38 
eisidalizo_4 SSF FUEL STUDY

Foreed ventlation - MCOWater - Sleeve/AJr - 880 MCO's - Canlstar at the End of the Vault - 5 htoh/2 vaults

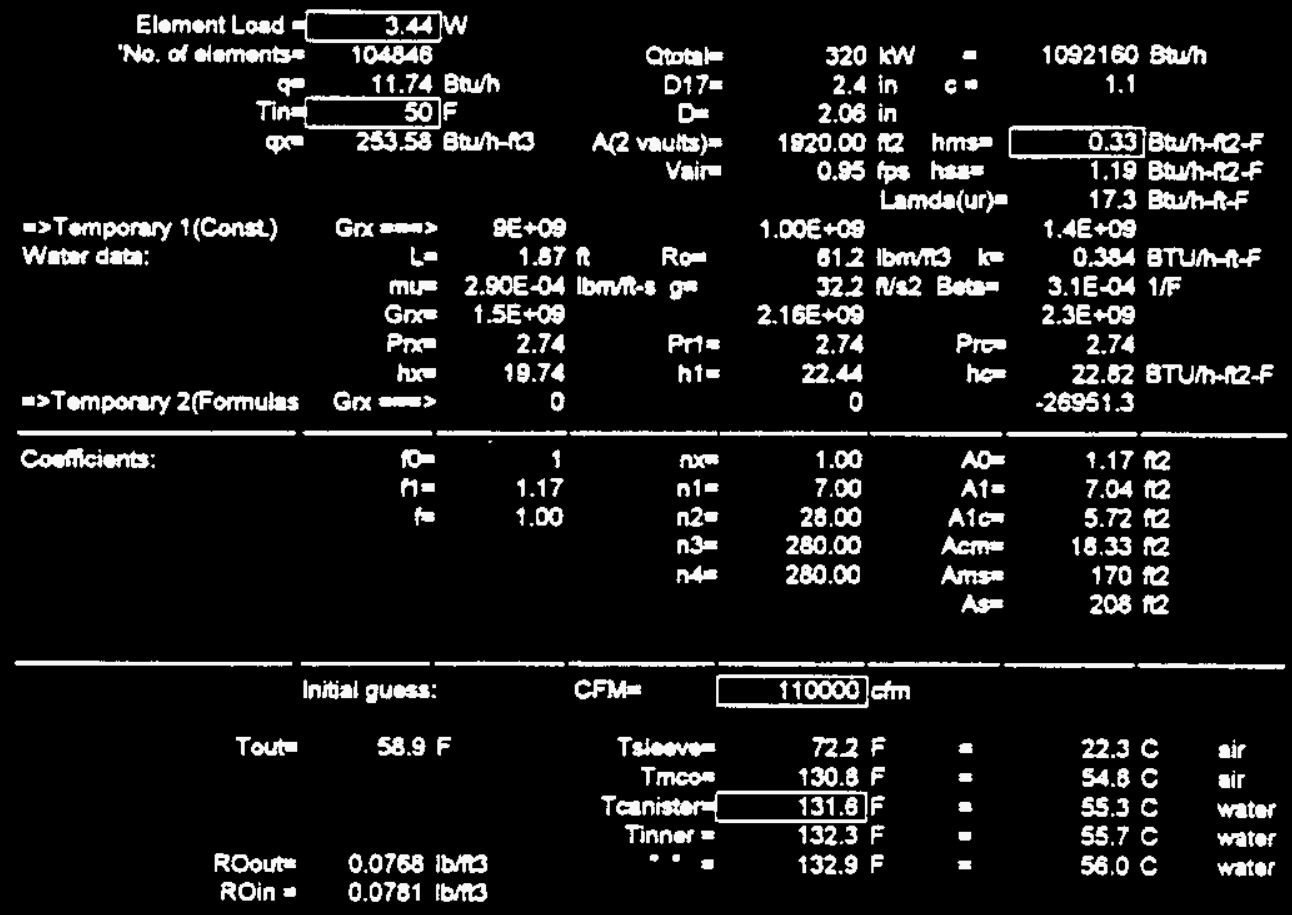

Notes: 1) Tolenve is ealeulated at the and of the vault.

2) Fres area for ainlow is calcutated for 2 vauts.

3) Water inside the MCO and air between MCO and slevero

Table 39 
eisiddi2D_4 SSF FUEL STUDY

Foreed ventilation - MCOWater - SlesvelAr - 880 MCO's - Canlster at the End of the Vault - 5 high/2 vaults

\begin{tabular}{|c|c|c|c|c|c|c|c|}
\hline 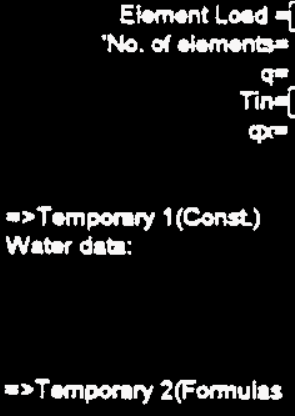 & 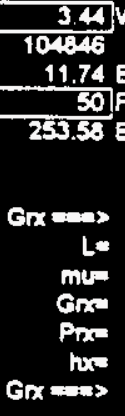 & $\begin{array}{r}85+00 \\
1.87 \\
2.805=04 \\
1.58+09 \\
2.74 \\
19.74 \\
0\end{array}$ & 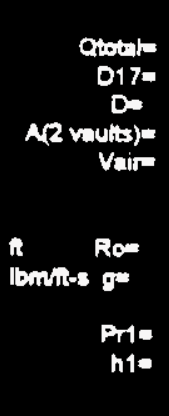 & $\begin{array}{r}320 \\
2.4 \\
2.06 \\
1920.00 \\
1.04 \\
1.00 E+09 \\
61.2 \\
32.2 \\
2.16 E+0.9 \\
2.74 \\
22.4 \\
0\end{array}$ & 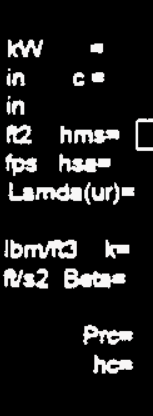 & \multicolumn{2}{|c|}{ 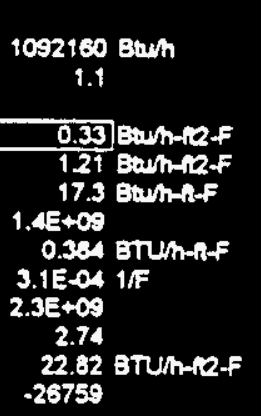 } \\
\hline \multirow[t]{2}{*}{ Covficients: } & pere & $\begin{array}{r}1 \\
1.17 \\
1.00\end{array}$ & $\begin{array}{l}n \times 0 \\
n 10 \\
n 2= \\
n 3=\end{array}$ & $\begin{array}{r}1.00 \\
7.00 \\
28.00 \\
280.00 \\
280.00\end{array}$ & $\begin{array}{l}\text { AO= } \\
\text { A10 } \\
\text { Ale= } \\
\text { Acme } \\
\text { Ans= } \\
\text { As= }\end{array}$ & $\begin{array}{r}1.17 \mathrm{re} \\
7.04 \mathrm{me} \\
5.72 \mathrm{me} \\
18.33 \mathrm{me} \\
170 \mathrm{~m} \\
208 \mathrm{ke}\end{array}$ & \\
\hline & tial gueas: & & CFM- & $120000 \mathrm{c}$ & atm & & \\
\hline $\begin{array}{l}\text { ROoute } \\
\text { ROin = }\end{array}$ & $\begin{array}{l}0.0769 \text { it } \\
0.0781 \text { it }\end{array}$ & & 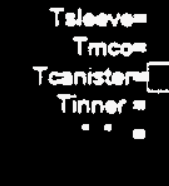 & $\begin{array}{r}71.3 \mathrm{~F} \\
129.9 \mathrm{~F} \\
130.7 \mathrm{~F} \\
131.4 \mathrm{~F} \\
131.9 \mathrm{~F}\end{array}$ & $\begin{array}{l}: \\
: \\
:\end{array}$ & $\begin{array}{l}21.8 \mathrm{C} \\
54.3 \mathrm{C} \\
54.8 \mathrm{C} \\
55.2 \mathrm{C} \\
55.4 \mathrm{C}\end{array}$ & $\begin{array}{l}\text { air } \\
\text { nir } \\
\text { wator } \\
\text { water } \\
\text { water }\end{array}$ \\
\hline \multicolumn{8}{|c|}{ 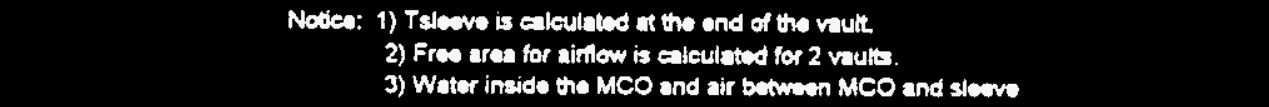 } \\
\hline
\end{tabular}


c:Sidal20_4

Foreed ventlation - MCOWater - Slenve/Ar - 880 MCo's - Canister at the End of the Vault - 5 high/2 vaults

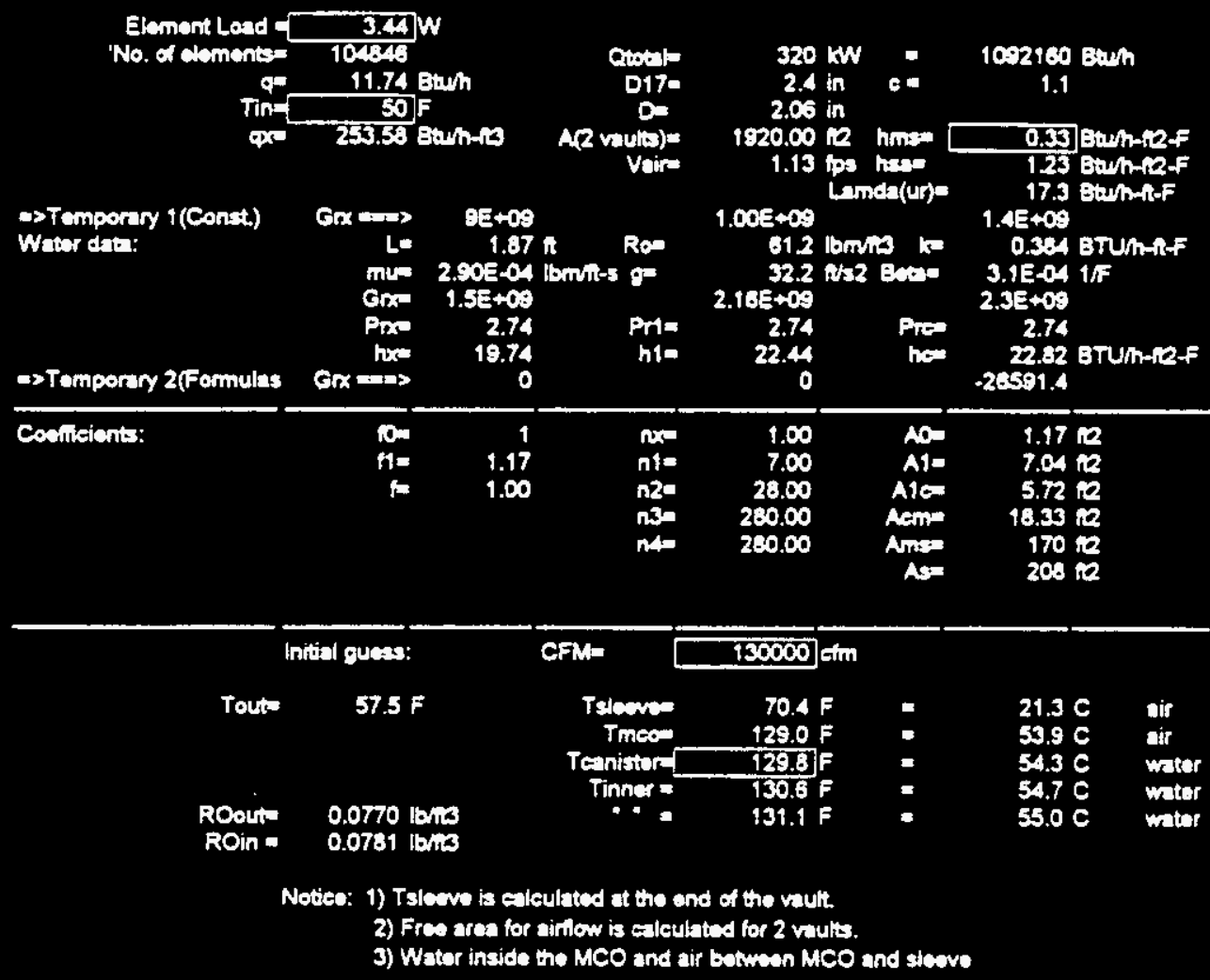

Table 41 
c:5idd20_4

SSF FUEL STUDY

Foresd ventiation - MCONater - SicavedAlr - 830 MCo's - Canister at the End of the Vautt - 5 high/2 vaults

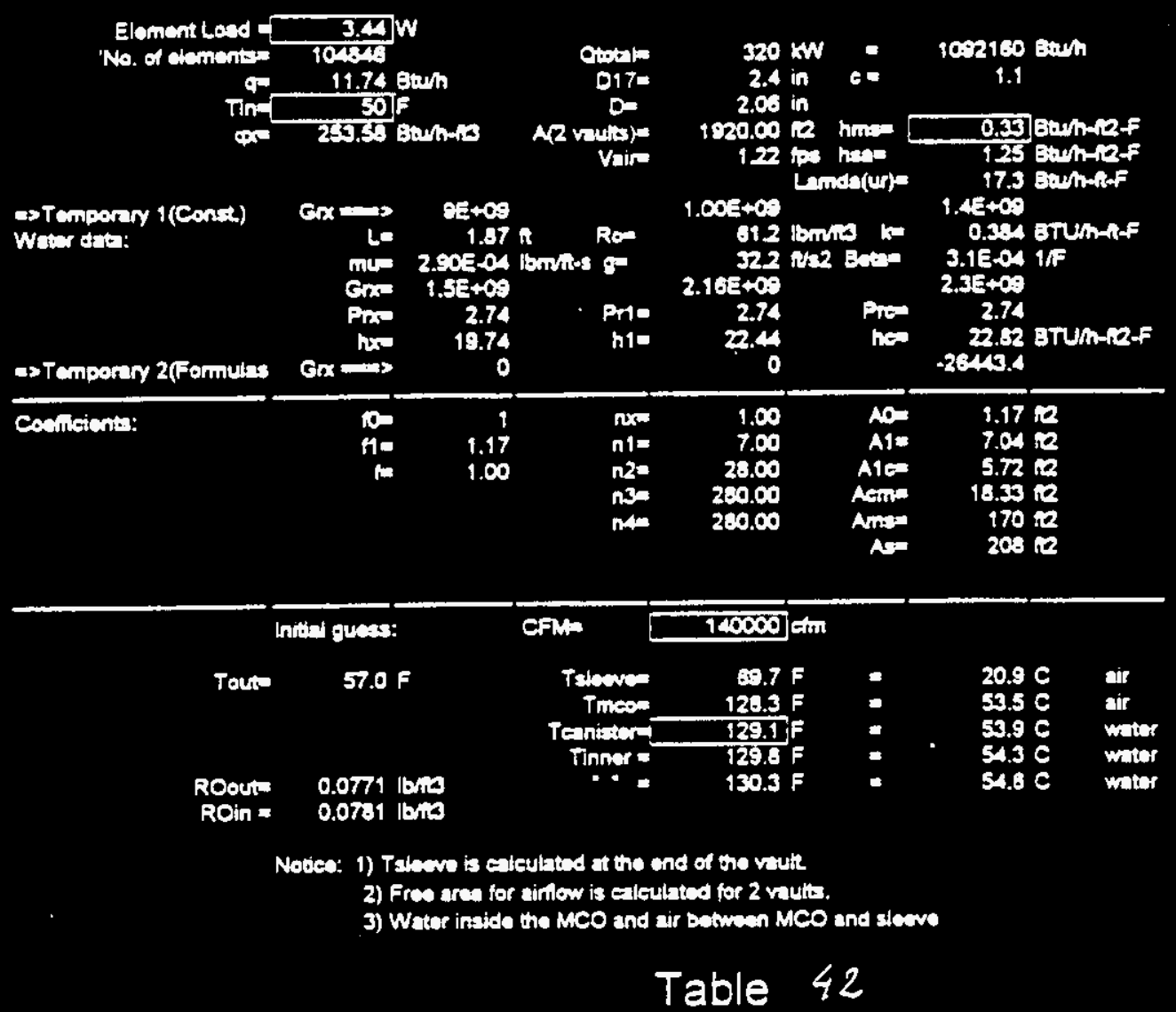




\section{TA 65}

c:Sidd 120,4

Forced ventlation - MCOWater - SlesvelAr - 880 MCO's - Canister at the End of the Vault - 5 hlgh/2 vaults

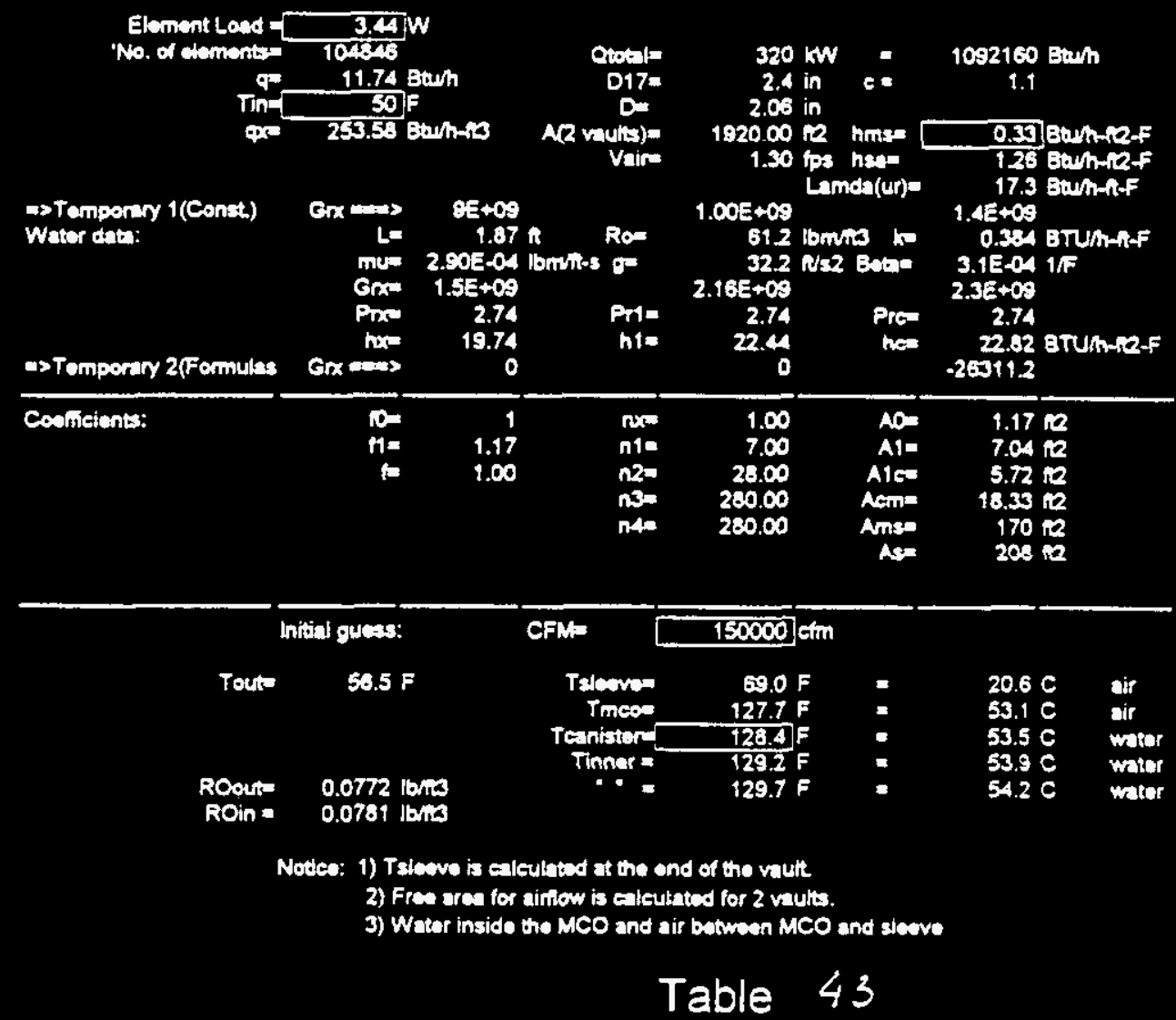


c:Siddu_4 SSF FUEL STUDY

Foreed ventilation - MCOWater - Slecve/Ar - 880 MCo's - Canistar at the End of the Vault - 5 high/2 vauts

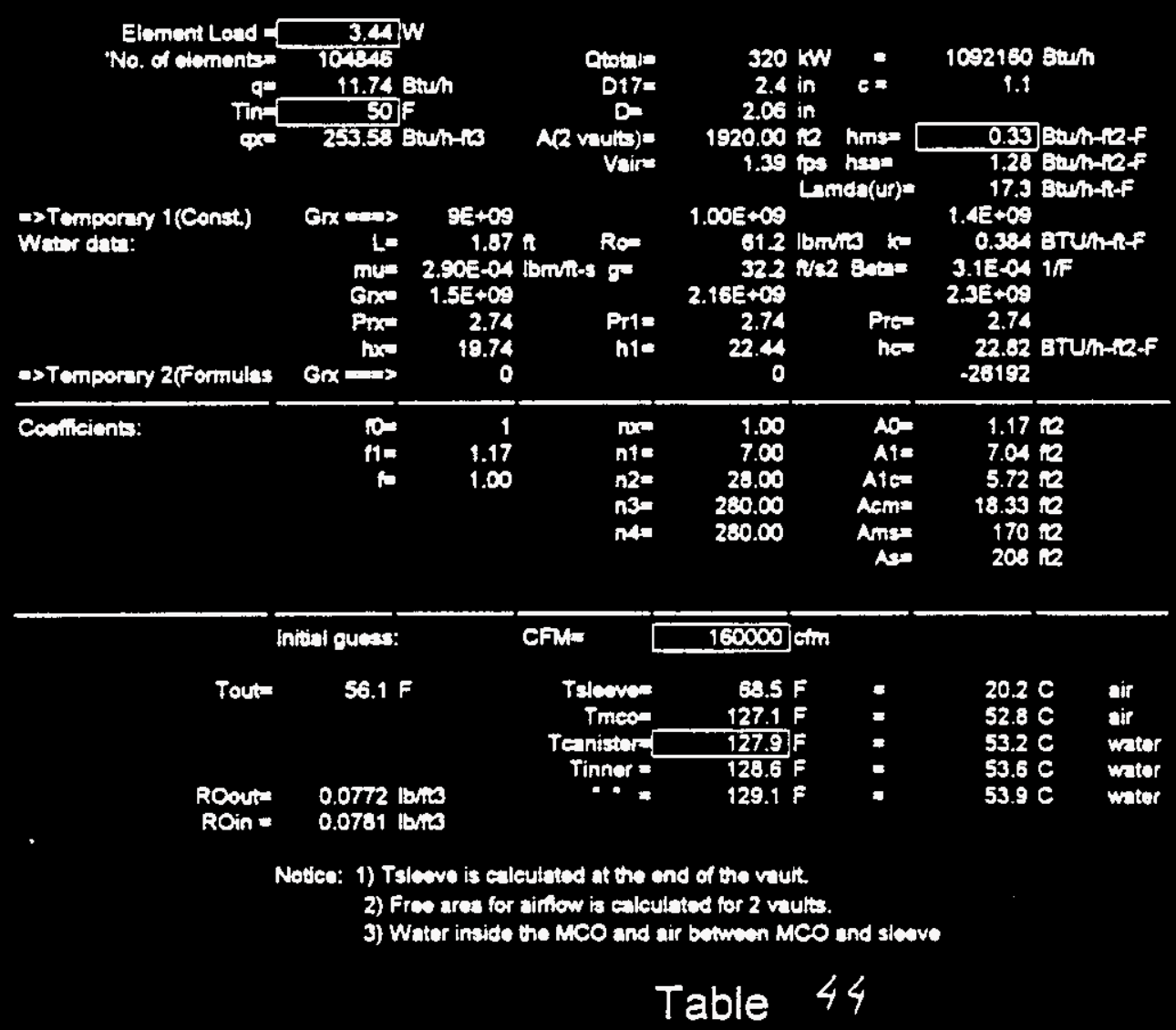


Foreed ventlation - MCOWater - Sleeve/Ajr - 880 MCO's - Canistar at the End of the Vault - 5 high/2 vaults

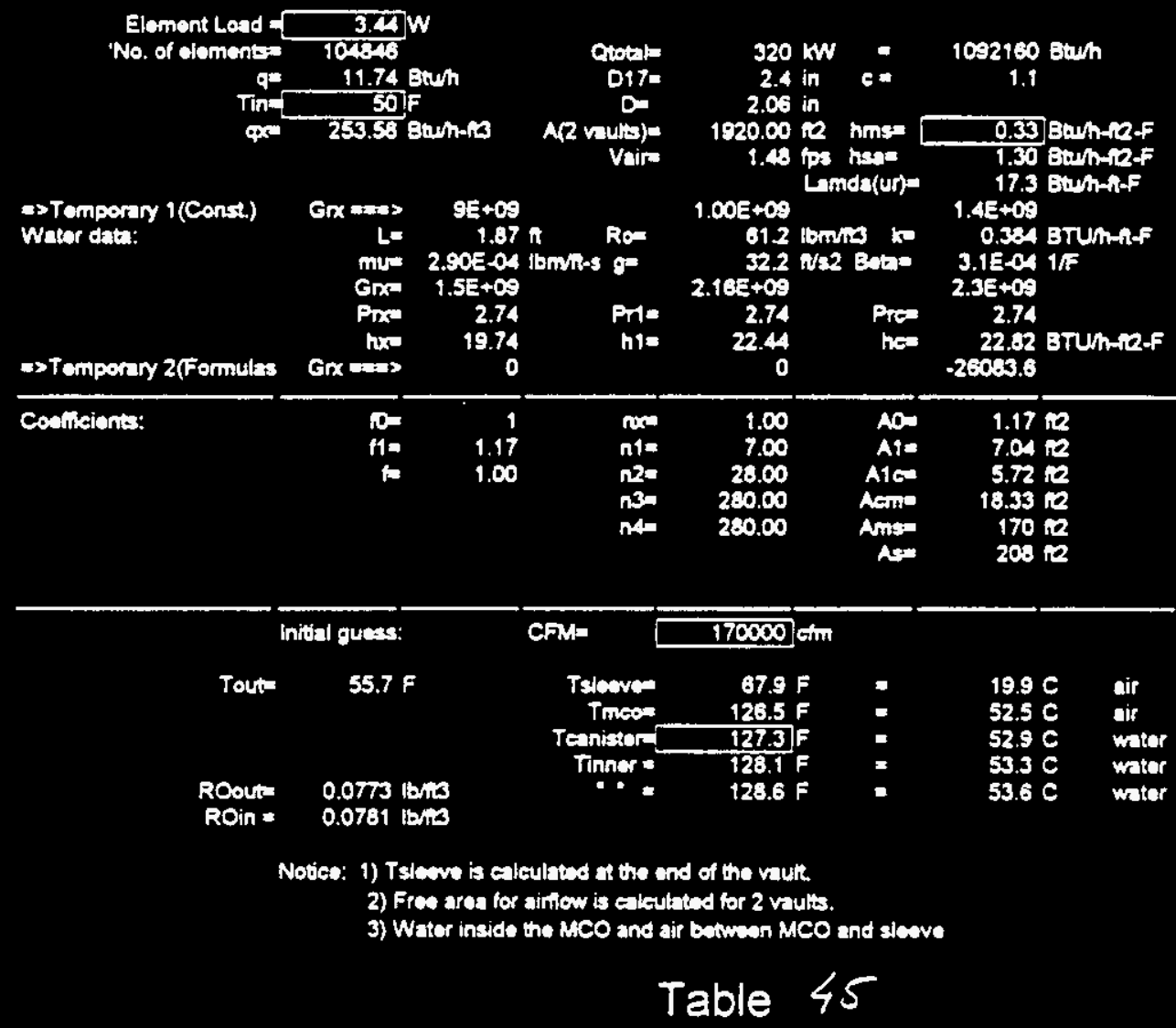


e:Siddiz_-4 SSF FUEL STUDY

Foresd ventlatton - MCOWater - StenvalAr - 880 MCO's - Canlater at the End of the Vault - 5 high/2 vaults

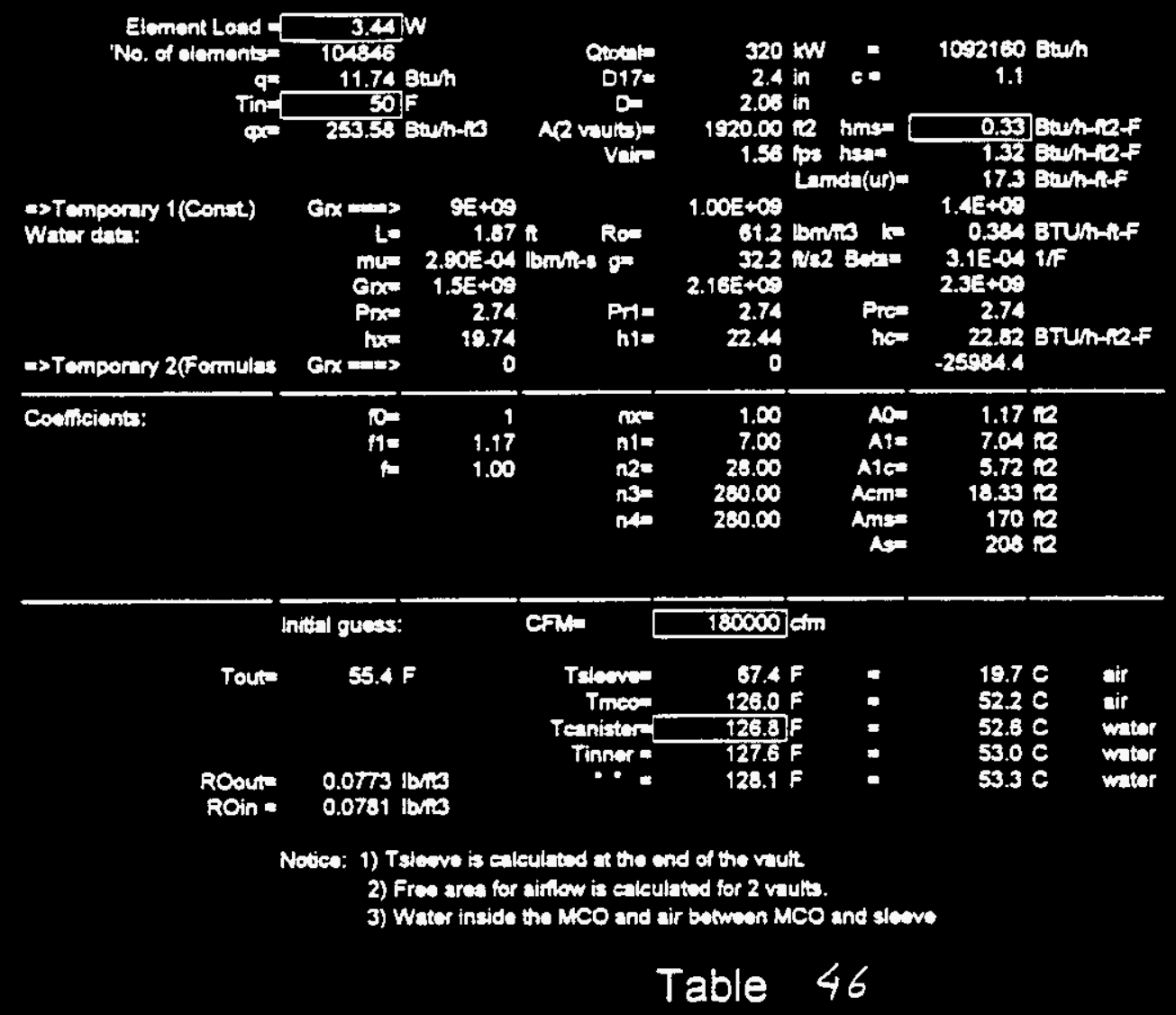


e:Sidd20_4 SSF FUEL STUDY

Foreed ventilaton - MCOWater - Sleeve/Ar - 800 MCO's - Canlster at the End of the Vault - 5 high/2 vaults

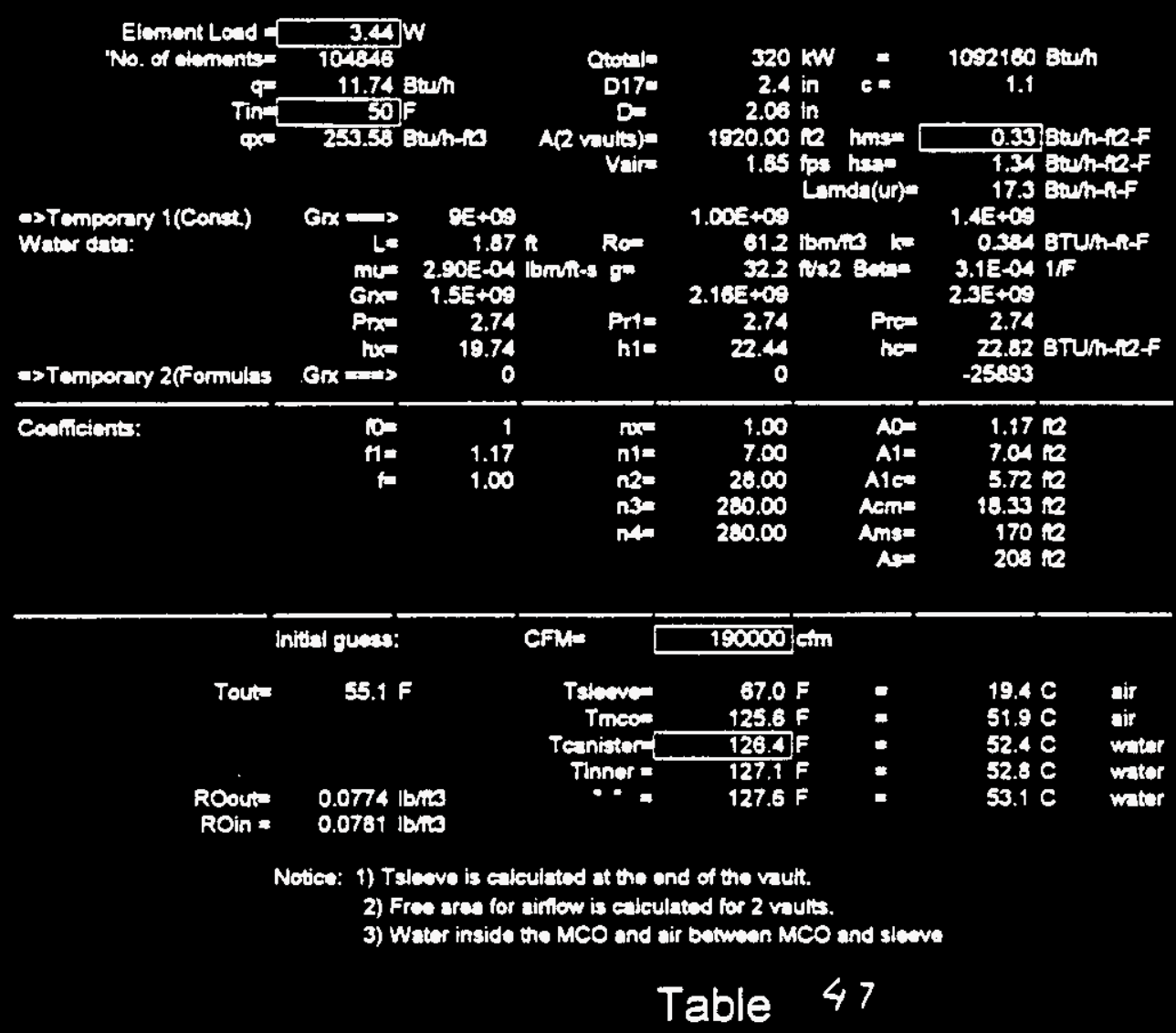


e:Sidd2D_4 SSF FUEL STUDY

Foread ventlation - MCOWater - Slevve/Alr - 880 MCo's - Canlatar at the End of the Vault - 5 high/2 vaults

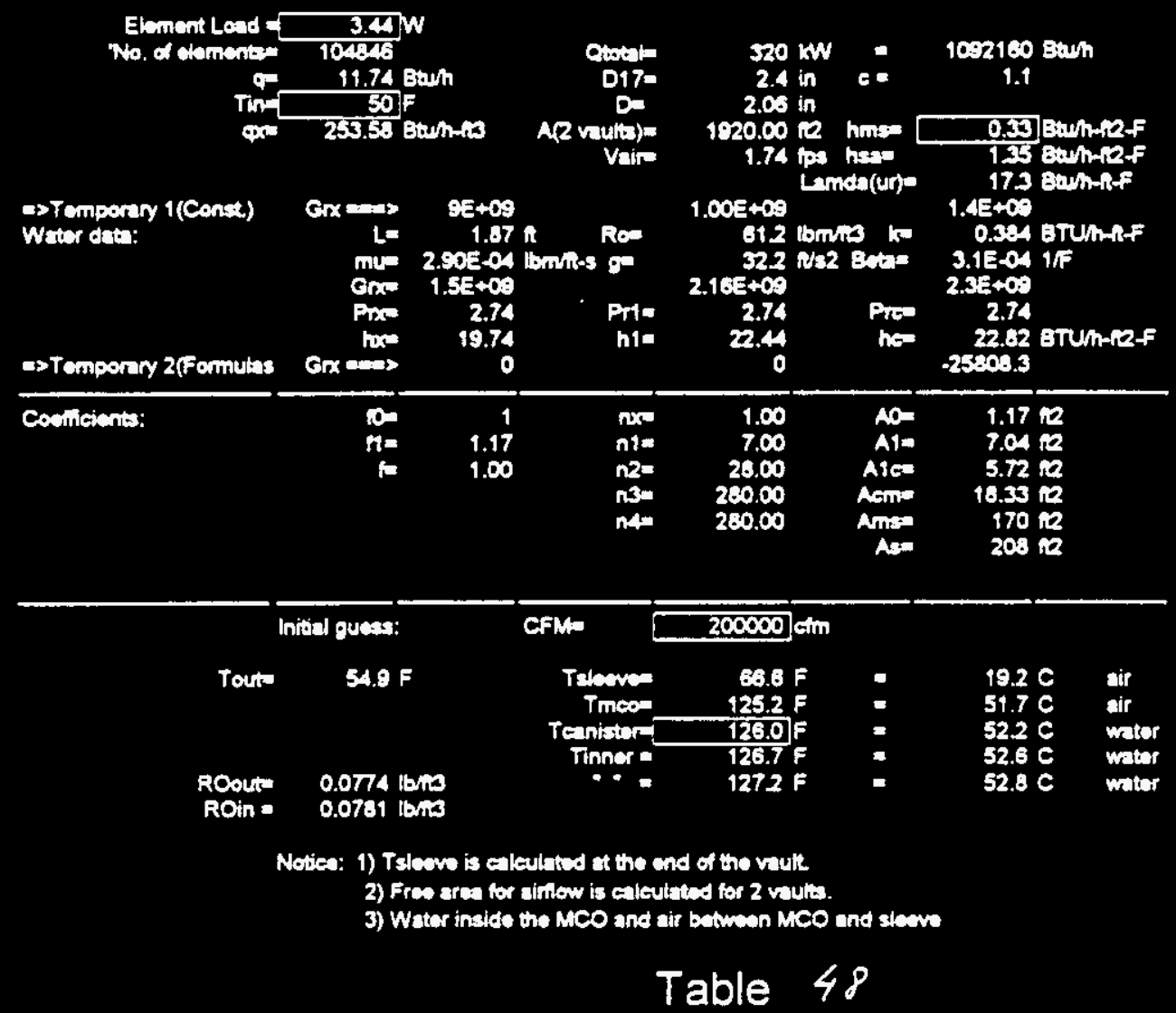


e:Sididi20_4 SSF FUEL STUDY

Forserd ventlation - mcowater - Slesvelair - 890 Mco's - Canlster at the End of the Vault - 5 high/2 vaults

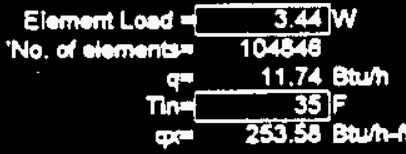

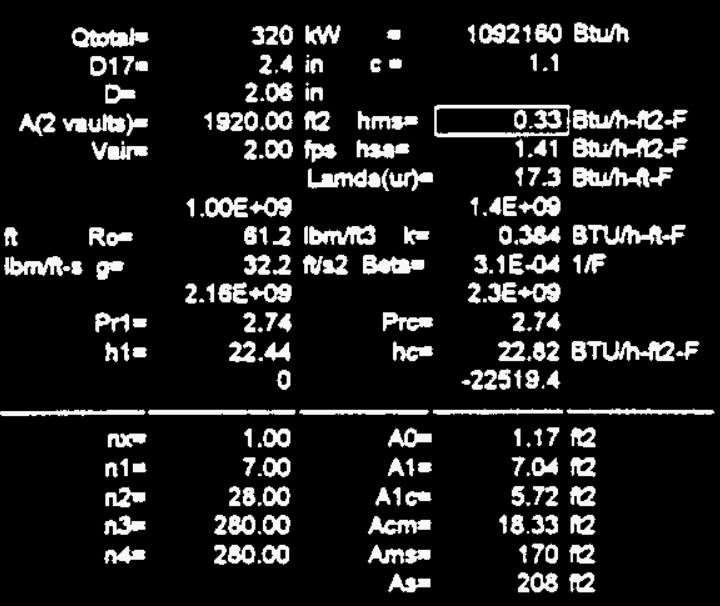

aremporan 1 (Conat)
Water data:

Gx $\Rightarrow 8+09$

Le $\quad 1.87$

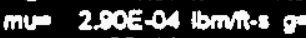

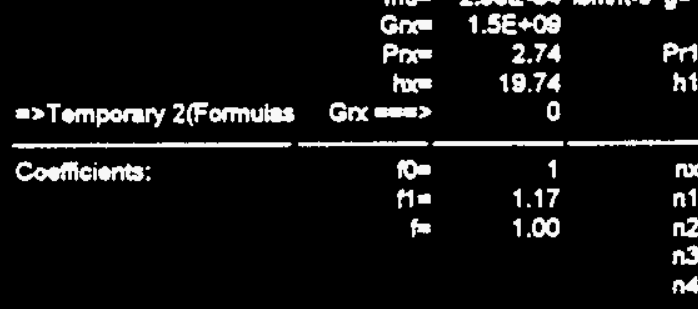

CFM= 230000 Gim

Iritial guess:

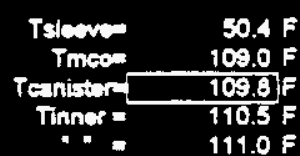

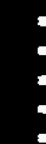

ROove $\quad 0.0798$ tbita

$39.1 \mathrm{~F}$

ROin : 0.0804 ibins

Noteo: 1) Talowe is caleulated of the ond of the vautt

2) Fres area for aimow is caleulated for 2 vautits.

3) Water inside the MCO and air batwen MCO and sleove

Table 49 
e:SSid120_4 SSF FUEL STUDY

Foreed ventlation - MCOWater - SteavalAr - 880 MCo's - Canlster at the End of the Vauth - 5 high/2 vaulta

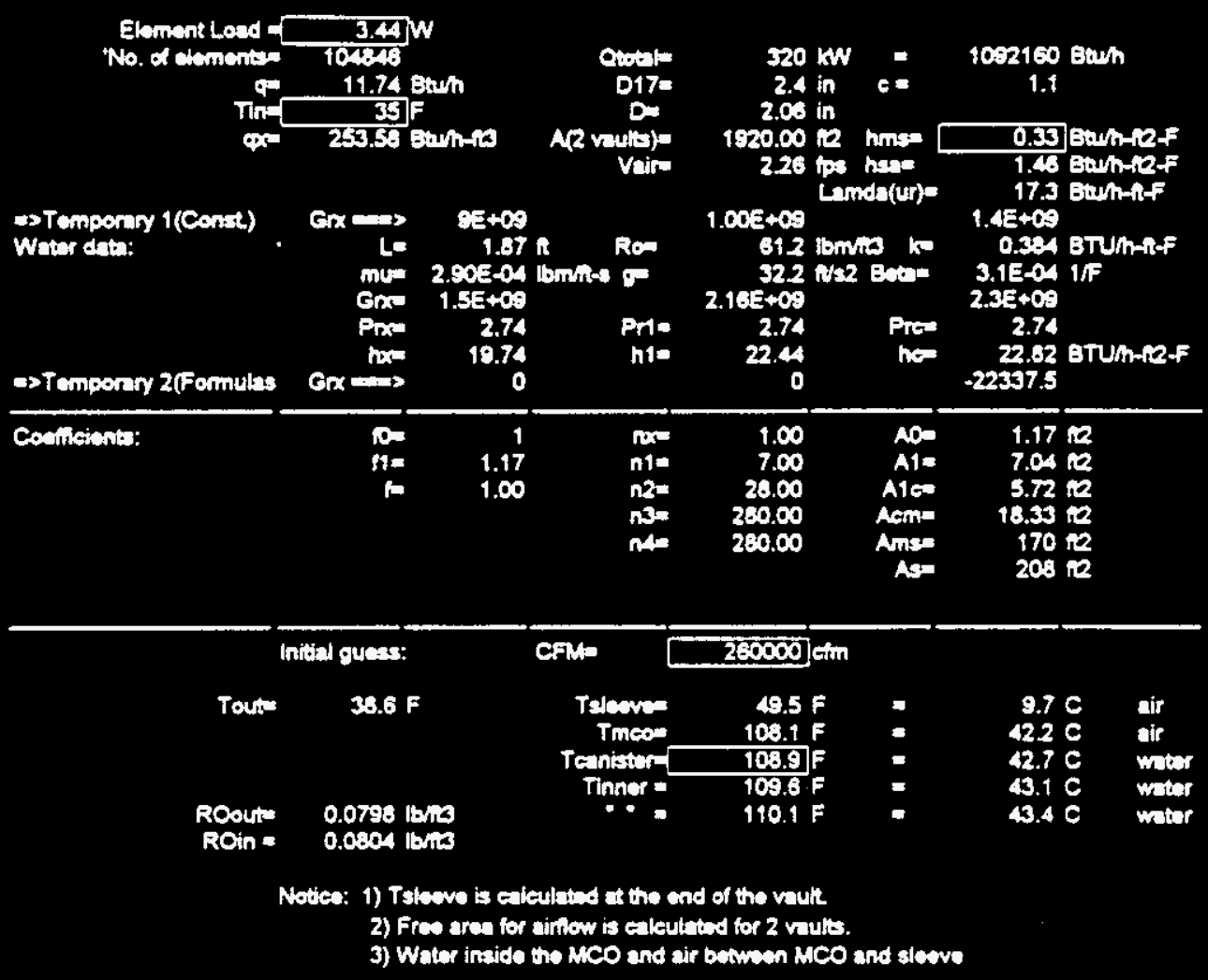

Table 50 
c:Sidd12D_4

Foread ventiation - MCOWater - Sleeve/Ait - 880 MCo's - Canister at the End of the Vautt - 5 hlgh/2 vaults

\begin{tabular}{|c|c|c|c|c|c|c|c|c|}
\hline \multirow[b]{3}{*}{$\begin{array}{l}\text { OTomporary 1(Const) } \\
\text { Woter data: } \\
\text { MTemporary 2(Formulas }\end{array}$} & \multirow{2}{*}{\multicolumn{2}{|c|}{ 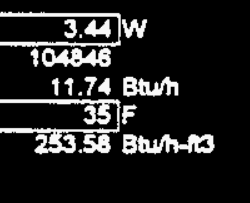 }} & \multirow{2}{*}{$\begin{array}{c}\text { Qubal: } \\
\text { D170 } \\
\text { Da } \\
\text { AR valbje } \\
\text { Vair: }\end{array}$} & \multirow{2}{*}{$\begin{array}{r}320 \\
2.4 \\
2.06 \\
1020.00 \\
2.00 \\
1.005+09 \\
612 \\
32.2\end{array}$} & \multirow{2}{*}{ 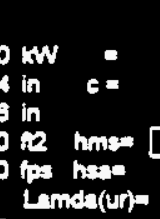 } & \multirow{3}{*}{\multicolumn{3}{|c|}{ 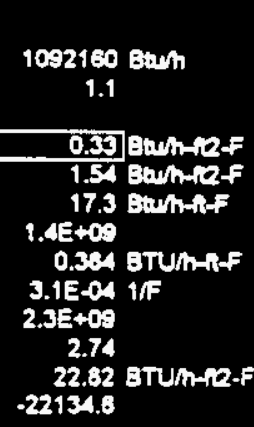 }} \\
\hline & & & & & & & & \\
\hline & 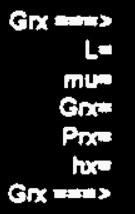 & $\begin{array}{r}8 E+09 \\
1.07 \\
2.00 E-04 \\
1.5 E+09 \\
2.74 \\
19.74 \\
0\end{array}$ & $\begin{array}{l}\text { Rer } \\
\text { Prie } \\
\text { h1e }\end{array}$ & $\begin{array}{r}1.005+09 \\
612 \\
32.2 \\
2.165+0.9 \\
2.74 \\
22.44 \\
0\end{array}$ & 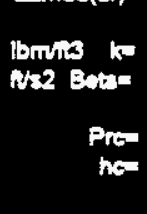 & & & \\
\hline Contheients: & $10=$ & $\begin{array}{r}1 \\
1.17 \\
1.00\end{array}$ & $\begin{array}{l}n \times= \\
n 10 \\
n 2= \\
n 3=\end{array}$ & $\begin{array}{r}1.00 \\
7.00 \\
28.00 \\
280.00 \\
280.00\end{array}$ & 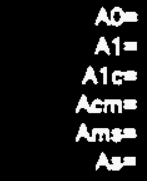 & $\begin{array}{r}1.17 \\
7.04 \\
5.72 \\
18.33 \\
170 \\
208\end{array}$ & $\frac{12}{102}$ & \\
\hline & ival guas: & & CFM= & 300000 & stm & & & \\
\hline $\begin{array}{l}\text { ROout } \\
\text { ROin = }\end{array}$ & $\begin{array}{l}0.0799 \mathrm{lb} \\
0.0804 \mathrm{lb}\end{array}$ & & 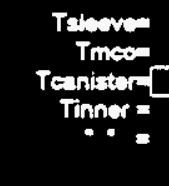 & 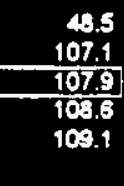 & $\begin{array}{l}: \\
: \\
=\end{array}$ & $\begin{array}{r}9.1 \\
41.7 \\
42.4 \\
42.5 \\
42.8\end{array}$ & & $\begin{array}{l}\text { air } \\
\text { air } \\
\text { water } \\
\text { water } \\
\text { water }\end{array}$ \\
\hline & en: 1) Ts & $\begin{array}{l}\text { o is a } \\
\text { area fic } \\
\text { finside }\end{array}$ & $\begin{array}{l}\text { lated at the } \\
\text { frow is ale } \\
\text { Mco and }\end{array}$ & $\begin{array}{l}\text { f the } v \\
\text { for } 2 \\
\text { and }\end{array}$ & $\begin{array}{l}\text { the } \\
\text { ultes. } \\
\text { ico and : }\end{array}$ & & & \\
\hline
\end{tabular}

\section{Table 51}


e:Siddro_4 SSF FUEL STUDY

Foreed ventilation - MCOWater - SleevelAir - 880 MCO's - Canlstar at the End of the Vault - 5 hlgh/2 vaults

Element laad $=-3.4 w$

No. of clementar 10.468

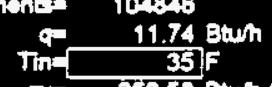

Qtate $\quad 320 \mathrm{~kW}=1092160 \mathrm{Bth}$

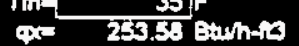

AR voutar

andis $=$

24 in $c=1.1$

$1920.00 \mathrm{ke}$ hms: 0.33 Btum-10.F

3.04 tpe hase 1.63 Bumbef

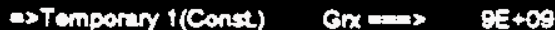

Water dats:

$1.00 E+\infty$

Lamda(ur)o $\quad 17.3$ Bumntif

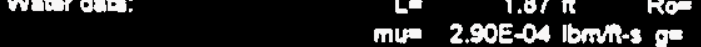

$1,5 \mathrm{E}+09$

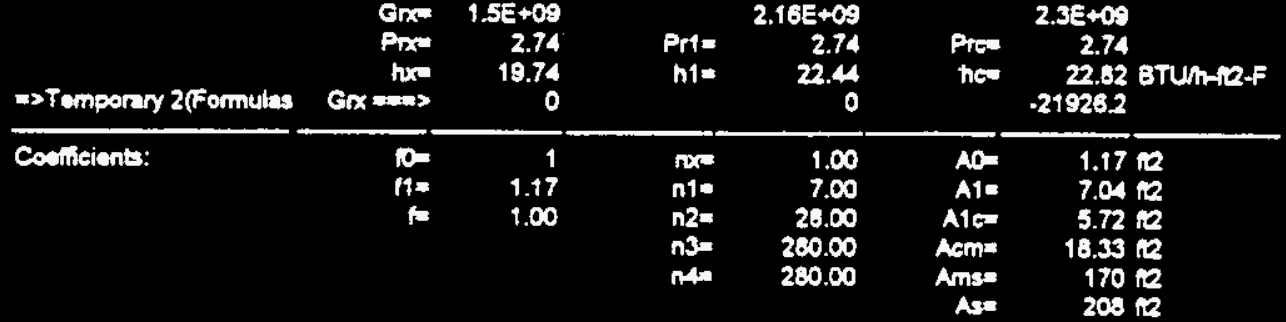

\begin{tabular}{|c|c|c|c|c|c|c|}
\hline & Al gucas: & CFM= & $35000 \mathrm{cth}$ & & & \\
\hline $\begin{array}{l}\text { ROout } \\
\text { ROin = }\end{array}$ & 0.0800 lbins & $\begin{array}{c}\text { Talcove: } \\
\text { Tmeor } \\
\text { Teanistorn } \\
\text { Tinner: } \\
. .-\end{array}$ & $\begin{array}{r}47.4 \mathrm{~F} \\
108.0 \mathrm{~F} \\
106.8 \mathrm{~F} \\
107.6 \mathrm{~F} \\
108.1 \mathrm{~F}\end{array}$ & $\begin{array}{l}: \\
:\end{array}$ & $\begin{array}{l}8.6 \mathrm{C} \\
41.1 \mathrm{C} \\
41.5 \mathrm{C} \\
41.9 \mathrm{C} \\
42.2 \mathrm{C}\end{array}$ & $\begin{array}{l}\text { air } \\
\text { sir } \\
\text { wator } \\
\text { wator } \\
\text { wator }\end{array}$ \\
\hline
\end{tabular}

Noties: 1) Tsloovo is calculated at the end of the valk.

2) Fres ares for airlow is calculated for 2 veults.

3) Wator inside the MCO and air between MCO and sleove

Table 52 
Foreed ventlation - MCOWater - SleevelAyr - 880 MCO's - Canister at the End of the Vault - 5 high/2 vaults

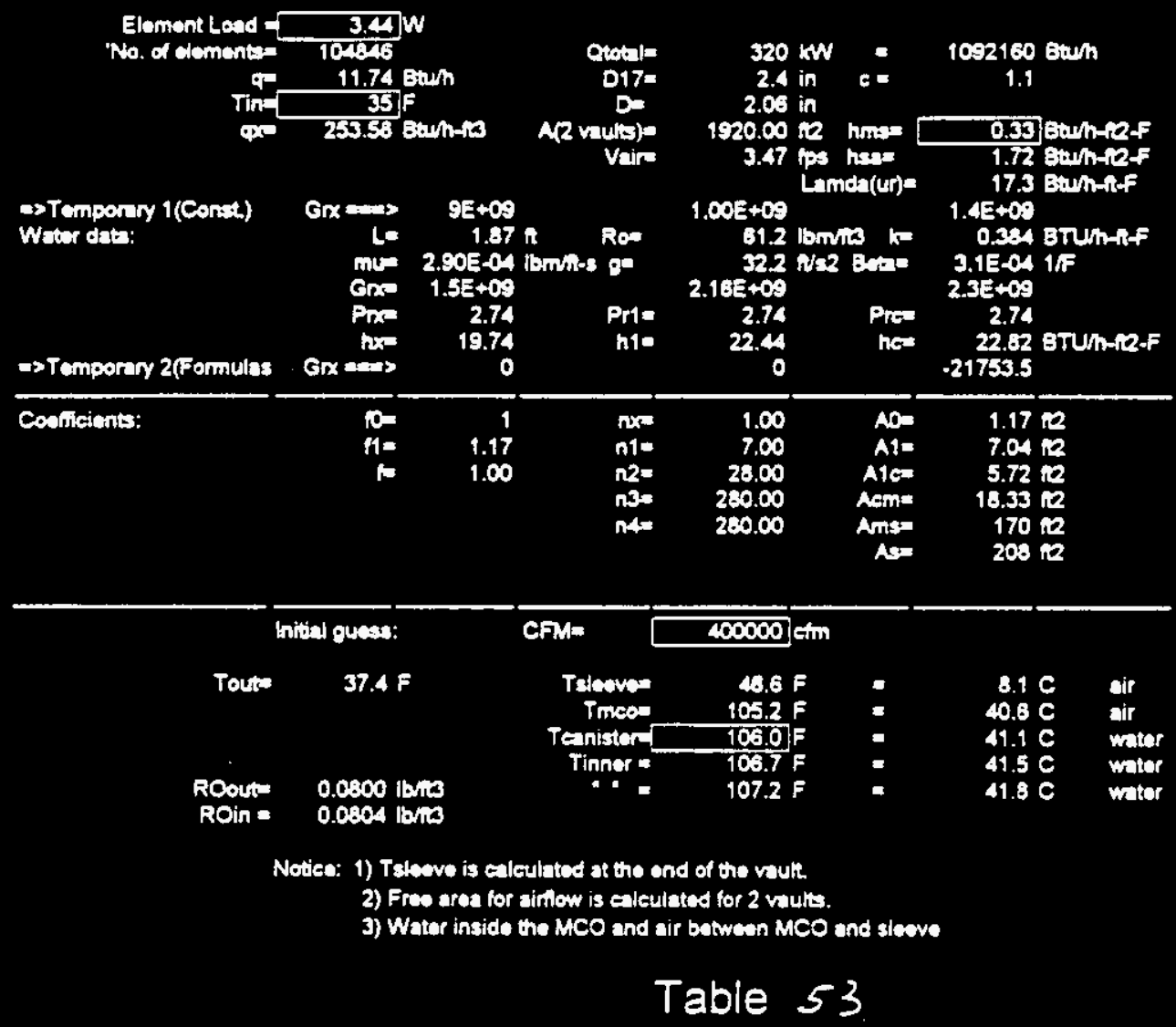


e:Sidd20_4 SSF FUEL STUDY

Foreed ventlation - MCOWater - SlesvelAt - 880 mCo's - Conlster at the End of the Vault - 5 high/2 vaults

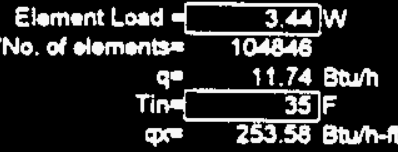
Water dat:

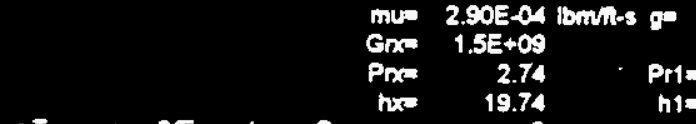

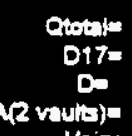

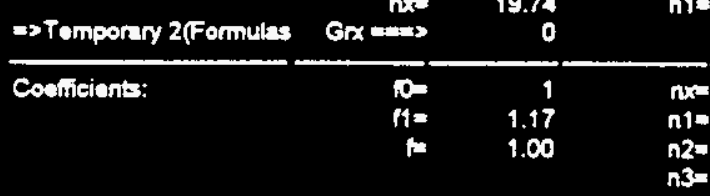$$
\text { ת. }
$$$$
1.00 E+0
$$

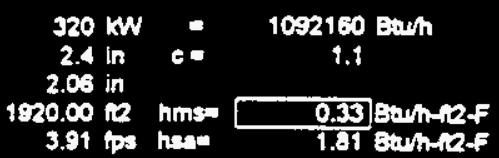

\begin{tabular}{|c|c|c|c|c|c|c|}
\hline \multicolumn{2}{|c|}{ lnitinl gucas: } & \multirow{2}{*}{$\begin{array}{c}\text { Crise } \\
\text { Tsleover } \\
\text { Tmeos } \\
\text { Tenistors } \\
\text { Tinner = } \\
-\cdot=\end{array}$} & \multirow{2}{*}{$\begin{array}{r}\text { ro000 } \mathrm{fm} \\
45.9 \mathrm{~F} \\
104.5 \mathrm{~F} \\
105.2 \mathrm{~F} \\
106.0 \mathrm{~F} \\
106.5 \mathrm{~F}\end{array}$} & \multirow[b]{2}{*}{$\begin{array}{l}= \\
= \\
= \\
=\end{array}$} & \multirow[b]{2}{*}{$\begin{array}{r}7.7 \mathrm{C} \\
40.2 \mathrm{C} \\
40.7 \mathrm{C} \\
41.1 \mathrm{C} \\
41.3 \mathrm{C}\end{array}$} & \multirow[b]{2}{*}{$\begin{array}{l}\text { air } \\
\text { air } \\
\text { wates } \\
\text { water } \\
\text { whter }\end{array}$} \\
\hline $\begin{array}{l}\text { ROout: } \\
\text { Roin = }\end{array}$ & $\begin{array}{l}0.0801 \text { lo/na } \\
0.0804 \text { lb/in }\end{array}$ & & & & & \\
\hline \multicolumn{7}{|c|}{$\begin{array}{l}\text { Notica: 1) Tsleeve is ealculated at the end of the vault. } \\
\text { 2) Free area for sirfow is ealculated for } 2 \text { veuts. } \\
\text { 3) Water inside the MCO and air batween MCO and steove }\end{array}$} \\
\hline
\end{tabular}


eisiddi2D_4 SSF FUEL STUDY

Forced ventlatton - MCOWater - SleevedAir - 880 MCO's - Canlster at the End of the Vault - 5 high/2 vaults

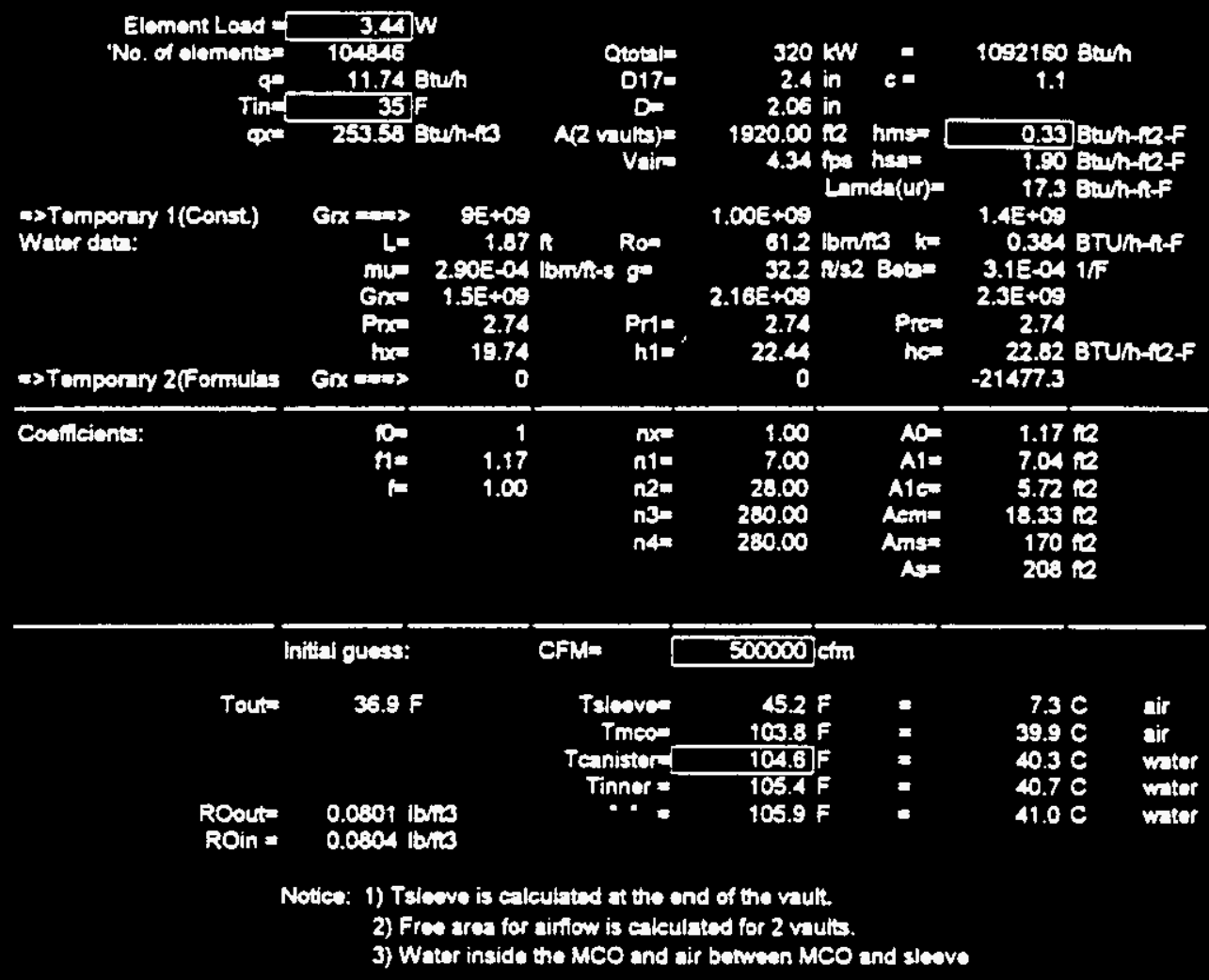

Table 55 
Foreed alr - MCOIAr- SLEgVJJAr- 880 MCO's- 2 vaults - Canistar at the End of the Vault

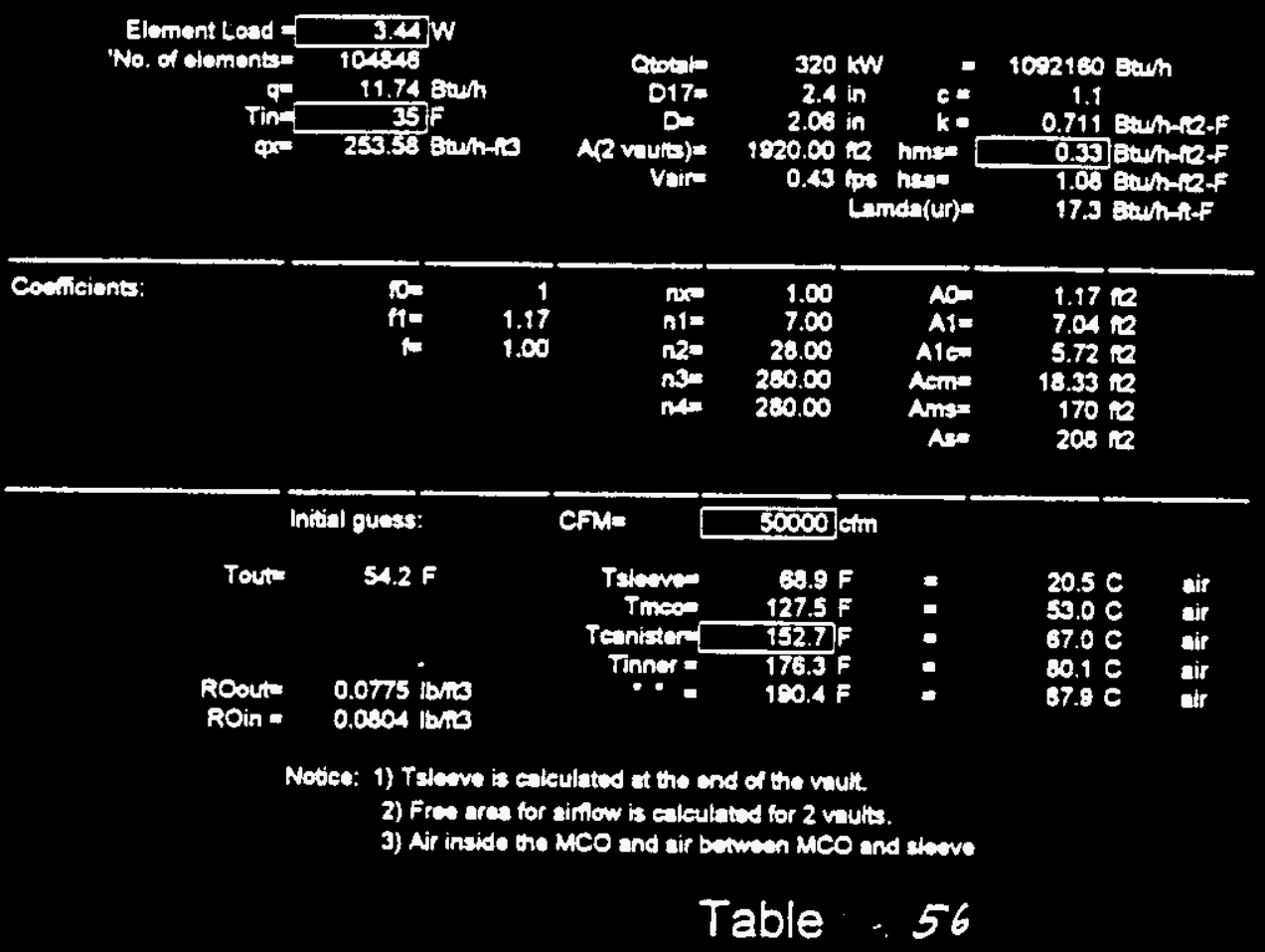

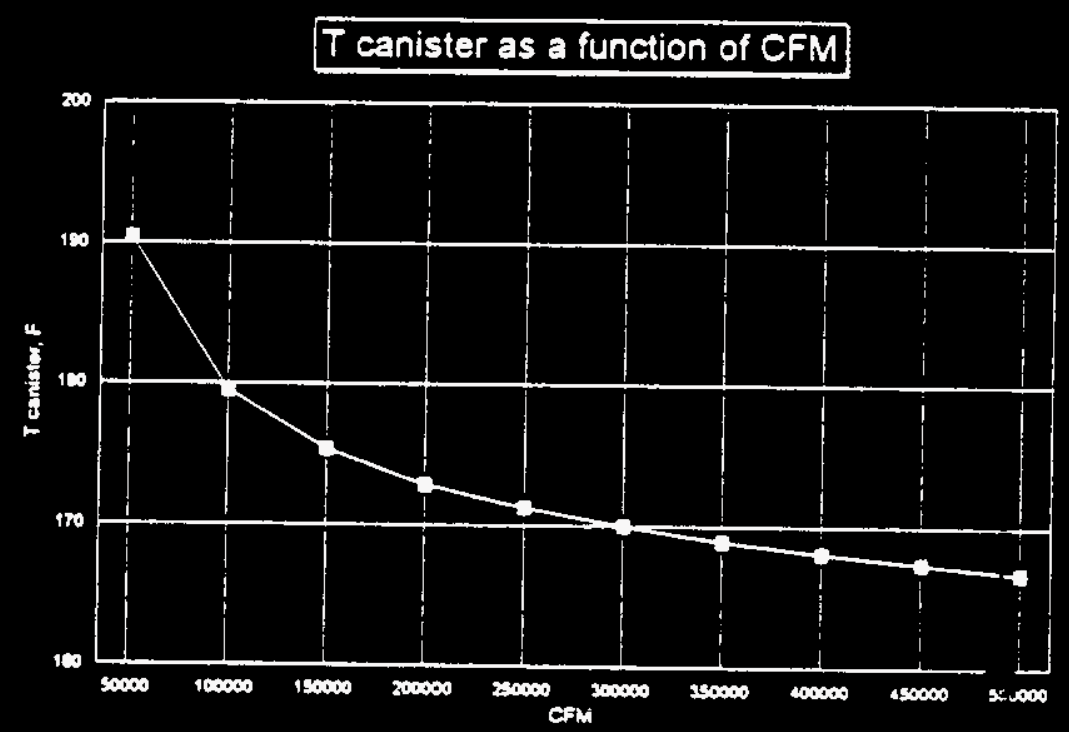

Figure 5 
e:Sidduir_2

SSF FUEL STUDY

Foreed air - MCOIAr-SLEEVE/AVr- 880 MCO's- 2 vaults - Canlster at the End of the Vault

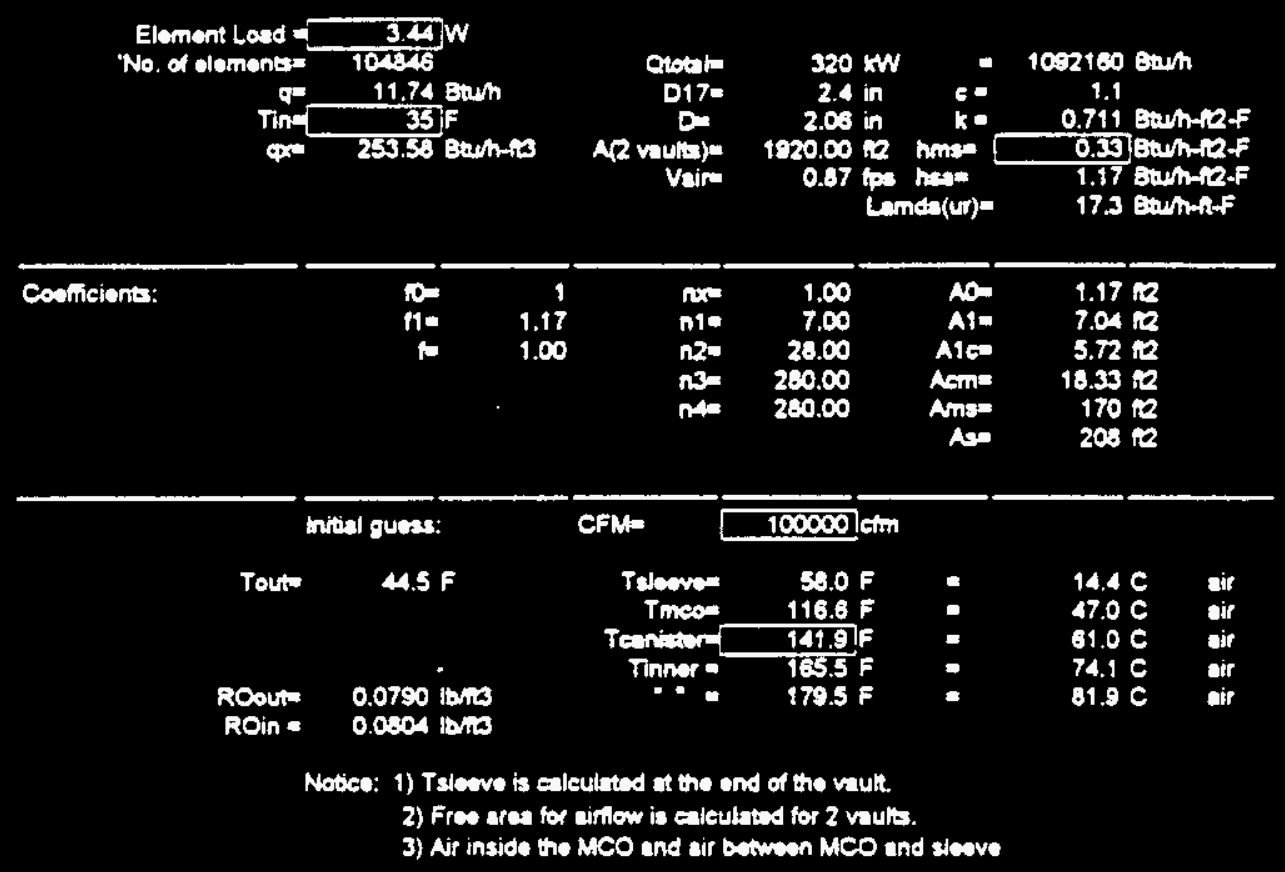

Table 57 
e:siddar_z SSF FUEL STUDY

Foreed alr - MCOIAr-SLEEVE/Alr- 880 MCO's - 2 vaults - Canister at the End of the Vault

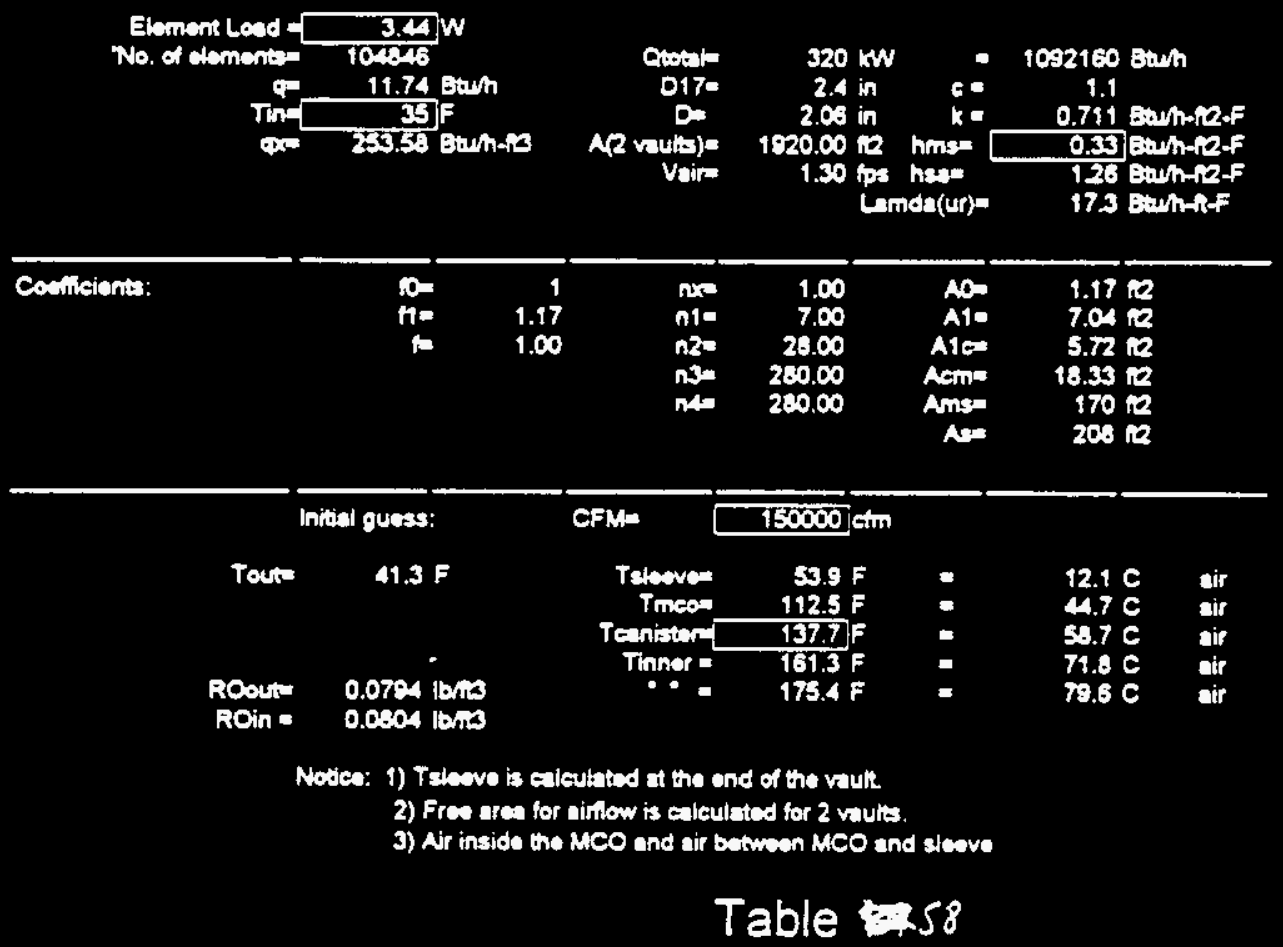


Foreed air - MCOIAr- SLEEVEJAr- 880 MCO's - 2 vaults - Cantster th the End of the Vault

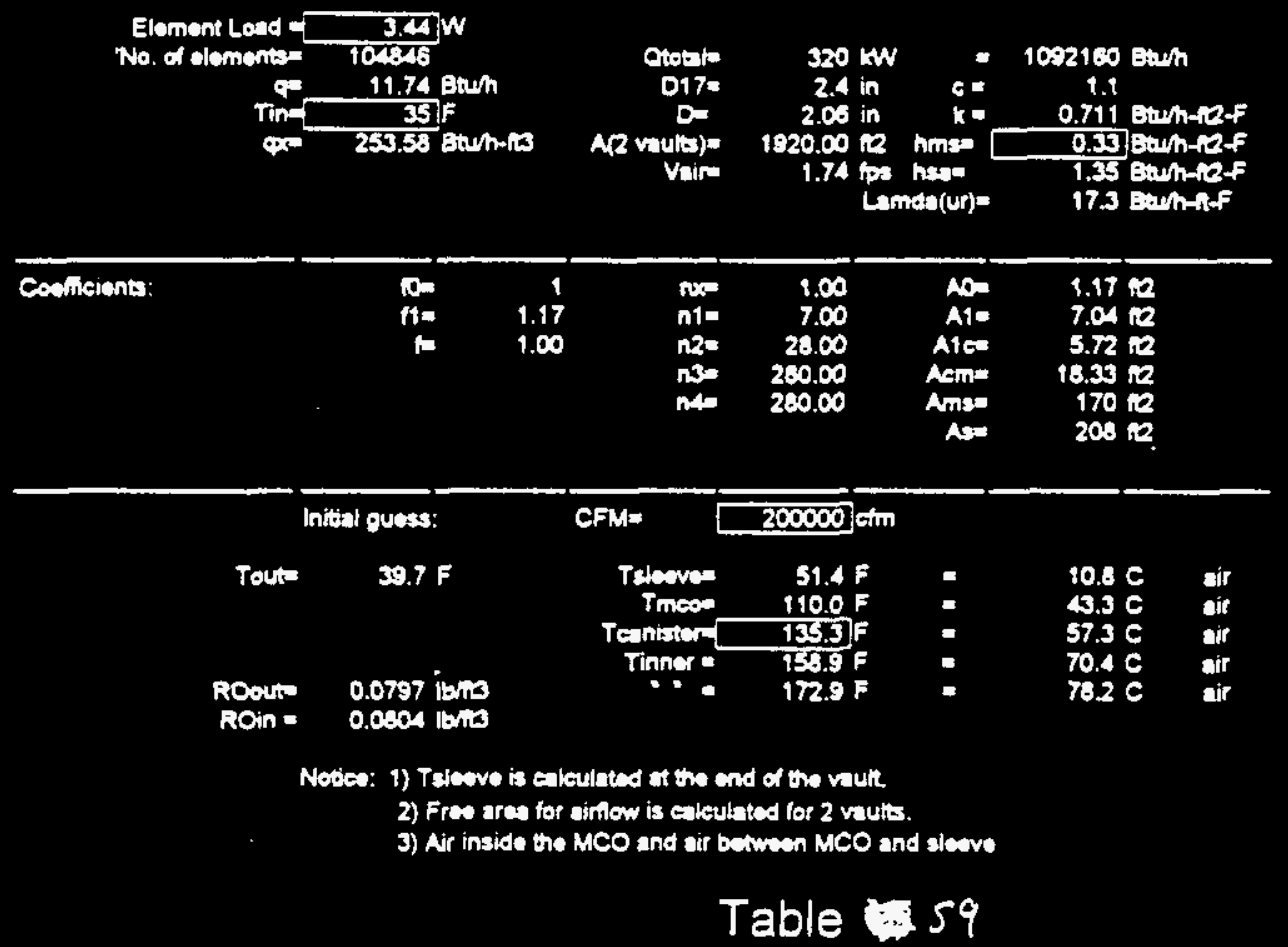




$$
T A-82
$$

e:Sidalait_2 SSF FUEL STUDY

Foreed alr - MCOIAIr- SLEEVEJAIr- 880 MCO's - 2 vaulta - Canister at the End of the Vault

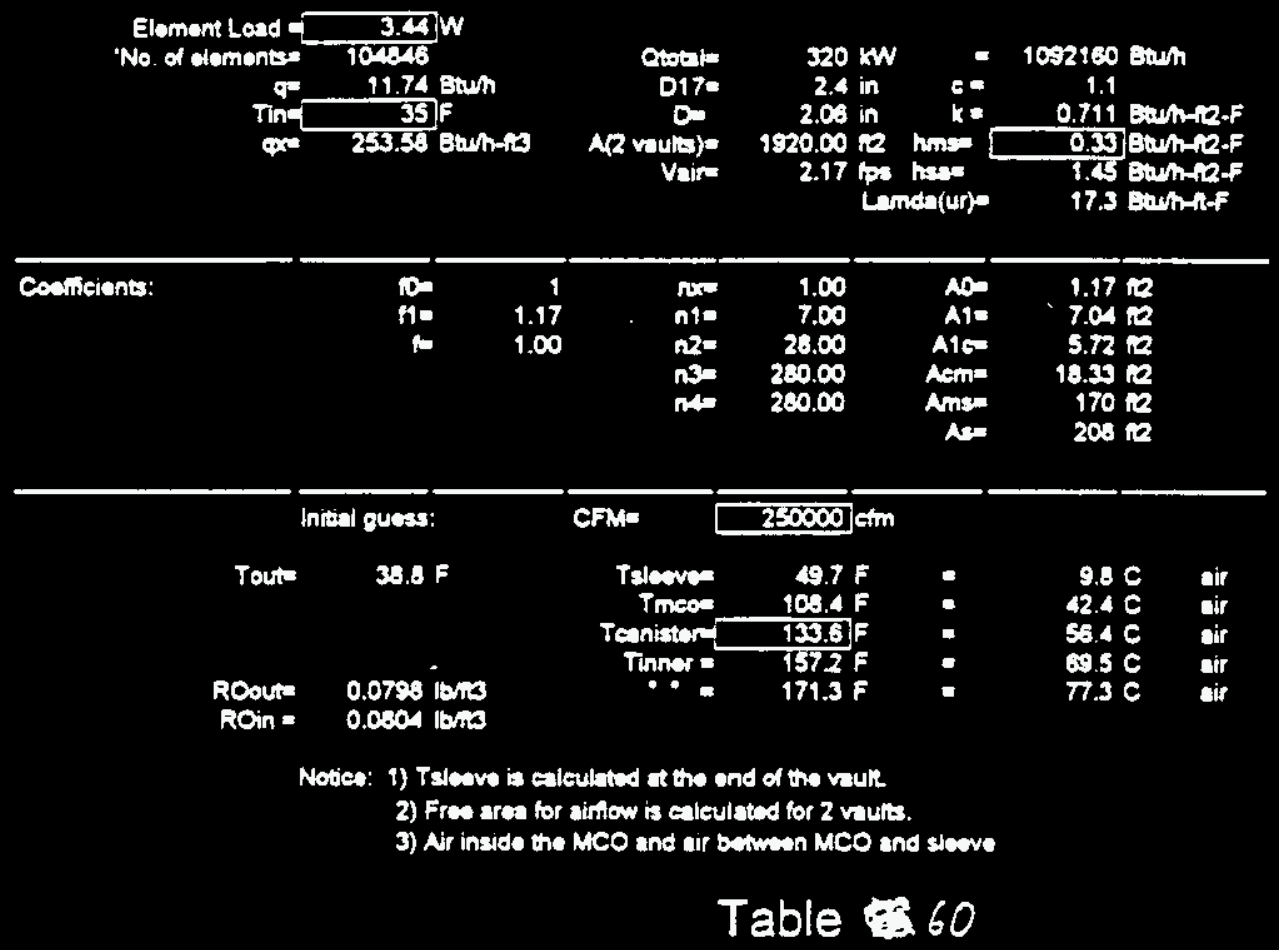


e:Sidduir_2 SSF FUEL STUDY

Foreed air - MCOANr- SLEEVEJAr- 980 MCO's- 2 vauts - Canister at the End of the Vault

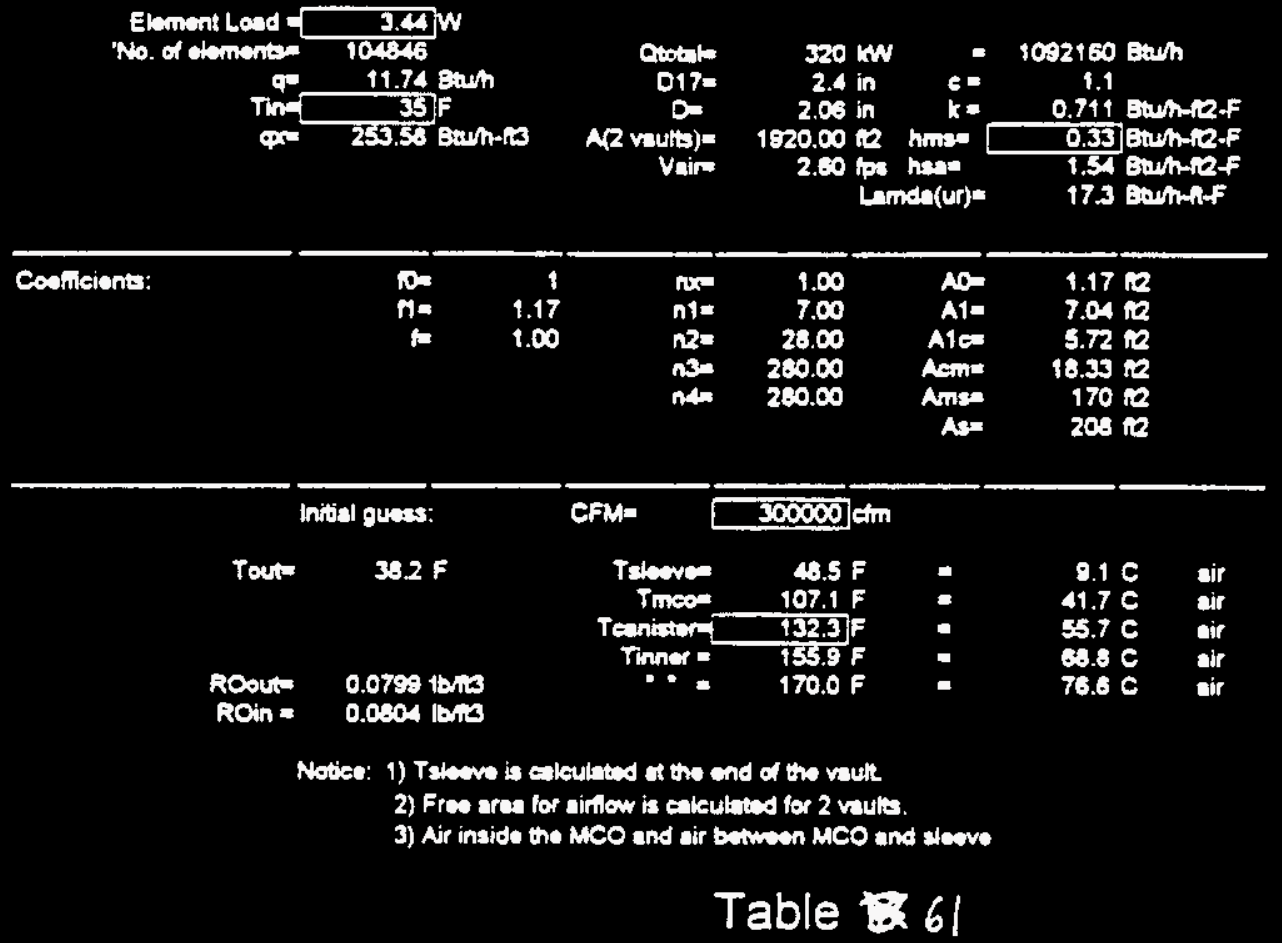


e:Sidalair_2 SSF FUEL STUDY

Foreed air - MCOINr-SLEEVEJAI- 880 MCO's - 2 vaults - Canlstar at the End of the Vault

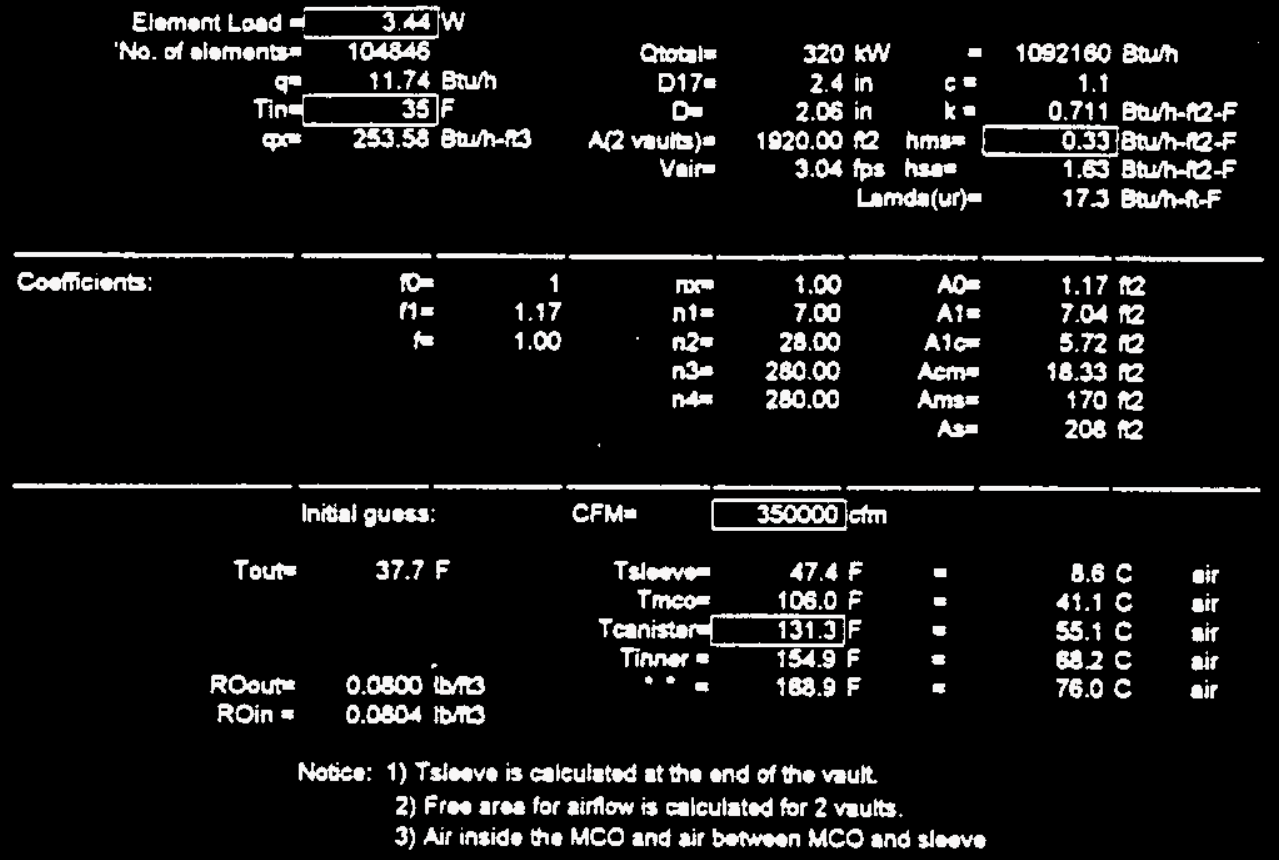

Table 62 
e:Siddair_2 SSF FUEL STUDY

Foreed alr - MCOIAr- SLEEVE/Ar- 880 MCO's - 2 vaults - Canlster at the End of the Vault

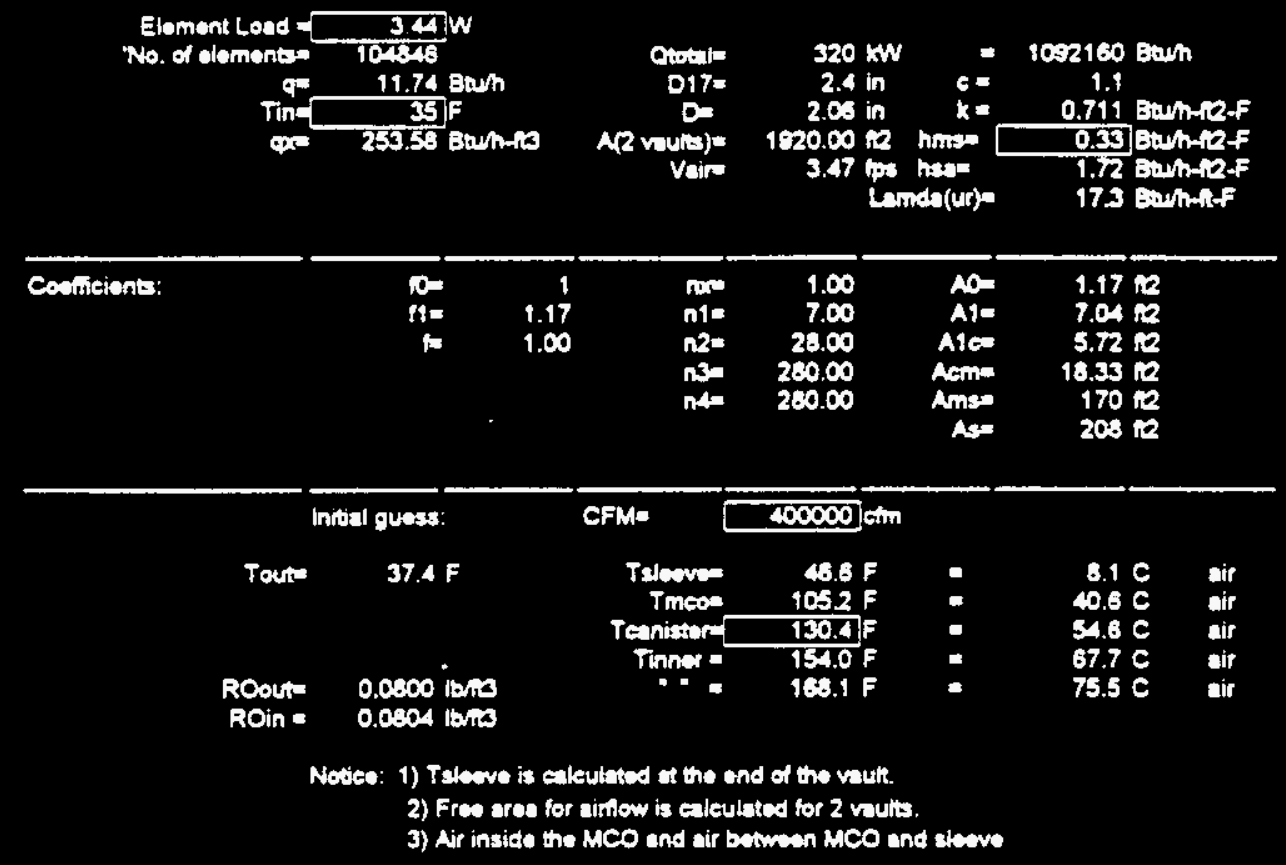

Table 63 
c:Siddair_2 SSF FUEL STUDY

Forced alr - MCOIAIr- SLEEVEARr- 880 MCO's- 2 vaulta - Canlster at the End of the Vault

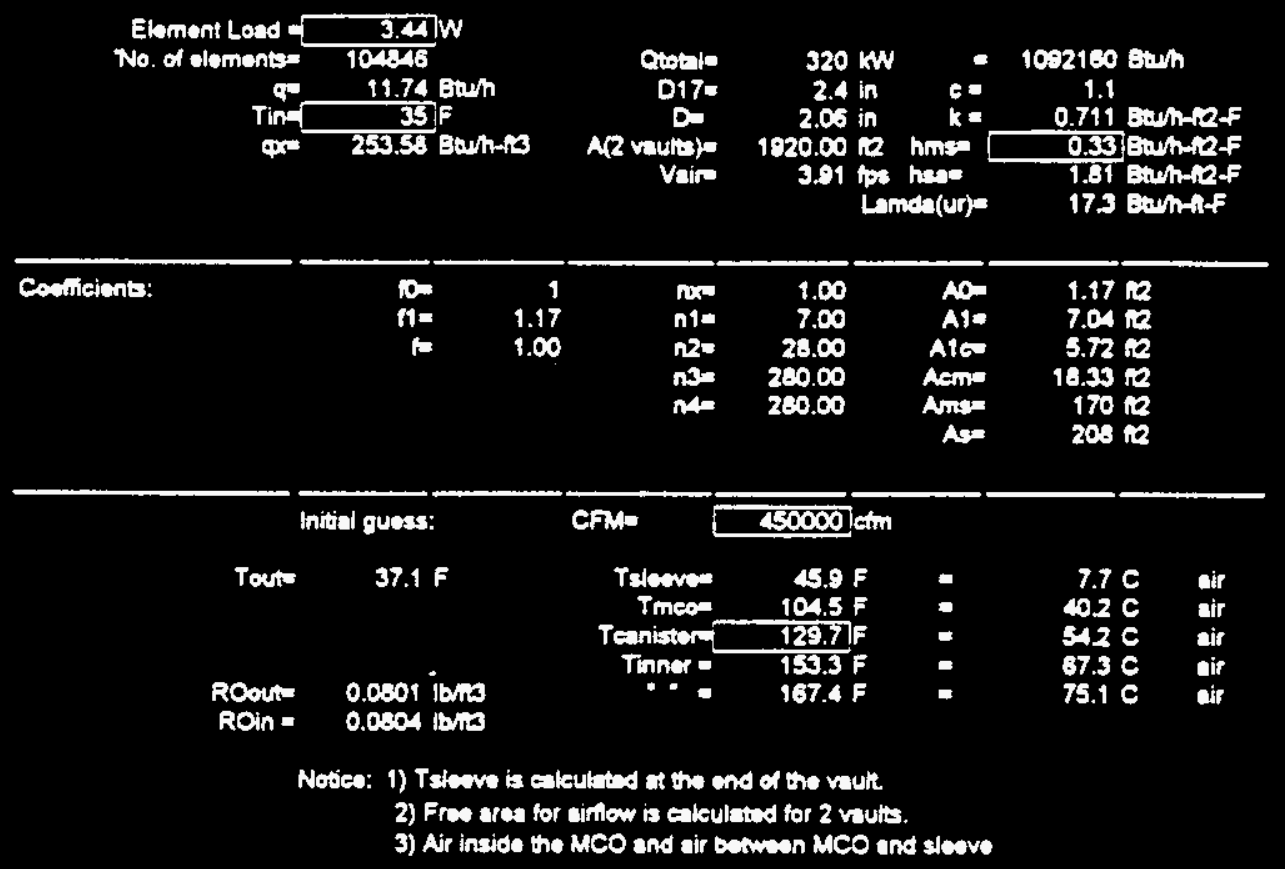

Table 64 
c:siddair_2 SSF FUEL STUDY

Foreed alt - MCOANr- SLEgVEIAIr- 880 MCO's- 2 vaulta - Canlster at the End of the Vault

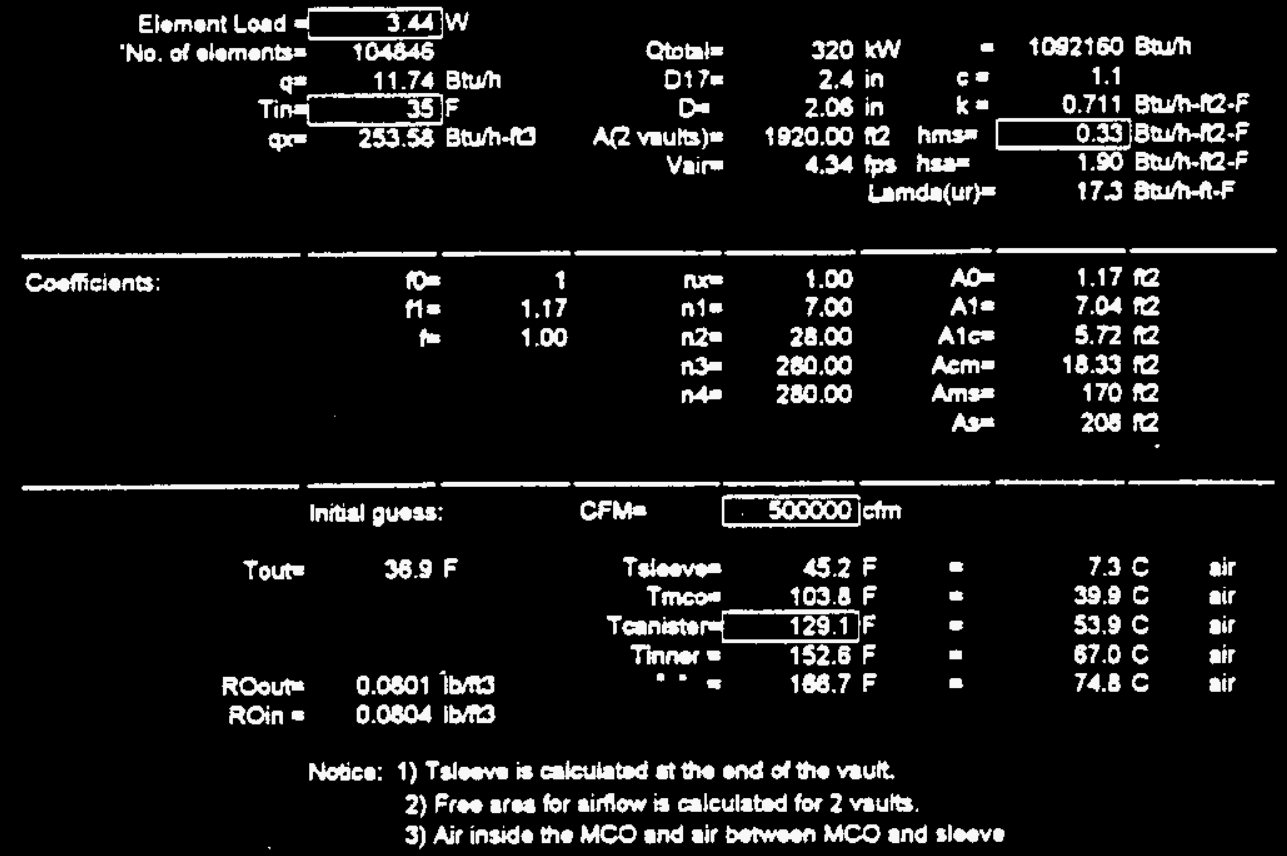

Table 65 
$T A-88$

e:Siedhir_2 SSF FUEL STUDY

Foread alr - MCOIAIr-SLEEVEJAr- 880 MCO's- 2 vaults - Canister the End of the Vault

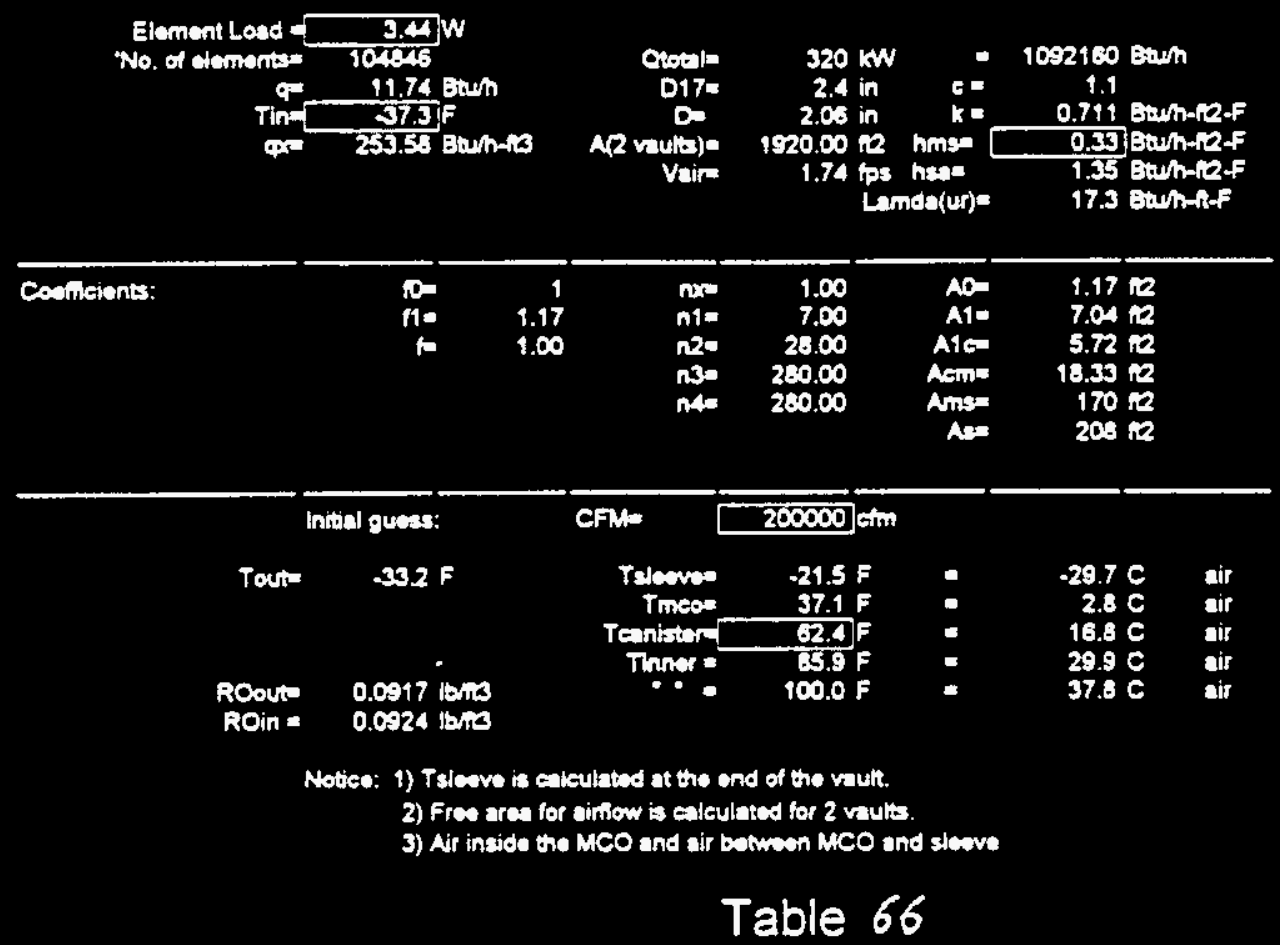


e:Sidalair_4 SSF FUEL. STUDY

Natural convectlon - MCOIAP-SLEEVE/AF- 880 MCO's- 2 vaults - Canlster at the End of the Vault

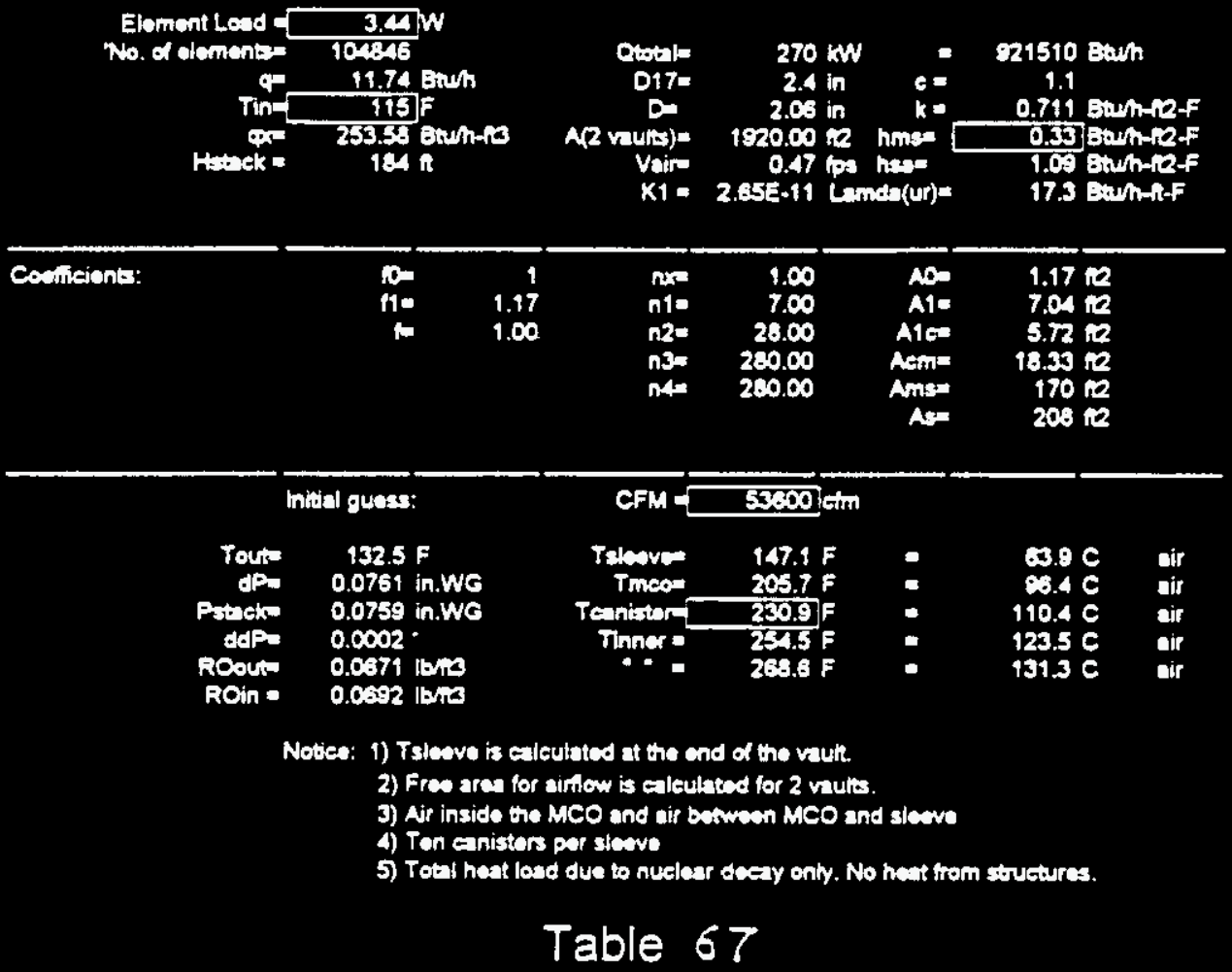


C:șlotime2

Total heat load, Btwh

Mass per sleeve, lb

Total mass in vaults, it Specific heat, Btulb-F $T$ initial, $F$

Ti, F

T2, F

T3, F

T4, F

T5, F

T6, F

Enthalpy 1 -in, Btu

Enthalpy 2-in, Btu

Enthalpy 3 -in, Bty

Enthalpy 4-in, Btu

Enthalpy 5 -in, Btu

Enthalpy 6-in, Btu

\section{Transient Analysis}

$320 \mathrm{~kW}=1092160 \mathrm{Btwh}$

\begin{tabular}{rrrrrrr} 
Element & $\begin{array}{c}\text { Cyllinder } \\
\text { Water }\end{array}$ & Assembly & \multicolumn{1}{l}{ Sleeve } & \multicolumn{1}{l}{ Air } & Total & Time \\
14330 & 2233 & 3178 & 5498 & - & - & \\
6305200 & 982520 & 1398320 & 2419120 & 11618 & - & \\
0.027 & 0.11 & 0.11 & 0.11 & 0.24 & - & \\
111.8 & 110.8 & 110.0 & 51.4 & 37.4 & - & \\
123.0 & 122.0 & 121.2 & 62.6 & 41.8 & - & \\
133.0 & 132.0 & 131.2 & 72.6 & 46.4 & - & \\
143.0 & 142.0 & 141.2 & 82.6 & 51.2 & - & \\
153.0 & 152.0 & 151.2 & 92.6 & 56.1 & - & \\
163.0 & 162.1 & 161.3 & 102.7 & 61.6 & - & \\
173.0 & 172.0 & 171.2 & 112.6 & 66.1 & - & \\
1906692 & 1210465 & 1722730 & 2980356 & 12269 & 7832512 & 7.2 \\
3609096 & 2291237 & 3260882 & 5641388 & 25095 & 14827698 & 13.6 \\
5311500 & 3372009 & 4799034 & 8302420 & 38618 & 21823581 & 20.0 \\
7013904 & 4452781 & 6337186 & 10963452 & 52281 & 28819604 & 26.4 \\
8716308 & 5544360 & 7890720 & 13651094 & 67617 & 35870100 & 32.8 \\
10418712 & 6614325 & 9413490 & 16285516 & 80164 & 42812207 & 39.2
\end{tabular}

\section{Table 68}

\section{Transient Temperature Analysis}

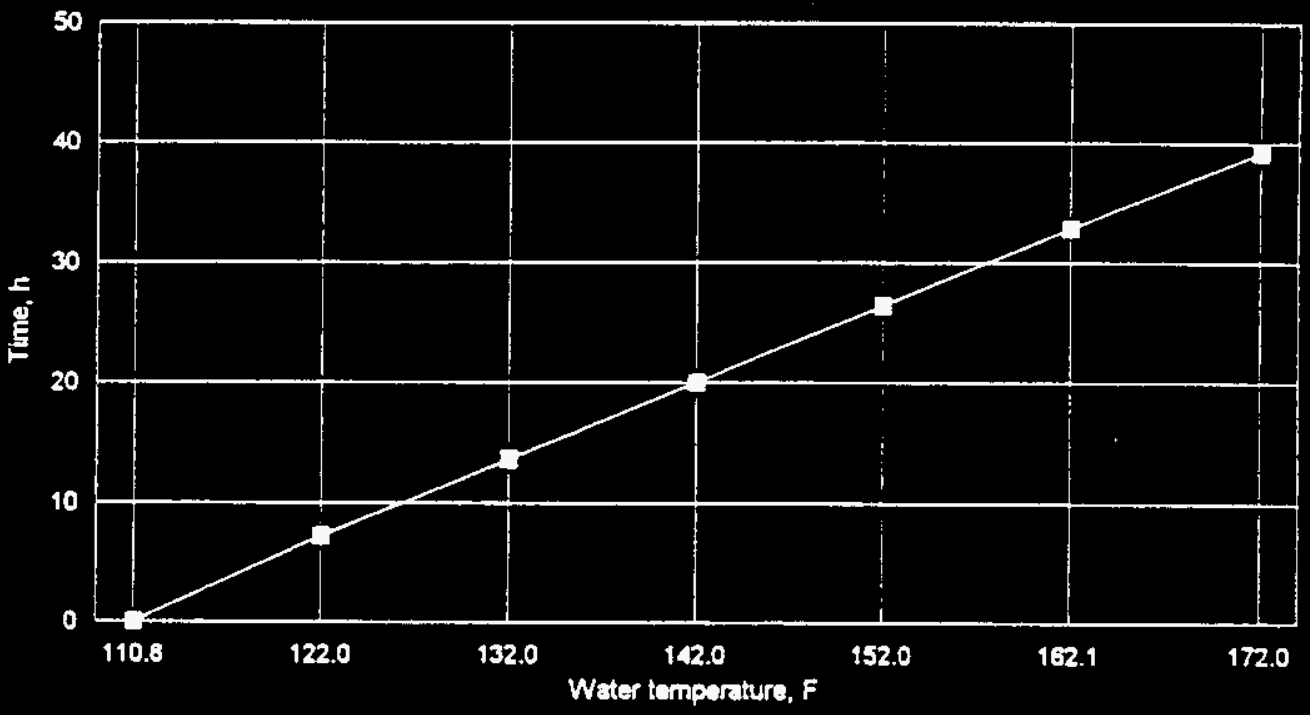

Figure 6 
e:Sidda_4

SSF FUEL STUDY

Foreed ventitaton - MCOWatar - SLEgVEJAr - 880 mCO's - Canistar at the End of the Vault - 5 high/2 vaults

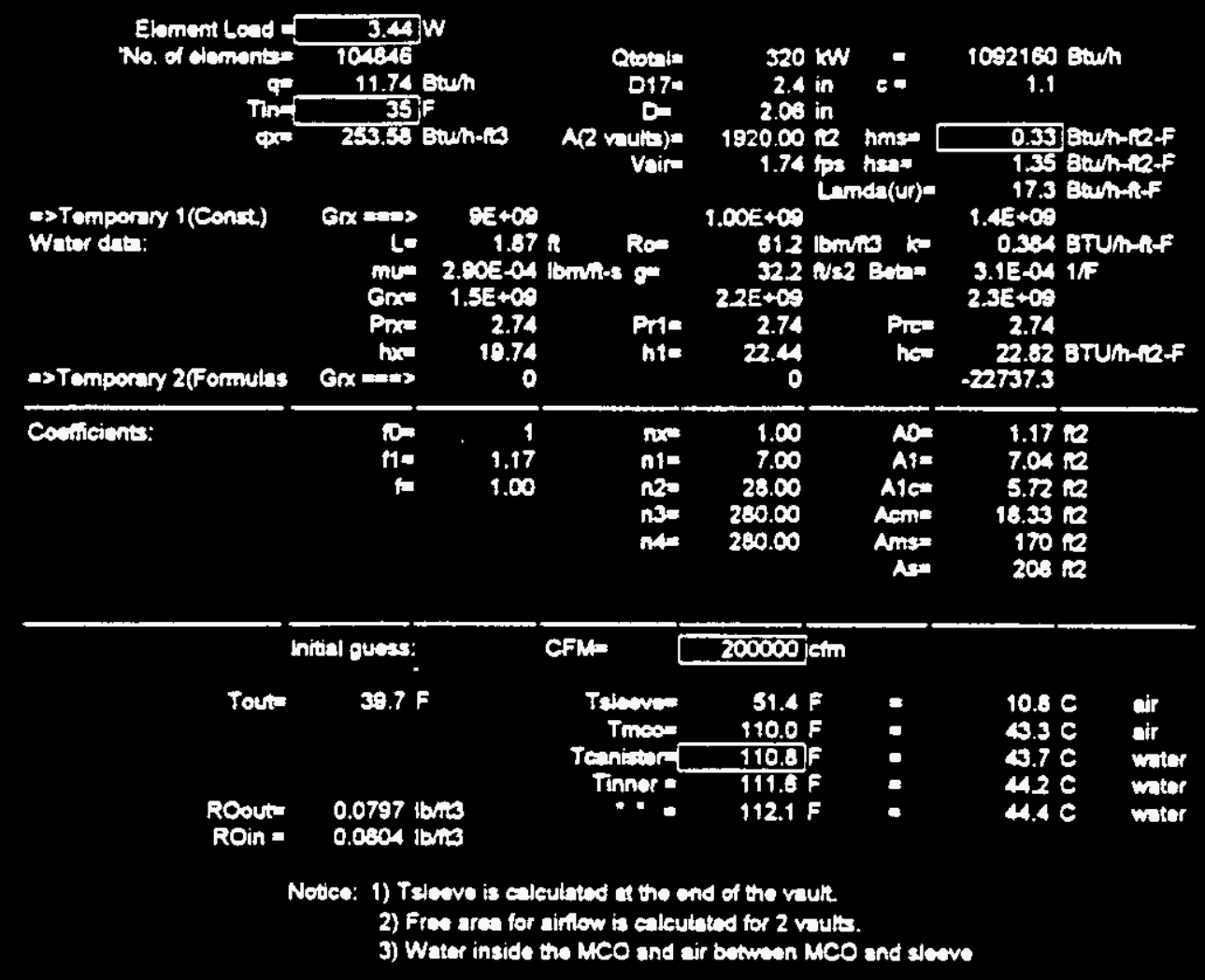

Table 25.69 
c:Sida120_4 SSF FUEL STUDY

Foreed ventilation - MCOWater - SLEEVEJAP - 880 MCO's - Canlstar at the End of the Vaut - 5 high/2 vaults

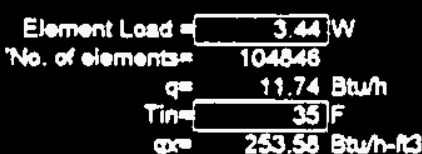

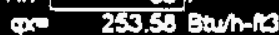

$$
\begin{gathered}
\text { Ototale } \\
\text { D17a } \\
\text { Do }
\end{gathered}
$$

A(2 valib)e
Vuip
$320 \mathrm{~kW}$

2.4 is 2.08 in

$1920.00 \mathrm{ke}$ hmes

0.62 top hase

$1.006+09$
012 Lama(ur):

-STemporary 1(Const)

Water dota: Lo 1.07 in

2.05-04 lonntis of

Cre $1.5 E+00$

Prxe 2.74

$\Rightarrow$ Temporary 2(Formulas Grx heme.

Cowneinnts:

$\begin{array}{ll}10 & 1 \\ t= & 1.17\end{array}$
$322 \mathrm{~N} 2 \mathrm{E}$ Eter

$225+00$

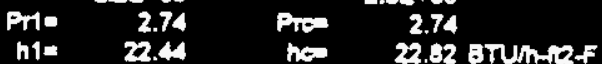

0

1 nese

$\begin{array}{ll}n \times & 1.00 \\ n 1= & 7.00\end{array}$

n1= $\quad 7.00$

n2- 28.00

n3= 200.00

nim 200.00
$1002160 \mathrm{Bm}$

t.1

0.33 Benther

1.12 Eurherf

17.3 Bhinnte

$45+00$

0.394 BRUhifF

3.1E-OA $1 / F$

$2.35 \times 00$

22.82 BTUM-12F $-25004.4$

$1.17 \mathrm{re}$

$7.04 \mathrm{ke}$

5.72 th

$18.23 \mathrm{fa}$

170

200 ia

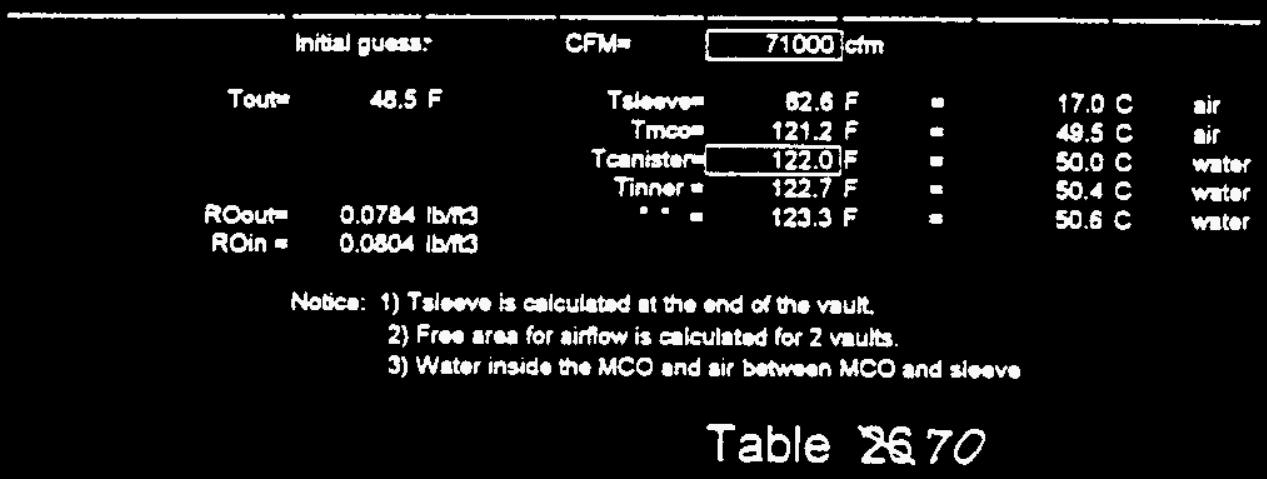

$-!$

WHC-SD-W379-ES-003 ReV. 0 
C:Sidd20_4

\section{SSF FUEL STUDY}

Foreed ventilation - MCOWater - SLEgVE/Ar - 680 MCO's - Canlstar at the End of the Vault - $\$$ high/2 vaults

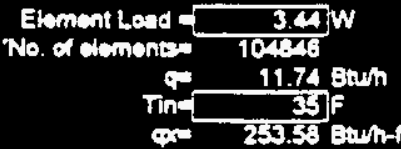

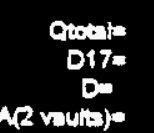

$320 \mathrm{kw}$
$2.4 \mathrm{in}$
2.00 2.06 in

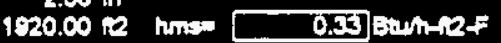

0.37 the her $\quad 1.07$ Bun-12. $1.005 \times 09$ Lendu(ur)= $\begin{array}{r}17.3 \\ 1.45 \times 00\end{array}$

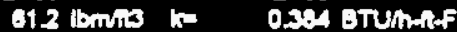
32.2 Riz Exte 3.1E.04 is $225 \times 00$

Pro

22.4 her 22.82 Btuh-12.5 $-27025.6$

0

estemperary 2fFemulas

(1)

\begin{tabular}{|c|c|c|c|}
\hline $\begin{array}{l}n= \\
n 1= \\
n 2= \\
n=m\end{array}$ & $\begin{array}{r}1.00 \\
7.00 \\
28.00 \\
280.00 \\
200.00\end{array}$ & $\begin{array}{l}\text { AOE } \\
\text { At= } \\
\text { Ater } \\
\text { Acm= } \\
\text { Ans: } \\
\text { Ase }\end{array}$ & $\begin{array}{r}8.17 \mathrm{ra} \\
7.04 \mathrm{ra} \\
5.72 \mathrm{ra} \\
18.33 \mathrm{re} \\
170 \mathrm{ka} \\
203 \mathrm{ra}\end{array}$ \\
\hline
\end{tabular}

Cowmeine:

$\begin{array}{ll}\text { tor } & \\ \text { te } & 1.17\end{array}$

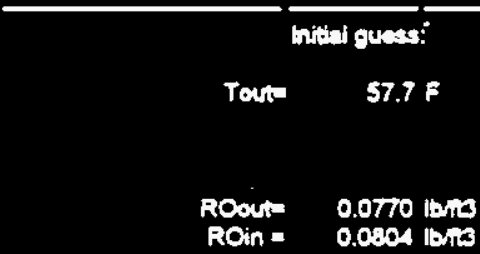

Notice: 1) Talesve is ealeutated th the end of the valt.

2) Fres ares for airilow is calsulated for 2 wults.

3) Water inside tho MCO and air botween MCO and stewo

Table 2771 
e:Sidd20_4 SSF FUEL STUDY

Foreed ventlation - MCOWater - SLEEVEJAI - 880 MCO's - Canlster at the End of the Vault - 5 high/2 vaults

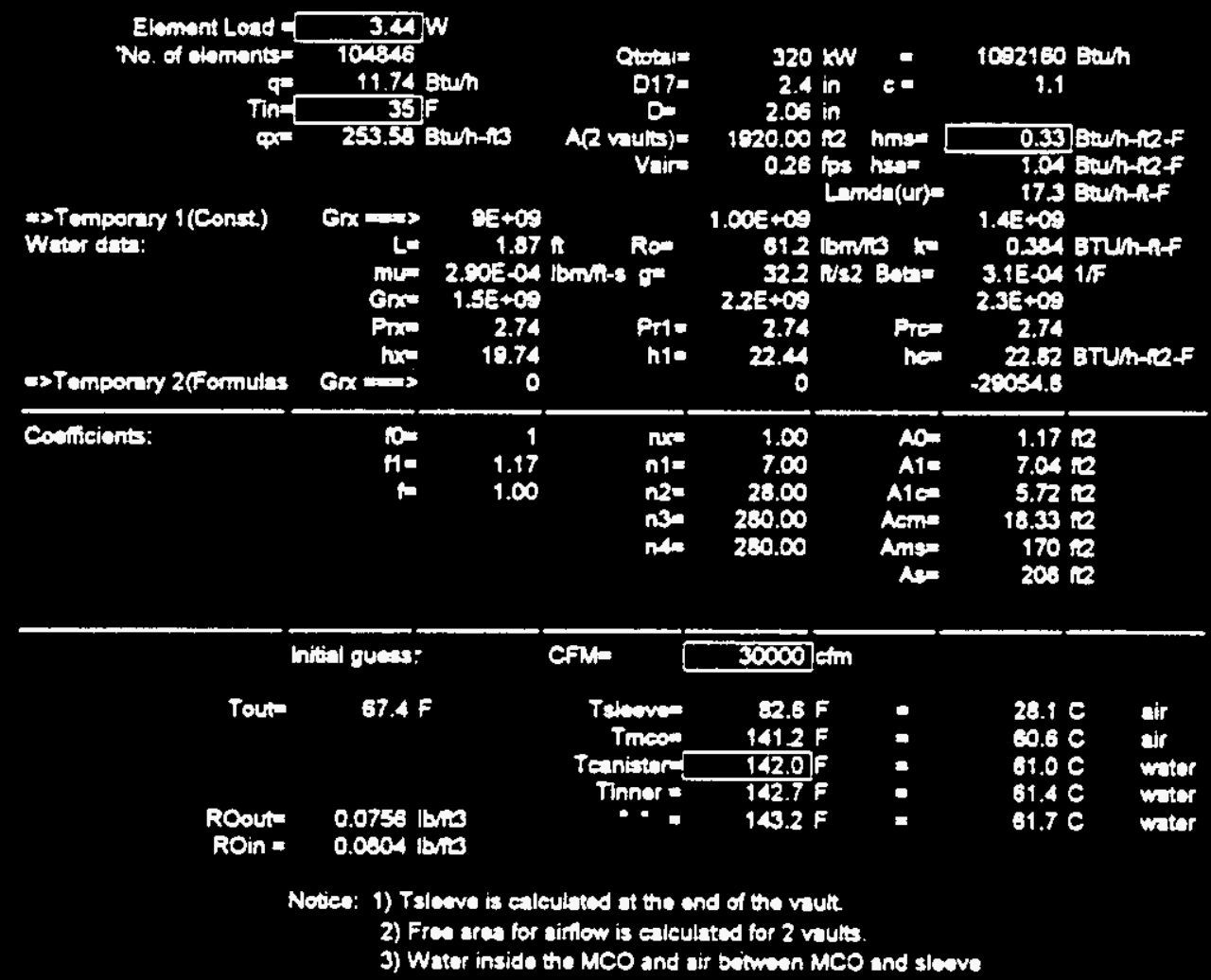

Table 28 72 
Sisidol20-4 SSF FUEL STUDY

Foreed ventlation - MCOWater - SLEgVEJNr - 890 MCO's - Canlstar at the End of the Vault - 5 high/2 vaults

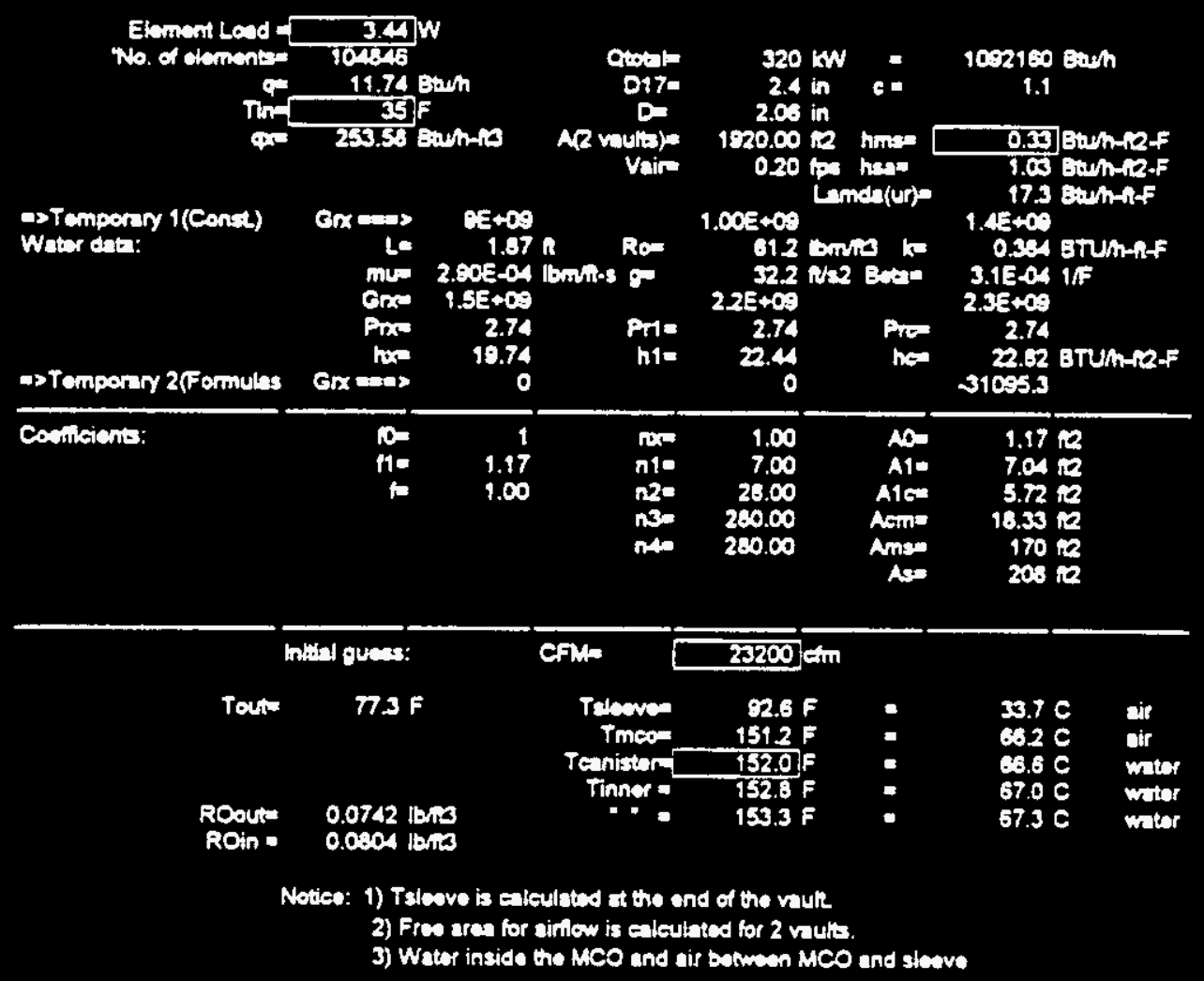

Table 2973 
:e:Sidaro_4 SSF FUEL STUDY

Foreed ventlation - MCOWater - SLEEVEJAI - 880 MCO's - Canister at the End of the Vault - 5 highz vaults

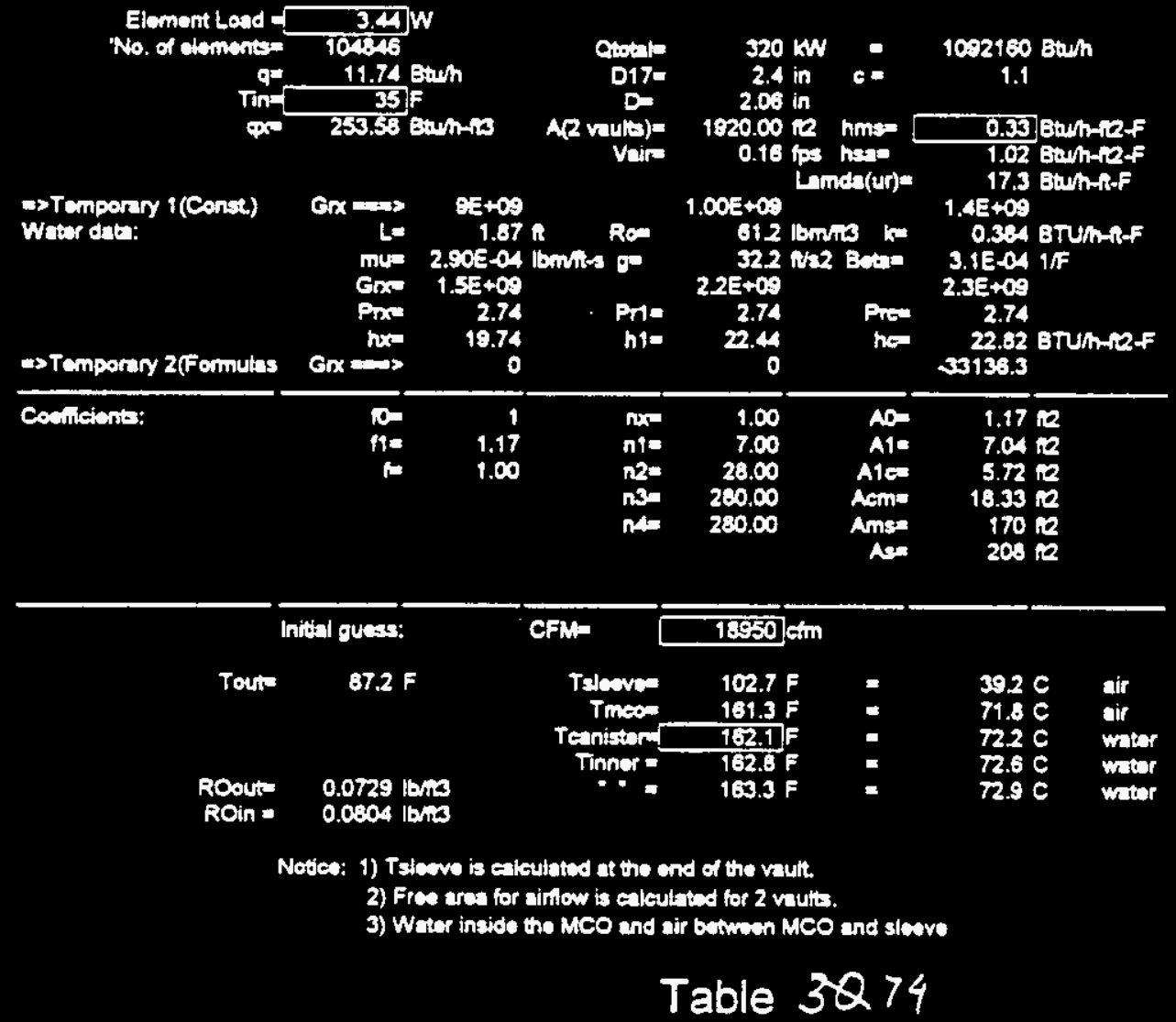


c:Sidd12D_4

Forced ventlation - MCOWater - SLEEVEJAir - 880 Mi:O's - Canister at the End of the Vault - 5 hlgh/2 vaults

\begin{tabular}{|c|c|c|c|c|c|c|c|}
\hline \multirow[b]{3}{*}{$\begin{array}{l}\text { Womporary } 1 \text { (Const) } \\
\text { Woter date: }\end{array}$} & \multirow{2}{*}{\multicolumn{2}{|c|}{$\begin{array}{l}\frac{3.44}{104546} \mathrm{~W} \\
11.74 \text { Btwh } \\
35 \mathrm{~F} \\
253.58 \text { Btwh-n }\end{array}$}} & \multirow{3}{*}{$\begin{array}{c}\text { Oobite } \\
\text { D17: } \\
\text { De } \\
\text { A(2 vaula }= \\
\text { vain }\end{array}$} & \multirow{3}{*}{$\begin{array}{r}320 \\
2.4 \\
2.06 \\
1920.00 \\
0.14 \\
1.006+00 \\
61.2 \\
32.2 \\
2.25+0 . \\
2.74 \\
22.44 \\
0\end{array}$} & \multirow{2}{*}{ 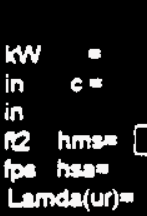 } & \multicolumn{2}{|l|}{$\begin{array}{c}1092160 \mathrm{Buwh} \\
1.1\end{array}$} \\
\hline & & & & & & \multirow{2}{*}{\multicolumn{2}{|c|}{ 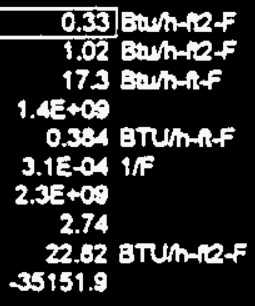 }} \\
\hline & 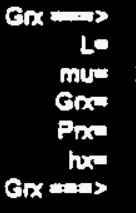 & $\begin{array}{r}95+09 \\
1.67 \\
2.80 E-04 \\
1.5 E+09 \\
2.74 \\
19.74 \\
0\end{array}$ & & & $\begin{array}{c}\text { lbmin } k= \\
\text { Wos Boten } \\
\text { Pres } \\
\text { her }\end{array}$ & & \\
\hline \multirow[t]{2}{*}{ Confilciont: } & if & $\begin{array}{r}1 \\
1.17 \\
1.00\end{array}$ & $\begin{array}{l}n \times w= \\
n 1= \\
n 2= \\
n 3= \\
n 4=\end{array}$ & $\begin{array}{r}1.00 \\
7.00 \\
28.00 \\
260.00 \\
280.00\end{array}$ & $\begin{array}{l}\text { AO= } \\
\text { A1= } \\
\text { A1c= } \\
\text { Acme } \\
\text { Ans= } \\
\text { As: }\end{array}$ & $\begin{array}{l}1.17 \mathrm{rl} \\
7.04 \mathrm{~m} \\
5.72 \mathrm{re} \\
18.33 \mathrm{re} \\
170 \mathrm{~m} \\
200 \mathrm{ra}\end{array}$ & \\
\hline & tid guass: & & $C F M=$ & 16060 & Ctin & & \\
\hline $\begin{array}{l}\text { ROouts } \\
\text { ROin = }\end{array}$ & $\begin{array}{l}0.0715 \mathrm{lb} \\
0.0804 \mathrm{lb}\end{array}$ & & 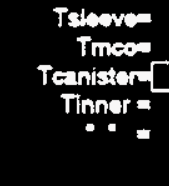 & $\begin{array}{l}112.8 \mathrm{~F} \\
171.2 \mathrm{~F} \\
172.0 \mathrm{~F} \\
172.8 \mathrm{~F} \\
173.3 \mathrm{~F}\end{array}$ & $\begin{array}{l}: \\
:\end{array}$ & $\begin{array}{l}44.7 \mathrm{C} \\
77.3 \mathrm{C} \\
77.7 \mathrm{C} \\
78.1 \mathrm{C} \\
78.4 \mathrm{C}\end{array}$ & $\begin{array}{l}\text { air } \\
\text { air } \\
\text { water } \\
\text { water } \\
\text { water }\end{array}$ \\
\hline \multicolumn{8}{|c|}{ 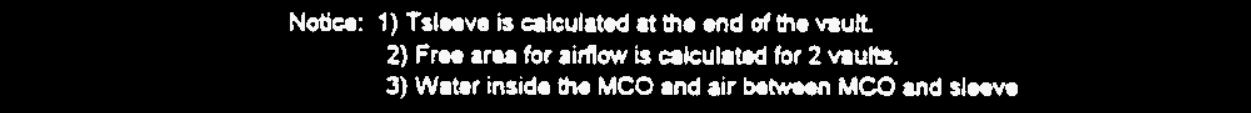 } \\
\hline
\end{tabular}




\section{1 tutoaial}

\section{FILENAME : SSF 20DED}

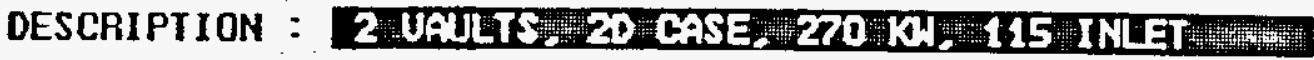

4 PREPARE

INPUT

5 ANALYZE

\section{REUIEW RESULTS}

This post processar allows you to graphically review the results of your CFD analysis. You can display any solved or stored dependent variable results as colored contour plots or as a colored filled contour plots at any plane of interest. Velocities can be shown as color coded vectors at any plane. This step runs the PHOTON progran. Refer to PHOTON User Manual TR140.

\section{Select Option and Press RReturns}



Vieupoint:
Up uector:
1.00
0. 000
$-0.25412-05$
$0.2545-05$
0.1272-85
1.00

Command?

46.1

47.6

48.4

49.1

49.9

58.7

51.4

52.2

53.0

53.7

54.5

55.3

56.0

56.8

$\stackrel{2}{\longrightarrow}$

2 UAULTS, 20 CASE, $270 \mathrm{KM}, 115$ IMLET

PHDENICS 


\section{Vieupoint: $\quad 1.00 \quad 0.000 \quad-8.254 \mathrm{Z}-05$ \\ Up vector: $0.254 \mathrm{D}-05 \quad 0.127 \mathrm{D}-05 \quad 1.00$}

Command? yis is 1 sololy 1

Uector 1 created.

Conmand?

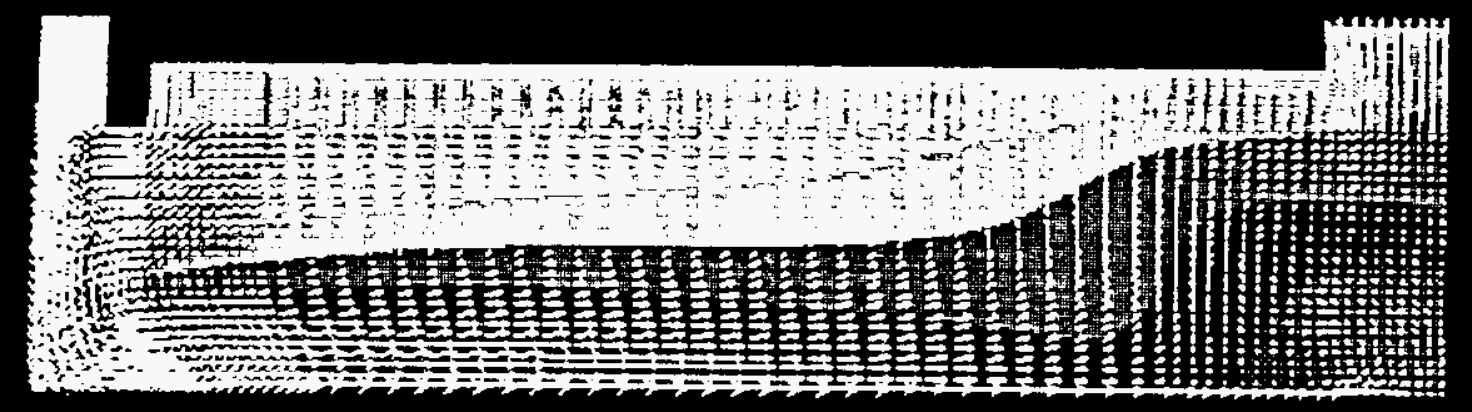

46.1

47.6

48.4

49.1

49.9

50.7

51.4

52.2

53.0

53.7

54.5

55.3

56.0

56.8

2

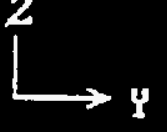

$2: 2.62 \mathrm{~m} / \mathrm{s}$

2 UAULTS, 2D CASE, $270 \mathrm{kH}, 115$ IKLET

PHOENICS 


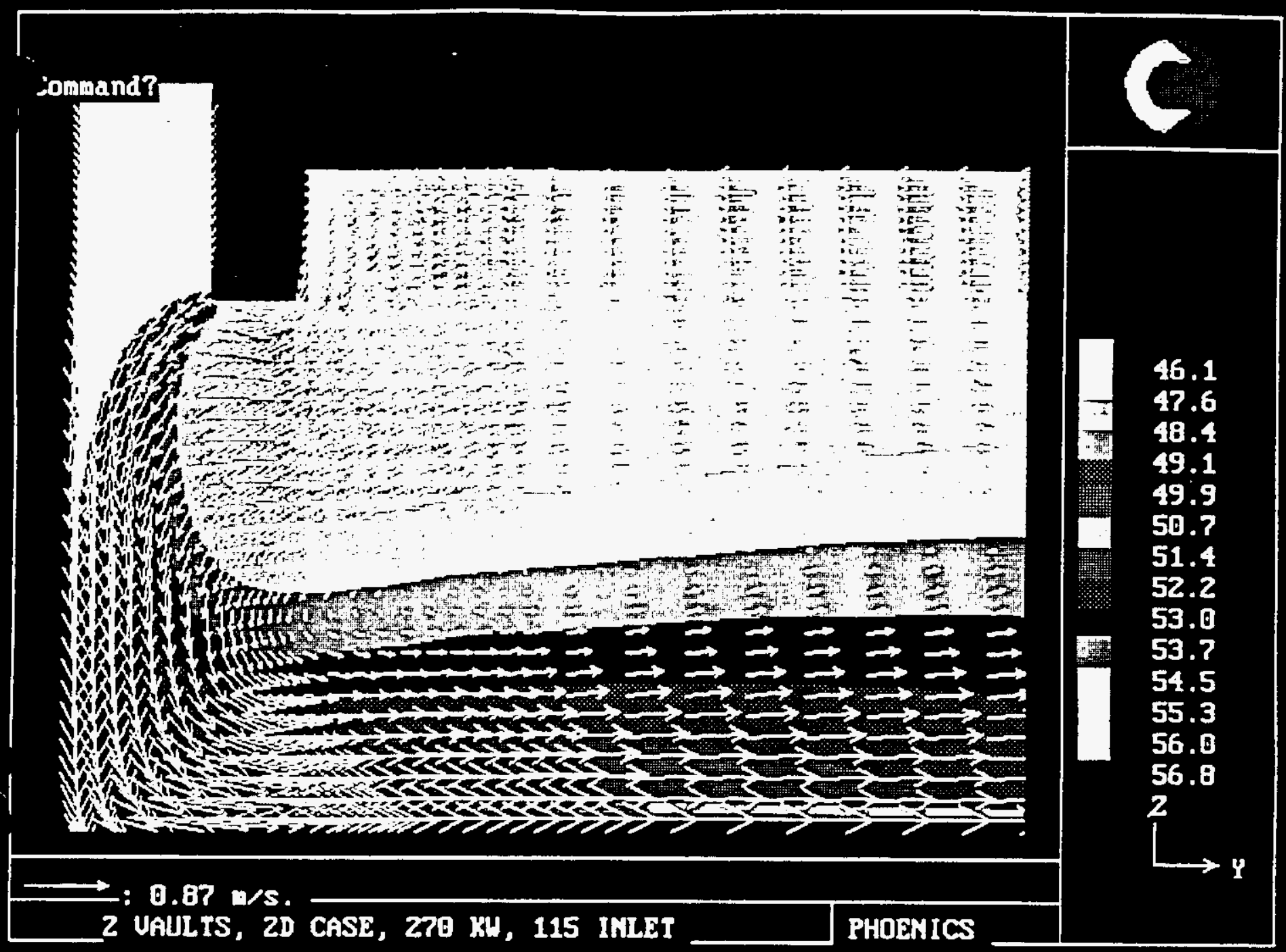

$$
\text { FIFURE II }
$$

WHC-SD-H379-ES-003 Rev.0 


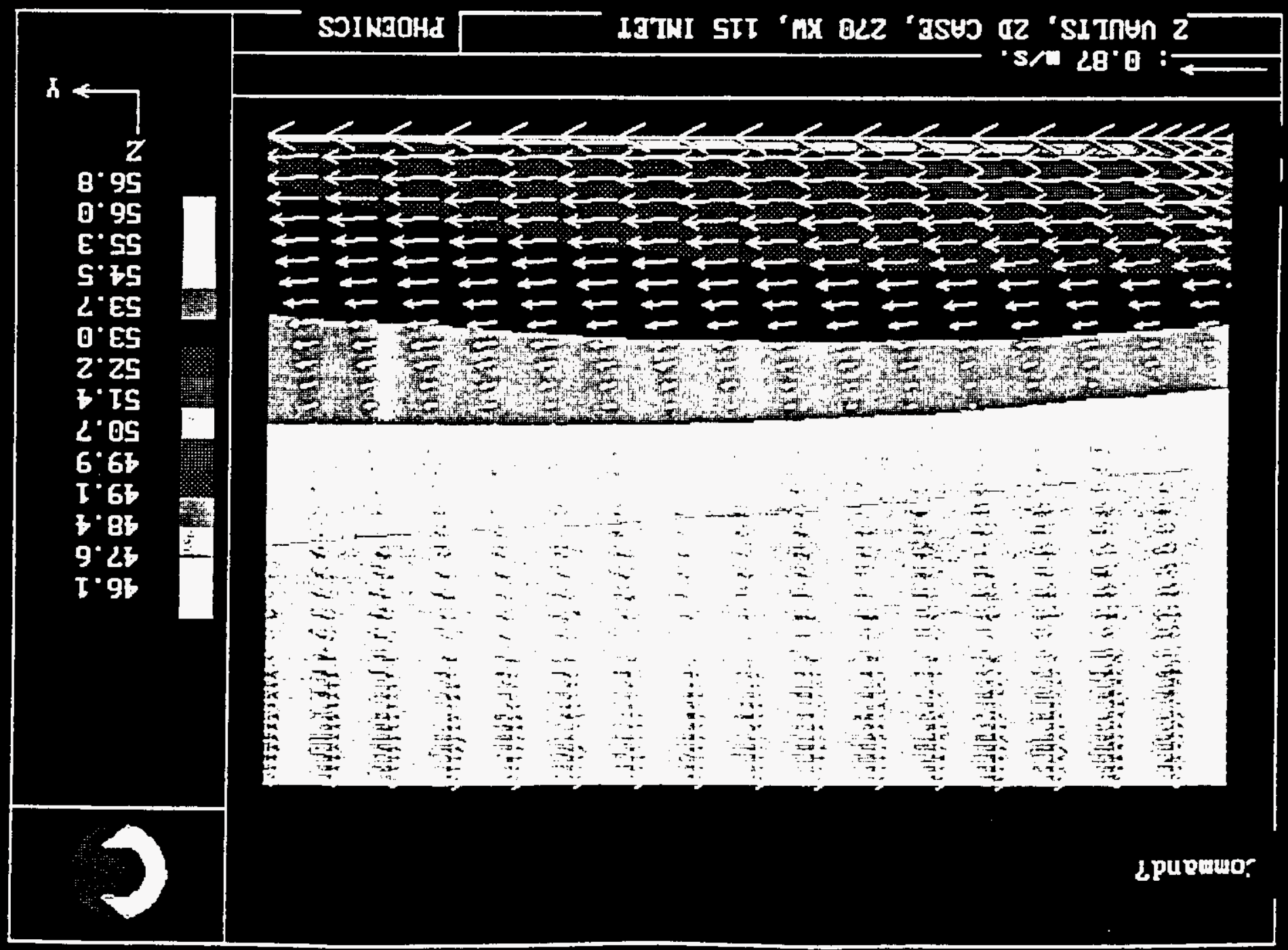




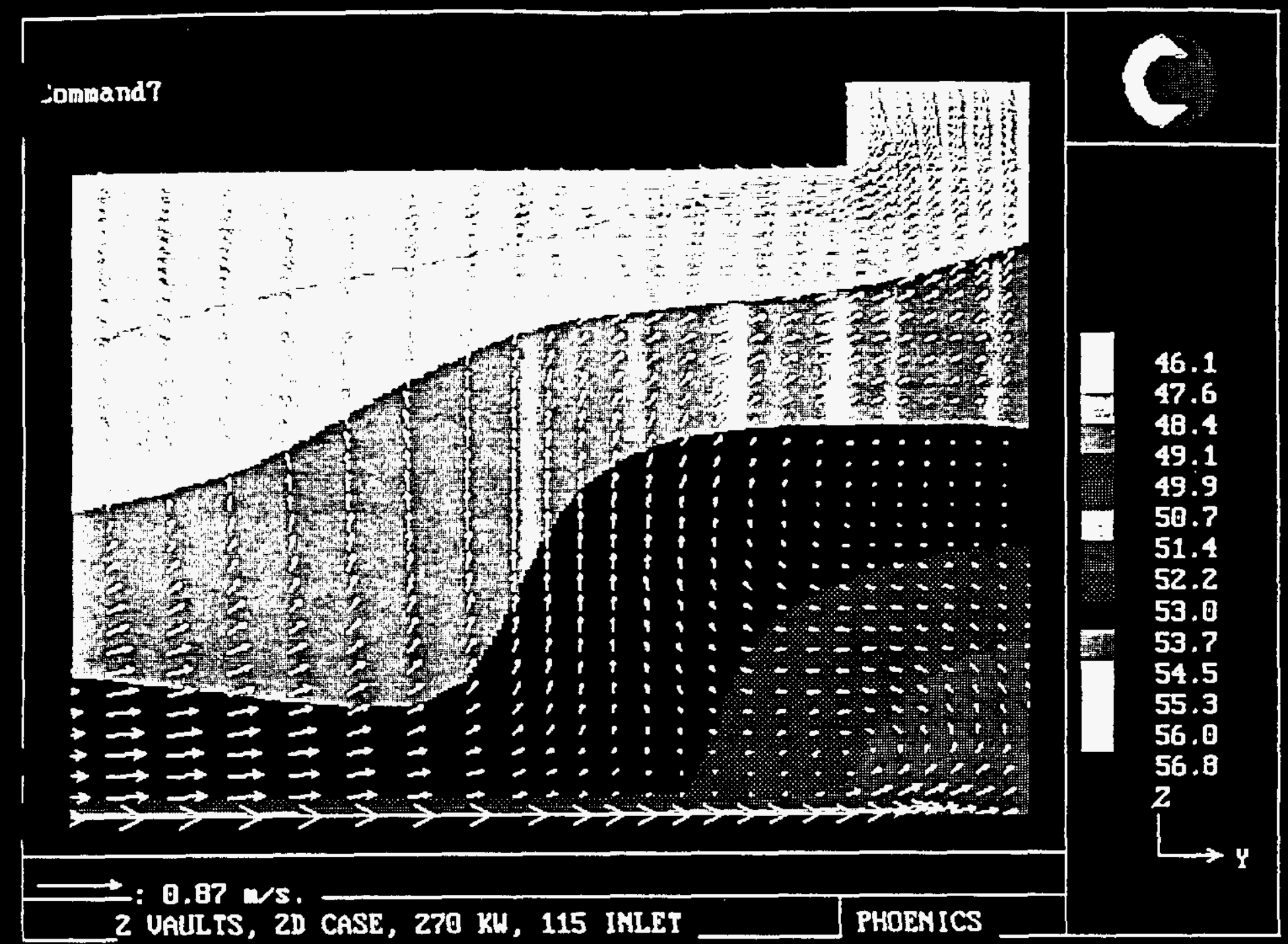




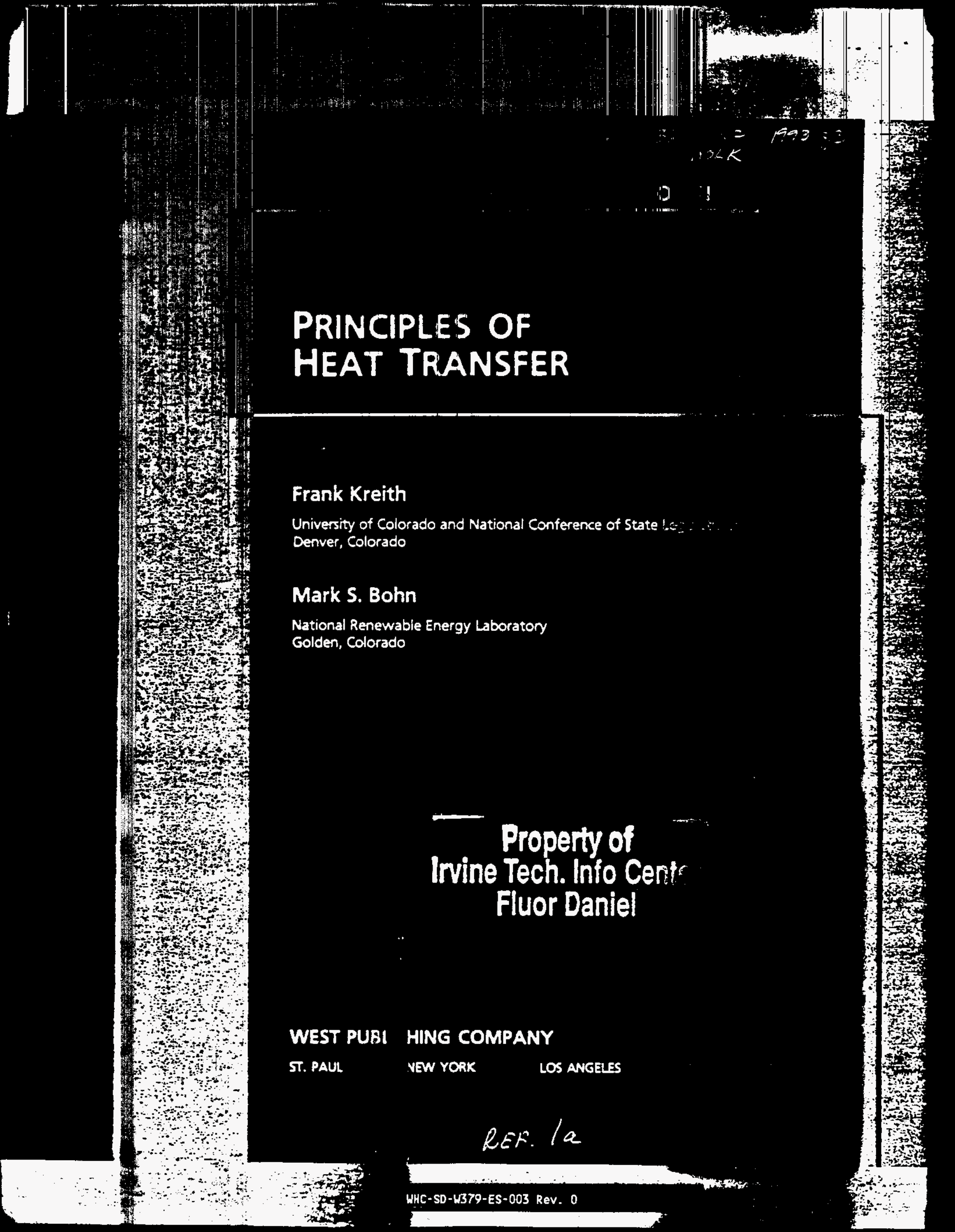




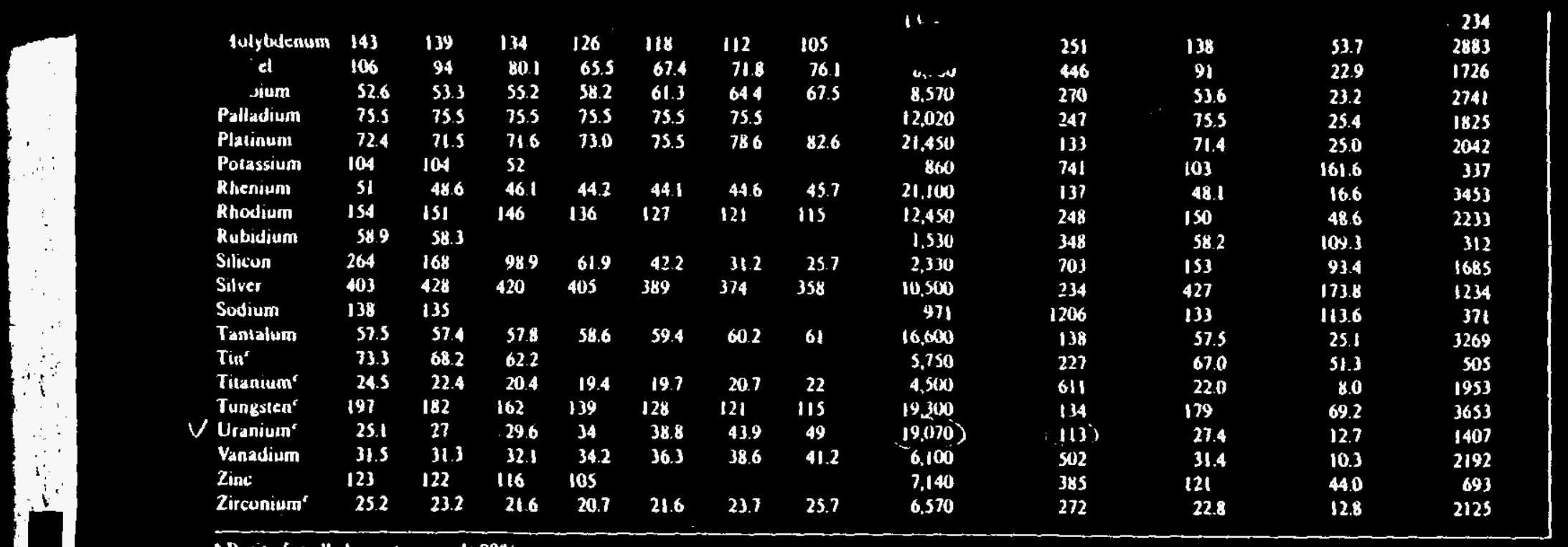

- Purily for all elements exceeds $99 \%$ in 7 The expecied percent errors in the thermal conductivily values are approximately within $\pm 5 \%$ of the true values neat room temperalure and wilhin about

$\pm 10 \%$ al other remperalures.
For crystilline materials, the values are given for the polycrystalline materials.

Source: E.R.G. Eckert and R.M. Drake, Anulysis DJ Heat and Mass Transfer, McGraw-Hill, New York, 1972; K. Raznjevic, Handbook of Thermodynamic Tables und Charis, 3d ed., MaCriw-14ill, New York, 1976; Y.S. Touluukjan, ed., Thermuphysical Properties of Matier, IFI/Plenum, New York, 1970. 


\section{ASHRAE HANDBOOK}

\section{FUNDAMENTALS}

\section{I-P Edition}

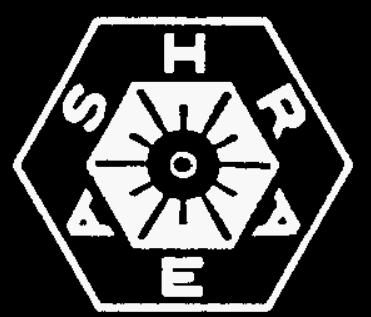

American Society of Heating, Refrigerating and Air Conditioning Engineers, Inc. 1791 Tullie Circle, N.E., Atlanta, GA 30329 404-636-8400

$$
\text { REF } 2 a
$$


This useful relationship gives a rough idea of the ipectral energy distribution from a black surface; $25 \%$ of the enercy is radiated at wavelengths shorter than the maximum, and $7.9 \%$ is radiated at wavelengths longer than the maximum.

\section{Actual Radiation}

Substnnces and surfaces diverge variously from the StefanBolezmanan and Planck Laws. $W_{b}$ and $W_{b u}$ are the maximum enissive powers at a surface temperature. Actual surfaces enit and absorb leas readily and are ealled nonblack. The emissive power of a nonblack surface, at temperature $T$, radiating to the hemispherical region above it is written as:

$$
W=\varepsilon W_{b}=\varepsilon 0 T^{*}
$$

where $t$ is enlled the hemispherical emittance. The term emittance conforms to physical and electrical terminology; the sufix "znee" denotes a property of a piece of material as it exists. The endins "ivity" denotes a property of the bulk material independent of geometry or surface condition. Thus, emittance, reflectance, absorptance, and transmittance refer to actual pieces of material. Emissivity, reflectivity, absorptiyity, and transmissivity refer to properties of materials which are optically stooth and thick enough 10 be opaque.

The emittance is a function of the material, the condition of its surface and the temperature of the surface. Table 3 lists selected values; Siegel and Howell (1981) have more extensive lists.

The monochromatic emissive power of a nonblack surface is similarly written as:

$$
W_{1}=\varepsilon_{1} W_{b 1}=\varepsilon_{1}\left(C_{1} \lambda^{-3} / c^{c_{2} / 1 T_{-}}-1\right)
$$

where $c_{2}$ is the monochromatic hemispherical emittance. The relationship between $c$ and $c_{1}$ is given by:

or

$$
W=\cot T^{4}=\int_{0}^{-} W_{1} d \lambda=\int_{0}^{-} c_{2} W_{\Delta 1} d \lambda
$$

$$
c=\left(1 / \sigma T^{2}\right) \int_{0}^{\infty} c_{2} W_{b 1} d \lambda
$$

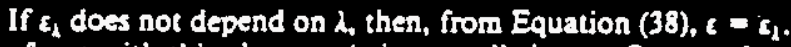
Surfaces with this characteristic are called groy. Oray-surface characteristics are often assumed in calculations. Several classes of surfaces approximate this condition in some regions of the spec. trum. The simplicity is desirable, but care must be exercised, expecially if cemperatures are high. Assumption of grayness is sometimes made, because of the absence of information relating $c_{1}$ and $\lambda$.

When radiant energy falls on a surface, it can be absorbed, rellected or transmitted through the material. Therefore from the First Law of Thermodynanies:

$$
a+r+e-1
$$

\section{where}

- F fnction of incident radiation absorbed or absorptance $r=$ fraction of incident radiation trensmitted or trensmittance $e=$ frection of incident rediation reflected or reftectonce

If the material is opaque as most solids are in the infrared, $\tau=0$ and $a+e=1$. For a black surface, $\alpha=1, e=0$ and $\tau=0$. Platinum black and gold black have absorptances of about $98 \%$ in the infrared, which is as black as any actual surface is. Any desired degree of blackness can be simulated by a small hole in a large enclosure. Consider a ray of radiant energy entering the opening. It will undergo many internal reflections and be almost completely absorbed before it has a reasonable probability of passing back out the opening.

Certain flat black paints also exhibit emittances of $98 \%$ over a wide range of conditions. They provide a much more durable surface than gold or platinum black and are frequently used on radiation instruments and as standard reference in emittance or reflectance measurements.

Kirchhoffs law, relating emittance and absorptance of any opaque surface from thermodymamic considerations, states that for any surface where the incident radiation is independent of angle or where the surface is diffuse, $\varepsilon_{\lambda}=\Delta_{k}$. If the surface is gray, or the incident radiation is from a black surface at the same temperature, then also $\varepsilon=a$, but many surfaces are not gray. For most surfaces listed in Table 3, absorpcance for solar radiation is different than emitunce for low temperature level radiation. This is because the wavelength distributions are different in the two cases, and $\varepsilon_{1}$ varies with wavelength.

The foregoing discussion relates to total hemispherical radiation from surfaces. Energy distribution over the hemispherical region above the surface also has an important effect on the rate of heat transfer in various geometric arrangements.

Toble 3 Euttuaces and Absorptances for a Few Surfaces"

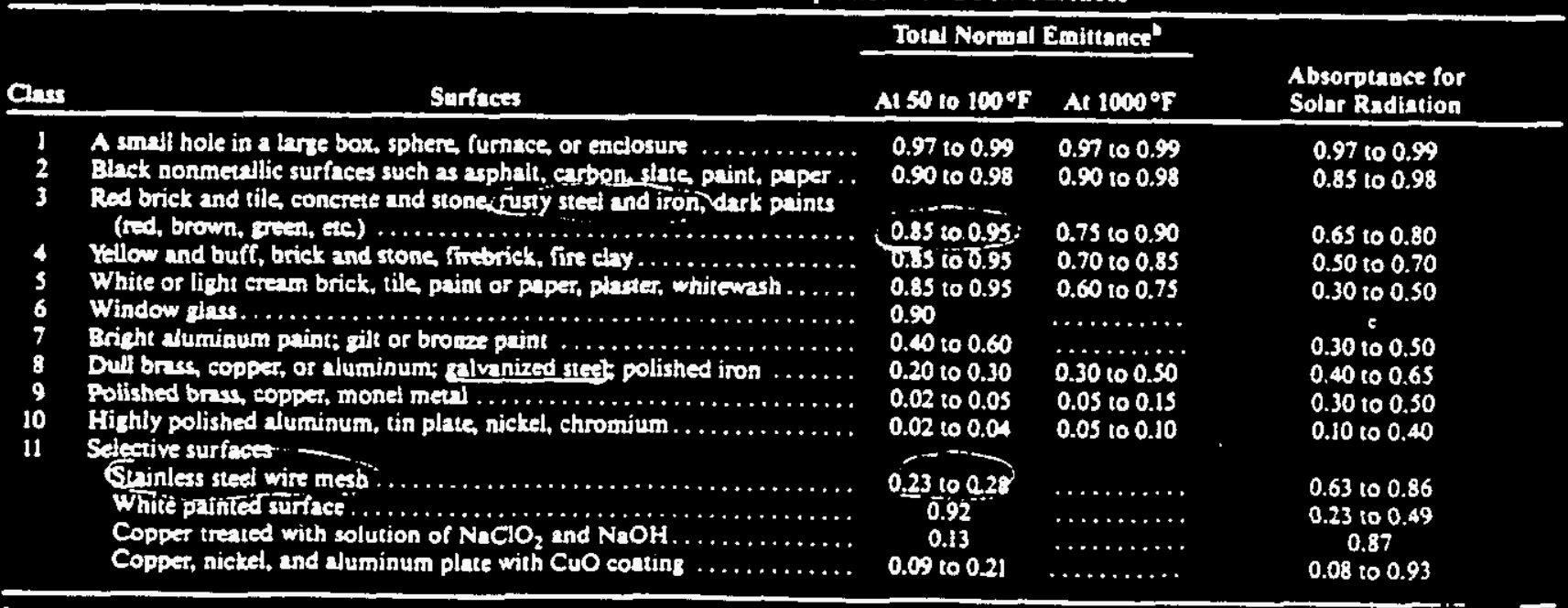

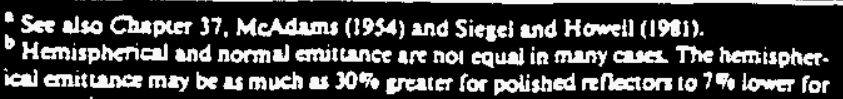

Absorbs 110 40\% depending upon its trensmuttance. nonconductors. 
laboratory test conditions. Air gaps in these types of insulation systems can seriously degrade thermal performance as a result of air movement due to both natural and forced convection. Sabine et al. (1975) found the tabular values are not necessarily additive for multiple-layer, low-emittance airspaces, and tests on actual constructions should be conducted to accurately determine thermal resistance values.

Values for foil insulation products supplied by manufacturers must also be used with eaution because they apply only to systems that are identical to the configuration in which the product was rested. In addition, surface oxidation, dust accumulation, and other factors that change the condition of the low-emirtance surface can reduce the thermal effectiveness of these insulation systems. Deterioration results from contact with several types of solutions, either acidic or basic (e.g., wet cement mortar or the preservatives found in decay-resistant lumber). Polluted environments may cause rapid and severe material degradation. However, site inspections show a predominance of well-preserved installations and only a small number of cases in which rapid and severe deterioration has occurred.

\section{CALCULATING OVERALL THERMAL RSSISTANCES}

Relatively small conductive elements within an insulating layer or thermal bridges can substantially reduce the average thermal resistance of a component. Examples include wood and metal studs in frame walls, concrete webs in concrete masonry walls, and metal ties or other elements in insulated wall panels. The following examples illustrate how to calculate R-values and U-factors for components containing thermal bridges.

The following conditions are assumed in calculating the design R-values:

(1) Equilibrium or steady-state heat iransfer, disregarding effects of heat storage;

- $R$.
(2) Surrounding surfaces at ambient air temperature;

(3) Exterior wind velocity of $15 \mathrm{mph}$ for winter (surface $w$ th $\mathrm{R}$ * $0.17^{\circ} \mathrm{F} \cdot \mathrm{ft}^{2} \cdot \mathrm{h} / \mathrm{Btu}$ ) and $7.5 \mathrm{mph}$ for summer (surface wich $\mathrm{k}$ $\left.=0.25{ }^{\circ} \mathrm{F} \cdot \mathrm{ft}^{2} \cdot \mathrm{h} / \mathrm{Btu}\right)$; and

(4) Surface emittance of ordinary building materials is 0.90.

Table I Surface Conductances, Btu $/ \mathrm{h} \cdot \mathrm{ft}^{2} \cdot{ }^{\circ} \mathrm{F}$, and Resistances, of $\cdot f^{2} \cdot h / B t u$, for Air ${ }^{\text {a.t.ced }}$

\begin{tabular}{|c|c|c|c|c|c|c|c|}
\hline \multirow{4}{*}{$\begin{array}{l}\text { Poditios of } \\
\text { Surface }\end{array}$} & \multirow{4}{*}{$\begin{array}{l}\text { Direction } \\
\text { of Heat } \\
\text { Flow }\end{array}$} & \multicolumn{6}{|c|}{ Sufnes Emittence, $t^{\circ}$} \\
\hline & & \multirow{2}{*}{\multicolumn{2}{|c|}{$\begin{array}{c}\begin{array}{c}\text { Nos- } \\
\text { refective } \\
t=0.90\end{array} \\
\end{array}$}} & \multicolumn{4}{|c|}{ Reflective } \\
\hline & & & & \multicolumn{2}{|c|}{$e=0.20$} & \multicolumn{2}{|c|}{$\theta=8.4$} \\
\hline & & $h_{i}$ & $\boldsymbol{R}$ & $h_{l}$ & $\boldsymbol{R}$ & $h_{i}$ & $R$ \\
\hline $\begin{array}{l}\text { STILL AIR } \\
\text { Horizontal } \\
\text { Sloping-45" } \\
\text { Vertical } \\
\text { Sloping-45 } \\
\text { Horizontal } \\
\end{array}$ & $\begin{array}{l}\text { Upward } \\
\text { Upward } \\
\text { Horizontal } \\
\text { Downward } \\
\text { Downward }\end{array}$ & $\begin{array}{l}\text { [1.63; } \\
1.60 \\
1.46 \\
1.32 \\
1.08\end{array}$ & $\begin{array}{l}0.61 \\
0.62 \\
0.68 \\
0.76 \\
0.92 \\
\end{array}$ & $\begin{array}{l}0.91 \\
0.88 \\
0.74 \\
0.60 \\
0.37 \\
\end{array}$ & $\begin{array}{l}1.10 \\
1.14 \\
1.35 \\
1.67 \\
2.70\end{array}$ & $\begin{array}{l}0.76 \\
0.73 \\
0.59 \\
0.45 \\
0.22 \\
\end{array}$ & $\begin{array}{l}1.32 \\
1.57 \\
2.2 \\
4.58\end{array}$ \\
\hline MOVING AIR & (Any Position) & $h_{0}$ & $\boldsymbol{R}$ & $h_{0}$ & $R$ & $h_{0}$ & $\boldsymbol{R}$ \\
\hline $\begin{array}{r}\text { 15-mph Wind } \\
\text { (for winter) }\end{array}$ & Any & 6.00 & 0.17 & & - & & - \\
\hline $\begin{array}{l}\text { 7.5-mph Wind } \\
\text { (for summer) }\end{array}$ & Any & 4.00 & 0.25 & & 一 & & - \\
\hline
\end{tabular}

- No surfece has both an tirspace resistance value and a surface resisane vine. No airspace value exists for any surface facing an tirspace of less than 0.5 in bFor ventilated attics or spaces above ceilings under summet sonditioas finem nlow dowa), see Table $\$$.

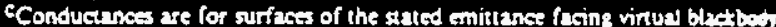
surroundings th the same temperature as the ambient air. Values ve bared a a surface-air temperature difference of $10^{\circ} \mathrm{F}$ and for surface temperature of $70 \%$. dse Chapter 3 fot more detailed information, especially Tables $\$$ and 6 . wh see Figure I for additional data.

e Condensare can have a signifieant impact on surface esnittance (sex Table 31

Table 2 Thermal Resistances of Plane Airspaces wae, of $\cdot \mathrm{ft}^{2} \cdot \mathrm{h} / \mathrm{Btu}$

\begin{tabular}{|c|c|c|c|c|c|c|c|c|c|c|c|c|c|}
\hline \multirow{2}{*}{$\begin{array}{c}\text { Position } \\
\text { of } \\
\text { Alripece }\end{array}$} & \multirow{2}{*}{$\begin{array}{c}\text { Direction } \\
\text { of } \\
\text { Heat } \\
\text { Fiow }\end{array}$} & \multicolumn{2}{|c|}{ Airspace } & \multicolumn{5}{|c|}{ 0.5-In. Aispacee } & \multicolumn{5}{|c|}{0.75 -in. Alrypaces } \\
\hline & & $\operatorname{Tomp}^{\alpha}$ & Diff. & 0.03 & $\begin{array}{l}\text { Exfet } \\
0.45\end{array}$ & $\begin{array}{c}\text { Smitu } \\
0.3\end{array}$ & $\begin{array}{l}E^{d e} \\
0.5\end{array}$ & 0.2 & 0.03 & $\stackrel{511}{0.05}$ & E. & $\begin{array}{c}E d e \\
0.5\end{array}$ & $\alpha$ \\
\hline Horiz. & up & $\begin{array}{r}90 \\
50 \\
50 \\
0 \\
0 \\
-50 \\
-50\end{array}$ & $\begin{array}{l}10 \\
30 \\
10 \\
20 \\
10 \\
20 \\
10\end{array}$ & $\begin{array}{l}2.13 \\
1.62 \\
2.13 \\
1.73 \\
2.10 \\
1.69 \\
2.04\end{array}$ & $\begin{array}{l}2.03 \\
1.57 \\
2.05 \\
1.70 \\
2.04 \\
1.64 \\
2.00\end{array}$ & $\begin{array}{l}1.51 \\
1.29 \\
1.60 \\
1.45 \\
1.70 \\
1.49 \\
1.75\end{array}$ & $\begin{array}{l}0.99 \\
0.96 \\
1.11 \\
1.12 \\
1.27 \\
1.23 \\
1.40\end{array}$ & $\begin{array}{l}0.73 \\
0.75 \\
0.84 \\
0.91 \\
1.00 \\
1.04 \\
1.16\end{array}$ & $\begin{array}{l}2.34 \\
1.71 \\
2.30 \\
1.83 \\
2.23 \\
1.77 \\
2.16\end{array}$ & $\begin{array}{l}2.32 \\
1.66 \\
2.21 \\
1.79 \\
2.16 \\
1.74 \\
2.11\end{array}$ & $\begin{array}{l}1.61 \\
1.35 \\
1.70 \\
1.52 \\
1.78 \\
1.55 \\
1.84\end{array}$ & $\begin{array}{l}1.04 \\
0.99 \\
1.16 \\
1.16 \\
1.31 \\
1.27 \\
1.46\end{array}$ & $\begin{array}{l}0.75 \\
0.7 \\
0.7 \\
0.93 \\
1.15 \\
1.07 \\
120\end{array}$ \\
\hline $\begin{array}{l}\text { 45" } \\
\text { Slope }\end{array}$ & $U_{p}$ & $\begin{array}{r}90 \\
50 \\
50 \\
0 \\
0 \\
-50 \\
-50\end{array}$ & $\begin{array}{l}10 \\
30 \\
10 \\
20 \\
10 \\
20 \\
10\end{array}$ & $\begin{array}{l}2.4 \\
2.05 \\
2.55 \\
2.20 \\
2.63 \\
2.08 \\
2.62\end{array}$ & $\begin{array}{l}2.31 \\
1.98 \\
2.44 \\
2.14 \\
2.54 \\
2.04 \\
2.56\end{array}$ & $\begin{array}{l}1.65 \\
1.56 \\
1.83 \\
1.76 \\
2.03 \\
1.78 \\
2.17\end{array}$ & $\begin{array}{l}1.06 \\
1.10 \\
1.22 \\
1.30 \\
1.44 \\
1.42 \\
1.65\end{array}$ & $\begin{array}{l}0.76 \\
0.83 \\
0.90 \\
1.02 \\
1.10 \\
1.17 \\
1.33\end{array}$ & $\begin{array}{l}2.90 \\
1.99 \\
2.90 \\
2.13 \\
2.72 \\
2.05 \\
2.53\end{array}$ & $\begin{array}{l}2.78 \\
1.92 \\
2.75 \\
2.07 \\
2.62 \\
2.01 \\
2.47\end{array}$ & $\begin{array}{l}1.88 \\
1.52 \\
2.00 \\
1.72 \\
2.08 \\
1.76 \\
2.10\end{array}$ & $\begin{array}{l}1.15 \\
1.08 \\
1.29 \\
1.28 \\
1.47 \\
1.41 \\
1.62\end{array}$ & $\begin{array}{l}02 \\
028 \\
010 \\
110 \\
110 \\
100\end{array}$ \\
\hline Verticll & Horiz. & $\begin{array}{r}90 \\
50 \\
50 \\
-\quad 0 \\
0 \\
-50 \\
-50\end{array}$ & $\begin{array}{l}10 \\
30 \\
10 \\
20 \\
10 \\
20 \\
10\end{array}$ & $\begin{array}{l}2.47 \\
2.57 \\
2.65 \\
2.82 \\
2.93 \\
2.90 \\
3.20\end{array}$ & $\begin{array}{l}2.34 \\
2.46 \\
2.54 \\
2.72 \\
2.82 \\
2.82 \\
3.10\end{array}$ & $\begin{array}{l}1.67 \\
1.84 \\
1.88 \\
2.14 \\
2.20 \\
2.35 \\
254\end{array}$ & $\begin{array}{l}1.05 \\
1.23 \\
1.24 \\
1.50 \\
1.53 \\
1.76 \\
1.87\end{array}$ & $\begin{array}{l}0.77 \\
0.90 \\
0.91 \\
1.13 \\
1.19 \\
1.39 \\
1.46\end{array}$ & $\begin{array}{l}3.50 \\
2.91 \\
3.70 \\
3.14 \\
3.77 \\
2.90 \\
3.72\end{array}$ & $\begin{array}{l}3.24 \\
2.77 \\
3.46 \\
3.02 \\
3.59 \\
2.53 \\
3.60\end{array}$ & $\begin{array}{l}2.08 \\
2.01 \\
2.35 \\
2.32 \\
2.64 \\
2.36 \\
2.87\end{array}$ & $\begin{array}{l}1.22 \\
1.30 \\
1.43 \\
1.58 \\
1.73 \\
1.77 \\
2.04\end{array}$ & 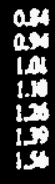 \\
\hline $\begin{array}{c}\text { 45* } \\
\text { Slope }\end{array}$ & Dawn & $\begin{array}{r}90 \\
50 \\
50 \\
0 \\
0 \\
-50 \\
-\$ 0\end{array}$ & $\begin{array}{l}10 \\
30 \\
10 \\
20 \\
10 \\
20 \\
10\end{array}$ & $\begin{array}{l}2.48 \\
2.64 \\
2.67 \\
2.91 \\
2.44 \\
3.16 \\
3.26\end{array}$ & $\begin{array}{l}2.34 \\
2.52 \\
2.55 \\
2.00 \\
2.83 \\
3.07 \\
3.16\end{array}$ & $\begin{array}{l}1.67 \\
1.57 \\
1.89 \\
2.19 \\
2.21 \\
2.52 \\
2.58\end{array}$ & $\begin{array}{l}1.06 \\
1.24 \\
1.25 \\
1.52 \\
1.53 \\
1.86 \\
1.89\end{array}$ & $\begin{array}{l}0.77 \\
0.91 \\
0.92 \\
1.15 \\
1.15 \\
1.45 \\
1.47\end{array}$ & $\begin{array}{l}3.53 \\
3.43 \\
3.81 \\
3.75 \\
4.12 \\
3.78 \\
4.35\end{array}$ & $\begin{array}{l}3.27 \\
3.23 \\
3.57 \\
3.57 \\
3.91 \\
3.65 \\
4.18\end{array}$ & $\begin{array}{l}2.10 \\
2.24 \\
2.40 \\
2.63 \\
2.81 \\
2.90 \\
3.22\end{array}$ & $\begin{array}{l}1.22 \\
1.39 \\
1.45 \\
1.72 \\
1.80 \\
2.05 \\
2.21\end{array}$ & 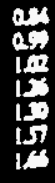 \\
\hline Horiz & Down & $\begin{array}{r}\$ 0 \\
\$ 0 \\
\$ 0 \\
0 \\
0 \\
-\$ 0 \\
-\$ 0\end{array}$ & $\begin{array}{l}10 \\
30 \\
10 \\
20 \\
10 \\
20 \\
10\end{array}$ & $\begin{array}{l}2.48 \\
2.66 \\
2.67 \\
2.4 \\
2.6 \\
3.25 \\
3.28\end{array}$ & $\begin{array}{l}2.34 \\
2.54 \\
2.55 \\
2.83 \\
2.05 \\
3.15 \\
3.18\end{array}$ & $\begin{array}{l}1.67 \\
1.88 \\
1.89 \\
2.20 \\
2.23 \\
2.58 \\
2.00\end{array}$ & $\begin{array}{l}1.06 \\
1.24 \\
1.25 \\
1.53 \\
1.53 \\
1.09 \\
1.50\end{array}$ & $\begin{array}{l}0.77 \\
0.91 \\
0.92 \\
1.15 \\
1.16 \\
1.47 \\
1.47\end{array}$ & $\begin{array}{l}3.59 \\
3.77 \\
3.84 \\
4.18 \\
4.25 \\
4.60 \\
4.71\end{array}$ & $\begin{array}{l}3.29 \\
3.52 \\
3.59 \\
3 . \% \\
4.02 \\
4.41 \\
4.51\end{array}$ & $\begin{array}{l}2.10 \\
2.38 \\
2.41 \\
2.83 \\
2.87 \\
3.36 \\
3.42\end{array}$ & $\begin{array}{l}1.27 \\
1.44 \\
1.45 \\
1.81 \\
1.82 \\
2.28 \\
2.30\end{array}$ & 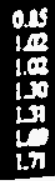 \\
\hline
\end{tabular}




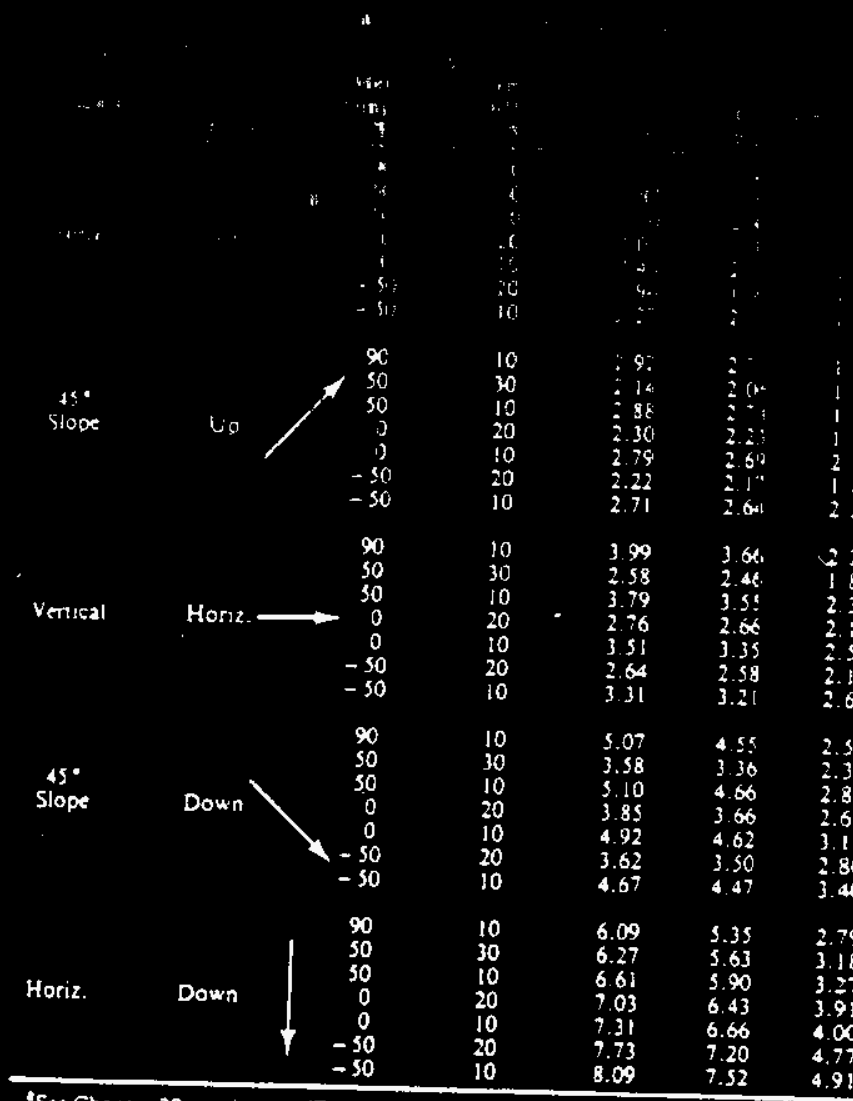

"See Chapter 20, section on "Factors Affecting Heat Transfer Across Airspaces:" Thermal resistance values were determined from the relation, $R=1 / C$, where $C=$

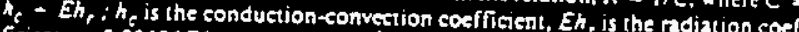
ficient $\equiv 0.00686 E\left[\left(t_{m}+460\right) / 100\right]^{3}$, and $t_{m}$ is the mean temperature of the airspace. Values for $h_{c}$ were determined fram das developed by Robinson et at (1944). Equations 5 through 7 in Yurbrough (1983) show the daca in fable 2 in analyic form. For extrapolation from Table 2 to arspaces less than 0.5 in. (as in insulating window glass), assume

$$
h_{c}=0.159\left(1+0.0016 t_{m}\right) / t
$$
where $l$ is the airspace thickness in in., and $h_{c}$ is heat tensfer through the airspace
oaly.

bValutes are baed on data prizented by Robinson et of. (I954). (A/so see Chapter

3. Tables 3 and 4 , and Chaper 39 ). Values apply for ideal conditions, ien, sirspoces

\section{Wood Frame Walls}

The average overall $R$-values and $U$-factors of wood frame wails an be calculated by assuming parallel heat flow paths through areas with different thermal resistances. Equations (1) through $(S)$ from Chapter 20 are used.

For simple stud walis 16 in. on center $(O C)$, the fraction of framing is assumed to be approximately 0.15 ; for studs $24 \mathrm{in.} \mathrm{OC,} \mathrm{ap-}$ proximately 0.12 . These fractions contain an ailowance for multiple studs, plates, silts, and extra framing around windows and doors but do not allow for headers or band joists.

Eximple 1. Calculate the U-fastor of the 2 by 4 stud wall shown in Figure 2. The studs are at 16 in. OC. There is a 3.5- in. mineral fiber batt insula. tion (R-II) in the stud space. The inside finish is 0.5-in. bypsum borrd; the outside is finished with 0.5 -in. vetgetable fiber bourd sheathing and 0.5 -in. by 8-in. wood lapped siding. The framing occupies approximately is\% of the transmission area.

Solution: Obtain the Rovalue of the various building elements from Tables $I$ and 4 .

$$
\text { LEF } 2 \sigma
$$

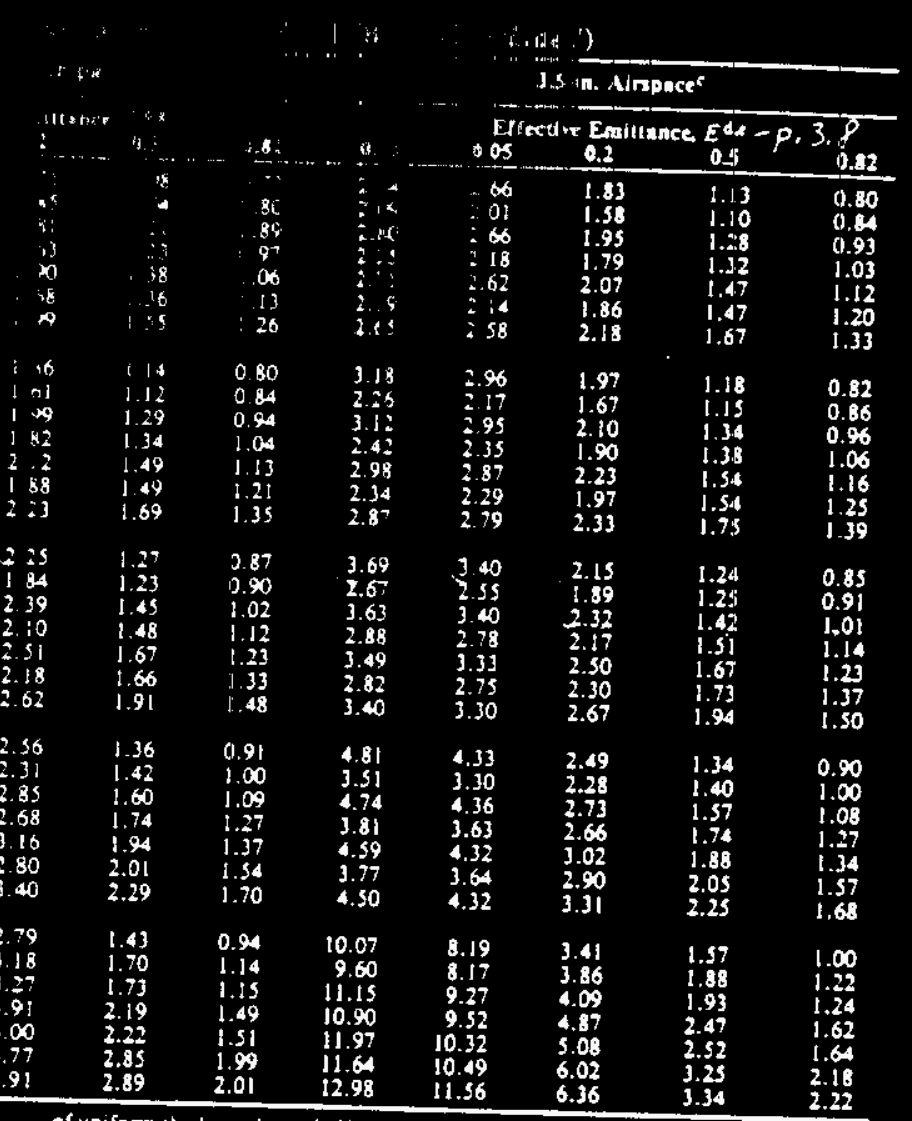

of uniform thickness bounded by plane smooth, pardlel surfaces with no air leakage mined through ealibnted hocurate values are requirad, use overall $U$-factors deter. mined through calibried hox box (ASTM C 976) or guarded hor box (ASTM C 236) lesting. Thermal resistance values for multiple airspaces must be based on careful

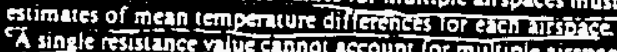

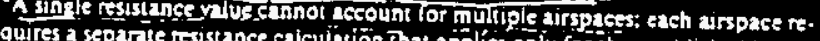
quires a separate fesistance eaiculation that applits only for the established boundary conditions. Resistances of horizontal spaces with heat flow downward are substantially independent of tempernture difference.

Interpolation is permicejbie for other vilues of menn temperature tginperature dif-

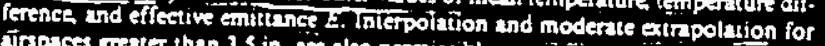
In

Effectivemitance $E$ of the cirspace is given by $1 / E=F_{-}$

and $t_{2}$ are the emitunces of the surfaces of the tinpace

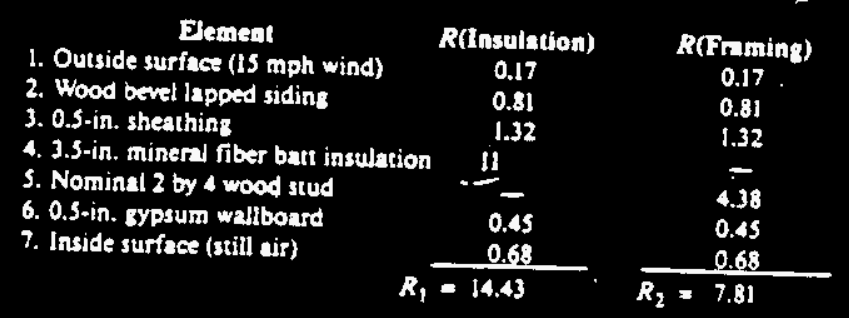

Therefore $U_{1}=0.069 ; U_{2}=0.128 \mathrm{Btu} / \mathrm{h} \cdot \mathrm{ft}^{2} \cdot \mathrm{F}$.

If the wood fruming (i.e., thermal bridging) is not included, Equation (3) from Chapter 20 may be used to ealculate the U-factor of the wall as follows:

$$
U_{c r}=U_{t}=1 / R_{1}=0.059 \mathrm{gtu} / \mathrm{h} \cdot \mathrm{ft}^{2 \cdot \bullet \mathrm{F}}
$$

If the wood framing is accounted for usine the parallel now method, the U-factor of the wll is determined using Equation (S) from Chapter 20 as
follows: it: $U_{-. .}=(0.85 \times 0.059)+(0.15 \times n+2$ WHC-SD-W379-ES-003 ReV. 0 


\section{TA 112}

Table 6 Equations for Forced Convection (Concluded)

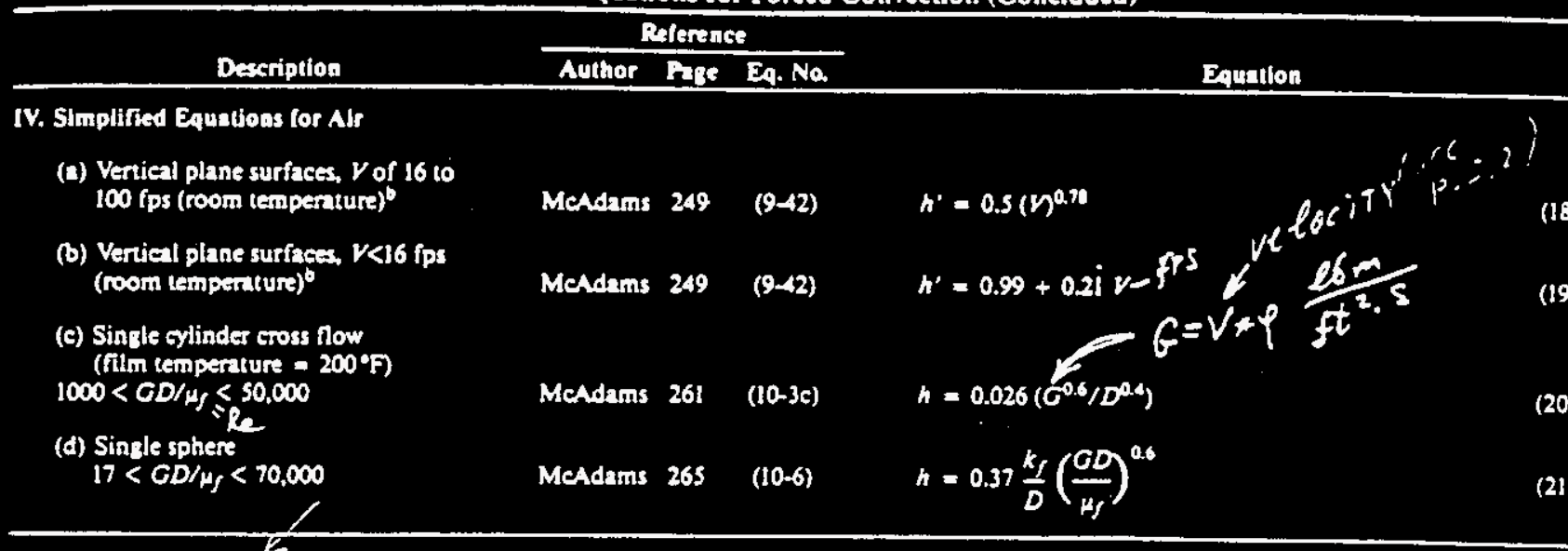

V. Gasas Flowiog Normal to Plpes (Dimeasionless)

(a) Single Cylinder Re from 0.1 to 1000 Re from 1000 to 50,000

(b) Unbaffled Stagzered Tubes, 10 rows. Approximate Equation for Turbulent Flow:

(c) Unbafiled In-Line Tubes, 10 Rows, Approximate Equation for Turbulent Flow $\left(G_{\text {max }} D / \mu f\right)$ from 2000 10 32,000
MeAdzms $272 \quad(10-11 a)$

MeAdams 260

MeAdams 260

MeAdams 272 (10-11a)

$$
\begin{aligned}
& \frac{h D}{k_{f}}=0.32+0.43\left(\frac{G D}{\mu}\right)^{0.52} \\
& \frac{h D}{k_{f}}=0.24\left(\frac{G D}{\mu_{f}}\right)^{0.6}
\end{aligned}
$$

$$
\frac{h D}{k_{f}}=0.33\left(\frac{G_{\operatorname{mux}} D}{\mu_{f}}\right)^{0.6}\left(\frac{\mu C_{p}}{k}\right)_{f}^{1 / 3}
$$

$$
\frac{h D}{k_{f}}=0.26\left(\frac{G_{\max } D}{\mu_{f}}\right)^{0.6}\left(\frac{\mu c_{p}}{k}\right)_{f}^{1 / 3}
$$

- Mcadams (1954) recommends this equation for heating and cooling. Other authors recommend an exponent of 0.4 for heating and 0.3 for cooling.

The characteristic length, $D, f 5$ the diameter of the tube outside $\sigma \mathrm{r}$ inside or the length of the plane plate. For other shapes, the hydraulic diameter, $D_{p}$, is used, where:

$$
D_{e}=2 r_{k}=4 \frac{\text { Cross-sectional area for flow }}{\text { Total wetted perimeter }}
$$

This reduces to twice the distance between surfaces for parallet plates or an annulus.

Simplified equations applicable to common fluids under normal operating conditions appear in Equations (8) through (25) of Table 6. Figure 11 gives graphical solutions for water.

\section{Techniques to Augment Forced Convection}

Turbulence promoters in smooth flow passages, such as coiled wires, twisted tapes, discs, bafnes, configurated surfaces, and packing, increase forced convection heat transfer coefficients for single- and two-phase flows. Pumping power is usually increased relative to that of smooth surfaces, the amount depending on the device.

Techniques applied to commercial heat exchange squipment to improve heat transfer to fow inside of tubes, usually at the expense of pumping power or external power applied to the system, include: (1) surface promoters, (2) displaced promoters, (3) vortex flows, (4) surface vibration, (5) fluid vibration, and (6) electrostatic frelds. Methods requiring external power (iterns 4,5 , and 6 ) are diffieult to apply to large-seale heat exchange equipment, and information on increased equipment cost and power requirements is

\footnotetext{
${ }^{0} h^{\prime}$ is expressed in Btu/h$\cdot \mathrm{fl}^{2} \cdot{ }^{\circ} \mathrm{F}$ initial temperature difference. - $G_{\max }$ is based on minimum free area. Coefficients for tube banks de. pend greatly on geometrical desails. These values approximate only.
}

lacking. Of the methods requiring no external power (items 1, 2 , and 3), displaced promoters are difficult to install inside tubes, and generally have large friction factors; surface promoters and vortex how appear most suited for commercial use Surface promoters range from selective finishing of the surface to increasing surface area by adding fins.

\section{DXTENDED SURFACE}

Heat transfer from a prime surface can be increased by attaching fins or extended surfoces, to inerease the area available for heat transfer. Fins provide a more compact heat exchanger with lower material costs for a given performance To achieve optimum design, fins are generally located on the side of the heat exchanger where the heat transfer coefficients are low (such as the air side of an air-to-water coil). Equipment with extended surface includes natural and foreed convection coils and shell-and-tube evaporators and condensers. Fins are also used inside tubes in condensers and dry expansion evaporators.

\section{Fin Efriciency}

As heat flows from the root of a fin to its tip, temperature drops because of the thermal resistance of the fin material. The temperature difference between the fin and the surrounding fluid is therefore greater at the roos than at the tip, causing a corresponding variation in the heat fux. Therefore increases in fin length result in proportionately less additional heat transfer. To account 